Tesis para optar por el título de Doctora en Ciencias Naturales

\title{
Paleopatología en poblaciones prehispánicas del sur del Noreste Argentino
}

\section{María Agustina Ramos van Raap}

\author{
DIRECTORES
}

MARIANO BONOMO Y CLARA SCABUZZO
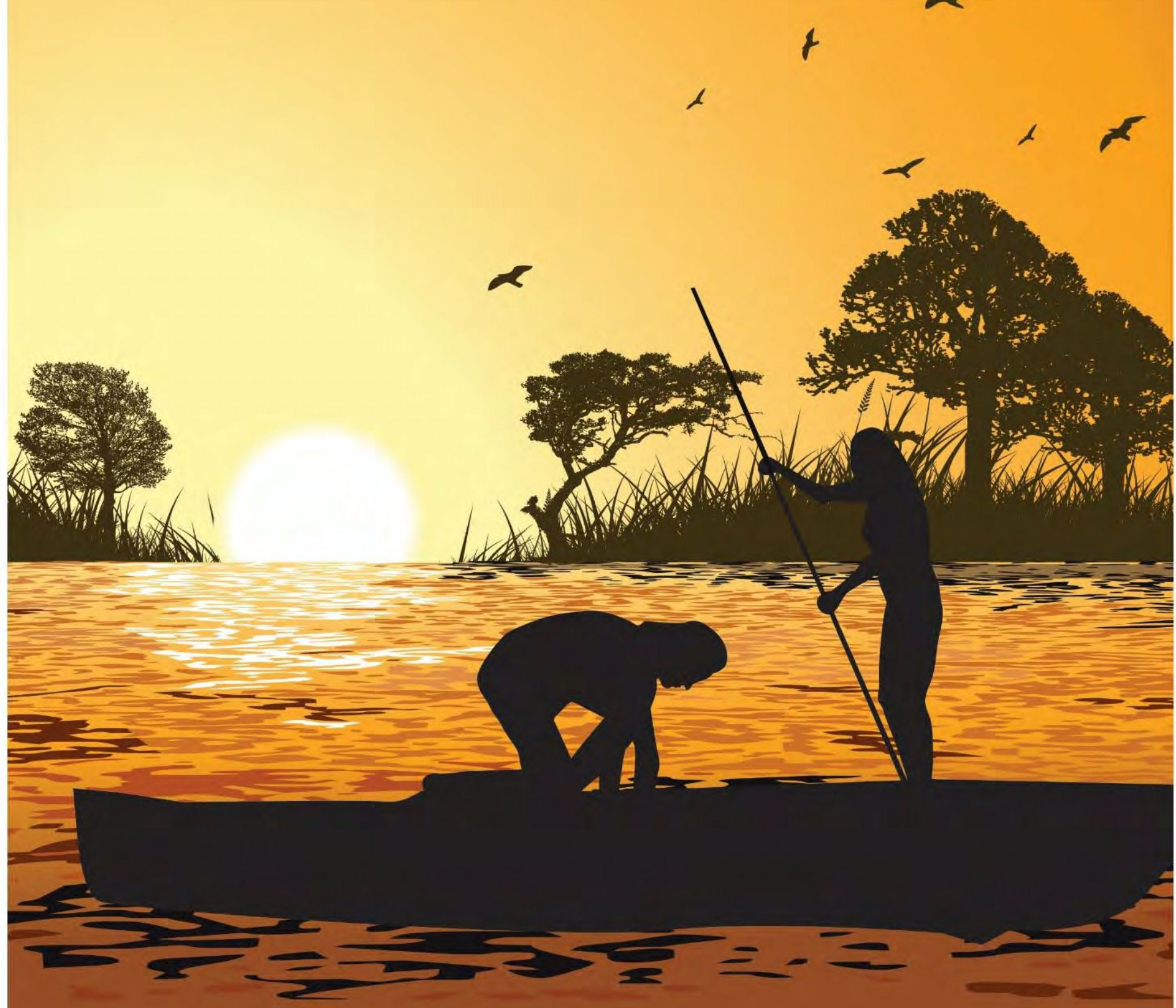

Facultad de Ciencias Naturales y Museo / Universidad Nacional de La Plata / Año: 2018 
A mis padres, María Nelly y Gustavo 


\section{Agradecimientos}

El desarrollo y culminación de esta investigación fue posible gracias a instituciones científico-académicas y a numerosas personas que colaboraron conmigo, incluso durante etapas previas. Estas siguientes líneas las dedico para agradecerles. En primer lugar, a la Universidad Nacional de La Plata, por haber tenido la posibilidad de transitar en ella todos los tramos de mi formación académica y ser el espacio donde se comenzó a gestar mi interés por la ciencia. Especialmente agradezco a la Facultad de Ciencias Naturales y Museo, que además me brindó el espacio físico para llevar a cabo mi proyecto de tesis. Para realizar esta investigación conté con el financiamiento del Consejo Nacional de Investigaciones Científicas y Técnicas, a través de una beca interna de doctorado; y de diferentes proyectos de investigación de la Universidad Nacional de La Plata, del Consejo Nacional de Investigaciones Científicas y Técnicas y de la Agencia Nacional de Promoción Científica y Tecnológica, dirigidos por G. Politis, M. Bonomo y C. Scabuzzo.

A mis directores de doctorado y de beca, Mariano Bonomo, Clara Scabuzzo y Gustavo Politis, les agradezco por integrarme en sus proyectos de investigación desde mis comienzos como estudiante de grado; y por haberme brindado su tiempo, confianza y enseñanzas a lo largo de todos estos años. Especialmente a Mariano y Clara, por sus consejos y por sus lecturas y comentarios críticos que contribuyeron positivamente a la tesis. Unas líneas aparte quiero dedicarlas a agradecer a Clara, por su acompañamiento y asesoramiento en el día a día y, por sobre todas las cosas, por brindarme su afecto y apoyo en momentos un tanto complicados.

Diferentes personas colaboraron conmigo en varias instancias de la tesis. En mis visitas y consultas a las colecciones del Museo de La Plata y Museo Arqueológico Manuel Almeida, he contado siempre con la buena predisposición y amabilidad de Mariano del Papa y de Raúl y Tomás Almeida. Ellos, junto a Maite Zavala y Rodrigo González, fueron importantes también para conseguir los lugares donde realizar las radiografías y tomografías computadas. El tratamiento de las imágenes tomográficas fue gracias a la asistencia de Marisol Anzelmo. Para la realización de los estudios 
arqueobotánicos sobre muestras de cálculo dental recibí la valiosa ayuda de Milagros Colobig. Juan Carlos Castro me facilitó bibliografía y fotografías que se incorporaron en este trabajo. Para la confección de los mapas conté con la paciente ayuda de Diego Gobbo. Luciano Prates y Graciela Britch me asistieron con la corrección del Abstract. Y Ma. Emilia Fiorincino me brindó su creatividad y habilidad para diseñar la tapa de la tesis. A todos ellos, muchas gracias. También quiero mencionar a Gustavo Flensborg, Jorge Suby, Mariana Fabra y Solana García Guraieb; sus conocimientos, bibliografía y experiencias compartidos durante charlas, pasantías y cursos de postgrado dictados por ellos, han contribuido en muchos aspectos para poder realizar los análisis.

El camino recorrido resultó enriquecedor al compartir numerosos momentos, espacios y charlas con los que integran o integraron el equipo de investigación: Alejandra Matarrese, Bianca Di Lorenzo, Canela Castro, Carola Castiñeira, Carolina Silva, Catriel Leon, Eduardo Apolinaire, Germán Moreira, Juan Carlos Castro, Laura Bastourre, Laura Maravilla, Luis Cappeletti, Marco Alvarez, Milagros Colobig, Patricia Madrid, Pilar Ríos, Rodrigo Angrizani, Vanesa Bagaloni, Violeta Di Prado y Yamila Batalla. Especialmente, les agradezco a Violeta y Carolina por su acompañamiento sobre todo en el último tiempo. No quiero dejar de mencionar mi reconocimiento a Catriel, con quien empecé a incursionar en la arqueología y me transmitió valiosos conocimientos; y a Luciano Prates, que me ayudó y aconsejó en varias oportunidades.

A Alejandro Serna y Emiliano Mange, por el acompañamiento diario en estos años colmado de muchas charlas y consejos y siempre con una buena cuota de humor. A Eloísa García Añino por compartir el proceso de tesis, sobre todo durante el último tiempo de escritura. Y a Camila, Emilia, Ignacio, Juan Ignacio, Maite, Mercedes, Nicolás y Victoria, que sin su cariño y valiosa compañía no hubiera sido lo mismo.

Finalmente, mi agradecimiento más profundo es hacia mis padres, María Nelly y Gustavo, y mi hermano, Santiago. Realizar la carrera y culminar esta tesis no hubiera sido posible sin su apoyo incondicional y sin su compañía, siempre presente. 


\section{Resumen}

El objetivo principal de esta tesis es caracterizar la salud y la dieta de las poblaciones que habitaron el sur del Noreste Argentino durante el Holoceno tardío, a partir del análisis paleopatológico de distintos bioindicadores óseos y bucales. Los resultados obtenidos se integran con la información arqueológica y etnohistórica disponible, con el fin de efectuar un estudio bioarqueológico integrador y así aportar al estudio de los modos de vida de los grupos prehispánicos que habitaron este sector.

Los análisis se efectuaron en un número mínimo de 162 individuos, que proceden de tres muestras bioarqueológicas: 1) Delta Superior del río Paraná, 2) cuenca inferior del río Uruguay y 3) Delta Inferior del río Paraná y ambientes litorales adyacentes. La primera de ellas corresponde a dos sitios arqueológicos excavados recientemente como parte de los proyectos de investigación que enmarcan esta tesis. La segunda se constituye por los entierros humanos hallados, durante la segunda mitad del siglo XX, por Sr. M. Almeida en ocho sitios arqueológicos. La última muestra se conforma por los conjuntos óseos de un sitio excavado por Almeida y de dos sitios trabajados por L.M. Torres y S.K. Lohtrop a principios del siglo XX. Estas dos últimas muestras se encuentran bajo la guarda del Museo Arqueológico Manuel Almeida y del Museo de La Plata, respectivamente.

Como resultado de esta investigación, los indicadores bucales observados en las tres muestras bioarqueológicas se ajustan a lo esperado para dietas mixtas. Los recursos animales constituyeron el componente principal de la alimentación, mientras que el consumo de vegetales fue una parte constitutiva importante y complementaria en la dieta. Se evidencian diferentes modos de procesar los alimentos que atenuaron el estrés masticatorio. En la muestra de la cuenca inferior del río Uruguay la dieta habría sido más abrasiva, relacionada principalmente con la molienda y el asado y cocción directa sobre el fuego. Por otro lado, el nucleamiento poblacional en las áreas residenciales con asentamientos semipermantentes (aldeas) y la ocupación durante los períodos de inundación en 
los lugares elevados del paisaje, habrían incidido en la salud de las personas al quedar expuestas a diferentes micro-organismos que favorecieron el desarrollo de enfermedades infecciosas. Finalmente, los escasos traumas relevados evidencian lo que las fuentes etnohistóricas reportan en cuanto a la existencia de buenas relaciones entre los grupos étnicos locales llamados chaná-timbú, que habitaban el sur del Noreste Argentino. 


\section{Abstract}

The main subject of this thesis is to characterize the health and diet of the populations inhabiting the south of the Northeastern Argentina over the Late Holocene, through the paleopathological analysis of bony and dental bioindicators. The results achieved are integrated with the available archaeological and ethnohistoric data, in order to carry out a holistic bioarchaeological study and thus contribute to the study of the prehispanic ways of life.

The analyzes were performed on a $M N I=162$, coming from three bioarchaeological samples: 1) Upper Delta of the Paraná River, 2) Lower basin of the Uruguay River and 3) Lower Delta of the Paraná River and adjacent litoral environments. The first sample come from two archaeological sites recently excavated as part of the research projects that frame this thesis. The second sample is constituted by the sketetons found by Mr. M. Almeida in eight archaeological sites during the second half of the 20th century. The last sample consists of the skeletal assemblages coming from a burial site excavated by Almeida, and of two sites excavated by L.M. Torres and S.K. Lothrop at the beginning of the 20th century. The last two samples are under the custody of Museo Arqueológico Manuel Almeida and Museo de La Plata, respectively.

The results of the analysis performed in this thesis shows that the buccal indicators of the three bioarchaeological samples match the expectations for mixed diets. Animal proteins were the main component of the diet, and the plants were important but complementary resourses. Different ways of processing food that eased the masticatory stress are evident. In the sample from the lower basin of the Uruguay river the diet seemed to have been more abrasive as a result of grinding, roasting and direct cooking over the fire. On the other hand, population aggregation in residential areas with semipermanent villages and occupation of highlands during floods affected the health of people who were exposed to microorganisms that favored the infectious diseases. Finally, the few traumas surveyed seems to be congruent with the ethnohistoric sources which shows good relations 
among local ethnic groups named chaná-timbú that inhabited the south of the Northeastern Argentina. 


\section{Índice de contenidos}

$\begin{array}{lr}\text { Capítulo } 1 \text { - Introducción } & 1\end{array}$

1.1 Objetivos generales y específicos 4

1.2 Expectativas paleopatológicas 5

$\begin{array}{ll}1.3 \text { Estructura de la tesis } & 7\end{array}$

Capítulo 2 - Consideraciones teórico-conceptuales 99

2.1 El abordaje de la salud de las poblaciones humanas del pasado 9

2.2 Conceptos de salud, enfermedad y estrés 13

$\begin{array}{ll}2.3 \text { Críticas al enfoque biocultural y propuestas alternativas } & 14\end{array}$

$\begin{array}{ll}2.4 \text { Sobre la representatividad de las muestras bioarqueológicas } & 17\end{array}$

2.5 Estudios sobre la salud de las poblaciones pasadas en Argentina 19

2.6 Palabras finales 23

Capítulo 3 - Investigaciones bioarqueológicas previas en el sur del Noreste Argentino y sistematización de la información disponible $\quad 26$

3.1 Arqueología en el sur del Noreste Argentino 26

3.2 El registro bioarqueológico 34

3.3 Análisis bioarqueológicos desarrollados 45

3.4 Palabras finales $\quad 52$

Capítulo 4 - Metodologías de análisis de las muestras bioarqueológicas $\quad 54$

4.1 Análisis cuantitativos iniciales $\quad 55$

4.2 Criterios empleados en la estimación de edad y determinación de sexo 56

$\begin{array}{ll}4.3 \text { Análisis patológico } & 60\end{array}$

4.3.1 Indicadores de salud bucal y adecuación fisiológica 62

4.3.1.1 Caries 63

4.3.1.2 Lesiones periapicales 66

4.3.1.3 Pérdidas dentales antemortem 68

4.3.1.4 Cálculos dentales $\quad 69$

$\begin{array}{ll}\text { 4.3.1.5 Desgaste dental } & 71\end{array}$ 
4.3.1.6 Hipoplasias lineales del esmalte dental

$\begin{array}{ll}\text { 4.3.2 Patologías óseas } & 77\end{array}$

4.3.2.1 Lesiones de estrés metabólico-nutricional 78

4.3.2.2 Lesiones infecciosas 82

$\begin{array}{ll}\text { 4.3.2.3 Lesiones de estrés inespecífico } & 86\end{array}$

4.3.2.4 Lesiones traumáticas $\quad 88$

$\begin{array}{ll}4.4 \text { Estadística descriptiva e inferencial } & 90\end{array}$

Capítulo 5 - Las muestras bioarqueológicas: información contextual y primeros $\begin{array}{ll}\text { resultados } & 91\end{array}$

5.1 Caracterización ambiental de las áreas de estudio 93

5.2 Estructura sexo-etaria y perfiles de edad de muerte 95

5.3 Delta Superior del río Paraná 99

5.3.1 Los Tres Cerros 1 (LTC1) 99

5.3.1.1 Caracterización general 99

5.3.1.2 Entierros humanos y muestra bioarqueológica estudiada 102

$\begin{array}{ll}\text { 5.3.2 Laguna de Los Gansos } 2 \text { (LDLG2) } & 119\end{array}$

$\begin{array}{ll}\text { 5.3.2.1 Caracterización general } & 119\end{array}$

5.3.2.2 Entierros humanos y muestra bioarqueológica estudiada 121

5.4 Cuenca inferior del río Uruguay (margen derecha) 123

$\begin{array}{ll}\text { 5.4.1 Cerro Lorenzo } 2 \text { (CL2) } & 124\end{array}$

$\begin{array}{ll}\text { 5.4.1.1 Caracterización general } & 124\end{array}$

5.4.1.2 Entierros humanos y muestra bioarqueológica estudiada 126

$\begin{array}{ll}\text { 5.4.2 Sambaquí de Puerto Landa (SPL) } & 130\end{array}$

$\begin{array}{ll}\text { 5.4.2.1 Caracterización general } & 130\end{array}$

$\begin{array}{ll}\text { 5.4.2.2 Entierros humanos y muestra bioarqueológica } & 133\end{array}$

5.4.3 Túmulo 1 - Cerro Norte de Machado (T1-CNM) 136

$\begin{array}{ll}\text { 5.4.3.1 Caracterización general } & 136\end{array}$

$\begin{array}{ll}\text { 5.4.3.2 Entierros humanos y muestra bioarqueológica estudiada } & 137\end{array}$

5.4.4 Túmulo 2 - Cerro Sur de Machado (T2-CSM) 139

$\begin{array}{ll}\text { 5.4.4.1 Caracterización general } & 139\end{array}$

$\begin{array}{ll}\text { 5.4.4.2 Entierros humanos y muestra bioarqueológica estudiada } & 140\end{array}$

$\begin{array}{ll}\text { 5.4.5 Cerro de los Pampas (CP) } & 141\end{array}$

$\begin{array}{ll}\text { 5.4.5.1 Caracterización general } & 141\end{array}$

$\begin{array}{ll}\text { 5.4.5.2 Entierros humanos y muestra bioarqueológica estudiada } & 143\end{array}$ 
$\begin{array}{ll}\text { 5.4.6 San Luis Médanos (SLM) } & 144\end{array}$

$\begin{array}{ll}\text { 5.4.6.1 Caracterización general } & 144\end{array}$

5.4.6.2 Entierros humanos y muestra bioarqueológica estudiada 145

$\begin{array}{ll}\text { 5.4.7 Túmulo de Lucuix (TL) } & 145\end{array}$

$\begin{array}{ll}\text { 5.4.7.1 Caracterización general } & 145\end{array}$

5.4.7.2 Entierros humanos y muestra bioarqueológica estudiada 146

$\begin{array}{ll}\text { 5.4.8 Fajina Quemada (FQ) } & 146\end{array}$

$\begin{array}{ll}\text { 5.4.8.1 Caracterización general } & 146\end{array}$

5.4.8.2 Entierros humanos y muestra bioarqueológica estudiada 147

5.5 Delta Inferior del río Paraná y ambientes litorales adyacentes 147

$\begin{array}{ll}\text { 5.5.1 Túmulo } 1 \text { - La Argentina (T1-LA) } & 148\end{array}$

$\begin{array}{ll}\text { 5.5.1.1 Caracterización general } & 148\end{array}$

5.5.1.2 Entierros humanos y muestra bioarqueológica estudiada 149

5.5.2 El Cerrillo / Túmulo I del Paraná Guazú 150

$\begin{array}{ll}\text { 5.5.2.1 Caracterización general } & 150\end{array}$

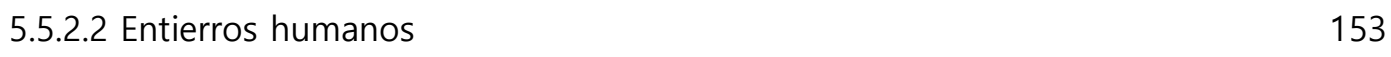

5.5.2.3 Muestra bioarqueológica estudiada 156

$\begin{array}{ll}\text { 5.5.3 Arroyo Sarandí } & 159\end{array}$

$\begin{array}{ll}\text { 5.5.3.1 Caracterización general } & 159\end{array}$

$\begin{array}{ll}\text { 5.5.3.2 Entierros humanos } & 160\end{array}$

5.5.3.3 Muestra bioarqueológica estudiada 162

$\begin{array}{ll}5.6 \text { Palabras finales } & 164\end{array}$

Capítulo 6 - Resultados: indicadores de salud bucal y adecuación fisiológica $\quad 165$

$\begin{array}{ll}6.1 \text { Caries } & 165\end{array}$

$\begin{array}{ll}\text { 6.1.1 Delta Superior del río Paraná } & 165\end{array}$

$\begin{array}{ll}\text { 6.1.2 Cuenca inferior del río Uruguay } & 167\end{array}$

6.1.3 Delta Inferior del río Paraná y ambientes litorales adyacentes 169

$\begin{array}{ll}6.2 \text { Lesiones periapicales } & 171\end{array}$

$\begin{array}{ll}\text { 6.2.1 Delta Superior del río Paraná } & 171\end{array}$

$\begin{array}{ll}\text { 6.2.2 Cuenca inferior del río Uruguay } & 173\end{array}$

6.2.3 Delta Inferior del río Paraná y ambientes litorales adyacentes 176

$\begin{array}{ll}6.3 \text { Pérdidas dentales antemortem (PDAM) } & 176\end{array}$

$\begin{array}{ll}\text { 6.3.1 Delta Superior del río Paraná } & 176\end{array}$

$\begin{array}{ll}\text { 6.3.2 Cuenca inferior del río Uruguay } & 178\end{array}$ 
6.3.3 Delta Inferior del río Paraná y ambientes litorales adyacentes

6.4 Cálculos dentales

6.4.1 Delta Superior del río Paraná

6.4.2 Cuenca inferior del río Uruguay

6.4.3 Delta Inferior del río Paraná y ambientes litorales adyacentes

6.5.1 Delta Superior del río Paraná

6.5.2 Cuenca inferior del río Uruguay

6.5.3 Delta Inferior del río Paraná y ambientes litorales adyacentes

6.6.1 Delta Superior del río Paraná

6.6.2 Cuenca inferior del río Uruguay

6.6.3 Delta Inferior del río Paraná y ambientes litorales adyacentes

\section{Capítulo 7 - Resultados: patologías óseas}

7.1 Lesiones de estrés metabólico-nutricional 222

7.1.1 Delta Superior del río Paraná 222

7.1.2 Cuenca inferior del río Uruguay 224

7.1.3 Delta Inferior del río Paraná y ambientes litorales adyacentes 225

$\begin{array}{ll}7.2 \text { Lesiones infecciosas } & 225\end{array}$

7.2.1 Delta Superior del río Paraná 225

7.2.2 Cuenca inferior del río Uruguay 243

7.2.3 Delta Inferior del río Paraná y ambientes litorales adyacentes 246

7. 3 Lesiones de estrés inespecífico 246

7.3.1 Delta Superior del río Paraná 246

7.3.2 Cuenca inferior del río Uruguay 250

7.3.3 Delta Inferior del río Paraná y ambientes litorales adyacentes 255

7. 4 Lesiones traumáticas 260

$\begin{array}{ll}\text { 7.4.1 Delta Superior del río Paraná } & 260\end{array}$

$\begin{array}{ll}\text { 7.4.2 Cuenca inferior del río Uruguay } & 261\end{array}$

7.4.3 Delta Inferior del río Paraná y ambientes litorales adyacentes 263

7.5 Integración y discusión de los resultados obtenidos 265 
8.1 Desafíos y reflexiones metodológicas

8.2 Tendencias sobre la dieta y la salud de los grupos prehispánicos que

habitaron el sur del Noreste Argentino

8.2.1 Indicadores de salud bucal y adecuación fisiológica y su relación con la dieta

8.2.2 Estrés metabólico-nutricional, enfermedades infecciosas y nucleamiento poblacional

8.2.3 Lesiones traumáticas y violencia interpersonal

8.3 Conclusiones

Bibliografía

Apéndice 1

Ficha A.1.1 Inventario de la dentición (adultos) y registro de patologías orales

Ficha A.1.2 Registro de patologías óseas 


\section{Índice de figuras}

Capítulo 3 - Investigaciones bioarqueológicas previas en el sur del Noreste Argentino y sistematización de la información disponible

Figura 3.1 Sitios arqueológicos con entierros humanos en el sur del Noreste Argentino

\section{Capítulo 5 - Las muestras bioarqueológicas: información contextual y primeros} resultados

Figura 5.1 Ubicación de los sitios arqueológicos de los cuales provienen las muestras bioarqueológicas estudiadas

Figura 5.2 Perfil de edad de muerte para cada muestra bioarqueológica

Figura 5.3 El montículo LTC1 diferenciando las dos zonas excavadas

Figura 5.4 Aplicación de sedimento arcilloso con pigmento rojo en LTC1-P3

Figura 5.5 Paquetes funerarios de LTC1

Figura 5.6 Rasgo de combustión en la cima del montículo LTC1

Figura 5.7 Planta de excavación del núcleo de inhumación de LTC1 con los entierros humanos

Figura 5.8 Entierros humanos hallados en LDGL2

Figura 5.9 Sitio arqueológico CL2

Figura 5.10 Sitio arqueológico SPL

Figura 5.11 Sitio arqueológico T1-CNM

Figura 5.12 Vista del lado sur del sitio T1-LA

Figura 5.13 Excavaciones arqueológicas en EC/T1PG

Figura 5.14 Esqueletos parcialmente articulados con reacomodación de elementos óseos encontrados en EC

Figura 5.15 Zonas excavadas en las elevaciones de AS

Figura 5.16 Entierros humanos en AS

Figura 6.1 Caries registradas en la muestra del DS 
Figura 6.4 Lesiones periapicales registradas en la muestra del DS

Figura 6.5 Lesiones periapicales registradas en la muestra de CIRU 175

Figura 6.6 PDAM registradas en la muestra del DS 177

$\begin{array}{ll}\text { Figura 6.7 PDAM registradas en la muestra de CIRU } & 179\end{array}$

Figura 6.8 PDAM registradas en la muestra del DI 182

Figura 6.9 Prevalencias de cálculo dental en la muestra del DS, por clases de dientes y ubicación en la arcada dental 184

Figura 6.10 Cálculos dentales registrados en la muestra del DS 184

Figura 6.11 Microrrestos vegetales en muestras de cálculo dental de individuos del DS 186

Figura 6.12 Prevalencias de cálculo dental en la muestra de CIRU, por clases de dientes y ubicación en la arcada dental 188

Figura 6.13 Cálculos dentales registrados en la muestra de CIRU 188

Figura 6.14 Microrrestos vegetales en muestras de cálculo dental de individuos de CIRU 190

Figura 6.15 Prevalencias de cálculo dental en la muestra del DI, por clases de dientes y ubicación en la arcada dental 192

Figura 6.16 Cálculos dentales registrados en la muestra de DI 192

Figura 6.17 Promedios de grados de desgaste en la muestra del DS según grupos de edad 194

Figura 6.18 Promedios de grados de desgaste en la muestra del DS según el sexo $\quad 195$

Figura 6.19 Promedios de grados de desgaste en la muestra de CIRU según grupos de edad 198

Figura 6.20 Promedios de grados de desgaste en la muestra de CIRU según el sexo $\quad 199$

Figura 6.21 Promedios de grados de desgaste en la muestra del DI según grupos de edad 201

Figura 6.22 Promedios de grados de desgaste en la muestra del DI según el sexo 202

Figura 6.23 HLED en ambos $C_{1}$ del individuo LTC1-P2 206

Figura 6.24 HLED en ambos I' del individuo CL2-76 208

\section{Capítulo 7 - Resultados: patologías óseas 222}

Figura 7.1. Cribra orbitalia registradas en la muestra bioarqueológica del DS 223

Figura 7.2. Hiperostosis porótica registrada en el occipital del individuo T2-CSM-81 225

Figura 7.3. Lesiones óseas en el miembro superior de LTC1-P3 227

Figura 7.4. Lesiones óseas en epífisis distal del fémur derecho de LTC1-P3 228

Figura 7.5. Surcos vasculares en la diáfisis de la tibia izquierda de LTC1-P3 228

Figura 7.6. Lesiones óseas en la tibia derecha de LTC1-P3 230 
Figura 7.7. Lesiones óseas en el miembro inferior de LTC1-P3

Figura 7.8. Lesiones óseas en huesos del pie de LTC1-P3 232

Figura 7.9. Lesiones óseas en el miembro inferior de LTC1-P4 236

Figura 7.10. Lesiones óseas en la tibia derecha de LTC1-P4 237

Figura 7.11. Lesiones óseas en el miembro inferior de LTC1-P4 238

Figura 7.12. Lesiones óseas en el cráneo de LTC1-P4 239

Figura 7.13. Lesiones óseas en la bóveda craneana de SLM-65 245

Figura 7.14. Lesiones de estrés inespecífico en la muestra del DS 249

Figura 7.15. Lesiones de estrés inespecífico en la muestra de CIRU 252

Figura 7.16. Lesiones de estrés inespecífico en la muestra de CIRU 254

Figura 7.17. Lesiones de estrés inespecífico en la muestra del DI 257

Figura 7.18. Lesiones de estrés inespecífico en la muestra del DI 259

Figura 7.19. Traumatismo en el frontal de LTC1-P3 261

Figura 7.20. Lesiones traumáticas registradas en la muestra de CIRU 263

Figura 7.21. Lesión traumática en tibia izquierda de T1-PG-28 265

Figura 7.22. Lesión traumática en parietal izquierdo de T1-PG-27 265

Figura 7.23. Lesión infecciosa en el cráneo n¹2 (38) de T1-PG 271 


\section{Índice de tablas}

Capítulo 3 - Investigaciones bioarqueológicas previas en el sur del Noreste Argentino y sistematización de la información disponible

Tabla 3.1. Sitios arqueológicos con entierros humanos en el sur del Noreste Argentino

Capítulo 4 - Metodologías de análisis de las muestras bioarqueológicas

Tabla 4.1. Categorías de edad

Tabla 4.2. Clasificación de los indicadores de salud bucal

Tabla 4.3. Sistema de clasificación de caries

Tabla 4.4. Sistema de clasificación de lesiones periapicales

Tabla 4.5. Sistema de clasificación de pérdidas dentales antemortem

Tabla 4.6. Sistema de clasificación de cálculos dentales

Tabla 4.7. Clasificación de severidad de hiperostosis porótica y cribra orbitalia

Tabla 4.8. Lesiones óseas para los distintos síndromes de Treponematosis

Tabla 4.9. Principales causas que pueden generar formación de nuevo hueso periosteal

\section{Capítulo 5 - Las muestras bioarqueológicas: información contextual y primeros} resultados

Tabla 5.1 Número mínimo de individuos y estructura sexo-etaria estimada para cada sitio arqueológico

Tabla 5.2. Información sobre los individuos hallados en LTC1

Tabla 5.3. Cálculos de abundancia anatómica de los paquetes funerarios de LTC1

Tabla 5.4. Cálculos de abundancia anatómica de la acumulación ósea de LTC1

Tabla 5.5. Cálculos de abundancia anatómica de los huesos aislados de LTC1

Tabla 5.6. Fechados radiocarbónicos obtenidos para los entierros humanos de LTC1

Tabla 5.7. Datos isotópicos obtenidos para individuos de LTC1

Tabla 5.8. Información sobre los individuos hallados en LDLG2

Tabla 5.9. Fechados radiocarbónicos obtenidos para los entierros humanos de LDLG2

Tabla 5.10. Información disponible en el catálogo y resultados obtenidos de los análisis para los entierros de CL2 
Tabla 5.13. Información disponible en el catálogo y resultados obtenidos de los análisis para los entierros de SPL

Tabla 5.14. Entierros humanos de SPL sin información contextual

Tabla 5.15. Cálculos de abundancia anatómica del conjunto óseo de SPL

Tabla 5.16. Información disponible en el catálogo y resultados obtenidos de los análisis para los entierros de T1-CNM

Tabla 5.17. Entierros humanos de T1-CNM sin información contextual

Tabla 5.18. Cálculos de abundancia anatómica del conjunto óseo de T1-CNM

Tabla 5.19. Información disponible en el catálogo y resultados obtenidos de los análisis para los entierros de T2-CSM

Tabla 5.20. Cálculos de abundancia anatómica del conjunto óseo de T2-CSM

Tabla 5.21. Cálculos de abundancia anatómica del conjunto óseo de CP

Tabla 5.22. Información disponible en el catálogo y resultados obtenidos de los análisis para los entierros de T1-LA

Tabla 5.23. Cálculos de abundancia anatómica del conjunto óseo de T1-LA

Tabla 5.24. Cálculos de abundancia anatómica del conjunto óseo de EC

Tabla 5.25. Datos isotópicos obtenidos para individuos de AS

Tabla 5.26. Cálculos de abundancia anatómica del conjunto óseo de AS

\section{Capítulo 6 - Resultados: indicadores de salud bucal y adecuación fisiológica}

Tabla 6.1. Prevalencias de caries en la muestra del DS

Tabla 6.2. Características de las caries registradas en la muestra del DS

Tabla 6.3. Prevalencias de caries en la muestra de CIRU

Tabla 6.4. Características de las caries registradas en la muestra de CIRU

Tabla 6.5. Prevalencias de caries por grupo de edad en la muestra del DI

Tabla 6.6. Prevalencias de caries por sexo (en maxilares) en la muestra del DI

Tabla 6.7. Características de las caries registradas en la muestra del DI

Tabla 6.8. Prevalencias de lesiones periapicales en la muestra del DS

Tabla 6.9. Características de las lesiones periapicales registradas en la muestra del DS

Tabla 6.10. Prevalencias de lesiones periapicales en la muestra de CIRU

Tabla 6.11 Características de las lesiones periapicales registradas en la muestra de CIRU 
Tabla 6.16. Prevalencias de PDAM por grupo de edad en la muestra del DI

Tabla 6.17. Prevalencias de PDAM por sexo (en maxilares) en la muestra del DI 180

Tabla 6.18. Características de las PDAM registradas en la muestra del DI 181

Tabla 6.19. Prevalencias de cálculos dentales en la muestra del DS

Tabla 6.20. Prevalencias de los grados de depositación de cálculo dental en la muestra del DS

Tabla 6.21. Muestras de cálculo dental del DS y resultados del análisis de microrrestos vegetales

Tabla 6.22. Prevalencias de cálculos dentales en la muestra de CIRU

Tabla 6.23. Prevalencias de los grados de depositación de cálculo dental en la muestra de CIRU

Tabla 6.24. Muestras de cálculo dental de CIRU y resultados del análisis de microrrestos vegetales

Tabla 6.25. Prevalencias de cálculo dental por grupo de edad en la muestra del DI

Tabla 6.26. Prevalencias de cálculo dental por sexo (en maxilares) en la muestra del DI

Tabla 6.27. Prevalencias de los grados de depositación de cálculo dental en la muestra del DI

Tabla 6.28. Prevalencias de las formas de desgaste dental en la muestra del DS

Tabla 6.29. Prevalencias de las direcciones de desgaste dental en la muestra del DS

Tabla 6.30. Prevalencias de las formas de desgaste dental en la muestra de CIRU

Tabla 6.31. Prevalencias de las direcciones de desgaste dental en la muestra de CIRU

Tabla 6.32. Prevalencias de las formas de desgaste dental en la muestra del DI

Tabla 6.33. Prevalencias de las direcciones de desgaste dental en la muestra del DI

Tabla 6.34. Índice de sensibilidad e Índice de supervivencia de HLED y sus respectivos rankings por clase dental en la muestra del DS

Tabla 6.35. Prevalencias de HLED en la muestra del DS

Tabla 6.36. Índice de sensibilidad e Índice de supervivencia de HLED y sus respectivos rankings por clase dental en la muestra de CIRU

Tabla 6.37. Prevalencias de HLED en la muestra de CIRU

Tabla 6.38. Índice de sensibilidad e Índice de supervivencia de HLED y sus respectivos rankings por clase dental en la muestra del DI

Tabla 6.39. Prevalencias de HLED por grupo de edad en la muestra del DI 
Tabla 7.1. Prevalencias de hiperostosis porótica y cribra orbitalia en la muestra del DS

Tabla 7.2. Características de las lesiones de cribra orbitalia registradas en la muestra del DS

Tabla 7.3. Prevalencias de hiperostosis porótica y cribra orbitalia en la muestra de CIRU 224

Tabla 7.4. Características de las lesiones de hiperostosis porótica y cribra orbitalia registradas en la muestra de CIRU

Tabla 7.5. Prevalencias de lesiones infecciosas en la muestra del DS

Tabla 7.6. Prevalencias de lesiones infecciosas en la muestra de CIRU

Tabla 7.7. Prevalencias de lesiones de estrés inespecífico en la muestra del DS

Tabla 7.8. Prevalencias de lesiones de estrés inespecífico en la muestra de CIRU

Tabla 7.9. Prevalencias de lesiones de estrés inespecífico en la muestra del DI

Tabla 7.10. Prevalencias de lesiones traumáticas en la muestra del DS

Tabla 7.11. Prevalencias de lesiones traumáticas en la muestra de CIRU

Tabla 7.12. Prevalencias de lesiones traumáticas en la muestra del DI

Tabla 7.13. Síntesis de los resultados obtenidos en las muestras bioarqueológicas

\section{Apéndice 1}

Tabla A.1.1. Nomenclatura utilizada para cada tipo diente según su desarrollo

Apéndice 2

Tabla A.2.1. Cálculos de abundancia anatómica del paquete funerario LTC1-S1

Tabla A.2.2. Cálculos de abundancia anatómica del paquete funerario LTC1-S2

Tabla A.2.3. Cálculos de abundancia anatómica del paquete funerario LTC1-S4

Tabla A.2.4. Cálculos de abundancia anatómica del paquete funerario LTC1-S5

Tabla A.2.5. Integración de los resultados de las lesiones buco-dentales y óseas 


\section{Capítulo 1}

\section{Introducción}

En el presente trabajo de tesis se realiza un análisis de diferentes bioindicadores bucales y óseos, utilizando conceptos del campo disciplinar de la paleopatología. A su vez, los resultados obtenidos se integran con la información arqueológica y etnohistórica disponible, con el fin de efectuar un estudio bioarqueológico integrador. Los análisis se desarrollan comparativamente entre tres muestras bioarqueológicas, procedentes de tres áreas del sur del Noreste Argentino (NEA). La primera de estas muestras se conforma por los entierros humanos hallados en dos sitios excavados en el Delta Superior del río Paraná, como parte de los proyectos de investigación que enmarcan esta tesis. La segunda muestra pertenece a la cuenca inferior del río Uruguay y está integrada por los entierros humanos encontrados en ocho sitios que fueron excavados por el Sr. M.S. Almeida entre 1955 y 2004; este conjunto óseo se encuentra actualmente en el Museo Arqueológico Manuel Almeida (Gualeguaychú, Entre Ríos). La tercera muestra bioarqueológica corresponde al Delta Inferior del río Paraná y ambientes litorales adyacentes. Se constituye, por un lado, por los conjuntos óseos de un sitio trabajado por Almeida"; y, por otro, de dos sitios excavados a principios del siglo XX por S.K. Lohtrop y L.M. Torres, y que actualmente se encuentran bajo la custodia de la División Antropología del Museo de La Plata. Es importante remarcar que en esta tesis no se consideran para su análisis a los sitios arqueológicos guaraníes, poblaciones indígenas que arribaron tardíamente al NEA -dos siglos antes de la llegada de los europeos (Noelli 1993; Bonomo et al. 2015).

A partir de los proyectos de investigación que se encuentran en desarrollo desde las últimas décadas en estas tres áreas del sur del NEA, se ha generado un

\footnotetext{
${ }^{1}$ Este sitio estrictamente se encuentra ubicado en el Delta Medio del Paraná pero, dada su cercanía geográfica, fue agrupado en la muestra del Delta Inferior (véase en detalle Capítulo 5).
} 
gran cúmulo de información sobre los modos de vida de las poblaciones que habitaron esta región desde ca. 2000 años AP. En el marco de estos proyectos, el registro arqueológico procedente de los trabajos de campo está siendo abordado desde diversos tipos de estudio. Como ejemplo, pueden mencionarse análisis cerámicos, geoarqueológicos, líticos, arqueobotánicos, zooarqueológicos; así como también análisis de isótopos estables (Acosta 2005; Loponte 2008; Bonomo et al. 2011a, b, 2016, 2017a; Loponte et al. 2011; Castiñeira et al. 2013, 2014; Bastourre 2014; Colobig et al. 2015; Di Prado 2015; Castro, J.C. 2016; Apolinaire 2017; Ottalagano y Loponte 2017; entre muchos otros). Estos estudios se aplican además sobre colecciones de museos, que corresponden a sitios excavados principalmente a principios del siglo XX (por ej. Bourlot 2008; Bonomo et al. 2009; Bonomo 2013; Politis et al. 2017).

Sobre el extenso registro osteológico procedente de los entierros humanos, se encuentran en desarrollo estudios bioarqueológicos. El interés se ha focalizado en distintos aspectos: caracterización sexo-etaria de los conjuntos óseos, deformaciones artificiales del cráneo, estudios de marcadores de estrés ocupacional, prácticas mortuorias y variaciones morfológicas y morfométricas (por ej. Béguelin et al. 2011; Mazza y Loponte 2012; Mazza y Béguelin 2013; Castro y Del Papa 2015; Mazza 2015; Scabuzzo et al. 2015; Del Papa et al. 2016, 2018; Ramos van Raap y Bonomo 2016; Scabuzzo y Ramos van Raap 2017; Ramos van Raap 2018). Otro de los temas de análisis dentro de este campo de estudio han sido diversas patologías óseas y dentales, con el fin de conocer la salud y la dieta de las poblaciones que habitaron esta región (Kozameh et al. 2007; Kozameh y Brunás 2009, 2011, 2013; Mazza y Barrientos 2012). Estos trabajos puntuales se realizaron en conjuntos óseos procedentes de algunos sitios del Delta Superior e Inferior del río Paraná y generalmente han sido a nivel intrasitio. Al considerar estos antecedentes y la importancia que posee este tipo de estudio al contribuir con información valiosa sobre los modos de vida de los grupos humanos del sector meridional del NEA, esta tesis constituye un aporte novedoso; y, de esta forma, se da inicio a análisis paleopatológicos sistemáticos.

En el Delta Superior del río Paraná (DS), se están llevando a cabo proyectos de investigación de largo plazo desde el 2006 bajo la dirección de los Drs. G. Politis 
y M. Bonomo; dentro de estos proyectos se enmarca esta tesis. Los trabajos arqueológicos sistemáticos tienen como fin conocer los patrones adaptativos y las trayectorias históricas de las poblaciones prehispánicas que habitaron el área durante el Holoceno tardío (Bonomo et al. 2010; 2011b). Dentro del mismo equipo y articulado con los estudios del Delta Superior, en el 2009 comenzaron a realizarse investigaciones arqueológicas sistemáticas sobre la margen derecha de la cuenca inferior del río Uruguay (CIRU), a cargo del Dr. J.C. Castro. Las mismas están orientadas a estudiar las ocupaciones prehispánicas y abordar las relaciones de estos grupos con los de áreas vecinas, como lo es el Delta del Paraná (Castro, J.C. 2016, 2017). En cuanto al Delta Inferior del río Paraná y ambientes litorales adyacentes (DI), el equipo de trabajo dirigido por los Drs. D. Loponte y A. Acosta se encuentra desarrollando investigaciones desde el 1991; en primer lugar, en el Noreste de Buenos Aires y luego desde 2002 en el sur de Entre Ríos. Su principal objetivo es comprender los procesos de colonización y ocupación humana del área definida como "Humedal del Paraná Inferior" (Acosta 2005; Loponte 2008).

A partir de los resultados obtenidos de las distintas líneas de análisis efectuadas en el marco de estos proyectos, se pudieron obtener datos precisos y hacer interpretaciones sobre diferentes aspectos de los grupos que habitaron estas áreas. El régimen hídrico que caracteriza a estos sectores es muy dinámico, generando recurrentes períodos de inundaciones. Frente a este contexto ambiental, la ocupación de lugares elevados habría funcionado como refugio frente a las crecidas del nivel del río. En el caso del DS, los sitios monticulares (antrópicamente elevados) fueron los asentamientos residenciales principales, ocupados de forma semi-permanente y en algunos casos constituyendo aldeas. Algunos sitios con menor densidad de ocupación sobre lugares elevados de forma natural, sobre todo albardones, habrían servido para la explotación de determinados recursos animales (por ej. ciervo de los pantanos y coipo; Politis et al. 2011; Politis y Bonomo 2012; Bonomo et al. 2014, 2016; Castiñeira et al. 2017a). En CIRU, además de la existencia de montículos como asentamientos residenciales y multifuncionales, se detectaron canteras-taller, campamentos de pesca y/o caza y puntos de recolección de moluscos y productos vegetales (Castro, J.C. 2017). Por su parte, en el DI, la mayoría de los sitios se ubican en geoformas elevadas naturalmente y también se reconocieron recientemente 
algunos asentamientos sobre elevaciones antrópicas (Acosta et al. 2013; Loponte et al. 2015, 2016).

En cuanto a la economía de los grupos que habitaron el DS, se basaba principalmente en la pesca y la caza de mamíferos acuáticos y terrestres, complementada con la recolección de vegetales silvestres (algarrobo, palmeras y arroz) y la horticultura de la tríada maíz-zapallo-poroto (Bonomo et al. 2011b; Sánchez et al. 2013; Bastourre 2014; Colobig et al. 2014). Los alimentos cultivados no habrían sido un componente importante en la dieta, sino más bien complementarios a los otros recursos consumidos (Bonomo et al. 2011a, 2017a). Para CIRU se evidenció la explotación de recursos faunísticos de distintos nichos ecológicos, siendo probablemente los peces un componente importante en la dieta. De acuerdo a la presencia arqueobotánica de frutos de palmeras y fitolitos afines a gramíneas, también se aprovecharon diferentes recursos vegetales. Si bien no fueron encontrados registros de cultivo de plantas, se plantea la posibilidad de la existencia de horticultura (Castro, J.C. 2017). En cuanto al DI, se practicó la pesca intensiva y la explotación sistemática de cérvidos y de medianos y pequeños roedores. Asimismo, los recursos vegetales fueron un importante complemento alimenticio, dada la presencia de fitolitos graminoides en cálculo dental y abundante cantidad de frutos de palmeras (Acosta 2005; Loponte 2008; Zucol y Loponte 2008; Acosta y Loponte 2013). También se identificaron restos botánicos de algarrobo, porotos, maíz y probable mandioca, sugiriendo el posible desarrollo de prácticas hortícolas (Bonomo et al. 2011a).

\subsection{Objetivos generales y específicos}

Los objetivos generales de este trabajo de tesis son:

- Caracterizar la salud y la dieta de las poblaciones que habitaron el Delta Superior del río Paraná, la cuenca inferior del río Uruguay y el Delta Inferior del río Paraná durante el Holoceno tardío, a partir del análisis paleopatológico de distintos bioindicadores óseos y bucales. 
- Discutir los resultados obtenidos de los distintos bioindicadores analizados, con la información arqueológica disponible para las áreas geográficas consideradas y así aportar al estudio de los modos de vida de los grupos prehispánicos que habitaron el sur del Noreste Argentino.

A partir de estos objetivos generales, se enuncian los siguientes objetivos específicos:

- Evaluar, para cada muestra bioarqueológica, la distribución y prevalencias de los indicadores óseos y dentales según el sexo y la edad de los individuos.

- Comparar las prevalencias, distribución e intensidad de los bioindicadores entre las tres muestras bioarqueológicas.

- Discutir el consumo de recursos vegetales y las posibles formas de procesamiento de los alimentos, principalmente mediante la evaluación de caries, cálculo dental y desgaste.

- Discutir sobre la intensidad de las ocupaciones en los sitios monticulares y la presencia de aldeas, a partir de la frecuencia de patologías infecciosas e indicadores de estrés metabólico.

\subsection{Expectativas paleopatológicas}

A partir de la información arqueológica sobre los modos de vida de los grupos que habitaron las áreas de estudio, es posible formular un conjunto de expectativas paleopatológicas que podrán ser discutidas a través del análisis bioarqueológico. Tal como fue mencionado antes y como se expone detalladamente en el Capítulo 3, los grupos humanos que habitaron el sur del NEA poseían una dieta basada en la explotación de diferentes especies animales y vegetales, mediante la caza, pesca y recolección. Los estudios isotópicos realizados en huesos humanos del Delta del río Paraná expresan el consumo predominante de plantas $C_{3}$, que podrían incluir tanto a especies silvestres como domesticadas (Bonomo et al. 2017a). Estas especies vegetales explotadas se caracterizan por presentar cantidades considerables de almidones y azúcares. A partir de estos datos y considerando la vinculación entre el 
desarrollo de caries y el consumo de carbohidratos, es esperable que los patrones de salud bucal correspondan a los observados en poblaciones con dietas mixtas. Asimismo, los análisis efectuados sobre el registro cerámico (Naranjo et al. 2010; Bonomo et al. 2012; Castro, C. 2018), sugieren que la preparación y cocción de los alimentos habría disminuido su dureza y fibrosidad (Molnar 1972; Hinton 1981; Smith 1984; Scott y Turner 1988). En conjunto, estos aspectos se traducirían, principalmente, en bajas a moderadas prevalencias de caries, de pérdidas dentales antemortem y de lesiones periapicales y moderados grados de desgaste coronario.

Otro aspecto a discutir se vincula con las características ambientales y los lugares de ocupación residencial elegidos por las poblaciones. La alta susceptibilidad hidrometeorológica que caracteriza a las áreas bajo estudio habría impactado en los sistemas de asentamiento y las estrategias de explotación de los recursos. De acuerdo a las investigaciones desarrolladas particularmente en DS, se han identificado al menos dos tipos de asentamientos: los campamentos residenciales ocupados de forma semipermanente y que no se verían afectados por las inundaciones estacionales (sitios monticulares); y los campamentos transitorios orientados a explotar recursos particulares y ubicados en lugares expuestos a los aumentos del nivel del río (sitios sobre albardones) (Castiñeira et al. 2017a). En el caso de CIRU y DI, los asentamientos establecidos en sitios monticulares también habrían funcionado como una solución frente a los anegamientos producidos por las inundaciones (Loponte et al. 2016; Castro, J.C. 2017). En este contexto, durante los períodos de regímenes hídricos altos, habría ocurrido un nucleamiento poblacional en los montículos durante períodos prolongados de tiempo. Por otro lado, en las fuentes etnohistóricas, algunos exploradores hacen mención a la existencia de conjuntos de viviendas formando un gran asentamiento (Politis 2014). Sería esperable, entonces, que estos tipos de asentamientos generen un aumento de la incidencia y prevalencia de enfermedades infecciosas de transmisión directa y/o asociadas con las condiciones de higiene y salubridad (por ej. enfermedades gastrointestinales). Como ya fue mencionado en otros trabajos (por ej. García Guraieb 2010), los infantes y niños podrían haber sido los individuos más vulnerables frente a este entorno, dado que en estos primeros años de vida desarrollan su sistema inmunológico y atraviesan el 
proceso de destete, mediante el cual incorporan nuevos alimentos y se exponen a nuevos patógenos. Este escenario podría haber propiciado episodios de estrés sistémico, los cuales pueden ser evaluados a partir de distintos indicadores (por ej. hipoplasias del esmalte dental, cribra orbitalia e hiperostosis porótica).

Finalmente, las fuentes escritas sobre las expediciones europeas en el extremo sur de la cuenca del Plata señalan la existencia de distintas etnias o diferentes parcialidades de una misma etnia. Más allá de las menciones sobre algunos conflictos resultantes del contacto, no se explicitan enfrentamientos entre los distintos grupos (Politis 2014; Apolinaire y Bastourre 2016a). De hecho, en varios documentos se hace referencia a la coexistencia pacífica entre varios de estos grupos, y que habrían establecido alianzas entre ellos a la llegada de los guaraníes (véase síntesis etnohistórica en Apolinaire y Bastourre 2016a). En concordancia con estos datos, y teniendo en cuenta los fechados disponibles para algunos de los sitios incluidos en este trabajo -anteriores a la llegada de los guaraníes-, sería esperable encontrar bajas prevalencias de lesiones óseas traumáticas producto de violencia interpersonal.

\subsection{Estructura de la tesis}

Este trabajo de tesis fue estructurado en ocho capítulos. El presente apartado -Capítulo 1-, como fue expuesto, incluye la presentación de esta investigación, los objetivos y las expectativas paleopatológicas. En el Capítulo 2 se exponen los principales enfoques, premisas y conceptos teóricos que guiaron los estudios desarrollados. Asimismo, se resumen los estudios sobre salud y dieta que han sido realizados en distintas regiones de Argentina. El Capítulo 3 sintetiza el desarrollo histórico de las investigaciones arqueológicas en el sur del Noreste Argentino, así como también las propuestas actualmente vigentes para explicar los modos de vida de los grupos humanos que habitaron las tres áreas consideradas en la tesis. Finalmente, se compila y sistematiza la información existente sobre el registro bioarqueológico y cuáles han sido los análisis realizados, principalmente los paleopatológicos. En el Capítulo 4 se detallan las metodologías aplicadas en los análisis. Asimismo, para cada uno de los indicadores bucales y óseos considerados, 
se presentan las características de su formación y desarrollo. El Apéndice 1 incluye las fichas de análisis confeccionadas y utilizadas en los relevamientos llevados a cabo de los distintos indicadores. En el inicio del Capítulo 5 se presenta la información ambiental de las áreas bajo estudio, así como también la estructura sexo-etaria de las muestras bioarqueológicas y los perfiles de edad de muerte obtenidos para cada una de ellas. Posteriormente, para cada sitio de procedencia, se detalla la información arqueológica contextual, las características de los entierros humanos y la conformación de cada conjunto osteológico (número mínimo de individuos y estructura sexo-etaria). En el Apéndice 2 se incluyen tablas accesorias a la información presentada en este capítulo. En los Capítulos 6 y 7 se exponen, analizan y discuten los resultados obtenidos del relevamiento de los indicadores bucales y óseos, respectivamente. En el Apéndice 2 también se incorpora una tabla integradora de los resultados obtenidos en estos capítulos. El Capítulo 8 constituye la integración y discusión general de la información generada en esta tesis con la disponible desde diferentes líneas de análisis y se evalúan las expectativas paleopatológicas aquí propuestas. Finalmente, se exponen las conclusiones que culminan esta investigación. 


\section{Capítulo 2}

\section{Consideraciones teórico-conceptuales}

Este trabajo de tesis, tal como fue desarrollado en el capítulo anterior, aborda el estudio de conjuntos óseos y dentales procedentes de sitios arqueológicos del extremo meridional del Noreste Argentino. Específicamente, se realiza el análisis de diferentes patologías, utilizando concepciones del campo disciplinar de la paleopatología. Los resultados obtenidos se integran con la información arqueológica y etnohistórica disponible, con el fin de efectuar un análisis bioarqueológico integrador y holístico y aportar al conocimiento de los modos de vida de los grupos que habitaron esta región en el Holoceno tardío. En este capítulo se exponen los principales enfoques y premisas teórico-conceptuales que guían tal estudio, y que sustentan las aproximaciones metodológicas desarrolladas en el Capítulo 4. En el apartado final, se resumen brevemente los estudios sobre salud y dieta que han sido desarrollados en las distintas regiones de Argentina.

\subsection{El abordaje de la salud de las poblaciones humanas del pasado}

Al considerar las distintas fases del desarrollo de la paleopatología como disciplina científica, se han esbozado diferentes definiciones de este campo de estudio. Una de ellas es la que propone Ortner (2003), quien la define como:

"the study of disease, both human and nonhuman, in antiquity using a variety of different sources including human mummified and skeletal remains, ancient documents, illustrations from early books, painting and sculpture from the past, and analysis of coprolites" (2003: 8).

Posteriormente, Zuckerman y colaboradores (2012) ofrecen una definición más restringida que la anterior, al focalizar que la paleopatología se encarga de investigar "the evolution of human diseases, the dynamic interactions between human societies 
and infectious and noninfectious disease, and ways in which humans have adapted to changes in their environments" (Zuckerman et al. 2012: 34).

Numerosos autores han ofrecido revisiones históricas detalladas sobre la paleopatología como disciplina científica (por ej. Aufderheide y Rodríguez-Martin 1998; Ortner 2003; Cook y Powell 2006; Zuckerman et al. 2012). Los comienzos de este campo del conocimiento se remontan al siglo XIX cuando se presentan los primeros estudios sistemáticos de diversas patologías, si bien en el siglo anterior ya se habían realizado algunas identificaciones de enfermedades en huesos fósiles de animales. Estos primeros estudios describían y diagnosticaban lesiones óseas en casos individuales, y eran realizados por médicos y anatomistas que tenían como objetivo documentar la variación morfológica humana. A principios del siglo XX se ubican los primeros análisis focalizados en relevar las frecuencias patológicas a nivel poblacional y examinar las influencias ecológico-culturales en muestras esqueletales, como el realizado por Hooton en 1930. Este autor, a su vez, interpreta contextualmente las lesiones observadas con información cultural, conductual y temporal, lo cual constituye un aporte novedoso en comparación a lo realizado hasta entonces. Sin embargo, este tipo de investigación no tuvo continuidad.

Después de un período de estancamiento -dominado por enfoques descriptivos, particularistas y tipológicos-, la década de 1960 estuvo marcada por el surgimiento de la paleopatología moderna. El desarrollo de la arqueología procesual, la aparición de enfoques ecológicos y bioculturales, y el reconocimiento de los indicadores de estrés esquelético, produjeron una transformación en el estudio de las enfermedades del pasado (Zuckerman et al. 2012). Una de las mayores influencias en la paleopatología de estos nuevos paradigmas y concepciones teóricas, fue la adopción del enfoque biocultural para abordar la salud. Éste surge en la Antropología entre 1960 y 1980 desde el enfoque ecológico y la Nueva Arqueología, y enfatiza explícitamente la interacción dinámica entre los humanos y sus entornos sociales, culturales y físicos (Zuckerman et al. 2012). En este contexto, en el campo disciplinar de la paleopatología, empezaron a cobrar interés las perspectivas ecológicas, el testeo de hipótesis y los análisis regionales. Asimismo, se iniciaron estudios sobre los procesos de adaptación de las poblaciones pasadas, indagando en los efectos sobre la salud humana de varios factores como el comercio, la agricultura, el sedentarismo 
y el contacto cultural (Cohen y Armelagos 1984; Armelagos 2003; Armelagos y Van Gerven 2003).

La investigación paleopatológica con orientación biocultural "focuses on examining patterns of pathologies in order to elucidate the effects of social, ecological, and political processes on health within and between populations" (Zuckerman et al. 2012: 39). En este sentido, se sostiene que la tecnología, el sistema social y las ideologías de una sociedad pueden impactar en la biología de los individuos. Bajo este enfoque biocultural, aún con vigencia en la actualidad, se generó un gran acervo de información sobre el diagnóstico de enfermedades, los indicadores no específicos de estrés, los signos de violencia, entre otros (por ej. El-Najjar et al. 1976; Cook 1979; Buikstra y Cook 1980; Larsen 1983, 1984; Stuart-Macadam 1985; Goodman y Armelagos 1989; Walker 1989; Jurmain 1990). Además, se fueron desarrollando manuales específicos sobre distintas patologías (por ej. Steinbock 1976; Ortner y Putschar 1981). Este crecimiento de los estudios de las enfermedades del pasado, estuvo acompañado también de la utilización de nuevas técnicas y metodologías procedentes de otros campos disciplinares, como la medicina clínica y de laboratorio; la utilización de información genética permitió a su vez el diagnóstico más preciso de algunas enfermedades, como por ejemplo la tuberculosis, lepra y sífilis (Buikstra 2006).

Además del enfoque biocultural, también se ha propuesto otro tipo de abordaje para el estudio de las enfermedades humanas. Se trata de adoptar un enfoque contextual bioarqueológico en los análisis paleopatológicos (Buzon 2012). La principal ventaja de encarar los estudios bajo esta aproximación radica en que, al integrar la arqueología en el estudio de la enfermedad, la paleopatología puede desarrollar una interpretación más completa e integradora de la salud y enfermedad del pasado. Asimismo, se puede alcanzar una mayor contribución a temas antropológicos más amplios (Buzon 2012). Desde esta perspectiva, se enfatiza la importancia de la presencia de los paleopatólogos en las excavaciones de entierros humanos, ya que ayudaría a comprender aspectos relacionados con el muestreo y recuperación de especímenes; también conocer las estructuras domésticas proporciona valiosa información para conocer sobre el entorno de vida de las personas y cómo ello influye en las posibles enfermedades a desarrollarse. Este 
enfoque se sustenta, por un lado, en que los estudios de enfermedades constituyen uno de los aspectos que interesa abordar en las investigaciones bioarqueológicas y, por otro, en la visión holística de la bioarqueología definida por Buikstra (Buzon 2012).

En 1977, la investigadora estadounidense Jane Buikstra propone el término Bioarqueología como un programa de investigación integrador y multidisciplinar sobre restos óseos humanos de sitios arqueológicos. Según la autora, el estudio osteológico integra diferentes problemáticas: organización social y funeraria; patrones de actividad y división de tareas; paleodemografía; movimiento poblacional; relaciones genéticas; dieta y enfermedad (Buikstra 1977). De esta forma, la bioarqueología permite abordar problemáticas antropológicas a nivel poblacional, dejando atrás los viejos abordajes descriptivos y generando hipótesis para evaluar la relación entre los procesos culturales y la biología humana (Buikstra 1991, 2006). Se constituye como una disciplina de amplio rango, que se nutre teórica y metodológicamente de distintas áreas del conocimiento, entre ellas la paleopatología (Larsen y Walker 2010; Buzon 2012; Suby 2012). En las últimas décadas, la bioarqueología ha crecido sustancialmente por la colaboración entre las subdisciplinas antropológicas y por abordar los estudios desde concepciones de la biología humana, la teoría social y económica, el ritual mortuorio, la identidad y la organización social (Buikstra y Beck 2006; Martin et al. 2013).

En el marco de las investigaciones osteoarqueológicas británicas, la arqueóloga Joanna Sofaer (2006) trata de saldar la brecha entre la arqueología y la osteoarqueología y defender el tipo de investigación propuesto por Buikstra (Buzon 2012). La autora propone entender al esqueleto humano como un tipo de cultura material y un fenómeno histórico, que se construye a través de las interacciones del individuo con su entorno. En este sentido, el cuerpo es comprendido como la representación de la experiencia vivida de una persona, por lo que al estudiarlo se observan las consecuencias esqueléticas de lo que las personas hicieron y cómo vivieron (Sofaer 2006: 45). Las determinaciones sexo-etarias y la observación de lesiones patológicas no son más que los primeros pasos para abordar luego aspectos antropológicos más amplios (Sofaer 2006). 


\subsection{Conceptos de salud, enfermedad y estrés}

El enfoque biocultural, como fue mencionado anteriormente, aboga por la existencia de la compleja interacción dinámica entre los individuos y su ambiente natural y cultural. Bajo esta concepción general, los huesos y los dientes son entendidos como "sistemas abiertos, dinámicos, históricos y adaptativos" (Luna 2006: 256). De esta forma, distintos estresores -estímulos presentes en el contexto socioambiental en el que se encuentra el individuo- influyen en el cuerpo y éste en consecuencia se modifica como una respuesta adaptativa (Selye 1956; Goodman et al. 1984; Bush 1991; Luna 2006). Si bien durante las etapas de crecimiento y desarrollo los tejidos óseos y dentales se encuentran más susceptibles a los estresores, pueden experimentar cambios durante todo el ciclo vital del individuo. Por lo tanto, el estudio de los esqueletos y la dentición permite abordar diferentes aspectos, como por ejemplo la dieta, la nutrición, la enfermedad y el uso del cuerpo de las poblaciones del pasado (Huss-Ashmore et al. 1982; Goodman et al. 1988; Larsen 1997; Armelagos y Van Germen 2003; Zuckerman et al. 2012). En este marco conceptual, la salud y la enfermedad son consideradas como estados dentro de un continuum, que reflejan la adaptación biológica de los individuos a su ambiente (Bush 1991; Bush y Zvelevil 1991; Goodman 1991).

Las interpretaciones bioarqueológicas sobre la salud de las poblaciones del pasado se basan en un conjunto de datos procedentes de diferentes marcadores esqueléticos de estrés (Goodman 1993; Larsen 1997; Cook y Powell 2006; Reitsema y Mcllvaine 2014). El estrés puede ser definido como cualquier disrupción fisiológica ocasionada por la incidencia, sobre un organismo, de cualquier perturbación del ambiente (Selye 1956; Goodman et al. 1984). Existen dos tipos de estrés: agudo o crónico; mientras el primero es acotado temporalmente, el segundo se manifiesta durante lapsos más prolongados. Goodman y colaboradores (1988), desarrollaron un modelo biocultural del estrés para su aplicación en bioarqueología, el cual examina las formas en las que los estresores afectan la adaptación. Según este modelo, el impacto de un evento de estrés se produce por tres factores que interactúan sinérgicamente: las restricciones ambientales, el sistema sociocultural y la resistencia individual. Asimismo, focalizan en la consideración de tres premisas fundamentales: 
1) el estrés constituye una respuesta a los estresores y no debe entenderse como un estímulo en sí mismo; 2) esta respuesta es inespecífica; 3) ante una situación de estrés, el organismo responde mediante un síndrome general de adaptación, conformado por tres fases (la reacción de alarma, la resistencia del organismo y finalmente, el colapso o la nueva adaptación). Por otro lado, los autores manifiestan que así como el sistema cultural puede ofrecer los mecanismos para amortiguar la situación de estrés, también puede producirlo. Según este modelo, las respuestas que genera el estrés podrían catalogarse jerárquicamente; de tal forma, mientras los tejidos blandos se ven afectados durante un estrés agudo, las condiciones crónicas alcanzarían el nivel de los tejidos óseos (Goodman et al. 1988; Bush y Zvelebil 1991).

Un aspecto relevante que debe ser tenido en cuenta en las interpretaciones bioarqueológicas es que los marcadores de estrés analizados no son reflejo directo de la salud que tuvieron esos individuos en vida. En este sentido, lo que se está evaluando no es la salud, sino las situaciones de estrés a las cuales estuvieron expuestas las personas (Temple y Goodman 2014). Por otro lado, las autopercepciones de la salud y calidad de vida que tuvieron las poblaciones pasadas puede (y seguramente sea así) no coincidir con el estado fisiológico de una persona, que se observa mediante un marcador de estrés (Reitsema y Mcllvaine 2014). En definitiva, para realizar aproximaciones sobre la calidad de vida, las experiencias de vida y la salud de poblaciones humanas mediante conjuntos esqueléticos, es importante evaluar múltiples indicadores de estrés (Steckel y Rose 2002; Reitsema y Mcllvaine 2014).

\subsection{Críticas al enfoque biocultural y propuestas alternativas}

En la década de 1990 comenzaron a exponerse críticas frente a la manera en la que el modelo biocultural realizaba las interpretaciones sobre la salud de los grupos humanos. Específicamente, se refutaba la idea de la existencia de una relación directa entre lo observado en las series esqueletales analizadas y lo experimentado por los individuos de las poblaciones que las generaron (Wood et al. 1992). 
Uno de los primeros trabajos que expone los problemas que acarrea el enfoque biocultural es el de Wood y colaboradores (1992), quienes integran esta serie de limitaciones bajo el término "Paradoja Osteológica". En este trabajo, los autores advierten la imposibilidad de obtener interpretaciones directas y no ambiguas en el estudio de la salud del pasado, debido a la presencia de tres problemas conceptuales. El primer aspecto que puntualizan es sobre la demografía no estacionaria, es decir, se asume que las poblaciones de las cuales derivan las muestras bajo estudio son estables, cuando en realidad la estructura poblacional es altamente dinámica. En este sentido, las investigaciones bajo un enfoque biocultural no consideran la existencia de migraciones y suponen una edad de fertilidad y mortalidad constante, una tasa de crecimiento nula y una distribución etaria equilibrada. El segundo aspecto -la mortalidad selectiva- hace hincapié en que en una muestra esqueletal nunca se posee a todos los individuos que estaban en riesgo de padecer enfermedad o morir a causa de ella, a determinada edad durante su vida. Por lo tanto, todas las series esqueletales son poco representativas de las poblaciones originales respecto a los riesgos de muerte a los que estaban expuestos los individuos; es así como las frecuencias observadas de condiciones patológicas sobrestiman la prevalencia de las condiciones reales que experimentaron los grupos humanos. Finalmente, los autores refieren al problema de la heterogeneidad oculta, según el cual las personas que conforman la población de estudio varían en cuanto a su fragilidad o susceptibilidad a las enfermedades. Esta situación es debido a diferentes aspectos, como por ejemplo factores genéticos, socioeconómicos y ambientales. Por lo tanto, se vuelve imposible interpretar las tasas de mortalidad por edad, en términos de riesgos individuales de muerte.

Los autores también enfatizan que las interpretaciones que se han hecho sobre la presencia y/o ausencia de lesiones óseas en distintas muestras esqueletales pueden significar otra cosa. En este sentido, la ausencia de patologías no refiere exclusivamente a un buen estado de salud en esa población. Esto es, un esqueleto sin lesiones óseas puede representar tanto a un individuo saludable como a uno que estaba lo suficientemente débil como para morir frente a la exposición a un patógeno, sin dar tiempo a la respuesta ósea. Por otro lado, aquellos esqueletos que sí poseen lesiones óseas pueden haber experimentado una menor probabilidad de morir, ya 
que pudieron sobrevivir a la presencia de la enfermedad. Frente a este contexto con el cual se enfrentan los estudios sobre la calidad de vida de las poblaciones que vivieron en el pasado, Wood et al. (1992) resaltan dos hechos inevitables: 1) es imposible hacer estimaciones directas sobre las tasas demográficas y epidemiológicas a partir de muestras arqueológicas y 2) las inferencias sobre la salud deben basarse en estadísticas a nivel poblacional, si bien la salud es una característica biológica individual. En búsqueda de solucionar alternativamente estas cuestiones, proponen lo siguiente: 1) investigar sobre las causas que generan la heterogeneidad en las poblaciones modernas; 2) realizar investigaciones demográficas para evaluar cómo la susceptibilidad de los individuos a determinadas patologías se pude relacionar con el riesgo de muerte; 3) mejorar el entendimiento de los procesos patológicos a nivel del individuo y cómo el riesgo de muerte y su susceptibilidad varían según los procesos involucrados en distintas enfermedades; y 4) mejorar la comprensión del papel que tienen los contextos culturales en la heterogeneidad de los riesgos y la mortalidad selectiva.

Este trabajo de Wood et al. (1992) causó gran impactó en el ámbito bioarqueológico generando gran cantidad de adeptos y estimulando un periodo de debate que, según Wright y Yoder (2003: 45), ha fortalecido la disciplina. Sin embargo, algunas críticas no tardaron en llegar. Al año siguiente de dicha publicación, Goodman (1993) expone algunas falencias de la Paradoja Osteológica, alegando que no valora numerosas variables que resultan indispensables en los estudios patológicos. Goodman (1993) propone la utilización de múltiples indicadores de la salud (por ej. la edad, el sexo, la estatura, el contexto social, económico y ambiental y los diferentes tipos de lesiones óseas). El autor recomienda en definitiva no quedarse en la descripción, sino corroborar los datos obtenidos del análisis paleopatológico con otro tipo de información arqueológica (Goodman 1993). En consonancia con esto, Wright y Yoder (2003) señalaron la necesidad de considerar información isotópica, molecular y paleodietaria en los estudios paleopatológicos, dado que permitirían examinar la variabilidad y la susceptibilidad individual a la enfermedad y a la muerte. Siguiendo esta misma línea de investigación multidisciplinar, Klaus (2014) hace un llamamiento a que los bioarqueólogos utilicen información de otros campos de estudio, principalmente de la fisiopatología y la 
biología molecular. Esto permitirá, según el autor, examinar y enriquecer de forma continua el concepto de "estrés" así como también tener una mejor comprensión de los factores, procesos y etiologías que impulsan la formación de lesiones patológicas (Klaus 2014).

\subsection{Sobre la representatividad de las muestras bioarqueológicas}

Tal como fue expuesto en el apartado anterior, la principal crítica que recibió el enfoque biocultural se relaciona con su interpretación de que los esqueletos recuperados en un sitio arqueológico son representativos de las poblaciones de las que formaron parte esos individuos en vida; y, por lo tanto, que los cambios observados en las muestras esqueletales reflejan los cambios reales que esa población atravesó (Cohen et al. 1994). Al considerar este aspecto principal y los tres problemas que puntualizó la Paradoja Osteológica, resulta imprescindible el planteo sobre la representatividad que poseen las muestras bioarqueológicas analizadas sobre las poblaciones vivas que las produjeron. En este sentido, según Waldron (1994), el escaso control que un investigador posee sobre las muestras que analiza incide directamente sobre los estudios realizados; este sesgo inevitable se manifiesta a partir diversos factores intrínsecos y extrínsecos (Waldron 1994), los cuales se mencionan a continuación.

El factor intrínseco está dado por la naturaleza misma de las muestras esqueletales estudiadas, esto es entenderlas como una población muerta y no viva. Considerando este aspecto básico, generalmente pasado por alto en los estudios, no es posible comparar directamente la muestra con cualquier población moderna sobre las cuales se construyen y toman modelos epidemiológicos. Los factores extrínsecos, en cambio, son aquellos aspectos independientes de las características biológicas de las poblaciones y que conducen a una reducción del número de la muestra respecto de la población viva que la origina. El primero de estos factores se relaciona con el hecho de que la muestra estudiada está constituida por los individuos fallecidos que son efectivamente sepultados en el sitio. En este punto, juegan un rol primordial los aspectos sociales e ideacionales vinculados con las prácticas mortuorias, dado que 
todas aquellas decisiones en cuanto a la forma y lugares elegidos para enterrar a los individuos crean variabilidad en la composición de la muestra esqueletal a estudiar. Además de este primer aspecto, hay que considerar los procesos postdepositacionales que afectan a los elementos óseos; no sólo los que inciden en la conservación y preservación y que modifican la proporción de los huesos recuperados, sino también los que pueden alterar características óseas y obstaculizar las determinaciones sexo-etarias y la identificación de patologías, por ejemplo. Un tercer factor que reduce aún más la muestra esqueletal, está relacionado con las prácticas arqueológicas que se diseñan y llevan a cabo en los sitios excavados. Por un lado, numerosas veces los entierros pueden ser encontrados a partir de actividades antrópicas como el uso de maquinarias o construcciones, lo cual genera daños en los registros y contextos. Por otro lado, cuando se trata de las actividades de campo de los arqueólogos, en algunos casos no suelen ser excavados en su totalidad los contextos mortuorios por diferentes motivos (por ej. tiempo, presupuesto), reduciendo también el conjunto osteológico. Finalmente, y relacionado con el factor anterior, durante las excavaciones no todos los huesos pueden ser recuperados dada su fragilidad o condición de preservación. Asimismo, el manejo y conservación del material extraído de los sitios puede sufrir alteraciones en sus lugares de guarda y custodia, incluso varios años después de su hallazgo. De qué manera y cuánto han impactado cada uno de estos factores sobre las muestras bioarqueológicas a estudiar resulta muy difícil de conocer, pero aun así es importante tenerlos siempre en cuenta cuando se realizan estudios bioarqueológicos.

Además de estos factores mencionados, debe contemplarse la dimensión temporal de la muestra esqueletal analizada (Waldron 1994). En términos generales, los entierros humanos excavados en un sitio arqueológico representan individuos que murieron en períodos temporales amplios (cientos a miles de años; en algunos casos excepcionales pueden presentar un rango cronológico acotado). De esta manera, el conjunto de los entierros presentes en un sitio arqueológico tiene una resolución temporal promediada del período durante el cual se enterraron esos individuos. Por lo tanto, si durante el transcurso del uso del área funeraria existieron cambios en las condiciones de vida que impactaron en la salud de las personas, tales cambios podrían permanecer ocultos en los análisis (Boldsen y Milner 2012). 


\subsection{Estudios sobre la salud de las poblaciones pasadas en Argentina}

En la segunda mitad del siglo XIX se conforman algunas instituciones y museos (por ej. Sociedad Científica Argentina, Academia de Ciencias en Córdoba y el Museo de La Plata), los cuales condujeron a la consolidación de la Antropología Biológica como disciplina independiente de las Ciencias Naturales en Argentina (Carnese et al. 1991-1992). En este contexto comenzó a formarse, por ejemplo, la colección osteológica del Museo de La Plata; en un principio a partir de cráneos y esqueletos que reunió Francisco P. Moreno durante sus expediciones y luego se fueron incorporando conjuntos procedentes de donaciones, compras y viajes auspiciados por el museo a distintas regiones del país (Farro 2008) ${ }^{1}$.

En los inicios de las investigaciones antropobiológicas (Carnese et al. 19911992; Guichón 1994; Carnese y Pucciarelli 2007) surgen los primeros estudios osteológicos, caracterizados por la descripción y clasificación de los huesos para la determinación de la antigüedad de los primeros humanos en el territorio (por ej. Ameghino 1880, 1889; Lehmann Nitsche 1907). También predominaron los enfoques tipológicos y raciales, con el fin de asignar los restos humanos a algunas de las "razas" propuestas a partir de la evaluación de las características morfológicas (por ej. ten Kate 1892; Imbelloni 1938; Vignati 1938). Por otro lado, durante estas épocas ocurren

\footnotetext{
${ }^{1}$ Los objetivos de los primeros trabajos sobre los conjuntos óseos recuperados en distintas situaciones y almacenados en los museos, focalizados en la craneometría para las clasificaciones raciales, se tradujo en un mayor interés sobre los cráneos por sobre el esqueleto postcraneal (Castro et al. 2009). Además, los contextos arqueológicos eran descartados, o bien una vez trasladados al museo, eran disasociados de los conjuntos óseos (Bordach et al. 2003). Como claro ejemplo de ello pueden mencionarse a las colecciones procedentes del Delta del Paraná depositadas en el Museo de La Plata: mientras que los huesos humanos pasaban a formar parte de la Sección Antropología, los distintos restos arqueológicos de los mismos sitios eran llevados a la Sección Arqueología. Recién a inicios de 1900, Lehmann-Nitsche ordenó las colecciones osteológicas de la Sección Antropología del museo y elaboró un catálogo sistemático de todo lo allí contenido, publicado en 1910. Debido que para la mayoría de los conjuntos óseos sólo se contaba con las regiones donde habían sido hallados, el criterio de catalogación de las colecciones siguió un orden geográfico (Podgorny 1999; Farro 2008).
} 
las primeras descripciones de lesiones óseas (por ej. Ambrosetti 1895; Verneau 1903; Torres 1911). Asimismo, se resalta la creación de un "gabinete de patologías" en el Museo de La Plata por el entonces encargado de las colecciones óseas de la institución, Lehmann Nitsche (Farro 2008). Este investigador estudió la incidencia de artritis deformante, osteonecrosis, periostitis y osteítis entre los antiguos Patagones y comparó los resultados con estudios realizados en las poblaciones de la Europa moderna (Lehmann Nitsche 1904).

Las concepciones tipológicas y el interés por las clasificaciones raciales comenzaron a dejarse de lado hacia la década de 1960, cuando se empezó a adoptar un enfoque evolutivo neodarwiniano en los estudios antropobiológicos, y por extensión los realizados sobre huesos humanos (Carnese et al. 1991-1992; Bordach et al. 2003; Carnese y Pucciarelli 2007; Mendonça de Souza y Guichón 2012). A partir de entonces, la población pasó a ser la unidad de análisis empleada en los estudios y los cambios en los grupos fueron explicados a través de procesos microevolutivos. También comenzó a enfatizarse la incidencia de los factores socioculturales sobre la biología de las poblaciones y se fueron incorporando análisis estadísticos multivariados, ya que permitían mejores aproximaciones sobre la variabilidad humana (Carnese et al. 1991-1992; Guichón 1994; Carnese y Pucciarelli 2007). Estos cambios, junto con el desarrollo del procesualismo en el campo de la arqueología, fueron fundamentales para el surgimiento y crecimiento de la disciplina bioarqueológica en Argentina, incluyendo el interés por el estudio de la enfermedad en las poblaciones humanas (Mendonça de Souza y Guichón 2012).

En la década de 1980 dos investigadores extranjeros visitan el país. Primero, Jane Buikstra brindó una serie de conferencias y estudió los restos humanos del asentamiento colonial de Santa Fe La Vieja. Luego, Walter Neves ofreció un curso de postgrado en Buenos Aires en 1987, que ayudó a desarrollar el estudio de la dieta y la salud. Los aportes de estos dos investigadores implicaron un quiebre en los estudios osteológicos desarrollados en el país. A partir de entonces, los trabajos bioarqueológicos dejaron de ser informes anexados a los estudios arqueológicos y se convirtieron en una valiosa fuente de información para estudiar las formas de vida de las poblaciones del pasado, a través del análisis de diversos indicadores bucales y óseos (Bordach et al. 2003; Mendonça de Souza y Guichón 2012). En este contexto 
se esbozan los primeros estudios paleopatológicos desde un enfoque bioarqueológico, principalmente en la región pampeana y la patagónica (por ej. Guichón 1994; Barrientos 1997; L’Heureux 1998; entre otros). Estos estudios estaban orientados a evaluar los cambios en la salud y las respuestas biológicas adaptativas de los grupos humanos que habitaron esas regiones durante el Holoceno. Desde entonces, como se verá a continuación, en las distintas regiones geográficas de Argentina se han ido desarrollando diversos estudios bioarqueológicos y paleopatológicos, generalmente enmarcados en problemáticas arqueológicas para evaluar la salud, la nutrición, los estilos de vida y la adaptación de las poblaciones a sus entornos socio-ambientales (Bernal y Luna 2011; Suby 2012; Luna y Suby 2014; Suby et al. 2017a).

En el sur de Patagonia y Patagonia Austral, tanto continental como insular, los análisis sobre la salud oral se han abordado con frecuencia, principalmente con el objetivo de comparar las prevalencias de los indicadores bucales entre poblaciones con dietas marítimas y terrestres (Schinder y Guichón 2003; Bernal y Luna 2011). En cuanto a los análisis de patologías óseas, en los últimos años se observa un mayor desarrollo de los mismos abordando diferentes aspectos: enfermedades articulares degenerativas, procesos infecciosos, patologías metabólicas, paleoepidemiología y paleodemografía (L'Heureux et al. 2003; Suby 2007a, 2014; L'Heureux y Barberena 2008; Suby et al. 2008, 2017b; García Laborde et al. 2010; entre otros). En algunos de estos trabajos se han incorporado distintas líneas de evidencia complementarias, como el uso de técnicas radiológicas (Suby 2007a; Suby et al. 2008), métodos de evaluación de la densidad mineral ósea (Suby 2007a, b; Suby y Guichón 2009), estudios paleoparasitológicos (Fugassa y Guichón 2005; Fugassa 2006; Fugassa y Barberena 2006) y estudios moleculares para examinar la presencia de tuberculosis precolombina en la región (Guichón et al. 2015).

En Patagonia centro-meridional y Norpatagonia existe un gran cúmulo de información proveniente de estudios sobre distintos indicadores dentales (Bernal y Luna 2011). Se han abordado aspectos nutricionales, procesos de estrés, cambios dietarios, desgaste, entre otros (Kozameh y Barbosa 1992; L'Heureux 1998, 2000; Kozameh 2004; Bernal et al. 2007; Menéndez 2010; Flensborg 2011, 2013; Gómez Otero y Novellino 2011; García Guraieb y Maldonado 2014). También se realizaron 
numerosos análisis de lesiones óseas de distintas etiologías (Della Negra y Novellino 2005; García Guraieb 2006, 2010; García Guraieb et al. 2007, 2010; Novellino et al. 2007; Kozameh et al. 2009; Flensborg 2012; Gordón 2015), y se destacan algunos trabajos por presentar datos novedosos sobre procesos infecciosos. Entre ellos se mencionan cinco casos de osteomielitis (Della Negra y Novellino 2005; Novellino et al. 2007; Flensborg et al. 2013) y dos casos de treponematosis (en la costa norte de Santa Cruz, Castro, A. et al. 2009; y uno en el interior de Chubut, García Guraieb et al. 2009).

En la región de Cuyo, la problemática arqueológica que guió los estudios bioarqueológicos se centra en el impacto de las prácticas agrícolas prehispánicas en la región y el grado de interacción entre grupos agricultores de filiación andina del Centro Oeste Argentino y grupos cazadores-recolectores de Norpatagonia. En este marco, utilizando indicadores inespecíficos de dieta (desgaste dental, caries, abscesos) y de salud (criba orbitaria, hipoplasias de esmalte dental), se evaluó la asignación a grupos cazadores-recolectores o agricultores de las muestras osteológicas del Sur de Mendoza y el Norte de Mendoza/San Juan (Novellino et al. 1996; Novellino y Guichón 1996-1997; Novellino 2002; Novellino y Gil 2007). También se están realizando análisis de marcadores de estrés ocupacional sobre conjuntos óseos del Valle del Atuel, y los resultados son integrados junto con los obtenidos de isótopos estables de ${ }^{13} \mathrm{C},{ }^{15} \mathrm{~N}$ y ${ }^{18} \mathrm{O}$ para evaluar la dieta y movilidad de los grupos poblacionales (Peralta 2015; Peralta y Gil 2016).

En la región pampeana (Pampa Húmeda y Seca), se han abordado distintos aspectos de la salud, dieta y demografía de los grupos cazadores-recolectores que habitaron distintos momentos del Holoceno. Entre ellos se destacan análisis de diversas lesiones (mecánicas, metabólica-nutricionales, traumáticas, neoplásicas), así como también análisis paleoparasitológicos y de fitolitos en cálculo dental (Barrientos 1997, 1999; L'Heureux 1998, 2000, 2014; Luna 2008, 2012; Luna et al. 2008; Zucol y Loponte 2008; Menéndez et al. 2009; Píccoli 2009; Píccoli y Barboza 2009; Ammann et al. 2010; Aranda et al. 2010; Luna y Aranda 2010, 2014; Scabuzzo 2010, 2012, 2013).

Los análisis bioarqueológicos en la región del Noroeste se han enfocado, principalmente, en caracterizar y evaluar las modificaciones en cuanto a patrones de subsistencia, tipos de recursos consumidos y estado de salud de las poblaciones, de 
acuerdo a los períodos arqueológicos definidos para la región. En este contexto, se han evaluado indicadores de estrés nutricional y funcional, traumas, infecciones y patologías orales. A su vez, se han realizado análisis de isótopos estables sobre huesos humanos con el fin de aportar más datos sobre la dieta de los grupos (Seldes 2002, 2006; Calo y Cortés 2009; Arrieta 2012; Gheggi 2012; Arrieta et al. 2014; Gheggi y Seldes 2012, 2014).

En la región central de Argentina, las investigaciones principalmente están dirigidas a indagar sobre la diferenciación regional para momentos tardíos del Holoceno y evaluar el impacto en la salud de las prácticas agrícolas. Específicamente, se han abordado análisis dentales de distintos indicadores, análisis fitolíticos en cálculo dental, estimaciones de talla y su relación con la salud, análisis paleoparasitológicos, estudios paleopatológicos sobre condiciones congénitas, violencia interpersonal y lesiones degenerativas articulares, cambios entesiales y facetas articulares (González y Fabra 2011; Fabra y González 2012; Salega y Fabra 2013; Fabra et al. 2015; González 2016; Salega 2017; Tavarone y Fabra 2017).

Finalmente, en la región del Noreste, como será detallado en el capítulo siguiente, se han realizado puntuales estudios patológicos en muestras osteológicas del Delta del Paraná (Kozameh et al. 2007; Kozameh y Brunás 2009, 2011, 2013; Mazza y Barrientos 2012). Hacia el norte, en el Paraná Medio, se han realizado análisis bioarqueológicos más sistemáticos, entre los que se relevaron diferentes indicadores orales y óseos para evaluar el estado de salud y la calidad de vida (Cornero y Puche 1995, 2000, 2002, 2007). Entre estos trabajos se destaca el empleo de técnicas radiológicas para la confirmación de algunos diagnósticos, así como también los análisis arqueobotánicos en muestras de cálculo dental y sedimento ventral de los entierros humanos (Cornero y Rangone 2015).

\subsection{Palabras finales}

Al exponer los distintos enfoques teóricos y principales premisas que guiaron los estudios bioarqueológicos y paleopatológicos, en este apartado se describen y sintetizan aquellos que formaron las bases de este trabajo. Esta tesis constituye un 
análisis bioarqueológico integrador y multidisciplinar, para aportar al conocimiento sobre los modos de vida de las poblaciones que habitaron el extremo meridional del Noreste Argentino. Para este análisis se realiza un estudio paleopatológico de múltiples indicadores de estrés (óseos y dentales) siguiendo una perspectiva teórica biocultural, entendiendo así que el contexto sociocultural y ambiental impacta en la salud de los individuos y que, de esta forma, el esqueleto representa los procesos y eventos vividos por la persona. Bajo esta concepción general, resulta importante contextualizar los resultados con la información arqueológica disponible, ya que se puede obtener una aproximación más holística sobre la salud y calidad de vida.

A lo largo del análisis y las interpretaciones realizadas, también se tuvieron en consideración todos aquellos aspectos relativos a la representatividad poblacional de las muestras bioarqueológicas bajo estudio. Particularmente en lo que respecta a los factores extrínsecos, son muy relevantes los procesos por los cuales se formaron las muestras bioarqueológicas estudiadas. Como se detallará en el Capítulo 5, una de ellas procede de excavaciones sistemáticas y controladas realizadas por el equipo de investigación que acompaña esta tesis (Delta Superior); mientras que las dos muestras restantes no fueron recuperadas mediante métodos arqueológicos modernos, provienen de colecciones de museos y su información contextual es escasa y/o imprecisa. Además de las variadas modalidades inhumatorias que caracterizan al registro bioarqueológico del Noreste Argentino (véase Capítulo 3), el contexto, la integridad, la representación anatómica y la estructura sexo-etaria de las muestras ha impactado en el análisis y generado sesgos que resultan difíciles de controlar.

En cuanto a las investigaciones paleopatológicas en Argentina, las mismas contribuyeron y contribuyen al conocimiento de la salud y dieta de las poblaciones del pasado abordando información paleodietaria y arqueológica y utilizando diversas técnicas teóricas e interpretativas. Se destaca la realización de trabajos sobre la salud y nutrición explorando múltiples indicadores y complementando la información con otros estudios, como los de isótopos estables. Por otro lado, se observa que los estudios paleopatológicos han estado enmarcados, principalmente, en problemáticas arqueológicas más amplias. También se resalta que en las últimas décadas hubo un incremento de los análisis realizados, incorporando distintas líneas de análisis y generando un importante volumen de información que ha permitido indagar distintos 
aspectos sobre los modos de vida de quienes habitaron en tiempos prehispánicos el actual territorio argentino. Tal como fue mencionado anteriormente y como se puntualizará en el capítulo siguiente, aún queda por realizar trabajos similares en el sur del Noreste Argentino y generar datos posibles de ser comparados con lo que ocurría con las poblaciones que habitaron otras regiones. Esta tesis constituye también un aporte en tal sentido. 


\section{Capítulo 3}

\section{Investigaciones bioarqueológicas previas en el sur del Noreste Argentino y sistematización de la información disponible}

En este capítulo se sintetiza y sistematiza la información bibliográfica disponible sobre las investigaciones bioarqueológicas en las áreas meridionales del Noreste Argentino (NEA) de las cuales provienen las muestras analizadas en esta tesis (Delta Superior e Inferior del río Paraná y cuenca inferior del río Uruguay). Particularmente se hará especial énfasis en el registro bioarqueológico existente en cada una de las áreas y qué análisis han sido realizados sobre él, puntualizando en los estudios patológicos. Cabe recordar que en esta tesis no se consideran a los sitios arqueológicos guaraníes, grupos con costumbres funerarias diferenciadas notoriamente de las practicadas por las poblaciones locales (Noelli 1993; Ramos van Raap y Bonomo 2016). Previo a esta síntesis sobre el registro bioarqueológico y los estudios sobre él efectuados, resulta imprescindible contextualizarlo en el marco de las investigaciones arqueológicas realizadas en el NEA desde sus inicios y cuáles son las propuestas vigentes para explicar los modos de vida de las poblaciones que habitaron esta región en tiempos prehispánicos; este apartado se extiende brevemente, dado que ya ha sido profundizado en diferentes trabajos y tesis doctorales (por ej. Ceruti y González 2007; Ottalagano 2009; Bonomo et al. 2011b; Politis y Bonomo 2012; Píccoli 2015; Apolinaire 2017; Castro, J.C. 2017).

\subsection{Arqueología en el sur del Noreste Argentino}

Los inicios de las investigaciones arqueológicas en el NEA se remontan a fines del siglo XIX y principios del XX, cuando se dan a conocer los primeros resultados de distintas exploraciones en la llanura aluvial del río Paraná. En las publicaciones presentadas, los investigadores describen el hallazgo de varios sitios, denominados generalmente como "túmulos", "paraderos" y "cementerios", en los que encuentran restos cerámicos, faunísticos y en muchos de ellos, entierros humanos (Lista 1878; 
Zeballos y Pico 1878; Ambrosetti 1894, 1895; Torres 1911; Outes 1918; Serrano 1922; Frenguelli y Aparicio 1923; Lothrop 1932). Desde entonces y bajo la influencia de enfoques histórico-culturales, los intereses de los estudios arqueológicos estuvieron focalizados en construir sistemas clasificatorios, basados principalmente en las características estilísticas de la cerámica. En este contexto, se fueron presentando las primeras síntesis culturales (Torres 1911; Lothrop 1932; Serrano 1936, 1946, 1950).

Además de los esquemas de clasificación para abordar la historia cultural del NEA, diversos autores (Ambrosetti 1893; Torres 1911; Outes 1918; Lothrop 1932; Aparicio 1939; Serrano 1950; Lafon 1971) trataron de asociar los conjuntos materiales hallados en los sitios con los grupos étnicos que se mencionaban en los documentos escritos de los siglos XVI a XVIII. Según estas fuentes etnohistóricas, al momento de la llegada de los europeos, en el sector de islas del río Paraná estaba presente un complejo multiétnico conformado por los grupos chaná, mbeguá, chaná-mbeguá, carcaraes, chaná-timbú, timbú y guaraníes (para una caracterización de las fuentes escritas, véanse Lothrop 1932; Politis y Bonomo 2012; Apolinaire y Bastourre 2016a). Se ha planteado que algunos de ellos podrían corresponder a distintas etnias o a diferentes parcialidades de una misma etnia, genéricamente conocida como chanátimbú (Serrano 1930; Aparicio 1939; Bonomo et al. 2011b). Asimismo, se propuso que el correlato arqueológico de este complejo étnico chaná-timbú sería la cultura de los Ribereños Plásticos (Serrano 1950).

Como se mencionó anteriormente, estas investigaciones se centraron en el curso medio e inferior del río Paraná. En cuanto al curso del río Uruguay, los primeros estudios arqueológicos le corresponden a Greslebin (1931), a partir de sus trabajos de campo y observaciones sobre las construcciones de los montículos en sitios del curso inferior. También Serrano (1932), además de sus estudios en las costas entrerrianas y santafesinas del río Paraná, realizó trabajos arqueológicos en el río Uruguay medio.

La multiplicación de los trabajos arqueológicos y las prevalencias de los enfoques teóricos históricos-culturales continuaron hasta la década de 1970, cuando ocurre un quiebre teórico-metodológico (Ottalagano 2009, 2012). A partir de entonces, fueron desarrollándose investigaciones regionales y sistemáticas, con metodologías de excavación controladas y rigurosas y también se realizaron las 
primeras dataciones radiocarbónicas para la región (Poenitz 1970; Cigliano et al. 1971; Lafon 1971, 1972; Schmitz et al. 1972; Cione et al. 1977; González 1977; Caggiano 1984; entre otros). Décadas posteriores, con la adopción de enfoques procesuales y ecológicos, los estudios se enfocaron en la adaptación al medio ambiente. En este contexto teórico, se revisaron las síntesis culturales propuestas anteriormente y se incorporaron nuevos conceptos (por ej. "Tipo Cultural, "Tradición" o "Entidad Cultural) que permitieran vincular las unidades arqueológicas con determinados ambientes ecológicos (Rodríguez 1997, 1998, 2001; Rodríguez y Ceruti 1999; Ceruti 2000). A partir de sus investigaciones en el Paraná Medio y basado en los cambios paleoclimáticos, la explotación de recursos, la organización tecnológica, los patrones de asentamiento y las relaciones con poblaciones de áreas aledañas, Ceruti (1993, 2003) propuso un modelo de desarrollo cultural. En este modelo el autor integra las entidades culturales planteadas anteriormente, entre las que se destaca GoyaMalabrigo redefinida a partir de la Cultura de los Ribereños Plásticos de Serrano (1972). Según Ceruti, esta entidad se caracterizaría por grupos canoeros ribereños con alta movilidad que basaban su subsistencia en la caza, recolección y pesca y que habitaban las islas y costas bajas del Paraná Medio y parte del Delta del Paraná desde 2000 años AP hasta la llegada de los europeos (Ceruti 1993, 2003). El autor también vincula esta entidad con los chaná-timbú mencionados en las crónicas (Ceruti 1995).

Desde las últimas décadas se registran numerosos proyectos de investigación a largo plazo en distintas áreas del NEA (por ej. Hocsman 1999; Ceruti 2003; Acosta 2005; Pérez Jimeno 2005; Loponte 2008; Cornero 2009; Ottalagano 2009; Acosta et al. 2010; Bonomo et al. 2010, 2011a, b; Cocco 2010; Feuillet Terzaghi 2010; Ávila 2011; Politis et al. 2011; Lamenza y Santini 2013; Barboza 2014; Píccoli 2015; Castro 2017). En ellos se vislumbra la utilización de diferentes líneas de investigación para abordar el extenso registro arqueológico; no sólo el obtenido durante los nuevos trabajos de campo, sino también el procedente de las investigaciones previas y que actualmente integran colecciones de museos. Entre las temáticas tratadas pueden mencionarse: el estudio de la subsistencia a partir de análisis arqueofaunísticos, arqueobotánicos y de isotópos estables (por ej. Acosta 2005; Zucol y Loponte 2008; Bonomo et al. 2011a, 2017b; Bastourre 2014; Barboza y Martín 2015; Colobig et al. 2015; Ottalagano y Loponte 2017); el origen de las estructuras monticulares en tierra desde abordajes 
geoarqueológicos (Castiñeira et al. 2013, 2014, 2017b); el análisis de materiales de distinta ergología -lítica, cerámica y ósea (Buc y Silvestre 2006; Bonomo et al. 2009, 2014, 2016; Bonomo y Blasi 2010; Loponte et al. 2011; Barboza y Píccoli 2013; Di Prado 2015; Apolinaire 2017); el abordaje de las prácticas mortuorias (Mazza 2010a; Mazza y Loponte 2012; Ramos van Raap y Bonomo 2016; Scabuzzo y Ramos van Raap 2017); los sistemas de asentamiento y movilidad (Loponte 2008; Apolinaire y Bastourre 2016b; Castiñeira et al. 2017a), entre muchos otros.

Uno de los equipos de investigación que se encuentra realizando estudios sistemáticos desde el 2006 en el Delta Superior del río Paraná es el dirigido por los Dres. G. Politis y M. Bonomo, cuyos proyectos enmarcan esta tesis. Durante las prospecciones se detectaron más de 80 sitios arqueológicos entre los departamentos Diamante, Victoria y Gualeguay (provincia de Entre Ríos) y San Jerónimo (provincia de Santa Fe); y en siete de ellos se realizaron excavaciones sistemáticas (Cerro Tapera Vázquez, Los Tres Cerros 1 y 2, Laguna de Los Gansos 1 y $2^{1}$, Cerro Farall y Laguna del Negro; Bonomo et al. 2010, 2014, 2016; Politis et al. 2011; Silva 2015; Apolinaire 2017; Bastourre y Apolinaire 2017). A partir de estos trabajos de campo, de los análisis de laboratorio y de la consulta de las fuentes etnohistóricas, se obtuvieron nuevas evidencias que permitieron discutir y redefinir la entidad arqueológica GoyaMalabrigo, asignándole una serie de rasgos característicos para su identificación (Politis y Bonomo 2012).

La dispersión espacial de Goya-Malabrigo comprende la llanura aluvial del río Paraná Medio e Inferior y el río Uruguay Inferior y sus afluentes; cronológicamente corresponde al Holoceno tardío entre ca. 2000 y 300 años AP (Politis y Bonomo 2012). Al menos desde ca. 1000 años AP se han detectado evidencias claras de construcción de montículos de tierra o cerritos. Estas estructuras antrópicas constituyen el $44 \%$ de los sitios hallados hasta el momento; se presentan aisladas o en grupos de dos o tres cerros, siendo generalmente uno más grande que los otros (Castiñeira et al. 2014; Bonomo y Politis 2018). Se ha propuesto un sistema de asentamiento con sitios de diferente función, jerarquía e intensidad de ocupación. Los asentamientos

1 Los entierros humanos procedentes de dos de estos sitios (Los Tres Cerros 1 y Laguna de Los Gansos 2) fueron analizados para esta tesis; para su caracterización detallada, véase Capítulo 5. 
residenciales principales estarían ubicados principalmente en cerritos o lugares elevados naturalmente; se tratarían de verdaderas aldeas ocupadas de forma semipermanente, con períodos prolongados de estabilidad seguidos por abandono y posterior reocupación. Los asentamientos de segundo orden se ubicarían en lugares del paisaje elevados naturalmente con ocupaciones menos intensas y que habrían funcionado para la explotación periódica de determinados recursos. Los asentamientos de tercer orden corresponden a geoformas poco elevadas, con ocupaciones menos densas. Por último, los asentamientos de cuarto orden están en lugares no elevados (márgenes de lagunas y riberas de arroyos menores) y con ocupaciones dependientes del nivel del agua. De acuerdo a un análisis de la red hidrográfica del Delta Superior, Apolinaire y Bastourre (2016b) propusieron además que el amplio sistema fluvial del área funcionó como una red de circulación de bienes, información y personas. En esta red, los montículos ocupan los lugares más centrales, es decir, puntos altamente accesibles del sistema fluvial permitiendo así un mayor control de la circulación de la red. Por otro lado, se ha asociado la entidad arqueológica Goya-Malabrigo con una organización socio-política del tipo rank society, en la cual determinados individuos de alto rango tendrían un acceso diferencial a productos exóticos y bienes de prestigio (Bonomo et al. 2017b), si bien todos los miembros de la sociedad accederían a los mismos recursos básicos. Los líderes tendrían la función de impedir la existencia de fisuras al interior de los grupos, coordinar el trabajo colectivo y controlar el intercambio a larga distancia (Politis y Bonomo 2012).

En cuanto a la economía de estos grupos, se basaba principalmente en la pesca y la caza, complementada con la recolección de vegetales silvestres y la horticultura (Bonomo et al. 2011a, b; Sánchez et al. 2013; Bastourre 2014; Colobig et al. 2014). En el conjunto arqueofaunístico se identificaron distintas especies animales con evidencias de procesamiento y consumo. Entre los mamíferos están representados el coipo, el carpincho, el cuis y los cérvidos (ciervo de los pantanos, venado de las pampas y ciervo de collar). También es amplio el componente ictiofaunístico, que incluye especies de Characiformes (sábalo, boga, dorado, pacú blanco) y Siluriformes (armado común y bagres). En menor medida, también se consumieron aves, reptiles y moluscos de agua dulce (Bastourre 2014; Bonomo et al. 
2014). Si bien los principales animales explotados corresponden a especies de ambientes fluviales, se han observado diferencias en la representación de éstas en algunos de los sitios excavados. Por ejemplo, mientras que en Los Tres Cerros 1 se identificó un elevado porcentaje de peces y roedores, en Laguna de los Gansos 1 los peces se registran en bajos porcentajes y el ciervo de los pantanos tiene una alta representación. Por su parte, en Cerro Tapera Vázquez el registro sugiere una explotación principal de coipo (Bastourre 2014; Bonomo et al. 2014, 2016). Estas diferencias podrían responder al lugar donde se emplazan estos sitios (montículos antropogénicos y albardones naturales) y la funcionalidad y ocupación de los mismos, como se mencionó anteriormente (Bonomo et al. 2011a, 2014, 2016; Politis et al. 2011). Por su parte, las evidencias arqueobotánicas sugieren la explotación de diversos recursos vegetales: cáscaras, frutas y semillas de plantas, como el algarrobo, palmeras yatay y pindó y arroz silvestre. A su vez, la presencia de maíz, zapallo y porotos indican la práctica de cultivo, que se habría desarrollado a pequeña escala (Bonomo et al. 2011a, c; 2016, 2017a; Sánchez et al. 2013; Colobig et al. 2015). Según los análisis efectuados, estos recursos vegetales domesticados no tuvieron un grado significativo de dependencia en la economía de Goya-Malabrigo (Bonomo et al. 2017a).

Junto a la explotación mayoritaria de recursos acuáticos, se asocia el desarrollo de una tecnología que incluye redes de pesca, arpones y canoas monóxilas. En cuanto a la cerámica, Goya-Malabrigo presenta un estilo alfarero propio, siendo las formas más emblemáticas las campanas y los apéndices zoomorfos (Politis y Bonomo 2012). Asimismo, se han identificado recipientes en una gran variedad de formas y tamaños; algunos de ellos habrían sido utilizados principalmente para el procesamiento, transporte y/o almacenaje, mientras que otros están vinculados con el procesamiento y servido de alimentos o líquidos (Bonomo et al. 2014, 2016).

La cuenca inferior del río Uruguay, en los últimos años, no estaba siendo investigada de forma intensiva y sistemática como las otras áreas circundantes (Castro, J.C. 2017). Desde 2009 el Dr. Castro comenzó con el desarrollo de proyectos de investigación a largo plazo. Hasta el momento se registraron varios montículos, se realizó la excavación de uno de ellos (Cerro de Boari 3) y se estudiaron colecciones de museos de otros sitios. Asimismo, se presentaron nuevas 
dataciones radiocarbónicas para el área, las cuales ubican las ocupaciones en el Holoceno tardío desde ca. 2000 hasta 600 años AP (Castro, J.C. 2016). A partir de estos trabajos, el autor concluye que los grupos humanos que habitaron esta área lo hicieron ocupando todos los ambientes disponibles asociados con cuerpos de agua, tanto en tierra firme como en islas. Algunas de las geoformas elevadas ocupadas fueron a su vez modificadas intencionalmente para incrementar su altura y así resguardarse del aumento del nivel del agua. Estos asentamientos residenciales y multifuncionales se suman a la existencia de canteras-taller, campamentos de pesca y/o caza y puntos de recolección de moluscos y productos vegetales. Según los restos materiales (por ej. la cerámica) hallados en algunos de los sitios -semejantes a los del río Paraná Medio e Inferior-, éstos podrían asociarse con la entidad arqueológica Goya-Malabrigo. Estos grupos humanos participaron de redes de circulación de rocas y minerales para la confección de instrumentos líticos, no sólo a nivel local sino también con el Delta Superior del Paraná y el área de la Depresión del Salado de la región pampeana. En cuanto a su economía, explotaron recursos faunísticos de distintos nichos ecológicos. Se propuso que probablemente los peces (armado, boga, surubí, boga, tararira) hayan sido un componente importante en la dieta. Entre las especies de mamíferos, se consumieron cérvidos (ciervo de los pantanos y venado de las pampas), carpincho, coipo, cuis, zorro gris y dasipódidos. También se habrían explotado aves, reptiles y moluscos (Castro, J.C. 2017). Asimismo, se aprovecharon diferentes recursos vegetales. En el sitio Cerro de Boari 3 se registraron endocarpos carbonizados de frutos de palmeras (probablemente correspondan a yatay y pindó) y fitolitos afines a gramíneas. Entre los carbones, se identificó algarrobo negro, anchico colorado, palo borracho y tala. Todos estos elementos arbóreos podrían haber sido consumidos como alimentos o bebidas, pero su presencia podría también estar vinculada con otros diferentes usos potenciales (por ej. combustible, medicinas, colorantes, hilandería, viviendas y artefactos). Por otro lado, pese a no existir por el momento evidencias de plantas domesticadas, se plantea la posibilidad de la existencia de horticultura, dada la identificación de la entidad Goya-Malabrigo en el área. Con respecto a la tecnología ósea y malacológica, se registró la elaboración de diversos instrumentos y adornos personales (Castro, J.C. 2017). 
En el extremo nororiental de la provincia de Buenos Aires, el Delta Inferior del río Paraná y parte de la cuenca inferior del río Uruguay, el equipo de trabajo dirigido por los Dres. D. Loponte y A. Acosta también se encuentra desarrollando diferentes líneas de estudio desde principios de la década de 1990 (Acosta 2005; Loponte 2008). Como parte de las tareas de campo, se retomaron las investigaciones en algunos sitios excavados previamente por otros investigadores y se llevaron a cabo excavaciones sistemáticas en algunos de ellos (por ej. Cerro Lutz). Los sitios arqueológicos son categorizados como de actividades múltiples y si bien la mayoría se ubica sobre lugares elevados naturalmente (albardones, médanos), otros empezaron a ser reconocidos recientemente como elevaciones antrópicas (Acosta et al. 2013; Loponte et al. 2015, 2016). La información cronológica para el área ubica las ocupaciones en el Holoceno tardío entre ca. 2300 y 300 años AP (Acosta y Loponte 2013). Los grupos que aquí habitaron practicaron la pesca intensiva de especies de Characiformes y Siluriformes, así como también la captura y procesamiento de cérvidos de tamaño mediano y grande (ciervo de los pantanos y venado de las pampas). De forma complementaria, se explotaron roedores (coipo y cuis) y moluscos fluviales (Acosta 2005; Loponte 2008; Acosta y Loponte 2013). A partir del registro arqueofaunístico y del análisis sobre el conjunto cerámico, se plantearon para el área dos tipos de organización económica: uno representado en los sitios con cerámica lisa y donde abunda el consumo de peces por sobre el de mamíferos y otro en el que está presente la cerámica incisa y un menor consumo de peces (Loponte 2008). Asimismo, se observó una baja representación del carpincho en los conjuntos arqueofaunísticos, lo cual fue interpretado por la existencia de cierta restricción en su consumo o tabú alimenticio (Acosta 2005); sí se habría aprovechado esta especie para extraer y usar sus pieles (Loponte 2008). El componente vegetal constituyó también una parte importante de la dieta de los grupos que habitaron esta área (Acosta 2007; Loponte 2008; Acosta y Loponte 2013). Por un lado, se registraron abundantes endocarpos carbonizados de palmera pindó (Acosta y Roman 2013). También, en otros sitios (Túmulo I del Brazo Largo y Río Paraná Miní) se realizaron análisis arqueobotánicos sobre material cerámico, los cuales indicaron la presencia de algarrobo, porotos, maíz y probable mandioca (Bonomo et al. 2011a). Estos restos botánicos sugieren que los grupos humanos habrían desarrollo también prácticas 
hortícolas (Bonomo et al. 2011a). Por otro lado, en comparación con otras áreas, como el Delta Superior por ejemplo, es evidente la presencia de mayor instrumental lítico (Loponte 2008; Sacur Silvestre et al. 2013). Aun así, en el registro predomina el instrumental óseo, por su gran cantidad y diversidad, que habría sido utilizado para diversas actividades como por ejemplo, la perforación de pieles, el alisado de cerámica y la manufactura de cestería (Buc y Silvestre 2006).

Las fuentes etnohistóricas no sólo cobraron especial interés en las investigaciones de las primeras décadas del siglo $\mathrm{XX}$, sino que también en los trabajos actuales se retomaron para explicar los registros arqueológicos y formular nuevos interrogantes que guíen las investigaciones (por ej. Loponte 2008; Bonomo et al. 2011b, 2017a; Bonomo y Latini 2012; Politis y Bonomo 2012; Politis 2014; Apolinaire y Bastourre 2016a). La delimitación espacial de cada uno de los grupos que habitaban estas latitudes a la llegada de los europeos no se distingue en los documentos, así como tampoco se expresan claras diferencias entre ellos. Aun así se ha podido estimar que el Paraná Medio habría estado habitado por mepenes, colastines y mocoretás; en el Delta Superior se ubicarían los timbú y chaná-timbú y en el Delta Inferior del Paraná y en el curso inferior del río Uruguay, los chaná, mbeguá y chaná-mbeguá (Politis y Bonomo 2012). Sí es clara la información que se brinda en los escritos en cuanto a la subsistencia, asentamientos y organización social de los grupos: en el sector de islas del Delta del Paraná, practicaban la caza, pesca y recolección, así como también el cultivo de maíz, legumbres y cucurbitáceas. Por otro lado, las descripciones sobre las estructuras de habitación indicarían la estabilidad temporal de los asentamientos de estos grupos. Además, se menciona la presencia de jefes a partir del uso de parafernalia (por ej. placas de metal) (Bonomo et al. 2011b; Politis y Bonomo 2012; Apolinaire y Bastourre 2016a).

\subsection{El registro bioarqueológico}

En el Delta del río Paraná y la cuenca inferior del río Uruguay existe un amplio registro bioarqueológico, el cual se conformó desde las primeras exploraciones realizadas a fines del siglo XIX hasta las investigaciones actuales. A partir de la búsqueda y relevamiento bibliográfico realizado (artículos científicos, resúmenes y 
actas de congresos y tesis), se contabilizaron 43 sitios arqueológicos en los que fueron hallados entierros humanos (Figura 3.1). Para cada uno de ellos se documentaron los siguientes datos: los fechados radiocarbónicos obtenidos para los entierros (en caso de no haber, se registraron los fechados para el sitio); el tipo de sitio (elevación antrópica -acrecional o intencional- o elevación natural -albardón o médano); su funcionalidad (actividades múltiples -actividades domésticas y entierros humanos- o funeraria -i.e. área exclusiva de entierros); su asignación a alguna entidad arqueológica (por ej. Goya-Malabrigo); el número mínimo de individuos inhumados; la estructura sexo-etaria; las modalidades de inhumación; la presencia de ocre; la presencia de huesos humanos termoalterados; materiales y objetos asociados con los entierros y alguna característica particular del entierro, que permita diferenciarlo de otros (por ej. cierta distinción del lugar del entierro a través de distintos objetos o materiales). En la Tabla 3.1 se sintetiza esta información, discriminando por área, junto con las referencias bibliográficas correspondientes. 


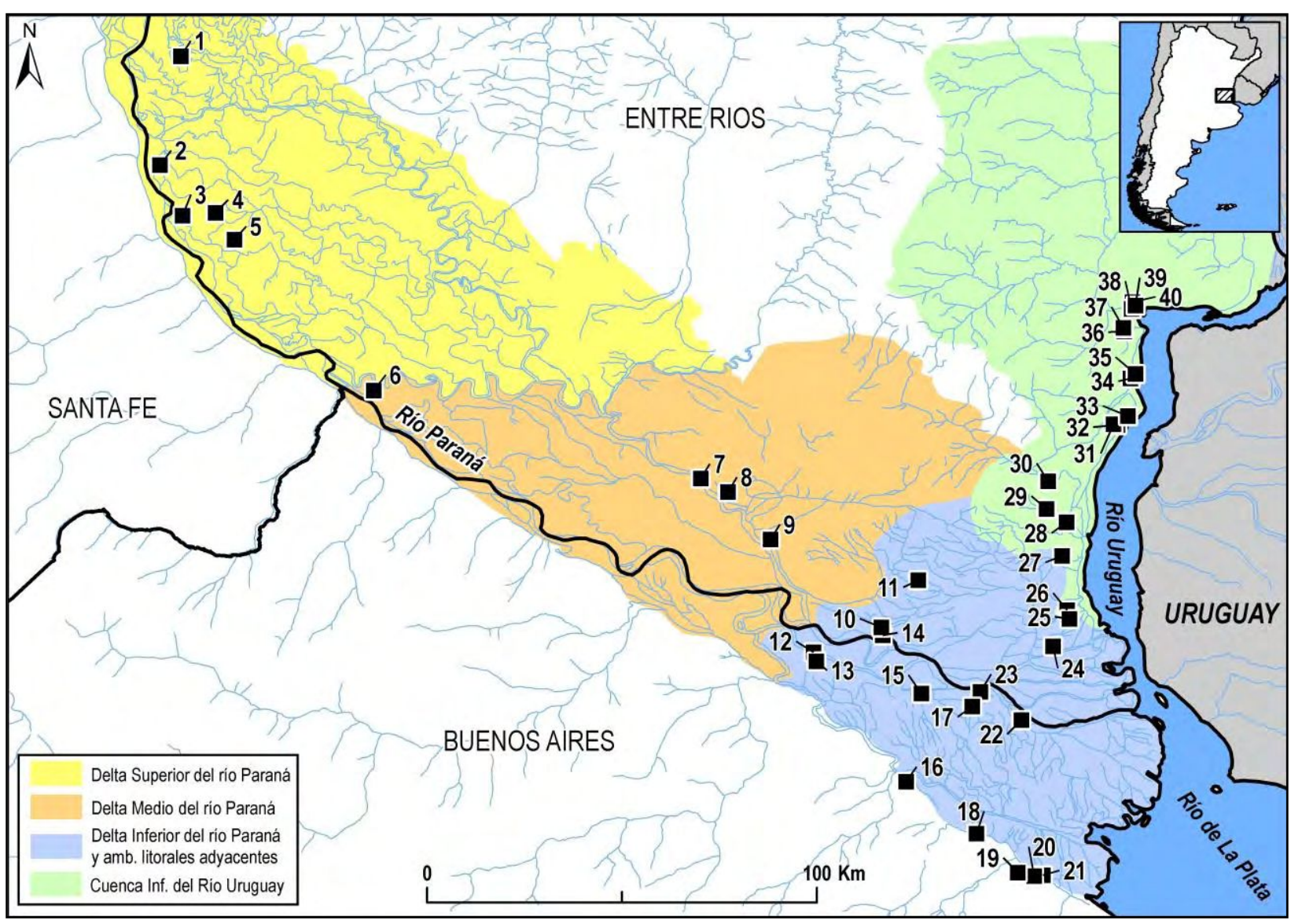

Figura 3.1 Sitios arqueológicos con entierros humanos en el sur del Noreste Argentino. Referencias: 1=Laguna de Los Gansos; $2=$ Co. La Cavada; 3=El Castaño 2; $4=$ Los Tres Cerros 1; $5=$ Co. Grande la Isla Los Marinos; $6=$ Co. Grande de Paraná Pavón; 7=Estancia La Argentina/Túm. 1-La Argentina; $8=$ Paraná Ibicuy $1 ; 9=$ Cem. de Mazaruca; 10=Escuela 31; 11=Don Santiago; 12=Isla Talavera BD-S1; $13=$ Isla Talavera BD-S2; $14=\mathrm{Cem} . \mathrm{n}^{\circ} 1$, del Paraná Guazú; 15=Isla Talavera BD-S5; 16=Túm. de Campana; 17=Anahí; 18=El Cazador sitio 3; 19=Garín; 20=La Bellaca 1 y 2; 21=Arroyo Sarandí; 22=El Cerrillo/Túm. I del Paraná Guazú; 23=Túm. || del Paraná Guazú; 24=Túm. I del Brazo Gutiérrez; 25=Paradero-Cem. del Brazo Largo; 26=Túm. I del Brazo Largo; 27=El Aserradero/Co. Lutz; 28=Las Ánimas; $29=$ Cem. de Medina; 30=Co. Mayor; $31=$ Co. de Los Pampas; 32=Fajina Quemada; 33=Sambaquí de Puerto Landa; 34=Túm. de Lucuix; 35=Túm. 1 de la Pesquería Nicolini; 36=Túm. I-Co. Norte de Machado; 37= Túm. II-Co. Sur de Machado; 38=Co. Lorenzo 2; 39=Co. de Boari 3; 40=San Luis Médanos. 
Tabla 3.1 Sitios arqueológicos con entierros humanos en el sur del Noreste Argentino.

\begin{tabular}{|c|c|c|c|c|c|c|c|}
\hline & SITIO & $\begin{array}{l}\text { FECHADOS } \\
\text { (años }{ }^{14} \mathrm{C} \text { AP) }\end{array}$ & $\begin{array}{l}\text { TIPO DE } \\
\text { SITIO }\end{array}$ & FUNCIONALIDAD & NMI & $\begin{array}{l}\text { TIPOS DE } \\
\text { ENTIERRO }\end{array}$ & FUENTES BIBLIOGRÁFICAS \\
\hline \multirow{6}{*}{ 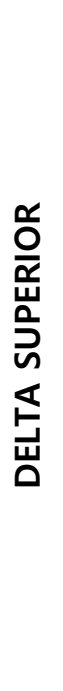 } & Laguna de los Gansos 2 & $570 \pm 43 ; 590 \pm 46$ & e. natural & múltiple & 2 & $\mathrm{P}, \mathrm{O}$ & Bonomo et al. 2016 \\
\hline & Co. La Cavada & $s / f$ & e. antrópica & in. & 1 & S & Carrara et al. 1998 \\
\hline & El Castaño II* & $700 \pm 90$ & e. antrópica & in. & 5 & $P, S, A$ & Cornero 2009 \\
\hline & Los Tres Cerros 1 & $\begin{array}{c}650 \pm 70 ; 657 \pm 43 ; \\
763 \pm 47 ; 775 \pm 85 ; \\
801 \pm 46 ; 802 \pm 48 ; \\
849 \pm 45\end{array}$ & e. antrópica & múltiple & 35 & $\begin{array}{c}P, S(s \text { y } m), A, \\
\text { Ac., } T\end{array}$ & $\begin{array}{l}\text { Politis et al. 2011; Scabuzzo et al. 2015; } \\
\text { Scabuzzo y Ramos van Raap } 2017\end{array}$ \\
\hline & $\begin{array}{l}\text { Co. Grande de la Isla Los } \\
\text { Marinos }\end{array}$ & $\begin{array}{c}460 \pm 50 ; 590 \pm 60 \\
660 \pm 70\end{array}$ & e. antrópica & múltiple & 48 & $P, S(m), A, T$ & Gaspary 1950; Kozameh y Brunás 2013 \\
\hline & Co. de los pescadores & $s / f$ & e. antrópica & in. & 2 & $P$ & Carrara et al. 1998 \\
\hline \multirow{3}{*}{ 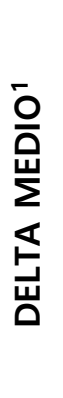 } & Co. Grande de Paraná Pavón & $630 \pm 45$ & e. antrópica & múltiple & 15 & $\begin{array}{c}P, S(m), A, T \\
\ln .\end{array}$ & González 1947; Bonomo et al. 2017a \\
\hline & $\begin{array}{l}\text { Estancia La Argentina / } \\
\text { Túm. } 1 \text { La Argentina }\end{array}$ & $s / f$ & e. natural & funeraria & 5 & $P, S$ & Aparicio 1928; Castro y Del Papa 2015 \\
\hline & $\begin{array}{l}\text { Paraná Ibicuy } 1 \text { / La } \\
\text { Argentina }\end{array}$ & $\begin{array}{c}979 \pm 44 ; 1480 \pm 70 \\
1810 \pm 70\end{array}$ & e. antrópica & múltiple & 6 & $P$ & $\begin{array}{c}\text { Caggiano et al. 1978a; Acosta y Mazza } \\
\text { 2016; Del Papa et al. } 2016\end{array}$ \\
\hline
\end{tabular}




\begin{tabular}{|c|c|c|c|c|c|c|c|}
\hline \multirow{14}{*}{ 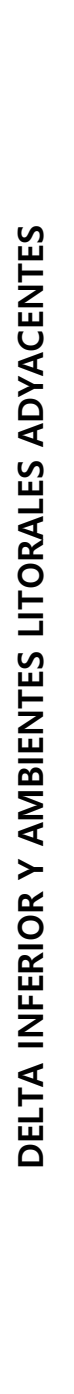 } & Cem. de Mazaruca & $s / f$ & e. natural & funeraria? & 10 & $P, A$ & Lista 1878; Torres 1903; Outes 1912 \\
\hline & Escuela 31 & $\begin{array}{l}1732 \pm 50 \\
1764 \pm 46 \\
1807 \pm 47\end{array}$ & e. antrópica & in. & 3 & $P, S(s)$ & $\begin{array}{l}\text { Loponte et al. 2015; } \\
\text { Ottalagano y Loponte } 2017\end{array}$ \\
\hline & Don Santiago & $\begin{array}{c}1090 \pm 80 * ; 1300 \pm \\
80^{*}\end{array}$ & in. & in. & 2 & $S$ & Caggiano 1984 \\
\hline & Isla Talavera BD-S1 & $310 \pm 80$ & e. antrópica & múltiple & 1 & $P$ & Caggiano y Flores 2001 \\
\hline & Isla Talavera BD-S2 & $590 \pm 60^{*}$ & e. natural & múltiple & 4 & $P, S$ & Caggiano y Flores 2001 \\
\hline & Cem. $n^{\circ} 1$, del Paraná Guazú & $s / f$ & e. natural & múltiple & 20 & $\ln$. & Torres 1911 \\
\hline & Isla Talavera BD-S5 & $570 \pm 70$ & e. natural & múltiple & 3 & $P$ & Caggiano y Flores 2001 \\
\hline & Túm. de Campana & $1600 \pm 20$ & e. antrópica & múltiple & 28 & $P, \ln$. & $\begin{array}{l}\text { Zeballos y Pico 1878; Politis y Bonomo } \\
2015\end{array}$ \\
\hline & Anahí & $1020 \pm 70^{*}$ & e. natural & múltiple & 6 & $P, \ln$. & Lafon 1971; Loponte 2008 \\
\hline & El Cazador sitio 3 & $1110 \pm 70^{*}$ & in. & in. & 3 & $\mathrm{P}$ & Mazza y Loponte 2012; Mazza 2016 \\
\hline & Garín & $1360 \pm 70$ & e. natural & múltiple & 1 & $\mathrm{P}$ & Loponte 2008; Acosta y Mazza 2016 \\
\hline & La Bellaca 1 & $1110 \pm 70^{*}$ & e. natural & in. & 1 & $P$ & Loponte 2008 \\
\hline & La Bellaca 2 & $680 \pm 80^{*}$ & e. natural & múltiple & 6 & In. & Loponte 2008 \\
\hline & Arroyo Sarandí & $688 \pm 42 ; 1290 \pm 40$ & e. antrópica & in. & 42 & $\begin{array}{c}P, S, A, A c ., O, \\
\text { In. }\end{array}$ & $\begin{array}{l}\text { Lothrop 1932; Loponte 2008; Bonomo et } \\
\text { al. 2011b; Ramos van Raap y Bonomo } \\
2016\end{array}$ \\
\hline
\end{tabular}




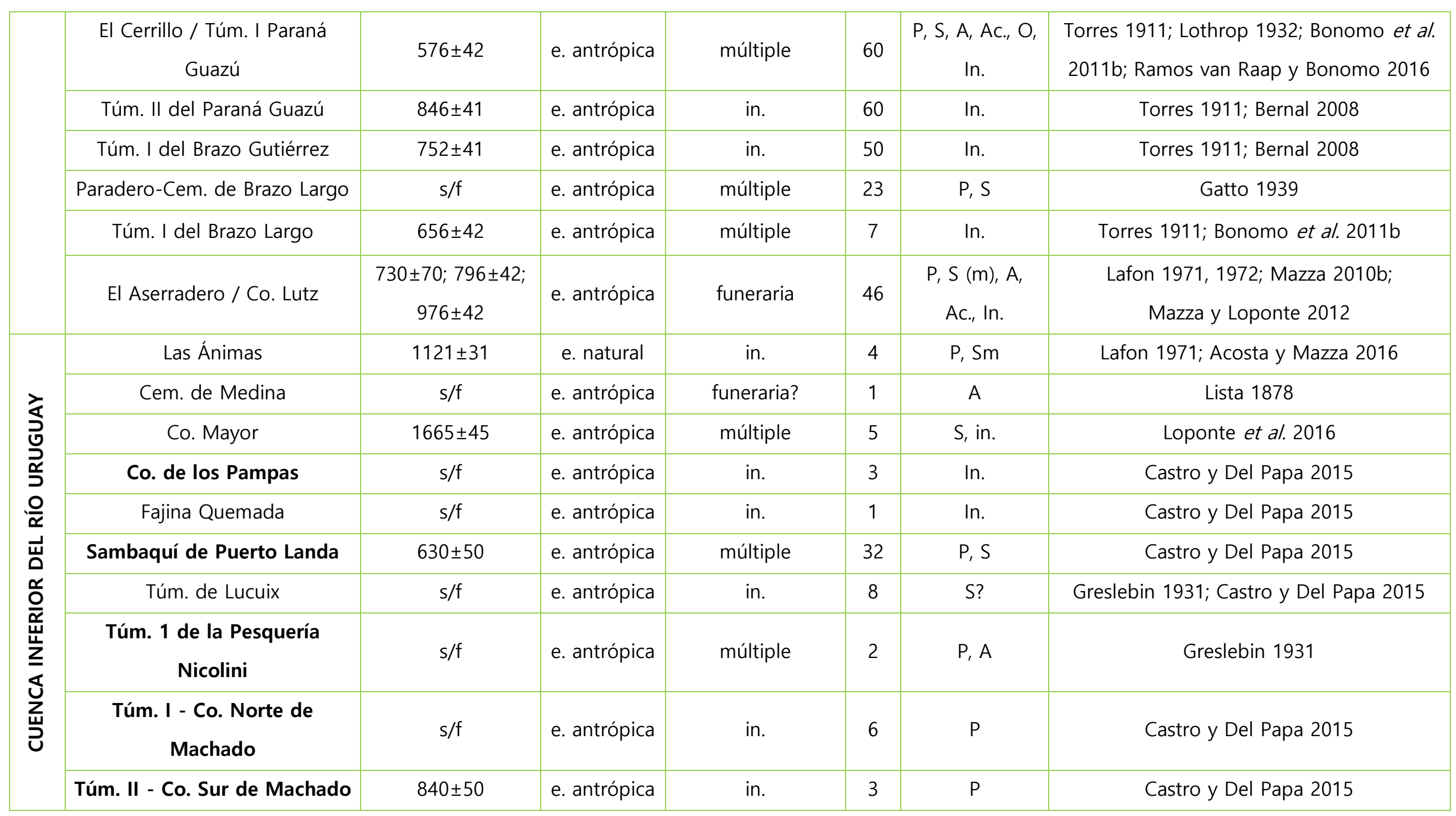




\begin{tabular}{|c|c|c|c|c|c|c|c|}
\hline Co. Lorenzo 2 & $2050 \pm 60$ & e. antrópica & múltiple & 25 & P, S & Castro y Del Papa 2015 \\
\hline Co. de Boari 3 & $1060 \pm 60$ & e. antrópica & múltiple & 3 & S (m) & Castro y Del Papa 2015 \\
\hline San Luis Médanos & S/f & e. natural & in. & 1 & In. & Castro y Del Papa 2015 \\
\hline Túm. de Irungaray & s/f & e. & in. & 1 & In. & Castro y Del Papa 2015 \\
\hline
\end{tabular}

Referencias: los nombres de los sitios en "negrita", corresponden a aquellos asignados a la entidad arqueológica Goya-Malabrigo; ${ }^{1}=$ los sitios del Delta Medio fueron reagrupados, de acuerdo a su cercanía geográfica, con sitios del Delta Superior (Co. Grande del Paraná Pavón) o del Delta Inferior (Túm. I La Argentina y Paraná Ibicuy 1); Co.=cerro; Cem.=cementerio; Túm.=túmulo; $\mathrm{s} / \mathrm{f}=\sin$ fechado; ${ }^{*}=$ fechados para el sitio; e.=elevación; in.=indeterminado; $P=$ primario; $\mathrm{S}=$ paquete funerario; $\mathrm{s}=$ paquete funerario simple; $\mathrm{m}=$ paquete funerario múltiple; $\mathrm{A}=$ aislados; $\mathrm{Ac}$ =acumulación ósea; $\mathrm{T}=$ contextos de huesos termoalterados; $\mathrm{O}=\mathrm{otro}$. 
Para el Delta Superior se relevaron siete sitios con entierros humanos, de los cuales seis corresponden a cerritos y el restante se ubica sobre una elevación natural del terreno. Aquellos con información relativa a su funcionalidad, fueron interpretados como lugares residenciales y donde también se hicieron inhumaciones. Según las dataciones radiocarbónicas, el uso de estos espacios para las prácticas mortuorias ocurrió entre ca. 450 y 850 años AP. La cantidad de individuos enterrados en estos sitios es amplia, varia entre 1 y 48 y alcanza un total de 108 para el área. En comparación con las otras dos áreas, en ésta es donde se registró la mayor variedad de modalidades inhumatorias: una gran parte de los individuos fue enterrado de forma primaria (en distintas posiciones) o formando parte de paquetes funerarios (simples y múltiples). Además, se registra la presencia de huesos y cráneos aislados en los sectores inhumatorios. Por otro lado, en Los Tres Cerros 1 (LTC1) se halló una acumulación ósea (véase en detalle su descripción en Capítulo 5). En Cerro Grande de Paraná Pavón (CGPV) fueron distinguidos cinco conjuntos de "huesos agrupados sin orden alguno" (González 1947: 24-25), que también podrían haber sido acumulaciones óseas (Mazza 2010a). Por su parte, en Laguna de Los Gansos 2 (LDLG2) fue descripto otro tipo de entierro; se trata de un esqueleto con gran parte de su cuerpo articulado pero con algunas partes ausentes y reubicación de algunos huesos (véase en detalle su descripción en Capítulo 5). Asimismo, en tres sitios (Co. G. de la Isla Los Marinos -CGILM-, CGPV y LTC1) se registraron huesos humanos en contextos de termoalteración. Según lo que describe Gaspary (1950), en CGILM estos huesos aparecieron en el medio de un basurero junto a huesos no calcinados. Por su parte, para CGPV, González (1947) comenta que los numerosos elementos de huesos largos astillados y fragmentos de cráneo, hallados en la cima del montículo, corresponderían a "la incineración de un gran número de individuos" (1947: 29). En el caso de LTC1, este conjunto de fragmentos de huesos largos y cráneo se encontraba contenido dentro de un fogón, junto con restos arqueofaunísticos, en la cima del montículo (Scabuzzo et al. 2015).

En el Delta Inferior del río Paraná y ambientes litorales adyacentes, se relevaron 22 sitios con entierros humanos. Aquí, los sitios se emplazan tanto en elevaciones naturales como antrópicas. La mayoría se corresponde con lugares de actividades múltiples. La excepción recae sobre tres sitios: en el caso de Estancia La Argentina, 
Aparicio (1928) lo considera como un lugar exclusivo para entierros; Cerro Lutz ha sido interpretado como un área formal de entierros, cuyo uso se prolongó durante varias generaciones (Mazza 2010b; Mazza y Lopone 2012); y según Lista (1878), el sitio Cementerio de Mazaruca estaría destinado al entierro de los muertos, pero que también habría servido como defensa durante inundaciones (Lista 1878). Los fechados radiocarbónicos para los entierros humanos arrojan un amplio rango, entre ca. 300 y 1800 años AP. Tal como fuera observado para las otras dos áreas, en estos sitios fueron enterrados desde un único individuo hasta 60 , sumando un total de 387 . Entre las modalidades inhumatorias se registraron: entierros primarios en distintas posiciones, paquetes funerarios, huesos y cráneos aislados y acumulaciones óseas. También se relevaron esqueletos con gran parte de su cuerpo articulado y algunos huesos reubicados, como los hallados en los sitios El Cerrillo y Arroyo Sarandí (Ramos van Raap y Bonomo 2016). A diferencia de lo registrado para el Delta Superior, no se reportan evidencias de huesos humanos termoalterados.

El registro mortuorio de la cuenca inferior del río Uruguay es menor en cuanto a la cantidad de hallazgos, comparando con las otras dos áreas. Se conocen 14 sitios con entierros humanos; la mayoría de estos lugares se corresponde con elevaciones antrópicas y donde se llevaron a cabo distintas actividades. Al igual que lo mencionado para el Delta Inferior, otro de los sitios excavados por Lista (Cementerio de Medina; Lista 1878) habría estado destinado como lugar para entierros humanos. El uso de estos espacios para la inhumación de los cuerpos, abarca un lapso temporal entre ca. 600 y 2000 años AP. La cantidad de individuos inhumados por sitios es variada, registrándose desde un solo entierro hasta 32 y alcanzando un total de 95 individuos. Las modalidades inhumatorias registradas incluyen entierros primarios en distintas posiciones, paquetes funerarios y huesos aislados. No fueron registrados contextos o conjuntos de huesos humanos termoalterados como los hallados en tres sitios del Delta Superior. De todas formas, en el sitio Las Ánimas se distinguieron huesos quemados contenidos dentro de paquetes funerarios; estos elementos óseos habrían sido expuestos al fuego sin tejido blando presente, durante un tiempo corto de exposición y a baja temperatura. Su presencia se ha vinculado con "la radiación del calor a través de sedimento, en eventos posteriores a la inhumación", aunque no 
se descarta que "los restos óseos hayan sido incinerados en otro espacio y, luego, trasladados y depositados en el área de entierro" (Guarido et al. 2016: 497).

Al analizar por tipo de entierro este amplio registro mortuorio de las tres áreas, se destacan algunas particularidades. En relación con los entierros primarios, los individuos masculinos fueron principalmente enterrados en posición decúbito dorsal, tal como ya fuera observado por Mazza y Loponte (2012) para el área definida como Humedal del Paraná Inferior. Por su parte, para los individuos femeninos fueron registradas inhumaciones tanto en posición dorsal como ventral, y algunos en decúbito lateral. Un aspecto observado de forma recurrente fue con respecto a los individuos subadultos de corta edad (infantes y niños), que sólo han sido relevados en paquetes funerarios, de forma aislada y en acumulaciones óseas. En cuanto a los paquetes funerarios, tanto simples como múltiples, están conformados principalmente por huesos largos y, a veces, con cráneo/s. Para aquellos entierros con los que se contaba con datos relativos a la edad y el sexo de los individuos que los conformaban, no se observaron distinciones en cuanto a estas categorías.

La aplicación de ocre sobre los huesos humanos se registró en las tres áreas. Las inhumaciones con huesos con pigmento corresponden a entierros primarios, paquetes funerarios y los contextos de huesos quemados. En relación con el sexo y la edad, no se observaron diferencias, en tanto que son subadultos y adultos femeninos y masculinos (Lothrop 1932; Gatto 1939; Gaspary 1950; Mazza 2010b; Scabuzzo y Ramos van Raap 2017). La prolongación temporal de los rituales mortuorios y la manipulación practicada en los restos esqueletales de determinados individuos, también se ve reflejada en los esqueletos con gran parte de su cuerpo articulado pero con determinadas regiones anatómicas ausentes y/o reubicación de algunos huesos (sitios LDLG2, El Cerrillo y Arroyo Sarandí). En estos casos, algunas regiones corporales o huesos (principalmente el cráneo) fueron removidos de manera intencional de su posición anatómica original, cuando aún el cuerpo no se encontraba completamente esqueletizado.

Otro aspecto interesante que se menciona al considerar todo el registro bioarqueológico, es la presencia de diversos objetos acompañando a algunos entierros. Por un lado, en la bibliografía consultada se describe la asociación de algunos entierros con cerámica, como por ejemplo: apéndices zoomorfos (Bonomo 
et al. 2016), contenedores fragmentados in situ (Castro, C. 2017) y fragmentos de dos vasos cerámicos hallados a pocos centímetros de los pies y de la pelvis de un esqueleto en el Cementerio de Mazaruca (Outes 1912). Por otro lado, algunos individuos fueron inhumados junto con diversos objetos: un entierro del sitio Paradero-Cementerio Brazo Largo se halló con un cráneo de aguará guazú, alisadores de cerámica, una manito de mortero y un pulidor de punzones (Gatto 1939); un entierro primario de El Cerrillo estaba acompañado con varios instrumentos óseos (siete raspadores y seis punzones; Ramos van Raap y Bonomo 2016); y un entierro primario del sitio Anahí se encontró junto con gran cantidad de cerámica decorada, material lítico, cuentas de adorno confeccionadas en valva de molusco, material de hueso y asta y un fragmento lítico (Lafon 1971). También se destacan las 21 cuentas de collar confeccionadas en valvas de Megalobulimus sp. asociadas con un cráneo del sitio Cerro Lorenzo 2 (Castro, J.C. 2017); y las cuentas, colgantes y láminas de cobre y bronce halladas por Torres (1911) en asociación con los cráneos de algunos individuos inhumados en los sitios Túmulo I y || del Paraná Guazú y Túmulo I del Brazo Gutiérrez (Bonomo et al. 2017b). Por otro lado, se han descripto diversos restos faunísticos junto a algunas inhumaciones. Como ejemplos de estos últimos contextos, sobresalen el hallazgo de un colmillo de yaguareté asociado con un entierro secundario del sitio Isla Talavera BD-S2 (Caggiano 1984); un premaxilar y maxilar de un yaguareté junto a un entierro secundario del sitio Don Santiago (Caggiano y Flores 2001); un cráneo de carpincho en cercanías de los entierros del sitio Las Ánimas y varios caninos de cánidos y carnívoros estrechamente asociados con un entierro primario en el sitio La Argentina (Acosta y Mazza 2016). Los hallazgos de cráneos de cánidos y/o félidos junto a entierros humanos, no sólo en estas áreas sino también en la región pampeana, han sido entendidos como el reflejo material de los aspectos simbólicos en el plano ideacional de los grupos humanos (Bonomo 2006). Específicamente, se ha planteado que serían producto de conductas rituales y que estos animales podrían haber sido referentes simbólicos o haber tenido un lugar especial en la esfera ideacional de las poblaciones (Bonomo 2006). Particularmente para los hallazgos del Delta Inferior, se ha propuesto también que su presencia en las inhumaciones podría indicar un "vínculo especial con la persona inhumada" (Acosta y Mazza 2016: 197-198). Finalmente, en la bibliografía se ofrece la información 
de que algunos paquetes funerarios se encontraban cubiertos por valvas de Diplodon sp. (LTC1, Scabuzzo y Ramos van Raap 2017); o que los entierros estaban comprendidos en el medio de una capa de valvas de estos moluscos (Las Ánimas; Acosta y Mazza 2016).

\subsection{Análisis bioarqueológicos desarrollados}

A lo largo del desarrollo de las investigaciones en el sur del NEA, se han abordado distintos aspectos del registro bioarqueológico. Una de las líneas de estudio, la de mayor tratamiento en las tres áreas consideradas, se ha focalizado en las prácticas mortuorias. Desde los primeros hallazgos de entierros humanos, el interés de los investigadores estuvo dirigido a la descripción de cómo habían sido encontrados los huesos, tanto en su disposición, como así también en la presencia de pigmento y objetos asociados (por ej. Lista 1878; Zeballos y Pico 1878; Aparicio 1928; Greslebin 1931; Lothrop 1932; Gatto 1939). Con el correr de las investigaciones, se incrementaron numerosas referencias sobre distintos tipos de inhumaciones (por ej. González 1947; Gaspary 1950; Lafon 1971; Caggiano et al. 1978a; Caggiano 1984). En años recientes, en el marco de nuevos proyectos de investigación con excavaciones sistemáticas y controladas, se obtuvieron datos más precisos de los entierros humanos encontrados (Mazza 2010a; Scabuzzo y Ramos van Raap 2011). A su vez, estas nuevas evidencias fueron analizadas junto con las ya existentes, abordando diferentes aspectos de las prácticas mortuorias: distinciones sexo-etarias en los tipos de entierro y en la aplicación de ocre; existencia o no de áreas formales de entierro; explicaciones sobre el origen de las acumulaciones óseas y huesos aislados; entre otros (Mazza 2010b; Mazza y Loponte 2012; Scabuzzo et al. 2015; Ramos van Raap y Bonomo 2016: Scabuzzo y Ramos van Raap 2017). Más allá de focalizar la atención sobre las modalidades inhumatorias, se han abordado otros aspectos del registro bioarqueológico, cuyo desarrollo ha sido desigual entre las tres áreas. A continuación se exponen, para cada área, estas principales líneas de estudio desarrolladas siguiendo un recorrido cronológico. 
El Delta Inferior es el área donde los estudios bioarqueológicos presentan mayor desarrollo temporal, desde principios del siglo XX hasta la actualidad. Uno de los aspectos abordados en una primera etapa de las investigaciones, ha sido la morfometría ósea con el fin de caracterizar y clasificar a los grupos prehispánicos. En la extensa y minuciosa obra de Torres (1911), el autor realiza un estudio descriptivo y métrico de los huesos procedentes de los entierros humanos de cinco sitios (Túmulo I y || del Paraná Guazú, Cementerio I del Paraná Guazú, Túmulo I del Brazo Gutiérrez y Túmulo I del Brazo Largo). Su objetivo es el "de contribuir...en el conocimiento de la primitiva población de Sud América, y especialmente, en el de los caracteres diferenciales de los grupos étnicos..." (1911: 62). También puede mencionarse la publicación de Outes de 1912; en ella describe y analiza caracteres e índices craneanos procedentes de varios sitios, algunos del Delta Inferior (por ej. Cementerio de Mazaruca), y concluye que "los indígenas del sur de Entre Ríos parecen vinculados estrechamente a ciertos elementos primitivos y agrupaciones étnicas actuales del Brasil meridional" (1912: 35). Varias décadas más tarde se presentaron otros trabajos con esta misma línea de estudio, como el de Fortich Bacca (1977) sobre los cráneos de los sitios Florencia (Santa Fé) y El Aserrado; y el de Caggiano y colaboradores (1978b) quienes describen diferentes caracteres de los esqueletos de Paraná Ibicuy 1. El interés en variaciones morfológicas y métricas de cráneos y huesos largos continúa hasta la actualidad, pero con objetivos distintos a los primeros estudios. La atención se dirige, principalmente, a examinar la dinámica poblacional y la variación biológica en el área. En este contexto, se han incluido conjuntos bioarqueológicos del NEA en análisis comparativos de la distribución espacial de rasgos epigenéticos craneofaciales (Del Papa 2008; Fabra 2013; Mazza y Fabra 2015); en estudios odontométricos (Bollini et al. 2012); en estudios de la morfología del esqueleto postcraneal (Béguelin 2009) y la vinculación del tamaño corporal con la temperatura ambiental (Béguelin 2010). Por otro lado, se han realizado aproximaciones métricas en dientes (Bollini y Atencio 2016) y en huesos largos para la generación de fórmulas discriminantes que permitan realizar determinaciones sexuales (Béguelin y González 2008; Béguelin et al. 2011; Mazza y Béguelin 2013).

En algunas publicaciones de la primera mitad del siglo XX también se han presentado descripciones y estudios de patologías óseas y dentales en conjuntos 
bioarqueológicos de distintos sitios del Delta Inferior (Outes 1911; Torres 1911). Particularmente, el trabajo de Torres (1911) adquiere relevancia por el grado de detalle que presenta sobre la dentición (desgaste, caries, pérdidas antemortem) y lesiones óseas (infecciosas, traumáticas) por él registradas en los cinco sitios analizados. En relación con el desgaste dental, en términos generales para todos los sitios, observa la erosión de tipo horizontal y también en varios casos con dirección linguo-bucal. En cuanto a las caries, sólo menciona dos de estas infecciones entre los 62 cráneos de los cinco sitios para los cuales brinda este tipo de información; en ambos casos se trata de molares superiores de un individuo adulto masculino y de un adulto femenino del sitio Túmulo I del Brazo Gutiérrez -TIBG (1911: 320, 332). Por otro lado, de acuerdo a las descripciones ofrecidas (1911: 236, 306, 339), registró tres individuos del Túmulo II del Paraná Guazú -TIIPG- con pérdidas dentales antemortem. Asimismo, en la mandíbula de un adulto masculino del sitio TIIPG, registra "indicios de periostitis?" sobre el lado derecho en relación con los dos primeros molares (1911: 223). En cuanto a lesiones óseas en los cráneos, se destaca la mención de probables traumas en cinco de ellos (Torres 1911). Uno corresponde al cráneo de un individuo adulto masculino del sitio Túmulo I de Paraná Guazú -T1PG (veáse Capítulo 7). Otros tres proceden del sitio TIIPG; en el occipital de un individuo juvenil femenino observa "un pequeño proceso del tamaño de un garbanzo, debido quizás a un golpe asestado en un punto inmediato, por la presencia de una pequeña incisura que muestra el hueso, como si fuera hecha con una punta o filo grueso" (1911: 200); en el frontal de un adulto masculino registra "tuberosidades pronunciadas, con una lesión traumática? en el costado derecho, más visible por una perforación" (1911: 202); y sobre el parietal derecho de otro adulto probable masculino encuentra "dos hendiduras probablemente causadas por golpe, denotando ciertos caracteres de un proceso inflamatorio que ha afectado al diploe" (1911: 225). Finalmente, en un cráneo de un adulto masculino del sitio TIBG, releva en el frontal "hendiduras y algunas lesiones, al parecer traumáticas extendidas en una buena superficie del hueso" (1911: 307). Asimismo, "el parietal derecho presenta signos de una fractura considerable que ha alterado la superficie de este hueso, con hendiduras y grietas recubiertas de nuevo tejido óseo" (1911: 308). Por otro lado, para TIIPG, en el cráneo de un adulto masculino registra osteoporosis en los parietales y que, según su consulta 
bibliográfica, asocia con cribra parietalia (1911: 194). Lo mismo observa en el occipital de otro cráneo de adulto masculino (1911: 219) y en los parietales de una bóveda craneana de un adulto femenino (1911: 227) procedentes del mismo sitio arqueológico.

Al tratar el conjunto de huesos largos recuperados, Torres (1911) también analiza el hallazgo de distintas patologías óseas. Para el sitio TIPG detalla lesiones infecciosas en un cráneo y huesos largos (véase Capítulo 7). Entre el conjunto óseo de TIIPG, menciona una clavícula que presenta anquilosis con la extremidad del acromion (i.e. la fusión total o parcial de los huesos de la articulación) y que posee gran deformación de su cuerpo dada la osteítis que la afecta (1911: 240-241). En TIBG, para ambos fémures y tibias asociados con un cráneo de un adulto masculino, describe detalladamente lesiones que diagnostica como osteomielitis (1911: 344-347). Finalmente, un esqueleto de un adulto masculino de TIBL presenta lesiones óseas en la bóveda craneana (1911: 361-365), clavícula izquierda (1911: 369), húmero derecho, cúbito izquierdo, uno de los radios (1911: 371) y ambas tibias (1911: 374-378). Específicamente sobre las tibias, describe su alteración en toda la diáfisis, las cuales a su vez se encuentran "arqueadas hacia adelante" (1991: 376). A partir del estudio de los huesos de este individuo y comparaciones bibliográficas, Torres atribuye todas las lesiones a una posible infección sifilítica hereditaria (1911: 378).

En el mismo año de la publicación de Torres, Outes (1911) presenta un análisis de diversos rasgos anatómicos en cráneos procedentes de varios sitios del sur de Entre Ríos y compara lo observado con poblaciones de distintas partes del mundo. En su escrito, sobresale una única mención sobre la identificación de lesiones óseas; se trata del cráneo incompleto de un adulto masculino (calvaria $110 \mathrm{M}$ ) ${ }^{2}$ que presenta "osteomielitis gomosa (?)" en el parietal, lo cual le impide observar los rasgos morfológicos de su interés (1911: 97).

Los estudios de patologías mencionados recién se caracterizaron por ser puntuales y descriptivos. En el marco de las investigaciones iniciadas en el siglo XXI

\footnotetext{
${ }^{2}$ No se detalla específicamente de qué sitio proviene este elemento óseo; sólo se menciona que, junto con otros cráneos, se encuentran en el Museo Nacional de Buenos Aires y que provienen de las investigaciones de Lista y Durand-Savoyat en la cuenca del Paraná Pavón y rincones del Ibicuy (Outes 1911: 549).
} 
en el Delta Inferior, se continuaron con análisis patológicos pero en el marco de nuevas preguntas vinculadas con estudiar los modos de vida de las poblaciones que habitaron esta área. En este contexto, se han registrado diferentes lesiones óseas sobre algunos de los entierros humanos hallados en el sitio Cerro Lutz (Kozameh et al. 2007; Kozameh y Brunás 2009). Entre ellas, pueden mencionarse dos hundimientos en el parietal derecho de un adulto masculino, de probable origen traumático. Este mismo esqueleto presentaba alteraciones del periostio en algunos huesos largos de lateralidad derecha (húmero, cúbito, fémur y tibia) y en la bóveda craneana, lo cual fue interpretado como producto de procesos infecciosos (Kozameh et al. 2007). Asimismo, en otro adulto masculino se registraron lesiones compatibles con osteomielitis en la clavícula derecha (Kozameh y Brunás 2009). También se observaron evidencias de violencia interpersonal en el esqueleto de un adulto medio masculino; específicamente se recuperaron dos puntas óseas ahuecadas en la cavidad torácicoabdominal y un ápice de otra punta ósea que atraviesa una vértebra torácica y se detiene en el canal medular (Mazza 2015). Por otro lado, para abordar el estudio de patrones de diferenciación social en el Delta Inferior, se analizaron marcadores óseos de actividad en el conjunto de este sitio y de otros excavados en el siglo XX (Mazza 2015).

Con el fin de indagar sobre la dieta de los grupos que habitaron esta área, se realizaron análisis dentales en individuos procedentes de distintos sitios; éstos incluyen a los excavados actualmente y algunos de los trabajados en el siglo anterior (Mazza y Barrientos 2012). El desgaste dental relevado presentó diferentes grados, predominando los intermedios. Las caries fueron registradas en bajas prevalencias a nivel individual y dental, y todas se ubican en la dentición posterior en las superficies oclusales e interproximales. También se relevaron bajos porcentajes de pérdidas dentales antemortem y abscesos, con asociación estadística en individuos de mayor edad. Por otro lado, se registró una alta prevalencia individual de cálculo dental, con diferencias significativas a favor de los masculinos. Finalmente, se registraron hipoplasias del esmalte dental de forma bilateral en el $16,7 \%$ de la muestra. En conjunto, todos estos resultados fueron interpretados como los esperados para grupos cazadores-recolectores, con una dieta con un alto componente animal y mediano consumo de vegetales (Mazza y Barrientos 2012). Estos datos se 
complementan a los obtenidos de los estudios arqueobotánicos en muestras de tártaro dental de entierros humanos de sitios del Noreste de Buenos Aires. Exceptuando lo relevado para sitios vinculados con ocupaciones guaraníes, se encontraron fitolitos de diferentes morfologías; particularmente para la muestra del sitio La Bellaca 2 se reconocieron fitolitos de afinidad graminoide y arecoide (Zucol y Loponte 2008).

A diferencia del Delta Inferior, los estudios bioarqueológicos en el Delta Superior y Medio del río Paraná se desarrollaron más tardíamente. Hacia la mitad del siglo XX se excavaron en estas áreas los dos primeros sitios arqueológicos con entierros humanos (Cerro Grande del Paraná Pavón, González 1947; y Cerro Grande de la Isla Los Marinos, Gaspary 1950). Además de la presentación minuciosa de las prácticas mortuorias observadas por los investigadores en ambos sitios, Gaspary también realiza un "estudio ántropo-físico" de los entierros por él hallados en CGILM (1950: 52). El autor calcula la talla de los individuos a partir de la longitud de los fémures, realiza un análisis craneométrico y analiza la presencia de deformaciones artificiales del cráneo; los resultados obtenidos los examina comparativamente con los obtenidos por Torres (1911). Asimismo, Gaspary lleva a cabo un análisis anátomopatológico macroscópico de los huesos y observa lesiones de distintas etiologías:

"una fractura de ambos huesos del antebrazo, consolidada en bayoneta; una fractura con hundimiento de tabla externa de cráneo, curada; varios casos de osteo-artritis reumáticas, prevalentemente en columna vertebral; un muy interesante caso de enfermedad de Paget, con groseras alteraciones en todos los huesos" (1950: 58).

Además, el autor expone brevemente información sobre distintos aspectos de la dentición: la muestra se caracteriza por no presentar caries y por tener gran desgaste dental; asimismo registró un absceso peridentario y varios dientes con "gruesos depósitos de sarro" (1950: 58). Este estudio, al igual que el realizado por Torres (1911), resulta puntual y descriptivo y con el objetivo de "establecer la cultura y los caracteres físicos de los primitivos habitantes de este cerro" (Gaspary 1950: 58).

Décadas posteriores a los trabajos de Gaspary, se retomaron los estudios sobre esta colección bioantropológica enfocándose en los análisis dentarios, pero con objetivos distintos (Kozameh 1996; Loponte y Kozameh 2009; Kozameh y Brunás 2011, 
2013). De un estudio comparativo sobre la dentición de esta muestra con otras dos de Patagonia (Kozameh 1996), se obtuvieron datos más precisos sobre estos individuos y se esbozaron algunas interpretaciones sobre la dieta. Según los análisis efectuados, se observaron diferentes grados de desgaste dental, siendo más prevalentes los grados bajos; a su vez, la dentición posterior presenta mayor desgaste que la anterior. En relación con las caries, se observó que la frecuencia es baja y que todas las lesiones se ubican en la dentición posterior. Finalmente, se registraron numerosos casos de patologías alveolares, mayormente en individuos maduros y femeninos. La autora concluye que la dieta de los individuos de CGILM, al presentar mayor aporte vegetal en comparación con las otras muestras de la región patagónica, "exigió menor esfuerzo de masticación, lo que habría atenuado los desgastes". Asimismo, entiende que la frecuencia de caries pudo verse atenuada por la incidencia del desgaste pero que aun así habría habido una baja ingesta de carbohidratos. Por último, la mayor frecuencia de pérdidas dentales antemortem, caries y patologías alveolares en mujeres sugiere que, además de factores ambientales, las variaciones hormonales habrían modificado su ambiente oral; de esta forma habrían padecido más caries, las cuales llevarían con el tiempo a la pérdida de la pieza dental y a las lesiones alveolares (Kozameh 1996: 474). Posteriormente, Kozameh y Brunás (2011, 2013) reanalizaron uno de los elementos óseos (una tibia, el único conservado) del individuo con enfermedad de Paget, utilizando nuevas técnicas (radiográficas, de tomografía computada e histológicas). A partir de este estudio, se pudo confirmar el diagnóstico realizado por Gaspary y se propone que tal enfermedad pudo ser producto tanto de una combinación de factores hereditarios y ambientales, como de una afección viral (Kozameh y Brunás 2013).

En cuanto al área correspondiente a la cuenca inferior del río Uruguay, como ya fuera mencionado en el apartado anterior de este capítulo, el registro bioarqueológico es menor en comparación con las otras dos áreas. A su vez, los estudios realizados sobre los conjuntos osteológicos son escasos; hasta el momento sólo se ha brindado información sobre los hallazgos y las prácticas mortuorias (Greslebin 1931; Lafon 1971; Castro y Del Papa 2015; Acosta y Mazza 2016; Loponte et al. 2016) y no se cuentan con análisis que indaguen sobre otros aspectos de este registro, como por ejemplo estudios de patologías. Recientemente, se comenzaron 
estudios sobre las deformaciones artificiales del cráneo de muestras procedentes de esta área (Del Papa et al. 2018); y también se inició el relevamiento de enfermedad degenerativa articular, como un potencial indicador de actividad física (Scabuzzo y Ramos van Raap 2018). Ambos estudios se realizan incluyendo también muestras del Delta del Paraná.

Finalmente, en los últimos años se ha incorporado con mayor fuerza otra vía de análisis que merece ser mencionada, ya que aporta valiosa información para comprender las dietas prehispánicas de los grupos que habitaron el sur del NEA. Se trata de los análisis de isótopos estables $\left(\delta^{13} \mathrm{C}\right.$ y $\left.\delta^{15} \mathrm{~N}\right)$ con muestras procedentes del Delta Superior e Inferior del Paraná (Loponte y Kozameh 2009; Bonomo et al. 2017a; Ottalagano y Loponte 2017). La discusión se ha centrado en diferenciar los grupos identificados arqueológicamente como Goya-Malabrigo y como guaraníes. En un trabajo reciente, Bonomo y colaboradores (2017a) presentaron nuevos resultados sobre huesos humanos y faunísticos. Estos datos los integraron con los ya existentes y los interpretaron junto con los resultados de los estudios arqueofaunísticos y arqueobotánicos de los sitios arqueológicos. Según los datos obtenidos a partir de los distintos tipos de evidencias (faunísticas, arqueobotánicas e isotópicas), los autores sugieren que la entidad arqueológica Goya-Malabrigo puede vincularse con una economía mixta. Específicamente, se plantea el aprovisionamiento de recursos silvestres mediante la caza, la pesca fluvial y la recolección de mariscos, frutas y semillas de plantas (algarrobo y eventualmente palmas y arroz silvestre). A su vez, estas actividades se complementaron con la horticultura de la tríada zapallo-maízporoto. Según los valores isotópicos, no se observa un consumo intensivo de maíz para la mayoría de los individuos, sino más bien un consumo predominante de plantas $C_{3}$, que podrían incluir tanto a especies silvestres como domesticadas.

\subsection{Palabras finales}

Desde los primeros trabajos de campo realizados en el NEA hasta la actualidad, se ha reportado el hallazgo de numerosos entierros humanos. Los objetivos de las investigaciones arqueológicas que enmarcaron tales excavaciones, 
influyeron directamente en la información contextual brindada sobre cada uno de estos entierros. De esta forma, la importancia que se le ha dado al registro bioarqueológico en general, y a ciertos aspectos de éste en particular, ha variado a lo largo del avance de los estudios realizados. Particularmente en lo que refiere a análisis de patologías dentales y óseas, se cuenta con antecedentes para algunos sitios del Delta del Paraná. Las primeras referencias de diversas anomalías óseas y dentales fueron meramente descriptivas, en el contexto de estudios de antropología física que buscaban caracterizar a los grupos bajo estudio (Outes 1911; Torres 1911; Gaspary 1950). Luego de varias décadas de estancamiento en cuanto a estudios bioarqueológicos, a fines del siglo XX y principios del XXI se esbozan los primeros trabajos -a nivel intrasitio- en los que, a partir de análisis de diferentes indicadores óseos y dentales, se aborda la dieta y el estado de salud de los individuos analizados (Kozameh 1996; Kozameh et al. 2007; Kozameh y Brunás 2009). Desde una perspectiva más regional y como una aproximación a la dieta prehispánica, se realizó el análisis de distintos indicadores bucales en individuos procedentes de diferentes sitios del Delta Inferior del río Paraná (Mazza y Barrientos 2012); sin embargo, estos análisis no han tenido continuidad ni profundización. Por su parte, a partir de los isótopos estables y análisis arqueobotánicos, se ha sumado evidencias para discutir las economías de estos grupos prehispánicos. Considerando lo antes expuesto, queda inconcluso un abordaje sistemático del estudio de patologías óseas y dentales, cuyos resultados sean integrados e interpretados con los datos obtenidos de diversas líneas de análisis para abordar de forma holística el estado de salud y nutrición de los grupos humanos que habitaron estas latitudes. 


\section{Capítulo 4}

\section{Metodologías de análisis de las muestras bioarqueológicas}

Los entierros humanos procedentes de cuatro de los cinco sitios arqueológicos estudiados del Delta del río Paraná (i.e. Los Tres Cerros 1, Laguna de Los Gansos 2, El Cerrillo/Túmulo I del Paraná Guazú y Arroyo Sarandí) comenzaron a ser analizados en momentos previos al inicio de este trabajo (Scabuzzo y Ramos van Raap 2011; Scabuzzo et al. 2015; Ramos van Raap y Bonomo 2016), de modo que ya se contaba con un primer inventario general de cada una de ellos y el cual fue completado durante el desarrollo de la presente tesis. En el caso de los entierros humanos del sitio restante del Delta del Paraná (Túmulo 1 - La Argentina) y los ocho sitios de la cuenca inferior del río Uruguay, el inventario fue realizado íntegramente durante el transcurso de la tesis ${ }^{1}$. Además de los datos correspondientes a la catalogación o referencia (i.e. entierro o número de inventario), en cada base de datos fue consignado para cada elemento identificado, su lateralidad y la porción presente. Este fue el primer paso efectuado en el análisis. En segunda instancia se llevaron a cabo estudios cuanti y cualitativos para conocer la conformación general de cada conjunto, el número mínimo de individuos representados y la estructura sexo-etaria. Para esto fue primordial identificar los tipos de entierros de los cuales provienen los conjuntos analizados, siempre y cuando la información contextual disponible para cada sitio lo permitió (véase en detalle Capítulo 5). En términos generales, los entierros fueron clasificados como primarios, paquetes funerarios, acumulaciones óseas, huesos aislados y entierros indeterminados por falta de información. La modalidad primaria es cuando todos los huesos del esqueleto se encuentran posicionados de acuerdo a su relación anatómica natural (Ubelaker 1989; White y Folkens 2005); se tuvo en cuenta la posición de los esqueletos (decúbito dorsal, decúbito ventral o lateral

\footnotetext{
${ }^{1}$ Los investigadores Castro y Del Papa (2015) ya habían realizado un análisis bioarqueológico preliminar sobre estas muestras, pero sin incluir la totalidad de ellas. Por lo cual, los resultados allí presentados sobre la estructura sexo-etaria no refieren a todo el conjunto.
} 
extendido/flexionado) y su orientación. Los paquetes funerarios son conjuntos de huesos -principalmente largos- que se hallan superpuestos siguiendo el eje axial, con la posible inclusión de cráneo/s. Estos elementos óseos presentan una disposición diferente a la anatómica o "natural", lo que involucra una desarticulación total o parcial de manera intencional, previa a la inhumación de los individuos dentro de los fardos (Ubelaker 1989; White y Folkens 2005); se relevó si se trataba de paquetes simples (un solo individuo) o múltiples (dos o más individuos) y cuál era su orientación cardinal. La categoría acumulación ósea refiere a conjuntos de huesos asociados espacialmente pero que no siguen un orden simétrico aparente como los paquetes funerarios. Los huesos aislados son elementos óseos que se hallan de manera aislada o articulados (por ej. un brazo o un pie) en el área de inhumación, sin formar parte de paquetes o acumulaciones óseas. En última instancia, se realizó el relevamiento paleopatológico.

\subsection{Análisis cuantitativos iniciales}

Los análisis cuantitativos estuvieron principalmente orientados a estimar el Número Mínimo de Individuos (NMI). Para ello, la consideración del tipo de entierro fue fundamental, dependiendo si lo permitía la información disponible para cada uno de los sitios arqueológicos. En este sentido, primero se trabajó con aquellos individuos enterrados bajo la modalidad primaria, haciendo el inventario de los huesos presentes y una primera estimación de la edad y determinación del sexo (véase en detalle más adelante). Estas estimaciones sirvieron de base para luego continuar con el análisis de los paquetes funerarios, acumulaciones óseas y conjuntos de huesos aislados o sin información de las inhumaciones. Para cada uno de estos casos se calcularon las medidas de abundancia taxonómica y anatómica, desarrolladas en el marco de análisis arqueofaunísticos (Lyman 1994). Concretamente, se calculó el Número de Especímenes Identificados (NISP), el Número Mínimo de Elementos (NME), el MAU y MAU\% (número mínimo de unidades anatómicas) y el Número Mínimo de Individuos (NMI) necesario para dar cuenta de los restos óseos identificados para cada elemento (Lyman 1994). Este último número se obtuvo 
considerando el valor de la unidad anatómica más numerosa y teniendo en cuenta distintos criterios, como la lateralidad y el estado de fusión y osificación de los elementos. Complementariamente, se realizó una búsqueda de apareamiento de huesos antímeros y huesos anatómicamente adyacentes. Esta metodología, denominada ensamblaje anatómico (Todd y Frison 1992), también ha sido desarrollada en el marco de análisis zooarqueológicos para reconocer piezas óseas pertenecientes a un mismo individuo y fue empleada en este trabajo con el mismo objetivo (para ver ejemplos de su aplicación en contextos bioarqueológicos consultar Barrientos 1997; Arrieta 2012). Existen dos formas de realizar el ensamblaje: 1) bilateral: comparación (morfológica y/o métrica) de elementos pareados de ambas lateralidades (por ej. húmero izquierdo y húmero derecho); 2) intermembral: comparación (morfológica y/o métrica) de elementos óseos adyacentes (por ej. fémur derecho y tibia derecha; maxilar y mandíbula) y no adyacentes (por ej. húmero y fémur)2. En ambos casos, las comparaciones implicaron la observación de distintos atributos de los elementos: las superficies articulares de los extremos proximales y distales; la forma y estructura del hueso; y las improntas de inserciones musculares. En el caso específico de maxilares y mandíbulas, también se utilizó como criterio el grado de desgaste dental. Asimismo, se tuvieron en cuenta otras características, como por ejemplo la presencia de ocre y la coloración de los elementos. Todo esto se realizó teniendo siempre en consideración la categoría de edad y cuando era posible, el sexo.

\subsection{Criterios empleados en la estimación de edad y determinación de sexo}

La elección de los métodos para estimar la edad al momento de muerte y determinar el sexo de los individuos varió según se tratara de esqueletos completos

\footnotetext{
2 Debido a que este tipo de ensamblaje entre huesos no adyacentes no se encuentra bien desarrollado y puede generar ambigüedades por la variación individual, se decidió no emplearlo en este trabajo.
} 
o conjuntos de huesos ${ }^{3}$. Cuando la integridad anatómica de los esqueletos lo permitió, se emplearon varios criterios diagnósticos teniendo en cuenta su confiabilidad en la exactitud y precisión de los resultados obtenidos (para mayor detalle véase Luna 2008).

Los criterios empleados para la estimación de la edad de muerte en individuos subadultos fueron cualitativos y cuantitativos. Todos ellos fueron aplicados de forma macroscópica. En huesos correspondientes a subadultos, se realizaron mediciones de longitudes diafisarias de huesos largos (Maresh 1970; Fazekas y Kósa 1978; Schaefer et al. 2009) y se consideró la secuencia de formación y fusión de centros de osificación. Dado que las uniones epífisis-diáfisis ocurren entre la adolescencia y la adultez temprana (15-23 años aproximadamente), para ese rango de edad fue evaluado el estado de fusión de las epífisis de los huesos largos utilizando los estándares publicados por Schaefer y colaboradores (2009). Asimismo, independientemente del estado de maduración y desarrollo de los elementos óseos, se consideró la secuencia de formación y erupción dental, siguiendo la propuesta de Ubelaker (1989). Cabe destacar que en caso de contar para un mismo individuo con huesos largos posibles de ser medibles y con maxilar y/o mandíbula, se utilizó la edad dental, ya que ha sido considerada como mejor estimador de la edad en individuos en desarrollo que la edad obtenida mediante la longitud de huesos largos (Ubelaker 1987; García Mancuso 2014). Para los adultos, se evaluaron los cambios morfológicos de la sínfisis del pubis (Todd 1920) y de la superficie auricular y retroauricular del ilion (Lovejoy et al. 1985); y el estado de fusión epifisiaria de algunos huesos (por ej. clavícula) que maduran durante la adultez temprana (Schaefer et al. 2009). Luego de aplicar las técnicas correspondientes, los individuos fueron incluidos dentro de una de las categorías de edad propuestas por Buikstra y Ubelaker (1994). Cabe aclarar que en lugar de feto, se prefirió utilizar la categoría perinato para aquellos individuos en los que el rango de edad fuera desde la semana 38 de gestación, considerando la posibilidad de nacimientos prematuros (Tabla 4.1).

3 Algunas de las estimaciones de edad y determinaciones de sexo ya habían sido efectuadas en los análisis iniciales de las muestras del Delta del Paraná. Las metodologías empleadas en ese entonces fueron las mismas que las utilizadas posteriormente. 
Tabla 4.1. Categorías de edad (sensu Buikstra y Ubelaker 1994).

\begin{tabular}{|cc|}
\hline Categoría de edad & Rango etario \\
\hline Feto & hasta el nacimiento \\
Infante & 0 a 3 años \\
Niño & 3 a 12 años \\
Adolescente & 12 a 20 años \\
Adulto joven & 20 a 35 años \\
Adulto medio & 35 a 50 años \\
Adulto viejo & más de 50 años \\
\hline
\end{tabular}

Con el objeto de evaluar la conformación etaria de los conjuntos analizados y explorar la incidencia de probables sesgos (por ej. preservación diferencial, prácticas mortuorias), se construyeron perfiles de edad de muerte para cada muestra bioarqueológica (por ej. García Guraieb et al. 2015; Suby et al. 2017b). Para graficar los resultados, se utilizaron intervalos de cinco años para los individuos subadultos menores a 20 años; los individuos adultos se agruparon según las categorías antes mencionadas propuestas por Buikstra y Ubelaker (1994). De esta forma, se conformaron los siguientes grupos de edad: 0-1; 1,1-5; 5,1-10; 10,1-15; 15,1-20; 20,135; 35,1-50; > 50.1 años.

La determinación sexual de los individuos adolescentes tardíos y adultos estuvo basada en la observación del grado de expresión y la presencia o ausencia de rasgos morfológicos en el cráneo y la pelvis. En el cráneo, los rasgos diagnósticos fueron aquellos propuestos por Acsádi y Nemeskéri (1970 en Buikstra y Ubelaker 1994): los procesos mastoideos, los márgenes supraorbitales, la cresta nucal, la glabela y la eminencia mentoniana. En la pelvis, se evaluaron los rasgos propuestos por Phenice (1969) para la región subpúbica: presencia/ausencia de arco ventral, el aspecto medial de la rama isquiopúbica y el ángulo de la concavidad subpúbica. También se observaron la presencia y el grado de expresión del surco preauricular y la amplitud de la escotadura ciática mayor sensu Buikstra y Ubelaker (1994). Las categorías empleadas fueron aquellas propuestas por Buikstra y Ubelaker (1994): femenino, probable femenino, masculino y probable masculino.

En la evaluación de los rasgos del cráneo y de la amplitud de la escotadura ciática mayor en la pelvis, las metodologías consisten en un sistema de grados de 
expresión utilizando una escala ordinal de cinco puntos. En estas escalas se muestra el rango de la variabilidad de los aspectos entre los extremos de la misma: el grado 1 con las características más gráciles -femeninas- y el 5 con las características más robustas -masculinas. Al aplicar esto en las muestras analizadas, se tuvieron en cuenta los siguientes criterios: se determinaron como femeninos a los elementos óseos en los que a la mayoría de los rasgos observados se les asignara grados 1 y 2; mientras que se determinaron como masculinos a aquellos en los que se les asignara principalmente grados 4 y 5 . En los casos en los que hubiera una combinación de grados 1-2 o 4-5 con grado 3, se los determinó como probable femenino y probable masculino, respectivamente. Cuando el grado predominante fue el 3, se los consideró como indeterminados.

Como se verá en el capítulo siguiente, en las muestras bioarqueológicas se cuenta con una considerable cantidad de huesos largos a los que no se los puede corresponder con un cráneo y/o pelvis. Por este motivo, como metodología cuantitativa complementaria para la determinación sexual en individuos adultos, se utilizaron fórmulas discriminantes en huesos largos. Esta metodología consiste en desarrollar fórmulas que permitan discriminar el sexo, utilizando variables métricas sobre los elementos óseos que reflejen diferencias de tamaño de las epífisis y las diáfisis; esto se sustenta en diversos estudios que han señalado que las diferencias en el tamaño, en la robustez y en las inserciones musculares de los huesos largos se debe al dimorfismo sexual que caracteriza a la especie humana (White y Folkens 2005). Aun así hay que considerar que el tamaño corporal es muy variable entre distintas poblaciones (Frayer y Wolpoff 1985), por lo que se requiere el desarrollo de fórmulas específicas para cada población. Para esto, en primer lugar, es necesario contar en el conjunto óseo a analizar con un número elevado de huesos correspondientes a individuos sexuados cualitativamente, de forma que sirvan de referencia. Debido a que esto no se cumple en las muestras analizadas, se decidió emplear fórmulas ya elaboradas para distintos huesos (húmero, radio, cúbito, clavícula, fémur y tibia) procedentes de colecciones osteológicas de sitios del Delta Inferior del río Paraná (Béguelin y González 2008; Béguelin et al. 2011; Mazza y Béguelin 2013). En primera instancia estas fórmulas fueron aplicadas en las muestras del Delta Superior (Batalla y Di Lorenzo 2016). Para corroborar la fiabilidad de su 
utilización, primero se aplicaron en los huesos que ya tenían asignación cualitativa de sexo; como los resultados fueron positivos, se continuó con su empleo en el resto del conjunto óseo. Al igual que lo observado por las autoras de las fórmulas (Mazza y Béguelin 2013), las variables métricas -y por ende las fórmulas correspondientesque mejor discriminaron para sexo fueron las del fémur y del húmero (Batalla y Di Lorenzo 2016). Por este motivo, para las muestras procedentes de la cuenca inferior del río Uruguay y del Delta Inferior, se realizaron estos análisis métricos sobre tales huesos largos (i.e. fémur y húmero); también corroborando en primera instancia la confiabilidad de su uso, tomando como referencia individuos sexuados con pelvis $y / 0$ cráneo.

Las determinaciones sexuales en individuos menores a 15 años no fueron realizadas. Esto se debe a la baja frecuencia de las unidades anatómicas diagnósticas para tal determinación (por ej. os coxae) y a que los métodos disponibles ofrecen poca precisión (Lewis 2006).

\subsection{Análisis patológico}

En todo análisis paleopatológico debe conocerse previamente la morfología normal del esqueleto humano (ya sea de subadultos o de adultos) para poder identificar cualquier anomalía que éste presente. Asimismo, es importante reconocer alteraciones postdepositacionales sobre los elementos óseos (Buisktra y Ubelaker 1994; Lovell 2000; Ortner 2012) para no confundirlas con las respuestas del esqueleto frente a determinado estresor o patógeno. Se han propuesto cuatro criterios diagnósticos en paleopatología: 1) la identificación de lesiones patológicas, 2) su localización en el elemento, 3) la distribución esquelética de las lesiones en un individuo, y 4) la distribución de lesiones en una población (Lovell 2000). Estos puntos han sido considerados en el análisis realizado, sumando como quinto criterio el diagnóstico diferencial (Ortner 2012). El primer y segundo punto se realizó mediante la observación macroscópica y con lupa binocular (de hasta 20x) de la lesión, acompañada de una descripción detallada (principalmente para las lesiones óseas), tal como ha sido sugerido por Ortner (2012). Las descripciones constituyen un punto 
fundamental, ya que no sólo permite el posterior análisis y diagnóstico de la lesión, sino que brinda información detallada para su evaluación por parte de otros investigadores (Lovell 2000). Aquí se tuvieron en cuenta los cuatro tipos de condiciones anormales básicas en los elementos óseos (sensu Ortner 2012): un tamaño anormal del hueso, una forma anormal del hueso, una formación ósea anormal y una ausencia anormal de tejido óseo. Las descripciones fueron acompañadas del registro fotográfico digital de las lesiones; para ello se utilizó una cámara semi reflex Kodak PIXPRO AZ251 (25X y 16 MP) y una cámara compacta Nikon COOLPIX S7000 (20X y 16MP). Asimismo, de manera complementaria al análisis macroscópico, en ciertos huesos se realizaron radiografías biplanares y/o tomografías computadas para evaluar con mayor detalle las lesiones que en su estudio macroscópico sugería la afección de las estructuras internas del hueso, o que por sus características superficiales dificultaba el diagnóstico. En los huesos de los sitios del Delta del Paraná, las radiografías se realizaron en el Hospital Interzonal General de Agudos Profesor Dr. Rodolfo Rossi, gracias a la coloraboración de los Dres. O. Cayero, S. Farca y equipo. Las tomografías computadas en huesos de un sitio del Delta Superior se efectuaron en el Hospital Interzonal Especializado de Agudos y Crónicos San Juan de Dios, bajo la supervisión del técnico E. D’Ovidio. Ambas instituciones públicas se encuentran en la ciudad de La Plata (Buenos Aires) y son dependientes del Ministerio de Salud de la provincia de Buenos Aires. En los huesos de los sitios arqueológicos de la cuenca inferior del río Uruguay, las radiografías se llevaron a cabo en la Clínica Centro de Diagnóstico Médico (CEDIME) en la ciudad de Gualeguaychú, gracias a la ayuda del Dr. L.C. Badano Gaona y el técnico G. Rodríguez. Posteriormente a la descripción y documentación de cada lesión, se observó su distribución en el esqueleto. Esto sólo pudo realizarse en aquellos esqueletos identificados, procedentes por ejemplo de entierros primarios o paquetes funerarios. En última instancia, se procedió a realizar el diagnóstico diferencial y clasificar las lesiones observadas dentro de los grupos etiológicos adoptados para el análisis (véase más adelante). Aquí se tuvieron en cuenta, como punto de partida, tanto a información clínica así como también a evidencia paleopatológica, lo cual permitió discriminar las posibles causas de las lesiones. 
A continuación, se exponen las características principales de los indicadores y condiciones paleopatológicas relevadas en cuanto a su etiología, desarrollo e implicancias en los estudios bioarqueológicos. A su vez, se especifica la metodología y los criterios utilizados en cada caso. Se dividió, por un lado, los indicadores de salud bucal y adecuación fisiológica y, por otro, las patologías óseas.

\subsubsection{Indicadores de salud bucal y adecuación fisiológica}

El análisis de indicadores de salud bucal y de adecuación fisiológica se concentró en el relevamiento de caries, lesiones periapicales, pérdidas dentales antemortem, cálculos dentales, desgaste e hipoplasias del esmalte. Una clasificación de los indicadores de salud bucal fue propuesta por Lukacs (1989) según su etiología primaria: infecciosas, degenerativas, de desarrollo y genéticas. En este trabajo se consideró dicha clasificación como base para el análisis, con algunas modificaciones de acuerdo a los estudios a realizar (Tabla 4.2). Es importante recordar la compleja interacción existente entre las enfermedades dentales y las causas que las originan (Lukacs 1989). En este sentido, la clasificación y catalogación de ellas según su etiología constituye sólo una primera aproximación a su estudio para alcanzar inferencias sobre la dieta, nutrición y salud de las poblaciones pasadas. También fue evaluado el desgaste dental, que no se considera una patología en sí, sino como una condición fisiológica erosiva producto del uso (masticatorio o no) de la dentición (Grippo et al. 2004; Hillson 2008).

Tabla 4.2. Clasificación de los indicadores de salud bucal (tomado y modificado de Lukacs 1989).

\begin{tabular}{|cc|}
\hline Categoría & Enfermedad Dental \\
\hline Infecciosas & $\begin{array}{c}\text { caries } \\
\text { lesiones periapicales } \\
\text { pérdida dental antemortem }\end{array}$ \\
\hline Degenerativas & $\begin{array}{c}\text { acumulación de cálculo } \\
\text { pérdida dental antemortem (por atrición) }\end{array}$ \\
\hline De desarrollo & líneas de hipoplasia del esmalte \\
\hline
\end{tabular}


En el Apéndice 1 - Tabla A.1.1 puede observarse la nomenclatura utilizada para las piezas dentales, ya sean deciduas o permanentes. Para el relevamiento de los indicadores de salud bucal y adecuación fisiológica, fue efectuada una planilla de inventario de la dentición para cada elemento (mandíbula y maxilar) (basada en la presentada por Buikstra y Ubelaker 1994) y una de registro de cada lesión (Ficha A.1.1). Las metodologías seleccionadas para el relevamiento de estas lesiones orales son las que suelen ser aplicadas de forma más recurrente en el ámbito de la bioarqueología y paleopatología en Argentina (L'Heureux 1998, 2000; Bernal et al. 2007; Luna 2008; Gómez Otero y Novellino 2010; Flensborg 2013; García Guraieb y Maldonado 2014; entre otros), con el fin de poder comparar resultados con las investigaciones realizadas por otros equipos de trabajo.

\subsubsection{Caries}

La caries es una de las patologías crónicas que afecta de forma frecuente a los seres humanos (Langsjoen 1998). Esta enfermedad -multifactorial, infecciosa y transmisible- consiste en la desmineralización focal y progresiva de los tejidos dentales (esmalte, dentina y cemento) y la posterior destrucción de la porción orgánica de la pieza dental (Langsjoen 1998; Hillson 2001, 2008). Para su desarrollo, básicamente deben estar presentes tres elementos: 1) carbohidratos fermentables, 2) placa bacteriana y 3) ácidos resultantes de la actividad metabólica de las bacterias (Waldron 2009).

Pueden diferenciarse principalmente dos tipos de caries según su localización en la pieza dental y los tejidos comprometidos (Langsjoen 1998; Hillson 2001, 2008). Una de ellas es la caries coronal, que se localiza sobre el esmalte de la superficie de la corona. En estos casos, los restos de alimentos blandos (por ej. hidratos de carbono) que quedan "atrapados" principalmente en hoyos y grietas del esmalte, forman una placa propicia para la proliferación de bacterias (Hillson 2001). Durante la fermentación de estos carbohidratos, la placa bacteriana libera ácidos orgánicos que causan la desmineralización del esmalte iniciando así el proceso gradual de la caries. En los primeros estadios de desarrollo de esta lesión oral, la desmineralización va ocasionando manchas blancas o marrones en el esmalte y éste, con el tiempo, termina por agrietarse y se produce una cavidad que afecta al esmalte, a la dentina e incluso puede llegar a exponer la cavidad pulpar generando 
infección, absceso y pérdida antemortem de la pieza dental. El otro tipo de caries es la de raíz, donde el tejido afectado es el cemento. Este tejido normalmente se encuentra cubierto por la gíngiva, pero en los casos donde ocurre una retracción de ella (por ej. enfermedad periodontal), la raíz queda expuesta a la actividad bacteriana y, por ende, las caries pueden desarrollarse de la misma forma que en las caries coronales, llegando también a afectar la dentina y cavidad pulpar (Langsjoen 1998; Hillson 2001; Waldron 2009).

Se ha propuesto una relación directa entre la frecuencia de caries y el tipo de dieta. El consumo de carbohidratos, alimentos suaves, "pegajosos" y azucarados (asociados con el desarrollo de la agricultura) produciría altas tasas de caries (Lukacs 1989, 2008; Hillson 2008). Teniendo en cuenta esto, el estudio de las caries brinda información no sólo sobre la salud de los individuos de una población, sino también sobre hábitos dietarios, estilos de vida y modos de subsistencia (por ej. Larsen 1983; Larsen et al. 1991; L'Heureux 1998; Bernal et al. 2007; Lanfranco y Eggers 2010). De todas maneras, no sólo el tipo de alimentos consumidos y sus modos de preparación influyen en el desarrollo de caries. Su etiología está vinculada con un complejo multifactorial. Los tipos de dientes poseen distinta susceptibilidad a padecer caries debido al tiempo de su erupción y, por lo tanto, al tiempo en el que están expuestos a los factores que influyen en el desarrollo de esta patología (Hillson 2008). Además, la morfología de cada tipo de diente está en relación con la acumulación de restos alimenticios en él, como suele darse por ejemplo en las fosas y hoyos de las superficies oclusales en premolares y molares y en los lugares por debajo de la línea de contacto entre dientes contiguos en sus caras interproximales (Langsjoen 1998; Hillson 2008). Por otra parte, el tipo de caries muestra una fuerte relación con la edad del individuo: es esperable una mayor prevalencia de caries coronales en individuos subadultos y adultos jóvenes en los que sólo la corona de las piezas dentales está expuesta a los restos de alimentos y a la actividad bacteriana; mientras que en los adultos mayores se desarrollan con mayor frecuencia las caries de raíz dado que diferentes procesos exponen las raíces a la actividad cariogénica (Langsjoen 1998). Los componentes de la saliva, los niveles hormonales (vinculados principalmente con estadios específicos durante la vida en individuos femeninos -por ej. menstruación y embarazo), la ecología de la placa dental y la higiene, son también otros factores que influyen en 
la cariogenicidad (Lukacs y Largaespada 2006; Lukacs 2008; Lanfranco y Eggers 2010).

En cuanto a los criterios definidos para el relevamiento de caries en las muestras bioarqueológicas estudiadas, a nivel del elemento óseo (mandíbula y maxilar) se consideraron todos aquellos que posean al menos un diente erupcionado in situ, ya sea deciduo o permanente. A nivel de la pieza dental, las caries fueron identificadas macroscópicamente y observadas en lupa binocular. Para el registro de cada caries, se empleó el sistema de clasificación de Buikstra y Ubelaker (1994) (Tabla 4.3). Además, fue considerado su grado de severidad: incipiente (puntos localizados de desmineralización); moderado (cavidad definida pero en las que aún se puede determinar el origen de la lesión) y severo (cavidad que abarca un porcentaje de la pieza tal que no permite determinar el origen de la lesión) (García Guraieb 2010). Por último, si bien el desarrollo cariogénico puede implicar la pérdida del diente, no fueron consideradas las pérdidas dentales antemortem como evidencia de caries ya que otros procesos (por ej. patológicos, traumas) pueden causarlas (Hillson 2008).

Tabla 4.3. Sistema de clasificación de caries (sensu Buikstra y Ubelaker 1994).

\begin{tabular}{|c|c|c|}
\hline Score & Nombre & Caracterización \\
\hline 0 & sin lesión & - \\
\hline 1 & en superficie oclusal & $\begin{array}{c}\text { fosas, surcos, cúspides de esmalte y zonas de exposición de } \\
\text { dentina oclusal; los surcos bucales y linguales de los } \\
\text { molares }\end{array}$ \\
\hline 2 & $\begin{array}{l}\text { en superficies } \\
\text { interproximales }\end{array}$ & incluye las regiones cervicales distales y mesiales \\
\hline 3 & en superficies lisas & $\begin{array}{l}\text { superficies labiales y linguales (excepto los surcos de los } \\
\text { molares, relevados en 1) }\end{array}$ \\
\hline 4 & lesión cervical & $\begin{array}{l}\text { uniones cemento-esmalte (excepto regiones } \\
\text { interproximales, relevadas como 2) }\end{array}$ \\
\hline 5 & lesión de raíz & región dental por debajo de las uniones cemento-esmalte \\
\hline 6 & $\begin{array}{l}\text { lesión de origen } \\
\text { indeterminado }\end{array}$ & $\begin{array}{l}\text { indeterminada debido a que el tamaño de la cavidad no } \\
\text { permite distinguir dónde se originó }\end{array}$ \\
\hline 7 & $\begin{array}{l}\text { exposición pulpar no } \\
\text { cariosa }\end{array}$ & no se considera en el análisis de las prevalencias de caries \\
\hline
\end{tabular}




\subsubsection{Lesiones periapicales}

Las lesiones periapicales resultan de una infección en la pulpa dental dada por su previa exposición a las bacterias orales (Dias y Tayles 1997; Hillson 2008; Ogden 2008). La exposición de la pulpa dental a la cavidad oral puede producirse por varios motivos, entre ellos una atrición severa, caries o trauma del diente en cuestión (Dias y Tayles 1997; Ogden 2008). Una vez expuesta, se vuelve susceptible a la actividad de una gran variedad de bacterias orales, produciendo su infección. Ésta, una vez establecida, sigue un mismo recorrido: pasa de la cámara pulpar a los canales de la raíz y, a través del foramen apical, penetra en la región periapical afectando los tejidos blandos allí presentes. En primera instancia, la pulpa dental responde mediante la inflamación que va a generar un aumento de la presión interna de la cámara pulpar y obstrucción del suministro de sangre desde los pequeños canalículos de la raíz. La pulpa dental no tiene la capacidad de autorreparación (Ogden 2008) y es por este motivo que una vez involucrada en una infección que no desaparece, el proceso patológico continúa su curso sin poder volver atrás. Así es que se produce la muerte local de la pulpa y, en caso de continuar la infección, la autólisis de ella. Los productos de desecho por tal degradación comienzan a avanzar hacia el ápice de la raíz del diente y se termina por desarrollar una inflamación de los tejidos blandos que lo rodean (Hillson 1996; Ogden 2008). El tejido óseo involucrado se reabsorbe a través de la actividad osteoclástica dando así lugar a lo que se conoce como granuloma periapical, una cavidad ósea conteniendo una masa de tejido granulomatoso. Si este tejido es reemplazado por fluido recubierto por una capa de tejido epitelial, se estará frente a un quiste periapical. Ambas lesiones son producto de una inflamación crónica y clínicamente son asintomáticas. En caso de desaparecer la fuente de infección (por extracción de la pieza dental, por ejemplo), el granuloma tiene solución, no así el quiste que continúa expandiéndose (Dias et al. 2007).

En caso de que la infección de la pulpa sea de carácter piogénico, comienza a acumularse pus en la zona infectada y se forma un absceso agudo. El pus fluye por los lugares que le presentan menor resistencia (por ej. cavidad nasal y sinus maxilar) y una vez drenado, se elimina la fuente de infección y el tejido se repara. Esta situación puede complicarse clínicamente si la infección alcanza la cavidad medular, produciendo así osteomielitis que será aguda o crónica dependiendo de 
sus efectos sistémicos. Por otro lado, si el drenaje del pus del absceso agudo no permite la liberación completa de la infección, ésta continúa y se desarrolla un absceso crónico. Ello implica que, a través de la actividad osteoclástica, se forme una cavidad ósea (fístula) para permitir el drenaje del pus (Dias y Tayles 1997). A diferencia de los granulomas y quistes, la presencia de un absceso periapical agudo o el desarrollo de una osteomielitis aguda conlleva ciertos efectos sistémicos en el individuo; en las condiciones crónicas de estas patologías los individuos no experimentan síntomas físicos (por ej. dolor, fiebre, inflamación de ganglios; Dias y Tayles 1997).

En las muestras bioarqueológicas estudiadas, en primer término, se registró la presencia de estas patologías periapicales, detallando sobre cuál cara del elemento se localiza. En segundo término, se discriminó específicamente el tipo de lesión, para lo cual se consideraron dos aspectos: la característica del borde de la lesión y su tamaño (medición efectuada con calibre digital; el ancho de la lesión se midió en la parte central más ancha de la cavidad ósea; Dias et al. 2007). En el caso de los granulomas, la cavidad generada por la actividad osteoclástica es de forma redondeada con bordes suaves y lisos, generalmente con un diámetro no mayor a 3 mm. En caso de superar este tamaño, se lo discriminó como quiste (Dias et al. 2007). Si la cavidad es menor a $3 \mathrm{~mm}$ de diámetro y presenta bordes ásperos con márgenes irregulares, fue clasificada como absceso crónico; incluso puede observarse deposición de nuevo hueso alrededor del orificio denotando su mayor cronicidad (Tabla 4.4). Frente a una osteomielitis crónica, las cavidades estarán relacionadas con zonas necróticas, serán más extensas, con bordes ásperos e irregulares (Dias y Tayles 1997; Ogden 2008). En tercer lugar, se evaluó la causa primaria de la lesión (caries, desgaste, trauma). 
Tabla 4.4. Sistema de clasificación de lesiones periapicales (sensu Dias y Tayles 1997 y Dias et al. 2007).

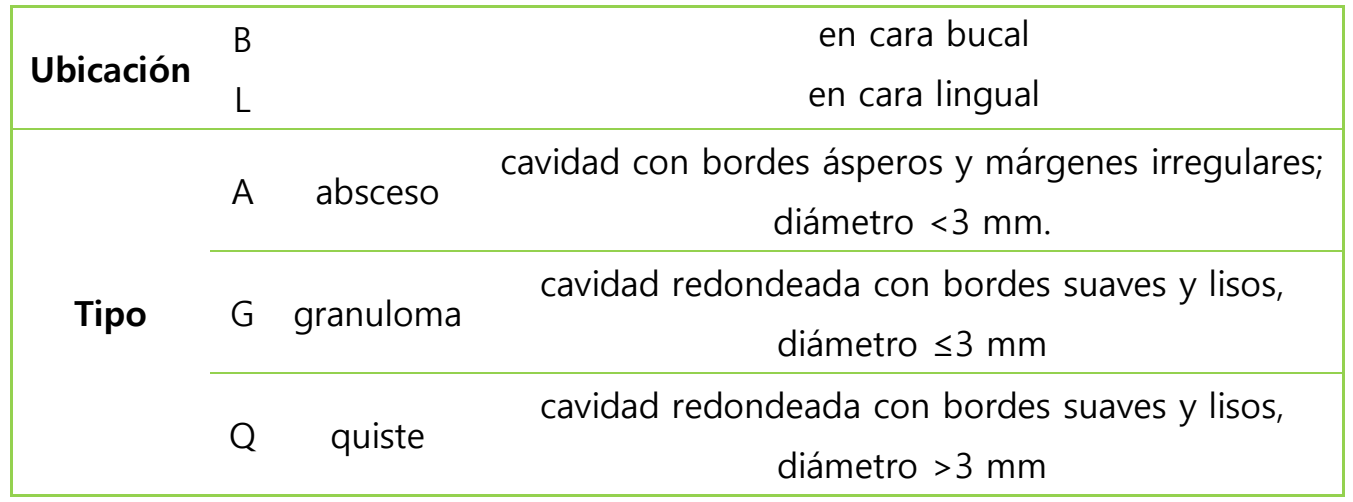

\subsubsection{Pérdidas dentales antemortem}

La pérdida de piezas dentales antes de la muerte del individuo (PDAM) está vinculada con procesos fisiológicos y/o patológicos que afectan el tejido de soporte de los dientes. El desgaste dental severo, la erupción continua, los traumas y los defectos del hueso alveolar de origen pulpar, son algunos de estos principales procesos (Clarke y Hirsch 1991; Hillson 2008). Asimismo, la enfermedad periodontal, la extracción intencional (Lukacs 2007; Waldron 2009) y la necrosis del ligamento periodontal (Hildelbolt y Molnar 1991). Las caries que llegan a exponer la cámara pulpar, generar abscesos y reabsorción del tejido, también pueden inducir la pérdida del diente (Lukacs 1989; Lanfranco y Eggers 2010). Lo mismo ocurriría con la acumulación moderada a severa de tártaro, que puede causar irritación de la gíngiva, una posterior enfermedad periodontal con consecuente reabsorción del hueso alveolar y pérdida del diente (Lukacs 1989).

Debido a que las PDAM son difíciles de interpretar en tanto su naturaleza multicausal, no deben ser analizadas de forma aislada de otras lesiones dentales (Lukacs 2007). Por este motivo, para cada uno de los casos, se trató de evaluar las causas que pudieron haber provocado estas pérdidas teniendo en cuenta las distintas lesiones orales predominantes en las arcadas dentales. En el inventario de la dentición se utilizaron las categorías de registro de Buikstra y Ubelaker (1994) para discriminar pérdidas dentales asociadas o no con reabsorción alveolar, es decir, antes de la muerte del individuo o posterior a ella. En el caso de las primeras, luego de identificarlas, se clasificaron siguiendo la propuesta de Flensborg (2011) (Tabla 4.5). 
Tabla 4.5. Sistema de clasificación de pérdidas dentales antemortem (sensu Flensborg 2011).

\begin{tabular}{|cccc|}
\hline & 1 & parcial & aún se observa el alvéolo \\
Tipo & 2 & moderado & alvéolo semi-presente \\
& 3 & total & alvéolo ausente y con reducción en la altura del maxilar/mandíbula \\
\hline
\end{tabular}

\subsubsection{Cálculos dentales}

Sobre la superficie de los dientes se acumulan depósitos de micro-organismos y material extracelular asociado. Estos depósitos son conocidos como placa dental y cuando ésta se mineraliza a lo largo del tiempo, pasa a formar lo que se denomina cálculo o tártaro dental (Lukacs 1989; Hillson 2008). El cálculo está conformado por un componente orgánico y uno inorgánico. El primero consiste en aminoácidos, péptidos, proteínas, carbohidratos y lípidos, mientras que el segundo componente incluye principalmente calcio, fósforo y sodio (Hillson 1996; Lieverse 1999). Dependiendo de su ubicación, el tártaro puede clasificarse en dos tipos. El supragingivial es aquél que se localiza sobre el esmalte por encima del margen gingivial; suele ser más abundante en aquellos dientes que se encuentran más cerca de las glándulas salivales submandibulares (por ej. cara lingual de los incisivos) y parótidas (por ej. cara bucal de los primeros molares superiores). Por su parte, el cálculo subgingivial se encuentra dentro de la encía en relación a la raíz de los dientes, formando un bolsillo periodontal (Hillson 2008).

La razón por la cual ocurre el proceso de mineralización de la placa bacterial es poco conocido y existen distintas explicaciones sobre cómo éste se desarrolla (Hillson 1996; Lieverse 1999). De todas formas, sí es sabido que es necesario un ambiente bucal alcalino para favorecer la precipitación mineral y por ende la formación del tártaro. Esta alcalinidad sería en parte favorecida por los microorganismos, a partir de la producción de amoníaco que generan. Asimismo, una dieta rica en proteínas tiene consecuencias sobre el $\mathrm{pH}$ oral, al aumentar la alcalinidad del medio oral (Lieverse 1999). Por otro lado, un consumo elevado de carbohidratos facilita indirectamente la formación del cálculo al favorecer una mayor acumulación de placa dental (Hillson 1996). Es importante remarcar que mientras la presencia de cálculo dental implica un proceso de mineralización, las caries resultan de un proceso de desmineralización; y si bien son fenómenos antagónicos en su origen, ello no 
significa que no puedan encontrarse presentes en una misma pieza dental (Hillson 2008; Waldron 2009). Además de estos aspectos fisiológicos y dietarios, la formación de cálculo y su extensión en la cavidad bucal se encuentra mediada por otros factores, tales como la higiene bucal y el uso de los dientes como herramientas, ya que pueden remover o reducir los depósitos de cálculo (Lieverse 1999).

Durante la formación del cálculo dental pueden quedar atrapadas en él partículas de alimentos, entre ellos microrrestos vegetales. Estos microfósiles (fitolitos y almidones, por ejemplo) permanecen protegidos dentro de la matriz del cálculo, y dado que este depósito se encuentra mineralizado, es recurrentemente encontrado en dientes hallados en contextos arqueológicos (Laluenza Fox et al. 1996; Lieverse 1999; Henry y Piperno 2008). Es por ello que el análisis arqueobotánico del cálculo dental brinda importante información sobre el consumo y/o manipulación de vegetales por parte de las poblaciones pasadas (Wesolowski et al. 2010; Musaubach 2012).

La metodología empleada para relevar la presencia de cálculo dental se basó en la propuesta de Buikstra y Ubelaker (1994; tomado y modificado de Brothwell 1981) (Tabla 4.6). Por otro lado, se tomaron muestras de cálculo dental para su análisis arqueobotánico. Esto se llevó a cabo en dientes procedentes de las muestras bioarqueológicas del Delta Superior del río Paraná y de la cuenca inferior del río Uruguay. Se siguió la propuesta de Musaubach (2012) con el fin de "observar con mejor claridad las muestras y que al mismo tiempo no sean destructivas para las piezas dentales" (2012: 106). Una vez seleccionados los dientes a muestrear (que tuviesen cálculo posible de ser extraíble fácilmente), se extrajeron fragmentos de tártaro de manera mecánica y se colocaron en tubos Eppendorf rotulados según correspondiese. En algunos casos fue necesario triturar en mortero los fragmentos extraídos para homogeneizar sus tamaños; esto fue realizado de forma suave y sin producir la molienda de los mismos. Luego se prepararon las muestras en líquido (aceite de cedro) para su observación en microscopio óptico (Nikon E200 con cámara digital Nikon Coolpix S4) y microscopio petrográfico (Nikon E200 con cámara USB). Esto fue realizado por la Dra. María de los Milagros Colobig (Laboratorio de Paleobotánica, CCYTTP, Diamante, Entre Ríos) utilizando y siguiendo las clasificaciones de códigos internacionales. 
Tabla 4.6. Sistema de clasificación de cálculos dentales (sensu Buikstra y Ubelaker 1994).

\begin{tabular}{|c|c|c|c|}
\hline \multirow{4}{*}{$\begin{array}{c}\text { Grado de } \\
\text { depositación }\end{array}$} & 0 & ausente & - \\
\hline & 1 & baja cantidad & $\begin{array}{l}\text { afecta a menos de } 1 / 3 \text { de la superficie } \\
\text { del diente; es una capa delgada }(<2 \mathrm{~mm})\end{array}$ \\
\hline & 2 & $\begin{array}{l}\text { moderada } \\
\text { cantidad }\end{array}$ & $\begin{array}{c}\text { afecta entre } 1 / 3 \text { y } 2 / 3 \text { de la superficie } \\
\text { del diente }\end{array}$ \\
\hline & 3 & $\begin{array}{c}\text { gran } \\
\text { cantidad }\end{array}$ & $\begin{array}{c}\text { afecta la mayor parte de la superficie del } \\
\text { diente } y / \text { o es una capa }>2 \mathrm{~mm}\end{array}$ \\
\hline
\end{tabular}

\subsubsection{Desgaste dental}

El desgaste de las piezas dentarias es un proceso dinámico y natural que se manifiesta durante la vida del individuo y mediante el cual se pierde de forma progresiva el tejido dental (Cruwys 1989). Esta pérdida tisular puede darse a través de tres mecanismos que actúan de forma simultánea durante la mecánica masticatoria: 1) la atrición (fricción entre dientes opuestos o vecinos que produce facetas de desgaste en la superficie oclusal o en los puntos de contacto entre dientes); 2) la abrasión (contacto entre el diente y agentes exógenos, principalmente los alimentos); 3) la corrosión (disolución química del esmalte y dentina por ácidos exógenos o endógenos no producidos por las bacterias orales) (Grippo et al. 2004; Hillson 2008). Distinguir en las colecciones bioarqueológicas entre estos tres mecanismos es una tarea casi imposible, por lo que al analizar el desgaste se está evaluando el resultado de la combinación de éstos durante la vida funcional de las piezas dentales, sin poder determinar la contribución relativa de cada factor (Scott y Turner II 1988; Cruwys 1989).

El esmalte es el primer tejido dental que comienza a ser desgastado. En este proceso pueden ocurrir fracturas traumáticas en la corona del diente, produciendo pérdida de esmalte. Este astillado dental (chipping) suele observarse alrededor del borde de facetas de desgaste oclusal, especialmente en molares (Scott y Turner II 1988; Hillson 2008). Ya sea mediante el chipping o por continuación de los mecanismos de desgaste sobre la dentina, se puede producir la exposición de la cámara pulpar a la cavidad oral, desencadenando reacciones de la pulpa y tejido periodontal asociado. Así como el desgaste puede generar diferentes lesiones bucales 
(por ej. procesos infecciosos, PDAM), también puede eliminar otras como son las caries oclusales poco profundas (Hillson 2001).

El grado y patrón de desgaste de la dentición es -en parte- resultante de la interacción de los dientes con los alimentos consumidos, por lo que su estudio revela información valiosa para abordar los tipos de alimentos ingeridos. A partir del tipo de consistencia y textura de los productos vegetales y/o animales consumidos y la forma de su procesamiento y preparación, las superficies oclusales de los dientes se desgastan en un grado y patrón determinado (Molnar 1971; Hillson 1979; Scott y Turner II 1988; Cruwys 1989). En términos generales, en grupos con una subsistencia basada en la caza y la recolección se esperaría encontrar grados de desgaste altos adquiriendo forma plana la superficie oclusal, dada una dieta fibrosa y la inclusión de partículas abrasivas durante la preparación de los alimentos. Por otro lado, en grupos que practicaban la agricultura el desgaste sería menor y con direcciones oclusales oblicuas, al consumir alimentos menos fibrosos y/o emplear técnicas de cocción que ablandan los mismos (Molnar 1971; Smith 1984; Walker y Erlandson 1986; Lukacs 1989; Larsen 1995; Sciulli 1997; Bernal et al. 2007; Deter 2009).

Si bien el registro del patrón de desgaste dental ha sido utilizado para obtener información sobre aspectos vinculados con la dieta de las poblaciones, éste es un proceso complejo en el cual intervienen otros factores (Cruwys 1989). Uno de ellos es la edad del individuo: dado que es un proceso acumulativo a lo largo de la vida funcional de los dientes, existe una correlación alta entre la edad cronológica y el grado y tasa de desgaste (Hillson 1996). Por otro lado, el empleo de la dentición durante un lapso de tiempo prolongado para realizar tareas no vinculadas con la masticación (por ej. uso parafuncional, es decir, dientes usados como "tercera mano") deja tipos de desgaste particulares, generalmente en forma de grietas o muescas en las caras oclusales, distales o mesiales de dos dientes adyacentes (Scott y Turner II 1988; Cruwys 1989). Asimismo, el bruxismo puede producir fuerzas más fuertes que las que se generan durante la masticación, contribuyendo así a una atrición dental mayor (Hillson 1996).

Para evaluar el grado de desgaste oclusal se utilizaron las metodologías de registro propuestas por Smith (1984) y Scott (1979). La primera de ellas (aplicada en incisivos, caninos y premolares) consiste en observar la cantidad de dentina expuesta 
en la superficie oclusal de las piezas dentales y adjudicarle a cada diente uno de los ocho puntos de la escala ordinal que se propone. La segunda metodología, desarrollada para los molares, implica dividir en cuadrantes (buco-mesial, buco-distal, linguo-mesial y linguo-distal) la superficie oclusal de cada molar. Cada una de estas cuatro secciones es ranqueada en una escala del 1 al 10 según la cantidad de esmalte observada; el score final de cada molar es la suma de los scores de cada cuadrante, teniendo así un rango posible entre 4 y 40 . En términos generales, se relevaron todos los dientes permanentes in situ en maxilares y mandíbulas de individuos adolescentes y adultos. Con fines analíticos, se promediaron los valores obtenidos para piezas antímeras, obteniendo un único valor por pieza dental por individuo; en el caso en el que no estuvieran presentes ambos dientes antímeros, se consideró igual el score del diente presente. Fueron excluidas aquellas piezas en las que se registraran diferencias marcadas en el desgaste entre antímeros (García Guraieb 2010); específicamente si la diferencia de los scores era del doble o más. El tipo de desgaste se analizó siguiendo la metodología presentada por Molnar (1971), en la cual se considera la dirección y la forma que presentan las superficies oclusales de los dientes. En cuanto a la dirección, se consideraron las siguientes: 1) natural; 2) oblicua (buco-lingual; linguo-bucal; mesio-distal; disto-mesial; 3) redondeada (buco-lingual; mesio-distal) y 4) horizontal. La forma de la superficie oclusal fue categorizada en: 1) natural; 2) plana; 3) parcialmente cóncava; 4) completamente cóncava y 5) redondeada. Para evaluar los patrones de cada muestra en cuanto a dirección y forma, se calcularon los porcentajes máximos de ocurrencias de cada tipo.

\subsubsection{Hipoplasias lineales del esmalte dental}

Las hipoplasias del esmalte dental son un tipo de defecto del desarrollo del esmalte debido a una interrupción en el proceso de amelogénesis. Específicamente, se trata de una deficiencia en el espesor del esmalte que afecta a la superficie de la corona y que ocurre por perturbaciones fisiológicas durante la secreción de la matriz del esmalte (Goodman y Rose 1991; Hillson 1996). Los ameloblastos son las células formadoras del esmalte, el cual se constituye en dos direcciones. La primera implica la superposición de capas de esmalte en forma de domos, las cuales van a constituir la cúspide del diente; a este esmalte se lo conoce como aposicional. Luego, se forma 
el esmalte imbricacional, es decir, el esmalte lateral del diente. El crecimiento de esta zona tiene evidencia superficial al intersectar las capas de formación con la superficie de la corona; tal manifestación consiste en una secuencia de surcos regularmente distanciados entre sí conocidos como líneas de perikymata o de imbricación. Dado esto último es que los defectos hipoplásicos sólo se encuentran en la zona imbricacional del diente (Goodman y Rose 1991; Hillson 1996; Hillson y Bond 1997). Las HED pueden manifestarse de distintas formas, ya sea como hoyos (simples o múltiples) o como surcos alrededor de la circunferencia de la corona (Lukacs 1989; Hillson 1996). Los hoyos o pits representan la interrupción de un grupo acotado de ameloblastos y en una zona concreta. Los surcos, generalmente conocidos como hipoplasias lineales (HLED), representan una exageración del espacio entre las perikymata, involucrando a una amplia banda de ameloblastos (Hillson 1996). Este último tipo de defecto es el más común de ser encontrado (Goodman y Rose 1991).

Dado que el esmalte es uno de los tejidos más duros del esqueleto y no experimenta remodelación alguna luego de su formación, los defectos producidos durante su crecimiento quedan grabados y permanecen durante la edad adulta. Por lo tanto, su estudio constituye una importante ventana hacia las condiciones de estrés bajo las cuales se encontraban los individuos durante los momentos en los que el esmalte estaba formándose (en la dentición decidua, este momento abarca desde la vida intrauterina hasta el primer año de edad; en la dentición permanente, desde el nacimiento hasta los 13 años de edad) (Lukacs 1989; Goodman y Rose 1991; Reid y Dean 2000; Hillson 2008). Las HED pueden ser causadas por condiciones genéticas, por traumas locales o por alteraciones sistémicas del crecimiento. A partir de numerosos estudios realizados, la mayoría de los defectos parece ser el resultado de condiciones de estrés metabólico a nivel sistémico (Goodman y Rose 1991; Hillson y Bone 1997). Las condiciones específicas que alteran los procesos fisiológicos de la amelogénesis son aún desconocidos; se ha relacionado la presencia de HED con enfermedades infecciosas, malnutrición, deficiencia de vitamina A o D, perturbaciones gestacionales, entre otros. Por lo tanto, los defectos hipoplásicos constituyen indicadores inespecíficos de estrés (Lukacs 1989; Goodman y Rose 1991; Hillson 1996). 
En las muestras bioarqueológicas estudiadas se llevó a cabo el relevamiento sólo de defectos hipoplásicos de tipo lineales, ya que son los que poseen una mayor aceptación como indicadores de estrés sistémico (Guatelli-Steinberg et al. 2004; García Guraieb 2010). La dentición elegida fue la permanente, debido a que la decidua sería menos propensa a mostrar HLED (para más detalle véase discusión presentada en García Guraieb 2010). A su vez, las piezas dentales seleccionadas para la observación de estos defectos fueron los incisivos y caninos (tanto superiores como inferiores). No se incluyeron aquellos dientes que presentaron cálculo que impidan visualizar la cara bucal de las piezas. Con respecto al desgaste, es importante tener en consideración que éste puede sesgar la frecuencia de HLED relevadas, ya que los defectos de formación más tempranos se expresan cerca de la superficie oclusal de la corona (King et al. 2005). Aun así, se prefirió incluir a los dientes que pese a que tuvieran desgaste severo (grados 6 o 7), se observara una porción del esmalte de la cara bucal de las coronas.

La detección de las HLED se hizo de forma macroscópica y con iluminación oblicua; sólo en caso de detectarlas se observaron bajo lupa de hasta 20x para su confirmación y cuantificación (Goodman y Rose 1991). Siguiendo la propuesta metodológica de Barrientos (1997), se calculó el Índice de Sensibilidad (Isen=cantidad de HLED observadas para cada clase de diente/cantidad de dientes de una clase dental observados) con el fin de "determinar cuál era el diente que registraba la mayor cantidad relativa de eventos de inhibición del crecimiento" (Barrientos 1999: 310). Con los resultados obtenidos, se calculó el Ranking de Sensibilidad; esto es ordenar las clases de dientes según su grado decreciente de sensibilidad para sufrir las detenciones del crecimiento y desarrollo del esmalte (Barrientos 1997). Por otra parte, para determinar las clases dentales más representadas en la muestra se calculó el Índice de Supervivencia (Isup=cantidad de dientes esperados/cantidad de piezas de una clase observados) y con los resultados obtenidos, se construyó el Ranking de Supervivencia para evaluar el estado de conservación general de la muestra (Barrientos 1997).

Para poder discriminar entre pares de HLED simétricos (lo cual ayuda a diferenciar entre defectos sistémicos de los que no lo son; por ej. los causados por traumas que afectarían a un solo diente; Barrientos 1997) y determinar la edad del 
individuo en la cual se formó el defecto, se realizó la medición de cada uno de ellos para conocer su ubicación en la corona. Específicamente, se midió desde la unión cemento-esmalte hasta el borde superior de la línea de hipoplasia, empleando un calibre digital /sard con Resolución de 0,01 mm y Precisión de \pm 0,02 mm. Con el fin de disminuir el error intraobservador, estas mediciones se tomaron en tres oportunidades para cada HLED, con una distancia temporal de una semana entre sí; luego se obtuvo una medida promedio para cada una. La discriminación de pares simétricos de HLED entre dientes antímeros se realizó siguiendo la propuesta metodológica de Barrientos (1999): primero se asume la inexistencia de asimetría fluctuante en la formación de las coronas de los dientes antímeros; segundo, cuando existe una diferencia igual o menor a 0,50 mm en la ubicación de líneas en dientes opuestos, se las considera como pares de HLED simétricas, es decir resultado de un mismo evento de estrés. A partir de esto, fue posible estimar un número mínimo de eventos de detención del crecimiento del esmalte por individuo, dado cada uno por un par de HLED simétricas. Una vez discriminados los pares simétricos de HLED y su ubicación en las coronas de las piezas dentales, se realizó la estimación de la edad en la que se formaron utilizando el modelo de deciles propuesto por Reid y Dean (2006). Para esto, solo fueron seleccionados aquellos dientes que presentaron una buena posición relativa en los Rankings de Sensibilidad y Supervivencia, previamente calculados. Luego, se siguieron distintos pasos (para una descripción más detallada véase García Guraieb 2010):

1. se calculó la altura de la corona (AC) de los dientes involucrados. En el caso de tratarse de dientes sin desgaste, se midió en tres oportunidades la $A C$, se promediaron los resultados y se obtuvo así un único valor de AC. Si los dientes presentaban desgaste, se calculó la AC de la misma forma pero en dientes de individuos del mismo sitio/muestra bioarqueológica, los cuales tuvieran los mismos dientes sin desgaste (considerándoles de esta forma como representativos de todos los individuos) (Ritzman et al. 2008).

2. se transformó la ubicación de cada HLED en un porcentaje de AC. Para ello se utilizó la fórmula propuesta por Martin et al. (2008) y modificada por García Guraieb (2010): PAC = 100 - (Ubic. HLED / AC) * 100. Referencia: PAC=porcentaje de la corona completa al momento de la formación de la HLED; Ubic. 
HLED=ubicación de la HLED en la corona (en mm); AC=altura de la corona de la clase dental analizada.

3. cada valor de PAC obtenido se redondea al decil anterior si el valor lo superaba hasta 4.9 y al decil posterior si era $\geq 5$.

4. dependiendo del decil obtenido, se lo compara con los deciles de los tiempos de formación del esmalte de I y C superiores e inferiores, presentados por Reid y Dean (2006: 343). ${ }^{4}$

\subsubsection{Patologías óseas}

Como fue mencionado previamente, en el ejercicio del diagnóstico diferencial de las lesiones se utilizó tanto información clínica como paleopatológica. En este trabajo de tesis, se consideraron los siguientes grupos etiológicos: lesiones metabólico-nutricionales, lesiones de etiología infecciosa, lesiones de estrés inespecífico y lesiones traumáticas.

En primera instancia, la unidad de análisis fue el elemento óseo. Para realizar la documentación de cada lesión se elaboró una planilla de registro (Ficha A.1.2) en la que se precisó: hueso; lateralidad; sección del elemento (esqueleto postcraneal: epífisis proximal y distal, metáfisis proximal y distal, diáfisis proximal, medial y distal; cráneo: el hueso afectado); cara (anterior, posterior, medial y lateral); tipo de hueso (primario/inmaduro o secundario/laminar) y bordes de la lesión (delimitados y circunscriptos o difusos). De forma complementaria, se llevó a cabo el registro fotográfico de cada lesión y, en caso de ser necesaria su evaluación con mayor detalle, se tomaron radiografías y/o tomografías computadas. En segunda instancia, en aquellos casos en los que era posible evaluar un esqueleto completo o varios huesos de uno, la unidad de análisis fue el individuo. Considerando todo lo anterior, es que

\footnotetext{
${ }^{4}$ La comparación de los datos se realizó con respecto a los valores obtenidos por Reid y Dean (2006) para la colección del norte de Europa, ya que los tiempos de formación de esmalte en el canino inferior coincide con el método de estimación de edad mediante erupción dentaria propuesto por Buikstra y Ubelaker (1994), el cual es empleado en este trabajo (García Guraieb 2010).
} 
se procedió a clasificar las lesiones en alguno de los grupos etiológicos antes mencionados, cuyas características principales serán mencionadas a continuación.

\subsubsection{Lesiones de estrés metabólico-nutricional}

Las patologías óseas de etiología metabólica-nutricional son producto de una disrupción de la formación, remodelación y/o mineralización normal del hueso (Brickley e Ives 2008; Mays 2008). Como ejemplo de éstas pueden mencionarse el escorbuto (bajos niveles de vitamina D), el raquitismo/osteomalacia (bajos niveles de vitamina C), la osteoporosis/osteopenia (disminución de la calidad y la cantidad ósea) y la anemia (Ortner 2003; Brickley e Ives 2008; Mays 2008; Kozlowski y Witas 2012). Con respecto a la anemia, ésta no es una enfermedad en sí sino un signo que refleja algún otro problema fisiológico que la causa (Walker et al. 2009). La anemia consiste en una baja concentración de hemoglobina en sangre, que puede estar acompañada por una baja cantidad de glóbulos rojos o por una deficiencia en la función de los mismos. Las hay hereditarias/genéticas (por ej. la talasemia), adquiridas (por ej. por deficiencia en la dieta o en la absorción de hierro, por pérdida de glóbulos rojos a causa de hemorragias) y debido a causas infecciosas (bacterianas y parasitarias) (Mensforth et al. 1978).

Las lesiones óseas que se han vinculado históricamente con la anemia son la hiperostosis porótica en la bóveda craneana y la cribra orbitalia en el techo de las órbitas, y son las que fueron analizadas en este trabajo de tesis. Ambas consisten en la presencia de porosidad en esas regiones del cráneo, usualmente vinculada con un aumento del espesor de la tabla externa del diploe (Stuart-Macadam 1985, 1989; Walker 1986). Muchos investigadores atribuyen la hiperostosis porótica y la cribra orbitalia a una hiperplasia medular (Blom et al. 2005; Walker et al. 2009), es decir, a un aumento de la cantidad de células hematopoyéticas de la médula ósea. Esta hiperplasia puede ser una respuesta a distintas causas que generen hipoxia (baja saturación de $\mathrm{O}^{2}$ en sangre arterial). Frente a esta condición, el cuerpo responderá incrementando la producción de eritrocitos $y$, en consecuencia, la cavidad medular se expandirá y así también el diploe. Existe consenso de que estas lesiones óseas son expresiones de anemias que tuvieron lugar durante la infancia del individuo, debido a la plasticidad que los huesos poseen en esa etapa de crecimiento en comparación 
con la adultez (El-Najjar et al. 1976; Stuart-Macadam 1985). De todas formas, se discute acerca de si su etiología responde a anemia adquirida o anemia hereditaria y esto repercute directamente sobre las explicaciones bioarqueológicas que luego pueden hacerse en las poblaciones estudiadas.

Muchos investigadores (Stuart-Macadam 1985; Walker 1986; Campillo 2001; Ortner 2003; Blom et al. 2005) han relacionado directamente la presencia de hiperostosis porótica con anemia por deficiencia de hierro, a pesar de que han sido propuestas diferentes patologías para explicar la presencia de este tipo de lesión (por ej. raquitismo, escorbuto, exposición a toxinas, traumas y procesos inflamatorios, etc.) y de hiperplasia medular (por ej. problemas cardíacos, renales, etc.). Esta idea se sustentaba en que, si bien es claro que las anemias hereditarias producen hiperostosis porótica, ellas son propias de poblaciones específicas y por lo tanto las anemias genéticas no explicarían los numerosos casos relevados en el registro bioarqueológico de diferentes regiones geográficas. Sumado a esto, las colecciones arqueológicas de las cuales provienen los restos humanos analizados en estos estudios, están asociadas con contextos de asentamientos semi/permanentes que sugieren enfermedades infecciosas y dietas deficientes en nutrientes esenciales (Walker et al. 2009). En este sentido, la transición nutricional de una subsistencia basada en la caza y recolección hacia una basada en el consumo de productos agrícolas (Cohen y Armelagos 1984; Popkin 1993), habría tenido alto impacto dado el bajo contenido de hierro que contiene el maíz y la inhibición que provoca uno de sus compuestos a la absorción de hierro. Sin embargo, investigaciones realizadas desde fines del siglo pasado demuestran que en poblaciones con una dieta basada principalmente en alimentos marinos, poseían alta frecuencia de cribra orbitalia (Walker 1986; Blom et al. 2005).

A partir de nuevos estudios, se ha propuesto que las anemias hereditarias proveen una mejor explicación, ya que la anemia tiene que tener el suficiente "potencial" como para estimular y sostener altos niveles de eritropoyesis para que ocurra una hiperplasia medular y consecuentemente hiperostosis porótica y cribra orbitalia (Waldron 2009; Walker et al. 2009). Sin embargo, esto no sería aplicable al continente americano, donde las anemias hereditarias habrían surgido luego de la llegada de los europeos (Blom et al. 2005; Walker et al. 2009). Entonces la causa de 
estas lesiones en el continente americano se relacionaría más con una conjunción de diferentes factores y no unidireccionalmente con una dieta con bajos niveles de hierro como se había propuesto en un primer momento. Aspectos socioculturales (por ej. cambios en la dieta, técnicas de cocción de los alimentos, tabúes alimenticios y crecimiento poblacional) y aspectos climáticos/ambientales (por ej. contaminación del agua y sanidad deficiente) englobarían los factores que influirían en la aparición de este tipo de lesiones (Walker et al. 2009). Las deficiencias nutricionales de vitamina B9 y B12 e infecciones parasitarias gastrointestinales que generen diarreas y así pérdidas de nutrientes (Walker 1986; Blom et al. 2005; Walker et al. 2009), terminarán por perjudicar a las mujeres embarazadas y aquellas en período de lactancia y de esta forma, influir en los niños y sus requerimientos nutricionales. Lo mismo ocurriría en infantes en momentos de destete y que estén bajo condiciones de contaminación de agua, por ejemplo. En este sentido, se entiende a la hiperostosis porótica como una patología inespecífica que refleja un incremento de la actividad de la médula ósea y en la cual entran en juego una dieta pobre en hierro, enfermedades infecciosas y factores culturales (El-Najjar et al. 1976). Con respecto a este último punto, éste se vuelve difícil de evaluar si la única fuente de estudio son los restos óseos humanos. Por lo tanto, si se quiere abordar un estudio sobre el estado de salud y nutrición y conocer la dieta de los grupos humanos del pasado, resulta fundamental cruzar la información de los análisis bioarqueológicos con otras líneas de evidencia para tratar de entender el contexto social, ambiental y biológico de esas poblaciones.

Diversos estudios han evidenciado que la hiperostosis porótica ocurre en asociación con la cribra orbitalia, y que esta co-ocurrencia se manifiesta aún más en los grados más severos de la hiperostosis porótica (Mensforth et al. 1978; StuartMacadam 1987, 1989). Esta situación ha llevado a plantear la misma etiología para ambos tipos de lesiones. En contraposición, otros autores discuten la estrecha vinculación entre ambas al argumentar que, en varias colecciones estudiadas, ha sido más frecuente el hallazgo de porosidades en el techo de las órbitas que en la bóveda craneana (Walker et al. 2009). En consonancia con esto, los autores descartan las posibilidades de que la cribra orbitalia constituya una primera manifestación a la hiperostosis porótica y que las dos lesiones sean producto de cambios etarios en la 
ubicación de la respuesta hematopoyética a la anemia. Asimismo, manifiestan que la evidencia clínica no permite relacionar fuertemente a la cribra orbitalia con la anemia. Análisis histológicos en casos de cribra orbitalia en adultos han permitido asociar estas lesiones con una variedad de factores; un bajo porcentaje de la muestra estudiada pudo ser relacionada con anemia, mientras que el resto se asoció con osteítis, erosiones postmortem y otras condiciones patológicas (Wapler et al. 2004).

En cuanto a la metodología empleada, el relevamiento de este indicador se realizó de forma macroscópica y con ayuda de lupa binocular (20x) y se describió cada lesión. Se distinguió la severidad de cada una siguiendo los criterios expuestos por Stuart-Macadam (1985) (Tabla 4.7) y el estado de la lesión al momento de muerte del individuo según la propuesta de Mensforth (1991):

1. lesión activa: concentraciones de microporos localizados en la superficie del hueso; éstos pueden agrandarse y unirse formando macroporos con márgenes irregulares, agudos y bien definidos. Pueden formarse canales hipervasculares bien desarrollados, dentro o en la periferia de la lesión. La textura de la lesión es fibrosa. 2. lesión remodelada (o en proceso de remodelación): los poros centrales y periféricos se van rellenando con nuevo hueso, volviéndose sus márgenes más suaves y redondeados. Si bien se reduce la microporosidad entre los poros mayores que forman la estructura de tamiz, surgen microporos secundarios dentro de los poros centrales y periféricos a causa de la formación del nuevo hueso que los va rellenando. La textura de la lesión es suave.

Tabla 4.7. Clasificación de severidad de hiperostosis porótica y cribra orbitalia (sensu Stuart-Macadam 1985).

\begin{tabular}{|cc|}
\hline Severidad & Características \\
\hline Leve & pequeños poros dispersos \\
\hline Media & $\begin{array}{r}\text { poros grandes y pequeños aislados y poros unidos } \\
\text { en la formación de estructuras trabeculares }\end{array}$ \\
\hline Severa & $\begin{array}{r}\text { crecimiento de la estructura trabecular por fuera del } \\
\text { contorno normal de la pared ectocraneal }\end{array}$ \\
\hline
\end{tabular}




\subsubsection{Lesiones infecciosas}

Las enfermedades infecciosas han estado presentes a lo largo de la evolución de los humanos modernos (Larsen 1997; Mitchell 2003; Ortner 2003). Ellas son causadas por una gran variedad de patógenos: bacterias, virus, protozoarios, hongos, así como también parásitos y gusanos (Aufderheide y Rodríguez-Martín 1998). Su abordaje desde la arqueología permite dar cuenta de las experiencias por las cuales atravesaron distintos grupos humanos del pasado (por ej. endemias y epidemias), qué acciones tomaron para protegerse de ellas y qué consecuencias sociales estuvieron implicadas (Mitchell 2003). A partir de numerosos estudios se ha evidenciado que, con el desarrollo de la agricultura asociada con un estilo de vida sedentario, las poblaciones humanas estuvieron más expuestas a enfermedades infecciosas endémicas que afectaron a todos los individuos (Ortner 2003). Mientras que en grupos cazadores-recolectores, con tamaños poblacionales menores y alta movilidad, las infecciones fueron menores (Mitchell 2003), siendo posiblemente las infecciones del sistema digestivo las que mayor causa de muerte provocaron en infantes y niños (Ornter 2003).

En el estudio de estas patologías a partir de colecciones bioarqueológicas, hay que considerar que un bajo porcentaje de los individuos que sufren su afección desarrollan lesiones a nivel óseo. Esto se debe a que las infecciones agudas, que desencadenan la muerte rápida del individuo antes de que lleguen a manifestarse lesiones óseas, serían las más frecuentes. En contraposición, las infecciones con mayor cronicidad pueden afectar al esqueleto pero éstas se presentan en un porcentaje menor de individuos y no serían las causas inmediatas de la muerte (Ortner 2008). Por otro lado, es importante mencionar que muchas de las enfermedades infecciosas crónicas producen respuestas óseas superpuestas, dificultando el diagnóstico específico (Ortner 2003). Hay que recordar que entre las distintas manifestaciones esqueletales que pueden ocurrir frente a una enfermedad, las dos más comunes entre las patologías infecciosas son la formación y la destrucción ósea anormal (Ortner 2008). A partir de esto, las patologías infecciosas con implicancia ósea pueden dividirse en dos grupos: inespecíficas y específicas (Larsen 1997). Estas últimas son aquellas en las que es posible discriminar el patógeno particular que las causó; generalmente pueden ser diagnosticadas a partir del tipo 
de lesión en el esqueleto y las categorías de edad y sexo involucradas. Entre estas patologías pueden mencionarse como ejemplo a la brucelosis, tuberculosis, lepra y treponematosis (Larsen 1997; Aufderheide y Rodríguez-Martín 1998; Ortner 2008; Waldron 2009). Como se detalló en el Capítulo 3, la treponematosis ha sido una de las pocas enfermedades infecciosas de tipo específicas mencionadas en trabajos bioarqueológicos sobre colecciones procedentes del Noreste Argentino.

La treponematosis es una infección crónica causada por microorganismos llamados spirochetes del género Treponema. Éstos suelen ingresar al individuo mediante la piel o membranas mucosas causando una pequeña lesión cutánea; si ésta no es tratada, la infección se puede expandir por todo el cuerpo vía sistema circulatorio y progresar la enfermedad en etapas secundarias y terciarias cada vez más perjudiciales (Larsen 1997; Cook y Powell 2012). Dentro de estas infecciones, se reconocen cuatro síndromes: sífilis venérea (T. pallidum pallidum), sífilis no venérea o endémica (T. pallidum endemicum), yaws (T. pallidum pertenue) y pinta (T. caretum) (Larsen 1997; Ortner 2008). En poblaciones vivas, está documentada la manifestación de estos tres últimos síndromes en contextos de asentamientos rurales con malas condiciones de sanidad (Larsen 1997). Asimismo, en ambientes de climas cálidos, el uso de poca vestimenta facilita la propagación de la infección a través del contacto directo del patógeno con heridas superficiales menores (Larsen 1997). La distribución geográfica de estos síndromes no es homogénea, de modo que están asociados a condiciones geográficas, climáticas y socioculturales distintivas (Aufderheide y Rodríguez-Martín 1998; Ortner 2003).

A excepción de la pinta, todos los síndromes generan respuestas en el tejido duro y, como son similares los tipos de lesiones que producen, resulta complejo poder determinar de qué tipo de síndrome se trata (Hackett 1976). Aun así, dependiendo del estadio de desarrollo en el que se encuentre la patología, las prevalencias de las lesiones óseas por elemento suelen variar (Cook y Powell 2012: Tabla 26.1). En la Tabla 4.8 pueden observarse las lesiones óseas esperables para cada uno de los tres síndromes. Asimismo, en individuos que padecen yaws se destaca la deformidad que suele observarse de la cresta tibial adquiriendo aspecto de sable debido al engrosamiento cortical en esta región del hueso (Ortner 2003). 
Tabla 4.8. Lesiones óseas para los distintos síndromes de Treponematosis (tomado y modificado de Lovell et al. 2000).

\begin{tabular}{|cccc|}
\hline Lesión & Yaws & Sífilis Endémica & Sífilis Venérea \\
\hline Destrucción naso-palatal & ocasional & común & ocasional \\
Articulaciones comprometidas & raro & raro & ocasional \\
Periostitis & muy común & muy común & común en congénita \\
Lesiones bóveda craneana & raro & raro & ocasional \\
Deformación dental & nunca & nunca & en congénita \\
\hline
\end{tabular}

En contraposición a las enfermedades infecciosas específicas, las inespecíficas son aquellas en las que el patógeno que las causa es desconocido. Dentro de este grupo puede mencionarse a la osteomielitis, ya documentada en análisis bioarqueológicos de colecciones de las áreas estudiadas (véase Capítulo 3). La osteomielitis consiste en una infección progresiva del hueso, que implica a la corteza, a la cavidad medular y a los tejidos blandos circundantes. Como resultado se produce inflamación, necrosis ósea y formación de nuevo hueso. La etiología de esta infección es principalmente bacteriana de carácter piogénica, siendo la más frecuente en casos clínicos Staphylococcus aureus. De todas formas, existen otras bacterias e incluso determinados hongos y virus que pueden causarla (Aufderheide y Rodríguez-Martín 1998; Ortner 2003; Calhoun et al. 2009; McNally y Nagarajah 2010). Si bien la contaminación del hueso mediante microorganismos es considerado un prerrequisito para el desarrollo de la osteomielitis, su evolución y las características que presente dependen de una tríada de factores: la virulencia bacteriana, la fisiología del huésped y la estabilidad anatómica (Mast y Horwitz 2002; Brady et al. 2006). En términos generales, una vez que el microorganismo ingresa al hueso mediante una arteria nutricia y se expande por los vasos sanguíneos, la respuesta inicial del huésped a la infección es una reacción inflamatoria aguda que desencadena varios cambios fisiológicos. Esta situación conduce a la formación de un área de necrosis en la corteza ósea (secuestro), que queda aislada mediante tejido de granulación. La lesión produce también la estimulación de las células osteoblásticas del periostio ${ }^{5}$ : el nuevo hueso

5 Una de las funciones principales del periostio en los individuos subadultos es formar hueso (circunsferencial) durante el crecimiento esquelético; mientras que en los adultos, es formar hueso frente a determinado estresor o estímulo (Waldron 2009). 
que comienza a formarse (involucro) envuelve al secuestro y puede ser perforado por cloacas para el drenaje del secuestro y/o pus y así liberar la presión interna de la cavidad medular. El nuevo tejido óseo formado va ganando densidad, grosor y madurez a lo largo del tiempo, hasta formar parte de la diáfisis remodelada (Ortner 2008; Calhoun et al. 2009). Estas tres características (secuestro, involucro y cloaca) son típicas de la osteomielitis y consideradas por algunos autores como patognomónicas (Waldron 2009). Sin embargo, no se manifiestan en todos los casos (Ortner 2008).

Existen diferentes clasificaciones de la osteomielitis según el criterio considerado: cronicidad, fuente de infección, porción del hueso afectado, organismo cultivado, entre otros (Calhoun et al. 2009; McNally y Nagarajah 2010). En el ámbito clínico suele utilizarse la clasificación propuesta por Waldvogel et al. (1970), basada en la duración y en el mecanismo de infección (Sia y Berbari 2006; Calhoun et al. 2009). La osteomielitis hematógena se presenta cuando la propagación de la bacteria hacia el hueso es desde el torrente sanguíneo (Aufderheide y Rodríguez-Martín 1998; Brady et al. 2006); en la mayoría de los casos la infección es monomicrobial (Sia y Berbari 2006). Este tipo de osteomielitis es común en los niños y suele aparecer en la zona metafisiaria de los huesos largos, ya que el crecimiento óseo se encuentra activo y la capilaridad de esta zona favorece la siembra de las bacterias (Brady et al. 2006). Algunos individuos pueden curarse definitivamente, mientras que otros lo hacen de forma temporal y sufren una reactivación de la patología en la adultez (Ortner 2003; Bohndorf 2004). Otro mecanismo de infección es cuando el patógeno llega al hueso de forma directa a través de heridas abiertas o fracturas expuestas (Aufderheide y Rodríguez-Martín 1998; Lew y Waldvogel 2004). Los estudios clínicos indican que es típica de individuos adultos, es generalmente de carácter polimicrobiana y el hueso más frecuente de padecerla es la tibia dada su predisposición a sufrir algún tipo de trauma (Sia y Berbari 2006; McNally y Nagarajah 2010). La osteomielitis causada por insuficiencia vascular es común en individuos mayores que presentan diabetes, propagándose la infección desde un tejido adyacente (por ej. úlceras de la piel) (Aufderheide y Rodríguez-Martín 1998; Sia y Berbari 2006). Estos dos últimos tipos de osteomielitis pueden ser tanto agudos como crónicos (Lew y Waldvogel 2004). 
Para ambos tipos de lesiones infecciosas (específicas e inespecíficas), el relevamiento fue realizado de manera detallada por elemento, considerando los aspectos antes mencionados (por ej. hueso, lateralidad, tipo de hueso, bordes de la lesión, tamaño). En los casos posibles, luego se observó su distribución en el esqueleto para precisar el diagnóstico. Asimismo, se evaluaron las prevalencias de este tipo de patologías por sexo y edad a nivel individual y de elemento óseo.

\subsubsection{Lesiones de estrés inespecífico}

Como parte de las lesiones de estrés inespecífico, en esta tesis se relevaron reacciones periósticas. En colecciones bioarqueológicas es recurrente la mención de este tipo de lesiones entre distintas manifestaciones patológicas relevadas (Ortner 2003; Waldron 2009); si bien son comúnmente observadas en huesos largos, se reporta principalmente en la tibia (Weston 2008; Waldron 2009). Estas reacciones consisten en la producción de nuevo hueso periosteal (Weston 2012). El primer hueso formado (woven bone) está caracterizado por una alta vascularización y escasa organización a nivel macro y microscópico. Con el tiempo, este hueso se va remodelando y adquiere las características del tejido óseo compacto o laminar (Weston 2008; Ortner 2012).

En la literatura bioarqueológica se han asociado las reacciones periósticas con enfermedades infecciosas. Tal como explica Weston (2008), esto se debió a la confusión de relacionar reacciones periósticas con periostitis (inflamación del periostio) y, a su vez, con infección. Mientras que la infección implica una respuesta inflamatoria (para neutralizar el estresor y reparar el daño), la inflamación no implica necesariamente el desarrollo de una infección. Cualquier factor que desgarre, rompa, extienda o simplemente toque el periostio, puede estimularlo para iniciar la formación de nuevo hueso (Weston 2012). Teniendo en cuenta estos aspectos, se han realizado distintos tipos de análisis (macroscópicos, radiográficos e histológicos) con el fin de tratar de relacionar las reacciones periósticas con un proceso de enfermedad específico, sin encontrar resultados positivos (Weston 2008, 2009) y argumentando que "it is not the disease that determines how these tissues respond, it is the tissues themselves" (Weston 2008: 56). Existen múltiples causas que pueden llevar a la 
formación de nuevo hueso periosteal, tal como las recopiló Waldron (2009); algunas de ellas pueden observarse en la Tabla 4.9.

Tabla 4.9. Principales causas que pueden generar formación de nuevo hueso periosteal (tomado y modificado de Waldron 2009: Tabla 6.7).

\begin{tabular}{|c|}
\hline Causas posibles de reacciones periósticas \\
\hline crecimiento fisiológico normal en infantes y niños \\
hiperostosis cortical infantil (enfermedad de Caffey) \\
infecciones (por ej. osteomielitis, sífilis) \\
traumas \\
estasis venosa (por ej. venas varicosas) \\
hemorragias (por ej. escorbuto) \\
raquitismo \\
tumores primarios (osteosarcoma) y secundarios (metástasis) \\
leucemia \\
osteoartropatía hipertrófica secundaria \\
fluorosis \\
hipervitaminosis A \\
condiciones congénitas \\
lesiones de los tejidos blandos suprayacentes
\end{tabular}

En concordancia con la idea de la vinculación de reacciones periósticas con patologías infecciosas, se entendía a la formación de nuevo hueso periosteal como un indicador de estrés que atravesó el individuo (Weston 2012). Ya se ha explicado por qué no debe considerarse como un indicador de enfermedad infecciosa, debido a las múltiples causas que pueden provocarlas. Por otro lado, recientemente se ha argumentado que tampoco debería ser considerado como indicador de estrés (Weston 2012). Esto se basa en información clínica sobre las respuestas fisiológicas del cuerpo frente a determinado estresor: el estrés provoca la estimulación de secreción de glucocorticoides, el cual a su vez inhibe la formación ósea. Por lo tanto, cuando el cuerpo humano se encuentra sometido a un evento de estrés, no puede producir nuevo hueso (Weston 2012). Teniendo en cuenta toda esta información, en este trabajo no fueron consideradas tales lesiones como indicadores de enfermedades infecciosas o indicadores de estrés específicos. 
Siguiendo la propuesta de Weston (2008) y de Ortner (s/f, en Weston 2012) para el relevamiento de reacciones periósticas, se relevaron las siguientes características para cada lesión: 1) hueso y lateralidad; 2) nivel de afectación (1 -0 a 33\%-, 2 -34 a 66\%- y 3 -67 a 100\%-); 3) sección afectada (esqueleto postcraneal: epífisis proximal y distal, metáfisis proximal y distal, diáfisis proximal, medial y distal; cráneo: el hueso afectado); 4) cara afectada (anterior, posterior, medial y lateral); 5) vascularización (alta, media y baja a nula); 6) tipo de hueso (primario/inmaduro, secundario/laminar o mixto); 7) bordes de la lesión (delimitados y circunscriptos o difusos). Luego, en una segunda instancia del análisis se realizó una descripción general de cada lesión, precisando el estado en el que se encontraba la misma al momento de muerte del individuo: activa o remodelada. En los casos en los que fuera posible se observó su distribución en el esqueleto, tratando de avanzar en discusiones sobre posibles diagnósticos etiológicos.

\subsubsection{Lesiones traumáticas}

En colecciones osteológicas es común encontrar diversos signos de trauma, siendo los más frecuentes las fracturas (Waldron 2009). Una lesión traumática refiere a una herida causada por una fuerza o mecanismo extrínseco al cuerpo, tanto intencional como accidental, y que puede afectar a distintos tejidos incluyendo el óseo (Lovell 1997). Los traumas óseos pueden ser causados por diversas circunstancias, tales como violencia accidental o intencional, prácticas culturales (cosméticas o terapéuticas) y diversas condiciones patológicas que implican un debilitamiento óseo frente a un estresor, aunque éste sea mínimo (Ortner 2003). Considerando esto es que el estudio de este tipo de lesiones en poblaciones del pasado brinda información relevante sobre distintos aspectos: violencia intra e interpersonal, accidentes domésticos o vinculados con estrategias de subsistencia y organización del trabajo (Larsen 1997; Lovell 1997). Evaluar la prevalencia, el tipo de trauma y la distribución anatómica de las lesiones, diferenciando por grupos de edad y sexo, contribuye a interpretar las causas sociales, culturales o medioambientales de este tipo de heridas (Lovell 1997).

Existe poco consenso acerca de cómo clasificar a los traumas (Judd y Redfern 2012). Entre los distintos tipos que se han considerado, pueden mencionarse como 
ejemplo a fracturas, dislocaciones, amputaciones, trepanaciones, osteocondritis disecante, espondilosis y heridas de arma (Lovell 1997; Bennike 2008; Ortner 2003; Judd y Redfern 2012). En este trabajo, se relevaron fracturas como primera aproximación a la temática en las áreas de estudio.

Una fractura consiste en una rotura o discontinuidad (completa o incompleta) de un hueso, pudiendo o no involucrar al tejido blando circundante (Bennike 2008; Waldron 2009). La misma resulta de la aplicación de una fuerza que excede las capacidades de elasticidad de la estructura ósea (Aufderheide y Rodríguez-Martín 1998). Estas fuerzas pueden ocurrir en distintas direcciones, teniendo así distintas consecuencias sobre el hueso (Aufderheide y Rodríguez-Martín 1998; Campillo 2001):

1. la flexión implica una fuerza perpendicular al eje axial del hueso, produciendo angulación con línea de fractura transversal u oblicua (por ej.: en cúbito distal cuando las personas elevan sus brazos para defenderse de un ataque).

2. el cizallamiento ocurre con dos fuerzas opuestas y perpendiculares a la diáfisis, resultando en una línea de fractura horizontal (por ej.: fractura de Colles -en la porción distal del radio, generalmente producida cuando las personas caen y tratan de amortiguarse).

3. la compresión consiste en la aplicación de una fuerza en dirección axial al hueso y que resulta en un aplastamiento del hueso (por ej.: en cráneo o vértebras).

4. la torsión sucede mientras un extremo del hueso se encuentra fijo y el otro extremo está rotando, produciendo así una fractura en espiral (por ej.: comunes en accidentes).

5. la tensión se produce cuando un ligamento o tendón que une dos huesos tira con intensidad sobre sus puntos de inserción ósea y uno de ellos cede originándose un arrancamiento (por ej.: en el maléolo tibial).

La metodología aplicada consistió en registrar: el hueso afectado; su lateralidad; la localización de la fractura en el hueso; el tipo de fractura según la dirección de la fuerza aplicada y el grado de remodelación ósea. En una segunda instancia, según lo propuesto por Lovell $(1997,2008)$, el análisis estuvo orientado en determinar el mecanismo por el cual se produjo la lesión (i.e. su causa próxima) y la causa última de la misma (aspecto comportamental). Esto último implica considerar no sólo las características de las lesiones, sino también el patrón esqueletal en el 
individuo y en la población y el contexto socio-ambiental del cual provienen los restos humanos.

\subsection{Estadística descriptiva e inferencial}

Luego de registrar las patologías dentales y óseas antes mencionadas, los datos obtenidos para cada una de ellas fueron analizados cuantitativamente. En primer lugar, fueron calculadas las prevalencias de cada tipo lesión, que determinan la relación entre el número total de elementos registrados con lesiones (numerador) y el número total de elementos relevados (denominador). Esto fue realizado a nivel individual y a nivel del elemento analizado. En el caso específico de las lesiones bucales, los cálculos variaron dependiendo de la lesión involucrada: mientras que en caries, cálculos dentales, desgaste e hipoplasias lineales del esmalte dental fueron evaluados por cantidad de piezas dentales observadas, en lesiones periapicales y pérdidas dentales antemortem fue por alveolos. Asimismo, se realizaron agrupaciones para cuantificar las prevalencias por grupo de edad y por sexo.

En una segunda instancia, se llevaron a cabo análisis estadísticos no paramétricos mediante el empleo del Test de $X^{2}$. Para ello se utilizó el programa Past 2.17 (Hammer et al. 2001). El nivel de significación empleado fue de $p \leq 0,05$. Cuando al menos de una de las celdas de la tabla de contingencia era menor a cinco, se utilizó la Prueba Exacta de Fisher. Con el fin de evaluar si la presencia de cada indicador en cada muestra bioarqueológica se asocia o no con los grupos de edad o sexos, se utilizó la Prueba de Independencia; esta prueba no explica acerca de la intensidad de la relación o la forma en la que las variables se relacionan entre sí, sólo indica que la relación entre ellas no es aleatoria o azarosa. Para comparar las frecuencias observadas en las tres muestras bioarqueológica con el objeto de medir si existen diferencias significativas entre los conjuntos, se utilizó la Prueba de Homogeneidad. 


\section{Capítulo 5}

\section{Las muestras bioarqueológicas: información contextual y primeros resultados}

Para este trabajo de tesis se analizaron 13 conjuntos osteológicos de 13 sitios arqueológicos. Las dataciones radiocarbónicas disponibles los ubican cronológicamente, a la mayoría, en el lapso temporal entre ca. 570 y 850 años AP; uno solo presenta un fechado de ca. 2000 años AP. Dos de estos conjuntos proceden de sitios ubicados en el Delta Superior del río Paraná (DS), uno en el Delta Medio del río Paraná, dos en el Delta Inferior del río Paraná y ambientes litorales adyacentes (DI) y ocho en la cuenca inferior del río Uruguay (CIRU). El Delta Superior comprende el sector desde el arroyo de la Ensenada (Diamante, Entre Ríos) hasta el río Paraná Pavón por el sur. Desde este último punto hasta el río Paraná Ibicuy se ubica el Delta Medio y a partir de allí se delimita el Delta Inferior hasta el Brazo Gutiérrez. El límite meridional del Delta Inferior corresponde al curso del río Luján (Buenos Aires); las áreas circundantes por debajo de este límite fueron consideradas aquí como ambientes litorales adyacentes. La cuenca inferior del río Uruguay se circunscribe desde el arroyo del Molino (Concepción del Uruguay, Entre Ríos) hasta su intersección con el avance del Delta del Paraná a la altura de la ciudad de Nueva Palmira (República Oriental del Uruguay) (Figura 5.1; Iriondo y Krohling 2008; Marcuzzo et al. 2016; Marcuzzo 2017; Bonomo y Politis 2018). Al considerar la ubicación geográfica de los sitios arqueológicos de los cuales provienen los conjuntos osteológicos analizados, es que se conformaron tres muestras bioarqueológicas (DS, DI y CIRU). Hay que remarcar que el sitio ubicado en el Delta Medio (Túmulo I-La Argentina, T1-LA) fue considerado junto con los sitios del DI, dada su cercanía geográfica con esa área. Por otro lado, el sitio Arroyo Sarandí se ubica a sólo $2 \mathrm{~km}$ al sur del río Luján, dentro de los ambientes litorales adyacentes al DI y fue integrado a esa muestra.

En el primer apartado de este capítulo se presentan brevemente las características ambientales, zoogeográficas y fitogeográficas de las tres áreas bajo 
estudio. En segundo lugar, se exponen los datos relativos a la estructura sexo-etaria de las tres muestras bioarqueológicas en conjunto y los perfiles de edad de muerte obtenidos para cada una de ellas. Las siguientes secciones se estructuran con información detallada para cada uno de los 13 sitios arqueológicos. Específicamente, en primer lugar, se presenta la información arqueológica contextual. En segunda instancia, se describen todos aquellos datos relativos a los entierros humanos en ellos recuperados. Finalmente, se exponen los números mínimos de individuos estimados y la estructura sexo-etaria. Es importante destacar que algunos resultados preliminares de una parte de la información bioarqueológica que se detalla a continuación, ha sido publicada en años recientes (Scabuzzo et al. 2015; Ramos van Raap y Bonomo 2016; Ramos van Raap y Scabuzzo 2017; Scabuzzo y Ramos van Raap 2018a).

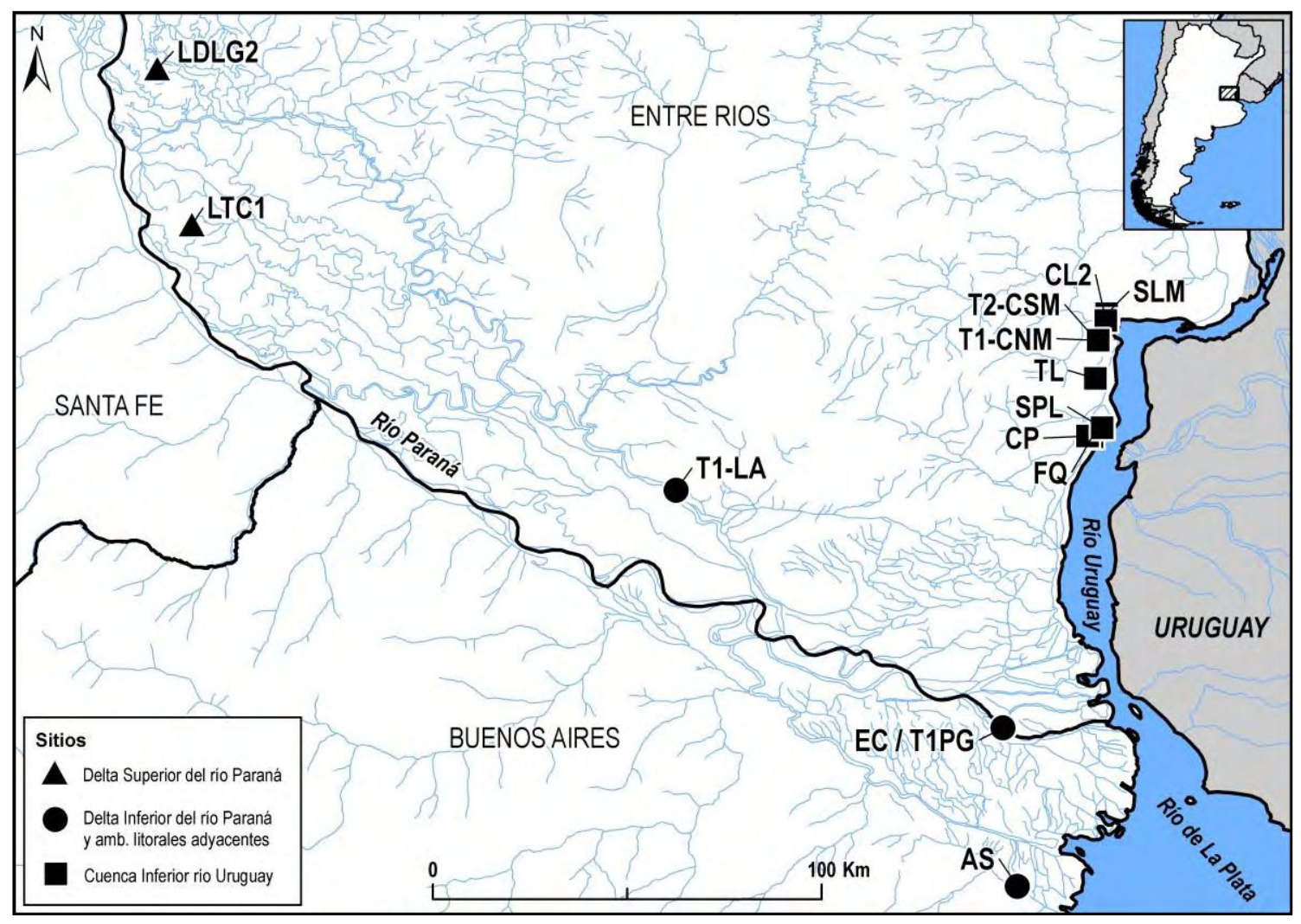

Figura 5.1. Ubicación de los sitios arqueológicos de los cuales provienen las muestras bioarqueológicas estudiadas. Referencias: LDLG2=Laguna de los Gansos 2; LTC1= Los Tres Cerros 1; T1-LA=Túmulo 1-La Argentina; EC/T1PG=El Cerrillo/Túmulo I del Paraná

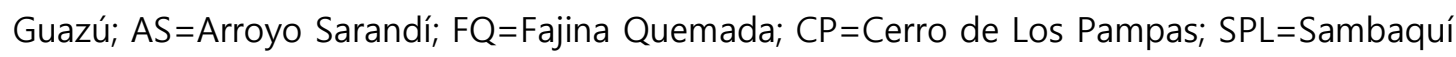
de Puerto Landa; TL=Túmulo de Lucuix; T1-CNM=Túmulo 1-Cerro Norte de Machado; T2CSM=Túmulo 2-Cerro Sur de Machado, CL2=Cerro Lorenzo 2; SLM=San Luis Médanos. 


\subsection{Caracterización ambiental de las áreas de estudio}

La constitución geomorfológica actual de las áreas bajo estudio se remonta al Holoceno Medio. El Delta del Paraná se formó sobre un complejo litoral marino en el tramo inferior del río Paraná. Hacia los 6000 años AP se produce el último evento transgresivo y a partir de allí comienza a formarse el Delta, hasta alcanzar su constitución actual luego de los 4000 años AP (Cavallotto et al. 2004, 2005; Codignotto 2004). Este ancho complejo deltaico se compone de un sector de tierras bajas, formado por numerosas islas en cuyos bordes se ubican los albardones (elevaciones rectilíneas naturales del terreno). Las crecidas de los ríos Paraná y Uruguay y las mareas de agua dulce del río de La Plata, conllevan al régimen hidrológico dinámico que caracteriza esta área (Baigún et al. 2008; Minotti y Borro 2011). Las inundaciones periódicas que producen la anegación de una gran extensión del terreno ocurren en distintos momentos del año, aunque son más frecuentes entre febrero y abril (Bó y Malvárez 1999). En cuanto al río Uruguay, cuya cuenca es la segunda más importante del sistema del Río de la Plata después de la del Paraná, corre encajonado desde el sur de Brasil hasta la cercanía de Concepción del Uruguay (Entre Ríos), donde se abre un amplio valle fluvial. Este sector inferior de la cuenca presenta dos características particulares, las cuales han influido para la conformación de su morfología actual. Una de ellas, se vincula con la influencia directa del mar durante la ingresión del Holoceno medio al cual estuvo sometido. La otra, es la gran abundancia de arena y sedimentos finos, que han dado origen a numerosos bancos arenosos e islas (Iriondo y Kröhling 2008). Específicamente, el tramo final del río (desde Galeguaychú hasta Nueva Palmira), consiste en una amplia depresión inundada y por su parte interior corre un cañón sumergido. Este tramo no presenta islas y se encuentra sometido a la erosión fluvial provocada por los vientos del noreste y la dinámica de las sudestadas y mareas del Río de La Plata (Iriondo y Kröhling 2008). Las grandes crecidas de los ríos Paraná, Uruguay y Gualeguay también influyen en las variaciones del régimen hídrico de la cuenca inferior. A diferencia de lo que ocurre con el Delta del río Paraná, las lluvias son más abundantes sobre la cuenca del río Uruguay durante los meses más fríos (Bó y Malvárez 1999). 
Desde el punto de vista zoogeográfico, las tres áreas bajo estudio pertenecen al Sector Meridional del Distrito Mesopotámico, Dominio Subtropical, Subregión Guayaño-Brasileña (Ringuelet 1961). Existe una gran variedad de especies, cuya distribución se ve afectada por los cambios hídricos recurrentes. Durante las inundaciones los espacios terrestres ocupables se reducen, de modo que los mamíferos (por ej. ciervo de los pantanos, Blastocerus dichotomus, y carpincho, Hydrochoerus hydrochaeris) se concentran en zonas interiores elevadas. Asimismo, los peces y moluscos se dispersan y se dificulta su obtención; pero cuando el nivel de agua comienza a retroceder, quedan atrapados en cursos secundarios y cuerpos de agua poco profundos. Entre la ictiofauna, las especies más abundantes son boga (Leporinus obtusidens), sábalo (Prochilodus lineatus), pacú (Piaractus mesopotamicus), tararira (Hoplias malabaricus), dorado (Salminus brasiliensis), armados (Doradidae) y viejas del agua (Loricariidae) (Ringuelet 1975; Burkart et al. 1999). Por otro lado, también se encuentran especies de reptiles, como el lagarto overo (Tupinambis merinae) y el yacaré ñato (Caiman latirostris) que se distribuyen desde el norte hasta el Delta Superior inclusive (Buckart et al. 1999); y varias especies de tortugas y serpientes. Las aves también son muy numerosas y existe una importante diversidad de aves acuáticas (por ej. biguá, garzas, patos, gallaretas).

Fitogeográficamente, el Delta del Paraná y cuenca inferior del río Uruguay corresponden al Distrito Uruguayense, dentro de la Provincia Pampeana, Dominio Chaqueño, Región Neotropical (Cabrera 1971). Este distrito, que cubre el sur de Entre Ríos y de Santa Fe, presenta a la pradera de flechilla como su comunidad clímax, con un tapiz casi continuo de distintas especies de gramíneas tiernas. También están presentes especies herbáceas no graminiformes. Por otro lado, existen bosques edáficos xerófilos sobre las barrancas de los ríos, entre los que predominan el algarrobo (Prosopis alba), el tala (Celtis spinosa), el coronillo (Scutia buxifolia), el sauce (Sambucus australis) y el ombú (Phytolacca dioica), entre otros. Este distrito presenta además comunidades edáficas, entre las que se encuentran especies propias de la Provincia Paranaense (Dominio Amazónico). Tal provincia se extiende hacia el sur a lo largo de los ríos Paraná y Uruguay, conformando selvas marginales que se empobrecen en especies hasta constituir estrechas franjas 
ribereñas a lo largo de los ríos (Muñoz et al. 2005). Específicamente en el sector de islas del Delta del Paraná, la distribución de la variada vegetación está influida por la topografía: mientras que sobre los albardones se desarrollan bosques (por ej. sauce criollo, seibo, curupí, laureles, timbó) y arbustales (por ej. espinillo, chilcas, duraznillo negro y sarandíes), en el interior de las islas prevalecen pajonales y pastizales. Además, en las riberas de lagunas y cursos de agua se encuentran comunidades de especies hidrófilas y acuáticas de camalotes y juncos, entre otros (Burkart et al. 1999).

\subsection{Estructura sexo-etaria y perfiles de edad de muerte}

Entre los conjuntos óseos de las tres muestras bioarqueológicas estudiadas fue estimado un número mínimo de 162 individuos (Tabla 5.1). El 22,8\% (n=37) proviene de los entierros humanos hallados en los dos sitios del DS, el 44,5\% $(n=72)$ de los ocho sitios ubicados en CIRU y el 32,7\% $(n=53)$ en los tres del DI. Se encuentran representados individuos de distintas edades; el 22,8\% ( $n=37)$ corresponde a individuos subadultos (desde perinatos hasta adolescentes) y el $77,2 \%(n=125)$ a adultos. Entre estos últimos, se distinguieron 19 adultos jóvenes, 7 adultos medios y 1 adulto mayor; 98 individuos quedaron agrupados bajo la categoría adulto sin poder precisar la edad con más detalle debido a la falta de partes diagnósticas. En cuanto al sexo, el 16,7\% $(n=27)$ corresponde a individuos femeninos, el 3,6\% $(n=6)$ a probables femeninos, el $24,1 \%(n=39)$ a individuos masculinos y $6,2 \%(n=10)$ a probables masculinos; finalmente el $49,4 \%(n=80)$ no pudo asignarse a algún sexo. 
Tabla 5.1 Número mínimo de individuos y estructura sexo-etaria estimada para cada sitio arqueológico.

\begin{tabular}{|c|c|c|c|c|c|c|c|c|c|c|c|c|c|c|c|c|c|c|c|c|c|c|c|c|c|c|c|c|c|c|}
\hline & \multirow[b]{2}{*}{ Sitio } & \multirow[b]{2}{*}{$\bar{\Sigma}$} & \multirow{2}{*}{ 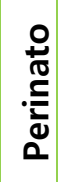 } & \multirow{2}{*}{ 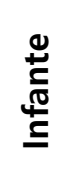 } & \multirow{2}{*}{$\stackrel{?}{\stackrel{?}{z}}$} & \multicolumn{5}{|c|}{ Adolescente } & \multicolumn{5}{|c|}{ Adulto joven } & \multicolumn{5}{|c|}{ Adulto medio } & \multicolumn{5}{|c|}{ Adulto mayor } & \multicolumn{5}{|c|}{ Adulto in. } \\
\hline & & & & & & $\dot{\leq}$ & 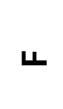 & $\frac{\omega}{a}$ & $\Sigma$ & $\sum_{a}$ & $\leqq$ & \llcorner & $\frac{\omega}{a}$ & $\Sigma$ & $\sum_{a}$ & $\leqq$ & ч & 㟔 & $\Sigma$ & $\sum_{a}$ & $\dot{\leq}$ & $\leftarrow$ & $\frac{\omega}{2}$ & $\Sigma$ & $\sum_{Q}$ & $\dot{\Xi}$ & 4 & $\frac{\omega}{2}$ & $\Sigma$ & $\sum_{a}$ \\
\hline \multirow{2}{*}{$\check{\Delta}$} & LTC1 & 35 & 3 & 4 & 3 & 2 & 4 & & 1 & & & & & 2 & & & 2 & & & & & 1 & & & & 6 & 1 & & 6 & \\
\hline & LDLG2 & 2 & & & & & & & & & & & & 1 & & & & & & & & & & & & 1 & & & & \\
\hline \multirow{8}{*}{ 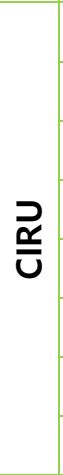 } & $\mathrm{CL2}$ & 25 & & 1 & 3 & & & & & & & 1 & 1 & 6 & 1 & & 2 & & 1 & & & & & & & 5 & 1 & & 2 & 1 \\
\hline & SPL & 32 & & 2 & 3 & & & & & & & 1 & & & & & & & & 1 & & & & & & 17 & 5 & & 3 & \\
\hline & T1-CNM & 6 & & 1 & & 1 & 1 & & & & & & & & & & & & & & & & & & & 2 & & & 1 & \\
\hline & T2-CSM & 3 & & & & & & & 1 & & & 1 & & & & & & & & & & & & & & & & 1 & & \\
\hline & $\mathrm{CP}$ & 3 & & & 1 & & & & & & & & & & & & & & & & & & & & & 1 & & 1 & & \\
\hline & SLM & 1 & & & & & & & & & & & & & & & & & & & & & & & & 1 & & & & \\
\hline & $\mathrm{TL}$ & 1 & & & & & & & & & & & & & & & & & & & & & & & & & & & 1 & \\
\hline & FQ & 1 & & & & & & & & & & & & & & & & & & & & & & & & 1 & & & & \\
\hline \multirow{4}{*}{$\overline{0}$} & T1-LA & 4 & & & & & & & 1 & & & & & & & & & & & & & & & & & 1 & 2 & & & \\
\hline & TI-PG & 20 & & & & & & & & & & & 1 & & & & & & & & & & & & & 2 & 2 & 2 & 9 & 4 \\
\hline & $\mathrm{EC}$ & 9 & & & & 1 & & & & & & & & & 2 & & & & & 1 & & & & & & 1 & 3 & & 1 & \\
\hline & AS & 20 & & & 1 & 2 & & & 1 & & & & & 2 & & & & & & & & & & & & 14 & & & & \\
\hline & TOTAL & 162 & 3 & 8 & 11 & & & 15 & & & & & 19 & & & & & 7 & & & & & 1 & & & & & 98 & & \\
\hline
\end{tabular}

Referencias: DS=Delta Superior del río Paraná, CIRU=cuenca inferior del río Uruguay; DI=Delta inferior del río Paraná y ambientes litorales adyacentes; LDLG2=Laguna de los Gansos 2; LTC1 = Los Tres Cerros 1; T1-LA=Túmulo 1-La Argentina; EC/T1PG=El Cerrillo/Túmulo I del Paraná Guazú; AS=Arroyo Sarandí; FQ=Fajina Quemada; $\mathrm{CP}=$ Cerro de Los Pampas; SPL=Sambaquí de Puerto Landa; TL=Túmulo de Lucuix; T1-CNM=Túmulo 1-Cerro Norte de Machado; T2-CSM=Túmulo 2-Cerro Sur de Machado, CL2=Cerro Lorenzo 2; SLM=San Luis Médanos. In.=indeterminado; F=femenino; PF=probable femenino; $M=$ masculino; PM=probable masculino. 
Los perfiles de edad de muerte obtenidos para cada una de las tres muestras bioarqueológicas exhiben algunas similitudes y diferencias entre sí (Figura 5.2). En la muestra del DS están presentes todos los grupos de edad; las frecuencias más altas corresponden a los grupos de 1,1-5 años y de 15,1-20 años. Asimismo, se observa una buena representación de individuos perinatos. La muestra de CIRU está conformada por individuos entre 0-1 y 35,1-50 años, con mayor representación del grupo de 1,1-5 años y de 20,1-35 años. Por su parte, la muestra del DI se constituye por los grupos de edad de entre 5,1-10 y 35,1-50, siendo más frecuentes los individuos adolescentes (15,1-20 años) y adultos jóvenes (20,1-35 años).

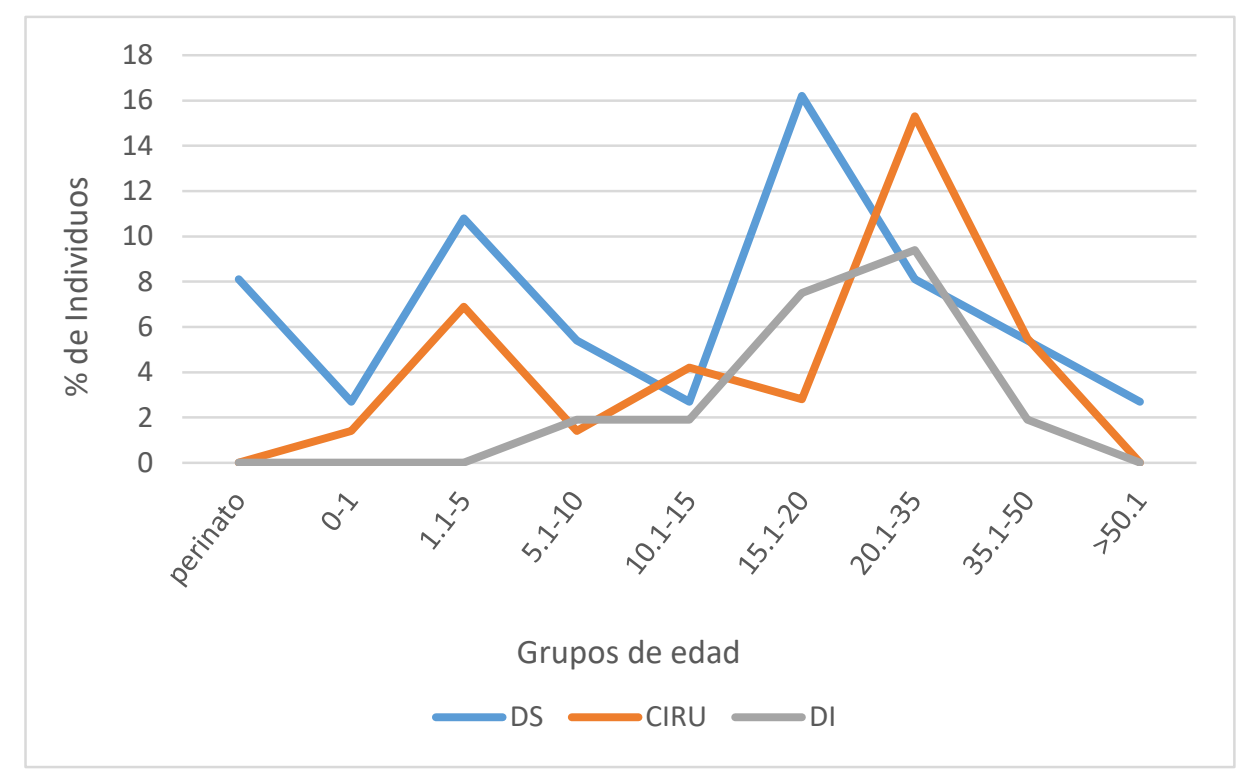

Figura 5.2. Perfil de edad de muerte para cada muestra bioarqueológica.

En relación con los individuos adultos, un porcentaje moderado a alto de individuos en las tres muestras quedó categorizado como "adulto indeterminado", sin poder precisar con mayor detalle el grupo de edad (DS: 37,8\%; CIRU: 59,7\%; DI: 77,4\%, Tabla 5.1). Esto, sin dudas, influye negativamente en la construcción de los perfiles de edad de muerte. En este sentido, la baja representación de individuos adultos medios y mayores en las tres muestras puede deberse al sesgo generado por tal circunstancia.

Con respecto a los individuos subadultos, es notable la diferencia entre las tres muestras. Para el conjunto del DS, el 29,7\% de los individuos falleció antes de 
alcanzar los 15,1 años de edad. En las muestras de CIRU y DI, estos porcentajes alcanzan las cifras de $16,7 \%$ y 3,8\%, respectivamente. En la literatura bioarqueológica, la baja frecuencia de individuos subadultos suele explicarse a partir de la incidencia de los procesos tafonómicos que afectan su preservación (Lewis 2006). En el caso de la muestra del DS, dada la considerable representatividad de estos grupos de edad en el conjunto (principalmente los perinatos y los individuos de 1,1-5 años), es posible pensar que los procesos postdepositacionales no influyeron significativamente. En cuanto a las muestras de CIRU y DI, deben considerarse los factores extrínsecos (véase Capítulo 2) que intervinieron en su conformación. Como se detallará en los apartados siguientes, mientras que la muestra del DS proviene de excavaciones controladas y sistemáticas, las otras dos muestras se conformaron a partir de trabajos de campo realizados con metodologías e intereses de investigación diferentes, y actualmente constituyen colecciones de museos. De hecho, para la muestra del DI, las fuentes escritas con información contextual de algunos de los sitios mencionan la presencia de individuos subadultos; algunos de ellos no pudieron ser rescatados del campo mientras que otros no fueron localizados en la colección consultada para el análisis realizado en esta tesis. Por estos motivos, la baja a nula representación de los grupos de edad de los individuos subadultos está mediada por los aspectos recién mencionados. Asimismo, hay que considerar la posible incidencia de las prácticas mortuorias en la representación de los subadultos. De acuerdo a la información bibliográfica disponible sobre el registro bioarqueológico del sur del NEA (véase Capítulo 3), los elementos óseos de infantes y niños han sido hallados en paquetes funerarios, en acumulaciones óseas o como huesos aislados.

Más allá de las limitaciones descriptas, en términos generales, los perfiles de edad de muerte obtenidos corresponderían al tipo atricional y no catastrófico. En este tipo de perfil atricional, los infantes y niños se encuentran bien representados, específicamente entre el año de vida y los cinco años. Luego, se observa una disminución abrupta de la mortalidad hasta el comienzo de la adolescencia, cuando aumenta durante la adultez temprana. Que los individuos adultos sean los más representados en los perfiles es indicio de que un alto porcentaje de los individuos alcanzó la edad reproductiva. Las frecuencias más bajas observadas en los grupos 
de edad mayores podrían deberse tanto a una menor esperanza de vida, como a los sesgos metodológicos y características de las muestras que impiden precisar la edad adulta (Chamberlain 2006). Los perfiles atricionales son los que caracterizan a los grupos de cazadores-recolectores. Específicamente en estudios paleodemográficos realizados para muestras de las regiones Pampeana y Patagónica de Argentina, se han observado también estos perfiles (Luna 2008; Flensborg et al. 2015; García Guraieb et al. 2015; Suby et al. 2017).

\subsection{Delta Superior del río Paraná}

\subsubsection{Los Tres Cerros 1 (LTC1)}

\subsubsection{Caracterización general}

La localidad arqueológica Los Tres Cerros (Victoria, Entre Ríos; Figura 5.1) se conforma por tres montículos de tierra de origen antropogénico (LTC1:

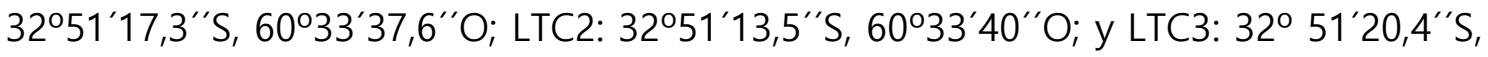
60³3'35,8“O), ubicados linealmente en dirección NO-SE a lo largo de 239 m. Los trabajos arqueológicos en la localidad se realizaron entre 2008 y 2012, incluyendo relevamientos planialtimétricos con estación total, barrenos y sondeos en la cima y pendiente de los montículos y en las planicies adyacentes. Las excavaciones sistemáticas, dirigidas por los Dres. G. Politis y M. Bonomo, se concentraron mayoritariamente en $\mathrm{LTC}^{1}$ (Figura 5.3) debido a que es el montículo central en relación con los otros dos y el que posee mayores dimensiones: 57,5 m de diámetro en su eje menor, $66,6 \mathrm{~m}$ en su eje mayor, 2,1 m de altura con respecto a la planicie circundante y un volumen de sedimentos de $1.703 \mathrm{~m}^{3}$ (Bonomo et al. 2010; Politis et al. 2011). La excavación se concentró en dos áreas. Por un lado, en la cima del cerrito se excavaron $23 \mathrm{~m}^{2}$ y se recuperaron abundantes materiales arqueológicos. Por otro lado, sobre su ladera Este y a $12 \mathrm{~m}$ de distancia de la cima, se excavaron $10 \mathrm{~m}^{2}$. Allí fueron encontrados numerosos entierros humanos, razón

\footnotetext{
1 En LTC2 y LTC3 se realizaron recolecciones superficiales y sondeos. Además en LTC2 se llevó a cabo una pequeña excavación de $4 \mathrm{~m}^{2}$, en la que se recuperaron restos cerámicos, huesos de fauna y escasos huesos humanos de un infante de forma aislada.
} 
por la se denominó a este sector como núcleo de inhumación (Scabuzzo y Ramos van Raap 2011; Scabuzzo et al. 2015).

El sitio LTC1 ha sido interpretado como un asentamiento residencial con ocupaciones relativamente estables (Bonomo et al. 2011b; Politis et al. 2011). Una serie de rasgos recurrentes (características de la tecnología y del estilo cerámico, la modalidad de ocupación del espacio, la fuerte adaptación a los ambientes fluviales, etc.), permitieron asignar estas ocupaciones a la entidad arqueológica GoyaMalabrigo (Politis y Bonomo 2012). Se disponen de 21 fechados radiocarbónicos que coinciden con el rango temporal de esta entidad arqueológica; estas dataciones ubican la construcción y ocupación de LTC1 en el Holoceno tardío final entre ca. 1227 y 560 años AP (Politis et al. 2011; Politis y Bonomo 2012; Gianotti y Bonomo 2013).

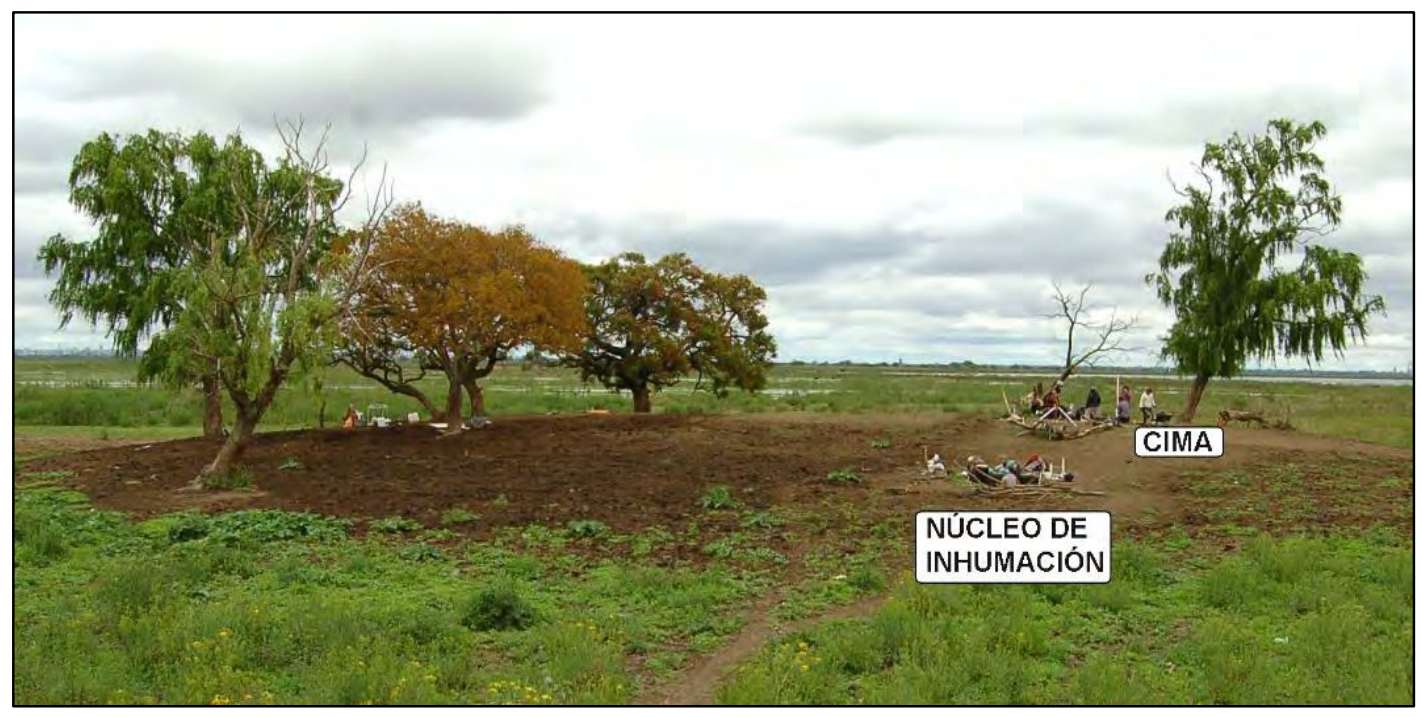

Figura 5.3. El montículo LTC1 diferenciando las dos zonas excavadas.

De acuerdo a los estudios de la secuencia estratigráfica del montículo y a los análisis mineralógicos y granulométricos, se pudo determinar que el cerrito fue sobreelevado mediante la incorporación intencional de arcillas, arenas y tiestos. Los fangos utilizados fueron seleccionados en áreas de suministro específicas, ubicadas fuera del emplazamiento inmediato de LTC1. Los distintos materiales que fueron incorporados con la intención de aumentar la acumulación y consolidar la estructura, formaron parte también de los desechos producidos por las múltiples 
actividades que se desarrollaron en el asentamiento (Politis et al. 2011; Castiñeira Latorre et al. 2013, 2014, 2017b).

Entre los restos faunísticos recuperados, se encuentran representados especímenes de mamíferos (coipo, carpincho y cuis), de peces (tararira, boga, chanchita, familias Doradidae y Pimelodidae), de aves, de reptiles y de moluscos de agua dulce. Entre los mamíferos, los más representados son el coipo y el carpincho, ambos con claras evidencias de aprovechamiento antrópico para consumo y manufactura de instrumentos. Por otro lado, en menor proporción se recuperaron restos de cánidos y cérvidos, animales que fueron explotados para la confección de instrumentos en hueso y asta (Bastourre 2014). Además de estos elementos de tecnología ósea, fueron recuperados escasos artefactos líticos. Específicamente se registraron 11 piezas -principalmente restos indiferenciados-, manufacturados con materias primas de diversa procedencia: las areniscas provienen de las formaciones Paraná e Ituzaingó, que afloran a más de 50 km de LTC1, en la margen izquierda del río Paraná y sus tributarios; las calizas silicificadas son de la Formación Puerto Yeruá y el basalto vesicular de la Formación Serra Geral, que se encuentran disponibles en el río Uruguay y tributarios, a una distancia mayor a $230 \mathrm{~km}$ del sitio (Politis et al. 2011; Apolinaire 2017).

El registro cerámico es uno de los más abundantes. Además de miles de tiestos (usados en la construcción monticular), se registraron campanas, apéndices zoomorfos (cabezas de aves, de mamíferos y de ofidios), cuentas de collar y masas de arcilla con improntas de dedos. Así como también vasijas de formas abiertas (escudillas, cuencos y platos) y recipientes con bordes de bocas pequeñas. La producción de la alfarería habría sido in situ, utilizando como materia prima a arcillas procedentes de distintos afloramientos con cierta homogeneidad composicional, ubicados en cercanías del sitio (Di Prado y Castro 2014; Di Prado 2015, 2016).

Los análisis del registro biosilíceo efectuados en muestras de la porción superior de la secuencia sedimentaria de LTC1, arrojaron resultados interesantes. En muestras de un perfil de la excavación, fueron identificados morfotipos silíceos relacionados con la presencia de vegetales silvestres, propios de la unidad fitogeográfica actual del área en el que se emplaza el sitio (Sanchez et al. 2013). Por 
otro lado, se registraron otros morfotipos que pudieron ser asignados a las familias Arecaceae, Cucurbitaceae y Poaceae (subfamilias Maideae y Oryzoideae); este material fitolítico proviene de muestras seleccionadas en la planta de excavación en asociación con rasgos determinados: sedimentos con indicios de termoalteración, restos de fogones, fogones con acumulaciones óseas, paredes internas de vasijas y sedimentos asociados con grandes fragmentos de tiestos. Estos resultados estarían indicando el manejo de plantas silvestres y el cultivo de domesticadas, como porotos, maíz y zapallo (Sánchez et al. 2013). Complementariamente, en los análisis antracológicos se identificaron elementos arbóreos-arbustivos de laurel, timbó colorado, algarrobo, espinillo, ceibo y peteribí, lianas de pasionaria y elementos herbáceos de papiro criollo. Su presencia indica una estrategia diversificada en la selección de distintos vegetales que forman parte de distintas unidades de vegetación de los ríos y arroyos del río Paraná (Brea et al. 2013). Su uso habría estado principalmente vinculado con el aprovisionamiento de combustibles (por ej. espinillo, algarrobo, laurel, timbó colorado y ceibo), así como también para la construcción de artefactos, viviendas y embarcaciones (por ej. timbó colorado y ceibo). Tampoco se descarta el uso medicinal que pudieron tener algunos de ellos (por ej. pasionaria, papiro criollo) (Brea et al. 2013). Por otro lado, los análisis de macrorrestos vegetales de la secuencia estratigráfica de LTC1 permitieron identificar diversas familias de plantas: Solanaceae, Chenopodiaceae, Poaceae (Maideae y Ehrhartoideae), Polygonaceae, y Amaranthaceae, la mayoría de ellas nativas con propiedades económicas o medicinales, que pudieron ser aprovechadas por los ocupantes de este sitio. Ya desde los momentos iniciales de la construcción antrópica del cerrito (ca. 1030 años AP), se evidencia el posible consumo del arroz nativo además de una variedad de maíz cultivado. Hacia aproximadamente 860 años AP, habría ocurrido una intensificación en el uso de recursos vegetales, sustentado en el análisis de microrrestos y en la mayor diversidad taxonómica y abundancia de macrorrestos (Colobig et al. 2015).

\subsubsection{Entierros humanos y muestra bioarqueológica estudiada}

En la pendiente del montículo fue identificado un sector destinado a la inhumación de numerosos individuos. Durante las tareas de campo en 2009, en uno 
de los distintos sondeos que se estaban realizando en la pendiente del cerrito fueron encontrados fragmentos óseos humanos. Frente a esta situación, se decidió comenzar una excavación sistemática que se prolongó hasta el 2012. En total, se abrieron 10 cuadrículas de $1 \mathrm{~m}^{2}$ cada una. La metodología empleada consistió en el mapeo de cada elemento óseo y el registro de su ubicación tridimensional, la identificación de los tipos de entierro y el registro fotográfico. Asimismo, se relevó la asociación entre los entierros y distintos rasgos, como por ejemplo la presencia de colorantes, concentraciones de valvas, materiales faunísticos y tiestos.

Las inhumaciones halladas se concentraban en una secuencia de aproximadamente 40 a $45 \mathrm{~cm}$ de potencia vertical. Fueron distinguidos entierros primarios simples, paquetes funerarios simples y múltiples, una acumulación ósea y huesos aislados. El NMI estimado es de 35; el 48,6\% $(n=17)$ corresponde a la categoría subadulto, determinándose entre ellos a 3 perinatos, 4 infantes, 3 niños y 7 adolescentes. El 51,4\% $(n=18)$ de la muestra corresponde a adultos; el 27,8\% $(n=5)$ de estos individuos pudo ser asignado a una de las siguientes categorías etarias: 2 adultos jóvenes, 2 adultos medios y 1 adulto mayor; en el 72,2\% ( $n=13)$ restante no se pudo establecer el grupo etario preciso debido a la falta de partes diagnósticas. Las determinaciones sexuales pudieron efectuarse en el $48,6 \%$ de la muestra $(n=17)$, de los cuales 8 fueron categorizados como femeninos ${ }^{2}$ y 9 como masculinos (Tabla 5.2).

2 Dos de estos individuos femeninos (LTC1-P5 y LTC1-S6) fueron determinados como tales en base a variables odontométricas, que mostraban un $75 \%$ o más de alocación coincidente con los sexos establecidos por los criterios de Buikstra y Ubelaker (1994) (Bollini y Atencio 2016; Atencio com. pers. 2017). 
Tabla 5.2. Información sobre los individuos hallados en LTC1.

\begin{tabular}{|c|c|c|c|c|}
\hline Tipo de entierro & Individuo & Grupo etario & Edad & Sexo \\
\hline Primario DD & LTC1-P1 & adolescente & 17-20 años & $\mathrm{F}$ \\
\hline Primario DD & LTC1-P2 & adulto & - & M \\
\hline Primario DV & LTC1-P3 & adulto mayor & 50-59 años & $\mathrm{F}$ \\
\hline Primario DLI & LTC1-P4 & adulto medio & 35-44 años & $\mathrm{F}$ \\
\hline Primario DD & LTC1-P5 & adolescente & $12-15$ años & $\mathrm{F}$ \\
\hline Primario DD & LTC1-P6 & adolescente & 19-20 años & - \\
\hline Primario in. & LTC1-P7 & adolescente & 19-20 años & $\mathrm{F}$ \\
\hline Paquete & LTC1-S1-1 & adulto joven & 20-21 años & M \\
\hline funerario múltiple & LTC1-S1-2 & adulto medio & 45-49 años & $\mathrm{F}$ \\
\hline Paquete & LTC1-S2-1 & adulto joven & 25-29 años & M \\
\hline funerario múltiple & LTC1-S2-2 & adolescente & 16-18 años & $\mathrm{F}$ \\
\hline Paquete funerario simple & LTC1-S3 & adulto & - & M \\
\hline \multirow{7}{*}{$\begin{array}{c}\text { Paquete } \\
\text { funerario múltiple }\end{array}$} & LTC1-S4-1 & adulto & - & M \\
\hline & LTC1-S4-2 & adulto & - & - \\
\hline & LTC1-S4-3 & adulto & - & M \\
\hline & LTC1-S4-4 & adolescente & 17-19 años & M \\
\hline & LTC1-S4-5 & niño & 4-6 años & - \\
\hline & LTC1-S4-6 & niño & 9-10 años & - \\
\hline & LTC1-S4-7 & perinato & $38-40 \mathrm{sem}$ & - \\
\hline Paquete funerario & LTC1-S5 & adulto & - & - \\
\hline múltiple & LTC1-S5 & adulto & - & - \\
\hline Paquete funerario simple & LTC1-S6 & adulto & - & $\mathrm{F}$ \\
\hline \multirow{3}{*}{ Acumulación ósea } & LTC1-AC-1 & infante & 2-4 años & - \\
\hline & LTC1-AC-2 & adulto & - & M \\
\hline & LTC1-AC-3 & adulto & - & - \\
\hline \multirow{10}{*}{ Huesos aislados } & LTC1 - A1 & perinato & 40 sem & - \\
\hline & LTC1 - A2 & perinato & $38-40 \mathrm{sem}$ & - \\
\hline & LTC1 - A3 & infante & 0,5-1 años & - \\
\hline & LTC1 - A4 & infante & 2-4 años & - \\
\hline & LTC1 - A5 & niño & - & - \\
\hline & LTC1 - A6 & infante & - & - \\
\hline & LTC1 - A7 & adolescente & 19-20 años & - \\
\hline & LTC1 - A8 & adulto & - & M \\
\hline & LTC1 - A9 & adulto & - & - \\
\hline & LTC1 - A10 & adulto & - & - \\
\hline
\end{tabular}

Referencias: $\mathrm{DD}=$ decúbito dorsal; $\mathrm{DV}=$ decúbito ventral; $\mathrm{DLI}=$ decúbito lateral izquierdo; in.=indeterminado; sem=semanas; $M=$ masculino; $F=$ femenino. 
Los siete entierros primarios corresponden a individuos adolescentes y adultos, de ambos sexos. A continuación, se detallan las características más relevantes de cada uno de estos entierros.

- LTC1-P1: adolescente femenino en posición dorsal con los miembros extendidos; orientación SSO-NNE. Varios de los huesos del brazo izquierdo, vértebras y costillas, se encontraban teñidos con pigmento rojo. Además, sobre la cara anterior de algunos huesos se registró adherido sedimento arcilloso. Por otro lado, en el sedimento asociado con los huesos, había pequeñas concentraciones de pigmento rojo. Asociados con este entierro, pudieron remontarse tiestos y reconstruir tres contenedores: una fuente de gran tamaño y un cuenco mediano (Castro, C. 2017). Datación radiocarbónica: $657 \pm 43$ años AP (Scabuzzo et al. 2015).

- LTC1-P2: adulto masculino en posición dorsal con los miembros extendidos; orientación SSO-NE. Se registró sedimento arcilloso adherido sobre la cara anterior de algunos huesos. Al lado del cráneo se hallaron cuatro tiestos superpuestos, pertenecientes a un plato, con depósitos de hollín en su cara externa. Asimismo, en cercanías de las piernas se encontró un cuenco mediando y sobre el coxal derecho, un cuenco grande, respectivamente (Castro, C. 2017).

- LTC1-P3: adulto femenino en posición ventral con los miembros extendidos; orientación NO-SE. Salvo los miembros inferiores, se encontraba cubierto en su parte dorsal por una gran cantidad de sedimento arcilloso mezclado con pigmento rojo (Figura 5.4). Al costado de la pierna derecha se registraron seis tiestos que remontados conforman un cuenco mediano (Castro, C. 2017). Datación radiocarbónica: 849₫45 años AP (Scabuzzo et al. 2015).

- LTC1-P4: adulto femenino en posición decúbito lateral izquierdo con los miembros inferiores y superiores flexionados; orientación SO-NE. Al lado del cráneo se hallaron siete tiestos agrupados que son parte de un cuenco de tamaño grande (Castro, C. 2017). Datación radiocarbónica: $801 \pm 46$ años AP (Scabuzzo et al. 2015). 
- LTC1-P5: adolescente femenino en posición dorsal con los miembros extendidos; orientación SO-NE. Datación radiocarbónica: $763 \pm 47$ años AP (Scabuzzo et al. 2015).

- LTC1-P6: adolescente encontrado de manera incompleta; orientación SO-NE. Por un lado, fueron hallados de forma articulada la rótula, la tibia, el peroné, los tarsos y los metatarsos derechos y la tibia y peroné izquierdos. Por otro lado, se encontró articulado el torso (esternón, columna vertebral, sacro y costillas). Los demás elementos estaban ausentes. La ubicación y la distancia entre estas porciones óseas se correspondían con la posición anatómica de un esqueleto extendido en posición decúbito dorsal.

- LTC1-P7: adolescente probablemente femenino que se halló de manera incompleta durante los días finales de la última campaña de excavación; orientación SO-NE. Los huesos (húmero, cúbito, radio, fémur, rótula, tibia, peroné y calcáneo izquierdos) fueron registrados en el perfil de dos cuadrículas contiguas (C11 y C12) del núcleo de inhumación, quedando apenas visibles otros huesos del esqueleto. No fue posible determinar la posición del mismo. 

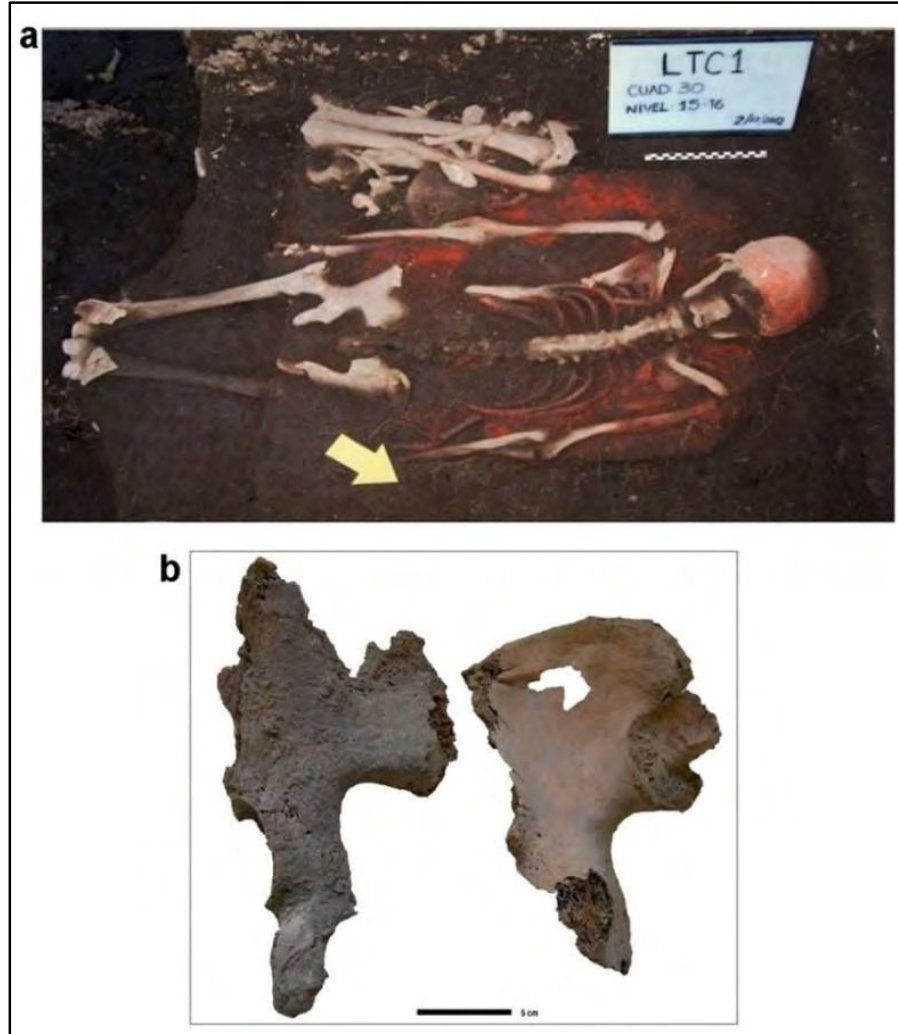

Figura 5.4. Aplicación de sedimento arcilloso con pigmento rojo en LTC1-P3: a) el entierro;

b) coxal izquierdo con el barro con pigmento sobre la cara dorsal (en comparación con cara ventral del coxal derecho).

Los seis paquetes funerarios presentan una gran variación entre sí con respecto a la cantidad de elementos óseos, los individuos representados y la composición sexo-etaria. A continuación, se detallan las características más relevantes de cada uno de estos entierros.

- LTC1-S1: paquete funerario múltiple conformado por 25 elementos óseos; están representados un adulto joven masculino y un adulto medio femenino. En el armado de este fardo, con orientación SSO-NNE, se ubicaron los huesos largos por encima y por debajo, conteniendo entre ellos a huesos planos, vértebras y costillas; el cráneo se colocó hacia uno de los extremos y los coxales se encontraban exactamente en los extremos del paquete (Figura 5.5.a). En el sedimento asociado con el entierro se hallaron valvas de molusco, tiestos y restos faunísticos. Datación radiocarbónica: $650 \pm 70$ años AP (Politis et al. 2011).

- LTC1-S2: paquete funerario múltiple conformado por 56 elementos óseos; están representados un adulto joven masculino y un adolescente femenino; orientación SE-NO. Al interior del paquete, las vértebras cervicales, torácicas y las 
costillas (probablemente pertenecientes al adolescente) estaban articuladas entre sí. En la mayoría de los elementos - de ambos individuos- se registró pigmento rojizo y específicamente en algunos de ellos, se distinguió arcilla mezclada con el pigmento rojo sobre la superficie cortical. Junto a este entierro se halló un contenedor de gran tamaño con restos de hollín en su superficie externa (Castro, C. 2017).

- LTC1-S3: paquete funerario simple, conformado por 11 huesos largos de un adulto de sexo indeterminado; orientación SSO-NNE. El entierro estaba cubierto parcialmente por valvas de Diplodon sp (Figura 5.5.b). Datación radiocarbónica: $802 \pm 48$ años AP (Scabuzzo et al. 2015).

- LTC1-S4: paquete funerario múltiple conformado por 80 elementos óseos; orientación SO-NE. Los individuos representados son 3 adultos, 1 adolescente probablemente masculino, 2 niños y 1 perinato. Los huesos de uno de los adultos (brazo y mano izquierdos) y algunos del adolescente (fémur y tibia), se encontraban articulados. A excepción de los huesos de un adulto y de un niño, varios de los elementos de los otros individuos estaban teñidos con pigmento rojo.

- LTC1-S5: paquete funerario múltiple conformado por 15 huesos de dos individuos adultos; orientación SSO-NNE. Huesos de un antebrazo (radio y cúbito) estaban articulados entre sí. Aproximadamente $5 \mathrm{~cm}$ por encima de este entierro fue hallada una concentración circular (ca. $20 \mathrm{~cm}$ de diámetro) de valvas de moluscos (Diplodon sp.); hacia los costados de ésta apareció otra concentración, pero conformada por numerosos tiestos, restos de valvas, restos óseos de fauna y espículas de carbón.

- LTC1-S6: paquete funerario simple conformado por 24 elementos de un adulto femenino. Es el entierro que a menor profundidad se encontró $(30-35 \mathrm{~cm}$ ) durante uno de los primeros sondeos efectuados en lo que luego se denominó núcleo de inhumación. Si bien estos elementos no poseían ninguna orientación u ordenamiento entre sí, este hallazgo fue considerado como un paquete funerario en el que distintos agentes postdepositacionales causaron su dispersión. Estos agentes tafonómicos, que deberán ser evaluados en análisis específicos, habrían causado también la fragmentación de los huesos que conforman el paquete 
(Scabuzzo y Ramos van Raap 2017). En el sedimento asociado con este entierro, fueron encontrados numerosos fragmentos de valvas, huesos de fauna y tiestos.

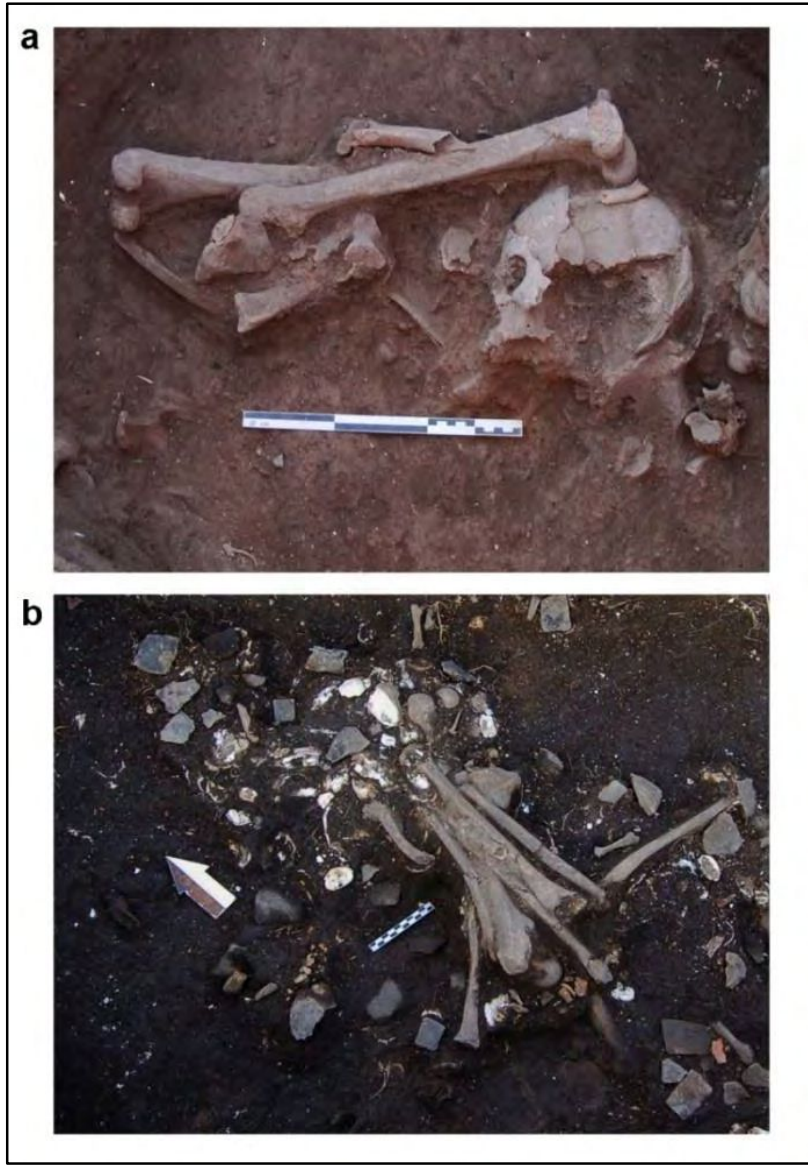

Figura 5.5. Paquetes funerarios de LTC1: a) LTC1-S1; b) LTC1-S3 con parte de las valvas de molusco que lo cubrían y tiestos cerámicos alrededor.

En la Tabla 5.3 se presentan los cálculos de abundancia efectuados para estos entierros (en las Tablas A.2.1 a A.2.4 se presentan de forma separada para cada paquete múltiple). En total son 207 elementos; están mayormente representados huesos del esqueleto apendicular (clavícula, húmero, radio, cúbito, coxal y fémur) y el cráneo. Lo contrario ocurre con huesos de pequeño tamaño (por ej. carpos, tarsos, metacarpos, metatarsos y falanges). El NMI que surge de estos cálculos es de 8. Sin embargo, al considerar independientemente a cada uno de los paquetes, el NMI asciende a 15; este último fue el criterio utilizado en este trabajo. 
Tabla 5.3. Cálculos de abundancia anatómica de los paquetes funerarios de LTC1.

\begin{tabular}{|c|c|c|c|c|c|c|c|c|c|c|c|c|c|}
\hline \multirow{2}{*}{$\begin{array}{c}\text { Unidad } \\
\text { anatómica }\end{array}$} & \multirow{2}{*}{ NISP } & \multicolumn{2}{|c|}{$S / F$} & \multicolumn{2}{|r|}{$L / F$} & \multicolumn{4}{|c|}{$\mathbf{F}$} & \multirow{2}{*}{ NMI } & \multirow{2}{*}{ NME } & \multirow{2}{*}{ MAU } & \multirow{2}{*}{ MAU\% } \\
\hline & & D & A In. & D & I A In. & D & I & A & In. & & & & \\
\hline cráneo & 71 & & 1 & & & & & 4 & & 5 & 5 & 5 & 83,3 \\
\hline mandíbula & 9 & & 1 & & & & & 3 & & 4 & 4 & 4 & 66,6 \\
\hline vért. cervicales & 23 & & & & 1 & & & 12 & & 3 & 13 & 1,9 & 31,6 \\
\hline vért. torácicas & 17 & & & & 4 & & & 12 & & 2 & 16 & 1,3 & 21,6 \\
\hline vért. lumbares & 13 & & & & & & & 8 & & 2 & 8 & 1,6 & 26,6 \\
\hline vértebras in. & 2 & & & & & & & 1 & & 1 & 1 & 0,04 & 0,6 \\
\hline costilla & 80 & & & 5 & 5 & 8 & 8 & & 13 & 2 & 39 & 1,6 & 26,6 \\
\hline clavícula & 10 & & & 1 & 1 & 4 & 4 & & & 5 & 10 & 5 & 83,3 \\
\hline esternón & 1 & & & & & & & 1 & & 1 & 1 & 1 & 16,6 \\
\hline escápula & 16 & & & & & 4 & 4 & & & 4 & 8 & 4 & 66,6 \\
\hline húmero & 17 & 2 & & 1 & & 5 & 3 & & & 8 & 11 & 5,5 & 91,6 \\
\hline radio & 17 & & & 1 & 2 & 1 & 1 & & 1 & 5 & 10 & 5 & 83,3 \\
\hline cúbito & 20 & 1 & & & & 4 & 5 & & & 6 & 10 & 5 & 83,3 \\
\hline carpos & 8 & & & & & & 8 & & & 2 & 8 & 0,5 & 8,3 \\
\hline metacarpos & 9 & & & & & 2 & 6 & & 1 & 2 & 9 & 0,9 & 15 \\
\hline falanges mano & 14 & & & & & 2 & 11 & & 1 & 1 & 14 & 0,5 & 8,3 \\
\hline coxal & 33 & 1 & & 1 & 1 & 3 & 3 & & 1 & 5 & 10 & 5 & 83,3 \\
\hline sacro & 11 & & & & & & & 2 & & 2 & 2 & 2 & 33,3 \\
\hline fémur & 26 & 62 & & 2 & 2 & 3 & 3 & & & 7 & 12 & 6 & 100 \\
\hline rótula & 1 & & & & & & 1 & & & 1 & 1 & 0,5 & 8,3 \\
\hline tibia & 13 & 1 & 1 & & 1 & 2 & 2 & & & 4 & 6 & 3 & 50 \\
\hline peroné & 15 & & & & & 3 & 2 & & & 3 & 5 & 2,5 & 41,4 \\
\hline tarsos & 0 & & & & & & & & & 0 & 0 & 0 & 0 \\
\hline metatarsos & 1 & & & & & & 1 & & & 1 & 1 & 0,07 & 1,16 \\
\hline falanges pie & 1 & & & & & & & & 1 & 1 & 1 & 0,01 & 0,16 \\
\hline dientes & 1 & & & & & & & & 1 & 1 & 1 & - & - \\
\hline huesos in. & 1 & & & & & & & & & 1 & 1 & - & - \\
\hline TOTAL & 430 & & & & & & & & & & 207 & & \\
\hline
\end{tabular}

Referencias: NISP= número mínimo de especímenes óseos; $\mathrm{S} / \mathrm{F}=\sin$ fusionar; $\mathrm{L} / \mathrm{F}=$ con línea de fusión; F=fusionados; $D$ =derecho; I=izquierdo; $A=$ =axial; In.=indeterminado; $N M I=$ número mínimo de individuos; $\mathrm{NME}=$ número mínimo de elementos; $\mathrm{MAU}=$ =unidades anatómicas mínimas; MAU\%=porcentaje de unidades anatómicas mínimas; vért.=vértebras.

Además de los entierros primarios y los paquetes funerarios, se identificó una acumulación ósea conformada por 28 elementos óseos ubicados principalmente con orientación SO-NE. Los huesos corresponden a un NMI de 7: 4 
adultos $^{3}, 1$ adolescente, 1 infante y 1 perinato. Al igual que en los paquetes funerarios, en este entierro predominan los huesos largos; además se hallaron fragmentos de dos cráneos (del perinato y del infante) (Tabla 5.4). La particularidad de este hallazgo es que, al analizarlo en el laboratorio, pudieron aparearse algunos de estos elementos con sus antímeros que se encontraban conformando el paquete múltiple LTC1-S4. Se trata de huesos del perinato (radio, tibia, cúbito, peroné y cráneo), del adolescente (radio, tibia, peronés y costillas) y de dos de los adultos (cúbito y húmero, respectivamente). Los huesos de la acumulación que no pudieron aparearse con huesos de otros entierros, corresponden a tres individuos: un infante y dos adultos.

3 La diferencia entre este número de individuos adultos y el presentado en la Tabla 5.4 radica en las tareas de ensamblaje anatómico, las cuales permitieron estimar el NMI total. 
Tabla 5.4. Cálculos de abundancia anatómica de la acumulación ósea de LTC1.

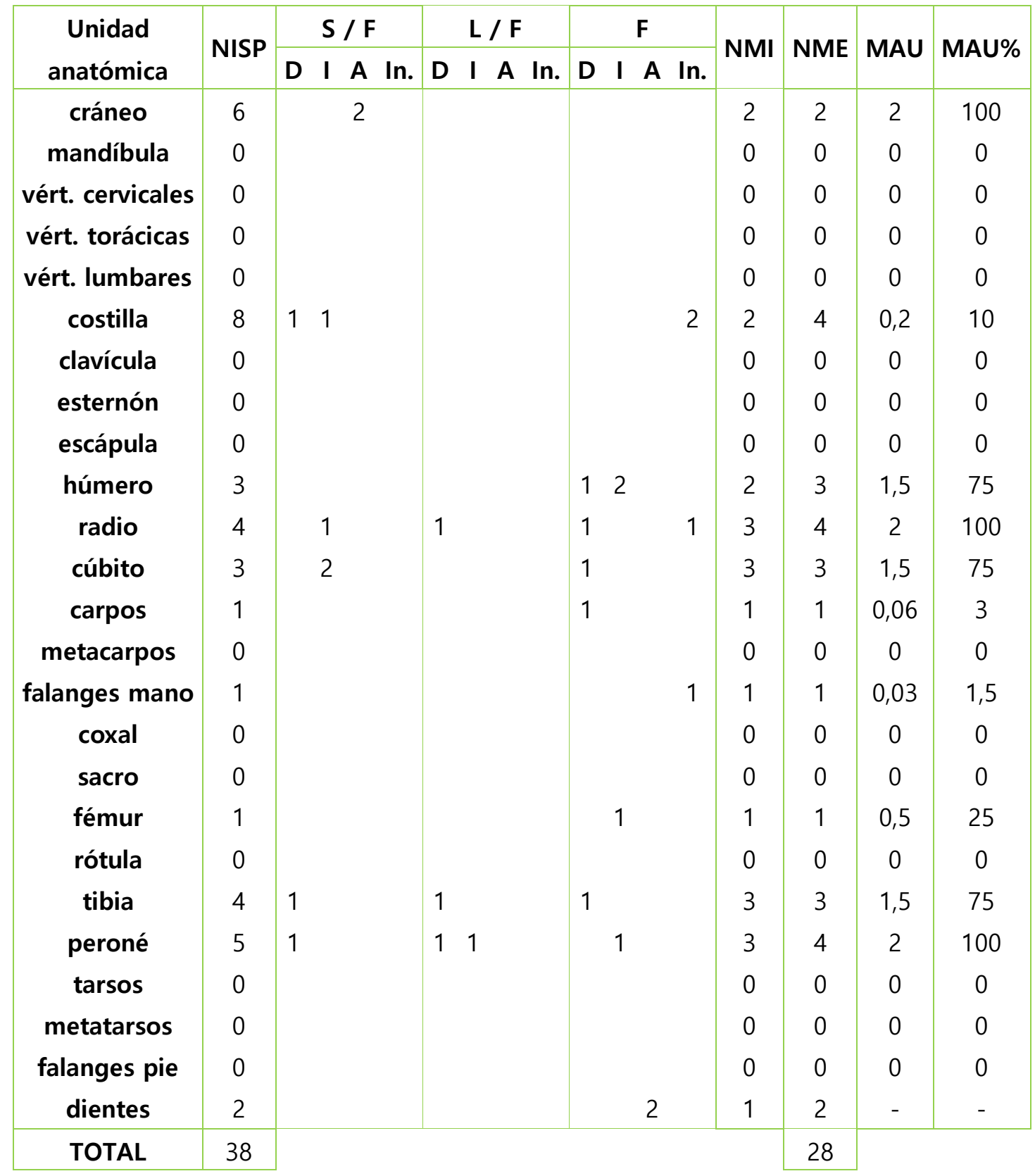

Referencias: NISP=número mínimo de especímenes óseos; $\mathrm{S} / \mathrm{F}=\sin$ fusionar; $\mathrm{L} / \mathrm{F}=$ con línea de fusión; $\mathrm{F}=$ =fusionados; $\mathrm{D}=$ derecho; $\mathrm{I}=$ izquierdo; $\mathrm{A}=$ =axial; $\mathrm{In}$.=indeterminado; $\mathrm{NMI}=$ número mínimo de individuos; $\mathrm{NME}=$ número mínimo de elementos; $\mathrm{MAU}=$ unidades anatómicas mínimas; MAU\%=porcentaje de unidades anatómicas mínimas; vért.=vértebras.

Al continuar con las tareas de ensamblaje anatómico, entre los huesos aislados que se hallaron en el área inhumatoria también pudieron identificarse huesos que corresponden al perinato (fémur, costilla y radio) y al adolescente (coxal) enterrados en el paquete LTC1-S4 y en la acumulación ósea. Asimismo, huesos de los dos niños representados en el mismo paquete funerario pudieron 
aparearse con sus antímeros que se encontraron de forma aislada (coxal, fémur, húmero y dos vértebras torácicas del LTC1-S4-5; maxilar del LTC1-S4-6). Por otro lado, un fémur de uno de los adultos de la acumulación ósea pudo corresponderse con su antímero, el cual se hallaba de manera aislada. Esta correspondencia pudo efectuarse no sólo al observar las mismas características morfológicas (tamaño, longitud y robusticidad) en ambos elementos, sino también al distinguir una reacción perióstica en el tercio distal de la cara anterior de la diáfisis de cada hueso (véase con mayor detalle Capítulo 7).

Los elementos aislados que quedaron sin poder corresponderse con individuos de otros entierros, fueron analizados de manera conjunta. Se contabilizaron 242 elementos y se determinó un número mínimo de 10 individuos de distintas edades (Tabla 5.5). La mayoría de estos elementos óseos corresponde a huesos planos y cortos. Sólo se identificaron 19 huesos largos, muchos de ellos fragmentados; siete de ellos pertenecen a perinatos e infantes. Como parte de este conjunto aislado también se incluyen las porciones anatómicas articuladas halladas. Se trata de los metatarsos de un pie derecho de un individuo adulto y la cintura pélvica y miembros inferiores de un adulto. Asimismo, los huesos de un pie derecho y un pie izquierdo -probablemente pertenecientes a un mismo individuofueron hallados con una estrecha proximidad espacial. 
Tabla 5.5. Cálculos de abundancia anatómica de los huesos aislados de LTC1.

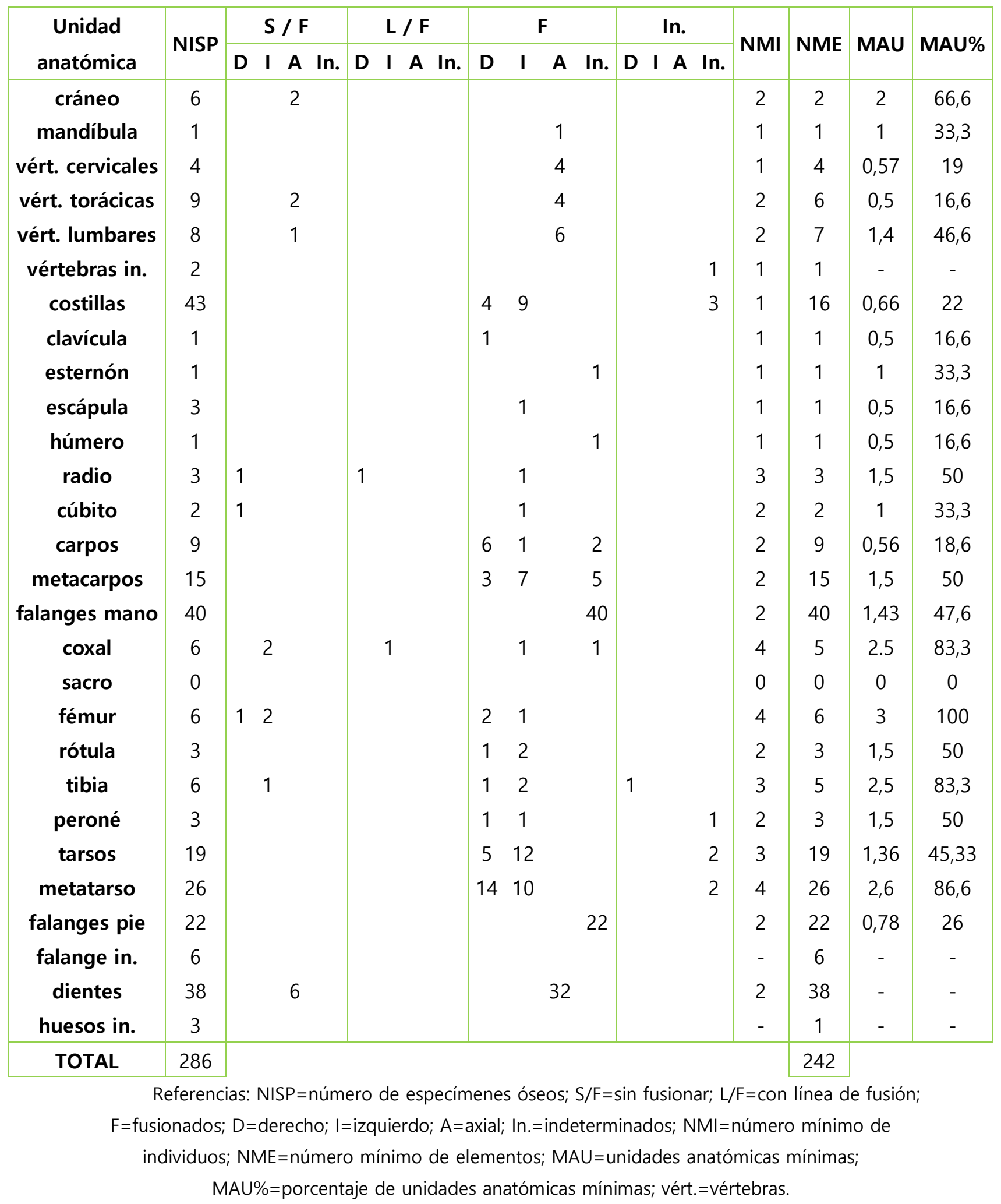

A partir del apareamiento que pudo realizarse entre elementos de la acumulación ósea, los huesos aislados y el paquete funerario LTC1-S4, se propuso que la presencia de la acumulación ósea y huesos aislados en el área inhumatoria 
es, en parte, el resultado de la remoción de los esqueletos previamente enterrados para conformar con ellos paquetes funerarios. Bajo la idea de que el fardo LTC1-S4 fue armado en el sitio, se cree que algunos de los siete individuos representados en ese paquete fueron enterrados de forma primaria en el sitio. Luego de un tiempo, se reabrió el lugar de inhumaciones, se seleccionaron huesos de estos individuos (algunos aún mantenían tejido blando) y finalmente se elaboró el fardo. Los huesos que no fueron elegidos para armar el paquete pasaron a ser acumulados en un sector cercano, mientras que otros quedaron dispersos. La presencia de porciones anatómicas articuladas podría responder a estas mismas acciones. La subrepresentación de partes esqueletarias entre estos entierros (paquete, acumulación y huesos aislados) podría reflejar el armado de otros paquetes funerarios que luego fueron enterrados en otros lugares de inhumación (Scabuzzo y Ramos van Raap 2017).

Un caso muy especial refiere a los huesos de al menos un individuo adulto contenidos en un fogón (Figura 5.6), el cual fue detectado en la cima del montículo (Scabuzzo et al. 2015). Se trata de fragmentos del cráneo, mandíbula, dientes y huesos largos (tibia, peroné, fémur), que presentan distintos grados de termoalteración (quemados, carbonizados y calcinados). Asimismo, en algunos casos se registró la presencia de pigmento rojo sobre la superficie. Junto con este conjunto y dentro del fogón, también se hallaron fragmentos de hueso de mamífero indeterminado de tamaño grande. Si bien este conjunto constituye una situación aparte a los entierros recuperados en la pendiente del cerrito, ha sido un evento de inhumación contemporáneo a los mismos (775 \pm 85 años AP; Bonomo et al. 2011b). Se ha propuesto que el individuo representado en tal registro podría haber sido enterrado inicialmente en el núcleo inhumatorio de LTC1 y luego de un tiempo, fue exhumado, se seleccionaron algunos huesos y se los incluyó en el fogón (Scabuzzo y Ramos van Raap 2017)4.

4 Estos huesos no fueron incluidos en el análisis patológico dado que son fragmentos pequeños, con la superficie quemada y en algunos casos también con pigmento, condiciones que dificultan su observación para tal análisis. 


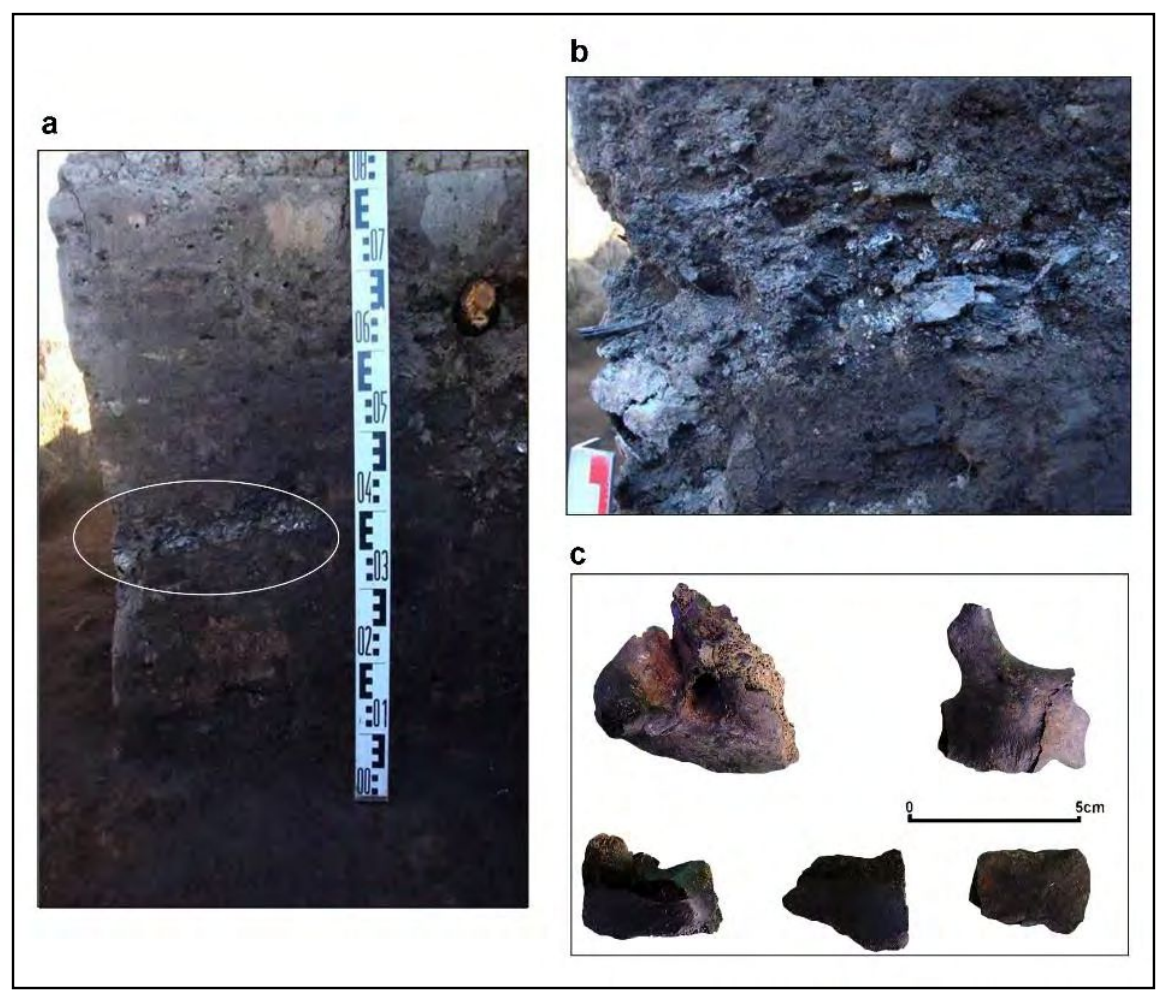

Figura 5.6. Rasgo de combustión en la cima del montículo LTC1: a) el fogón en estratigrafía; b) detalle del fogón; c) huesos humanos quemados y con pigmento rojo.

La manipulación de los entierros no sólo se expresa mediante la conformación de paquetes funerarios con individuos previamente enterrados en el mismo espacio o con el hallazgo de huesos contenidos en un fogón, sino también mediante la aplicación de pigmento en varios de ellos y, en otros, la aplicación de sedimento arcilloso mezclado con pigmento rojo. Fueron realizados análisis composicionales de estas adherencias y pigmentos, comparando los resultados con los obtenidos para muestras de sedimentos y de engobe de un tiesto del mismo sitio. Estos estudios, que estuvieron a cargo de la Dra. C. Castiñeira Latorre (FCNyMUNLP), evidenciaron que había diferencias entre las muestras de adherencias a los huesos y la del engobe del tiesto, con la de los sedimentos del montículo. Esto indicaría una estrategia intencional en el tratamiento de algunos entierros humanos, la cual coincide con la concebida para los procesos finales (por ej., engobe) implicados en la manufactura de la cerámica (Scabuzzo y Ramos van Raap 2017).

Al observar la distribución espacial de los entierros en el núcleo inhumatorio (Figura 5.7), se puede observar la estrecha relación existente entre algunos entierros primarios y secundarios: al costado izquierdo de los primarios LTC1-P1, LTC1-P2 y 
LTC1-P3 se ubican paquetes funerarios de forma paralela siguiendo el eje axial. A partir de los seis fechados radiocarbónicos obtenidos sobre los entierros (Tabla 5.6) y de la ubicación de los mismos, Castro y Castiñeira Latorre (2017) propusieron la existencia de una sectorización cronológica para el área: mientras que hacia el Norte las edades ubican los eventos inhumatorios en torno a los 800-700 años AP, hacia el Sur el registro se corresponde a periodos de ca. 650 años AP.

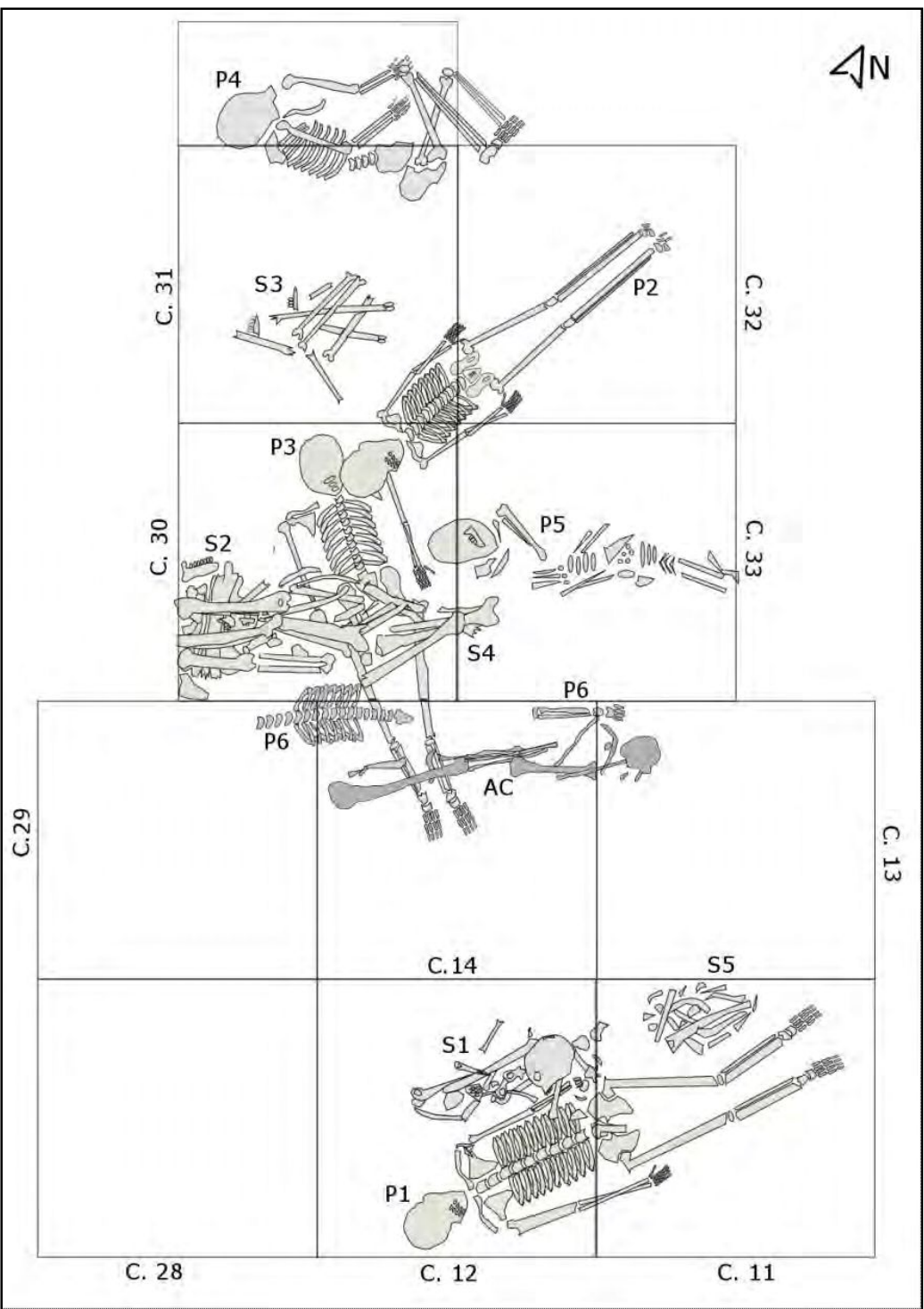

Figura 5.7. Planta de excavación del núcleo de inhumación de LTC1 con los entierros humanos. 
Tabla 5.6. Fechados radiocarbónicos obtenidos para los entierros humanos de LTC1.

\begin{tabular}{|lccc|}
\hline Entierro & Código & ${ }^{14}$ C años AP & Referencia \\
\hline LTC1-S1 & LP-2292 & $650 \pm 70$ & Politis et al. 2011 \\
\hline LTC1-P1 & AA-98852 & $657 \pm 43$ & \\
LTC1-P5 & AA-103893 & $763 \pm 47$ & Scabuzzo et al. \\
LTC1-P4 & AA-103891 & $801 \pm 46$ & 2015 \\
LTC1-S3 & AA-103892 & $802 \pm 48$ & \\
LTC1-P3 & AA-98853 & $849 \pm 45$ & \\
\hline
\end{tabular}

Al considerar las dataciones de los entierros y teniendo en cuenta los estudios de la secuencia estratigráfica del núcleo de inhumación, Castro y Castiñeira Latorre (2017) han planteado que el mismo fue utilizado como tal antes de comenzar la construcción del cerrito (ca. 1030 años AP). En un periodo inicial, la pendiente del cerro fue empleado como área de concentración de desechos, dada la gran cantidad de restos arqueofaunísticos recuperados (Bastourre 2014). Hacia ca. 850 años $A P$, este sector es reclamado como área para llevar a cabo el entierro de los cuerpos humanos; este hecho se sustenta en la aparición de una lente arenosa en la secuencia estratigráfica que habría sido ingresada al lugar para delimitar la nueva funcionalidad espacial.

Como fue detallado anteriormente, en estrecha cercanía a los entierros LTC1-P1, LTC1-P2, LTC1-P3, LTC1-P4, LTC1-S1 y LTC1-S2, fueron recuperados conjuntos de tiestos que, al ser remontados, pudieron ser reconstruidas 10 vasijas cerámicas de diferentes morfotipos: platos, fuentes y cuencos de tamaños grandes y medianos. Estos contenedores habrían tenido inicialmente un uso en contexto doméstico, para luego pasar a formar parte del acompañamiento de los entierros humanos. Se destaca que al menos uno de estos contenedores (el plato hallado junto al cráneo de LTC1-P2), habría sido roto in situ de forma intencional; esta idea se sustenta en que los fragmentos de esta vasija se hallaron unos encima de otros en un agrupamiento discreto y poco disturbado, siendo un contexto parecido a los registrados etnográfica y arqueológicamente en grupos de Amazonía, Perú y México (Castro, C. 2017).

Como parte de los distintos estudios que el equipo de investigación ha realizado, se cuenta con información isotópica de nueve individuos de LTC1. 
Específicamente, se obtuvieron valores isotópicos de $\delta^{15} \mathrm{~N}$ y $\delta^{13} \mathrm{C}$ en ambas fracciones (colágeno y apatita) (Tabla 5.7).

Tabla 5.7. Datos isotópicos obtenidos para individuos de LTC1.

\begin{tabular}{|lcccccc|}
\hline Entierro & Código & Muestra & $\begin{array}{c}\text { (\%o) } \\
\boldsymbol{\delta}^{13} \mathbf{C}(\mathbf{c o l} .)\end{array}$ & $\begin{array}{c}\text { (\%o) } \\
\boldsymbol{\delta}^{13} \mathbf{C} \text { (apat.) }\end{array}$ & $\begin{array}{c}(\%) \\
\boldsymbol{\delta}^{15} \mathbf{N}\end{array}$ & Referencia \\
\hline LTC1-P1 & UGAMS-11475 & falange & $-18,4$ & -13 & 11 & Bonomo \\
LTC1-P3 & UGAMS-11477 & falange & $-20,1$ & $-14,7$ & 12,4 & et al. 2017a \\
LTC1-S1 & UGAMS-11474 & clavícula & -21 & -16.7 & 11,1 & \\
\hline LTC1-P2 & S-UCT-16999 & costilla & $-19,5$ & - & 11,2 & \\
LTC1-P4 & S-UCT-17000 & costilla & $-19,6$ & - & 12 & \\
LTC1-P5 & S-UCT-17003 & costilla & $-21,7$ & - & 10,7 & Salazar-García \\
LTC1-S2 & S-UCT-17001 & vértebra & $-21,2$ & - & 11 & et al. 2018 \\
LTC1-S3 & S-UCT-16998 & sacro & $-19,7$ & - & 12 & \\
LTC1-S4 & S-UCT-17002 & húmero & $-19,1$ & - & 10,7 & \\
\hline
\end{tabular}

\subsubsection{Laguna de Los Gansos 2 (LDLG2)}

\subsubsection{Caracterización general}

El sitio Laguna de Los Gansos 2 (32²9'37,1"S; 60³8'25,7"O; Diamante, Entre Ríos; Figura 5.1) forma parte de la localidad arqueológica homónima, constituida por tres sitios (LDLG1, LDLG2 y LDLG3). Los mismos están emplazados a lo largo de un extenso albardón de 140 m de longitud al oeste de una laguna. Entre 2012 y 2014 se realizaron tres campañas en las que se excavaron LDLG1 y LDLG2. En el primero de ellos se recuperaron numerosos fragmentos cerámicos, entre los cuales -a partir de las tareas de remontaje- pudieron identificarse platos, fuentes, cuencos medianos a pequeños y posiblemente campanas (Silva 2014). Asimismo, se recuperaron modelados cerámicos zoomorfos (Bonomo et al. 2016). Algunos tiestos fueron sometidos a análisis fitolíticos y de almidones, obteniendo como resultado restos herbáceos y almidones de maíz; sin embargo, esta evidencia debe aún confirmarse con el estudio de más muestras (Colobig et al. 2014). Por otro lado, también se halló un gran conjunto arqueofaunístico. Mediante su estudio, pudo observarse una elevada frecuencia de coipo, así como también de carpincho y 
ciervo de los pantanos; todas estas especies evidenciaban marcas de aprovechamiento vinculadas con su consumo. Entre las especies menos representadas, algunas también con claras evidencias de procesamiento, se identificaron restos de cávidos, sigmodontinos y carnívoros (cánidos, mustélidos y félidos); los restos de peces (principalmente Siluriformes) son poco abundantes (Bonomo et al. 2016). Se obtuvieron tres fechados radiocarbónicos por AMS sobre huesos de fauna, que ubican la ocupación de LDLG1 entre 1775 y 1236 años AP (Bonomo et al. 2016). El estilo y la tecnología cerámica presentan características similares a las reconocidas para la entidad arqueológica Goya-Malabrigo (Bonomo et al. 2016). De acuerdo a la propuesta de Politis y Bonomo (2012), en la que se distinguen distintos tipos de asentamientos para esta entidad, LDLG1 se relacionaría con ocupaciones esporádicas y recurrentes asociadas con momentos de estabilidad hidrológica de la cuenca del Paraná, ya que en momentos de crecida del río el sitio se cubre de agua (Bonomo et al. 2016; Castiñeira Latorre et al. 2017a).

En cuanto al sitio LDLG2, los pobladores del lugar fueron quienes informaron su ubicación al equipo de investigación. Mientras hacían los pozos para los postes de un corral del campo, hallaron material cerámico y un esqueleto humano que se perdió. Aproximadamente a 1,5 m al Este de la tranquera del corral, por fuera de éL, se planteó la excavación alcanzando en total $17 \mathrm{~m}^{2}$. Entre los primeros $30 \mathrm{~cm}$ de profundidad se hallaron numerosos restos cerámicos, faunísticos y espículas de carbón; entre los 35 y $45 \mathrm{~cm}$ se hallaron dos entierros humanos y huesos humanos aislados. Con respecto al material cerámico, se destaca el registro de un asa zoomorfa (probablemente una cabeza de mamífero) y un apéndice en forma de cabeza de ave (psitácido). El conjunto arqueofaunístico es similar al hallado en LDLG1, en tanto que predominan los mamíferos, siendo los más representados coipo, carpincho y ciervo de los pantanos. Sin embargo, hay una mayor representatividad de peces (Actinopterygii y Siluriformes) y presencia de Mollusca (Bonomo et al. 2016). En términos generales, LDLG2 es un depósito arqueológico con materiales cerámicos, restos faunísticos y entierros humanos de alrededor de 600 años de antigüedad. Estas edades indican una ocupación mucho más reciente a LDLG1. Además de su ubicación sobre el mismo albardón, las evidencias indican que los ocupantes de ambos sectores explotaron recursos faunísticos vinculados 
con ambientes acuáticos y que los rasgos estilísticos cerámicos son compatibles con Goya-Malabrigo.

\subsubsection{Entierros humanos y muestra bioarqueológica estudiada}

Durante la primera campaña en LDLG2, se realizaron tres sondeos de $1 \mathrm{~m}^{2}$ cada uno, hallando un entierro humano en los sondeos 1 y 3 . Al año siguiente, esta zona de excavación fue ampliada con nueve cuadrículas de $1 \mathrm{~m}^{2}$, en las cuales se registraron algunos huesos humanos aislados y un segundo entierro humano (Tabla 5.8). En la campaña de principios de 2014, se realizaron cinco sondeos más alrededor de la zona de excavación con el fin de conocer la extensión del sitio y evaluar si había más entierros; como resultado se encontraron restos cerámicos y algunos huesos de fauna concentrados en los primeros $25 \mathrm{~cm}$.

Tabla 5.8. Información sobre los individuos hallados en LDLG2.

\begin{tabular}{|ccccc|}
\hline Tipo de entierro & Individuo & Grupo etario & Edad & Sexo \\
\hline $\begin{array}{c}\text { Esqueleto incompleto } \\
\text { con reacomodación de huesos }\end{array}$ & LDLG2-1 & adulto joven & $22-26$ años & $M$ \\
\hline Primario DD & LDLG2-2 & adulto & - & - \\
\hline
\end{tabular}

Referencias: $M=$ masculino; $\mathrm{DD}=$ decúbito dorsal.

El primer entierro humano encontrado (LDLG2-1), con orientación S-N, es particular en cuanto a la modalidad de inhumación: consiste en la cintura pélvica y los miembros inferiores articulados, con el cráneo localizado sobre la pelvis; el torso y los miembros superiores estaban ausentes (Figura 5.8a; Figura A.2.2). Este esqueleto corresponde a un adulto joven (22-26 años) masculino. Por otro lado, fueron encontrados juntos un húmero y las tres primeras vértebras cervicales (Figura 5.8.b), que corresponderían a un individuo adulto. No se descarta que estos restos pertenezcan al individuo descripto anteriormente, de manera que se prefiere adoptar un criterio conservador y no considerar estos restos como un individuo más. El segundo entierro (LDLG2-2) es de tipo primario en posición dorsal extendido, con orientación NE-SO (Figura 5.8.b). Debido a que se encontraba a poca profundidad $(0,35-0,40 \mathrm{~m})$ en un sedimento con presencia de pequeñas raíces y en la entrada del corral de ganado, todos los restos óseos están muy 
fragmentados (Figura A.2.2). De acuerdo a lo que pudo ser analizado, se trataría de un individuo adulto, sin poder determinar con mayor precisión la edad, y de sexo indeterminado. Es de destacar que, junto a la parte posterior de la bóveda craneana, se encontraba una concentración de sedimento con espículas de carbón y restos de ictiofauna.

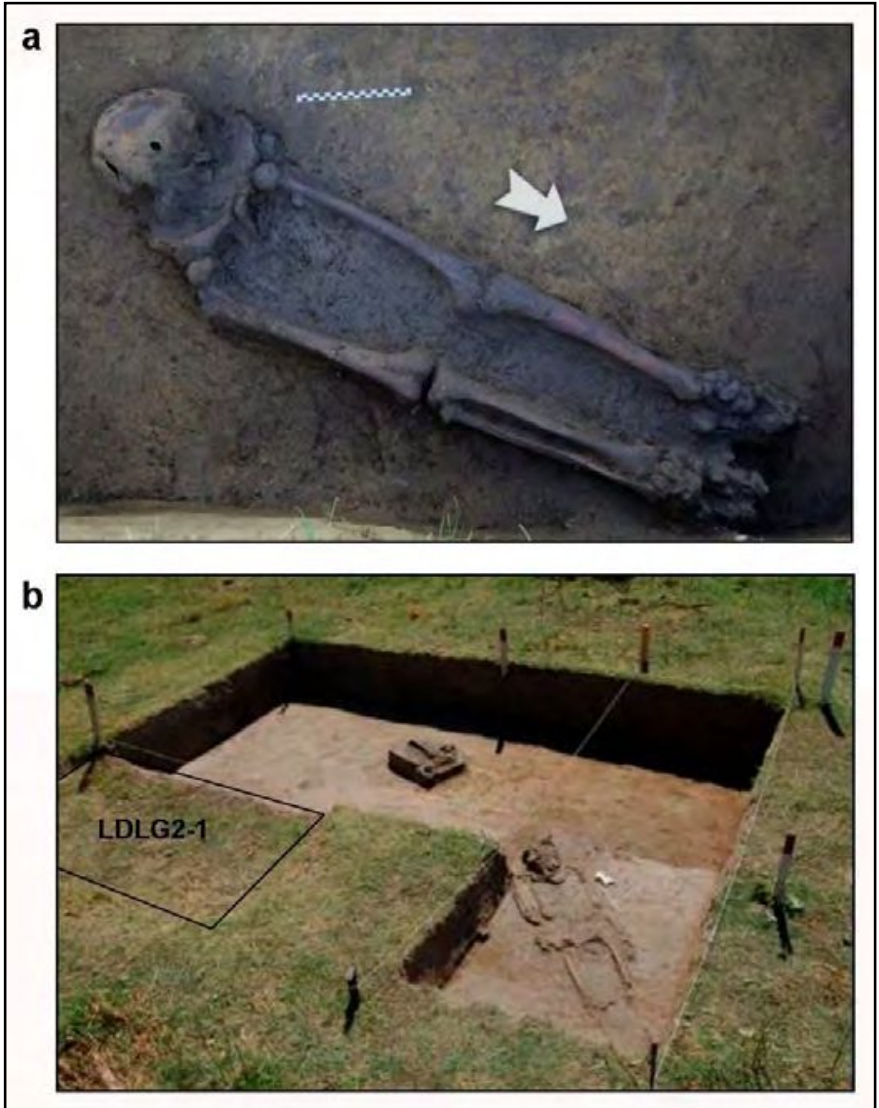

Figura 5.8. Entierros humanos hallados en LDGL2: a) entierro de LDLG2-1; b) área excavada con LDLG2-2 y los huesos aislados (en detalle la ubicación donde fue hallado LDLG2-1).

Se obtuvieron dos fechados radiocarbónicos para cada uno de los entierros (Tabla 5.9). También se cuenta con valores isotópicos para el individuo LDLG2-1, en base a los análisis sobre un metacarpo de este individuo: -20,6 \%o $\delta^{13} \mathrm{C}$ (colágeno) y 11,7 \% $\delta^{15} \mathrm{~N}$ (código muestra: S-UCT-17011; Salazar-García et al. 2018).

Tabla 5.9. Fechados radiocarbónicos obtenidos para los entierros de LDLG2.

\begin{tabular}{|cccc|}
\hline Entierro & Código & ${ }^{14}$ C años AP & Referencia \\
\hline LDLG2-1 & AA-98851 & $570 \pm 43$ & Bonomo et al. 2016 \\
LDLG2-2 & AA-103899 & $590 \pm 46$ & Bonomo et al. 2016
\end{tabular}




\subsection{Cuenca inferior del río Uruguay (margen derecha)}

Entre 1955 y 2004 el Sr. Manuel Salvador Almeida realizó trabajos de campo en la margen derecha del río Uruguay, principalmente en Gualeguaychú (Entre Ríos). Este profesor en nivel secundario de Biología y Física, oriundo de Gualeguaychú y con profundo interés por la arqueología y paleontología, realizó un relevamiento exhaustivo de la zona junto a distintos colaboradores (amigos y algunos de sus hijos). Como producto de ello localizó y estudió numerosos sitios arqueológicos, algunos previamente estudiados por otros investigadores (Greslebin 1931; Krapovickas 1957; Cione et al. 1977). A partir de las recolecciones superficiales, los sondeos y las excavaciones estratigráficas, Almeida encontró numerosos materiales arqueológicos (cerámicos, líticos, faunísticos) y entierros humanos, que ha adjudicado a "dos pueblos que precedieron a los 'gualeguaychenses': el pueblo Chaná y el pueblo Guaraní"; el primero de ellos lo vincula con los "Ribereños Plásticos del área paranaense" (Almeida 1983: 9) definidos por Serrano (1950, 1972). El autor interpreta a la mayoría de los sitios del pueblo Chaná como lugares sobreelevados artificialmente donde vivían los antiguos pobladores, resguardándose de las inundaciones que afectan recurrentemente el área: son "...'cerros' o elevaciones de tierra de dimensiones variadas, muchos de ellos artificiales..." (Almeida 1971: 1). Actualmente el material arqueológico recuperado en estos sitios conforma el acervo del Museo Arqueológico Manuel Almeida (MAMA). Este museo, ubicado en Gualeguaychú, fue conformado oficialmente en 1992 y con el correr de los años, ha experimentado traslados edilicios hasta su locación actual en 2011.

Un estudio inicial de la colección Almeida fue realizado por Bourlot (2008), con el objetivo de contextualizar y difundir la colección; se focalizó principalmente en el análisis de la cerámica y de los artefactos óseos y líticos, para abordar las expresiones artísticas y la tecnología de los grupos que habitaron el Litoral entrerriano. En años recientes, el Dr. J.C. Castro (FCNyM, UNLP) ha comenzado a realizar investigaciones arqueológicas en la cuenca media e inferior del río Uruguay (Castro y Costa Angrizani 2014; Castro y Del Papa 2015; Castro, J.C. 2016, 2017). En este contexto, tomaron relevancia los trabajos iniciados por Almeida y se lograron 
ubicar las coordenadas geográficas precisas de algunos de los sitios excavados por él. También se hicieron nuevos sondeos en dos de ellos, se realizaron dataciones radiocarbónicas y se reanalizaron los materiales líticos, cerámicos, faunísticos y los entierros humanos que se localizan en el MAMA (Castro y Costa Angrizani 2014; Castro y Del Papa 2015; Castro, J.C. 2017; Ramos van Raap y Scabuzzo 2017).

Con respecto al conjunto bioarqueológico, en el museo se encuentra organizado por números de inventario (resguardados de forma independiente entre sí), que en su mayoría son coincidentes con los ofrecidos en el Catálogo de Restos Humanos $(\mathrm{CRH})$ de la institución. En este catálogo, para la mayoría de los números se brinda información sobre el sitio de procedencia, el sector del sitio donde fue hallado el entierro y breves características del mismo. De esta forma, cada número de inventario correspondería a una inhumación y así es como fueron considerados en este trabajo. Sin embargo, es importante remarcar dos puntos: primero, que no todos los entierros humanos hallados en los sitios fueron ingresados en el catálogo; y segundo, que las mudanzas del museo han impactado de forma negativa en la organización y en la información contextual de los materiales (Castro, J.C. 2017). Es por estos motivos que algunos números de inventario no han podido ser correspondidos con el sitio del cual provienen, quedando conformado un conjunto osteológico sin procedencia. Para esta tesis se analizaron sólo los entierros humanos con los que se contaba con el dato del sitio de procedencia, lo que permitía contar con información contextual del registro bioarqueológico 5 .

\subsubsection{Cerro Lorenzo 2 (CL2)}

\subsubsection{Caracterización general}

También denominado por Almeida como Túmulo del Arroyo Lorenzo, este sitio es un montículo sobre un gran albardón ubicado a $30 \mathrm{~m}$ de la margen izquierda del arroyo Lorenzo (334'35"S; 58²6'43,08"O; Gualeguyachú, Entre Ríos, Figura 5.1). Tiene forma elipsoidal, su eje mayor $\mathrm{N}-\mathrm{S}$ mide $45 \mathrm{~m}$, el eje O-E mide 18 m y alcanza una altura de 1,5 m (Castro, J.C. 2017; Figura 5.9). Entre los restos

5 No se incluyeron en los análisis de esta tesis a los entierros humanos hallados en sitios cuyas ocupaciones se atribuyeron a los guaraníes. Estos sitios son Ensenada del Bellaco y La Correntina (Castro y Costa Angrizani 2014; Castro, J.C. 2017). 
arqueológicos recuperados en este sitio por Almeida que se localizan en el MAMA y reestudiados por Castro, J.C. (2017), se encuentran 5 artefactos líticos (mano y mortero de arenisca, piedra con hoyuelos y dos núcleos), 2 restos cerámicos (entre ellos una vasija de boca subcuadrangular decorada incisa y con apliques) y 34 elementos faunísticos. Entre los 11 instrumentos óseos, se identificaron tubos y puntas realizados en huesos de ave, de venado y de mamíferos indeterminados. Por otro lado, se registraron 21 cuentas de collar confeccionadas en valvas de Megalobulimus sp.; las mismas fueron recuperadas asociadas con un cráneo humano. El fechado radiocarbónico efectuado sobre un hueso humano de uno de los entierros ( $\mathrm{n}^{072}$, véase en apartado siguiente) hallados por Almeida arrojó una edad de 2050 \pm 60 años AP (código muestra: LP-2830), convirtiéndose hasta el momento en la datación más antigua para la margen derecha del río Uruguay (Castro y Del Papa 2015).

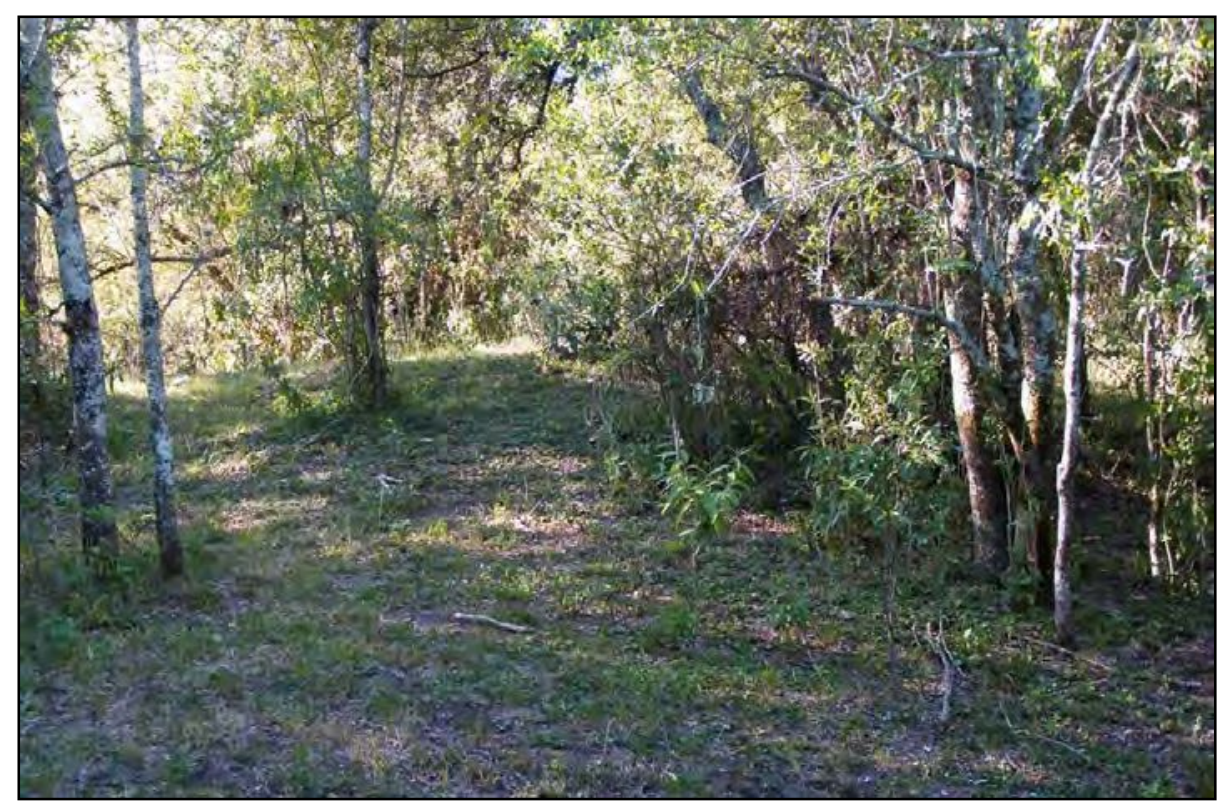

Figura 5.9. Sitio arqueológico CL2 (tomada por Castro, J.C.).

Los trabajos de campo realizados en el lugar por Castro, J.C. (2017) incluyeron una recolección superficial dirigida y tres sondeos estratigráficos en la parte más elevada del montículo, sin llegar a los niveles estériles. Los materiales líticos recuperados incluyen un instrumento, 31 desechos de talla y un núcleo. Asimismo, se hallaron 790 tiestos correspondientes a fragmentos de borde y cuerpo. Entre el conjunto arqueofaunístico, se identificaron 2213 restos 
principalmente de peces (boga y tararira) y valvas de bivalvos (Diplodon sp.) y de gasterópodos; entre los restos de mamíferos se determinaron carpincho, cuis y coipo. En varios taxas (peces, ciervo, venado, carpincho, coipo y mamíferos indeterminados) se registraron evidencias antrópicas de consumo (huellas de corte y/o termoalteración). Por otro lado, se recuperaron instrumentos óseos: una punta acanalada y un gancho de propulsor, realizadas sobre huesos de mamífero y de cérvidos. También se registró una cuenta de collar confeccionada sobre valva de un gasterópodo. Por otro lado, de forma desarticulada y aislada en dos de los sondeos se encontraron 11 elementos óseos humanos (cráneo -dos fragmentos de la bóveda-, molar, vértebra torácica, esternón, costilla, cúbito, peroné, metatarso, falanges y un hueso indeterminado) correspondientes a un individuo adolescente (14-18 años). Para este sitio, Castro, J.C. (2017) propone que se trata de un sitio de actividades múltiples con alta estabilidad residencial, donde se llevaron a cabo entierros humanos y tareas asociadas a la subsistencia (procesamiento y consumo de alimentos). Asimismo, se realizaron actividades de aprovisionamiento, manufactura, uso, mantenimiento, reciclaje y descarte de instrumentos líticos; y manufactura, uso, reparación y descarte de vasijas cerámicas e instrumentos óseos y adornos personales. El autor relaciona la ocupación del sitio con la entidad arqueológica Goya-Malabrigo.

\subsubsection{Entierros humanos y muestra bioarqueológica estudiada}

En el $\mathrm{CRH}$ del museo figuran 18 números de inventario procedentes de $\mathrm{CL2}$, de los cuales se localizaron y analizaron 16. Para cada uno de ellos, en la Tabla 5.10 se resumen los datos relativos al tipo de entierro que se describen en el catálogo y los datos obtenidos del análisis efectuado. Con respecto a los tipos de entierro, se destacan algunas particularidades. Para aquellos casos donde se menciona que el esqueleto se encontraba posicionado en decúbito lateral o dorsal, se puede suponer que se trata de entierros primarios. Sin embargo, en uno de ellos ( $n^{\circ} 76$ ) se aclara en el catálogo que podría corresponder con un entierro secundario. En el caso del entierro $n^{\circ} 73$, se hace referencia también a que el esqueleto estaba acostado sobre su lado derecho, pero cuando se analizó este conjunto óseo se estimó un NMI de dos. Dada esta situación, no puede confirmarse que ambos 
individuos correspondan a un entierro primario. Por otro lado, es interesante el conjunto de las inhumaciones $n^{\circ} 53$ a 57. En el registro del Catálogo de Yacimientos del museo, se describe lo siguiente:

"Es indudable que será muy difícil determinar lo ocurrido pero todo hace presumir que donde fueron enterrados los dos primeros individuos señalados con los $n^{\circ} 53$ y 54, se realizó una excavación posterior para dar sepultura secundaria a los restos de tres o más individuos, cuyos huesos fueron colocados junto a los dos ya existentes, en total desorden y fragmentados además de muchos huesos faltantes" (Catálogo Yacimientos, MAMA).

Dada esta información, el $n^{\circ} 53$ y el $n^{\circ} 54$ serían entierros primarios, en cuyas cercanías se ubicaba al menos un entierro secundario múltiple ( $n^{\circ} 55,56$ y 57 ). También sobresale la mención del hallazgo de huesos de un infante $\left(n^{\circ} 80\right)$ ubicados junto al cráneo de un individuo adulto ( $\left.n^{\circ} 78\right)$; dado el análisis realizado al conjunto óseo correspondiente a este contexto, no se trataría de solamente un infante, sino de huesos de dos subadultos y un adulto joven.

Además de estos entierros, se localizaron en el museo y se estudiaron otros tres conjuntos óseos ( $n^{\circ} 204,223$ y 232) (Tabla 5.11); cada uno de ellos se encuentra acompañado por una etiqueta que indica su procedencia de este mismo sitio. Tales hallazgos podrían corresponder a los números de inventario que figuran en el catálogo pero no pudieron ser localizados ( $n^{\circ} 51$ y 79), y/o a entierros que no fueron incluidos directamente en el registro del museo. 
Tabla 5.10. Información disponible en el catálogo y resultados obtenidos de los análisis para los entierros de CL2.

\begin{tabular}{|c|c|c|c|c|c|}
\hline \multicolumn{2}{|r|}{ CATÁLOGO DE RESTOS HUMANOS } & \multicolumn{4}{|c|}{ RESULTADOS ANÁLISIS } \\
\hline $\mathbf{N}^{\circ}$ & Entierro & NMI & Grupo etario & $\begin{array}{l}\text { Edad } \\
\text { (años) }\end{array}$ & Sexo \\
\hline 52 & $\begin{array}{l}\text { Esqueleto completo bien conservado en } \\
\text { tierras arcillosas mezcladas con cenizas de } \\
\text { fogones y bien compactadas. Posición fetal, } \\
\text { vertical. Orientación NE. }\end{array}$ & 1 & adulto joven & $30-35$ & M \\
\hline 53 & Grupo de cinco individuos. En total desorden & 1 & adulto & - & M \\
\hline 54 & anatómico. Junto a los restos de los & 1 & adulto medio & $40-49$ & $\mathrm{~F}$ \\
\hline 55 & de todo su esqueleto, se amontonaban en & 1 & adulto joven & $20-35$ & PM \\
\hline 56 & desorden fragmentados los cráneos y & 1 & adulto & - & - \\
\hline & quebrados la mayoría de los huesos largos & 2 & adulto medio & $40-49$ & M \\
\hline $5 /$ & de los otros tres individuos. & 2 & adulto joven & $25-34$ & M \\
\hline 66 & - & 1 & adulto & - & $\mathrm{F}$ \\
\hline 67 & Orientación N. Acostado lado izquierdo. & 1 & adulto & - & M \\
\hline 71 & Orientación NE. Acostado lado derecho. & 1 & adulto joven & $25-34$ & M \\
\hline 72 & Orientación NNE. Extendido boca arriba. & 1 & adulto joven & $30-35$ & $\mathrm{~F}$ \\
\hline 73 & Orientación N Acectado lado derecho & 2 & adulto & - & - \\
\hline 10 & Uriemlacion iv. Acostado lado derecrio. & 2 & adulto & - & PM \\
\hline 76 & $\begin{array}{c}\text { Orientación NE. Acostado lado derecho; } \\
\text { entierro secundario quizá. }\end{array}$ & 1 & adulto joven & $30-35$ & M \\
\hline 77 & - & 1 & adulto joven & $30-35$ & M \\
\hline & & & niño & $5-12$ & - \\
\hline 78 & - & 2 & adulto joven & 30-35 & M \\
\hline & Infante asociado con los individuos 78 y 79 . & & infante & $1-1,5$ & - \\
\hline 80 & Ubicado junto al cráneo del $n^{\circ} 78$, lado & 3 & niño & $8-9$ & - \\
\hline & derecho. & & adulto joven & $20-24$ & PF \\
\hline 103 & - & 1 & adulto medio & $35-44$ & $\mathrm{~F}$ \\
\hline
\end{tabular}

Tabla 5.11. Entierros humanos de CL2 sin información contextual.

\begin{tabular}{|ccccc|}
\hline $\mathbf{N}^{\circ}$ & NMI & Grupo etario & Edad (años) & Sexo \\
\hline 204 & 1 & adulto & - & - \\
\hline 223 & 1 & adulto & - & - \\
\hline 232 & 2 & $\begin{array}{c}\text { adulto } \\
\text { niño }\end{array}$ & - & - \\
& & & $3-4$ & \\
\hline
\end{tabular}


El total de los elementos estudiados para CL2 fue de 387. El cráneo es el hueso más representado, junto con la mandíbula y el fémur (Tabla 5.12). Se determinó un $\mathrm{NMI}=25$, entre los que se encuentran representados individuos de distintas categorías etarias. El $84 \%(n=21)$ son adultos (9 adultos jóvenes y 3 adultos medios). El 16\% ( $n=4)$ restante son individuos subadultos, entre los que se pudo determinar la presencia de un infante y tres niños. Las determinaciones sexuales pudieron efectuarse en el $64 \%$ de la muestra $(n=16)$, de los cuales 4 fueron categorizados como femeninos, 1 como probable femenino, 9 como masculinos y 2 como probables masculinos. 
Tabla 5.12. Cálculos de abundancia anatómica del conjunto óseo de CL2.

\begin{tabular}{|c|c|c|c|c|c|c|c|c|c|c|c|c|c|c|}
\hline \multirow{2}{*}{$\begin{array}{c}\text { Unidad } \\
\text { anatómica }\end{array}$} & \multirow{2}{*}{ NISP } & \multicolumn{2}{|c|}{$\mathrm{S} / \mathrm{F}$} & \multicolumn{2}{|r|}{$L / F$} & \multicolumn{3}{|c|}{$\mathbf{F}$} & \multicolumn{2}{|l|}{ In. } & \multirow{2}{*}{ NMI } & \multirow{2}{*}{ NME } & \multirow{2}{*}{ MAU } & \multirow{2}{*}{ MAU\% } \\
\hline & & D I A & In. & D & I A In. & D & A & In. & D I A I & In. & & & & \\
\hline cráneo & 58 & 1 & I & & & & 20 & & & & 21 & 21 & 21 & 100 \\
\hline mandíbula & 17 & 1 & & & 2 & 11 & 12 & & & & 16 & 16 & 16 & 76,2 \\
\hline vért. cervicales & 16 & & & & & & 16 & & & & 4 & 16 & 2,3 & 10,9 \\
\hline vért. torácicas & 22 & & & & 2 & & 20 & & & & 2 & 22 & 1,8 & 8,6 \\
\hline vért. lumbares & 27 & & & & & & 27 & & & & 6 & 27 & 5,4 & 25,7 \\
\hline costillas & 4 & & & & & 12 & & & & & 1 & 3 & 0,1 & 0,5 \\
\hline clavícula & 15 & 1 & & & & 66 & & & & & 7 & 13 & 6,5 & 30,9 \\
\hline esternón & 2 & & & & & & 2 & & & & 2 & 2 & 2 & 9,5 \\
\hline escápula & 5 & & & & & 2 & & & & & 3 & 5 & 2,5 & 11,9 \\
\hline húmero & 25 & & & 1 & & 9 & & & & 1 & 13 & 23 & 11,5 & 54,8 \\
\hline radio & 18 & & & & & 8 & & & & & 8 & 16 & 8 & 38,1 \\
\hline cúbito & 20 & & & & 1 & $10 \varepsilon$ & & & & & 11 & 19 & 9,5 & 45,2 \\
\hline carpos & 0 & & & & & & & & & & 0 & 0 & 0 & 0 \\
\hline metacarpos & 13 & & & & & 112 & & & & & 2 & 13 & 1,3 & 6,2 \\
\hline falanges mano & 16 & & & & & & & 16 & & & 1 & 16 & 0,6 & 2,8 \\
\hline coxal & 25 & & & 1 & & 121 & & & & & 13 & 24 & 12 & 57,1 \\
\hline sacro & 7 & & & & & & 6 & & & & 6 & 6 & 6 & 28,6 \\
\hline fémur & 30 & 1 & 1 & & & 141 & & & & 1 & 16 & 29 & 14,5 & 69 \\
\hline rótula & 12 & & & & & 66 & & & & & 6 & 12 & 6 & 28,6 \\
\hline tibia & 25 & & & & & 121 & & & & & 12 & 24 & 12 & 57,1 \\
\hline peroné & 17 & & & & & 97 & & & & 1 & 9 & 17 & 8,5 & 40,5 \\
\hline tarsos & 28 & & & & & 141 & & & & & 6 & 28 & 4 & 19 \\
\hline metatarso & 27 & & & & & 141 & & & & & 4 & 27 & 2,7 & 12,8 \\
\hline falanges pie & 6 & & & & & & & 6 & & & 1 & 6 & 0,2 & 0,9 \\
\hline dientes & 2 & & & & & & & 2 & & & 1 & 2 & - & - \\
\hline huesos in. & 2 & & & & & & & & & 2 & 1 & - & - & - \\
\hline TOTAL & 439 & & & & & & & & & & & 387 & & \\
\hline
\end{tabular}

Referencias: NISP=número de especímenes óseos; $\mathrm{S} / \mathrm{F}=\sin$ fusionar; $\mathrm{L} / \mathrm{F}=$ con línea de fusión; $\mathrm{F}=$ fusionados; $\mathrm{D}=$ derecho; I=izquierdo; $\mathrm{A}=$ axial; In.=indeterminados; $\mathrm{NMI}=$ número mínimo de individuos; $\mathrm{NME}=$ número mínimo de elementos; $\mathrm{MAU}=$ unidades anatómicas mínimas; MAU\%=porcentaje de unidades anatómicas mínimas; vért.=vértebras.

\subsubsection{Sambaquí de Puerto Landa (SPL)}

\subsubsection{Caracterización general}

Este sitio es un montículo ubicado a $500 \mathrm{~m}$ de la margen derecha del río Uruguay (33¹9'25,03"S; 58²7'13,39"O; Gualeguaychú, Entre Ríos; Figura 5.1). Tiene 
forma elipsoidal, actualmente su eje mayor NE-SO mide $80 \mathrm{~m}$, el eje NO-SE mide $38 \mathrm{~m}$ y alcanza una altura de $3 \mathrm{~m}$ en relación con el terreno circundante conformado por selva ribereña, bañados y pajonales (Castro, J.C. 2017; Figura 5.10).

Este sitio arqueológico fue excavado inicialmente por Greslebin (1931), quien supone que no es el mismo mencionado por Torres durante su excursión al rincón de Puerto Landa (1911). Greslebin considera al sitio totalmente artificial, con la presencia de una continua acumulación de cenizas, pescados y valvas de moluscos. Durante sus trabajos extrajo gran cantidad de restos, entre los que menciona huesos de animales, piedras fragmentadas, fragmentos de bordes incisos y numerosos tiestos (1931: 36). Décadas más tarde, Krapovickas (1957) estudia tres sitios arqueológicos en la Estancia Rincón de Landa. Uno de ellos, al que nombra Cerro de Godoy, es SPL trabajado por Greslebin (1931). A partir de sondeos realizados en este sitio, el investigador presenta un esquema estratigráfico detallado y concluye que es un basural sobreelevado por acumulación gradual de desechos (Krapovickas 1957).

En el reanálisis de los materiales excavados por Almeida que están en el MAMA, se identificaron 4 piedras con hoyuelos dentro del conjunto lítico. Entre los instrumentos óseos, se registraron 14 espinas aguzadas realizadas en base a espinas de distintas especies de peces y 34 puntas (acanaladas, ahuecadas, con epífisis) sobre huesos largos de ave, corzuela, ciervo de los pantanos, venado de las pampas y mamíferos y cérvidos indeterminados. Asimismo, dos ornamentos labiales inferiores con forma de "T" (tembetás) confeccionados sobre valvas de Diplodon sp. (MAMA-SPL-163 y 164) y dos artefactos decorados: una diáfisis de cúbito de ave indeterminada decorada con líneas incisas y un fragmento de diáfisis de hueso largo de taxón indeterminado (probable ave) decorada también con líneas incisas (Castro, J.C. 2017). Sobre un hueso humano de un entierro (n95; véase apartado siguiente) hallado por Almeida se realizó una datación radiocarbónica, cuyo resultado arrojó una edad de $630 \pm 50$ años AP (código muestra: LP-2828; Castro y Del Papa 2015). 


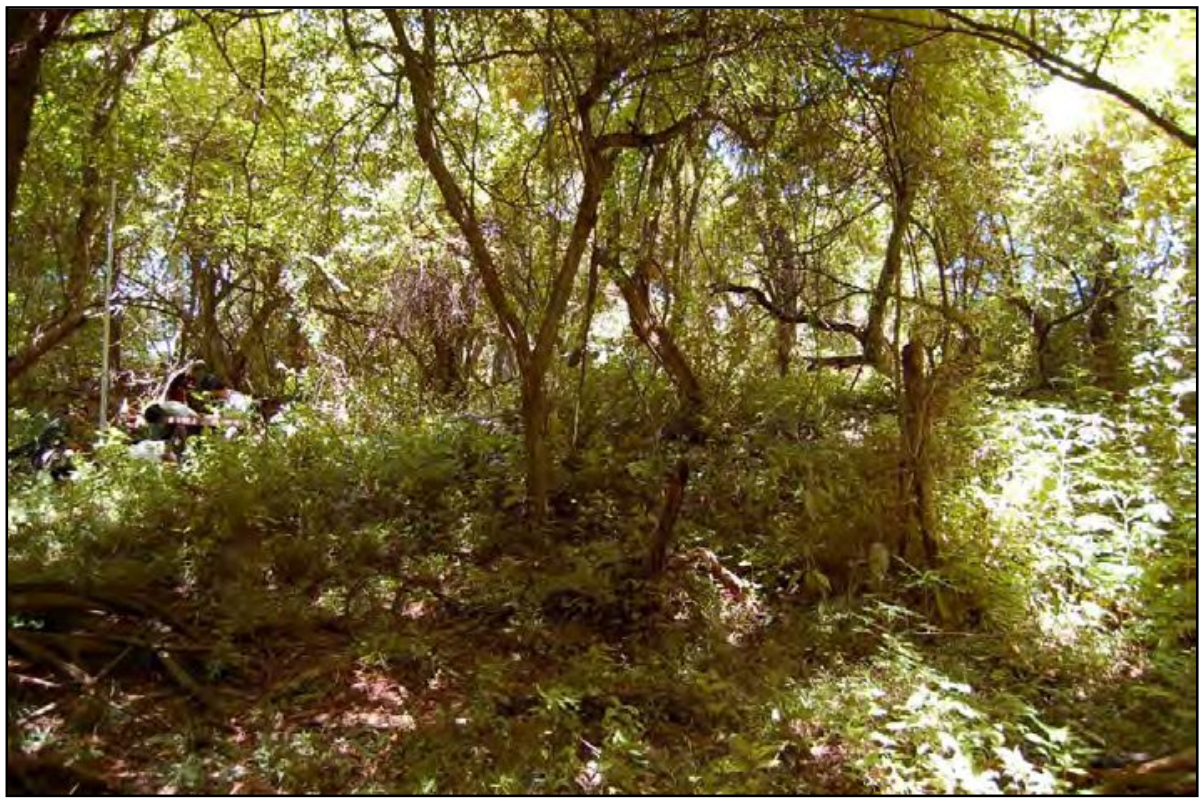

Figura 5.10. Sitio arqueológico SPL (tomada por Castro, J.C.).

Los trabajos más actuales en el sitio corresponden al sondeo estratigráfico realizado por Castro, J.C. (2017) en el extremo noreste del montículo. Los materiales recuperados incluyen 77 desechos de talla y 2 núcleos; 2848 tiestos pertenecientes a borde y cuerpo de vasijas y 1288 masas de arcilla cocida; 129 concreciones de pigmentos minerales rojos y numerosos endocarpos de palmera carbonizados y fragmentados. Por otro lado, se recuperó un gran conjunto arqueofaunístico en el que están representados 22242 restos de peces (boga y Doradidae), 3513 de moluscos (valvas de bivalvos Diplodon sp. y gasterópodos), 717 de mamíferos (ciervo, venado de las pampas, carpincho, cuis, coipo), 29 de reptiles, 6 de anfibios y 3 de aves. Evidencias de procesamiento antrópico (huellas de corte, aserrado perimetral y termoalteración) se registraron en 480 especímenes de peces, coipo, lagarto, venado y mamíferos grandes y medianos. Asimismo, se identificaron tres instrumentos óseos (puntas sobre metapodios de cérvidos) y un artefacto. Por otro lado, en el sondeo se encontraron 11 huesos y dientes humanos (1 falange, 1 carpo, 1 diente deciduo, 6 dientes permanentes y 2 cráneos -muy fragmentados) de al menos dos individuos: un adulto de sexo indeterminado y un niño de 2-4 años. Los elementos anatómicos estaban desarticulados; el cráneo del subadulto se encontraba muy frágil y deteriorado y estaba asociado con valvas enteras de bivalvo y dos grandes tiestos de dos vasijas (Castro, J.C. 2017). Este contexto 
arqueológico ha sido vinculado por Castro, J.C. (2017) con la entidad arqueológica Goya-Malabrigo. Asimismo, interpreta a SPL como un sitio de actividades múltiples con alta estabilidad residencial, donde se llevaron a cabo entierros humanos y tareas asociadas a la subsistencia (procesamiento y consumo de alimentos). Por otro lado, se realizaron tareas vinculadas con distintas etapas en el proceso de elaboración y uso de instrumentos líticos, óseos y adornos personales (aprovisionamiento, manufactura, uso, mantenimiento, reciclaje y descarte).

\subsubsection{Entierros humanos y muestra bioarqueológica}

Para este sitio pudieron ser localizados y estudiados los 13 números de inventario que figuran en el $\mathrm{CRH}$. En la Tabla 5.13 se resumen los datos relativos al tipo de entierro que se describen en el catálogo y los datos obtenidos del análisis efectuado para cada uno de ellos. De acuerdo a la información disponible, estos entierros corresponderían tanto a inhumaciones primarias como a secundarias. En cuanto a las primeras, se precisa que los esqueletos se encontraban tanto en posición decúbito dorsal y ventral como decúbito lateral derecho. Sin embargo, como ocurrió para CL2, algunos de estos entierros están conformados por los huesos de la menos dos individuos (por ej. no95). Por su parte, entre los entierros descriptos como secundarios, se destaca el entierro múltiple de al menos cuatro individuos: tres adultos y un niño ( $\left.n^{\circ} 102\right)$.

Por otro lado, se localizaron en el museo y estudiaron cinco números de inventario ( $n^{\circ} 203,206,207,211$ y 217) (Tabla 5.14) que estaban acompañados por etiquetas en las que se precisaba su procedencia de este mismo sitio. Dado que todos los entierros mencionados en el catálogo fueron localizados y estudiados, es probable que estos cinco números de inventario correspondan a entierros que no fueron incluidos en el registro del museo. 
Tabla 5.13. Información disponible en el catálogo y resultados obtenidos de los análisis para los entierros de SPL.

\begin{tabular}{|c|c|c|c|c|c|}
\hline \multicolumn{2}{|r|}{ CATÁLOGO DE RESTOS HUMANOS } & \multicolumn{4}{|c|}{ RESULTADOS ANÁLISIS } \\
\hline $\mathbf{N}^{\circ}$ & Entierro & NMI & Grupo etario & $\begin{array}{l}\text { Edad } \\
\text { (años) }\end{array}$ & Sexo \\
\hline \multirow{2}{*}{87} & \multirow{2}{*}{-} & \multirow{2}{*}{2} & adulto & - & M \\
\hline & & & adulto & - & - \\
\hline \multirow{2}{*}{88} & \multirow{2}{*}{-} & \multirow{2}{*}{2} & adulto & - & M \\
\hline & & & adulto & - & - \\
\hline \multirow{2}{*}{89} & \multirow{2}{*}{-} & \multirow{2}{*}{2} & adulto & - & $\mathrm{F}$ \\
\hline & & & adulto & - & - \\
\hline \multirow{2}{*}{90} & \multirow{2}{*}{-} & \multirow{2}{*}{2} & infante & $0,5-1,5$ & - \\
\hline & & & adulto & - & - \\
\hline \multirow{2}{*}{95} & \multirow{2}{*}{ En buen estado. Orientación N. Boca arriba. } & \multirow{2}{*}{2} & adulto & - & - \\
\hline & & & adulto joven & $20-24$ & $\mathrm{~F}$ \\
\hline 96 & Orientación SE. Costado derecho. & 1 & adulto & - & - \\
\hline 97 & Orientación NO. Boca abajo. & 1 & adulto & - & - \\
\hline 98 & Orientación NO. Costado derecho. & 1 & adulto & - & $\mathrm{F}$ \\
\hline 99 & Orientación SE. Boca arriba. & 1 & adulto & - & $\mathrm{F}$ \\
\hline \multirow{3}{*}{100} & \multirow{3}{*}{$\begin{array}{c}\text { Entierro secundario. Total desorden } \\
\text { anatómico. Huesos muy fragmentados. }\end{array}$} & \multirow{3}{*}{3} & niño & $9-12$ & - \\
\hline & & & infante & $1-1,5$ & - \\
\hline & & & adulto & - & - \\
\hline \multirow{2}{*}{101} & \multirow{2}{*}{$\begin{array}{l}\text { Orientación SE. Boca arriba. Restos } \\
\text { totalmente fragmentados y en total }\end{array}$} & \multirow{2}{*}{2} & adulto & - & - \\
\hline & & & adulto & - & - \\
\hline \multirow{4}{*}{102} & \multirow{4}{*}{$\begin{array}{l}\text { Restos totalmente fragmentados de tres } \\
\text { individuos. Entierro secundario. }\end{array}$} & \multirow{4}{*}{4} & adulto & - & - \\
\hline & & & adulto & - & - \\
\hline & & & adulto & - & - \\
\hline & & & niño & $3-4$ & - \\
\hline 104 & - & 1 & adulto & - & $\mathrm{F}$ \\
\hline
\end{tabular}

Tabla 5.14. Entierros humanos de SPL sin información contextual.

\begin{tabular}{|c|c|c|c|c|}
\hline $\mathbf{N}^{\circ}$ & NMI & Grupo etario & Edad (años) & Sexo \\
\hline 203 & 1 & adulto medio & $40-49$ & PM \\
\hline 206 & 1 & adulto & - & - \\
\hline \multirow{2}{*}{207} & \multirow{2}{*}{2} & adulto & - & $\mathrm{F}$ \\
\hline & & adulto & - & - \\
\hline \multirow{3}{*}{211} & \multirow{3}{*}{3} & niño & $5-12$ & - \\
\hline & & adulto & - & - \\
\hline & & adulto & - & - \\
\hline 217 & 1 & adulto & - & $M$ \\
\hline
\end{tabular}


El total de los elementos analizados para SPL fue de 256; la mandíbula es el hueso más representado, junto con cráneo y fémur (Tabla 5.15). De acuerdo a todos los números de inventario analizados, considerando a cada uno como un entierro, se determinó un $\mathrm{NMI}=32$. El $84,4 \%(n=27)$ de la muestra corresponde a individuos adultos, entre los que se pudo precisar un adulto joven y un adulto medio. El 15,6\% $(n=5)$ restante se determinó como subadulto, entre los que se encuentran dos infantes y tres niños. Las determinaciones sexuales pudieron efectuarse en el 31,2\% $(n=10)$, de los cuales 6 fueron categorizados como femeninos, 3 como masculino y 1 como probable masculino. 
Tabla 5.15. Cálculos de abundancia anatómica del conjunto óseo de SPL.

\begin{tabular}{|c|c|c|c|c|c|c|c|c|c|c|c|c|c|c|}
\hline \multirow{2}{*}{$\begin{array}{c}\text { Unidad } \\
\text { anatómica }\end{array}$} & \multirow{2}{*}{ NISP } & \multicolumn{3}{|c|}{$\mathrm{S} / \mathrm{F}$} & $L / F$ & \multicolumn{3}{|c|}{$\mathbf{F}$} & \multicolumn{2}{|c|}{ In. } & \multirow{2}{*}{ NMI } & \multirow{2}{*}{ NME } & \multirow{2}{*}{ MAU } & \multirow{2}{*}{ MAU\% } \\
\hline & & D & I A & In. & D I A In. & D & I A & In. & D I A & In. & & & & \\
\hline cráneo & 75 & & & & 1 & & 13 & & & & 14 & 14 & 14 & 87,5 \\
\hline mandíbula & 19 & & 1 & & & & 114 & & & & 16 & 16 & 16 & 100 \\
\hline hioides & 1 & & & & & & 1 & & & & 1 & 1 & 1 & 6,25 \\
\hline vért. cervicales & 26 & & & & & & 26 & & & & 4 & 26 & 3,7 & 23,1 \\
\hline vért. torácicas & 36 & & & & & & 36 & & & & 3 & 36 & 3 & 18,7 \\
\hline vért. lumbares & 8 & & & & & & 8 & & & & 2 & 8 & 1,6 & 10 \\
\hline costillas & 0 & & & & & & & & & & 0 & 0 & 0 & 0 \\
\hline clavícula & 6 & 1 & & & & 3 & 2 & & & & 4 & 6 & 3 & 18,7 \\
\hline esternón & 2 & & & & & & 2 & & & & 2 & 2 & 2 & 12,5 \\
\hline escápula & 4 & & & & & 2 & 2 & & & & 2 & 4 & 2 & 12,5 \\
\hline húmero & 21 & 1 & 2 & & & 7 & 8 & & & & 10 & 18 & 9 & 56,2 \\
\hline radio & 21 & 1 & 1 & & & 6 & 9 & & 21 & & 11 & 20 & 10 & 62,5 \\
\hline cúbito & 16 & 1 & 1 & & & 6 & 7 & & & 1 & 8 & 16 & 8 & 50 \\
\hline carpos & 2 & & & & & & 2 & & & & 1 & 2 & 1,1 & 6,9 \\
\hline metacarpos & 8 & & & & & 3 & 5 & & & & 1 & 8 & 0,8 & 5 \\
\hline falanges mano & 1 & & & & & & & 1 & & & 1 & 1 & 0,1 & 0,6 \\
\hline coxal & 6 & & 1 & & & 2 & 2 & & & & 3 & 5 & 2,5 & 15,6 \\
\hline sacro & 3 & & & & & & 3 & & & & 3 & 3 & 3 & 18,7 \\
\hline fémur & 21 & 2 & 2 & & & $8 \varepsilon$ & 8 & & 1 & & 11 & 21 & 10,5 & 65,6 \\
\hline rótula & 4 & & & & & 13 & 3 & & & & 3 & 4 & 2 & 12,5 \\
\hline tibia & 17 & 1 & 1 & 1 & & 3 & 6 & & & & 8 & 12 & 6 & 37,5 \\
\hline peroné & 12 & 1 & 1 & & & & 3 & & 1 & 1 & 7 & 12 & 6 & 37,5 \\
\hline tarsos & 19 & & & & & 10 & 9 & & & & 6 & 19 & 2,7 & 16,9 \\
\hline metatarso & 2 & & & & & & 1 & & & & 1 & 2 & 0,2 & 1,2 \\
\hline falanges pie & 0 & & & & & & & & & & 0 & 0 & 0 & 0 \\
\hline TOTAL & 330 & & & & & & & & & & & 256 & & \\
\hline
\end{tabular}

MAU\%=porcentaje de unidades anatómicas mínimas.

\subsubsection{Túmulo 1 - Cerro Norte de Machado (T1-CNM)}

\subsubsection{Caracterización general}

Es un montículo ubicado a $2 \mathrm{~m}$ de la margen derecha del arroyo Bellaco $\left(33^{\circ} 7 ' 18,24 " S ; 58^{\circ} 27^{\prime} 45,60 " O ;\right.$ Gualeguaychú, Entre Ríos; Figura 5.1). Tiene forma oval, su eje mayor NE-SO mide $58,5 \mathrm{~m}$, el eje NO-SE mide $40 \mathrm{~m}$ y alcanza una 
altura de 4,5 $\mathrm{m}$ en relación con el terreno circundante conformado por selva ribereña, bañados y pajonales (Castro, J.C. 2017). En el MAMA se encuentran los siguientes materiales recuperados en este sitio: 2 piedras con hoyuelos; 2 desechos de talla (lascas); 3 fragmentos cerámicos correspondientes a campanas; 1 apéndice zoomorfo representando una tortuga; 6 instrumentos óseos (puntas) confeccionadas sobre huesos de venado de las pampas, corzuela y Mammalia indeterminado (Castro, J.C. 2017; Figura 5.11). Es a partir del registro cerámico que Castro, J.C. (2017) asocia este sitio con la entidad arqueológica Goya-Malabrigo.

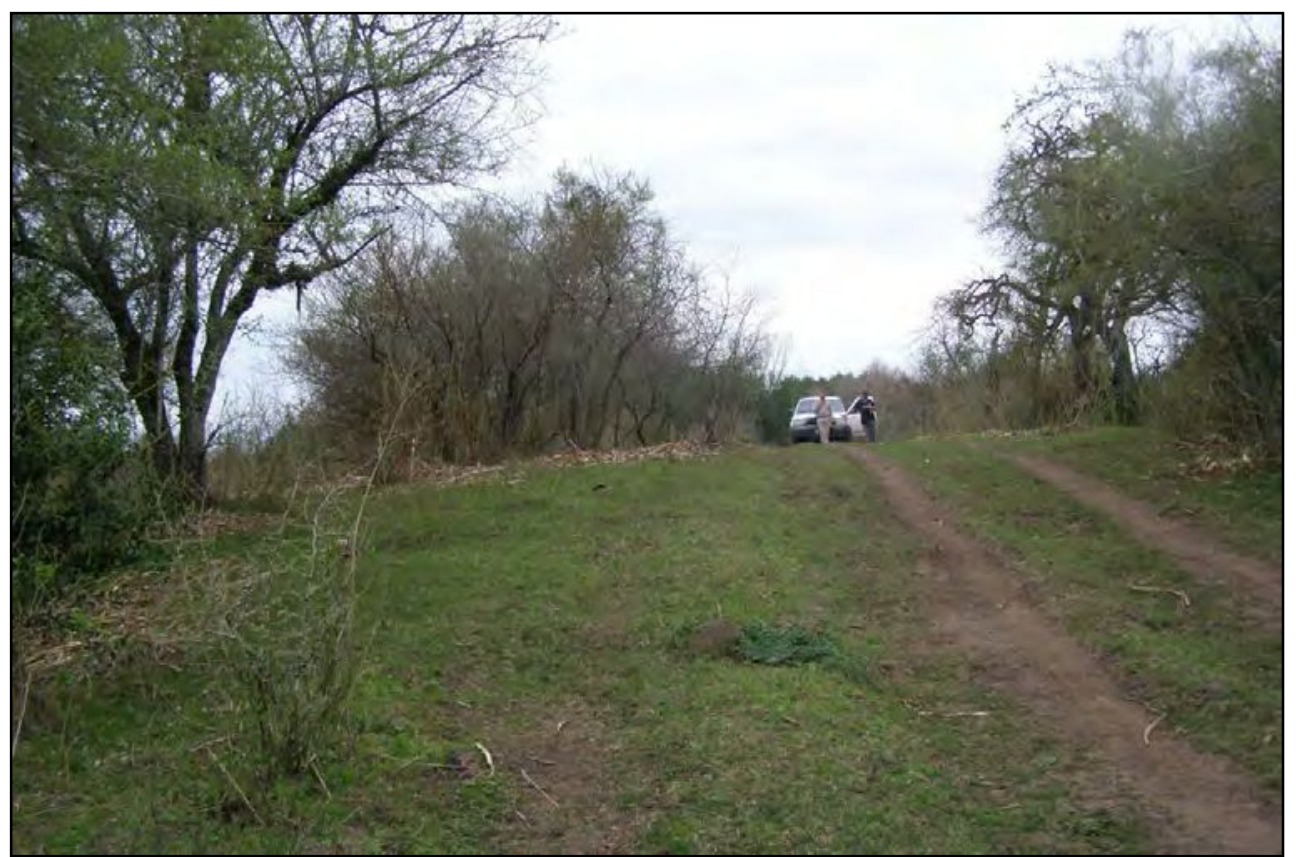

Figura 5.11. Sitio arqueológico T1-CNM (tomada por Castro, J.C.).

\subsubsection{Entierros humanos y muestra bioarqueológica estudiada}

De los cuatro números de inventario que figuran en el catálogo procedentes de este sitio, pudieron ser localizados y analizados tres (Tabla 5.16). De acuerdo a la información que se describe en el registro del museo, se destaca la relación entre dos entierros, al parecer constituyendo un entierro primario múltiple: los restos de un infante junto a la pierna de un adolescente femenino. Más allá de estos entierros, fueron analizados otros dos conjuntos óseos ( $n^{\circ} 215$ y 227-4; Tabla 5.17) que, a partir de las etiquetas que los acompañaban, pudieron ser asociados con 
este sitio. Ambos números, tal como fuera mencionado para los sitios anteriores, podrían corresponder a entierros que no fueron incorporados al catálogo.

Tabla 5.16. Información disponible en el catálogo y resultados obtenidos de los análisis para los entierros de T1-CNM.

\begin{tabular}{|c|c|c|c|c|c|}
\hline \multicolumn{2}{|r|}{ CATÁLOGO DE RESTOS HUMANOS } & \multicolumn{4}{|c|}{ RESULTADOS ANÁLISIS } \\
\hline $\mathbf{N}^{\circ}$ & Entierro & NMI & $\begin{array}{l}\text { Grupo } \\
\text { etario }\end{array}$ & $\begin{array}{l}\text { Edad } \\
\text { (años) }\end{array}$ & Sexo \\
\hline 74 & $\begin{array}{l}\text { Orientación SE. Acostado boca arriba. Asociado } \\
\text { con los restos del infante }\left(n^{\circ} 75\right) \text {. }\end{array}$ & 1 & adolescente & $17-20$ & $\mathrm{~F}$ \\
\hline 75 & $\begin{array}{l}\text { Los restos de este individuo (infante) estaban } \\
\text { ubicados junto al muslo izquierdo del nº74, y } \\
\text { como rodeados por los huesos del brazo } \\
\text { izquierdo. Acostado lado der. }\end{array}$ & 1 & infante & $1-1,5$ & - \\
\hline 83 & - & 1 & adulto & - & $M$ \\
\hline
\end{tabular}

Tabla 5.17. Entierros humanos de T1-CNM sin información contextual.

\begin{tabular}{|ccccc|}
\hline$N^{\circ}$ & NMI & Grupo etario & Edad (años) & Sexo \\
\hline 215 & 1 & adulto & - & - \\
\hline $227-4$ & 2 & $\begin{array}{c}\text { adolescente } \\
\text { adulto }\end{array}$ & $12-15$ & - \\
& & - & - \\
\hline
\end{tabular}

En total fueron analizados 60 elementos óseos (Tabla 5.18) correspondientes a los seis individuos identificados en los entierros humanos de este sitio. El cráneo y la mandíbula son los huesos más representados; es importante notar la diferencia entre la cantidad de especímenes y la cantidad de elementos para el cráneo, denotando la alta fragmentación en la que se encontraban estos huesos. 
Tabla 5.18. Cálculos de abundancia anatómica del conjunto óseo de T1-CNM.

\begin{tabular}{|c|c|c|c|c|c|c|c|c|c|c|c|c|}
\hline \multirow{2}{*}{$\begin{array}{c}\text { Unidad } \\
\text { anatómica }\end{array}$} & \multirow{2}{*}{ NISP } & \multicolumn{2}{|r|}{$S / F$} & \multicolumn{2}{|r|}{$L / F$} & \multicolumn{3}{|c|}{$\mathbf{F}$} & \multirow{2}{*}{ NMI } & \multirow{2}{*}{ NME } & \multirow{2}{*}{ MAU } & \multirow{2}{*}{ MAU\% } \\
\hline & & D & I A In. & D & I A In. & D & I A & In. & & & & \\
\hline cráneo & 36 & & 1 & & 1 & & 3 & & 5 & 5 & 5 & 100 \\
\hline mandíbula & 5 & & 1 & 1 & 1 & & 11 & & 5 & 5 & 5 & 100 \\
\hline vért. cervicales & 3 & & & & & & 3 & & 1 & 3 & 0,4 & 8 \\
\hline vért. torácicas & 2 & & 1 & & & & 1 & & 2 & 2 & 0,2 & 4 \\
\hline vért. lumbares & 3 & & & & & & 3 & & 1 & 3 & 0,6 & 12 \\
\hline costillas & 7 & 1 & 2 & & & 22 & & & 2 & 7 & 0,3 & 6 \\
\hline clavícula & 2 & & & & 1 & & & & 1 & 2 & 1 & 20 \\
\hline esternón & 0 & & & & & & & & 0 & 0 & 0 & 0 \\
\hline escápula & 4 & 1 & 1 & & & 11 & 1 & & 2 & 4 & 2 & 40 \\
\hline húmero & 5 & 1 & & 1 & 1 & 1 & 1 & & 3 & 5 & 2,5 & 50 \\
\hline radio & 3 & 1 & & & & 2 & & & 3 & 3 & 1,5 & 30 \\
\hline cúbito & 2 & 1 & 1 & & & & & & 1 & 2 & 1 & 20 \\
\hline carpos & 0 & & & & & & & & 0 & 0 & 0 & 0 \\
\hline metacarpos & 0 & & & & & & & & 0 & 0 & 0 & 0 \\
\hline falanges mano & 0 & & & & & & & & 0 & 0 & 0 & 0 \\
\hline coxal & 3 & 1 & 1 & & & 1 & & & 2 & 3 & 1,5 & 30 \\
\hline sacro & 0 & & & & & & & & 0 & 0 & 0 & 0 \\
\hline fémur & 4 & 1 & & & & 12 & 2 & & 3 & 4 & 2 & 40 \\
\hline rótula & 0 & & & & & & & & 0 & 0 & 0 & 0 \\
\hline tibia & 5 & 1 & 1 & 1 & 1 & 1 & & & 3 & 5 & 2,5 & 50 \\
\hline peroné & 0 & & & & & & & & 0 & 0 & 0 & 0 \\
\hline tarsos & 4 & & & & & 22 & 2 & & 1 & 4 & 0,6 & 12 \\
\hline metatarso & 2 & & & & & & & & 1 & 2 & 0,2 & 4 \\
\hline falanges pie & 1 & & & & & & & 1 & 1 & 1 & 0,1 & 2 \\
\hline TOTAL & 91 & & & & & & & & & 60 & & \\
\hline
\end{tabular}

Referencias: $\mathrm{NISP}=$ número de especímenes óseos; $\mathrm{S} / \mathrm{F}=\sin$ fusionar; $\mathrm{L} / \mathrm{F}=$ con línea de fusión; F=fusionados; $D$ =derecho; I=izquierdo; $A$ =axial; In.=indeterminados; $N M I=$ número mínimo de individuos; $\mathrm{NME}=$ número mínimo de elementos; $\mathrm{MAU}=$ unidades anatómicas mínimas;

MAU\%=porcentaje de unidades anatómicas mínimas.

\subsubsection{Túmulo 2 - Cerro Sur de Machado (T2-CSM)}

\subsubsection{Caracterización general}

A $5 \mathrm{~m}$ al sudoeste de T1-CNM, se ubica este montículo adyacente a la margen derecha del arroyo Bellaco (337'40,14"S; 58²7'43,56"O; Gualeguaychú, Entre Ríos; Figura 5.1). Tiene forma elipsoidal, el eje mayor NE-SO mide 200 m, el eje NO-SE mide $20 \mathrm{~m}$ y alcanza una altura de $4,5 \mathrm{~m}$ en relación con el terreno 
circundante conformado por selva ribereña, bañados y pajonales (Castro, J.C. 2017). Los materiales hallados por Almeida que están depositados en el MAMA son: 1 núcleo de caliza silicificada, 4 fragmentos cerámicos y 12 puntas confeccionadas sobre huesos de aves, venado de las pampas, corzuela, mamíferos y cérvidos indeterminados. Durante los trabajos de campo realizados por Castro, J.C. (2017), se recolectó superficialmente un núcleo de caliza silicificada. Al igual que T1-CNM, Castro, J.C. (2017) vincula este sitio con la entidad arqueológica Goya-Malabrigo. Se obtuvo una datación radiocarbónica de $840 \pm 50$ años AP efectuada sobre un hueso humano de uno de los entierros hallados por Almeida ( $n^{\circ} 81$, véase en apartado siguiente; código muestra: LP-2838; Castro y Del Papa 2015).

\subsubsection{Entierros humanos y muestra bioarqueológica estudiada}

En el catálogo del MAMA se mencionan cuatro números de inventario para T2-CSM. De ellos, sólo pudieron ser localizados y estudiados dos que, según la información que se detalla, corresponderían a entierros primarios (Tabla 5.19). Asimismo, fue localizado un cráneo y su mandíbula (n²27-2) que también son procedentes de este sitio y corresponderían a un individuo adulto probable femenino. En total fueron analizados 50 elementos óseos de estos tres individuos; el cráneo y la mandíbula son los huesos más representados (Tabla 5.20).

Tabla 5.19. Información disponible en el catálogo y resultados obtenidos de los análisis para los entierros de T2-CSM.

\begin{tabular}{|l|c|cccc|}
\hline \multicolumn{2}{|c|}{ CATÁLOGO DE RESTOS HUMANOS } & \multicolumn{4}{|c|}{ RESULTADOS ANÁLISIS } \\
\hline N $^{\circ}$ & NMItierro & NMrupo etario & $\begin{array}{c}\text { Edad } \\
\text { (años) }\end{array}$ & Sexo \\
\hline 81 & Orientación S. Acostado lado derecho & 1 & adulto joven & $20-22$ & $\mathrm{~F}$ \\
82 & Acostado boca arriba. Orientación S. & 1 & adolescente & $18-21$ & $\mathrm{M}$ \\
\hline
\end{tabular}


Tabla 5.20. Cálculos de abundancia anatómica del conjunto óseo de T2-CSM.

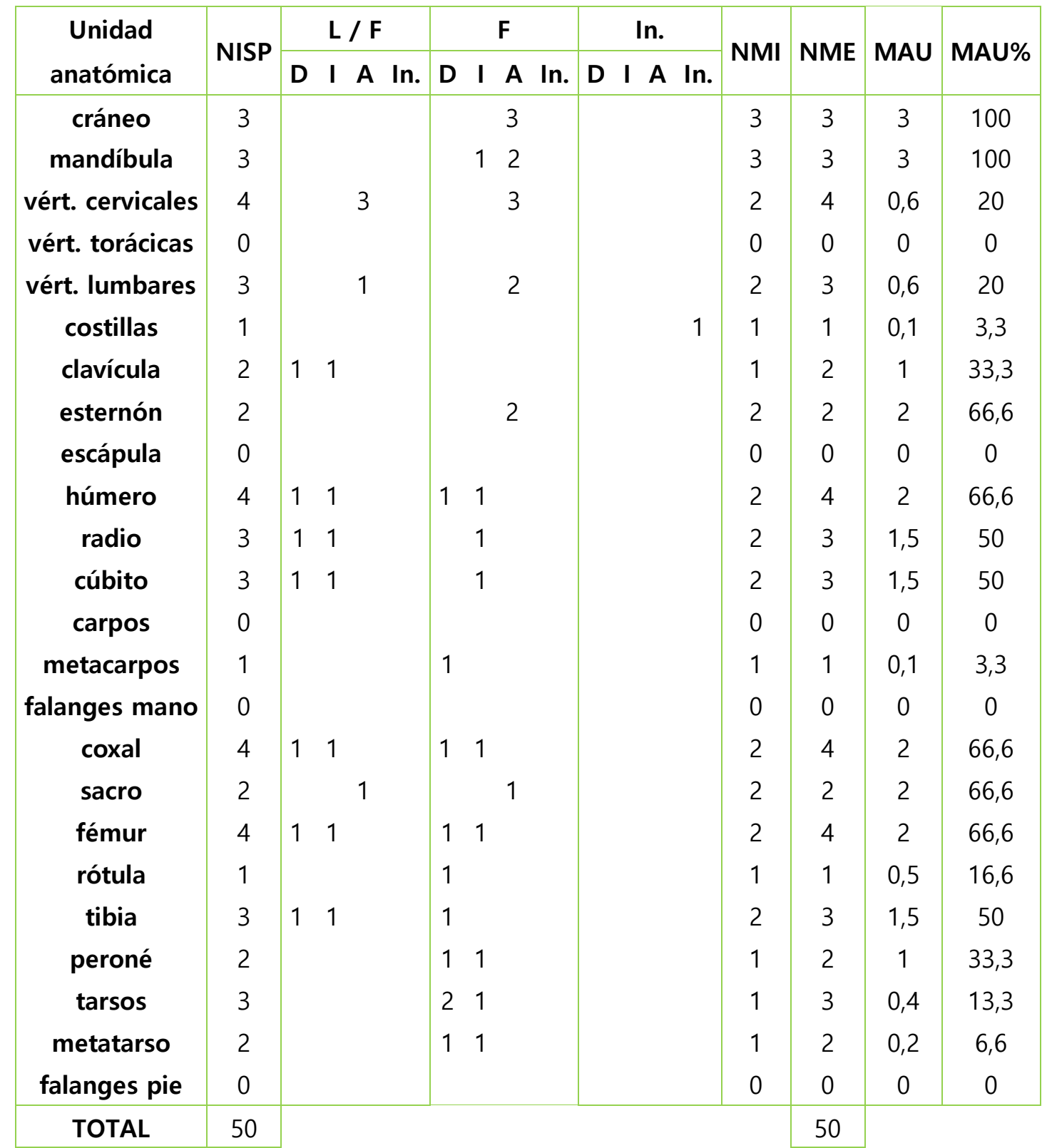

Referencias: NISP=número de especímenes óseos; L/F=con línea de fusión; F=fusionados; $D=$ derecho; I=izquierdo; $\mathrm{A}=$ axial; In.=indeterminados; $\mathrm{NMI=número} \mathrm{mínimo} \mathrm{de} \mathrm{individuos;} \mathrm{NME}=$ número mínimo de elementos; MAU=unidades anatómicas mínimas; MAU\%=porcentaje de unidades anatómicas mínimas.

\subsubsection{Cerro de los Pampas (CP)}

\subsubsection{Caracterización general}

A $1100 \mathrm{~m}$ de la margen derecha del río Uruguay se encuentran dos elevaciones que antiguamente constituían un solo montículo, conocido como Cerro de los Pampas (33²0'32,86"S; 58²9'14,75"O; Gualeguaychú, Entre Ríos; Figura 5.1). La forma original del montículo era elipsoidal, su eje mayor NE-SO medía 315 m, el 
eje NO-SE $55 \mathrm{~m}$ y alcanzaba una altura aproximada de $7 \mathrm{~m}$ desde el nivel de los bañados que lo circundan (Castro, J.C. 2017). Este sitio, en momentos recientes, se ha visto afectado por la construcción de caminos que permitieran comunicar las llanuras altas con la costa del río, produciendo así su división en dos sectores (Castro, J.C. 2017).

Antes de los trabajos realizados por Almeida, este sitio arqueológico fue visitado y estudiado por Greslebin (1931), Krapovickas (1957) y Cione et al. (1977). Durante la expedición arqueológica que realiza Greslebin en 1926 hacia el sur de Gualeguaychú, le indican la existencia de túmulos indígenas. Al visitarlos da cuenta que son dos elevaciones contiguas, al parecer artificiales, que están intactas y que son muy interesantes de ser exploradas. Observa que las superficies estaban afectadas por las vizcachas, dejando al descubierto numerosos restos arqueológicos: fragmentos de cerámica (entre ellos bodes decorados), valvas de moluscos y una piedra con hoyuelos. A estos sitios, Greslebin los llama Túmulos de Estoponda (Greslebin 1931). En el caso de Krapovickas (1957), a partir de los trabajos que realiza en el mismo lugar -al que llama Cerro de Las Pampas-, el autor interpreta que el montículo fue construido sobre un médano preexistente y que los restos culturales se encuentran mezclados intencionalmente junto con la tierra utilizada para su construcción. En la década de 1970 los investigadores Cione, Rizzo y Tonni (1977) presentan los resultados de la excavación de un sector del sitio; para estos trabajos de campo contaron con la colaboración del profesor Almeida. En el marco de abordar la relación cultura indígena-medio ambiente, realizan un estudio sobre la biogeografía actual del sitio, la estratigrafía y el conjunto arqueofaunístico y cerámico hallado. Con los resultados obtenidos, los autores concluyen que el sitio se localiza en un área que no llegaba a afectarse por las inundaciones. Asimismo, indican que la ocupación del lugar habría sido en momentos pre-guaraníes y que la alimentación de los pobladores se basaba principalmente en peces (bagres, armados, bogas), así como también en nutrias y ciervos. Por otro lado, la ausencia de representaciones de psitácidos en los apéndices cerámicos, a diferencia de lo que ocurre en otros sitios, lo atribuyen a la baja frecuencia de estas aves en la zona (Cione et al. 1977). 
Durante su expedición al lugar, Almeida distinguió cinco sectores sobre el albardón, llamando a cada uno de ellos como "núcleos" (las dos elevaciones estudiadas por los autores antes mencionados se corresponden con el núcleo 1 y 2 de Almeida; Castro, J.C. 2017). El MAMA conserva materiales líticos (piedras con hoyuelos, desechos de talla y núcleos), cerámicos (apéndices -uno de ellos zoomorfo representando una cabeza de ave-, apliques en cresta, vertederos cerrados, cuentas) y varios instrumentos óseos confeccionados sobre huesos de venado, ciervo y corzuela y sobre astas de cérvidos) (Castro, J.C. 2017). Este sitio ha sido asociado, principalmente a partir de la cerámica, con la entidad arqueológica Goya-Malabrigo (Castro, J.C. 2017).

\subsubsection{Entierros humanos y muestra bioarqueológica estudiada}

En el $\mathrm{CRH}$ no se mencionan entierros humanos para CP. Sin embargo, pudieron ser localizados y asociados con este sitio (a partir de etiquetas) cinco números de inventario (n²10, 214, 216, 227-3 y 228). Tres de ellos (n²10, 216 y 228) están conformados por un solo elemento óseo (húmero, fémur y mandíbula, respectivamente). Dada esta situación y sumando a la falta de información contextual, se decidió no considerar a cada uno de estos cinco números como un entierro particular. De acuerdo a los resultados obtenidos de los cálculos de abundancia anatómica (Tabla 5.21), en los 19 elementos óseos que componen este conjunto, se determinó un NMI de 3 (a partir de cráneo y mandíbula, que son los huesos más representados). Uno de los individuos sería un niño de 10-12 años y los dos restantes, adultos (uno de ellos probable femenino). 
Tabla 5.21. Cálculos de abundancia anatómica del conjunto óseo de CP.

\begin{tabular}{|c|c|c|c|c|c|c|c|c|}
\hline \multirow{2}{*}{$\begin{array}{c}\text { Unidad } \\
\text { anatómica }\end{array}$} & \multirow{2}{*}{ NISP } & $S / F$ & \multicolumn{2}{|r|}{$\mathbf{F}$} & \multirow{2}{*}{ NMI } & \multirow{2}{*}{ NME } & \multirow{2}{*}{ MAU } & \multirow{2}{*}{ MAU\% } \\
\hline & & D I A In. & D & I A In. & & & & \\
\hline cráneo & 16 & & & 2 & 2 & 2 & 2 & 100 \\
\hline mandíbula & 3 & 1 & & 1 & 2 & 2 & 2 & 100 \\
\hline vért. cervicales & 0 & & & & 0 & 0 & 0 & 0 \\
\hline vért. torácicas & 1 & & & 1 & 1 & 1 & 0,1 & 5 \\
\hline vért. lumbares & 1 & & & 1 & 1 & 1 & 0,2 & 10 \\
\hline costillas & 3 & & & 1 & 1 & 2 & 0,1 & 5 \\
\hline clavícula & 0 & & & & 0 & 0 & 0 & 0 \\
\hline esternón & 0 & & & & 0 & 0 & 0 & 0 \\
\hline escápula & 0 & & & & 0 & 0 & 0 & 0 \\
\hline húmero & 2 & & 2 & & 2 & 2 & 1 & 50 \\
\hline radio & 0 & & & & 0 & 0 & 0 & 0 \\
\hline cúbito & 1 & & & 1 & 1 & 1 & 0,5 & 25 \\
\hline carpos & 0 & & & & 0 & 0 & 0 & 0 \\
\hline metacarpos & 2 & & & 2 & 1 & 2 & 0,2 & 10 \\
\hline falanges mano & 0 & & & & 0 & 0 & 0 & 0 \\
\hline coxal & 0 & & & & 0 & 0 & 0 & 0 \\
\hline sacro & 0 & & & & 0 & 0 & 0 & 0 \\
\hline fémur & 1 & & 1 & & 1 & 1 & 0,5 & 25 \\
\hline rótula & 3 & & & 2 & 2 & 3 & 1,5 & 75 \\
\hline tibia & 2 & 1 & & & 1 & 1 & 0,5 & 25 \\
\hline peroné & 0 & & & & 0 & 0 & 0 & 0 \\
\hline tarsos & 0 & & & & 0 & 0 & 0 & 0 \\
\hline metatarso & 1 & & 1 & & 1 & 1 & 0,1 & 5 \\
\hline falanges pie & 0 & & & & 0 & 0 & 0 & 0 \\
\hline TOTAL & 36 & & & & & 19 & & \\
\hline
\end{tabular}

Referencias: NISP=número de especímenes óseos; $\mathrm{S} / \mathrm{F}=\sin$ fusionar; F=fusionados; $\mathrm{D}=$ derecho; $\mathrm{I}=$ izquierdo; $\mathrm{A}=$ axial; In.=indeterminados; $\mathrm{NMI=número} \mathrm{mínimo} \mathrm{de} \mathrm{individuos;} \mathrm{NME}=$ número mínimo de elementos; $\mathrm{MAU}=$ unidades anatómicas mínimas; $\mathrm{MAU} \%=$ porcentaje de unidades anatómicas mínimas.

\subsubsection{San Luis Médanos (SLM)}

\subsubsection{Caracterización general}

Almeida recogió el material arqueológico que había quedado expuesto, por vientos y lluvia, en una hondonada sobre los médanos ubicados en la margen derecha del río Gualeguaychú. Este sitio, al que Almeida denominó San Luis Médanos, fue relocalizado a partir de los trabajos de Castro, J.C. en el área 
(33³'38,63"S; 58²6'35,52"O; Gualeguaychú, Entre Ríos; Figura 5.1.). Sin embargo, dada la falta de información sobre los trabajos de Almeida en este lugar y que el área en el que se ubica ha sido muy explotada para la extracción de arena, se desconoce si SLM correspondería a un montículo o no (Castro, J.C. 2017).

\subsubsection{Entierros humanos y muestra bioarqueológica estudiada}

En el catálogo se mencionan dos números de inventario ( $n^{\circ} 65$ y 85 ) procedentes de SLM. Para ambos casos, se describe que sólo pudieron recogerse fragmentos de cráneo. De ellos, sólo pudo localizarse en el MAMA una bóveda craneana ( $\left.\mathrm{n}^{\circ} 65\right)$, correspondiente a un individuo adulto, sin poder precisar el rango etario ni el sexo por ausencia de las partes diagnósticas.

\subsubsection{Túmulo de Lucuix (TL)}

\subsubsection{Caracterización general}

Este sitio es un túmulo (33²'36,18"S; 58²8'9,30"O; Gualeguaychú, Entre Ríos; Figura 5.1.) de forma semielipsoidal con dirección NE-SO, que alcanza una altura de 2,8 m y que se encuentra en el centro de un bañado (Greslebin 1931). Los primeros trabajos arqueológicos en el lugar le corresponden a Greslebin, quien en 1926 realizó dos zanjas que le permitieron observar la estratigrafía del sitio y concluir su construcción artificial. Al distinguir en los alrededores de este túmulo sectores elevados naturalmente, que bien podrían haber sido ocupados sin requerir esfuerzo, el autor concluye que el túmulo ha sido construido por los pobladores con el fin de "procurarse una pesca fácil, en época de creciente, o en épocas que el régimen del río inundaba continuamente esta zona" (1931: 27). Asimismo, señala que primero habrían ocupado las zonas medanosas contiguas al túmulo y que, para pescar, accedían a estas elevaciones a través del uso de canoas. Entre los restos arqueológicos que halló, menciona tiestos, asas, bordes, huesos de animales, valvas de moluscos, piedras trabajadas y un punzón de hueso. Además, encuentra siete entierros humanos sobre los cuales ofrece las siguientes descripciones (1931: 2930): 1) un entierro primario cuyo cráneo estaba mezclado con tiestos y huesos de ciervo, se encontraba apoyado sobre una capa de cenizas y "se hallaba rellenado, 
exprofeso, con escamas y con otros residuos de pescado"; 2) restos de un segundo esqueleto, hallado de forma desarticulada; 3 ) esqueleto con sus piezas en completo desorden y con señales de incineración; 4) esqueleto en posición decúbito ventral, también con sus piezas desarticuladas; 5) formado únicamente por un fragmento de bóveda craneana y por un trozo de húmero esqueletizado; 6) cráneo acomodado sobre fragmentos de cerámica, y con sus restantes piezas desarticuladas y en desorden. Pese a hablar de esqueletos para cada uno de estos hallazgos, finalmente Greslebin los identifica como entierros secundarios (1931: 50).

En relación con los trabajos realizados por Almeida en este sitio, en el MAMA se localizaron tres instrumentos líticos y cuatro instrumentos óseos (puntas hechas sobre huesos y astas de mamíferos indeterminados y cérvidos) (Castro, J.C. 2017).

\subsubsection{Entierros humanos y muestra bioarqueológica estudiada}

En el catálogo se remite el hallazgo de un sólo entierro ( $\left.n^{\circ} 64\right)$, el cual se vio afectado por la remoción de tierra del túmulo al reparar un camino adyacente. Este número de inventario pudo ser localizado en el MAMA; el mismo se encuentra conformado solamente por cinco elementos óseos (cráneo, mandíbula, atlas, axis y sacro), correspondientes al menos a un individuo adulto masculino.

\subsubsection{Fajina Quemada (FQ)}

\subsubsection{Caracterización general}

Es un montículo ubicado a $40 \mathrm{~m}$ de la margen izquierda del arroyo Malo (33²0'40,78"S; 58²8'37,81"O; Gualeguaychú, Entre Ríos; Figura 5.1). Tiene forma elipsoidal, su eje mayor NE-SO mide $57 \mathrm{~m}$, el eje NO-SE mide $35 \mathrm{~m}$ y alcanza una altura de $2,5 \mathrm{~m}$ en relación con el terreno circundante conformado por selva ribereña, bañados y pajonales (Castro, J.C. 2017). En el acervo del MAMA se localizaron cinco huesos de fauna, entre los que se destacan dos puntas realizadas sobre huesos de ciervo de los pantanos y cérvidos (Castro, J.C. 2017). 


\subsubsection{Entierros humanos y muestra bioarqueológica estudiada}

No se cuenta con información en el catálogo sobre entierros humanos hallados en este sitio. Sin embargo, en el museo se localizó un conjunto óseo (n²33), acompañado por una etiqueta que menciona el nombre de este sitio. Los tres huesos presentes (húmero, cráneo y mandíbula) se encuentran fragmentados e incompletos, y pertenecerían a un individuo adulto sin determinación de sexo.

\subsection{Delta Inferior del río Paraná y ambientes litorales adyacentes}

Esta muestra bioarqueológica se compone de los conjuntos óseos hallados en tres sitios. Por un lado, el sitio Túmulo 1-La Argentina fue trabajado por Almeida en el marco de sus trabajos de campo (véase detalle en el apartado 5.4. en este mismo capítulo); los materiales arqueológicos y entierros humanos allí encontrados se encuentran depositados en el MAMA. Por otro lado, los sitios El Cerrillo/Túmulo I del Paraná Guazú y Arroyo Sarandí fueron excavados en la primera mitad del siglo XX y los entierros humanos se encuentran en la División Antropología de Museo de La Plata.

Durante 1924, en el marco de lazos de cooperación entre el Museum of American Indian (New York, Estados Unidos), Heye Foundation (New York, Estados Unidos) y el Museo de La Plata (Buenos Aires, Argentina), los directores de tales instituciones -George Heye y Luis María Torres- acordaron el desarrollo de una expedición arqueológica conjunta. La misma estuvo a cargo de Samuel Kirkland Lothrop -quien formaba parte del museo estadounidense- y se realizó en el Delta del río Paraná al año siguiente entre los meses de abril y junio. En el marco de estos trabajos de campo se excavaron tres sitios arqueológicos: Arroyo Malo ${ }^{6}, \mathrm{El}$ Cerrillo y Arroyo Sarandí, localizados en los ambientes insulares y litorales del Paraná Inferior (Lothrop 1932; Bonomo 2013). Las tareas de excavación fueron las que solían ser empleadas en la época, es decir, mediante la apertura de trincheras

\footnotetext{
6 La colección bioarqueológica del sitio Arroyo Malo no fue incluida en los análisis efectuados en esta tesis, ya que ha sido interpretado como una aldea guaraní (Lothrop 1932; Bonomo 2013).
} 
con palas por medio de peones contratados. Mientras los colaboradores Rachel Warren (la esposa de Lothrop) y Antonio Castro (preparador del Museo de La Plata) se encargaban de lavar, clasificar y empacar los materiales extraídos, Lothrop tomaba notas y dibujaba detalladamente los hallazgos; el registro fotográfico también estuvo presente (Bonomo 2013; Bonomo y Farro 2014). Los hallazgos recolectados tuvieron distintos destinos. La colección de cerámica y de instrumentos óseos y líticos fue enviada a Estados Unidos; actualmente estos materiales se encuentran depositados en el National Museum of the American Indian (NMAl; Washington DC). Por su parte, los restos de animales y los entierros humanos, de acuerdo a lo solicitado por Torres, fueron trasladados al Museo de La Plata (MLP) (Bonomo 2013; Bonomo y Farro 2014).

\subsubsection{Túmulo 1 - La Argentina (T1-LA)}

\subsubsection{Caracterización general}

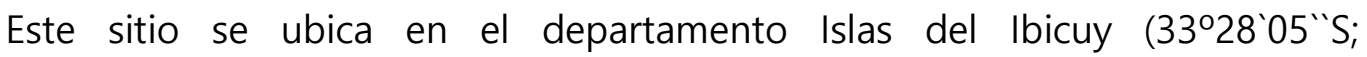
59²6’22,9“O; Entre Ríos; Figura 5.1). En el MAMA se conservan los siguientes materiales: 3 fragmentos gruesos de cuerpo que probablemente correspondan a campanas; 1 apéndice zoomorfo -representando quizás una serpiente- y 2 puntas ahuecadas realizadas sobre hueso largo de mamífero indeterminado (Castro, J.C. 2017).

Este sitio corresponde al estudiado por Aparicio (Castro y Del Papa 2015; Castro, J.C. 2017; Figura 5.12), en el cual realizó "ligeras excavaciones poco profundas" (1928: 9). Dicho autor destaca "la abundancia del material osteológico" sobre la extensión del "cerro" y que "todos los restos denotan una inhumación secundaria" (1928: 10-11). Si bien junto a los huesos se encontraban mezclados fragmentos cerámicos (entre ellos un apéndice macizo representando una cabeza de psitácido), una piedra con hoyuelos, instrumentos óseos (puntas) y restos de fauna (coipo, carpincho, ciervos, aves, peces y moluscos), interpreta al sitio como un cementerio que sólo sería ocupado para habitar en tiempos de inundación (Aparicio 1928: 11). De acuerdo a los hallazgos de Aparicio y a los estudios de Castro, este sitio ha sido vinculado con la entidad arqueológica Goya-Malabrigo. 


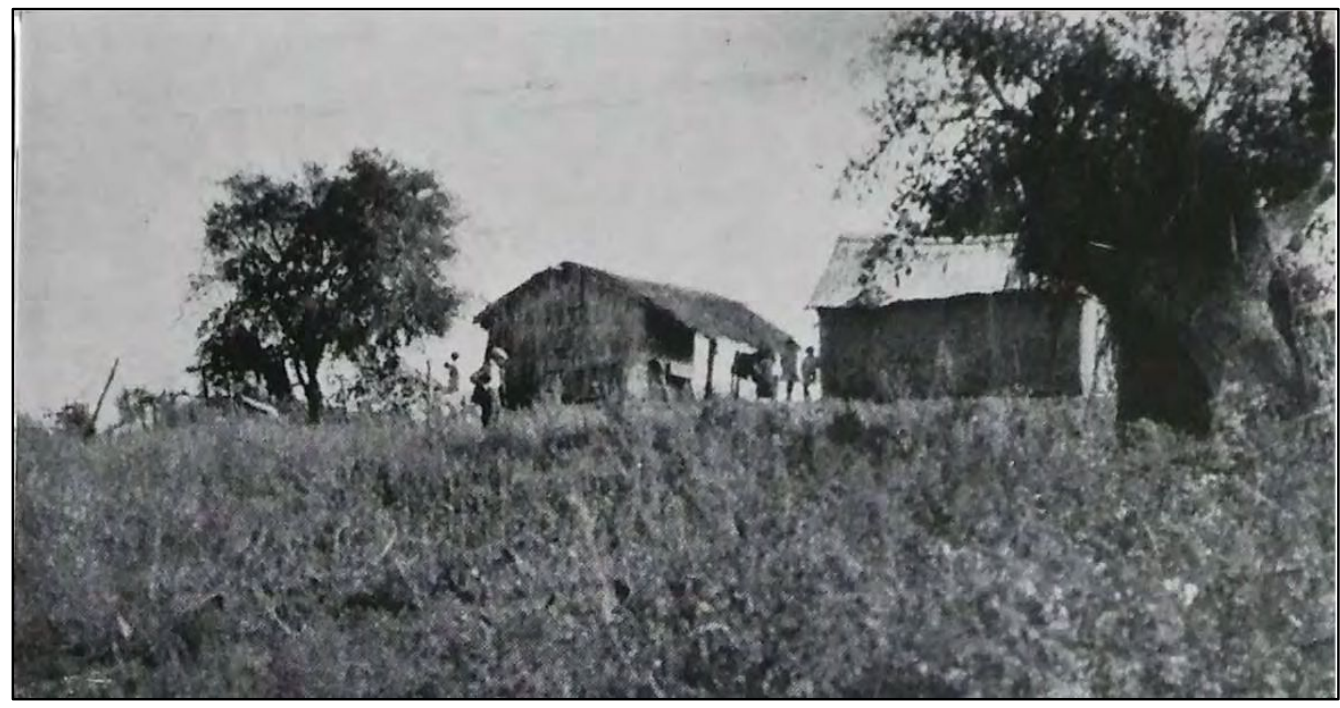

Figura 5.12. Vista del lado sur del sitio T1-LA (tomado de Aparicio 1928: 11).

\subsubsection{Entierros humanos y muestra bioarqueológica estudiada}

En el $\mathrm{CRH}$ se remiten tres números de inventario que pudieron ser ubicados y analizados. Como puede observarse en la Tabla 5.22, sólo se cuenta con información sobre el tipo de entierro para uno sólo; correspondería a un individuo enterrado de forma primaria en posición decúbito dorsal. Sin embargo, al analizar este conjunto óseo se determinaron al menos dos individuos, por repetición de cúbitos y tibias.

Tabla 5.22. Información disponible en el catálogo y resultados obtenidos de los análisis para los entierros de T1-LA.

\begin{tabular}{|c|c|c|c|c|c|}
\hline \multicolumn{2}{|c|}{ CATÁLOGO DE RESTOS HUMANOS } & \multicolumn{4}{|c|}{ RESULTADOS ANÁLISIS } \\
\hline $\mathbf{N}^{\circ}$ & Entierro & NMI & Grupo etario & $\begin{array}{l}\text { Edad } \\
\text { (años) }\end{array}$ & Sexo \\
\hline 68 & Extendido, boca arriba & 2 & $\begin{array}{c}\text { adolescente } \\
\text { adulto }\end{array}$ & $17-20$ & $\begin{array}{l}M \\
\text { in. }\end{array}$ \\
\hline 69 & - & 1 & adulto & - & $\mathrm{F}$ \\
\hline 70 & - & 1 & adulto & - & $\mathrm{F}$ \\
\hline
\end{tabular}

El número total de elementos óseos analizados correspondientes a los cuatro individuos determinados, es de 57. El cráneo y la mandíbula son los huesos más representados; también se encuentran con un porcentaje elevado algunos huesos largos, como el cúbito y la tibia (Tabla 5.23). 
Tabla 5.23. Cálculos de abundancia anatómica del conjunto óseo de T1-LA.

\begin{tabular}{|c|c|c|c|c|c|c|c|c|c|c|c|}
\hline \multirow{2}{*}{$\begin{array}{c}\text { Unidad } \\
\text { anatómica }\end{array}$} & \multirow{2}{*}{ NISP } & \multicolumn{2}{|c|}{$L / F$} & \multicolumn{3}{|c|}{$\mathbf{F}$} & In. & \multirow{2}{*}{ NMI } & \multirow{2}{*}{ NME } & \multirow{2}{*}{ MAU } & \multirow{2}{*}{ MAU\% } \\
\hline & & D I I & A In. & D & I A & In. & D I A In. & & & & \\
\hline cráneo & 3 & & 1 & & 2 & & & 3 & 3 & 3 & 100 \\
\hline mandíbula & 3 & & 1 & & 3 & & & 3 & 3 & 3 & 100 \\
\hline vért. cervicales & 3 & & & & 3 & & & 1 & 3 & 0,4 & 13,3 \\
\hline vért. torácicas & 1 & & & & 1 & & & 1 & 1 & 0,1 & 3,3 \\
\hline vért. lumbares & 7 & & 3 & & 4 & & & 2 & 7 & 1,4 & 46,6 \\
\hline costillas & 0 & & & & & & & 0 & 0 & 0 & 0 \\
\hline clavícula & 3 & 1 & & 2 & & & & 3 & 3 & 1,5 & 50 \\
\hline esternón & 1 & & & & 1 & & & 1 & 1 & 1 & 33,3 \\
\hline escápula & 0 & & & & & & & 0 & 0 & 0 & 0 \\
\hline húmero & 3 & & & 2 & 1 & & & 2 & 3 & 1,5 & 50 \\
\hline radio & 3 & & & 2 & 1 & & & 2 & 3 & 1,5 & 50 \\
\hline cúbito & 7 & & & 2 & 3 & & & 3 & 5 & 2,5 & 83,3 \\
\hline carpos & 0 & & & & & & & 0 & 0 & 0 & 0 \\
\hline metacarpos & 1 & & & 1 & & & & 1 & 1 & 0,1 & 3,3 \\
\hline falanges mano & 0 & & & & & & & 0 & 0 & 0 & 0 \\
\hline coxal & 4 & & & 2 & 2 & & & 2 & 4 & 2 & 66,6 \\
\hline sacro & 1 & & & & 1 & & & 1 & 1 & 1 & 33,3 \\
\hline fémur & 3 & & & 1 & 2 & & & 2 & 3 & 1,5 & 50 \\
\hline rótula & 2 & & & 1 & 1 & & & 1 & 2 & 1 & 33,3 \\
\hline tibia & 5 & & & 2 & 2 & & 1 & 3 & 5 & 2,5 & 83,3 \\
\hline peroné & 2 & & & 1 & 1 & & & 1 & 2 & 1 & 33,3 \\
\hline tarsos & 3 & & & 3 & & & & 2 & 3 & 0,4 & 13,3 \\
\hline metatarso & 2 & & & 1 & 1 & & & 1 & 2 & 0,2 & 6,6 \\
\hline falanges pie & 2 & & & & & 2 & & 1 & 2 & 0,1 & 3,3 \\
\hline TOTAL & 59 & & & & & & & & 57 & & \\
\hline
\end{tabular}

Referencias: NISP=número de especímenes óseos; L/F=con línea de fusión; F=fusionados; $D=$ derecho;

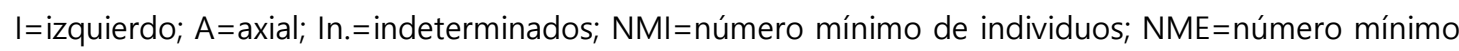
de elementos; $\mathrm{MAU}=$ unidades anatómicas mínimas; $\mathrm{MAU} \%=$ porcentaje de unidades anatómicas mínimas.

\subsubsection{El Cerrillo / Túmulo I del Paraná Guazú}

\subsubsection{Caracterización general}

En 1905, a partir del dato de la existencia de un túmulo en una isla del Delta, Luis María Torres (en ese entonces a cargo de la Sección Arqueológica del Museo de La Plata) emprendió una expedición arqueológica hacia esta área. Sobre un albardón ubicado en un pequeño arroyo que desemboca sobre la margen 
derecha del río Paraná Guazú, encontró el túmulo que le habían comunicado y al

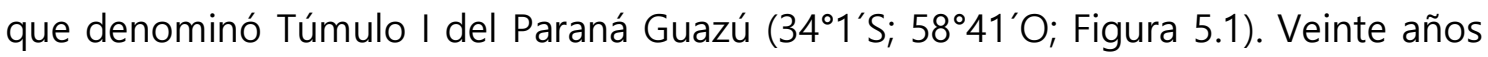
después, y sin conocer el trabajo de Torres, Lothrop realizó una excavación en este mismo sitio en el marco de la expedición arqueológica comentada anteriormente. A continuación, se presenta información sobre ambos trabajos de campo, dado que los conjuntos óseos humanos recuperados en las dos excavaciones fueron analizados en la presente tesis.

En el informe elevado por Torres al Director del MLP7, se detallan las tareas realizadas en el sitio. Los trabajos implicaron, en primer término, la medición del túmulo y la toma de fotografías. Luego, se construyó una zanja localizada en la parte central del montículo abarcando toda su longitud. Como resultado de la excavación (hecha por dos peones contratados y realizada con palas), recuperó distintos materiales arqueológicos. Al continuar la excavación hacia el perfil oeste de la zanja, encontró un cráneo humano en mal estado de conservación que requirió un mayor cuidado para extraerlo. En cercanías, apareció otro entierro. Por este motivo se decidió realizar otra zanja, paralela a la primera, que comprendía el pie del montículo; allí fueron encontradas numerosas inhumaciones. Luego de extraer los huesos humanos encontrados, se profundizaba la excavación debajo de ellos. De esta forma encontraron distintos materiales: fragmentos de piedra, puntas de arpón, carbón de leña, punzones de hueso, fragmentos de alfarería, dos pequeñas piedras con hoyuelos y grandes amontonamientos de unos pequeños cocos. Asimismo, dispersos y mezclados por el túmulo, aparecieron "huesos de cuices (partidos longitudinalmente), mandíbulas de nutria y carpincho, espinas y huesos de peces grandes de río, dos mandíbulas de gato del monte y dos molares de tigre; las astas de ciervo con cortaduras e incisiones abundaban"8. Para Torres, el sitio demostraba, por su forma y extensión, ser de origen artificial. Los distintos materiales hallados evidenciaban "indicios de una habitación numerosa y permanente". Según su análisis, en primer lugar el montículo habría funcionado

\footnotetext{
7 Informe elevado por L. M. Torres al Director del Museo de La Plata, Francisco P. Moreno. La Plata, 6 de noviembre de 1905, Museo de La Plata.

8 Parte de esta colección (depositada en la División Arqueología del Museo de La Plata) ha sido reestudiada por Bonomo y colaboradores (2009).
} 
como "enterratorio" (hacia una de las laderas del túmulo) y luego habría sido utilizado como paradero en ciertas ocasiones (Torres 1911: 184).

El área excavada por Lothrop $\left(335 \mathrm{~m}^{2}\right)$ estaba a continuación de la zona trabajada por Torres y restringida a un sector de la pendiente del montículo (Figura 5.13). Durante los trabajos de campo, se recuperaron materiales cerámicos, líticos y faunísticos (principalmente de nutria, carpincho y peces) y esqueletos humanos (Lothrop 1932). Para el arqueólogo, el sitio fue lentamente construido y su ocupación atribuye a las poblaciones indígenas chaná-mbeguá o chaná (1932: 149). En los últimos años se han estudiado parte de estos materiales arqueológicos (Bonomo 2013). En la colección predomina la alfarería, reconociéndose entre los morfotipos a un cuenco pequeño y un colador; también se registraron tres masas de arcilla y un rollo de arcilla sin cocer, evidenciando la manufactura de cerámica in situ. En cuanto a los materiales líticos, se reconocieron artefactos (de granitos, areniscas y rodados), una punta de proyectil y rodados sin modificación; estos últimos posiblemente utilizados para pulir las vasijas. Por otra parte, se registraron restos de fauna entre los que se encuentran siete valvas de moluscos de agua dulce y huesos de distintas especies (coipo, carpincho, cérvidos y peces). Asimismo, se identificaron 111 instrumentos óseos elaborados sobre huesos y astas de cérvidos (Bonomo 2013). 


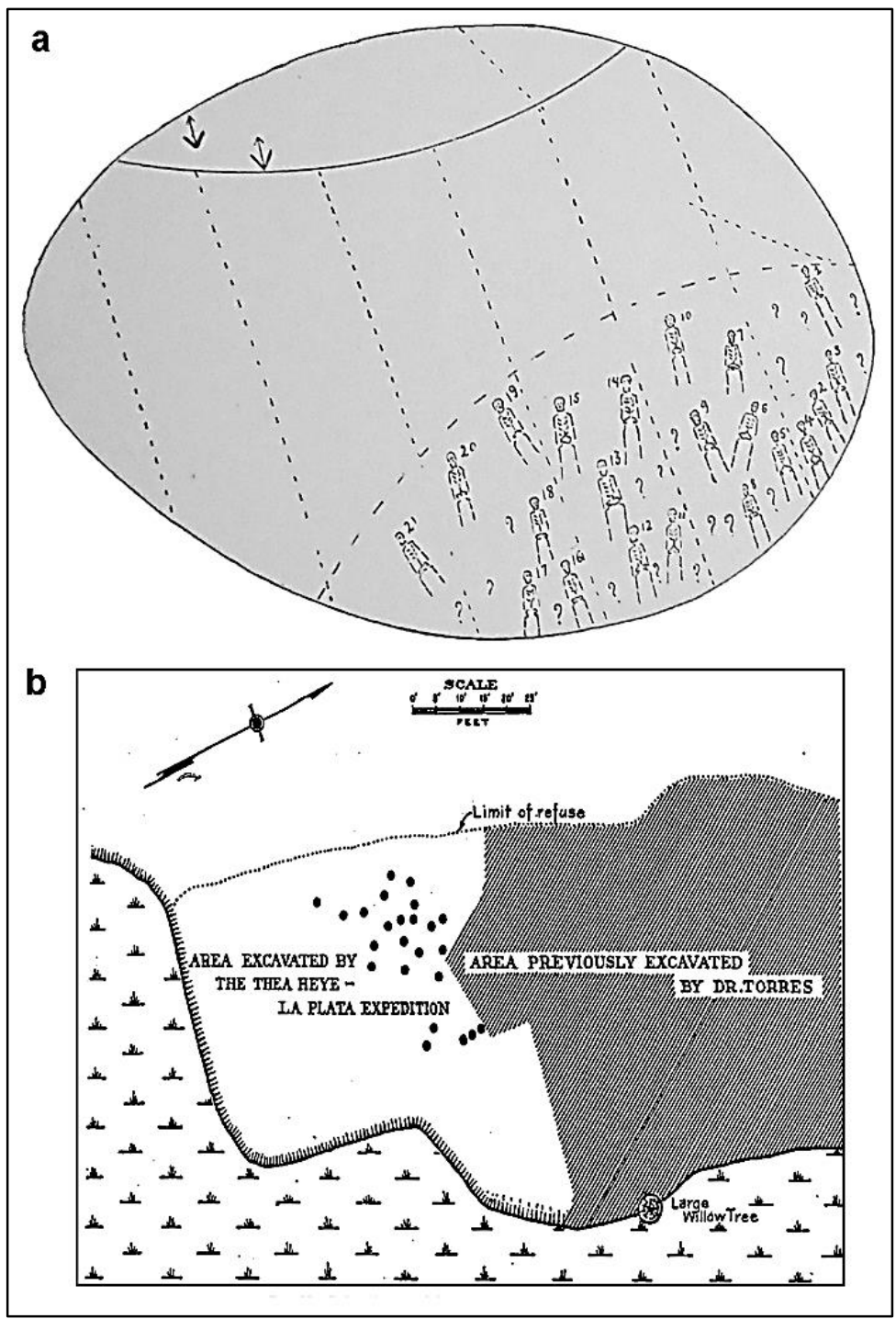

Figura 5.13. Excavaciones arqueológicas en EC/T1PG: a) croquis del túmulo con la ubicación de los entierros encontrados por Torres (tomado de Torres 1911: 185); b) esquema del área excavada por Lothrop, en blanco, y por Torres, en gris (Lothrop 1932: 148).

\subsubsection{Entierros humanos}

Durante los trabajos de campo de Torres fueron hallados más de 40 esqueletos humanos. Lamentablemente, en su obra de 1911, el autor no menciona detalladamente la cantidad de esqueletos encontrados ni especifica las modalidades de inhumación. Describe que no ha encontrado "restos de niños, ni excepción á la forma de disponer los cadáveres directamente en la tierra, como á su orientación" (1911: 185). Como se observa en la Figura 5.13a, los entierros que se esquematizan en su obra de 1911 corresponden a esqueletos completos enterrados de forma primaria. Sin embargo, Torres aclara que "los esqueletos no estaban completos sino 
que los distintos huesos largos que yacían con los cráneos, completamente fracturados, no servían sino para la indicación de la posición en que habían sido inhumados los cuerpos" (1911: 186). Particularmente, junto al cráneo n³ encontró algunos huesos largos (2 cúbitos, 1 radio, 2 fémures y 1 tibia) que estaban "como ya se ha observado en los anteriores hallazgos, en el mayor desorden, pues para identificar los distintos huesos he tenido que proceder con sumo cuidado" (Torres 1911: 105). Además, describe para este mismo hallazgo que, junto con el "gran amontonamiento de restos óseos humanos", estaban mezclados "residuos de cocina, fragmentos de alfarería y, especialmente, valvas de moluscos de agua dulce" (Torres 1911: 105). Considerando los detalles de este registro, se podría suponer que los entierros hallados por Torres en el montículo no estarían todos inhumados en modalidad primaria (tal como se esquematizaron), sino que algunos de ellos podrían corresponder a paquetes funerarios. Como resultado final de la campaña, el conjunto de huesos que se conservó y que fue remitido al museo platense se compone de 15 cráneos, 3 calotas y algunos fragmentos del occipital y parietales. Además, varios de estos cráneos $\left(n^{\circ} 2,3,5,7,8,12,17,18,1^{9}\right)$ fueron acompañados por vértebras y huesos largos (Torres 1911).

Con respecto a los entierros humanos excavados por Lothrop, en su publicación de 1932 detalla haber encontrado 23, de los cuales sólo cuatro estaban completos y articulados; otros no tenían algunos huesos en posición anatómica y el resto son entierros desarticulados e incompletos (1932: 150-151). A partir de la consulta de distintas fuentes inéditas (el diario de campo de Lothrop -con dibujos e información sobre cada hallazgo- y fotografías tomadas durante las excavaciones) pudieron identificarse con mayor precisión las modalidades inhumatorias (Ramos van Raap y Bonomo 2016). Se distinguieron 8 entierros primarios (3 en decúbito dorsal y 5 en decúbito ventral) y 2 paquetes funerarios formados cada uno por huesos largos y un cráneo. Asimismo, se presentaron tres casos de esqueletos con gran parte de su cuerpo articulado, pero con algunos huesos (cráneo y/o huesos

9 En el Catálogo de la Sección Antropológica del Museo de La Plata (Lehman-Nitsche 1911) se menciona que los cráneos que ingresaron al museo junto con huesos largos son: $n^{\circ} 2,3$, $5,8,12,17$ y 19 . Asimismo, para el $n^{\circ} 18\left(43 \frac{1}{1} 2\right)$ de la serie se aclara que corresponde a un lote de huesos sin cráneo. 
largos) removidos de manera intencional de su posición anatómica. Por otro lado, se registraron dos acumulaciones óseas (Figura 5.14a) y huesos dispersos. Según las descripciones de Lothrop (1932), las inhumaciones generalmente implicaban una previa preparación del lugar elegido: con posterioridad a un posible "fogón" se depositaba una capa de alimentos (por ej., pescados y moluscos) y sobre ellos volvía a encenderse fuego para finalmente, una vez consumido éste, colocar el cadáver. También Lothrop detalla la presencia de restos de "comida" junto a dos entierros primarios y rastros de pigmento rojizo debajo de los cuerpos. Por otro lado, junto con un entierro primario incompleto, se halló instrumentos óseos (siete raspadores y seis punzones, uno de ellos realizado sobre un hueso de pescado).

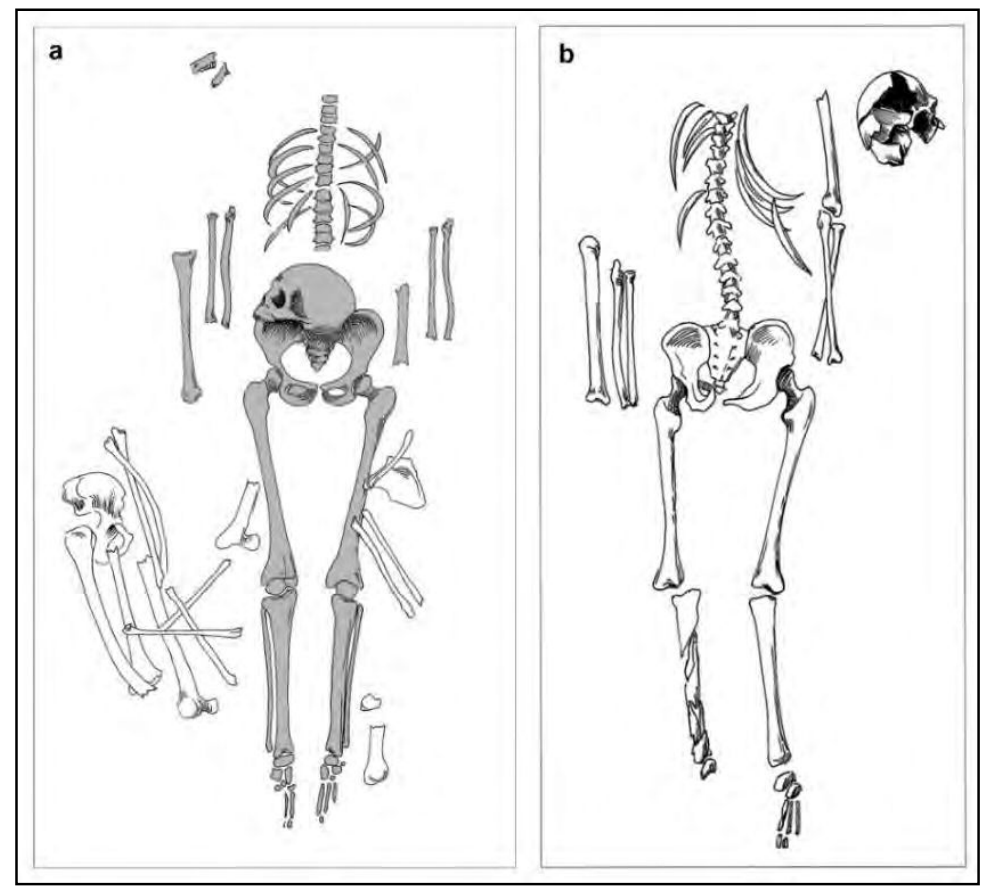

Figura 5.14. Esqueletos parcialmente articulados con reacomodación de elementos óseos encontrados en EC: a) entierro $n^{\circ} 4$ junto con una acumulación ósea $\left(n^{\circ} 5\right)$; b) entierro $n^{\circ} 10$; (tomado y modificado de Ramos van Raap y Bonomo 2016).

Se dispone de un fechado radiocarbónico sobre hueso humano de esta colección, de 576 \pm 42 años AP (código muestra: AA-93215; Bonomo et al. 2011b). También se cuenta con datos isotópicos obtenidos de un metatarso de un individuo adulto hallado en los trabajos de campo de Lothrop: $-20,1 \%$ o $\delta^{13} \mathrm{C}$ 
(colágeno); -14,5 \%o $\delta^{13} \mathrm{C}$ (apatita); y 9,8 \%o $\delta^{15} \mathrm{~N}$ (código muestra: UGAMS-11466; Bonomo et al. 2017a).

\subsubsection{Muestra bioarqueológica estudiada}

En el análisis realizado en esta tesis, se incluyeron los conjuntos óseos procedentes de las campañas de Torres y de Lothrop; ambos se encuentran actualmente bajo la guarda de la División Antropología del MLP. Con respecto a la colección de Torres (Túmulo I del Paraná Guazú), ésta se compone de 19 cráneos (cuatro de ellos junto con su mandíbula) catalogados bajo los números 27 a 37 y 39 a $46^{10}$. Los 19 individuos representados son adultos; uno de ellos fue estimado como adulto joven ya que los terceros molares del maxilar se encontraban en proceso de erupción. En cuanto al sexo, se determinaron 2 como femeninos, 3 como probables femeninos (uno de ellos es el adulto joven), 9 como masculinos y 4 como probables masculinos; el cráneo restante no presentaba los rasgos diagnósticos para su análisis (Tabla 5.1) ${ }^{11}$. Asimismo, pudieron ser localizados y estudiados huesos postcraneales bajo los números de inventario 28 (2) y 43 1/2 (18). El conjunto de huesos catalogados con el n²8 (húmero, radio y tibia izquierdos, cúbito derecho) corresponden al cráneo de misma numeración, de un adulto femenino. Los huesos identificados bajo el n043 1/2 son húmero y cúbito derecho, húmero y tibia izquierdos; corresponden al menos a un individuo adulto y tal como fuera mencionado previamente, este conjunto óseo no está asociado a un cráneo.

De la colección procedente de El Cerrillo (excavación Lothrop), se analizaron los siguientes números de inventario: 6439-A, 6440 a 6442, 6445, 6446-B, 6450 a 6453, 6455 a 6458, 6460, 7599, 7729 a 7735 y 7739. En la colección no se encontró todo el material inventariado en el Libro de Entrada de la División Antropología ni

10 No pudo ser localizado el cráneo n³8 (12), así como tampoco la totalidad de los elementos vertebrales y huesos largos que ingresaron al museo junto con algunos de los cráneos. La numeración de los cráneos 27 a 46 es análoga a la ofrecida también por Torres (1911), cuyos números son del 1 al 21.

11 Torres (1911) presenta las determinaciones sexuales de estos cráneos (utilizando la metodología de Bartels 1897; Torres 1911: 63). Durante las determinaciones realizadas en el análisis de esta tesis, los datos ofrecidos por Torres no fueron tenidos en cuenta, para evitar el sesgo. Luego, al comparar ambos resultados, se observó coincidencia en 13 casos. 
todo el conjunto bioarqueológico mencionado por Lothrop (1932) para este sitio ${ }^{12}$. Esto se debe probablemente a pérdidas ocurridas durante su recuperación, manipulación y almacenaje a lo largo de los años. Algunos de los números de inventario están constituidos por un solo elemento óseo (por ej. 7599 y 7729 a 7734), mientras que la mayoría se conforma por un conjunto de huesos (tres o más). Esto ha llevado a pensar que cada número de inventario no representa uno de los entierros encontrados en el sitio. Además, si bien algunos de estos números están acompañados por etiquetas que indican el número de esqueleto al que pertenecería ese conjunto de huesos, existen varias discrepancias al comparar esto con la publicación de Lothrop (1932) y los datos relevados en su diario de campo. Estas diferencias están dadas entre las modalidades de entierro, los elementos representados y los NMI. Dada esta situación, no fue posible corresponder los números de esqueletos dados por Lothrop con el inventario de la colección y, por ende, se decidió considerar a toda la colección como un conjunto sin poder discriminar por individuos y/o entierros.

De acuerdo a los análisis cuantitativos (Tabla 5.24), este conjunto osteológico se compone de 216 elementos; están mayormente representados fémures, mandíbulas, húmeros, rótulas, radios y cúbitos. A partir de los fémures se estimó un $\mathrm{NMI}=9$. Según los estados de fusión de las epífisis de estos elementos, están representados un adolescente (18-21 años) y ocho adultos. Entre los adultos, a partir de los coxales, se estimó la presencia de dos adultos jóvenes (21-23 y 30-34 años) y un adulto medio (35-44 años), todos ellos como probables masculinos ${ }^{13}$. Si bien no se identificaron subadultos (a excepción del adolescente mencionado), Lothrop describe en su diario de campo que uno de los entierros correspondería a un niño; y otros tres, a adolescentes (Ramos van Raap y Bonomo 2016). A partir de mediciones sobre los fémures derechos (lateralidad más representada) y la

12 Los números de inventario que no pudieron ser localizados son: $6437,6438,6443,6444$, 6447 a $6449,6454,6459,6461,6462,7600$ a 7603 y 7736.

13 Las determinaciones sexo-etarias presentadas aquí difieren con las previamente publicadas por la autora (Ramos van Raap y Bonomo 2016), debido a un nuevo reanálisis del material. Misma situación corresponde a la muestra bioarqueológica de Arroyo Sarandí. 
aplicación de fórmulas discriminantes, pudo determinarse la presencia de cuatro individuos masculinos y tres femeninos.

Tabla 5.24. Cálculos de abundancia anatómica del conjunto óseo de EC.

\begin{tabular}{|c|c|c|c|c|c|c|c|c|c|c|c|c|c|}
\hline \multirow{2}{*}{$\begin{array}{c}\text { Unidad } \\
\text { anatómica }\end{array}$} & \multirow{2}{*}{ NISP } & \multicolumn{4}{|c|}{$L / F$} & \multicolumn{4}{|c|}{$\mathbf{F}$} & \multirow{2}{*}{ NMI } & \multirow{2}{*}{ NME } & \multirow{2}{*}{ MAU } & \multirow{2}{*}{ MAU\% } \\
\hline & & D & $\mathbf{I}$ & A & In. & D & I & A & In. & & & & \\
\hline cráneo & 17 & & & & & & & 3 & & 3 & 3 & 3 & 37,5 \\
\hline mandíbula & 9 & & & & & 4 & 2 & 3 & & 7 & 7 & 7 & 87,5 \\
\hline vért. cervicales & 15 & & & & & & & 15 & & 5 & 15 & 2,1 & 26,2 \\
\hline vért. torácicas & 8 & & & & & & & 8 & & 1 & 8 & 0,7 & 8,7 \\
\hline vért. lumbares & 7 & & & & & & & 7 & & 2 & 7 & 1,4 & 17,5 \\
\hline costilla & 0 & & & & & & & & & 0 & 0 & 0 & 0 \\
\hline clavícula & 8 & & & & & 4 & 4 & & & 4 & 8 & 4 & 50 \\
\hline esternón & 2 & & & & & & & 2 & & 2 & 2 & 2 & 25 \\
\hline escápula & 0 & & & & & & & & & 0 & 0 & 0 & 0 \\
\hline húmero & 13 & & & & & 8 & 5 & & & 8 & 13 & 6,5 & 81,2 \\
\hline radio & 11 & & & & & 7 & 4 & & & 7 & 11 & 5,5 & 68,7 \\
\hline cúbito & 11 & & & & & 8 & 3 & & & 8 & 11 & 5,5 & 68,7 \\
\hline carpos & 2 & & & & & & 1 & & 1 & 1 & 2 & 0,2 & 2,5 \\
\hline metacarpos & 39 & & & & & 20 & 15 & & 4 & 4 & 39 & 3,9 & 48,7 \\
\hline falanges mano & 25 & & & & & & & & 25 & 2 & 25 & 1,8 & 22,5 \\
\hline coxal & 5 & & & & & 3 & 1 & & & 3 & 4 & 2 & 25 \\
\hline sacro & 2 & & & & & & & 2 & & 2 & 2 & 2 & 25 \\
\hline fémur & 16 & 1 & 1 & & & 8 & 6 & & & 9 & 16 & 8 & 100 \\
\hline rótula & 12 & & & & & 5 & 7 & & & 7 & 12 & 6 & 75 \\
\hline tibia & 7 & & & & & 3 & 4 & & & 4 & 7 & 3,5 & 43,75 \\
\hline peroné & 3 & & & & & 1 & 2 & & & 2 & 3 & 1,5 & 18,7 \\
\hline tarsos & 5 & & & & & 1 & 4 & & & 2 & 5 & 0,7 & 8,7 \\
\hline metatarsos & 6 & & & & & 2 & 4 & & & 1 & 6 & 0,6 & 7,5 \\
\hline falanges pie & 3 & & & & & & & & 3 & 1 & 3 & 0,2 & 2,5 \\
\hline dientes & 3 & & & & & & & & & 1 & 3 & - & - \\
\hline falanges in. & 3 & & & & & & & & 3 & 1 & 3 & - & - \\
\hline huesos in. & 1 & & & & & & & & 1 & 1 & 1 & - & - \\
\hline TOTAL & 233 & & & & & & & & & & 216 & & \\
\hline
\end{tabular}

Referencias: $N I S P=$ número mínimo de especímenes óseos; $L / F=$ con línea de fusión; F=fusionados; $\mathrm{D}=$ derecho; I=izquierdo; $\mathrm{A}=$ axial; In.=indeterminados; $\mathrm{NMI}=$ número mínimo de individuos; $\mathrm{NME}=$ número mínimo de elementos; $\mathrm{MAU}=$ unidades anatómicas mínimas; $\mathrm{MAU \% =porcentaje} \mathrm{de}$ unidades anatómicas mínimas. 


\subsubsection{Arroyo Sarandí}

\subsubsection{Caracterización general}

El sitio Arroyo Sarandí se ubica sobre la margen derecha del arroyo

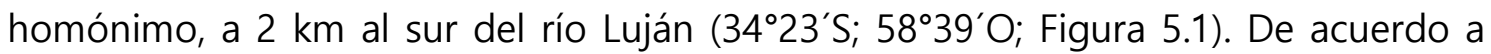
la descripción de Lothrop (1932: 164), se compone de una fina capa de desechos, en cuyos extremos norte y sur se destacan dos elevaciones (A y B) (Figura 5.15); las mismas se vieron afectadas por las actividades de arado y por el pisoteo del ganado, lo que redujo su altura original. Este sitio fue relocalizado por Lafon, quien realizó allí trabajos de campo a fines de la década de 1960 (Lafon 1971).

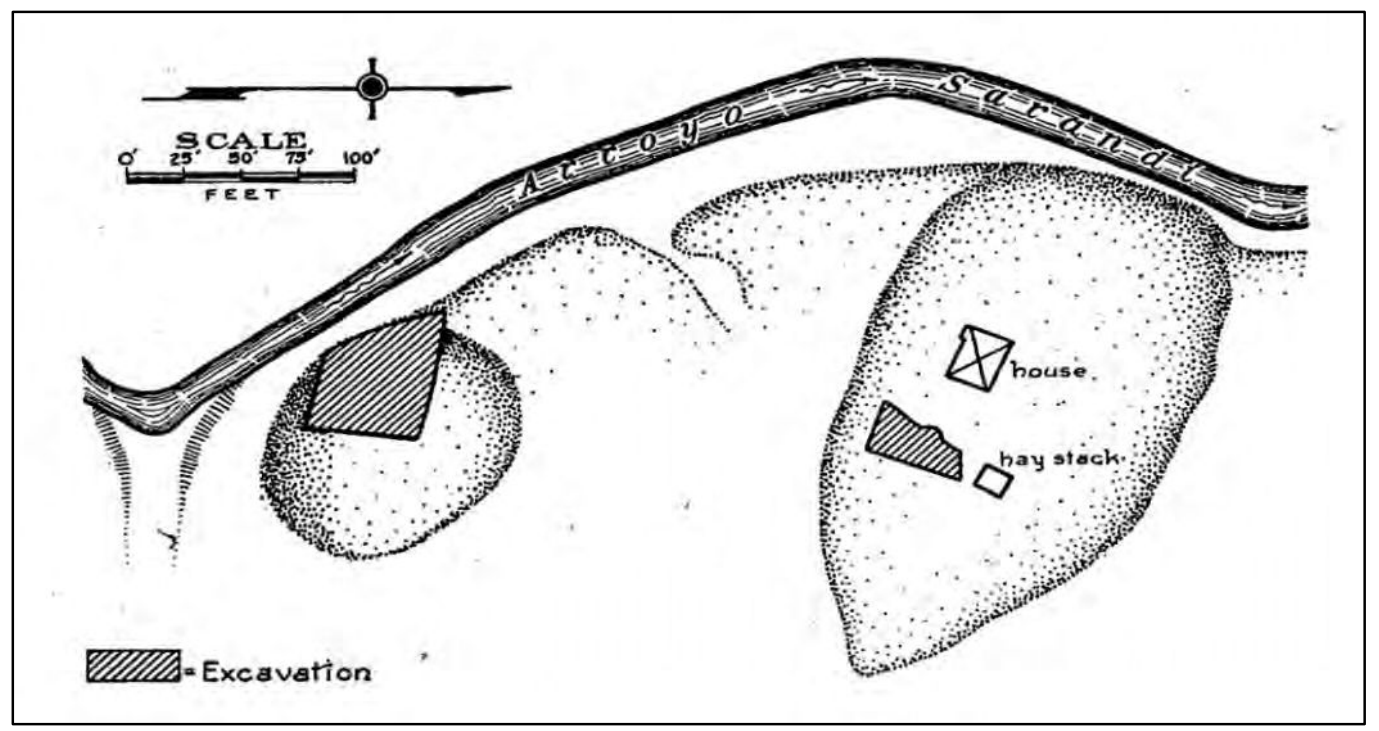

Figura 5.15. Zonas excavadas en las elevaciones de AS (tomado de Lothrop 1932: 163).

Las excavaciones dirigidas por Lothrop se realizaron en forma de trincheras en ambas elevaciones. En la ubicada hacia el norte (elevación B), se abrió una superficie de $80 \mathrm{~m}^{2}$, mientras que en la del sur (elevación A) el área excavada alcanzó los $225 \mathrm{~m}^{2}$. Además de encontrar entierros humanos, se hallaron numerosos materiales arqueológicos (cerámicos, líticos, instrumentos óseos). Si bien la mayoría de ellos fueron transportados hacia el NMAl, algunos fueron al MLP. De acuerdo a los estudios realizados en los últimos años (Bonomo et al. 2009; Bonomo 2013), entre los restos cerámicos se destacan 47 fragmentos de alfarerías tubulares, 2 pendientes perforados, 1 cuenco entero y 1 tortero. Entre los materiales líticos hay 2 puntas de proyectil y 1 disco auricular, así como también 40 rodados sin 
modificación antrópica y artefactos abradidos y/o modificados por su uso (percutores, yunques, morteros, molinos y manos); dada la ausencia de desechos de talla, la manufactura de estos artefactos no se realizó en el sitio (Bonomo 2013). Por otro lado, se encontraron 220 cuentas confeccionadas en valvas de moluscos (marinos y de río) y 70 instrumentos óseos de distintos tipos (puntas, biseles, ganchos de propulsor y horquetas perforadas) realizados principalmente sobre astas y huesos largos de cérvidos. A partir de los trabajos realizados en el sitio y la observación de los materiales hallados, Lothrop adjudicó la ocupación de Arroyo Sarandí a grupos querandíes (1932: 101).

\subsubsection{Entierros humanos}

Los entierros humanos hallados en el sitio alcanzan una cifra de 42; uno de ellos se ubicaba en la elevación del norte (B) mientras que los restantes 41 en la elevación del sur (A). Entre estos últimos, Lothrop describe que 17 eran primarios, 17 eran claramente secundarios, 2 correspondían a restos de infantes y 5 se encontraban muy fragmentados como para su identificación (1932: 164). Debido a que 21 fueron encontrados a una profundidad de seis pulgadas o menos (equivalente a ca. $15 \mathrm{~cm}$ ), en muchos casos los huesos estaban disturbados por el arado. Lothrop asumió que ésta habría sido una de las causas por las cuales la mayoría de los entierros primarios, y seguramente también los secundarios, se encontraron de forma incompleta: al arar la tierra, algunos huesos fueron removidos hacia la superficie y quedaron expuestos al pisoteo del ganado, generando así su fragmentación (1932: 164).

De acuerdo a lo observado en el diario de campo de Lothrop y a las fotografías tomadas durante las excavaciones, se han podido relevar con mayor detalle los distintos tipos de entierros (Ramos van Raap y Bonomo 2016). Entre los 19 entierros determinados como de tipo primario, los esqueletos yacían tanto en posición decúbito dorsal $(n=7)$ como ventral $(n=6)$ (Figura 5.11). Por otro lado, se identificaron un paquete funerario (compuesto por cráneo, mandíbula, pelvis, huesos largos y fragmentos indeterminados), dos acumulaciones óseas (conformadas sólo por huesos largos) y dos hallazgos de huesos dispersos. 
Asimismo, se observaron dos esqueletos con reacomodación intencional del cráneo sobre la pelvis, en un caso, y al costado de ella, en el otro (Figura 5.16).

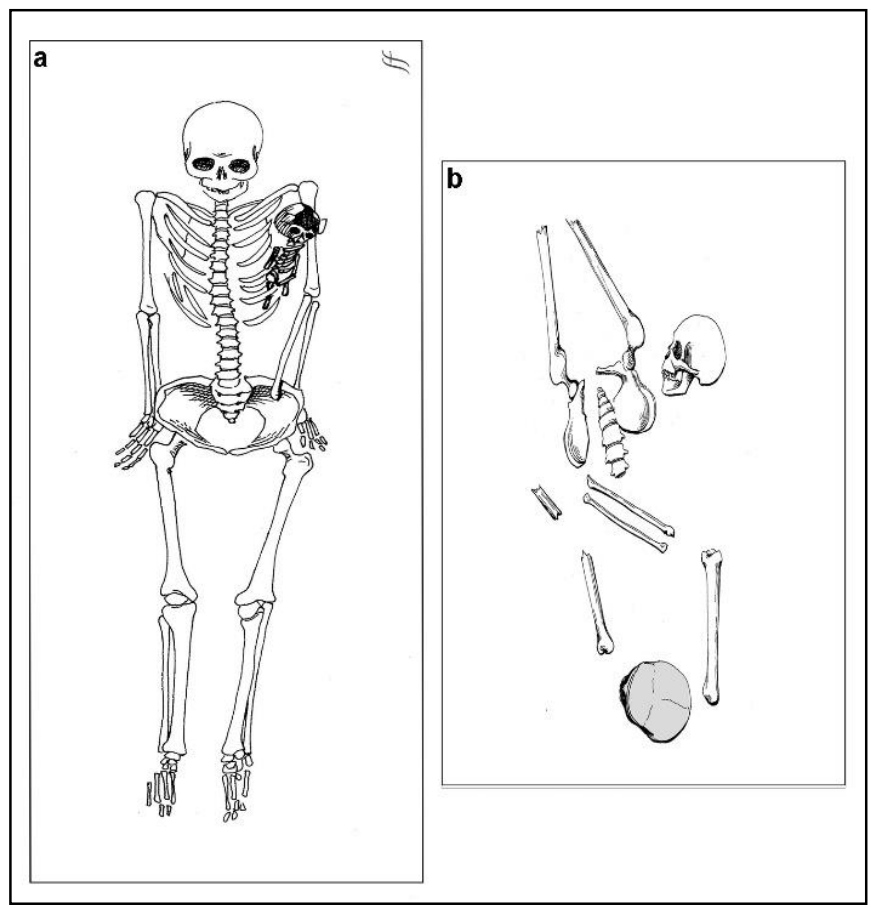

Figura 5.16. Entierros humanos en AS: a) entierro primario de un adulto $\left(n^{\circ} 25\right)$ junto con el de un infante sobre su brazo izquierdo $\left(n^{\circ} 34\right) ;$ b) esqueleto $\left(n^{\circ} 6\right)$ incompleto y con reacomodación del cráneo al costado de la pelvis derecha (el cráneo en color gris es de otro individuo) (tomado y modificado de Ramos van Raap y Bonomo 2016).

Se han realizado dos fechados radiocarbónicos sobre huesos humanos de

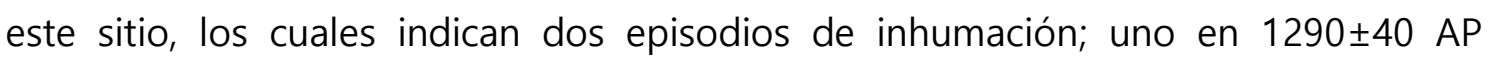
(código muestra: UGA-10788; Loponte 2008) y otro más tardío de 688 \pm 42 años AP (código muestra: AA-93219; Bonomo et al. 2011b). También se cuenta con información de isótopos estables de $\delta^{13} \mathrm{C}$ y $\delta^{15} \mathrm{~N}$, sobre huesos de individuos adultos recuperados en los trabajos de campo de Lothrop (Tabla 5.25).

Tabla 5.25. Datos isotópicos obtenidos para individuos de AS.

\begin{tabular}{|cccccc|}
\hline Código & Muestra & (\%o) $\boldsymbol{\delta}^{13} \mathbf{C}$ & $\mathbf{( \% o )} \boldsymbol{\delta}^{13} \mathbf{C}$ & (\%o) & Referencia \\
\hline UGAMS-11468 & clavícula & $-19,6$ & $-13,1$ & 12,4 & Bonomo et al. 2017a \\
UGA-10788 & - & $-20,17$ & - & - & Loponte y Acosta 2007 \\
AIE-12366 & - & $-20,3$ & - & - & Loponte y Acosta 2007 \\
\hline
\end{tabular}




\subsubsection{Muestra bioarqueológica estudiada}

Los números de inventario del Libro de Entradas de la División Antropología del MLP que fueron analizados son: 6463 a 6481, 6484 a 6486, 6489 a 6493, 7658 y 765914. Tal como fuera relevado para El Cerrillo, algunos de estos números de inventario de Arroyo Sarandí se encuentran conformados por uno o dos elementos (por ej. 6464, 6472, 7658) y varios de ellos están acompañados por etiquetas que indican el número de esqueleto asignado por Lothrop. Debido a la imposibilidad de corresponder de forma precisa los entierros descriptos por Lothrop (1932) con cada número de inventario, la muestra bioarqueológica fue considerada de manera conjunta sin poder discriminar por esqueletos.

Se analizaron 298 elementos (Tabla 5.26). Los huesos con mayor representación en el conjunto son los húmeros, cúbitos, fémures y, principalmente, las mandíbulas. Es a partir de ellas que se estimó un NMI de 18; entre estos individuos se identificó un niño (9-10 años), un adolescente (18-21 años) y 16 adultos. Por otro lado, al analizar los elementos postcraneales, se registraron coxales y huesos largos de los miembros superiores e inferiores de al menos tres adolescentes: uno entre 14-16 años y dos entre 18-20 años (uno de ellos masculino). En el grupo etario de los adultos, a partir de coxales, se pudo determinar la presencia de dos adultos jóvenes (25-35 años) masculinos. Es interesante notar que la cantidad de individuos analizados es mucho menor a los 42 esqueletos referidos por Lothrop. Además, el autor detalla en el diario de campo la edad y el sexo de los individuos: al menos dos infantes habrían sido enterrados junto con individuos adultos (uno es el de la Figura 5.16.a, el otro no pudo ser recuperado en el campo); y se mencionan siete individuos masculinos y cinco femeninos entre los esqueletos hallados.

14 No pudieron ser localizados algunos números de inventario: 6482, 6483, 6487, 6488, 7660 y 7741. 
Tabla 5.26. Cálculos de abundancia anatómica del conjunto óseo de AS.

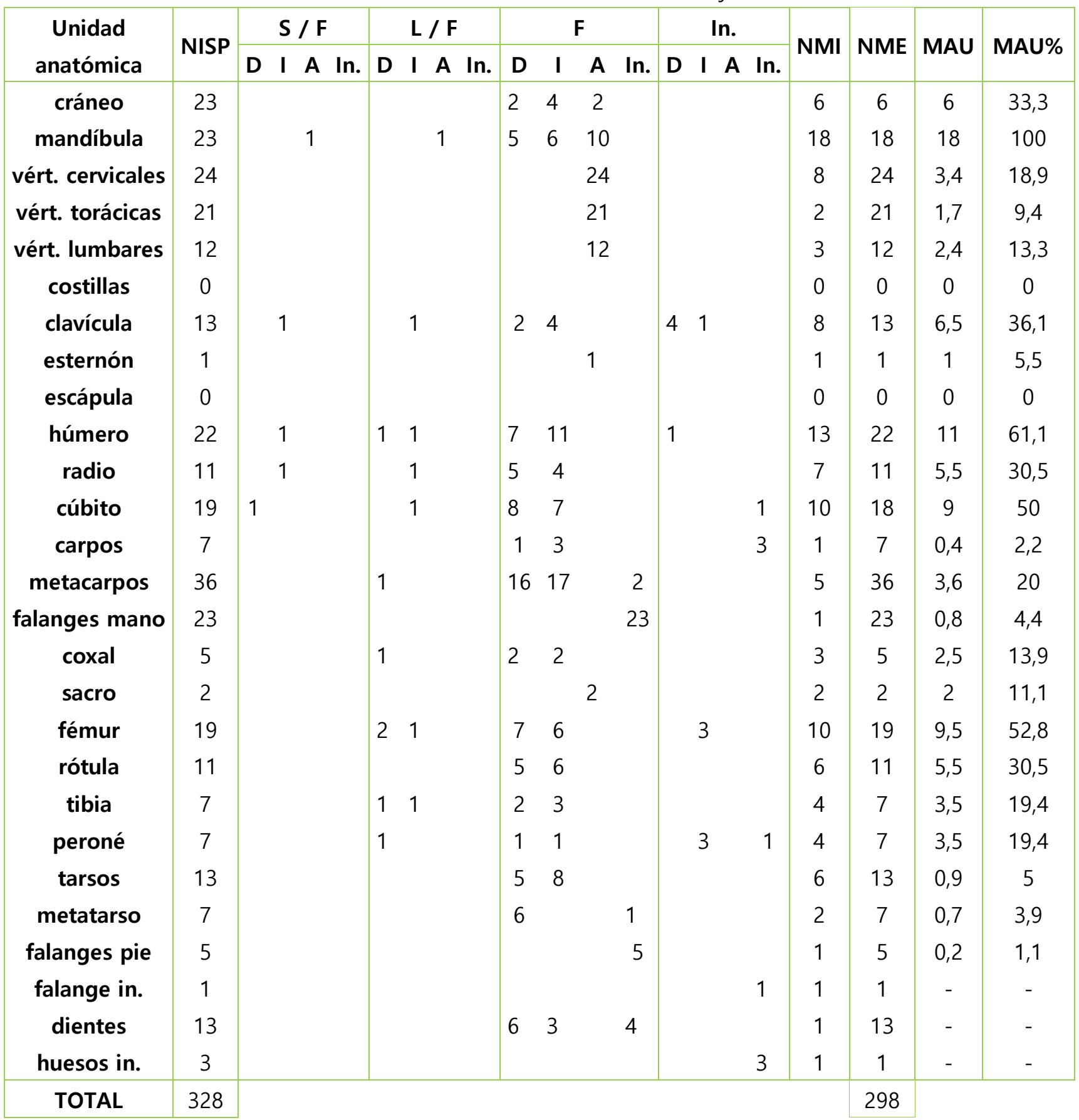

Referencias: NISP=número de especímenes óseos; $S / F=\sin$ fusionar; $L / F$ con línea de fusión;

$\mathrm{F}=$ fusionados; $\mathrm{D}=$ derecho; I=izquierdo; $\mathrm{A}=$ axial; In.=indeterminados; $\mathrm{NMI}=$ número mínimo de individuos; $\mathrm{NME}=$ número mínimo de elementos; $\mathrm{MAU}=$ unidades anatómicas mínimas;

MAU\%=porcentaje de unidades anatómicas mínimas. 


\subsection{Palabras finales}

A partir de lo que fue expuesto en los apartados precedentes, se destaca que la información arqueológica contextual y los datos relativos a los entierros humanos de cada una de las muestras bioarqueológicas estudiadas no presenta el mismo grado de detalle y precisión. Esto se debe a que algunos de los sitios arqueológicos, precisamente los dos ubicados en el DS, han sido excavados de forma sistemática con métodos contemporáneos en el marco de proyectos de investigación a largo plazo (Bonomo et al. 2011b, 2016, 2017a; Politis et al. 2011; Politis y Bonomo 2012; Castiñeira Latorre et al. 2013, 2014). Las tareas de campo en estos sitios implicaron el registro minucioso de cada hallazgo y se estudiaron distintas líneas de evidencia. Por su parte, la muestra bioarqueológica de los ocho sitios ubicados en CIRU proceden de los trabajos de campo realizados allí por un aficionado a la arqueología, el Sr. Manuel Almeida, y que actualmente se encuentran en el museo que lleva su nombre (Gualeguaychú, Entre Ríos). Si bien sus tareas han sido bastante meticulosas, llevando a cabo anotaciones y el inventariado de lo hallado, la mayor información contextual de cada sitio procede principalmente de las investigaciones actuales de Castro, J.C. (2017), quien retoma y estudia parte de estos mismos sitios. En este contexto también se encuentra el sitio Túmulo 1-La Argentina, de la muestra del DI. En el caso de los otros dos sitios arqueológicos del DI, se encuentran bajo la guarda de la División Antropología del Museo de La Plata y proceden de expediciones arqueológicas llevadas a cabo a principios del siglo XX; las publicaciones científicas realizadas por los investigadores a cargo de los trabajos de campo (Torres 1911; Lothrop 1932) y los reanálisis efectuados en los últimos años (Loponte 2008; Bonomo et al. 2009; Bonomo 2013; Ramos van Raap y Bonomo 2016), han aportado distintos datos sobre estos sitios.

Estos contextos particulares en los cuales se conformaron cada una de las muestras bioarqueológicas estudiadas, tienen relevancia en los análisis efectuados en esta tesis. Específicamente con respecto a la estructura sexo-etaria de cada uno de los conjuntos osteológicos, lo cual ha impactado en los análisis cuantitativos a nivel individual de las prevalencias de los indicadores de salud bucal y adecuación fisiológica y las lesiones óseas, que se detallan en los capítulos siguientes. 


\section{Capítulo 6}

\section{Resultados: indicadores de salud bucal y adecuación fisiológica}

En este capítulo se presentan los resultados del relevamiento y evaluación de los indicadores de salud bucal y adecuación fisiológica analizados en cada muestra bioarqueológica. Es importante recordar que no se cuenta con el mismo grado de información para todas las muestras en cuanto a la estructura sexo-etaria y que, por este motivo, los estudios cuantitativos que se realizaron variaron entre ellas. Finalmente, se integran y discuten los resultados de manera comparativa entre las tres muestras.

\subsection{Caries}

\subsubsection{Delta Superior del río Paraná}

Se analizaron 294 dientes pertenecientes a al menos 15 individuos y se registraron en total cinco caries (Tabla 6.1). A nivel de piezas dentales afectadas, la prevalencia obtenida es baja (1,7\%). A nivel individual, se observaron estas lesiones infecciosas en un $33,3 \%$ de la muestra, que corresponden a un adolescente y cuatro adultos. No se obtuvieron valores estadísticos que permitan asociar la ocurrencia de las caries y la edad de los individuos (subadultos vs. adultos: $p=1$; adolescente y adulto joven vs. adulto medio y adulto mayor: $p=1$ ). En cuanto al sexo (Tabla 6.1), al considerar la distribución de las caries por individuo, los femeninos fueron los más afectados en comparación con los masculinos; mientras que a nivel de dientes afectados se registraron prevalencias similares entre ambos sexos $(1,9 \%$ y $2 \%$, respectivamente). Estadísticamente no existe dependencia de la presencia de caries por pieza dental y sexo $(p=1)$. De todas maneras, el $20 \%$ de los individuos afectados en los que no se pudo determinar el sexo (incluyendo a los subadultos), puede estar sesgando este resultado. 
Tabla 6.1. Prevalencias de caries en la muestra del DS.

\begin{tabular}{|c|c|c|c|c|c|}
\hline & \multicolumn{2}{|c|}{ Individuos } & \multicolumn{2}{|c|}{ Dientes completos } \\
\hline & & A / O & $\%$ & A / O & $\%$ \\
\hline \multirow{9}{*}{$\begin{array}{l}. ㅇ \\
\frac{0}{5} \\
\frac{0}{0} \\
\circ \\
\frac{0}{2} \\
\frac{3}{0}\end{array}$} & Infante & $0 / 1$ & 0 & $0 / 6$ & 0 \\
\hline & Niño & $0 / 1$ & 0 & $0 / 13$ & 0 \\
\hline & Subadultos (deciduos)* & - & - & $0 / 6$ & 0 \\
\hline & Adolescente & $1 / 3$ & 33,3 & $1 / 64$ & 1,6 \\
\hline & Adulto joven & $0 / 2$ & 0 & $0 / 20$ & 0 \\
\hline & Adulto medio & $1 / 2$ & 50 & $1 / 32$ & 3,1 \\
\hline & Adulto mayor & $0 / 1$ & 0 & $0 / 31$ & 0 \\
\hline & Adulto in. & $3 / 5$ & 60 & $3 / 91$ & 3,3 \\
\hline & In. (permanentes)* & - & - & $0 / 31$ & 0 \\
\hline \multirow{4}{*}{ 文 } & Femenino & $3 / 7$ & 42,8 & $3 / 154$ & 1,9 \\
\hline & Masculino & $1 / 3$ & 33,3 & $1 / 50$ & 2 \\
\hline & In. & $1 / 5$ & 20 & $1 / 90$ & 1,1 \\
\hline & Total & $5 / 15$ & 33,3 & $5 / 294$ & 1,7 \\
\hline
\end{tabular}

Referencias: $\mathrm{A}=$ afectado; $\mathrm{O}=$ observado; in.=indeterminado; *dientes sueltos, que podrían corresponder a cualquiera de los individuos identificados.

En la Tabla 6.2 pueden observarse las características de cada caries relevada en los cinco individuos. Según su distribución por tipo de pieza dental, únicamente fueron afectados los Pm y M3, tanto del maxilar como de la mandíbula. A excepción de una lesión localizada en la cara interproximal mesial del diente, todas fueron lesiones moderadas y se encontraron en la superficie oclusal afectando tanto al esmalte como a la dentina (Figura 6.1).

Tabla 6.2. Características de las caries registradas en la muestra del DS.

\begin{tabular}{|ccccccc|}
\hline Individuo & $\begin{array}{c}\text { Grupo } \\
\text { etario }\end{array}$ & Sexo & Diente & Ubicación & $\begin{array}{c}\text { Tejido } \\
\text { afectado }\end{array}$ & Severidad \\
\hline LTC1-P1 & adolescente & $\mathrm{F}$ & $\mathrm{M}^{3} \mathrm{~d}$ & oclusal & dentina & moderada \\
LTC1-P2 & adulto & $\mathrm{M}$ & $\mathrm{M}_{3} \mathrm{~d}$ & oclusal & esmalte & moderada \\
LTC1-S1-2 & a. medio & $\mathrm{F}$ & $\mathrm{Pm}^{1} \mathrm{~d}$ & borde interproximal mesial & dentina & moderada \\
LTC1-S6 & adulto & $\mathrm{F}$ & $\mathrm{M}_{3} \mathrm{i}$ & oclusal & esmalte & moderada \\
LDLG2-2 & adulto & in. & $\mathrm{Pm}_{2} \mathrm{i}$ & oclusal & dentina & moderada \\
\hline
\end{tabular}

Referencias: $\mathrm{a} .=$ adulto; $\mathrm{F}=$ femenino; $\mathrm{M}=$ masculino; in.=indeterminado. 


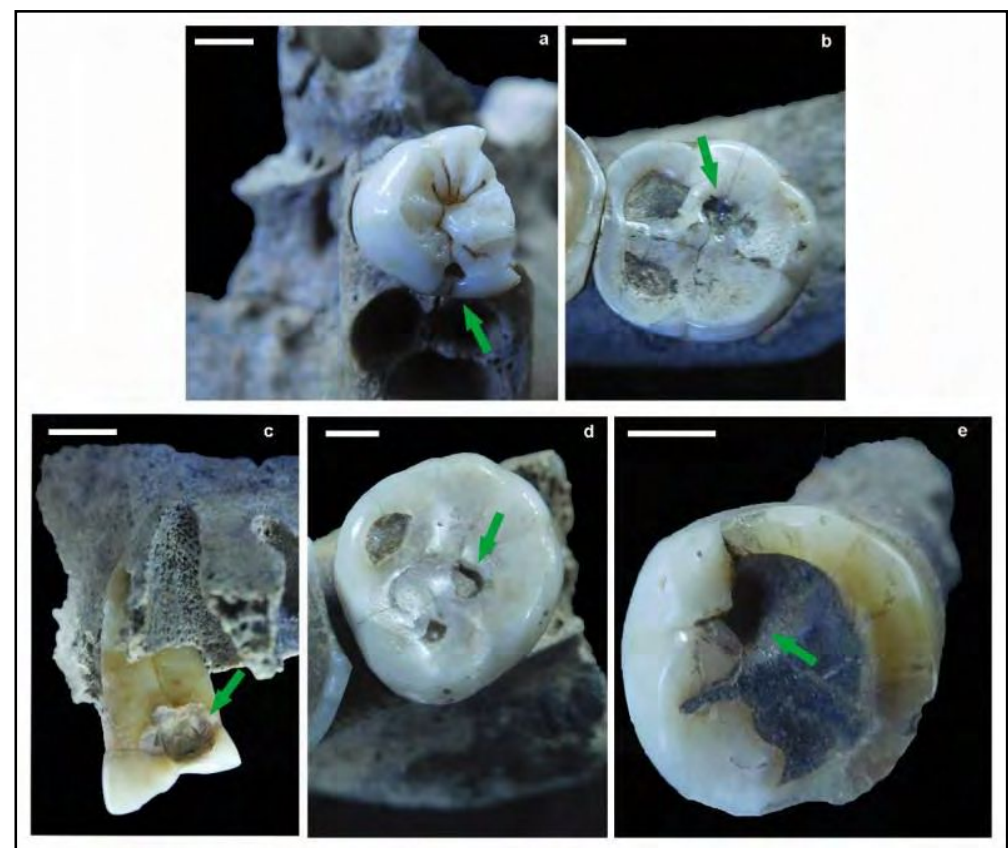

Figura 6.1. Caries registradas en la muestra del DS: a) LTC1-P1; b) LTC1-P2; C) LTC1-S1-2; d) LTC1-S6; e) LDLG2-2. Escalas $=0,5 \mathrm{~cm}$.

\subsubsection{Cuenca inferior del río Uruguay}

Se analizaron 715 dientes pertenecientes a 50 individuos y se registraron en total cinco caries (Tabla 6.3). Las prevalencias obtenidas a nivel dental e individual son muy bajas: $0,7 \%$ y $10 \%$, respectivamente. Al evaluar la presencia de estas lesiones y la edad de los individuos (adultos vs. subadultos), no se obtuvieron valores estadísticos a nivel de piezas dentales para asociar la ocurrencia de caries con la edad de los individuos $(p=1)$. En cuanto al sexo, las prevalencias son similares entre los femeninos y masculinos (Tabla 6.3); tampoco existe dependencia entre estas variables $(p=1)$. 
Tabla 6.3. Prevalencias de caries en la muestra de CIRU.

\begin{tabular}{|c|c|c|c|c|c|}
\hline & \multicolumn{2}{|c|}{ Individuos } & \multicolumn{2}{|c|}{ Dientes completos } \\
\hline & & $\mathrm{A} / \mathrm{O}$ & $\%$ & A / O & $\%$ \\
\hline \multirow{6}{*}{$\begin{array}{l}.0 \\
\frac{0}{2} \\
\frac{1}{0} \\
8 \\
\frac{8}{2} \\
\frac{0}{0}\end{array}$} & Infante & $0 / 1$ & 0 & $0 / 6$ & 0 \\
\hline & Niño & $0 / 3$ & 0 & $0 / 23$ & 0 \\
\hline & Adolescente & $0 / 3$ & 0 & $0 / 59$ & 0 \\
\hline & Adulto joven & $1 / 9$ & 11,1 & $1 / 176$ & 0,6 \\
\hline & Adulto medio & $0 / 1$ & 0 & $0 / 24$ & 0 \\
\hline & Adulto in. & $4 / 33$ & 12,1 & $4 / 427$ & 0,9 \\
\hline \multirow{4}{*}{ 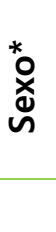 } & Femenino & $1 / 10$ & 10 & $1 / 215$ & 0,5 \\
\hline & Masculino & $2 / 16$ & 12,5 & 2 / 292 & 0,7 \\
\hline & In. & $2 / 24$ & 8,3 & $2 / 208$ & 1 \\
\hline & Total & $5 / 50$ & 10 & $5 / 715$ & 0,7 \\
\hline
\end{tabular}

Referencias: $\mathrm{A}=$ afectado; $\mathrm{O}=$ observado; In.=indeterminado; ${ }^{*}=$ entre los femeninos y los masculinos se incluyó en cada categoría a un individuo probable femenino y a un probable masculino.

Las cinco lesiones cariosas registradas afectaron principalmente a piezas de la dentición posterior, tanto superior como inferior, en cinco individuos adultos (Tabla 6.4; Figura 6.2). Se destaca que una de estas caries afectó a los bordes interproximales de dos dientes contiguos del maxilar de un adulto (Figura 6.2.d). Las severidades de todas estas lesiones fueron moderadas a severas e involucraron al esmalte en unos casos y a la cámara pulpar, en otros.

Tabla 6.4. Características de las caries registradas en la muestra de CIRU.

\begin{tabular}{|c|c|c|c|c|c|c|}
\hline Individuo & $\begin{array}{l}\text { Grupo } \\
\text { etario }\end{array}$ & Sexo & Diente & Ubicación & $\begin{array}{c}\text { Tejido } \\
\text { afectado }\end{array}$ & Severidac \\
\hline CL2-67 & adulto & M & $M^{3} \mathrm{i}$ & oclusal & esmalte & moderada \\
\hline CL2-52 & a. joven & $M$ & $M^{1} i$ & indeterminada & cámara pulpar & severa \\
\hline SPL-104 & adulto & $\mathrm{F}$ & $M_{3} d$ & oclusal & esmalte & moderada \\
\hline SPL-87 & adulto & in. & $\mathrm{Pm}^{1}$ y $\mathrm{C}^{1} \mathrm{~d}$ & borde interproximal & cámara pulpar & severa \\
\hline CP-228 & adulto & in. & $\mathrm{M}_{3} \mathrm{i}$ & oclusal & esmalte & moderada \\
\hline
\end{tabular}

Referencias: $\mathrm{a} .=$ adulto; $\mathrm{F}=$ femenino; $\mathrm{M}=$ masculino; in.=indeterminado. 


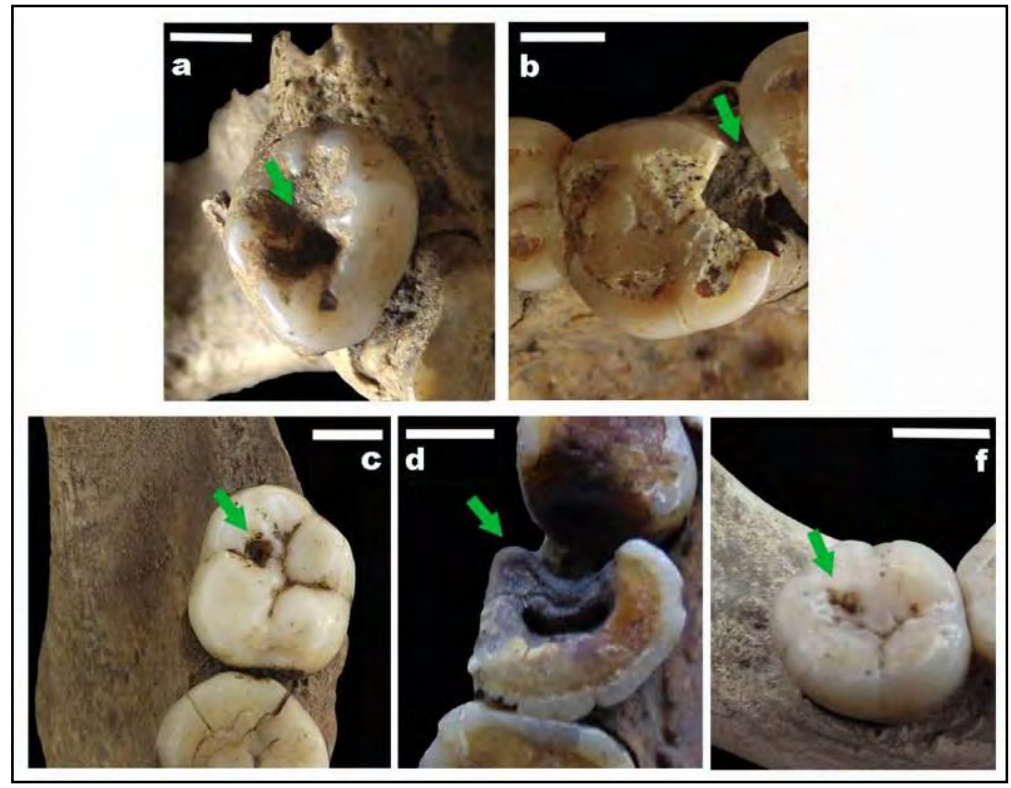

Figura 6.2. Caries registradas en la muestra de CIRU: a) CL2-67; b) CL2-52; c) SPL-104; d) SPL-87; e) CP-228. Escalas $=0,5 \mathrm{~cm}$.

\subsubsection{Delta Inferior del río Paraná y ambientes litorales adyacentes}

Se analizaron 404 dientes de 26 maxilares y de 37 mandíbulas y se registraron en total seis caries (Tabla 6.5). A nivel de las piezas dentales, estas lesiones presentan una frecuencia baja en la muestra (1,5\%). A nivel individual, las prevalencias fueron calculadas por separado para cada una de las arcadas dentarias; esto se debe a las características de dos de los conjuntos bioarqueológicos de esta muestra que impiden asociar maxilares y mandíbulas (véase en detalle Capítulo 5). Teniendo en cuenta esto, para los maxilares se obtuvo una prevalencia de $11,5 \%$ y de 2,7\% para las mandíbulas. Precisamente 16 de los 17 individuos de esta muestra en los que se pudo determinar el sexo, poseen maxilar (Tabla 6.6); en estos casos no se obtuvieron resultados estadísticos que permitan asociar la ocurrencia de caries con el sexo $(p=0,2)$. Tampoco existe dependencia entre la ocurrencia de caries y la edad de los individuos (adultos vs. subadultos; $p=1$ ). 
Tabla 6.5. Prevalencias de caries por grupo de edad en la muestra del DI.

\begin{tabular}{|c|cccc|cc|}
\hline \multirow{2}{*}{ Grupo etario } & \multicolumn{4}{|c|}{ Individuos } & \multicolumn{2}{c|}{ Dientes completos } \\
& A / O & $\%$ & A / O & $\%$ & A / O & $\%$ \\
\hline Niño & - & - & $0 / 1$ & 0 & $0 / 4$ & 0 \\
Adolescente & $0 / 1$ & 0 & $0 / 2$ & 0 & $0 / 27$ & 0 \\
Adulto joven & $0 / 1$ & 0 & - & - & $0 / 15$ & 0 \\
Adulto in. & $3 / 23$ & 13 & $1 / 34$ & 2,9 & $5 / 335$ & 1,5 \\
In. & $0 / 1$ & 0 & - & - & $1 / 23^{*}$ & 4,3 \\
\hline Total & $\mathbf{3} / \mathbf{2 6}$ & $\mathbf{1 1 , 5}$ & $\mathbf{1} / \mathbf{3 7}$ & $\mathbf{2 , 7}$ & $\mathbf{6} / \mathbf{4 0 4}$ & $\mathbf{1 , 5}$ \\
\hline
\end{tabular}

Referencias: $\mathrm{A}=$ afectado; $\mathrm{O}=$ observado; In.=indeterminado; * además de los dientes del maxilar de un individuo indeterminado, se incluyen los dientes sueltos permanentes.

Tabla 6.6. Prevalencias de caries por sexo (en maxilares) en la muestra del DI.

\begin{tabular}{|c|cc|cc|}
\hline \multirow{2}{*}{ Sexo* } & \multicolumn{2}{|c|}{ Individuos } & \multicolumn{2}{|c|}{ Dientes completos } \\
& A/O & $\%$ & A/O & $\%$ \\
\hline Femenino & $0 / 5$ & 0 & $0 / 49$ & 0 \\
Masculino & $2 / 11$ & 18,2 & $3 / 72$ & 4,2 \\
In. & $1 / 10$ & 10 & $1 / 49$ & 2 \\
\hline Total & $\mathbf{3} / \mathbf{2 6}$ & $\mathbf{1 1 , 5}$ & $\mathbf{4} / \mathbf{1 7 0 * *}$ & $\mathbf{2 , 3}$ \\
\hline
\end{tabular}

Referencias: * = se incluyó en cada categoría a dos individuos probable femeninos y a dos probable masculinos. $\mathrm{A}=$ afectado; $\mathrm{O}=$ observado; In.=indeterminado; ${ }^{* *}=$ las dos caries restantes fueron registradas en un diente de una mandíbula y en un diente superior aislado.

Las seis lesiones infecciosas se ubican principalmente en la superficie oclusal de la dentición posterior del maxilar y afectaron a la dentina (Tabla 6.7, Figura 6.3). Se destacan los $\mathrm{M}^{1}$ y $^{2}$ contiguos de un adulto masculino que presentan cada uno una caries sobre el borde interproximal distal. La severidad relevada para todos los casos fue moderada, a excepción de una lesión severa que alcanzó la cámara pulpar del diente. 
Tabla 6.7. Características de las caries registradas en la muestra del DI.

\begin{tabular}{|ccccccc|}
\hline Hueso & $\begin{array}{l}\text { Grupo } \\
\text { etario }\end{array}$ & Sexo & Diente & Ubicación & Tejido afectado & Severidad \\
\hline AS-12C-6468 & adulto & in. & $\mathrm{Pm}^{1} \mathrm{i}$ & oclusal & dentina & moderada \\
\hline EC-12B-6441 & adulto & in. & $\mathrm{M}_{1} \mathrm{~d}$ & oclusal & dentina & moderada \\
\hline EC-27B-6452 & adulto & in. & $\mathrm{M}^{3} \mathrm{~d}$ & oclusal & esmalte & moderada \\
\hline T1PG-29 & adulto & $\mathrm{M}$ & $\mathrm{M}^{2} \mathrm{~d}$ & borde interproximal distal & dentina & moderada \\
& & & $\mathrm{M}^{1} \mathrm{~d}$ & borde interproximal distal & cámara pulpar & severa \\
\hline T1PG-44 & adulto & $\mathrm{M}$ & $\mathrm{M}^{3} \mathrm{~d}$ & oclusal & esmalte & moderada \\
\hline
\end{tabular}

Referencias: in.=indeterminado; $M=$ masculino.

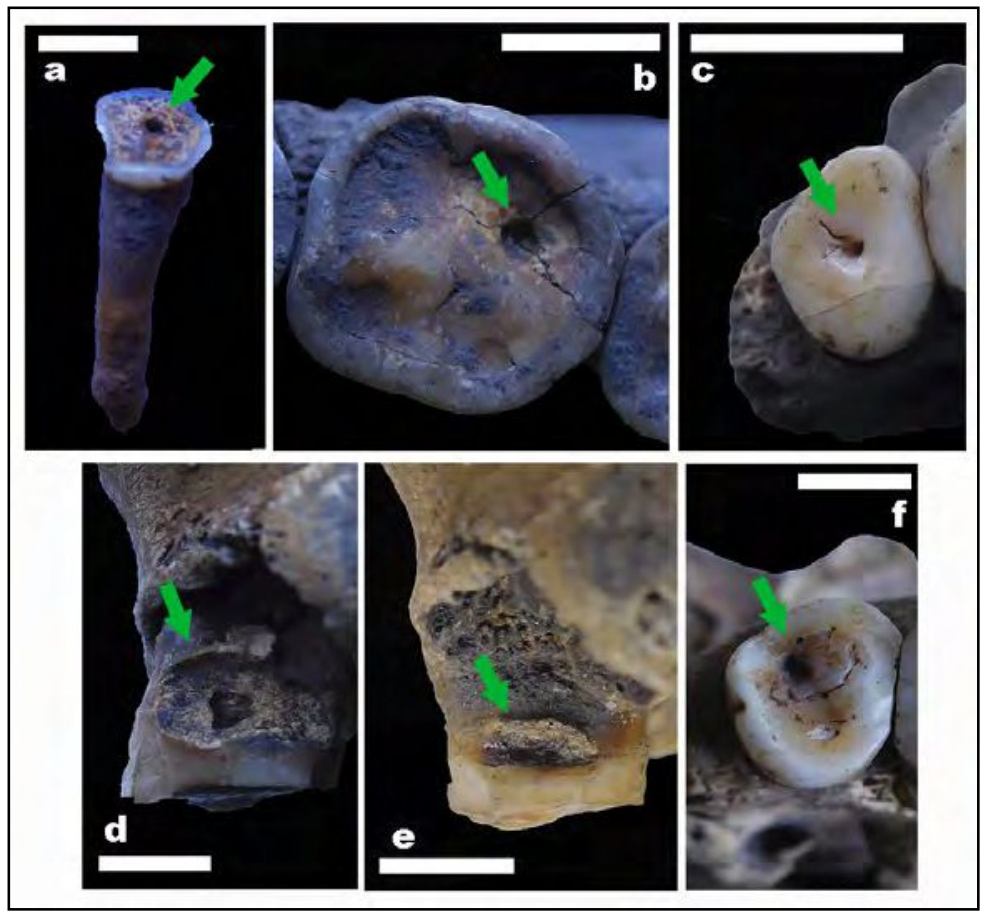

Figura 6.3. Caries registradas en la muestra del DI: a) AS-12C-6468; b) EC-12B-6441; c) EC27B-6452; d) T1PG-29, $M^{2}$ d; e) T1PG-29, M1; f) T1PG-44. Escalas=0,5 cm.

\subsection{Lesiones periapicales}

\subsubsection{Delta Superior del río Paraná}

Se analizaron 285 alveolos de 15 individuos y se registraron cuatro lesiones periapicales. En la Tabla 6.8 se presentan las prevalencias de estas lesiones según grupo etario y sexo, calculado tanto a nivel individual como de alveolo. Los tres individuos que tienen las lesiones periapicales representan el 20\% de la muestra; mientras que a nivel de alveolos afectados, es el 1,4\%. No se encontró asociación 
estadística entre la edad (adolescentes y adulto joven vs. adulto medio y mayor) y la ocurrencia de estas lesiones $(p=0,07)$. Al evaluar por sexo y cantidad de alveolos, tampoco se obtuvieron resultados que indiquen la dependencia entre esta variable y la presencia de las lesiones $(p=1)$.

Tabla 6.8. Prevalencias de lesiones periapicales en la muestra del DS.

\begin{tabular}{|c|c|c|c|c|c|}
\hline & \multicolumn{2}{|c|}{ Individuos } & \multicolumn{2}{|c|}{ Alveolos completos } \\
\hline & & $\mathrm{A} / \mathrm{O}$ & $\%$ & A / O & $\%$ \\
\hline \multirow{7}{*}{$\begin{array}{l}\cdot \frac{0}{\frac{1}{\pi}} \\
\pm 0 \\
0 \\
\frac{2}{3} \\
\frac{3}{3} \\
0\end{array}$} & Infante & $0 / 1$ & 0 & $0 / 11$ & 0 \\
\hline & Niño & $0 / 1$ & 0 & $0 / 16$ & 0 \\
\hline & Adolescente & $0 / 3$ & 0 & $0 / 67$ & 0 \\
\hline & Adulto joven & $0 / 2$ & 0 & $0 / 32$ & 0 \\
\hline & Adulto medio & $1 / 2$ & 50 & $1 / 41$ & 2,4 \\
\hline & Adulto mayor & $1 / 1$ & 100 & $2 / 31$ & 6,4 \\
\hline & Adulto in. & $1 / 5$ & 20 & $1 / 87$ & 1,1 \\
\hline \multirow{4}{*}{ 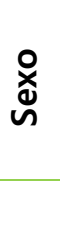 } & Femenino & $2 / 7$ & 28,6 & $3 / 164$ & 1,8 \\
\hline & Masculino & $1 / 3$ & 33,3 & $1 / 60$ & 1,7 \\
\hline & In. & $0 / 5$ & 0 & $0 / 61$ & 0 \\
\hline & Total & $3 / 15$ & 20 & $4 / 285$ & 1,4 \\
\hline
\end{tabular}

Referencias: $\mathrm{A}=$ afectado; $\mathrm{O}=$ observado; In.=indeterminado.

En la Tabla 6.9 se presentan las características de cada lesión relevada (Figura 6.4). Estas afecciones se registraron en la dentición posterior de tres adultos (dos femeninos y uno masculino). Todas las lesiones fueron clasificadas como quistes a excepción de un granuloma, dado su diámetro menor a $3 \mathrm{~mm}$. Se destaca el caso del alveolo correspondiente al $\mathrm{M}^{1} \mathrm{i}$ del individuo LTC1-P4 que presenta un granuloma sobre el lado lingual y un quiste sobre el bucal. Asociado con este último, se observó una pequeña reacción ósea en su borde superior así como también en el malar de la misma lateralidad. Es importante destacar que esta pieza dental presenta desgaste severo en su mitad oclusal lingual, con chipping (i.e. astillado dental) y pérdida de tejido alveolar (Figura 6.4d), siendo esto la posible causa no sólo del quiste sino también del granuloma y de las reacciones óseas. A partir de esto, ambas lesiones fueron consideradas y cuantificadas como una sola, ya que serían parte del mismo proceso infeccioso que afectó al alveolo. 
Tabla 6.9. Características de las lesiones periapicales registradas en la muestra del DS.

\begin{tabular}{|cccccccc|}
\hline Individuo & Grupo etario & Sexo & Alveolo & Ubicación & Tipo & Posible causa* \\
\hline LTC1-P2 & adulto & $\mathrm{M}$ & $\mathrm{Pm}_{2} \mathrm{~d}$ & bucal & quiste & desgaste (6) \\
\hline LTC1-P3 & a. mayor & $\mathrm{F}$ & $\mathrm{M}^{1} \mathrm{i}$ & lingual & quiste & desgaste (39) \\
LTC1-P4 & a. medio & $\mathrm{F}$ & $\mathrm{Mm}^{1} \mathrm{i}$ & $\begin{array}{c}\text { bucal } \\
\text { bucal } \\
\text { lingual }\end{array}$ & $\begin{array}{c}\text { quiste } \\
\text { quiste } \\
\text { granuloma }\end{array}$ & desgaste (7) \\
& & & & & desgate (34) \\
\hline
\end{tabular}

Referencias: $\mathrm{a}$.=adulto; $\mathrm{M}=$ masculino; $\mathrm{F}=$ femenino; ${ }^{*}=$ entre paréntesis se detalla el grado de desgaste.

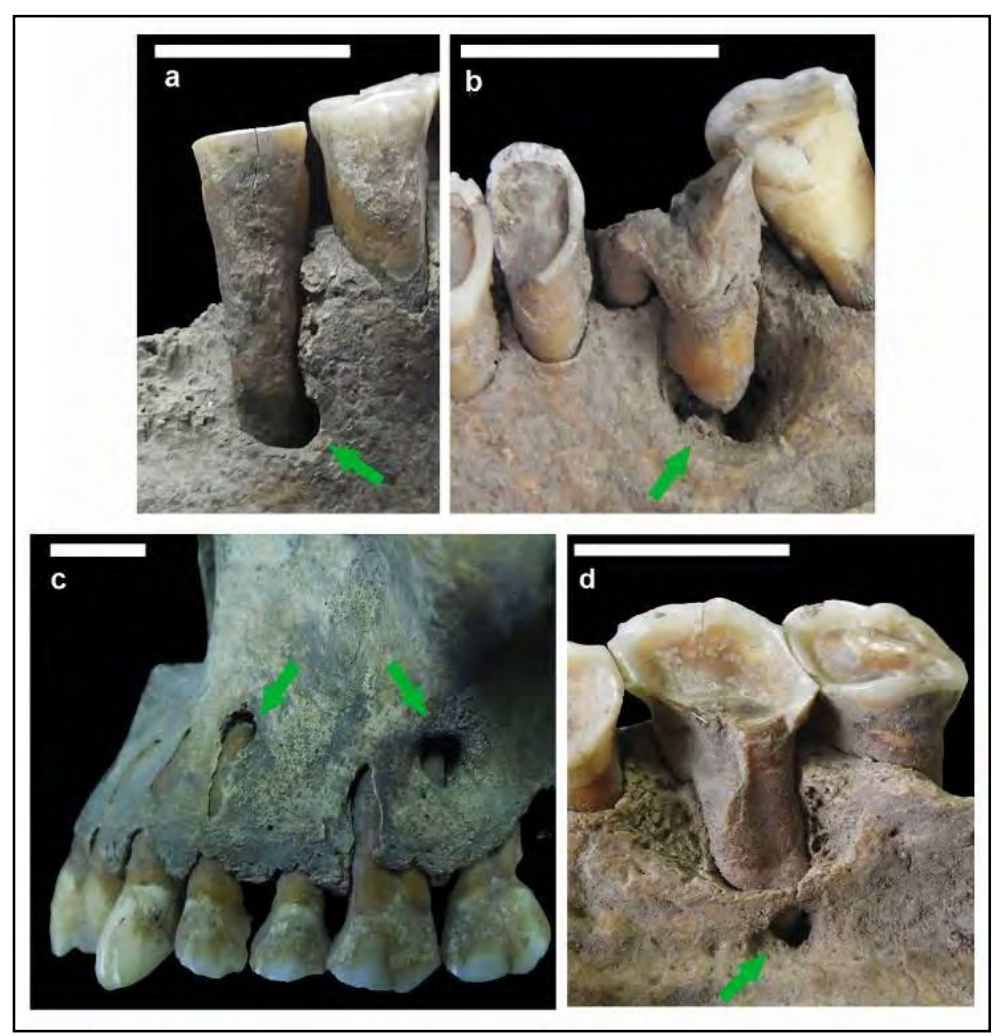

Figura 6.4. Lesiones periapicales registradas en la muestra del DS: a) LTC1-P2; b) LTC1-P3; c) LTC1-P4, Pm¹ i y $\mathrm{M}^{1}$ i lado bucal; d) LTC1-P4, $\mathrm{M}^{1}$ i lado lingual. Escalas $=2 \mathrm{~cm}$.

\subsubsection{Cuenca inferior del río Uruguay}

Se analizaron 929 alveolos en 54 individuos y se registró un total de 17 lesiones periapicales (Tabla 6.10). Tanto a nivel alveolar como individual, las prevalencias son bajas: $14,8 \%$ y $1,8 \%$, respectivamente. Al evaluar la incidencia de este tipo de lesiones en los adultos (por alveolos), no hay asociación estadística entre su ocurrencia y la edad (adulto joven vs. adulto medio: $p=0,3$ ). En cuanto al sexo (Tabla 6.11), a nivel individual las prevalencias son mayores en los masculinos, 
mientras que a nivel de alveolos las prevalencias son similares para ambas sexos; no hay dependencia entre ambas variables $(\chi 2=0,09 ; p=0,8)$.

Tabla 6.10. Prevalencias de lesiones periapicales en la muestra de CIRU.

\begin{tabular}{|c|c|c|c|c|c|}
\hline & \multicolumn{2}{|c|}{ Individuos } & \multicolumn{2}{|c|}{ Alveolos completos } \\
\hline & & A / O & $\%$ & A / O & $\%$ \\
\hline \multirow{7}{*}{$\begin{array}{l}\text { 은 } \\
\frac{\pi}{0} \\
0 \\
\frac{0}{2} \\
\frac{2}{2}\end{array}$} & Infante & $0 / 1$ & 0 & $0 / 22$ & 0 \\
\hline & Niño & $0 / 3$ & 0 & $0 / 35$ & 0 \\
\hline & Adolescente & $0 / 3$ & 0 & $0 / 67$ & 0 \\
\hline & Adulto joven & $2 / 9$ & 22,2 & $7 / 212$ & 3,3 \\
\hline & Adulto medio & $1 / 1$ & 100 & $2 / 32$ & 6,2 \\
\hline & Adulto in. & $5 / 36$ & 14,3 & $8 / 558$ & 1,4 \\
\hline & In. & $0 / 1$ & 0 & $0 / 3$ & 0 \\
\hline \multirow{4}{*}{ 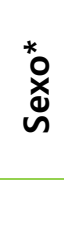 } & Femenino & $2 / 11$ & 18,2 & $6 / 268$ & 2,2 \\
\hline & Masculino & $4 / 16$ & 25 & $9 / 345$ & 2,6 \\
\hline & In. & $2 / 27$ & 7,4 & $2 / 316$ & 0,6 \\
\hline & Total & $8 / 54$ & 14,8 & $17 / 929$ & 1,8 \\
\hline
\end{tabular}

Referencias: $\mathrm{A}=$ afectado; $\mathrm{O}=$ observado; In.=indeterminado; ${ }^{*}=$ entre los femeninos y los masculinos se incluyó en cada categoría a un individuo probable femenino y a un probable masculino.

Las 17 lesiones periapicales fueron observadas en ocho individuos adultos, de ambos sexos (Tabla 6.11). Estas lesiones se ubicaron todas sobre la cara bucal del alveolo y afectaron principalmente a la dentición inferior; sólo el 29,4\% involucró a alveolos de la arcada superior. Asimismo, se vieron afectadas mayormente las piezas posteriores. En cuanto a los tipos de lesiones, fueron identificados granulomas, quistes y abscesos. Con respecto a las posibles causas que las habrían generado, en algunas (CL2-66 y CL2-78) fue posible establecer su asociación con la exposición pulpar no cariosa de la pieza dental comprometida, dado por el desgaste de su superficie oclusal; esta situación habría favorecido la entrada de bacterias orales y desencadenado la infección. Es interesante notar que la mitad de los individuos afectados presentan múltiples lesiones periapicales; se destacan los individuos CL2-66 y CL2-78 con cuatro y cinco cada uno. Entre todas las lesiones sobresale la registrada en el $\mathrm{M}_{1} \mathrm{~d}$ de $\mathrm{CL2}-103$ (Figura 6.5d), dada la expandida reacción perióstica y posible cloaca de drenaje que habría generado la infección. 
Tabla 6.11. Características de las lesiones periapicales registradas en la muestra de CIRU.

\begin{tabular}{|c|c|c|c|c|c|c|}
\hline Individuo & Grupo etario & Sexo & Alveolo & Ubicación & Tipo & Posible causa* \\
\hline \multirow{4}{*}{ CL2-66 } & \multirow{4}{*}{ adulto } & \multirow{4}{*}{$\mathrm{F}$} & $I^{2} d$ & bucal & quiste & caries (7) \\
\hline & & & $M_{2} d$ & bucal & quiste & caries (7) \\
\hline & & & $C_{1} d$ & bucal & quiste & caries (7) \\
\hline & & & $C_{1}$ y $P m_{1} i$ & bucal & quiste & caries $(7)$ \\
\hline CL2-57 & adulto & M & $\mathrm{Pm}^{1} \mathrm{~d}$ & bucal & granuloma & in. \\
\hline \multirow{5}{*}{ CL2-78 } & \multirow{5}{*}{ a. joven } & \multirow{5}{*}{$M$} & $M^{1} d$ & bucal & quiste & In. \\
\hline & & & $\mathrm{Pm}^{2} \mathrm{i}$ & bucal & granuloma & caries $(7)$ \\
\hline & & & $\mathrm{M}_{2} \mathrm{~d}$ & bucal & quiste & desgaste (36)? \\
\hline & & & $M_{1} d$ & bucal & granuloma & desgaste (39)? \\
\hline & & & $M_{2} i$ & bucal & quiste & caries (7) \\
\hline \multirow{2}{*}{$C L 2-52$} & \multirow{2}{*}{ a. joven } & \multirow{2}{*}{$M$} & $M_{1} d$ & bucal & absceso? & in. \\
\hline & & & $\mathrm{M}_{1} \mathrm{i}$ & bucal & quiste & in. \\
\hline$C L 2-56$ & adulto & in. & $\mathrm{Pm}^{1} \mathrm{~d}$ & bucal & quiste & in. \\
\hline \multirow{2}{*}{ CL2-103-1 } & \multirow{2}{*}{ a. medio } & \multirow{2}{*}{$\mathrm{F}$} & $M^{1} \mathrm{i}$ & bucal & absceso & in. \\
\hline & & & $M_{1} d$ & bucal & absceso & in. \\
\hline SPL-206 & adulto & in. & $M^{1} \mathrm{i}$ & bucal & absceso & in. \\
\hline TL-64 & adulto & M & $\mathrm{Pm}_{1} \mathrm{i}$ & bucal & granuloma & in. \\
\hline
\end{tabular}

Referencias: a.=adulto; F=femenino; $M=$ masculino; in.=indeterminado; *cuando se especifica caries (7), se hace referencia a la exposición pulpar no cariosa (véase clasificación utilizada en el Capítulo 4).

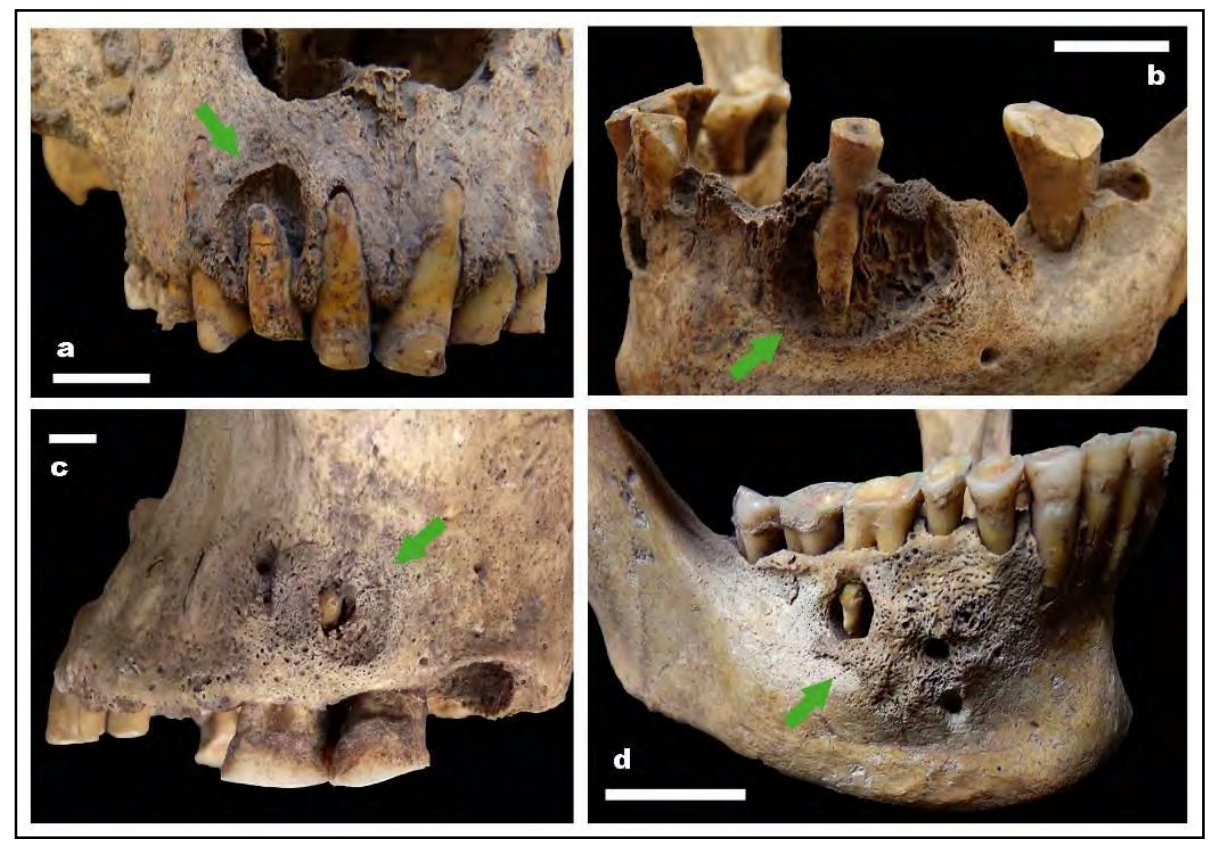

Figura 6.5. Lesiones periapicales registradas en la muestra de CIRU: a) $C L 2-66, I^{2} d$; b) $C L 2-$ 66, $C_{1}$ y $\mathrm{Pm}_{1}$ i; c) CL2-103-1, M1 i y d) CL2-103-1, $M_{1}$ d. Escalas=1 cm. 


\subsubsection{Delta Inferior del río Paraná y ambientes litorales adyacentes}

Se analizaron 567 alveolos en 25 maxilares y 35 mandíbulas, sin registrarse ninguna lesión periapical.

\subsection{Pérdidas dentales antemortem (PDAM)}

\subsubsection{Delta Superior del río Paraná}

Se analizaron 285 alveolos en 15 individuos y se registraron ocho PDAM en dos individuos (Tabla 6.12). A nivel de piezas dentales, representan el 2,8\%; mientras que a nivel individual, es el $13,3 \%$ de la muestra total. Al considerar las prevalencias por sexo, a nivel individual son más altas en los masculinos que los femeninos; mientras que a nivel alveolar la tendencia es a la inversa dado que siete de las ocho PDAM registradas pertenecen al mismo individuo femenino. Estadísticamente no se refleja una asociación entre la ocurrencia de las PDAM y el sexo $(p=0,7)$. Sí se tuvieron resultados estadísticos que permiten confirmar la asociación entre las PDAM y los individuos de mayor edad (adolescente y adulto joven vs. adulto medio y adulto mayor; $p=0,002$ ).

Tabla 6.12. Prevalencias de PDAM en la muestra del DS.

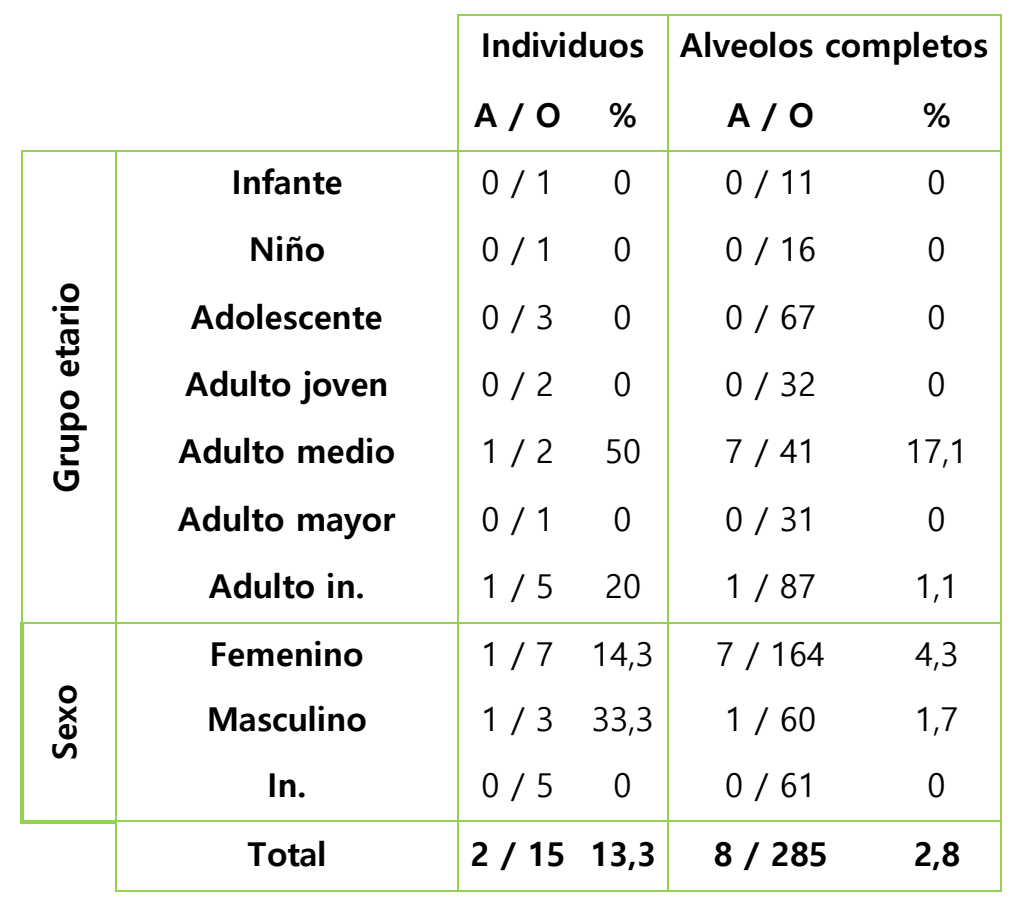

Referencias: $\mathrm{A}=$ afectado; $\mathrm{O}=$ observado; In.=indeterminado. 
Los individuos con PDAM son un adulto masculino y un adulto medio femenino. En la Tabla 6.13 se resumen las características registradas, destacándose que todas las piezas perdidas son de la dentición posterior. En el caso del adulto masculino, el alveolo se encuentra parcialmente remodelado, siendo más evidente hacia el lado bucal (Figura 6.6a). Por su parte, en el maxilar del adulto femenino (Figura 6.6b) se registró PDAM de las piezas posteriores, a excepción del $\mathrm{Pm}^{1} \mathrm{~d}$ (con caries interproximal mesial; Tabla 6.2). Lamentablemente no puede evaluarse de forma completa la arcada dentaria dado que la región correspondiente a la dentición anterior está rota y tampoco se cuenta con la mandíbula.

Tabla 6.13. Características de las PDAM registradas en la muestra
\begin{tabular}{|cccccc|}
\hline Individuo & Grupo etario & Sexo & Alveolo & Remodelación \\
\hline LTC1-P2 & adulto & $\mathrm{M}$ & $\mathrm{M}_{1} \mathrm{~d}$ & moderada \\
\hline & & & $\mathrm{M}^{2} \mathrm{~d}$ & total \\
& & & $\mathrm{M}^{1} \mathrm{~d}$ & total \\
LTC1-S1-2 & a. medio & $\mathrm{F}$ & $\mathrm{Pm}^{2} \mathrm{i}$ & moderada \\
& & & $\mathrm{M}^{1} \mathrm{i}$ & total \\
& & & $\mathrm{M}^{2} \mathrm{i}$ & total \\
& & $\mathrm{M}^{3} \mathrm{i}$ & total \\
\hline
\end{tabular}

Referencias: $a$.=adulto; $M=$ masculino; $F=$ femenino.

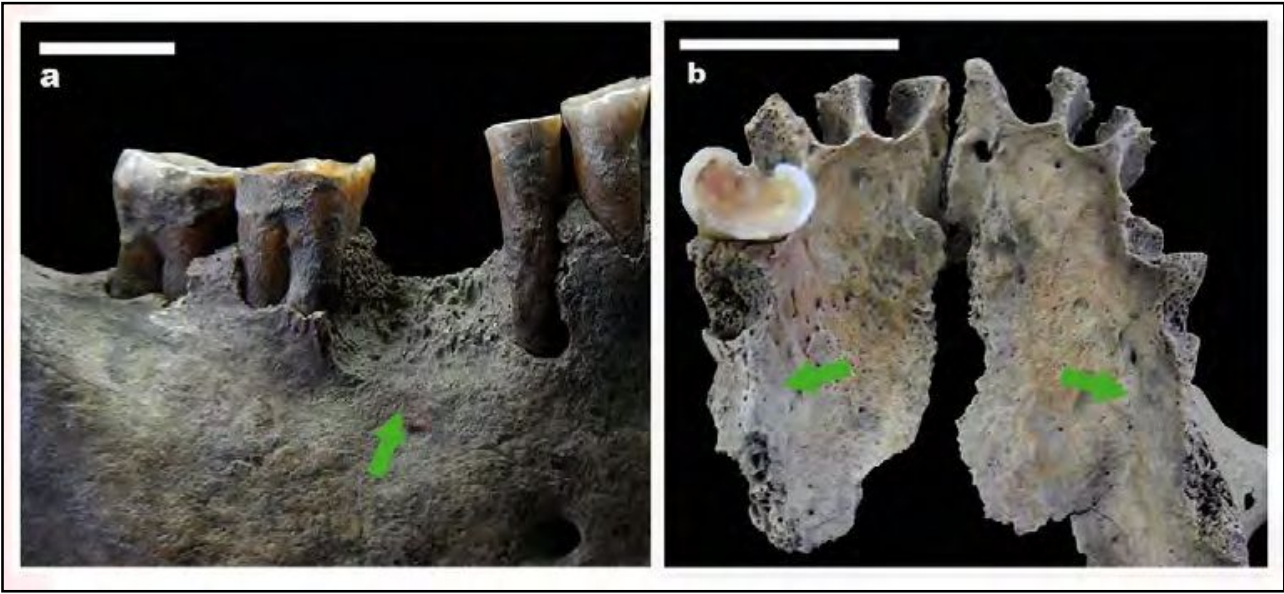

Figura 6.6. PDAM registradas en la muestra del DS: a) LTC1-P2; b) LTC1-S1-2. Escalas=2 cm. 


\subsubsection{Cuenca inferior del río Uruguay}

Se analizaron 929 alveolos en 54 individuos y se registraron 17 PDAM en seis individuos (Tabla 6.14). Las prevalencias son bajas, tanto a nivel alveolar $(1,8 \%)$ como individual $(11,1 \%)$. Pese a que todas las PDAM registradas fueron en adultos, estadísticamente no existe asociación entre su presencia y la edad de los individuos (subadultos vs. adultos: $p=0,1$; adolescente y adulto joven vs. adulto medio: $p=1$ ). Igualmente, los adultos en los que no pudo estimarse con mayor precisión la edad pueden estar alterando estos resultados. Al evaluar el sexo a nivel individual las prevalencias son mayores en los masculinos y a la inversa a nivel alveolar; sin embargo estadísticamente no existe dependencia entre la presencia de estas lesiones y el sexo $\left(\chi^{2}=0,2 ; p=0,6\right)$.

Tabla 6.14. Prevalencias de PDAM en la muestra de CIRU.

\begin{tabular}{|c|c|c|c|c|c|}
\hline & \multicolumn{2}{|c|}{ Individuos } & \multicolumn{2}{|c|}{ Alveolos completos } \\
\hline & & A / O & $\%$ & A / 0 & $\%$ \\
\hline \multirow{7}{*}{$\begin{array}{l}\cdot \frac{0}{\frac{1}{5}} \\
\frac{1}{0} \\
\circ \\
\frac{0}{2} \\
\frac{0}{0}\end{array}$} & Infante & $0 / 1$ & 0 & $0 / 22$ & 0 \\
\hline & Niño & $0 / 3$ & 0 & $0 / 35$ & 0 \\
\hline & Adolescente & $0 / 3$ & 0 & $0 / 67$ & 0 \\
\hline & Adulto joven & $2 / 9$ & 22,2 & $6 / 212$ & 2,8 \\
\hline & Adulto medio & $0 / 1$ & 0 & 0 / 32 & 0 \\
\hline & Adulto in. & $4 / 36$ & 11,4 & $11 / 558$ & 2 \\
\hline & In. & $0 / 1$ & 0 & $0 / 3$ & 0 \\
\hline \multirow{4}{*}{ 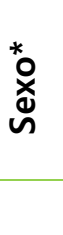 } & Femenino & $1 / 11$ & 9,1 & 7 / 268 & 2,6 \\
\hline & Masculino & $3 / 16$ & 18,7 & $7 / 345$ & 1,9 \\
\hline & In. & $2 / 27$ & 7,4 & $3 / 316$ & 0,9 \\
\hline & Total & $6 / 54$ & 11,1 & 17 / 929 & 1,8 \\
\hline
\end{tabular}

Referencias: $\mathrm{A}=$ afectado; $\mathrm{O}=$ observado; In.=indeterminado; *=entre los femeninos y los masculinos se incluyó en cada categoría a un individuo probable femenino y a un probable masculino.

De los seis individuos con PDAM, tres de ellos presentaron múltiples alveolos remodelados por el extravío de los dientes (Tabla 6.15). De las 17 PDAM, el $82,3 \%(n=14)$ se corresponde con molares, el $64,7 \%(n=11)$ afectó a la dentición inferior y el 70,6\% $(n=12)$ de los alveolos tiene remodelación de tipo moderada (Tabla 6.15, Figura 6.7). 

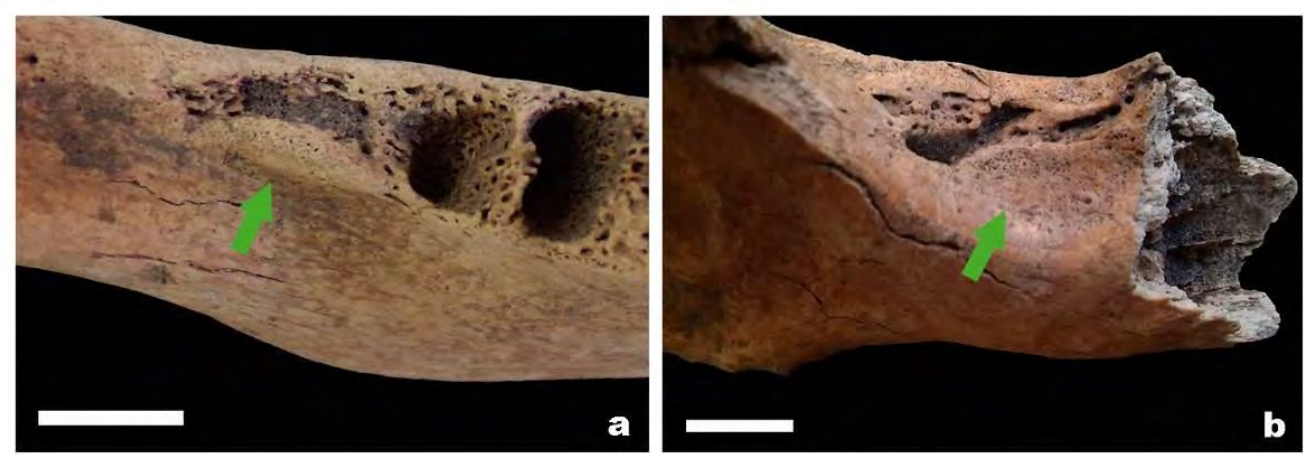

Figura 6.7. PDAM registradas en la muestra de CIRU: a) CL2-232-1, $M_{3}$ d;

b) $S P L-90, M_{3}$ y $M_{2}$ d. Escalas $=1 \mathrm{~cm}$.

Tabla 6.15. Características de las PDAM registradas en la muestra de CIRU.

\begin{tabular}{|c|c|c|c|c|}
\hline Individuo & Grupo etario & Sexo & Alveolo & Remodelación \\
\hline \multirow{7}{*}{ CL2-66 } & \multirow{7}{*}{ adulto } & \multirow{7}{*}{$\mathrm{F}$} & $M^{2} i$ & moderada \\
\hline & & & $M_{1} d$ & total \\
\hline & & & $\mathrm{l}_{1} \mathrm{~d}$ & moderada \\
\hline & & & $\mathrm{I}_{1} \mathrm{i}$ & total \\
\hline & & & $\mathrm{I}_{2} \mathrm{i}$ & moderada \\
\hline & & & $M_{1} \mathrm{i}$ & moderada \\
\hline & & & $M_{3} \mathrm{i}$ & parcial \\
\hline CL2-67 & adulto & M & $M_{3} \mathrm{i}$ & total \\
\hline \multirow{5}{*}{ CL2-78 } & \multirow{5}{*}{ a. joven } & \multirow{5}{*}{$M$} & $M^{2} d$ & parcial \\
\hline & & & $M^{1} \mathrm{i}$ & moderada \\
\hline & & & $M^{2} i$ & moderada \\
\hline & & & $\mathrm{M}^{1} \mathrm{i}$ & moderada \\
\hline & & & $M_{3} d$ & moderada \\
\hline $\mathrm{CL} 2-76$ & a. joven & $M$ & $M^{3} d$ & moderada \\
\hline CL2-232-1 & adulto & in. & $M_{3} d$ & moderada \\
\hline \multirow{2}{*}{ SPL-90 } & \multirow{2}{*}{ adulto } & \multirow{2}{*}{ in. } & $M_{3} d$ & moderada \\
\hline & & & $M_{2} d$ & moderada \\
\hline
\end{tabular}

Referencias: $a .=$ adulto; $F=$ femenino; $M=$ masculino; in.=indeterminado.

\subsubsection{Delta Inferior del río Paraná y ambientes litorales adyacentes}

Se analizaron 567 alveolos en 25 maxilares y 35 mandíbulas, y se registraron en total 31 PDAM (Tabla 6.16). A nivel de alveolos, las PDAM afectaron a un bajo porcentaje $(5,5 \%)$ de la muestra (Tabla 6.17). El análisis estadístico no indica una asociación entre la presencia de PDAM y los adultos (adultos vs. subadultos; $p=0,4$ ). 
Como fue realizado para las caries, a nivel individual las prevalencias fueron calculadas separadamente para los maxilares y las mandíbulas, obteniendo valores levemente más altos para la arcada inferior. Al evaluar la remodelación ósea de los alveolos (en maxilares) según el sexo, las prevalencias son ampliamente mayores en los femeninos (Tabla 6.17); estadísticamente hay relación entre el sexo y la ocurrencia de las PDAM $(p=0,05)$.

Tabla 6.16. Prevalencias de PDAM por grupo de edad en la muestra del DI.

\begin{tabular}{|c|cccc|cc|}
\hline \multirow{2}{*}{ Grupo etario } & \multicolumn{3}{|c|}{ Maxilar } & \multicolumn{2}{c|}{ Mandíbula } & \multicolumn{2}{c|}{ clveolos } \\
& A / O & $\%$ & A / O & $\%$ & A / O & $\%$ \\
\hline Niño & - & - & $0 / 1$ & 0 & $0 / 4$ & 0 \\
Adolescente & $0 / 1$ & 0 & $0 / 1$ & 0 & $0 / 25$ & 0 \\
Adulto Joven & $0 / 1$ & 0 & - & - & $0 / 15$ & 0 \\
Adulto in. & $3 / 22$ & 13,6 & $6 / 33$ & 18,2 & $31 / 513$ & 6 \\
In. & $0 / 1$ & 0 & - & - & $0 / 10$ & 0 \\
\hline TOTAL & $\mathbf{3 / 2 5}$ & $\mathbf{1 2}$ & $\mathbf{6} / \mathbf{3 5}$ & $\mathbf{1 7 , 1}$ & $\mathbf{3 1} / \mathbf{5 6 7}$ & $\mathbf{5 , 5}$ \\
\hline
\end{tabular}

Referencias: $\mathrm{A}=$ afectado; $\mathrm{O}=$ observado; In.=indeterminado.

Tabla 6.17. Prevalencias de PDAM por sexo (en maxilares) en la muestra del DI.

\begin{tabular}{|c|cc|cc|}
\hline \multirow{2}{*}{ Sexo* } & \multicolumn{2}{|c|}{ Individuos } & \multicolumn{2}{c|}{ Alveolos completos } \\
& A/O & $\%$ & A/O & $\%$ \\
\hline Femenino & $2 / 4$ & 50 & $5 / 58$ & 8,60 \\
Masculino & $1 / 10$ & 10 & $2 / 107$ & 1,90 \\
In. & $0 / 10$ & 0 & $0 / 76$ & 0 \\
\hline Total & $\mathbf{3} / \mathbf{2 4}$ & $\mathbf{1 2}$ & $\mathbf{7 / 2 4 1}$ & $\mathbf{2 , 9}$ \\
\hline
\end{tabular}

Referencias: * =entre los femeninos y los masculinos se incluyó en cada categoría a dos individuos probable femeninos y a dos probable masculinos. $\mathrm{A}=$ afectado; $\mathrm{O}=$ observado; In.=indeterminado.

Las PDAM se registraron en seis mandíbulas y en tres maxilares. Como puede observarse en la Tabla 6.18, en dos de los nueve elementos óseos se registró una sola PDAM, mientras que el resto presenta múltiples alveolos afectados. Entre estos últimos se destaca la mandíbula de un adulto con pérdida de todas las piezas dentales, aunque los alveolos de los M3 no pudieron observarse debido a que se encontraba roto el hueso en ambos lados. En términos generales, los tipos de PDAM relevados son con remodelación ósea moderada $(41,9 \% ; n=13)$ o total 
(38,7\%; $n=12)$, con pocos casos de tipo parcial $(19,3 \% ; n=6)$. La dentición más afectada resultó ser la posterior $(58,1 \% ; n=18)$. En la Figura 6.8 se presentan algunos de los alveolos registrados.

Tabla 6.18. Características de las PDAM registradas en la muestra del DI.

\begin{tabular}{|c|c|c|c|c|}
\hline Individuo & Grupo etario & Sexo & Alveolo & Remodelación \\
\hline AS-12B-6466 & adulto & in. & $\mathrm{l}_{1} \mathrm{~d}$ & moderada \\
\hline \multirow{3}{*}{ AS-12A-6469 } & \multirow{3}{*}{ adulto } & \multirow{3}{*}{ in. } & $M_{1} d$ & total \\
\hline & & & $M_{1} \mathrm{i}$ & moderada \\
\hline & & & $\mathrm{M}_{2} \mathrm{i}$ & parcial \\
\hline \multirow{14}{*}{ EC-12A-7599 } & \multirow{14}{*}{ adulto } & \multirow{14}{*}{ in. } & $M_{2} d$ & moderada \\
\hline & & & $M_{1} d$ & total \\
\hline & & & $\mathrm{Pm}_{2} \mathrm{~d}$ & total \\
\hline & & & $\mathrm{Pm}_{1} \mathrm{~d}$ & moderada \\
\hline & & & $C d$ & moderada \\
\hline & & & $\mathrm{I}_{2} \mathrm{~d}$ & moderada \\
\hline & & & $\mathrm{l}_{1} \mathrm{~d}$ & parcial \\
\hline & & & $\mathrm{I}_{1} \mathrm{i}$ & total \\
\hline & & & $\mathrm{I}_{2} \mathrm{i}$ & total \\
\hline & & & $\mathrm{Ci}$ & parcial \\
\hline & & & $\mathrm{Pm}_{1} \mathrm{i}$ & moderada \\
\hline & & & $\mathrm{Pm}_{2} \mathrm{i}$ & moderada \\
\hline & & & $M_{1} \mathrm{i}$ & total \\
\hline & & & $\mathrm{M}_{2} \mathrm{i}$ & total \\
\hline AS-42A-6489 & adulto & in. & $\mathrm{l}_{1} \mathrm{i}$ & moderada \\
\hline \multirow{2}{*}{ AS-12C-6468 } & \multirow{2}{*}{ adulto } & \multirow{2}{*}{ in. } & $M_{2} d$ & total \\
\hline & & & $M_{1} \mathrm{i}$ & moderada \\
\hline \multirow{3}{*}{ AS-12C-6468 } & \multirow{3}{*}{ adulto } & \multirow{3}{*}{ in. } & $M_{3} d$ & parcial \\
\hline & & & $\mathrm{Pm}_{1} \mathrm{i}$ & total \\
\hline & & & $M_{3} \mathrm{i}$ & total \\
\hline \multirow{3}{*}{ T1PG-28 } & \multirow{3}{*}{ adulto } & \multirow{3}{*}{$\mathrm{F}$} & $l^{1} d$ & total \\
\hline & & & $\mathrm{I}^{1} \mathrm{i}$ & total \\
\hline & & & $\mathrm{I}^{2} \mathrm{i}$ & moderada \\
\hline \multirow{2}{*}{ T1PG-40 } & \multirow{2}{*}{ adulto } & \multirow{2}{*}{ M } & $\mathrm{I}^{2} \mathrm{i}$ & moderada \\
\hline & & & $\mathrm{Pm}^{1} \mathrm{i}$ & moderada \\
\hline \multirow{2}{*}{ T1PG-46 } & \multirow{2}{*}{ adulto } & \multirow{2}{*}{$\mathrm{F}$} & $M^{1}$ & parcial \\
\hline & & & $I^{1} d$ & parcial \\
\hline
\end{tabular}

Referencias: in.=indeterminado; $F=$ femenino; $M=$ masculino. 

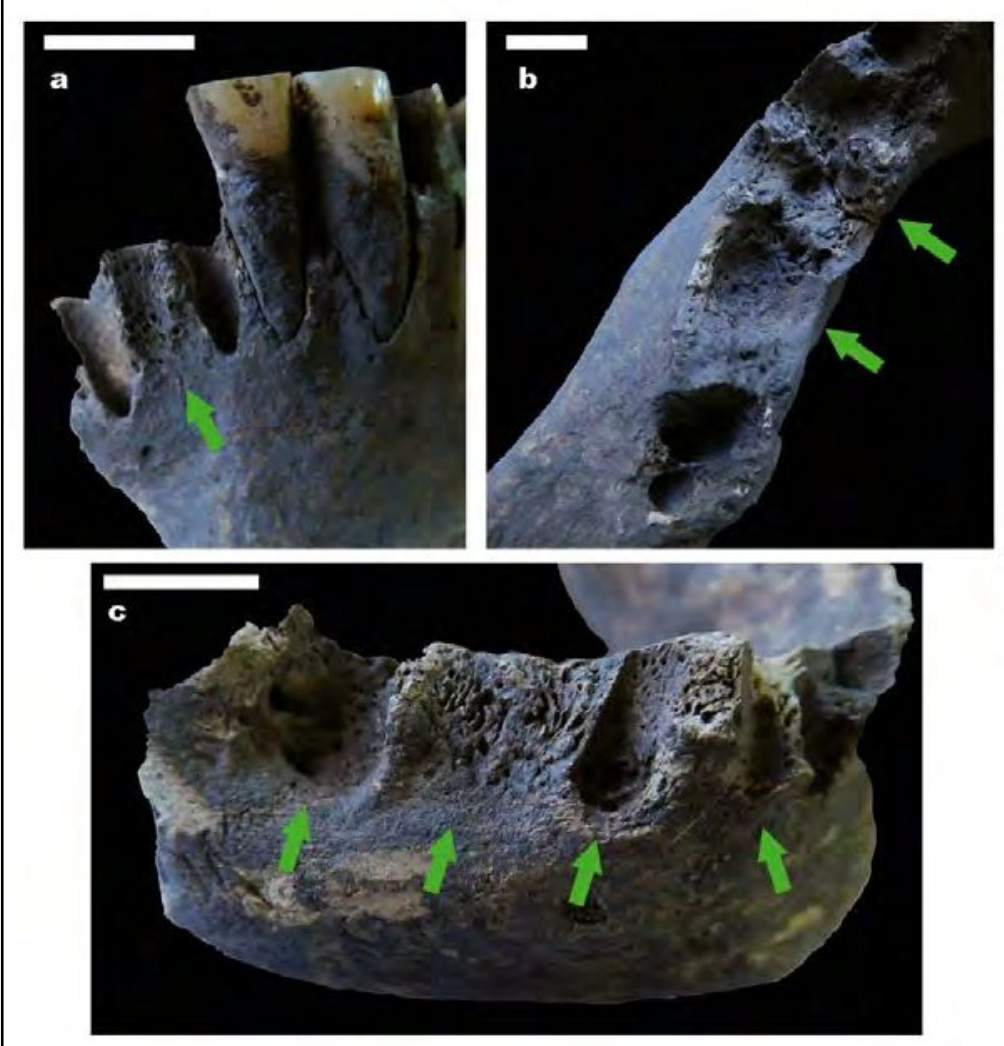

Figura 6.8. PDAM registradas en la muestra del DI: a) AS-12B-6466, $l_{1} d$; b) AS-12A-6469, $M_{1}$ y $M_{2}$ i; c) EC-12A-7599, $M_{2}, M_{1}, P_{2}$ y $P m_{1}$ d. Escalas $=1 \mathrm{~cm}$.

\subsection{Cálculos dentales}

\subsubsection{Delta Superior del río Paraná}

Se analizaron 294 dientes en 15 individuos. En el 80\% de los individuos se registró la presencia de cálculo dental; a nivel de piezas dentales, esto corresponde al 52,7\% (Tabla 6.19). Los individuos con tártaro son principalmente adolescentes y adultos, registrándose en muy pocos dientes de subadultos menores a 10 años; existe asociación estadística entre la ocurrencia de cálculo y la edad (adultos vs. subadultos; $\chi 2=0,0000051947 ; \quad p=0,0000071114)$. Al considerar el sexo de los individuos (Tabla 6.19), los masculinos presentan prevalencias más altas, tanto a nivel individual como de pieza dental. Estadísticamente, los resultados obtenidos indican la dependencia entre el sexo masculino y la ocurrencia de cálculo en las piezas dentales $(\chi 2=7,2 ; p=0,007)$. 
Tabla 6.19. Prevalencias de cálculos dentales en la muestra del DS.

\begin{tabular}{|c|c|c|c|c|c|}
\hline & \multicolumn{2}{|c|}{ Individuos } & \multicolumn{2}{|c|}{ Dientes completos } \\
\hline & & $\mathrm{A} / \mathrm{O}$ & $\%$ & $\mathrm{~A} / \mathrm{O}$ & $\%$ \\
\hline \multirow{9}{*}{ 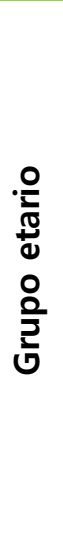 } & Infante & $0 / 1$ & 0 & $0 / 6$ & 0 \\
\hline & Niño & $0 / 1$ & 0 & $0 / 13$ & 0 \\
\hline & Subadultos (deciduos)* & - & - & $3 / 6$ & 50 \\
\hline & Adolescente & $3 / 3$ & 100 & $26 / 64$ & 40,6 \\
\hline & Adulto joven & $2 / 2$ & 100 & $14 / 20$ & 70 \\
\hline & Adulto medio & $1 / 2$ & 50 & $23 / 32$ & 71,9 \\
\hline & Adulto mayor & $1 / 1$ & 100 & $11 / 31$ & 35,5 \\
\hline & Adulto in. & $5 / 5$ & 100 & $59 / 91$ & 64,8 \\
\hline & In. (permanentes)* & - & - & $19 / 31$ & 59,5 \\
\hline \multirow{4}{*}{ 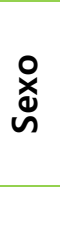 } & Femenino & $6 / 7$ & 85,7 & $84 / 154$ & 54,5 \\
\hline & Masculino & $3 / 3$ & 100 & $38 / 50$ & 76 \\
\hline & In. & $3 / 5$ & 60 & 33 / 90 & 36,6 \\
\hline & Total & $12 / 15$ & 80 & $155 / 294$ & 52,7 \\
\hline
\end{tabular}

Referencias: $\mathrm{A}=$ afectado; $\mathrm{O}=$ observado; In.=indeterminado; *dientes sueltos, que podrían corresponder a cualquiera de los individuos identificados.

El cálculo dental fue registrado en toda la arcada dental, tanto superior como inferior. Aun así, como se observa en la Figura 6.9, tiene mayor ocurrencia en las piezas dentales de la mandíbula; situación aparte son los molares con prevalencias similares para los superiores e inferiores. Si se evalúa por clases de dientes afectados, la dentición posterior ( $\mathrm{Pm}$ y $\mathrm{M}$ ) es la que presenta las mayores prevalencias de cálculo (56,1\% vs. $47,5 \%$ de la dentición anterior $)^{1}$. Al considerar los grados de depositación del cálculo sobre las piezas dentales, los resultados indican que el $74,2 \%$ del total de los dientes observados lo presentan en baja cantidad (grado 1) mientras que el 9\% en gran cantidad (grado 3) (Tabla 6.20; Figura 6.10).

1 Para estos cálculos no fueron incluidos los dientes indeterminados $(n=13)$, es decir aquellos en los que no se pudo precisar clase de diente y/o ubicación en la arcada dental (i.e., superior o inferior). 


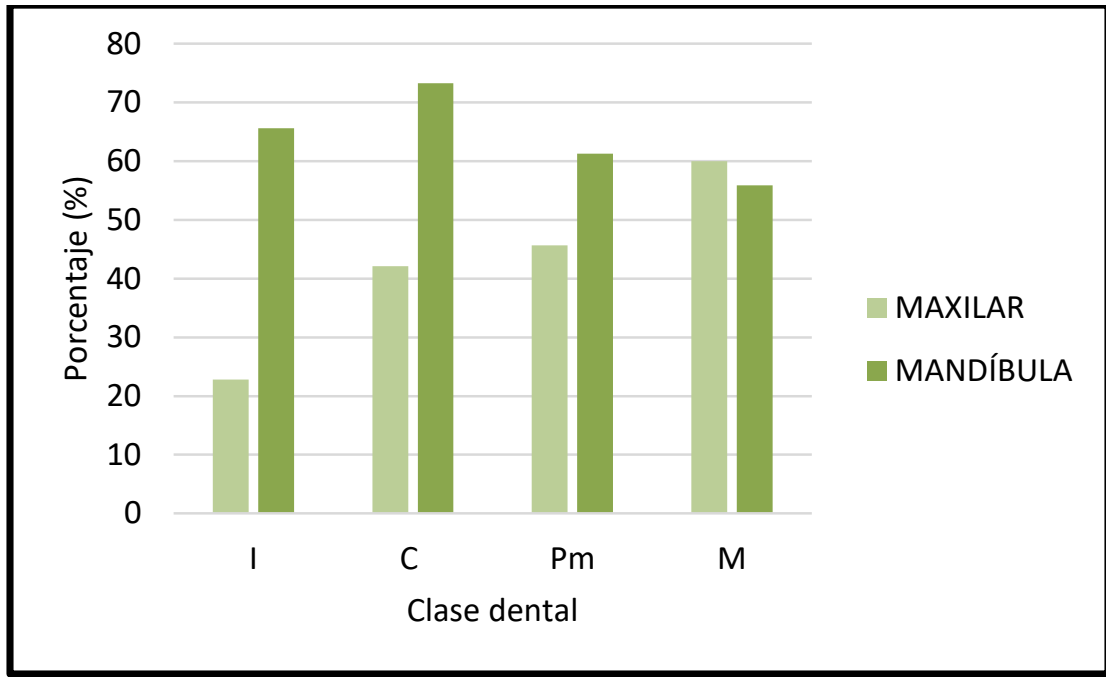

Figura 6.9. Prevalencias de cálculo dental en la muestra del DS, por clases de dientes y ubicación en la arcada dental.

Tabla 6.20. Prevalencias de los grados de depositación de cálculo dental en la muestra del DS.

\begin{tabular}{|ccc|}
\hline $\begin{array}{c}\text { Grado de } \\
\text { depositación }\end{array}$ & \multicolumn{2}{c|}{ Dientes completos } \\
\hline $\mathbf{1}$ & $115 / 155$ & $\mathbf{0}$ \\
$\mathbf{2}$ & $26 / 155$ & 16,8 \\
$\mathbf{3}$ & $14 / 155$ & 9 \\
\hline Total & $\mathbf{1 5 5} / \mathbf{1 5 5}$ & $\mathbf{1 0 0}$ \\
\hline
\end{tabular}

Referencias: $\mathrm{A}=$ afectado; $\mathrm{O}=$ observado.

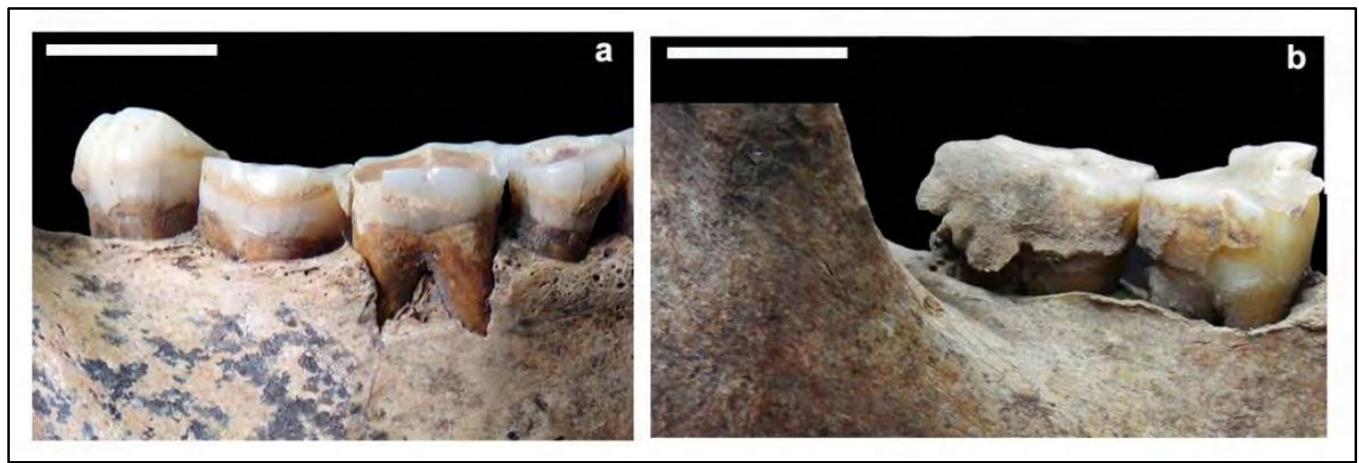

Figura 6.10. Cálculos dentales registrados en la muestra del DS: a) LTC1-S6, grado de depositación 1 en molares de la mandíbula; b) LTC1-P3, grado de depositación 3 sobre $M_{3}$. Escalas $=1 \mathrm{~cm}$.

Como actividad complementaria al relevamiento de cálculos dentales, se llevó a cabo su estudio microscópico. Para ello se seleccionaron siete muestras de tártaro procedentes de dos adolescentes y cinco adultos, de ambos sexos. Se 
hallaron varios microrrestos vegetales en cuatro de ellas (Tabla 6.21; Figura 6.11). Entre los elementos biosilíceos se distinguieron fitolitos prismáticos, poliédricos y buliformes; todos ellos vinculados con gramíneas (Poaceae). Asimismo, en una de las muestras se observaron espículas de espongiario. Por otro lado, fueron identificados en tres de las muestras granos de almidón no diagnósticos, que se caracterizan por ser ovales, sin fisuras visibles y algunos de mayor tamaño (más de 20 micrones), mientras que otro es de forma esférica y pequeño. Finalmente, se hallaron fibras vegetales en tres de las muestras. A su vez, en una se distinguió un fragmento de lo que podría ser un insecto y en otra un fragmento de algún tipo de tejido vegetal.

Tabla 6.21. Muestras de cálculo dental del DS y resultados del análisis de microrrestos vegetales.

\begin{tabular}{|c|c|c|c|c|c|}
\hline \multicolumn{3}{|c|}{ Muestras } & \multicolumn{3}{|c|}{ Resultados* } \\
\hline Individuo & Diente & Cara & $\begin{array}{l}\text { Elementos } \\
\text { biosilíceos }\end{array}$ & Almidones & Otros \\
\hline LTC1-P1 & $C_{1} d$ & L & no & no & tejido? $(H)$ \\
\hline LTC1-P2 & $M^{3} i$ & $L, B$ & no & $\begin{array}{c}\text { esférico, } \\
\text { pequeño }\left(E_{,} E^{\prime}\right)\end{array}$ & no \\
\hline LTC1-P3 & $M_{3} i$ & B & $\begin{array}{l}\text { fitolitos prismáticos; } \\
\text { buliformes }(A, B, C)\end{array}$ & no & no \\
\hline LTC1-P4 & $M_{3} i$ & L & $\begin{array}{c}\text { espículas de } \\
\text { espongiario (D) }\end{array}$ & $\begin{array}{l}\text { oval, sin fisura visible, } \\
\text { cruz de extinción } \\
\text { asimétrica }\left(F, F^{\prime}\right)\end{array}$ & $\begin{array}{c}\text { fibras } \\
\text { vegetales; } \\
\text { parte de } \\
\text { insecto? (I) }\end{array}$ \\
\hline LTC1-P5 & $I_{1} d$ & $L, I$ & no & no & no \\
\hline LTC1-S6 & $\mathrm{Pm}_{2} \mathrm{~d}$ & $\mathrm{~L}$ & no & no & fibra vegetal \\
\hline LDLG2-2 & $\mathrm{Pm}_{1} \mathrm{i}$ & B & $\begin{array}{l}\text { fitolito poliédrico } \\
\text { (célula buliforme) }\end{array}$ & $\begin{array}{l}\text { oval, fisura no visible, } \\
\text { cruz de extinción } \\
\text { simétrica }\left(G, G^{\prime}\right)\end{array}$ & fibra vegetal \\
\hline
\end{tabular}

Referencias: $\mathrm{L}=$ lingual; $\mathrm{B}=$ bucal. ${ }^{*}=$ entre paréntesis se menciona la referencia de la Figura 6.11 . 

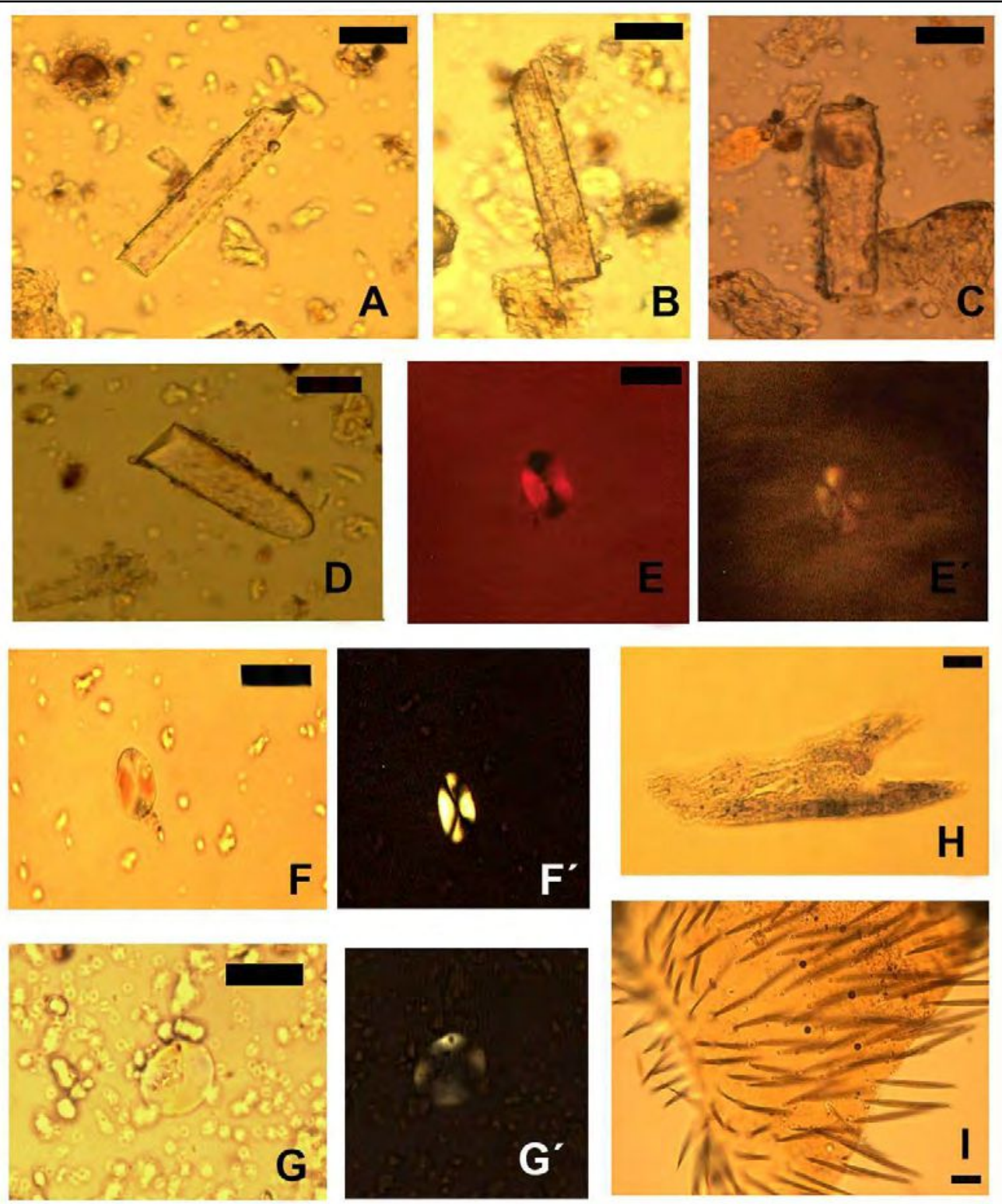

Figura 6.11. Microrrestos vegetales en muestras de cálculo dental de individuos del DS. Aclaración: ver referencias en la Tabla 6.21. Escalas: 20 micrones.

\subsubsection{Cuenca inferior del río Uruguay}

Se analizaron 715 dientes de 50 individuos. El cálculo dental fue registrado en el $94 \%$ de los individuos y en el $55,4 \%$ de las piezas dentales relevadas (Tabla 6.22). Los individuos en los que se observó este tipo de depósito fueron principalmente adultos; ambas variables (presencia de cálculo y adultos) están estadísticamente asociadas $\left(\chi^{2}=17,4 ; p=0,00003\right)$. En cuanto al sexo, todos los individuos que pudieron ser sexuados presentaron tártaro dental en su dentición; sin embargo al evaluar por piezas dentales, los masculinos presentan prevalencias 
más altas que los femeninos (Tabla 6.22); esta disparidad se asocia estadísticamente $\left(\chi^{2}=5,2 ; p=0,02\right)$.

Tabla 6.22. Prevalencias de cálculos dentales en la muestra de CIRU.

\begin{tabular}{|c|c|c|c|c|c|}
\hline & \multicolumn{2}{|c|}{ Individuos } & \multicolumn{2}{|c|}{ Dientes completos } \\
\hline & & A / O & $\%$ & A / O & $\%$ \\
\hline \multirow{6}{*}{ 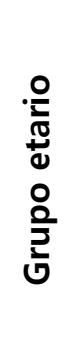 } & Infante & $0 / 1$ & 0 & $0 / 6$ & 0 \\
\hline & Niño & $1 / 3$ & 33,3 & $4 / 23$ & 17,4 \\
\hline & Adolescente & $3 / 3$ & 100 & $27 / 60$ & 45 \\
\hline & Adulto joven & $9 / 9$ & 100 & $112 / 175$ & 64 \\
\hline & Adulto medio & $1 / 1$ & 100 & $16 / 24$ & 66,6 \\
\hline & Adulto in. & $33 / 33$ & 100 & 237 / 427 & 55,5 \\
\hline \multirow{4}{*}{ 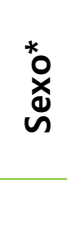 } & Femenino & $10 / 10$ & 100 & $113 / 215$ & 52,5 \\
\hline & Masculino & $16 / 16$ & 100 & $183 / 292$ & 62,7 \\
\hline & In. & $21 / 24$ & 87,5 & $100 / 208$ & 48,1 \\
\hline & Total & $47 / 50$ & 94 & $396 / 715$ & 55,4 \\
\hline
\end{tabular}

Referencias: $\mathrm{A}=$ afectado; $\mathrm{O}=$ observado; In.=indeterminado; * =entre los femeninos y los masculinos se incluyó en cada categoría a un individuo probable femenino y a un probable masculino.

Tal como se grafica en la Figura 6.12, se registraron porcentajes más elevados de este depósito en la dentición inferior $y$, en general, con mayor incidencia en la dentición posterior. Los molares superiores e inferiores presentaron prevalencias muy similares entre sí. En cuanto al grado de depositación, más de la mitad de los dientes con cálculo exhibían baja cantidad (Tabla 6.23; Figura 6.13). 


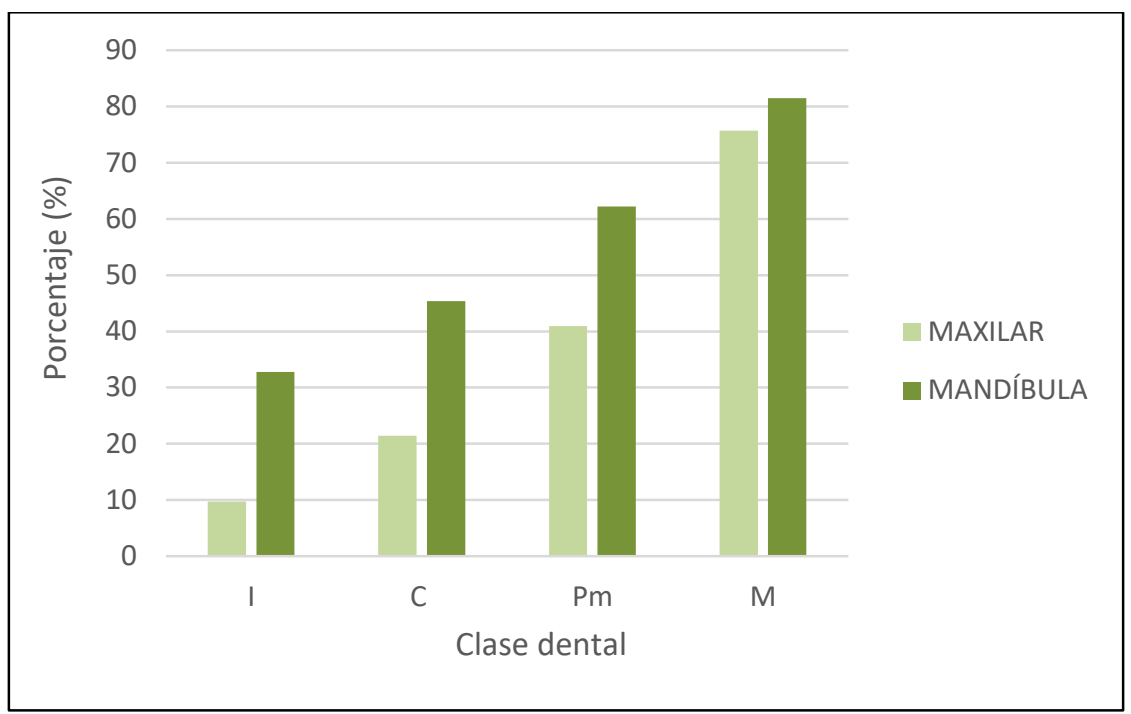

Figura 6.12. Prevalencias de cálculo dental en la muestra de CIRU, por clases de dientes y ubicación en la arcada dental.

Tabla 6.23. Prevalencias de los grados de depositación de cálculo dental en la muestra de CIRU.

\begin{tabular}{|ccc|}
\hline Grado de & \multicolumn{3}{c|}{ Dientes completos } \\
depositación & A / O & $\%$ \\
\hline $\mathbf{1}$ & $223 / 396$ & 56,3 \\
$\mathbf{2}$ & $126 / 396$ & 31,8 \\
$\mathbf{3}$ & $47 / 396$ & 11,9 \\
\hline Total & $\mathbf{3 9 6} / \mathbf{3 9 6}$ & $\mathbf{1 0 0}$ \\
\hline
\end{tabular}

Referencias: $\mathrm{A}=$ afectado; $\mathrm{O}=$ observado.

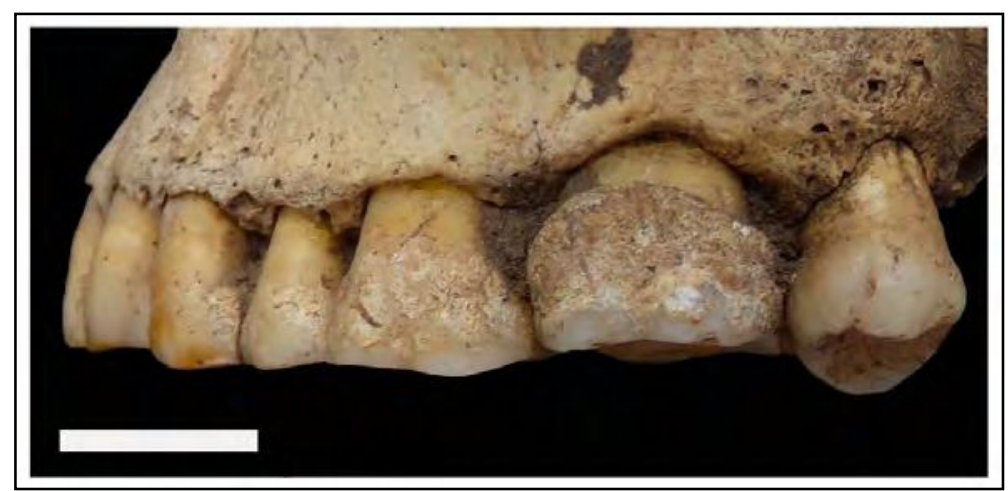

Figura 6.13. Cálculos dentales registrados en la muestra de CIRU: T1-CNM-74, grado de depositación 3 sobre $\mathrm{M}^{2}$ i. Escalas=1 cm.

Para el análisis de microrrestos vegetales en el tártaro dental de individuos de esta muestra bioarqueológica, fueron extraídas y preparadas para su observación microscópica nueve muestras de individuos diferentes (un adolescente, siete adultos 
de ambos sexos y un indeterminado). En seis de ellas pudieron ser observados fitolitos y/o granos de almidón (Tabla 6.24; Figura 6.14). Con respecto a los primeros, se registraron elementos panicoides, prismáticos y poliédricos en tres muestras de CL2. Por otro lado, en la muestra de CP se halló un grano de almidón pentagonal con fisura, que podría tratarse de un grano de almidón de maíz. También se observaron granos de almidón no diagnósticos en las muestras de TL y T2-CSM. Por otro lado, se relevaron fibras vegetales en cuatro muestras y una posible espora de hongo en una de ellas.

Tabla 6.24. Muestras de cálculo dental de CIRU y resultados del análisis de microrrestos vegetales.

\begin{tabular}{|c|c|c|c|c|c|}
\hline \multicolumn{3}{|c|}{ Muestras } & \multicolumn{3}{|c|}{ Resultados } \\
\hline Individuo & Diente & Cara & $\begin{array}{l}\text { Elementos } \\
\text { biosilíceos }\end{array}$ & Almidones & Otros \\
\hline CL2-76 & $\mathrm{I}^{1} \mathrm{~d}, \mathrm{i}$ & B & $\begin{array}{l}\text { poliédrico }(A) ; \\
\text { prismático }(B)\end{array}$ & no & no \\
\hline CL2-232 & $M_{2} i$ & L & poliédricos (C) & no & fibra vegetal \\
\hline CL2-80 & $M^{2} d$ & B & no & no & $\begin{array}{c}\text { fibra vegetal; } \\
\text { espora de hongo? } \\
\text { (G) }\end{array}$ \\
\hline CL2-103 & $P m_{1 y 2} i$ & B & $\begin{array}{c}\text { bilobado } \\
\text { panicoide (D) }\end{array}$ & & fibra vegetal $(\mathrm{H})$ \\
\hline SPL-95 & $M_{1} d$ & L & no & no & no \\
\hline SPL-217 & $M_{2} i$ & $\mathrm{~L}$ & no & no & no \\
\hline TL-64 & $M_{1} d$ & L & no & $\begin{array}{c}\text { muy pequeños } \\
\text { (en racimos) }\left(E_{1} E^{\prime}\right)\end{array}$ & fibra vegetal \\
\hline CP-228 & $\mathrm{M}_{2} \mathrm{i}$ & L & no & $\begin{array}{l}\text { pentagonal con } \\
\text { fisura }\left(F, F^{\prime}\right)\end{array}$ & no \\
\hline T2-CSM-82 & $\mathrm{M}_{2} \mathrm{~d}$ & L & no & oval, in. & no \\
\hline
\end{tabular}

Referencias: $L=$ lingual; $B=$ bucal; In.=indeterminado; ${ }^{*}=$ entre paréntesis se menciona la referencia de la Figura 6.14. 


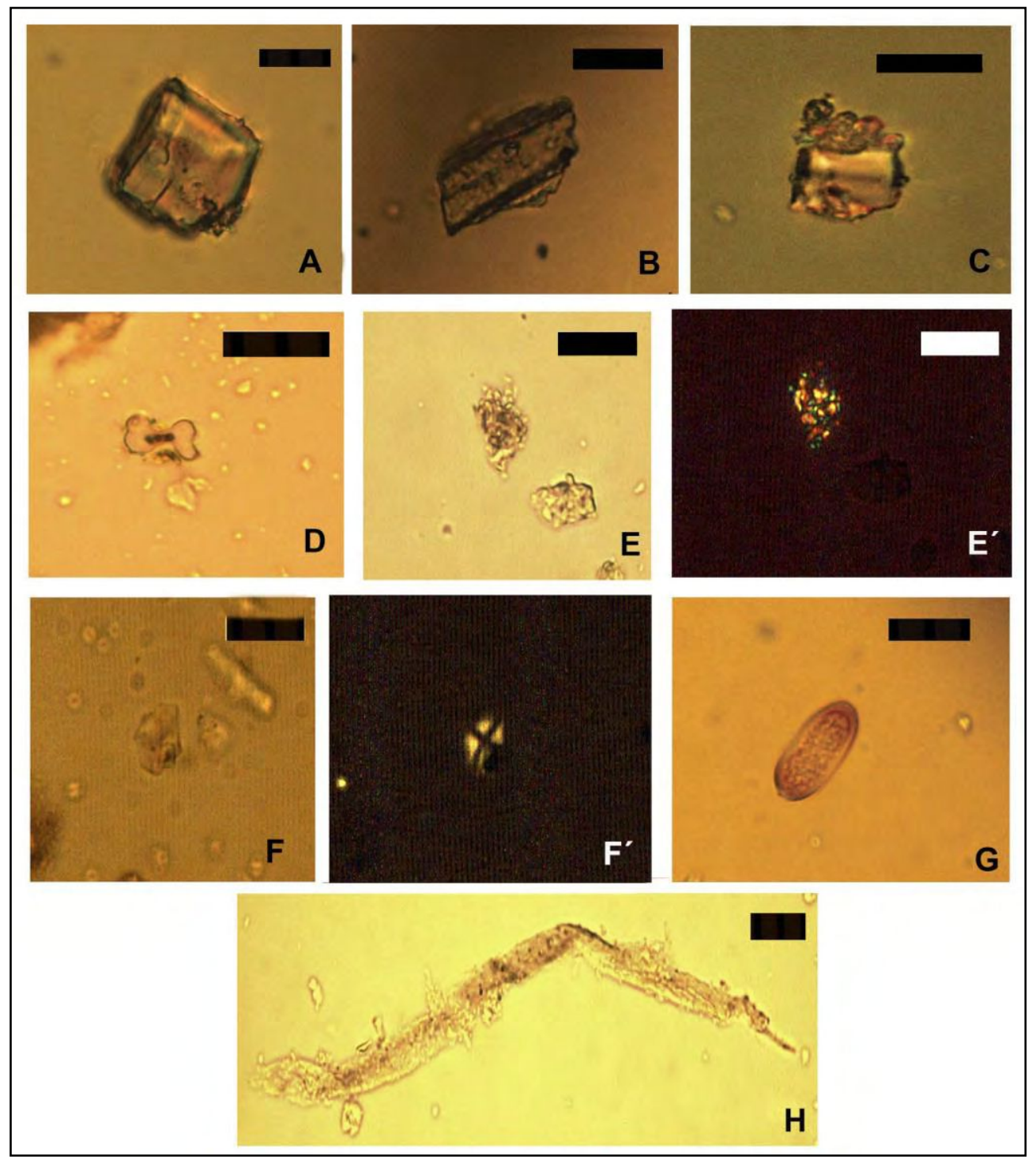

Figura 6.14. Microrrestos vegetales en muestras de cálculo dental de individuos de CIRU.

Aclaración: ver referencias en la Tabla 6.24. Escalas: 20 micrones.

\subsubsection{Delta Inferior del río Paraná y ambientes litorales adyacentes}

Se analizaron 404 dientes de 26 maxilares y 37 mandíbulas. A nivel de piezas dentales, se registró tártaro dental en el 57,4\% y a nivel individual, 65,4\% en los maxilares y $81,1 \%$ en las mandíbulas (Tabla 6.25). Los individuos afectados son adolescentes y adultos, con asociación estadística entre la presencia de cálculo y la edad (subadultos vs. adultos; $\chi 2=12,9 ; p=0,0003$ ). Al analizar la distribución sexual considerando solo los maxilares- (Tabla 6.26), se observa que los individuos masculinos tienen prevalencias más altas que los femeninos, tanto a nivel individual como por piezas dentales. Estadísticamente no existe asociación entre ambas variables (presencia de cálculo y sexo; $\chi^{2}=0,1 ; p=0,7$ ) 
Tabla 6.25. Prevalencias de cálculo dental por grupo de edad en la muestra del DI.

\begin{tabular}{|c|cccc|cc|}
\hline \multirow{2}{*}{ Grupo etario } & \multicolumn{4}{|c|}{ Individuos } & \multicolumn{2}{c|}{ Dientes } \\
& Maxilar & \multicolumn{3}{|c|}{ Mandíbula } & \multicolumn{2}{c|}{ completos } \\
\hline Niño & - & - & $0 / 1$ & 0 & $0 / 4$ & 0 \\
Adolescente & $1 / 1$ & 100 & $2 / 2$ & 100 & $21 / 27$ & 77,8 \\
Adulto joven & $0 / 1$ & 0 & - & - & $0 / 15$ & 0 \\
Adulto In. & $15 / 23$ & 65,2 & $29 / 34$ & 85,3 & $194 / 335$ & 57,9 \\
In. & $1 / 1$ & 100 & - & - & $17 / 23^{*}$ & 73,9 \\
\hline TOTAL & $\mathbf{1 7 / 2 6}$ & $\mathbf{6 5 , 4}$ & $\mathbf{3 0} / \mathbf{3 7}$ & $\mathbf{8 1 , 1}$ & $\mathbf{2 3 2} / \mathbf{4 0 4}$ & $\mathbf{5 7 , 4}$ \\
\hline
\end{tabular}

Referencias: $\mathrm{A}=$ afectado; $\mathrm{O}=$ observado; In.=indeterminado; * además de los dientes del maxilar de un individuo indeterminado, se incluyen los dientes sueltos.

Tabla 6.26. Prevalencias de cálculo dental por sexo (en maxilares) en la muestra del DI.

\begin{tabular}{|c|cc|cc|}
\hline \multirow{2}{*}{ Sexo* } & \multicolumn{2}{|c|}{ Individuos } & \multicolumn{2}{|c|}{$\begin{array}{c}\text { Dientes } \\
\text { completos }\end{array}$} \\
& A/O & $\%$ & A/O & $\%$ \\
\hline Femenino & $2 / 5$ & 40 & $11 / 49$ & 22,4 \\
Masculino & $5 / 11$ & 45,4 & $18 / 72$ & 25 \\
In. & $10 / 10$ & 100 & $36 / 49$ & 73,5 \\
\hline Total & $\mathbf{1 7 / 2 6}$ & $\mathbf{6 5 , 4}$ & $\mathbf{6 5} / \mathbf{1 7 0}$ & $\mathbf{3 8 , 2}$ \\
\hline
\end{tabular}

Referencias: *=entre los femeninos y los masculinos se incluyó en cada categoría a dos individuos probable femeninos y a dos probable masculinos. $\mathrm{A}=$ afectado; $\mathrm{O}=$ observado; In.=indeterminado.

Como se observa en la Figura 6.15, en el maxilar las prevalencias del cálculo son más altas en la dentición posterior; misma tendencia se registra en la mandíbula. El grado de depositación predominante fue el de baja cantidad (81\%) y en menor medida, el moderado; sólo tres dientes presentaron gran cantidad de depositación (Tabla 6.27). 


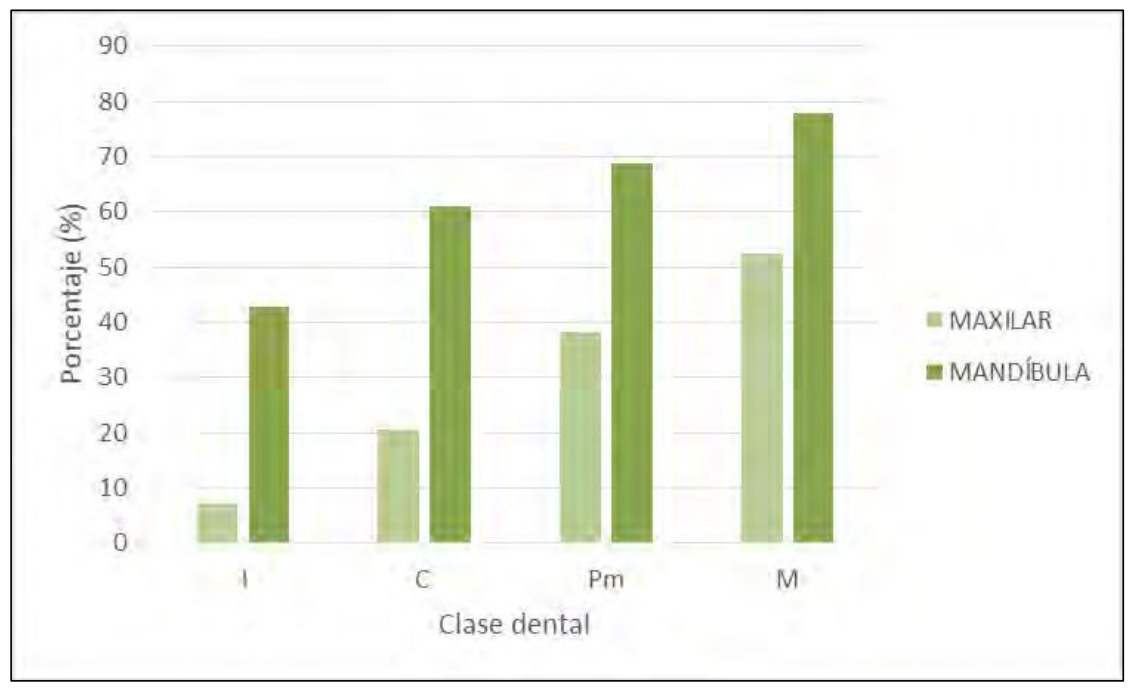

Figura 6.15. Prevalencias de cálculo dental en la muestra del DI, por clases de dientes y ubicación en la arcada dental.

Tabla 6.27. Prevalencias de los grados de depositación de cálculo dental en la muestra del DI.

\begin{tabular}{|ccc|}
\hline Grado de & \multicolumn{3}{c|}{ Dientes completos } \\
depositación & A / O & $\%$ \\
\hline $\mathbf{1}$ & $188 / 232$ & 81 \\
$\mathbf{2}$ & $41 / 232$ & 17,7 \\
$\mathbf{3}$ & $3 / 232$ & 1,3 \\
\hline Total & $232 / 232$ & 100 \\
\hline
\end{tabular}

Referencias: $\mathrm{A}=$ afectado; $\mathrm{O}=$ observado.

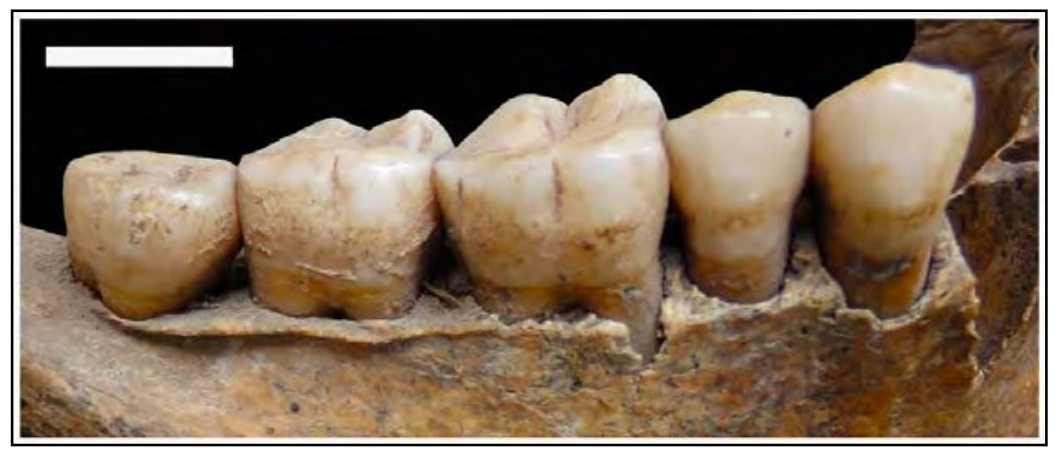

Figura 6.16. Cálculos dentales registrados en la muestra de DI: T1-LA-69, grado de depositación 1 sobre dentición posterior de la mandíbula. Escalas $=1 \mathrm{~cm}$. 


\subsection{Desgaste dental}

\subsubsection{Delta Superior del río Paraná}

Se analizaron 233 dientes de 12 individuos. En la Figura 6.17 se grafican los promedios obtenidos del grado de desgaste dental por clase de dientes y grupos de edad analizados ( 3 adolescentes, 2 adultos jóvenes, 2 adultos medios, 1 adulto mayor y 4 adultos indeterminados). Como tendencia general, para todos los grupos de edad, se observa que en los molares los grados de desgaste están asociados con los tiempos de erupción: los M1, que son los primeros molares en erupcionar, tienen los grados más altos; y los M3, los últimos en alcanzar el estado de oclusión, son los que presentan menor desgaste. Asimismo, los grados aumentan conforme aumenta la edad de los individuos: mientras los molares de los adolescentes y el adulto joven tienen grados bajos a medios ( 4 a 17), los molares del adulto medio y mayor presentan grados medios a altos (12 a 35). Entre estos dos últimos individuos se destaca que el adulto medio presenta mayor desgaste en todas sus piezas en comparación con el adulto mayor (Figura 6.17a). Es interesante notar que entre las piezas dentales analizadas, el $\mathrm{M}^{1} \mathrm{i}$ de un adulto masculino con grado de desgaste 38, presenta una cavidad no cariosa con exposición de la cámara pulpar por el alto desgaste. En cuanto a los premolares y la dentición anterior, la tendencia se repite en tanto el adolescente y el adulto joven presentan grados bajos a medios (1 a 4), mientras que el adulto medio y el mayor presentan grados medios a altos de desgaste $(4,5$ a 6,5$)$ en todas las clases de dientes. No se observan claras diferencias de desgaste entre los dientes de ambas arcadas, tanto para la dentición posterior como para la anterior. En la Figura 6.18 se grafican los promedios de grados de desgaste de los dientes anteriores y posteriores según el sexo de los individuos. En ella se puede observar que los masculinos poseen en general mayor desgaste que los femeninos. 


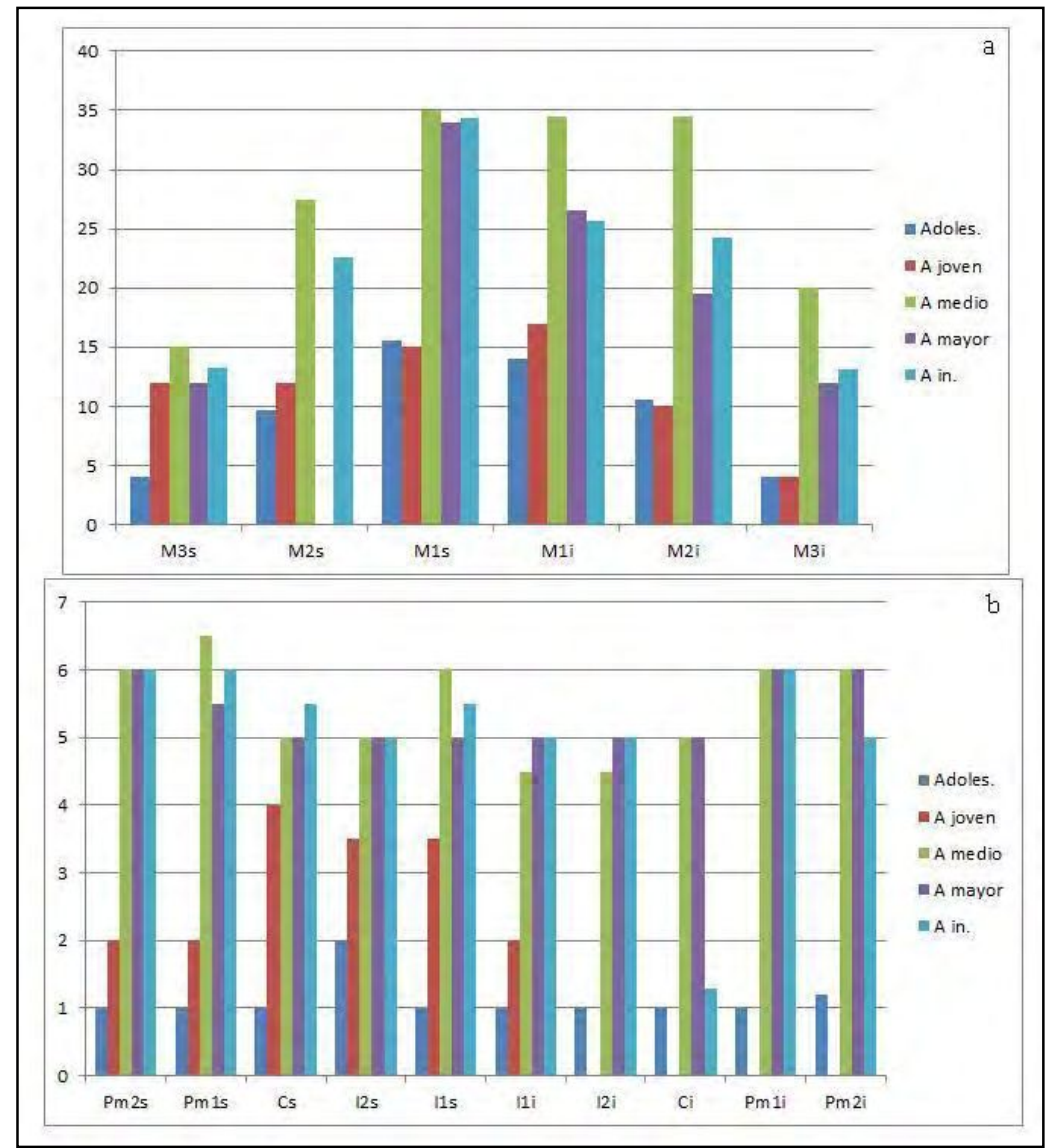

Figura 6.17. Promedios de grados de desgaste en la muestra del DS según grupos de edad: a) molares (escala de Scott 1979) y b) premolares, caninos e incisivos (Smith 1984).

Referencias $=\mathrm{s}=$ superior; $\mathrm{i}=$ inferior . 


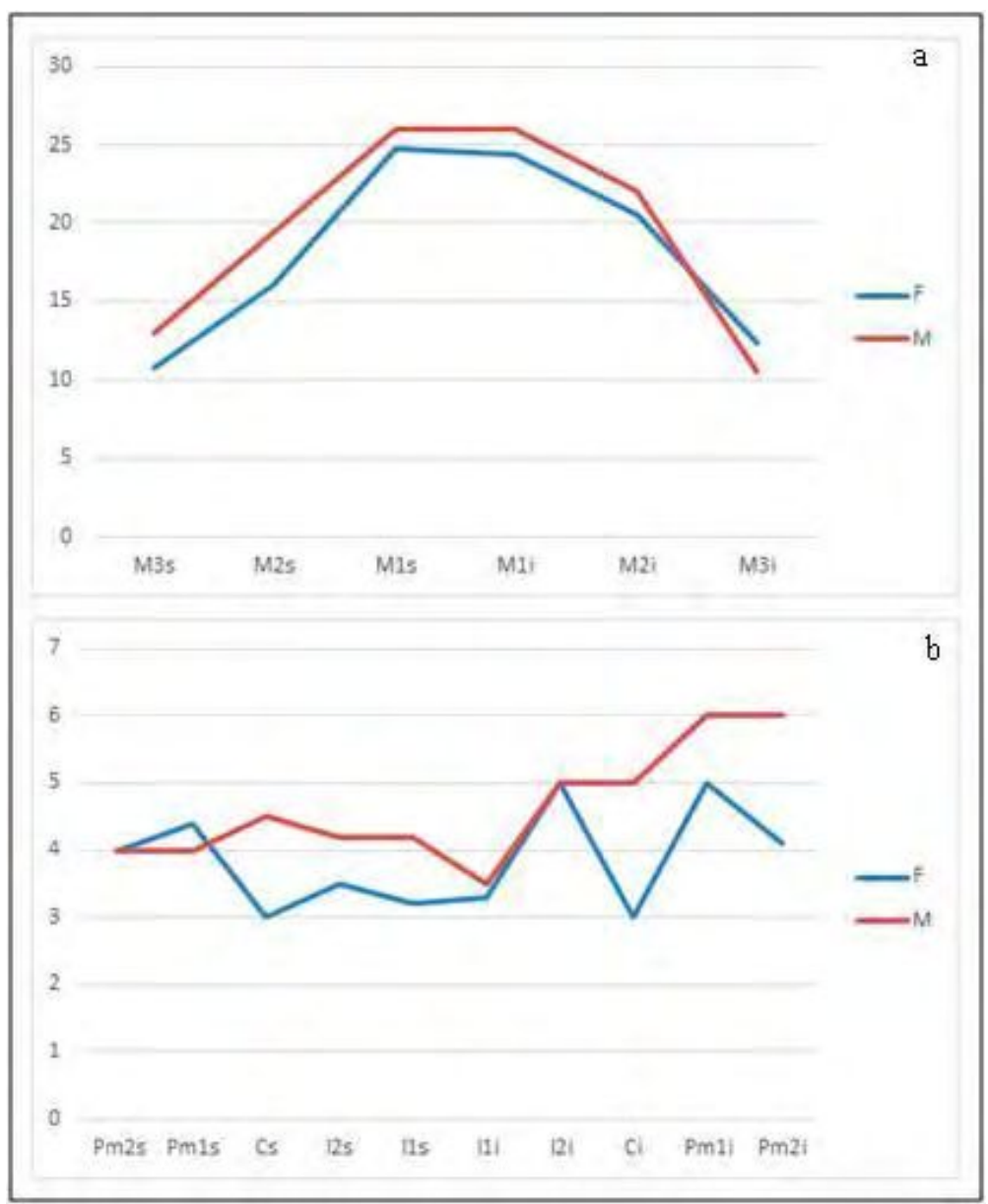

Figura 6.18. Promedios de grados de desgaste en la muestra del DS según el sexo: a) molares y b) premolares, caninos e incisivos. Referencias $=\mathrm{s}=$ superior; $i=$ inferior.

En cuanto a la forma de desgaste, en la dentición posterior se observó que en los molares prevalecen las formas cóncavas (parcial y total) seguidas por las naturales y planas (Tabla 6.28). Con respecto a la relación entre la forma y los grados de desgaste, los molares con forma de desgaste cóncava (mayormente de manera parcial), corresponden a los M1 y M2 con grados de desgaste más altos (entre 20 y 35); las formas naturales corresponden a aquellas piezas que tienen grados de desgaste bajos a medios (4 a 20) y las formas planas son coincidentes con los que presentan grados medios a altos (12 a 32). Al evaluar las direcciones de los planos de desgaste en molares (Tabla 6.29), las naturales, horizontales y oblicuas buco-linguales se encuentran con porcentajes similares. Las dos primeras están relacionadas principalmente con las formas naturales y planas, en tanto que las oblicuas con los desgastes en forma cóncava. 
Los resultados obtenidos para los premolares son similares a las de los molares, ya que predominan las formas cóncavas (mayormente las parciales) y naturales. Asimismo, las direcciones más representadas son las naturales y oblicuas buco-linguales y mesio-distales. Con respecto a los caninos e incisivos, los tipos de desgaste son semejantes en estas clases dentales: predominan las formas planas seguidas por las naturales, mientras que las direcciones son principalmente naturales aunque también se encuentran en porcentajes altos las oblicuas y las horizontales.

Tabla 6.28. Prevalencias de las formas de desgaste dental en la muestra del DS.

\begin{tabular}{|cccccccccc|}
\hline Forma & \multicolumn{2}{c}{$\mathbf{M}$} & \multicolumn{2}{c}{$\mathbf{P M}$} & \multicolumn{2}{c}{} & \multicolumn{2}{c|}{ I } \\
& $\mathbf{n}$ & $\%$ & $\mathbf{n}$ & $\%$ & $\mathbf{n}$ & $\%$ & $\mathbf{n}$ & $\%$ \\
\hline Natural & 30 & 32,6 & 21 & 33,9 & 11 & 36,6 & 20 & 40 \\
Plana & 29 & 31,5 & 16 & 25,8 & 15 & 50 & 28 & 56 \\
Cóncava parcial & 18 & 19,6 & 19 & 30,6 & 3 & 10 & 0 & 0 \\
Cóncava total & 13 & 14,1 & 6 & 9,7 & 1 & 3,3 & 2 & 4 \\
Redondeada & 1 & 1,1 & 0 & 0 & 0 & 0 & 0 & 0 \\
\hline
\end{tabular}

Tabla 6.29. Prevalencias de las direcciones de desgaste dental en la muestra del DS.

\begin{tabular}{|c|c|c|c|c|c|c|c|c|}
\hline \multirow{2}{*}{ Dirección } & \multicolumn{2}{|c|}{ M } & \multicolumn{2}{|c|}{ PM } & \multicolumn{2}{|c|}{ C } & \multicolumn{2}{|c|}{ I } \\
\hline & $\mathbf{n}$ & $\%$ & $\mathbf{n}$ & $\%$ & $\mathbf{n}$ & $\%$ & $\mathbf{n}$ & $\%$ \\
\hline Natural & 30 & 32,9 & 21 & 33,9 & 12 & 40 & 20 & 40 \\
\hline Oblicua B-L & 27 & 29,7 & 18 & 29,1 & 10 & 33,3 & 11 & 22 \\
\hline Oblicua L-B & 2 & 2,2 & 3 & 4,8 & 0 & 0 & 0 & 0 \\
\hline Oblicua M-D & 3 & 3,3 & 11 & 17,7 & 5 & 16,7 & 5 & 10 \\
\hline Oblicua D-M & 0 & 0 & 0 & 0 & 0 & 0 & 1 & 2 \\
\hline Redondeada B-L & 1 & 1,1 & 0 & 0 & 0 & 0 & 0 & 0 \\
\hline Redondeada L-B & 0 & 0 & 0 & 0 & 0 & 0 & 0 & 0 \\
\hline Horizontal & 28 & 30,8 & 9 & 14,5 & 3 & 10 & 13 & 26 \\
\hline
\end{tabular}

Referencias: $B-L=$ buco-lingual; $L-B=$ linguo-bucal; $M-D=$ medio-distal; $D-M=$ disto-mesial.

\subsubsection{Cuenca inferior del río Uruguay}

Se analizaron 686 dientes de 46 individuos (3 adolescentes, 9 adultos jóvenes, 1 adulto medio y 33 adultos indeterminados). En la Figura 6.19a puede observarse que, en términos generales, los grados de desgaste de los molares se ajustan a los tiempos de erupción de los mismos, teniendo así los M3 menor 
desgaste que las otras dos piezas dentales. Los grados de desgaste alcanzados por estas clases de dientes son medios a altos (15,5 a 35). En cuanto a los premolares y la dentición anterior (Figura 6.19b), el grado de desgaste corresponde a valores medios a altos (4 a 8). No se observaron diferencias entre ambas arcadas según las clases dentales. Al comparar por grupos de edad, tanto en la dentición anterior como posterior, el alto número de adultos indeterminados puede estar sesgando los patrones obtenidos; aun así puede observarse que el desgaste se asocia con la edad de los individuos, en tanto los adolescentes presentan grados más bajos que los adultos jóvenes y éstos a su vez más bajos que los adultos medios. Por otro lado, de los 715 dientes relevados, 7 de ellos (1\%) presentan cavidades no cariosas dada la exposición de la cámara pulpar por el alto desgaste. Estas cavidades las presentan tres individuos (un adulto femenino, un adulto masculino y un adulto joven masculino) y se corresponden con piezas dentales anteriores y posteriores que alcanzaron altos grados de desgaste (8 para los I, C y Pm; y 36 y 38 para los molares). En cuanto a la relación entre el sexo y los grados de desgaste, se observaron escasas diferencias en los promedios de los grados de desgaste entre ambos sexos, levemente mayores en los masculinos (Figura 6.20). 


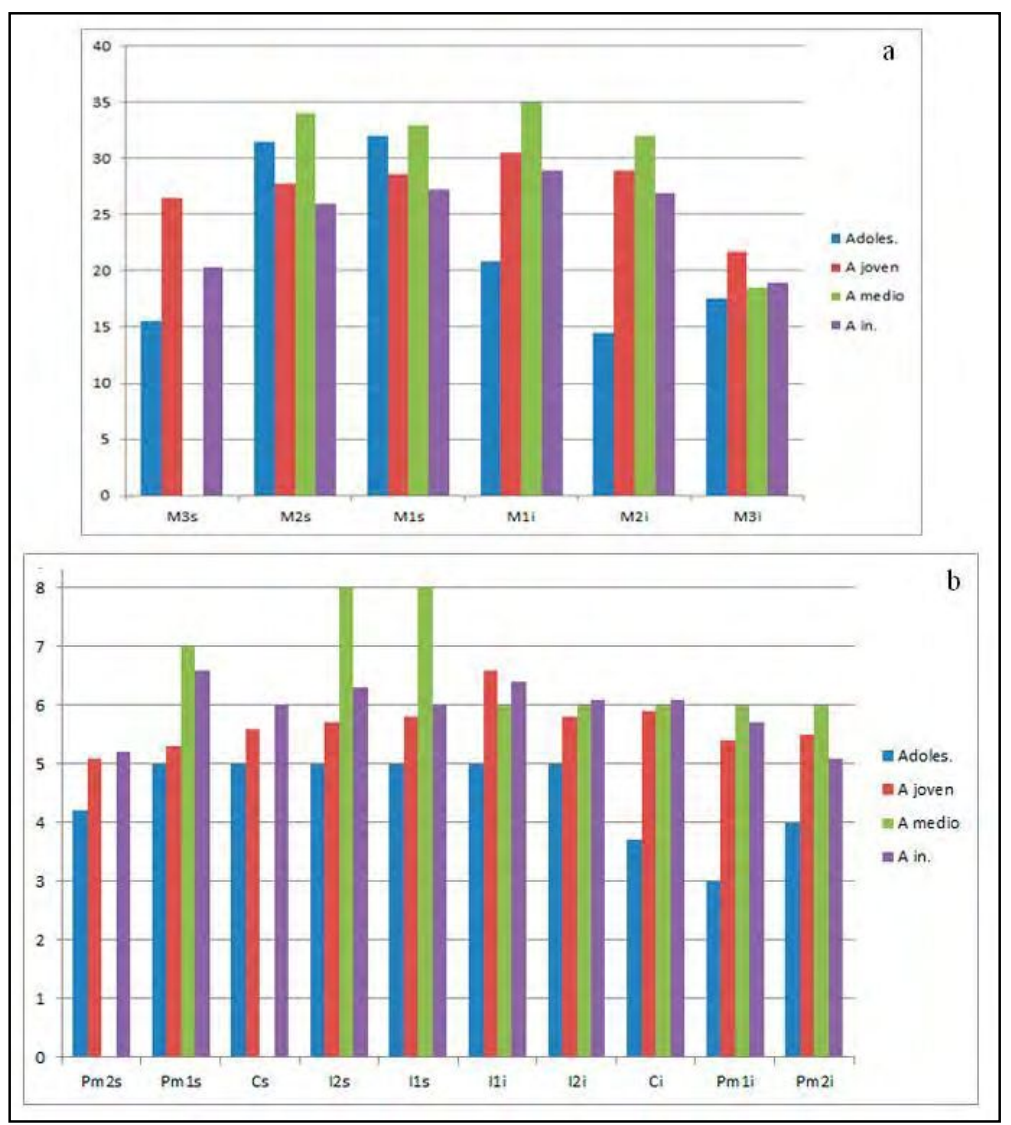

Figura 6.19. Promedios de grados de desgaste en la muestra de CIRU según grupos de edad: a) molares (escala de Scott 1979) y b) premolares, caninos e incisivos (Smith 1984). Referencias $=\mathrm{s}=$ superior; $\mathrm{i}=$ inferior. 


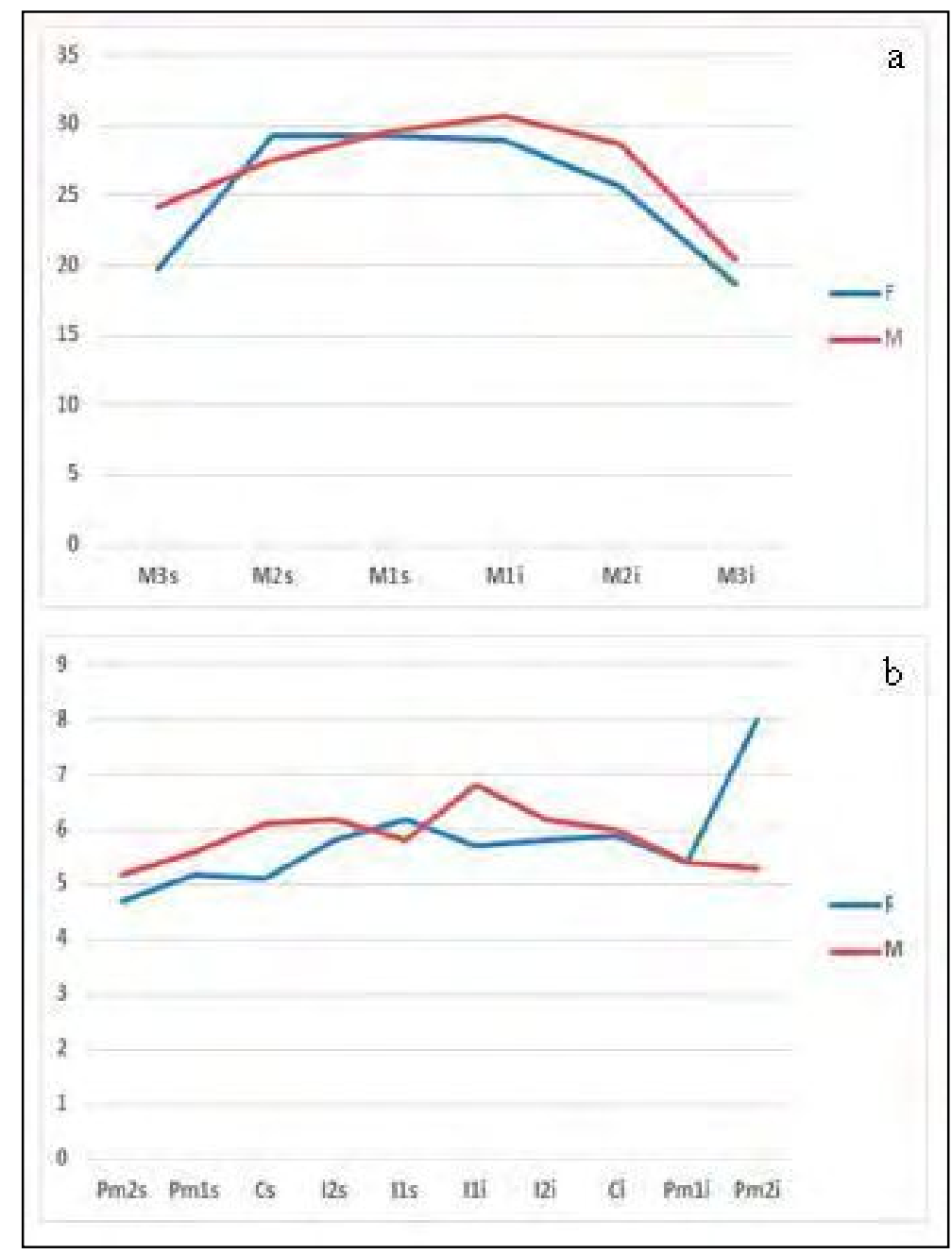

Figura 6.20. Promedios de grados de desgaste en la muestra de CIRU según el sexo: a) molares y b) premolares, caninos e incisivos. Referencias $=s=$ superior; $i=$ inferior.

La forma predominante de la superficie oclusal adquirida por el desgaste en todas las clases de dientes, es plana (Tabla 6.30). En cuanto a las direcciones (Tabla 6.31), las oblicuas (principalmente buco-linguales y linguo-bucales) son las más representadas en molares y premolares; en los caninos predominan las direcciones tanto oblicuas como horizontales; mientras que en los incisivos se encuentran en porcentajes similares las direcciones oblicuas, redondeadas y horizontales. Más allá de estas generalidades, se destaca la forma cóncava parcial en los molares, vinculada con las direcciones oblicuas y con grados de desgaste altos (24 a 39). También sobresalen los incisivos y caninos con forma y dirección redondeada, que presentan grados altos de desgaste (6 a 8 ). Es importante subrayar que las 48 piezas dentales anteriores con desgaste de tipo redondeado corresponden al 26,1\% $(n=12)$ de los individuos relevados en esta muestra, siendo tres adultos joven, un 
adulto medio y ocho adultos indeterminados. En cuanto al sexo, siete de estos individuos son masculinos, uno es femenino y cuatro son indeterminados.

Tabla 6.30. Prevalencias de las formas de desgaste dental en la muestra de CIRU.

\begin{tabular}{|cccccccccc|}
\hline Forma & \multicolumn{2}{c}{$\mathbf{M}$} & \multicolumn{2}{c}{$\mathbf{P M}$} & \multicolumn{3}{c}{$\mathbf{c}$} & \multicolumn{2}{c|}{} \\
& $\mathbf{n}$ & $\%$ & $\mathbf{N}$ & $\%$ & $\mathbf{n}$ & $\%$ & $\mathbf{n}$ & $\%$ \\
\hline Natural & 37 & 12,9 & 23 & 12,2 & 5 & 6,1 & 4 & 3,1 \\
Plana & 165 & 57,7 & 143 & 75,7 & 61 & 74,4 & 89 & 69 \\
Cóncava parcial & 70 & 24,5 & 5 & 2,6 & 0 & 0 & 0 & 0 \\
Cóncava total & 13 & 4,6 & 8 & 4,2 & 3 & 3,7 & 1 & 0,8 \\
Redondeada & 1 & 0,3 & 10 & 5,3 & 13 & 15,8 & 35 & 27,1 \\
\hline
\end{tabular}

Tabla 6.31. Prevalencias de las direcciones de desgaste dental en la muestra de CIRU.

\begin{tabular}{|cccccccccc|}
\hline Dirección & \multicolumn{3}{c}{ M } & \multicolumn{2}{c}{ PM } & \multicolumn{3}{c}{ C } & \multicolumn{2}{c|}{ I } \\
& $\mathbf{n}$ & $\%$ & $\mathbf{N}$ & $\%$ & $\mathbf{n}$ & $\%$ & $\mathbf{n}$ & $\%$ \\
\hline Natural & 41 & 14,3 & 30 & 15,9 & 7 & 8,5 & 6 & 4,6 \\
Oblicua B-L & 36 & 12,6 & 27 & 14,3 & 7 & 8,5 & 12 & 9,3 \\
Oblicua L-B & 100 & 35 & 66 & 34,9 & 20 & 24,4 & 20 & 15,5 \\
Oblicua M-D & 22 & 7,7 & 7 & 3,7 & 3 & 3,7 & 3 & 2,3 \\
Oblicua D-M & 6 & 2,1 & 0 & 0 & 1 & 1,2 & 6 & 4,6 \\
Redondeada B-L & 0 & 0 & 10 & 5,3 & 13 & 15,9 & 34 & 26,4 \\
Redondeada L-B & 0 & 0 & 0 & 0 & 0 & 0 & 0 & 0 \\
Redondeado M-D & 1 & 0,3 & 0 & 0 & 0 & 0 & 1 & 0,8 \\
Horizontal & 80 & 28 & 49 & 25,9 & 31 & 37,8 & 47 & 36,5 \\
\hline
\end{tabular}

Referencias: $B-L=$ buco-lingual; $L-B=$ linguo-bucal; $M-D=$ medio-distal; $D-M=$ disto-mesial.

\subsubsection{Delta Inferior del río Paraná y ambientes litorales adyacentes}

Se analizaron 382 dientes correspondientes a una mandíbula de adolescente, un maxilar y mandíbula de otro adolescente, un maxilar de adulto joven y 22 maxilares y 33 mandíbulas de adultos indeterminados. En la Figura 6.21 puede observarse que los molares presentan grados de desgaste conforme su tiempo de erupción, alcanzando en general grados bajos a medios (7 a 25). Dadas las características de la muestra y que no se pudieron realizar estimaciones etarias más precisas, no pueden observarse patrones en cuanto a la edad y los grados de desgaste; sí se destaca que los molares del adolescente presentan más desgaste que el adulto joven. Por otro lado, sólo un individuo (adulto) presenta dos molares 
inferiores (M1 y M2) con cavidades no cariosas que expusieron la cámara pulpar dado el gran desgaste (34 y 32) que afectó su superficie oclusal. En cuanto a los premolares, caninos e incisivos, éstos muestran grados bajos a medios de desgaste (2 a 5,7). Al evaluar los promedios de los grados de desgaste por clase dental según el sexo (Figura 6.22), se destaca que los molares superiores de los individuos masculinos presentan grados más altos que los femeninos; misma tendencia le corresponde a dos de las tres piezas anteriores que pudieron ser evaluadas. Sin embargo, estos datos deben tomarse con cautela debido a que para varias clases dentales solo se cuenta con uno o dos valores de desgaste. Esto significa que en realidad se están comparando entre uno o dos individuos y no se tiene información que permita evaluar mejor el desgaste según el sexo en esta muestra.

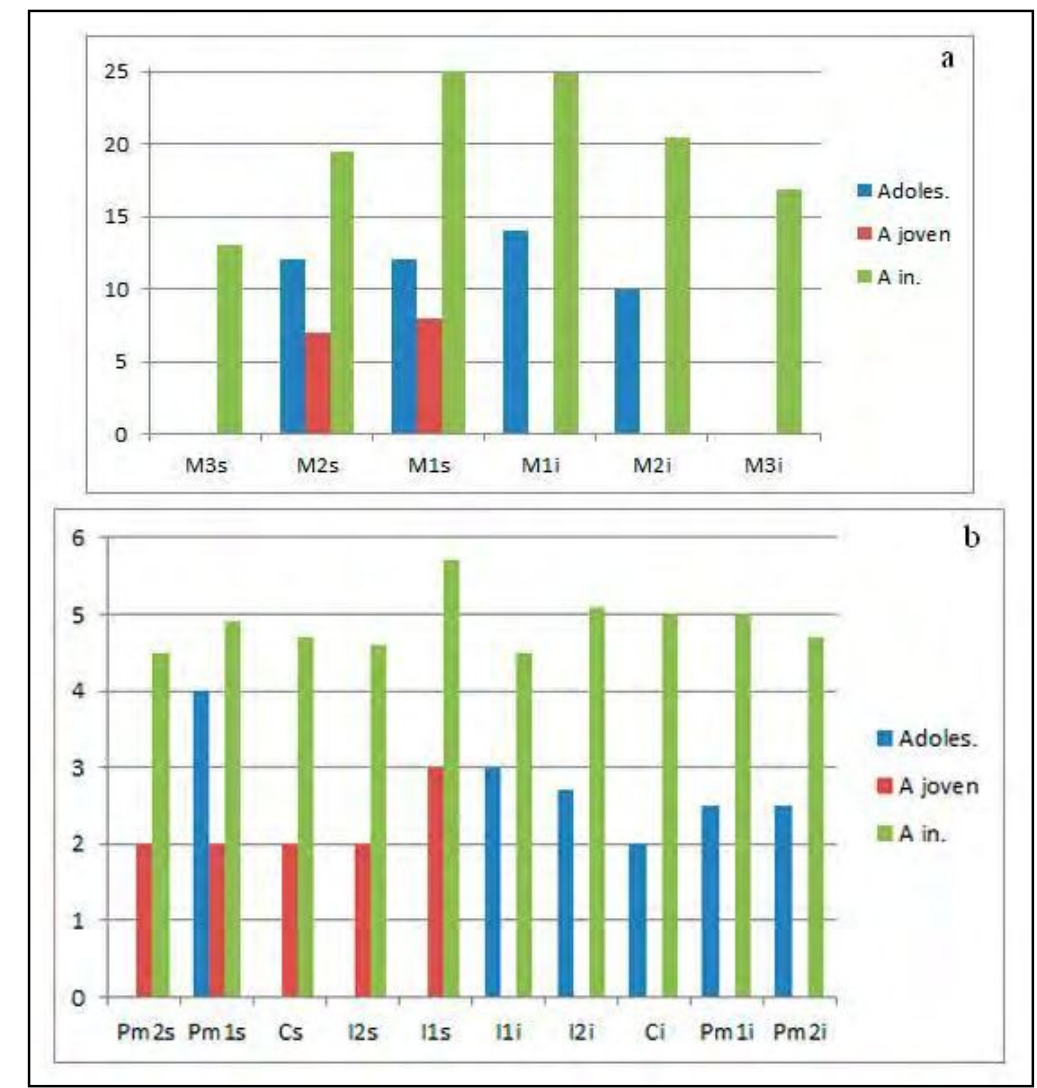

Figura 6.21. Promedios de grados de desgaste en la muestra del DI según grupos de edad: a) molares (escala de Scott 1979) y b) premolares, caninos e incisivos (Smith 1984). Referencias $=\mathrm{s}=$ superior; $\mathrm{i}=$ inferior. 


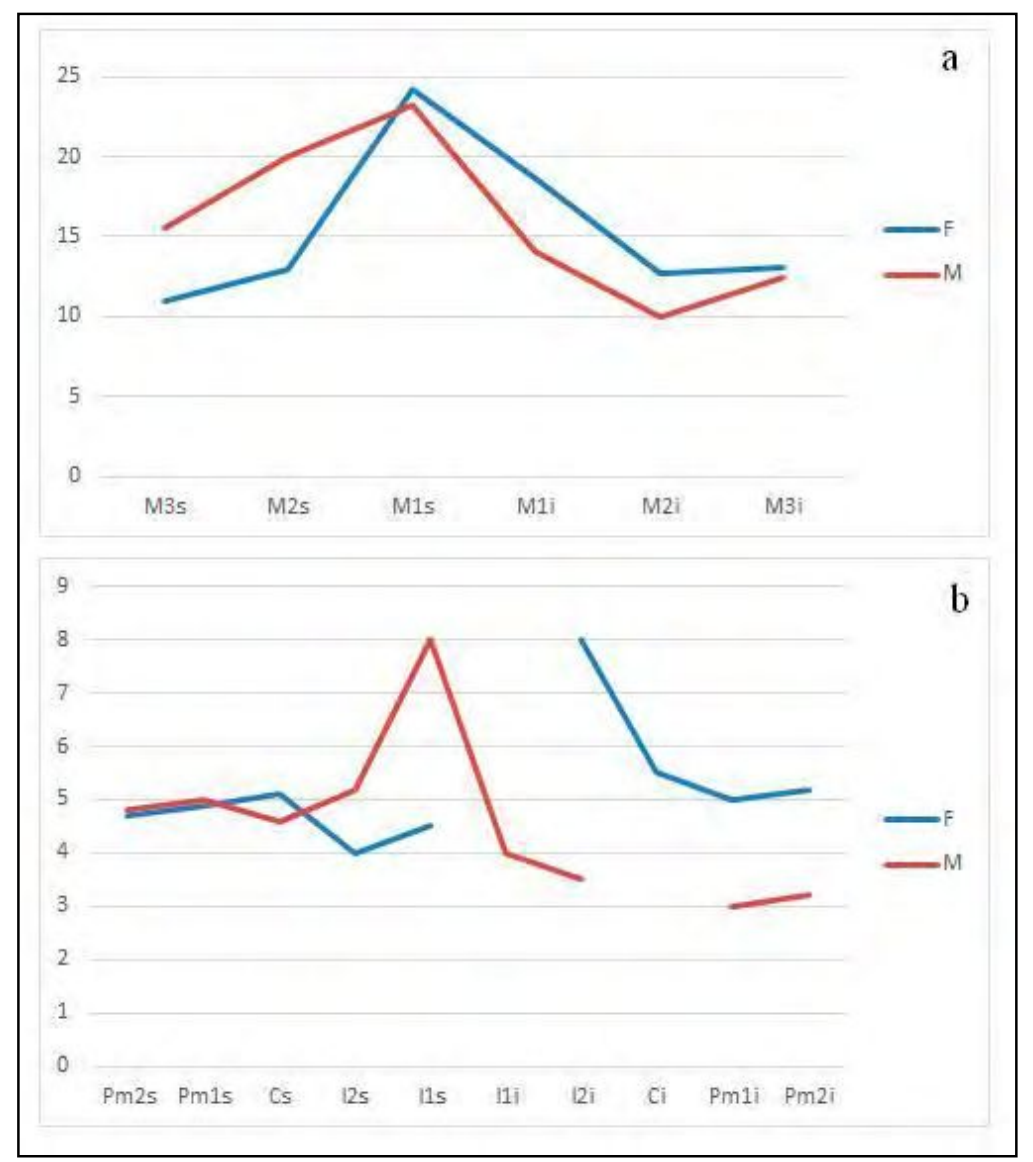

Figura 6.22. Promedios de grados de desgaste en la muestra del DI según el sexo: a) molares y b) premolares, caninos e incisivos. Referencias $=s=$ superior; $i=$ inferior.

Las superficies oclusales presentan, principalmente, formas planas y naturales en todas las clases de dientes (Tabla 6.32). En cuanto a las direcciones de los planos de desgaste, en $\mathrm{M}, \mathrm{Pm}$ y $\mathrm{C}$ predominan las oblicuas, seguidas por las horizontales y naturales; mientras que en los I son mayoritarias las direcciones horizontales y luego las oblicuas. Las formas planas se encuentran vinculadas en su mayoría con las direcciones oblicuas (en todas sus variantes) y horizontales en la dentición posterior, y con las naturales y oblicuas en la dentición anterior (Tabla 6.33). Las superficies oclusales en convexidad fueron registradas principalmente en $\mathrm{Pm}$ y $\mathrm{M}$, con diferentes grados de desgaste pero en su mayoría con grados altos (27 a 40). 
Tabla 6.32. Prevalencias de las formas de desgaste dental en la muestra del DI.

\begin{tabular}{|cccccccccc|}
\hline Forma & \multicolumn{3}{c}{$\mathbf{M}$} & \multicolumn{2}{c}{$\mathbf{P M}$} & \multicolumn{3}{c}{$\mathbf{c}$} & \multicolumn{2}{c|}{} \\
& $\mathbf{n}$ & $\%$ & $\mathbf{n}$ & $\%$ & $\mathbf{n}$ & $\%$ & $\mathbf{n}$ & $\%$ \\
\hline Natural & 53 & 27 & 41 & 36 & 15 & 35,7 & 16 & 53,3 \\
Plana & 92 & 47 & 55 & 48,2 & 21 & 50 & 13 & 43,4 \\
Cóncava parcial & 44 & 22,4 & 8 & 7,1 & 1 & 2,4 & 0 & 0 \\
Cóncava total & 7 & 3,6 & 7 & 6,1 & 2 & 4,8 & 0 & 0 \\
Redondeada & 0 & 0 & 3 & 2,6 & 3 & 7,1 & 1 & 3,3 \\
\hline
\end{tabular}

Tabla 6.33. Prevalencias de las direcciones de desgaste dental en la muestra del DI.

\begin{tabular}{|c|c|c|c|c|c|c|c|c|}
\hline \multirow{2}{*}{ Dirección } & \multicolumn{2}{|c|}{$\mathbf{M}$} & \multicolumn{2}{|c|}{ PM } & \multicolumn{2}{|c|}{ C } & \multicolumn{2}{|c|}{ I } \\
\hline & $\mathbf{n}$ & $\%$ & $\mathbf{n}$ & $\%$ & $\mathbf{n}$ & $\%$ & $\mathbf{n}$ & $\%$ \\
\hline Natural & 53 & 27 & 41 & 36 & 15 & 35,7 & 16 & 53,3 \\
\hline Oblicua B-L & 41 & 21 & 22 & 19,3 & 6 & 14,3 & 11 & 36,8 \\
\hline Oblicua L-B & 29 & 14,8 & 12 & 10,5 & 3 & 7,1 & 1 & 3,3 \\
\hline Oblicua M-D & 15 & 7,6 & 4 & 3,5 & 6 & 14,3 & 0 & 0 \\
\hline Oblicua D-M & 0 & 0 & 0 & 0 & 2 & 4,8 & 0 & 0 \\
\hline Redondeada B-L & 0 & 0 & 3 & 2,6 & 1 & 2,4 & 1 & 3,3 \\
\hline Redondeada L-B & 0 & 0 & 0 & 0 & 0 & 0 & 0 & 0 \\
\hline Horizontal & 58 & 29,6 & 32 & 28,1 & 9 & 21,4 & 1 & 3,3 \\
\hline
\end{tabular}

Referencias: $B-L=$ buco-lingual; $L-B=$ linguo-bucal; $M-D=$ medio-distal; $D-M=$ disto-mesial.

\subsection{Hipoplasias lineales del esmalte dental (HLED)}

\subsubsection{Delta Superior del río Paraná}

Se analizaron 86 dientes de maxilares y/o mandíbulas de 11 individuos. Se registraron 13 dientes con HLED (15,1\%) correspondientes a cuatro individuos adultos (36,4\%). En la Tabla 6.34 se presentan los resultados obtenidos de los Índices de Sensibilidad y Supervivencia y sus respectivos rankings. Los mismos indican que los incisivos centrales superiores, junto con los caninos inferiores, son las piezas dentales más sensibles a presentar hipoplasias. Sin embargo, en el Ranking de Supervivencia, estas clases dentales no son las mejores representadas en la muestra, como sí los caninos e incisivos laterales superiores. Esta situación está indicando que las PDAM o las pérdidas postmortem de los dientes están sesgando los resultados obtenidos y por ende, subestimando las prevalencias de HLED 
registradas; principalmente las pérdidas postmortem, dado que las prevalencias de las PDAM en esta muestra son bajas.

Tabla 6.34. Índice de Sensibilidad e Índice de Supervivencia de HLED y sus respectivos rankings por clase dental en la muestra del DS.

\begin{tabular}{|ccccccccc|}
\hline $\begin{array}{c}\text { Clase } \\
\text { dental }\end{array}$ & $\begin{array}{c}\text { Total } \\
\text { dientes } \\
\text { esperados }\end{array}$ & $\begin{array}{c}\text { Total } \\
\text { dientes } \\
\text { observados }\end{array}$ & $\begin{array}{c}\text { Dientes } \\
\text { con } \\
\text { HLED }\end{array}$ & $\begin{array}{c}\text { Total } \\
\text { HLED }\end{array}$ & $\begin{array}{c}\text { Índice } \\
\text { Sen }\end{array}$ & $\begin{array}{c}\text { Ranking } \\
\text { Sen }\end{array}$ & $\begin{array}{c}\text { Índice } \\
\text { Sup }\end{array}$ & $\begin{array}{c}\text { Ranking } \\
\text { Sup }\end{array}$ \\
\hline $\mathbf{C}^{1}$ & $18^{*}$ & 17 & 3 & 3 & 17,6 & 4 & 94,4 & 1 \\
$\mathbf{I}^{\mathbf{2}}$ & 20 & 16 & 2 & 3 & 18,7 & 3 & 80 & 2 \\
$\mathbf{I}^{1}$ & 20 & 12 & 4 & 7 & 58,3 & 1 & 60 & 5 \\
$\mathbf{I}_{\mathbf{1}}$ & 18 & 13 & 0 & 0 & 0 & 6 & 72,2 & 4 \\
$\mathbf{I}_{2}$ & 18 & 14 & 0 & 0 & 0 & 6 & 77,7 & 3 \\
$\mathbf{C}_{\mathbf{1}}$ & 18 & 14 & 4 & 8 & 57,1 & 2 & 77,7 & 3 \\
\hline
\end{tabular}

Referencias: *Los caninos son 18 porque en la muestra de subadultos menores aún no han erupcionado; Sen=sensibilidad; Sup=supervivencia.

Para minimizar la probabilidad de incluir en el análisis a HLED producto de estrés local (por ej. por trauma), se debe excluir al único individuo (adulto joven masculino) que presentó sólo un diente con este defecto. De esta forma, la prevalencia por piezas dentales en la muestra del DS es de $16,2 \%$ mientras que a nivel individual es de 30\% (Tabla 6.35). Al evaluar por sexo (Tabla 6.35), se observan mayores prevalencias para los masculinos tanto a nivel individual como de piezas dentales; con respecto a estas últimas, existe asociación estadística entre la ocurrencia de estos defectos y los individuos masculinos $(p=0,006)$. Sin embargo, estos datos deben considerarse con cautela, dado el pequeño tamaño de la muestra y que sólo uno de los individuos analizados fue determinado como masculino, lo cual puede generar un sesgo en los cálculos realizados. 
Tabla 6.35. Prevalencias de HLED en la muestra del DS.

\begin{tabular}{|c|c|c|c|c|c|}
\hline & \multicolumn{2}{|c|}{ Individuos } & \multicolumn{2}{|c|}{ Dientes completos } \\
\hline & & A / O & $\%$ & A / O & $\%$ \\
\hline \multirow{5}{*}{$\begin{array}{l}\frac{0}{\frac{2}{5}} \\
\pm 0 \\
\frac{0}{0} \\
\frac{2}{2} \\
\frac{0}{2}\end{array}$} & Niño & $0 / 1$ & 0 & $0 / 3$ & 0 \\
\hline & Adolescente & $0 / 3$ & 0 & $0 / 25$ & 0 \\
\hline & Adulto medio & $1 / 1$ & 100 & $3 / 11$ & 27,3 \\
\hline & Adulto mayor & $0 / 1$ & 0 & $0 / 12$ & 0 \\
\hline & Adulto in. & $2 / 4$ & 50 & $9 / 23$ & 39,1 \\
\hline \multirow{4}{*}{ 离 } & Femenino & $1 / 6$ & 16,6 & $3 / 54$ & 5,5 \\
\hline & Masculino & $1 / 1$ & 100 & $6 / 11$ & 43,7 \\
\hline & In. & $1 / 3$ & 33,3 & $3 / 9$ & 33,3 \\
\hline & Total & $3 / 10$ & 30 & $12 / 74$ & 16,2 \\
\hline
\end{tabular}

Referencias: $\mathrm{A}=$ afectado; $\mathrm{O}=$ observado; In.=indeterminado.

En dos de los tres individuos con HLED (LTC1-P2 -adulto masculino- y LTC1P4 -adulto medio femenino) pudieron determinarse pares simétricos en cada uno de ellos (diferencia menor a 0,50 mm en su ubicación en la corona dental); en el tercer individuo esto no fue posible dada la ausencia de los dientes opuestos. En el caso del individuo masculino (LTC1-P2), se trata de un par simétrico en los caninos inferiores (Figura 6.23) y otro en los incisivos centrales superiores. Por su parte, el individuo femenino (LTC1-P4) presenta un par simétrico en los caninos mandibulares. Es importante remarcar que la presencia de estas hipoplasias simétricas en estas clases de dientes es coincidente con que son las piezas dentales mejor ubicadas en el Ranking de Sensibilidad (Tabla 6.34). Luego de identificar estos defectos simétricos, se procedió a estimar la edad en la que habrían ocurrido a través del modelo de deciles de Reid y Dean $(2000,2006)$. En LTC1-P2, en los $C_{1}$ las hipoplasias se corresponden al rango 1,7-2,3 años de edad; en los 1 1', al rango 2,4-2,9 años de edad. En LTC1-P4, el rango de edad estimado para los $C_{1}$ es de 3,13,6 años de edad. 


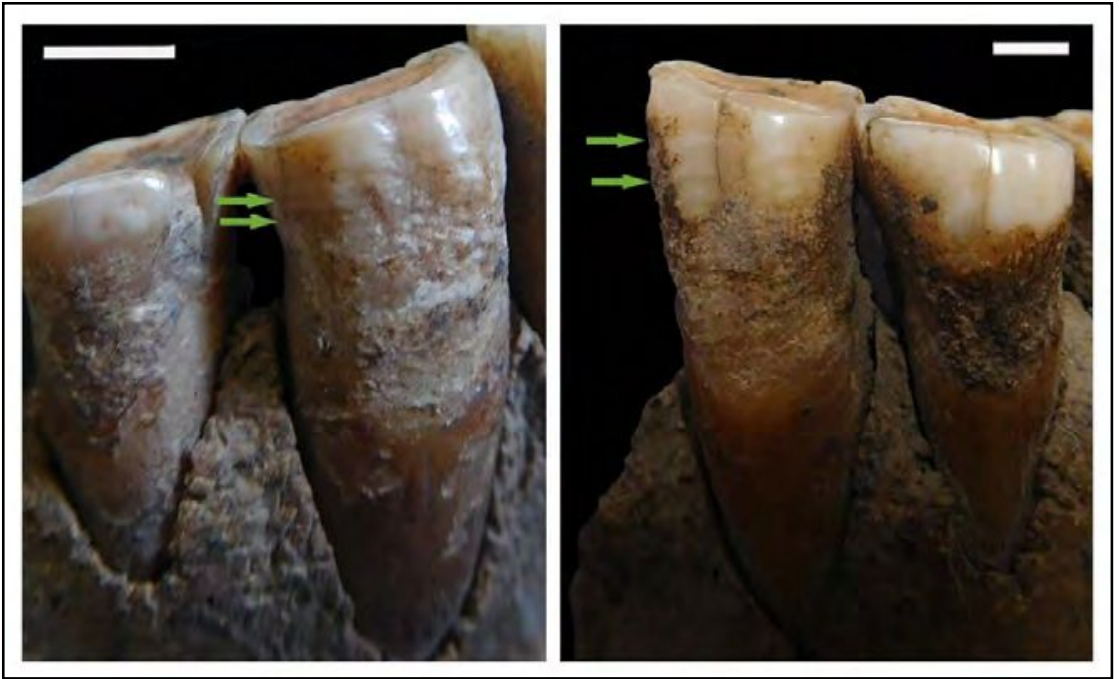

Figura 6.23. HLED en ambos $C_{1}$ del individuo LTC1-P2. Escalas $=0,5 \mathrm{~cm}$

\subsubsection{Cuenca inferior del río Uruguay}

Se analizaron 155 dientes de maxilares y/o mandíbulas de 37 individuos, registrándose ocho piezas con HLED en cuatro individuos. Los Rankings de Sensibilidad y de Supervivencia calculados para las piezas dentales relevadas (Tabla 6.36) arrojaron los siguientes resultados: los dientes con mayor sensibilidad a presentar HLED son los incisivos centrales superiores y los caninos inferiores, en ese orden. Mientras que los primeros son los menos representados en la muestra, los segundos tienen buena posición en el Ranking de Supervivencia. A su vez, si bien los caninos superiores son los mejor representados, son los menos sensibles a presentar HLED. Estas situaciones indican que las pérdidas postdepositacionales de piezas dentales sensibles a padecer este tipo de defectos, puede estar sesgando sobre la prevalencia de este indicador en la muestra bajo estudio. 
Tabla 6.36. Índice de Sensibilidad e Índice de Supervivencia de HLED y sus respectivos rankings por clase dental en la muestra de CIRU.

\begin{tabular}{|cccccccccc}
\hline $\begin{array}{c}\text { Clase } \\
\text { dental }\end{array}$ & $\begin{array}{c}\text { Total } \\
\text { dientes } \\
\text { esperados }\end{array}$ & $\begin{array}{c}\text { Total } \\
\text { dientes } \\
\text { observados }\end{array}$ & $\begin{array}{c}\text { Dientes } \\
\text { con } \\
\text { HLED }\end{array}$ & $\begin{array}{c}\text { Total } \\
\text { HLED }\end{array}$ & $\begin{array}{c}\text { Índice } \\
\text { Sen }\end{array}$ & $\begin{array}{c}\text { Ranking } \\
\text { Sen }\end{array}$ & $\begin{array}{c}\text { Índice } \\
\text { Sup }\end{array}$ & $\begin{array}{c}\text { Ranking } \\
\text { Sup }\end{array}$ \\
\hline $\mathbf{C}^{\mathbf{1}}$ & 46 & 28 & 0 & 0 & 0 & 4 & 60,9 & 1 \\
$\mathbf{I}^{\mathbf{2}}$ & 46 & 24 & 1 & 2 & 8,3 & 3 & 52,2 & 3 \\
$\mathbf{I}^{\mathbf{1}}$ & 46 & 27 & 3 & 4 & 14,8 & 1 & 2,2 & 6 \\
$\mathbf{I}_{\mathbf{1}}$ & 54 & 19 & 1 & 2 & 8,3 & 3 & 35,2 & 5 \\
$\mathbf{I}_{\mathbf{2}}$ & 54 & 25 & 1 & 2 & 8,3 & 3 & 46,3 & 4 \\
$\mathbf{C}_{\mathbf{1}}$ & 54 & 32 & 2 & 3 & 9,4 & 2 & 59,2 & 2 \\
\hline
\end{tabular}

Referencias: Sen=sensibilidad; Sup=supervivencia.

De los 37 individuos analizados (representados por maxilares y/o mandíbulas), cuatro adultos (10,8\%) presentaron cada uno dos piezas dentales con HLED; a nivel de dientes analizados esto representa el 5,2\% de la muestra (Tabla 6.37). En relación con el sexo, los individuos masculinos tienen mayor porcentaje de HLED que los femeninos a nivel individual y de piezas dentales. Sin embargo, ambas variables son independientes $(p=0,7)$.

Tabla 6.37. Prevalencias de HLED en la muestra de CIRU.

\begin{tabular}{|c|c|c|c|c|c|}
\hline & \multicolumn{2}{|c|}{ Individuos } & \multicolumn{2}{|c|}{ Dientes completos } \\
\hline & & $\mathrm{A} / \mathrm{O}$ & $\%$ & A / O & $\%$ \\
\hline \multirow{4}{*}{ 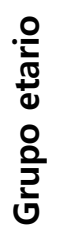 } & Adolescente & $0 / 3$ & 0 & $0 / 20$ & 0 \\
\hline & Adulto joven & $2 / 9$ & 22,2 & $4 / 48$ & 8,33 \\
\hline & Adulto medio & $1 / 1$ & 100 & $2 / 6$ & 33,3 \\
\hline & Adulto in. & $1 / 24$ & 4,2 & $2 / 81$ & 2,5 \\
\hline \multirow{4}{*}{ 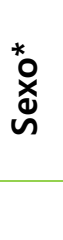 } & Femenino & $1 / 10$ & 10 & $2 / 59$ & 3,4 \\
\hline & Masculino & $2 / 16$ & 12,5 & $4 / 62$ & 6,4 \\
\hline & In. & $1 / 11$ & 9,1 & $2 / 34$ & 5,9 \\
\hline & Total & $4 / 37$ & 10,8 & $8 / 155$ & 5,2 \\
\hline
\end{tabular}

Referencias: $\mathrm{A}=$ afectado; $\mathrm{O}=$ observado; In.=indeterminado; ${ }^{*}=$ entre los femeninos y los masculinos se incluyó en cada categoría a un individuo probable femenino y a un probable masculino, respectivamente.

Los defectos lineales de crecimiento del esmalte pudieron observarse de forma simétrica en dos individuos: un adulto joven masculino ( $C L 2-76)$ y un adulto 
de sexo indeterminado (SPL-89). En el primer caso se trata de un par simétrico sobre los incisivos centrales superiores (Figura 6.24) y en el segundo, de un par simétrico sobre los caninos inferiores. En los dos individuos restantes (CL2-103-1, adulto medio femenino y CL2-71, adulto joven masculino), los dos dientes que presentan HLED en cada uno, no son antímeros entre sí. Al estimar la edad en la que habrían ocurrido tales defectos del esmalte, se obtuvieron los siguientes resultados: CL2-76, I1: 2,4-2,9 años de edad; SPL-89, C 1 : 2,3-2,7 años de edad.

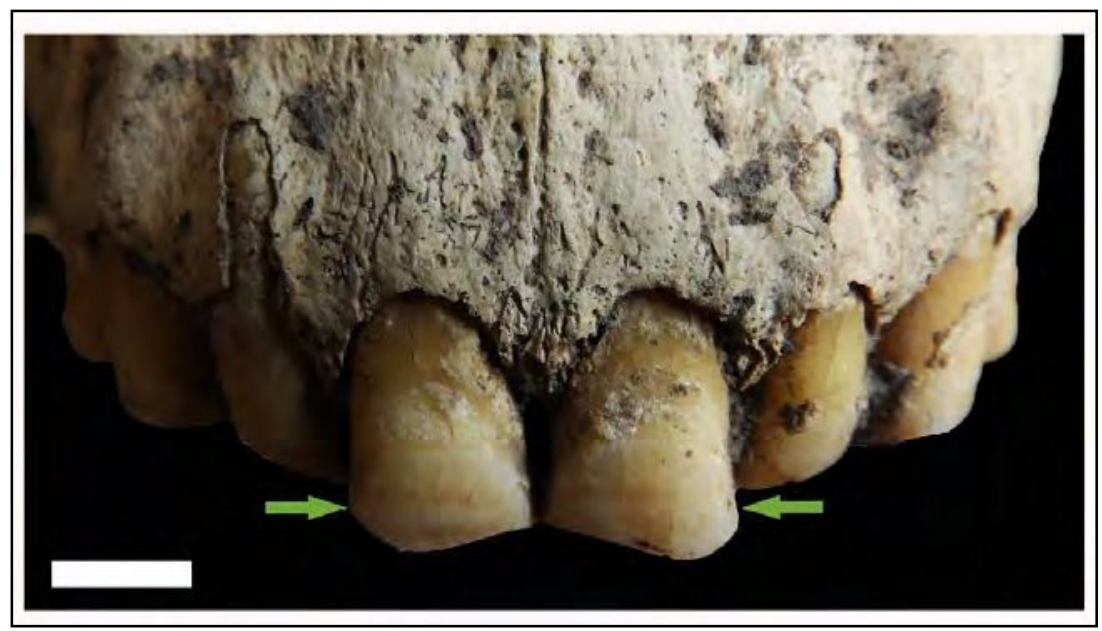

Figura 6.24. HLED en ambos $\mathrm{I}^{1}$ del individuo $\mathrm{CL2}-76$. Escala $=1 \mathrm{~cm}$

\subsubsection{Delta Inferior del río Paraná y ambientes litorales adyacentes}

Se analizaron 59 dientes de 14 maxilares y 13 mandíbulas, registrándose dos piezas con HLED en dos individuos. A partir de la construcción de los Rankings de Sensibilidad y de Supervivencia (Tabla 6.38), se observa que los caninos superiores e inferiores, en ese orden, son los más sensibles (y únicos) a presentar este tipo de defectos en el esmalte. Al mismo tiempo, son los dientes mejor representados en la muestra. Esto indica el bajo grado de impacto de los procesos postdepositacionales sobre la pérdida de los dientes más sensibles $y$, por ende, que las prevalencias obtenidas no se encuentran subestimadas por dichos aspectos. 
Tabla 6.38. Índice de sensibilidad e Índice de supervivencia de HLED y sus respectivos rankings por clase dental en la muestra del DI.

\begin{tabular}{|ccccccccc|}
\hline $\begin{array}{c}\text { Clase } \\
\text { dental }\end{array}$ & $\begin{array}{c}\text { Total } \\
\text { dientes } \\
\text { esperados }\end{array}$ & $\begin{array}{c}\text { Total } \\
\text { dientes } \\
\text { observados }\end{array}$ & $\begin{array}{c}\text { Dientes } \\
\text { con } \\
\text { HLED }\end{array}$ & $\begin{array}{c}\text { Total } \\
\text { HLED }\end{array}$ & $\begin{array}{c}\text { Índice } \\
\text { Sen }\end{array}$ & $\begin{array}{c}\text { Ranking } \\
\text { Sen }\end{array}$ & $\begin{array}{c}\text { Supdice } \\
\text { Sup }\end{array}$ & $\begin{array}{c}\text { Ranking } \\
\text { Sup }\end{array}$ \\
\hline $\mathbf{C}^{\mathbf{1}}$ & 28 & 20 & 1 & 2 & 10 & 1 & 71,4 & 1 \\
$\mathbf{I}^{\mathbf{2}}$ & 28 & 8 & 0 & 0 & 0 & 3 & 28,6 & 4 \\
$\mathbf{I}^{1}$ & 28 & 3 & 0 & 0 & 0 & 3 & 10,7 & 6 \\
$\mathbf{I}_{\mathbf{1}}$ & 26 & 4 & 0 & 0 & 0 & 3 & 15,4 & 5 \\
$\mathbf{I}_{\mathbf{2}}$ & 26 & 9 & 0 & 0 & 0 & 3 & 34,6 & 3 \\
$\mathbf{C}_{\mathbf{1}}$ & 26 & 15 & 1 & 1 & 6,7 & 2 & 57,7 & 2 \\
\hline
\end{tabular}

Referencias: Sen=sensibilidad; Sup=supervivencia.

Las dos piezas dentales que presentaron HLED fueron un canino superior y uno inferior, con dos líneas el primero y una el segundo. Esto representa el 3,4\% de los dientes relevados (Tabla 6.39). En ningún de los dos casos se cuenta con información sexual del individuo. Por otro lado, al no estar presentes sus dientes antímeros, estos defectos registrados no pueden asociarse con eventos sistémicos de estrés.

Tabla 6.39. Prevalencias de HLED por grupo de edad en la muestra del DI.

\begin{tabular}{|c|cccc|cc|}
\hline \multirow{2}{*}{ Grupo etario } & \multicolumn{3}{|c|}{ Individuos } & \multicolumn{2}{c|}{ Dientes } \\
& Aaxilar & \multicolumn{2}{c|}{ Mandíbula } & \multicolumn{2}{c|}{ completos } \\
\hline Adolescente & - & - & $0 / 2$ & 0 & $0 / 6$ & 0 \\
Adulto joven & $0 / 2$ & 0 & - & - & $0 / 9$ & 0 \\
Adulto In. & $1 / 11$ & 9,1 & $1 / 11$ & 9,1 & $2 / 42$ & 4,8 \\
In. & $0 / 1$ & 0 & - & - & $0 / 2$ & 0 \\
\hline TOTAL & $\mathbf{1 / 1 4}$ & $\mathbf{7 , 1}$ & $\mathbf{1 / 1 3}$ & $\mathbf{7 , 7}$ & $\mathbf{2} / \mathbf{5 9}$ & $\mathbf{3 , 4}$ \\
\hline
\end{tabular}

Referencias: $\mathrm{A}=$ afectado; $\mathrm{O}=$ observado; In.=indeterminado. 


\subsection{Integración y discusión de los resultados obtenidos}

En la Tabla 6.40 se resumen los resultados de cada uno de los indicadores analizados de salud bucal y adecuación fisiológica, en las tres muestras bioarqueológicas. Se detallan las prevalencias obtenidas a nivel individual y alveolar/dental, así como también se mencionan algunos de los aspectos relevados (por ej. dentición afectada, severidad, remodelación). Asimismo, se detalla si existe asociación estadística entre la ocurrencia de cada indicador y las variables sexoetarias. A continuación, se discuten los datos presentados atendiendo a su etiología y las inferencias que de ellos se desprenden, principalmente aquellas vinculadas con la dieta y con procesos metabólicos (en el caso de las HLED). 
Tabla 6.40. Síntesis de los resultados obtenidos en las muestras bioarqueológicas.

\begin{tabular}{|c|c|c|c|c|c|}
\hline & & & & & \\
\hline & & & DS & CIRU & $\begin{array}{c}\text { DI } \\
\text { (max. / mand.) }\end{array}$ \\
\hline \multirow{6}{*}{$\frac{\mathscr{\Xi}}{\frac{\pi}{\pi}}$} & \multirow{6}{*}{\multicolumn{2}{|c|}{$\begin{array}{c}\text { Individuos (\%) } \\
\text { Dientes (\%) } \\
\text { Dentición afectada } \\
\text { Severidad } \\
\text { Edad (asoc. est.) } \\
\text { Sexo (asoc. est.) }\end{array}$}} & 33,3 & 10 & $11,5 / 2,7$ \\
\hline & & & 1,7 & 0,7 & 1,5 \\
\hline & & & posterior & posterior & posterior \\
\hline & & & moderada & moderada a severa & moderada \\
\hline & & & no & no & no \\
\hline & & & no & no & no \\
\hline \multirow{6}{*}{ 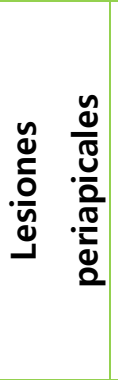 } & \multirow{6}{*}{\multicolumn{2}{|c|}{$\begin{array}{l}\text { Individuos (\%) } \\
\text { Alveolos (\%) } \\
\text { Dentición afectada } \\
\text { Posibles causas } \\
\text { Edad (asoc. est.) } \\
\text { Sexo (asoc. est.) }\end{array}$}} & 20 & 14,8 & 0 \\
\hline & & & 1,4 & 1,8 & 0 \\
\hline & & & posterior & posterior & - \\
\hline & & & desgaste & desgaste & - \\
\hline & & & no & no & - \\
\hline & & & no & no & - \\
\hline \multirow{6}{*}{$\sum_{\substack{a \\
\alpha}}$} & \multirow{6}{*}{\multicolumn{2}{|c|}{$\begin{array}{c}\text { Individuos (\%) } \\
\text { Alveolos (\%) } \\
\text { Dentición afectada } \\
\text { Remodelación } \\
\text { Edad (asoc. est.) } \\
\text { Sexo (asoc. est.) }\end{array}$}} & 13,3 & 11,1 & $12 / 17,1$ \\
\hline & & & 2,8 & 1,8 & 5,5 \\
\hline & & & posterior & posterior & posterior \\
\hline & & & total & moderada & $\begin{array}{c}\text { moderada y } \\
\text { total }\end{array}$ \\
\hline & & & si (a. medio, mayor) & no & no \\
\hline & & & no & no & si (femeninos) \\
\hline \multirow{7}{*}{ 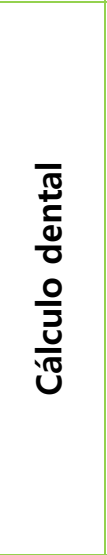 } & \multirow{7}{*}{\multicolumn{2}{|c|}{$\begin{array}{c}\text { Individuos (\%) } \\
\text { Dientes (\%) } \\
\text { Arcada dental } \\
\text { afectada } \\
\text { Dentición afectada } \\
\text { Grado de } \\
\text { depositación } \\
\text { Edad (asoc. est.) } \\
\text { Sexo (asoc. est.) }\end{array}$}} & 80 & 94 & $65,4 / 83,3$ \\
\hline & & & 52,7 & 55,4 & 57,4 \\
\hline & & & mnd & mnd & mnd \\
\hline & & & posterior & posterior & posterior \\
\hline & & & $1(74,2)$ & $1(56,3)$ & $1(81)$ \\
\hline & & & no & si (adultos) & si (adultos) \\
\hline & & & si (masculinos) & si (masculinos) & no \\
\hline \multirow{3}{*}{ 默 } & \multirow{3}{*}{\multicolumn{2}{|c|}{$\begin{array}{l}\text { Individuos (\%) } \\
\text { Dientes (\%) } \\
\text { Sexo (asoc. est.) }\end{array}$}} & 30 & 10,8 & $7,1 / 7,7$ \\
\hline & & & 16,2 & 5,2 & 3,4 \\
\hline & & & si (masculinos) & no & - \\
\hline 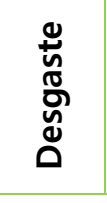 & Grados & $\begin{array}{c}\text { Score } \\
\text { Dif. edad } \\
\text { Dif. sexo }\end{array}$ & $\begin{array}{l}\text { medios a altos } \\
\text { si } \\
\text { si (masculinos) }\end{array}$ & $\begin{array}{c}\text { medios a altos } \\
\text { si } \\
\text { si (en masculinos) }\end{array}$ & $\begin{array}{c}\text { bajos a medios } \\
\text { no } \\
\text { si (masculinos) }\end{array}$ \\
\hline
\end{tabular}

Referencias: asoc. est.=asociación estadística; $\max =$ maxilar; $m$ nd=mandibula; a.=adulto. 
Los procesos bucales infecciosos (caries, lesiones periapicales y PDAM), tuvieron bajas incidencias sobre las denticiones de los individuos analizados en las tres muestras. Estos porcentajes son los esperados para grupos con economías basadas en la caza y recolección (Turner II 1979; Larsen 1987; Lukacs 1989). A continuación, para cada indicador, se detallan distintos aspectos.

La ubicación y profundidad de las caries son puntos interesantes a ser analizados ya que pueden brindar información sobre las causas de su desarrollo y los alimentos consumidos (Hillson 2001; Lanfranco y Eggers 2010). Todas las caries relevadas afectaron a los premolares y molares y el $68,7 \%$ de ellas -tomando las tres muestras en conjunto- se ubica en las superficies oclusales y afectaron al esmalte o dentina más superficial. Teniendo en cuenta estos dos aspectos pueden plantearse algunas cuestiones. Por un lado, pareciera que la ocurrencia de estas lesiones se relaciona estrechamente con la morfología de las piezas dentales afectadas: las fosas y hoyos de las superficies oclusales de los dientes posteriores y en los lugares por debajo de la línea de contacto entre dientes contiguos en sus caras interproximales (donde también fueron registradas algunas caries), son espacios propicios para la acumulación de alimentos, lo cual favorece el desarrollo de este tipo de lesiones infecciosas (Hillson 2000). Por otro lado, puede pensarse que los procesos atricionales pudieron haber contribuido a la eliminación de placas bacterianas de las capas más superficiales de las coronas de los dientes y así disminuir la probabilidad de desarrollar caries. De manera complementaria, por el desgaste se pudieron haber eliminado algunas cavidades cariosas del esmalte o la dentina inmediata subyacente de las superficies oclusales de los primeros y segundos molares; esta idea se desprende del hecho de que el $50 \%$ de las caries observadas afectaron a los terceros molares y que el desgaste en la dentición posterior se relacionó con los tiempos de erupción (los primeros y segundos molares son los primeros en oclusionar, en ese orden). Esta explicación de la relación negativa entre caries y desgaste que se habría dado en las muestras bajo estudio, ya ha sido mencionada por algunos autores en sus investigaciones (Maat y van der Velde 1987; Kerr et al. 1990).

Al considerar la distribución de las caries por edad, en cada una de las tres muestras no se observó asociación estadística entre estas variables. En cuanto al 
sexo, considerando las tres muestras en conjunto, las pocas caries registradas fueron en cuatro individuos femeninos y cinco masculinos; tampoco se encontró asociación estadística entre caries y sexo, a nivel dental $\left(\chi^{2}=0,3 ; p=0,6\right)$. Diferentes investigadores han explicado que las mayores prevalencias de caries que suelen ser reportadas en individuos femeninos en contraposición con los masculinos, se deben a la importancia que tienen ciertos aspectos socioculturales en el desarrollo de estas afecciones, como por ejemplo la preparación y el consumo de los alimentos (Larsen 1983, 1997; Lukacs 1996). Sin embargo, estudios más actuales han puntualizado en que estas diferencias entre ambos sexos están relacionadas fuertemente con factores hormonales y fisiológicos, los cuales tienen un gran impacto sobre la salud oral de las mujeres (Lukacs y Largaespada 2006; Lukacs 2008). Teniendo en cuenta las frecuencias de caries similares entre sexos, puede pensarse en una baja incidencia de los factores fisiológicos y la ausencia de diferencias entre sexos en cuanto a los alimentos consumidos.

Las prevalencias de caries a nivel dental obtenidas fueron bajas en las tres muestras (similares en las muestras del Delta del río Paraná y un poco menor en la muestra de la cuenca inferior del río Uruguay). Estadísticamente, no existen diferencias en cuanto a las frecuencias observadas de caries y las muestras consideradas (DS vs. DI: $\chi 2=0,05, p=0,8$; DS vs. CIRU: $\chi 2=2,1, p=0,1 ; \mathrm{CIRU}$ vs. DI: $\chi 2=1,6, p=0,2)$. Diferentes investigadores han asociado rangos de prevalencias de caries con distintas economías llevadas a cabo por los grupos humanos. Por ejemplo, Turner II (1979) propuso que en grupos con una subsistencia basada en la caza y la recolección las tasas de caries rondan entre 0 y 5,3\%; en grupos con economías mixtas o desarrollo de agricultura incipiente son esperables tasas entre 0,44 y $10,3 \%$ y en poblaciones agrícolas, de 2,3 a 26,9\%. Asimismo, Lukacs (1992) sugiere tasas de 0-5,3\% y de 2,3-26,9\% para economías cazadoras-recolectoras y agrícolas, respectivamente. Si se consideran entonces las bajas prevalencias dentales obtenidas en este trabajo $(0,7$ a $1,8 \%)$, éstas se corresponden con las esperadas para sociedades con una subsistencia basada en la caza y la recolección o con economías mixtas (sensu Turner II 1979). Asimismo, al considerar en conjunto estas bajas prevalencias con los otros aspectos antes discutidos (los dientes afectados fueron aquellos con mayor predisposición a padecer la invasión bacterial 
y las caries afectaron principalmente a las capas más superficiales de las coronas), los grupos de individuos analizados en las tres áreas no habrían consumido alimentos cariogénicos en cantidad suficiente como para favorecer el desarrollo de estos procesos infecciosos.

Las lesiones periapicales relevadas en dos de las tres muestras afectaron a la dentición posterior, siendo en su mayoría procesos inflamatorios crónicos y asintomáticos como son los quistes y granulomas. Tal como fuera explicado en el Capítulo 4, estas infecciones se deben a que la cámara pulpar de los dientes queda expuesta a la acción bacterial a consecuencia, por ejemplo, del desgaste, caries y/o trauma. Estas dos últimas causas son descartadas en primer término, ya que no fueron observadas en relación con ninguno de los dientes y alveolos analizados. Además, como se presentó antes, las caries registradas en general no produjeron la exposición de la cámara pulpar de las piezas. En aquellos casos en los que pudo evaluarse el posible origen de la exposición de la pulpa dental, ésta se relacionó con el desgaste de las piezas dentales comprometidas, ya que presentaban altos grados de desgaste y otras tenían cavidades no cariosas causadas por el mismo proceso erosivo de la corona. Por otro lado, en ningún caso se registraron asociaciones estadísticas entre la presencia de estas lesiones y la edad o el sexo de los individuos.

Para estas lesiones fueron cuantificadas bajas prevalencias en las muestras del DS y CIRU y con total ausencia en la muestra del DI. Estadísticamente, estas diferencias entre DI con DS y CIRU resultan significativas (DS vs. DI: $p=0,01 ; \mathrm{CIRU}$ vs. DI: $p=0,001)$. Una posible explicación a esta situación puede ser por el desgaste, ya que se plantea como la causa principal de las lesiones periapicales en las muestras del DS y CIRU y que, como se verá más adelante, la dentición analizada de la muestra del DI fue la que presentó menor desgaste en comparación con las otras dos muestras.

Así como las caries y las lesiones periapicales, también se registraron bajas prevalencias en las tres muestras de pérdidas dentales antemortem, la que presentó mayores prevalencias es la muestra del DI, seguida por la del DS y finalmente, CIRU. Estadísticamente, las diferencias no son significativas entre las muestras DS y DI $(\chi 2=3,1, p=0,1)$ y entre DS y CIRU $(\chi 2=1,03, p=0,3)$; sí entre CIRU 
y $\mathrm{DI}\left(\chi^{2}=15, p=0,0001\right)$. La dentición principalmente afectada fue la posterior y el $66,7 \%$ de los individuos presentaron múltiples PDAM. El origen de las remodelaciones alveolares producto de la pérdida de los dientes en vida está relacionado, según propone Lukacs $(1989,2007)$, con el tipo de subsistencia: la dureza de los alimentos y sus métodos de preparación junto con el desgaste y las caries, son factores muy significantes. En este sentido, en grupos con economía cazadora-recolectora las PDAM se deben principalmente al desgaste dental, presiones masticatorias y el uso de los dientes para actividades extramasticatorias. Por su parte, en grupos agrícolas la enfermedad periodontal y caries severas que exponen la cámara pulpar del diente serían las principales causas (Scott y Turner II 1988). Al evaluar estas distintas causas en las muestras analizadas, se observa que la edad de los individuos y el desgaste fueron los aspectos que mayor incidencia tuvieron sobre las PDAM, ajustándose de esta forma a lo esperado para grupos con economía cazadora-recolectora. En la muestra del DS existe asociación estadística que avala esto, en tanto los adultos medio y mayor serían más susceptibles a tener tales pérdidas. Por otro lado, los resultados indican que el desgaste en la dentición posterior afectó según los tiempos de erupción y en consonancia con esto, los primeros molares fueron los que más sufrieron las PDAM $(n=13)$, seguido por los segundos $(n=10)$ y terceros molares $(n=9)$. Asimismo, en la dentición anterior, los incisivos centrales, una de las primeras piezas en erupcionar, también fueron los que más se perdieron en vida $(n=8)$ y los que a su vez presentaron mayores grados de desgaste. De haber ocurrido entonces las PDAM por el desgaste, se puede inferir que tales cambios óseos alveolares se debieron a procesos degenerativos y no infecciosos. Más allá de esto, no se descarta la posible ocurrencia de otros factores, como las pérdidas por traumas/accidentes o por extracciones voluntarias (Lukacs 2007).

En la muestra del DI se registró la asociación estadística -a nivel alveolarentre los individuos femeninos y la ocurrencia de PDAM. Esto debe considerarse con cautela dado los bajos números de casos analizados y los alveolos que no se pudieron relacionar con uno de los dos sexos. Más allá de esto, la tendencia observada no podría encontrar explicación a través del desgaste: tres de las cinco PDAM registradas en los individuos femeninos corresponden a los incisivos 
centrales superiores; y en promedio, esta clase dental tuvo menor grado de desgaste en los femeninos que en los masculinos. En este sentido, no deberían descartarse la acción de otros agentes como las pérdidas voluntarias o los accidentes.

Con respecto al grado de remodelación ósea en el que se encontraban los alveolos al momento de muerte de los individuos, fueron clasificados como moderados y totales. Esto significa que las pérdidas de tales piezas dentales habrían ocurrido varios años antes de la muerte de los individuos. Asimismo, la ausencia de alveolos registrados con remodelación parcial puede implicar la dificultad que acarrea identificar de forma clara este tipo de cambio en huesos de contextos arqueológicos.

El cálculo dental fue registrado con alta prevalencia a nivel individual y moderada a nivel dental en las tres muestras. Las distribuciones de las frecuencias de la presencia de cálculo por muestra bioarqueológica no resultan significativas (DS vs. DI: $\chi^{2}=1,5, p=0,2 ;$ DS vs. CIRU: $\chi 2=0,6, p=0,4 ; \mathrm{CIRU}$ vs. DI: $\left.\chi 2=0,4, p=0,5\right)$. En cuanto al grado de depositación, en las muestras del Delta del Paraná predominó el de baja cantidad, mientras que en la de CIRU se documentó también un porcentaje considerable de depositación moderada. En primera instancia, la presencia de estos depósitos en una gran cantidad de individuos de las tres muestras está indicando que presentaban un ambiente oral alcalino y una escasa higiene bucal. Estos dos factores se relacionan entre sí, en tanto la no remoción de residuos alimenticios conlleva a una proliferación de microorganismos y la producción de amoníaco que éstos generan aumentaría la alcalinidad de la boca (Lieverse 1999).

Más allá de las explicaciones fisiológicas y de higiene oral, algunos investigadores han simplificado la etiología del cálculo dental al asociar de manera directa su presencia con el tipo de alimentos consumidos (Evans 1973; Hillson 1979, 1996; Lukacs 1989; Littleton y Frohlich 1993; Lieverse 1999; Greene et al. 2005). Entre los factores dietarios que intervienen en la mineralización de la placa dental, se ha detallado que el elevado consumo de proteínas aumenta la alcalinidad del medio oral al mismo tiempo que tiene un efecto cariostático (i.e. detiene el desarrollo de caries). Por otro lado, el elevado consumo de carbohidratos favorece la acumulación de placa dental y, por ende, facilita indirectamente la formación de 
cálculo así como también el desarrollo de caries (Hillson 1979, 1996; Littleton y Frohlich 1993). Pese a que numerosos aspectos intervienen en la acumulación de cálculo (por ej. tasa del flujo de salivación, hidratación, contenido mineral del agua bebida; Lieverse 1999), puede realizarse un ejercicio para evaluar los factores dietarios intervinientes. Si tenemos en cuenta principalmente las bajas prevalencias de caries en las tres muestras, cabría pensar que la acumulación de cálculo se podría vincular con un mayor consumo de proteínas que de carbohidratos. Particularmente sobre la ingesta de hidratos de carbono, ésta queda evidenciada de forma directa en los análisis de las muestras de tártaro, dada la presencia de fitolitos de gramíneas (Poaceae en el DS y panicoideas en CIRU) y almidones (indeterminados en el DS y CIRU y de probable maíz en CIRU). No debe descartarse que la presencia de estos microrrestos vegetales en el cálculo dental pueda deberse no sólo a la ingesta dietaria, sino también a su consumo medicinal, por ejemplo.

En síntesis, teniendo en consideración los aspectos antes mencionados, para explicar las frecuencias moderadas a altas -a nivel individual- de cálculo dental obtenidas para las tres muestras bioarqueológicas estudiadas deben combinarse diferentes factores, tanto los dietarios (ingesta de proteínas) así como también los culturales (pobre higiene bucal) y fisiológicos. En este sentido, las diferencias significativas a favor de los individuos masculinos observadas en las muestras del Delta del Paraná, indicarían no solamente que existieron diferencias en la ingesta de recursos sino también en la limpieza oral.

Como se ha mencionado previamente, el desgaste ha tenido implicancias directas sobre el desarrollo de otros indicadores buco-dentales analizados. En términos generales, la dentición de las muestras del DS y CIRU presentó grados moderados sin llegar a ser severos como para exponer la cavidad pulpar (recordar los pocos casos de cavidades no cariosas registradas); comparativamente la muestra del DI fue la que menor promedio de desgaste presentó en todas las clases dentales. De esta forma, se disminuyeron los riesgos de padecer procesos infecciosos como las caries y lesiones periapicales, así como también pérdidas dentales antemortem. Por otro lado, en las tres muestras se observó que en los molares los procesos erosivos estuvieron mediados por los tiempos de erupción de 
tales piezas y que los individuos jóvenes presentaron menor desgaste que los adultos medios.

Algunos investigadores han asociado tipos de desgaste con la subsistencia de los grupos humanos. Mientras que los cazadores-recolectores tendrían un pronunciado desgaste con formas planas principalmente en la dentición anterior, los agricultores tenderían a tener menor desgaste en la dentición anterior y mayor en la posterior con formas cóncavas y direcciones oblicuas. Esto se debe a la dureza, textura y preparación de los alimentos consumidos; las técnicas de cocción y preparación (por ej. molienda de granos y alimentos hervidos) disminuyen la dureza y fibrosidad de los alimentos, y así el estrés masticatorio es menor (Molnar 1972; Hinton 1981; Smith 1984; Scott y Turner II 1988). Para analizar el desgaste en las muestras bioarqueológicas estudiadas desde esta perspectiva dietaria, primero hay que remarcar que, en términos generales, el desgaste fue moderado. Esto puede ser explicado desde dos aspectos. Uno se vincula con la casi total ausencia de adultos mayores (a excepción de uno en el DS que a su vez presentó múltiples PDAM), lo cual podría estar subestimando los promedios de desgaste alcanzados; en este sentido será interesante en un futuro poder realizar un trabajo minucioso para evaluar si a partir del desgaste pueden hacerse estimaciones etarias más precisas en las muestras estudiadas (Barrientos y L'Heureux 2001). El otro punto se relaciona con las técnicas de cocción de los alimentos consumidos, las cuales podrían haber disminuido su dureza y así reducir el estrés masticatorio y la abrasión dental. Esta idea del consumo de alimentos más blandos podría encontrar sustento en la presencia de individuos en las tres muestras con múltiples PDAM (con reabsorción moderada y total de los alveolos), que requirieron la ingesta de alimentos blandos y suaves (Gheggi 2012). El extenso registro cerámico en las tres áreas estudiadas del sur del Noreste Argentino (véase Capítulo 3 y 5) también evidenciaría el procesamiento de los alimentos.

En segundo término, la evaluación de las formas y direcciones de las superficies oclusales documentadas están indicando aspectos interesantes sobre la dieta de los individuos analizados. En la muestra del DS, los molares con menor desgaste presentaron formas planas horizontales y los molares con grados más altos, formas cóncavas oblicuas; en la dentición anterior las formas oclusales fueron 
planas oblicuas y horizontales. En la muestra del CIRU, en general, los molares con menor desgaste presentaron formas planas oblicuas y aquellos con grados más altos, formas cóncavas; los incisivos con formas y direcciones redondeadas fueron los que poseían mayores grados de desgaste. En cuanto a la muestra del DI, el tipo de desgaste principal fue plano y oblicuo en general, y cóncavo en molares y premolares con alto desgaste. A partir de estos datos y considerando las propuestas mencionadas que vinculan determinado tipo de desgaste con el tipo de subsistencia (Smith 1984), puede decirse que las muestras bioarqueológicas estudiadas no se ajustan estrictamente a los patrones esperados para los cazadores-recolectores o agricultores, sino que tienen características de ambos. Las formas y direcciones de las superficies oclusales aquí registradas responderían al consumo de alimentos con diferentes métodos de preparación: la cocción de comida sobre el fuego y su secado al aire libre pudo haber incorporado partículas abrasivas de la superficie oclusal de los dientes. Asimismo se ha reportado que la ingesta de pescado, sobre todo si se seca, produciría mayor tasa de desgaste. Por su parte, la cocción mediante hervido en los recipientes cerámicos vuelve más blandos los alimentos allí procesados (Littleton y Frohlich 1993; Eshed et al. 2006; Gómez Otero y Novellino 2011; Gheggi 2012; L’Heureux 2014). Más allá de esta generalidad, se destacan las formas y direcciones redondeadas observadas en la dentición anterior del $26,1 \%$ de los individuos (adultos jóvenes, medios e indeterminados) de la muestra de CIRU, las cuales no fueron registradas en los otros dos conjuntos. Estas piezas dentales anteriores corresponden a aquellos dientes con los grados más altos de desgaste; cabe recordar que estos altos grados no fueron reportados para los incisivos y caninos de las otras dos muestras, ya que presentaron desgaste moderado. Asimismo, las piezas con morfologías redondeadas estaban acompañadas, en los mismos individuos, con un predominio de patrones cóncavos en la dentición posterior. Este registro sugiere que estos individuos en particular presentaron mayor estrés masticatorio, asociado con la incorporación de abrasivos en los alimentos ingeridos (L’Heureux 2014). En cuanto al tipo de desgaste y el sexo de los individuos en las tres muestras, se registró que los masculinos presentan mayor promedio de desgaste que sus pares femeninos; estas discrepancias, si bien fueron sutiles, podrían deberse a una ingesta diferencial 
de tipos de recursos. Esto último se complementa con la diferencia sexual observada en el análisis del cálculo dental, a favor también de los individuos masculinos.

Por último, más allá de los análisis de los indicadores buco-dentales discutidos recientemente y vinculados con factores dietarios, se presenciaron en las muestras bajo estudio defectos del desarrollo del esmalte, bajo la modalidad de líneas de hipoplasia del esmalte dental. De acuerdo a los rankings de Sensibilidad y Supervivencia, tanto en la muestra del DS como en CIRU, las pérdidas postmortem subestimaron estos números obtenidos; asimismo, es esperable que el desgaste coronario pueda haber borrado líneas de hipoplasia y así disminuir aún más las tasas observadas. La muestra del DS mostró valores moderados de prevalencias en relación con las otras dos muestras que presentaron valores bajos, siendo menor en la del DI. Estadísticamente, las diferencias en las frecuencias del DI en comparación con las otras dos muestra son significativas (DS vs. DI: $p=0,02 ;$ DS vs. $\mathrm{CIRU}: p=0,01 ; \mathrm{CIRU}$ vs. $\mathrm{DI}: p=0,7)$.

Con respecto a la distribución sexual de estos defectos, en la muestra del DS se documentó asociación estadística con los masculinos. En el caso de CIRU también se observaron prevalencias mayores en los masculinos, aunque en este caso sin asociación estadística. Como se mencionó previamente, el pequeño tamaño de las muestras puede estar incidiendo en estos resultados y por ello deben considerarse con precaución. Si bien en numerosas colecciones de distintas partes del mundo no se han reportado claros indicios que demuestren una mayor susceptibilidad a padecer HLED según el sexo, cuando existen diferencias significativas suele ser a favor de masculinos; y esto se lo ha explicado a partir de una mayor vulnerabilidad masculina y mejor amortiguación del estrés de los individuos femeninos (Guatelli-Stenberg y Lukacas 1999). Variables ambientales, culturales o de desarrollo deben considerarse conjuntamente para explicar estas diferencias, lo cual resulta difícil en contextos arqueológicos. A modo de una interpretación inicial sobre la mayor cantidad de HLED reportada en masculinos que femeninos, puede pensarse en la exposición diferencial al estrés y/o factores culturales o sociales que afectaron negativamente la salud de los individuos 
masculinos durante su infancia (González 2016). Esto deberá ser puesto a prueba en tanto se amplíen los estudios a desarrollar.

Los defectos lineales de desarrollo del esmalte pueden ser generados por distintas causas, considerándose a las de estrés sistémico como las principales condiciones: infecciones, enfermedades gastrointestinales, malnutrición, deficiencia de vitamina A o D, entre otros (Lukacs 1989; Goodman y Rose 1991; Hillson 1996, 2008; Ortner 2003). Dadas las prevalencias obtenidas y los resultados estadísticos, los individuos analizados en las muestras de CIRU y DI no habrían padecido, durante su infancia y niñez, eventos de estrés sistémico de manera recurrente como sí habrían sufrido los individuos de la muestra del DS. Por otro lado, todas las HLED registradas en las muestras fueron en adultos, lo cual sugiere que estos individuos padecieron eventos de estrés suficientes para generar la detención de procesos no vitales para el organismo (la amelogénesis) pero que no resultaron en su muerte (Langsjoen 1998). Igualmente, hay que considerar la baja a nula representación de subadultos en los que se contó con dentición permanente para analizar este indicador, lo cual puede estar invisibilizando situaciones de estrés con mayor riesgo de morbilidad y mortalidad en las muestras bajo estudio. De acuerdo a los contados casos en los que se pudo calcular la edad en la que ocurrieron tales eventos, se observa que en los dos individuos masculinos fueron entre el año y medio y los tres años de vida; mientras que en el individuo femenino, el evento de estrés fue entre los tres y tres años y medio. Diferentes investigaciones han vinculado la presencia de estos eventos de estrés, en infantes y niños, con el proceso de destete. Tal explicación se basa en que el fin de la lactancia implica el paso hacia la incorporación de alimentos menos nutritivos y/o contaminados, los cuales pueden generar infecciones gastrointestinales severas como para desarrollar un estrés sistémico (Goodman et al. 1984; Blakely et al. 1994; Wood 1996). Estos procesos podrían ser las causas del estrés sufrido por los individuos que presentaron HLED; el análisis con otros bioindicadores óseos serán necesarios para profundizar sobre este punto. 


\section{Capítulo 7}

\section{Resultados: patologías óseas}

En este capítulo se presentan los resultados del relevamiento y evaluación de lesiones óseas de diferentes etiologías (de estrés metabólico-nutricional, infecciosas, de estrés inespecífico y traumáticas), analizadas en cada muestra bioarqueológica. En el apartado final se integran y discuten los datos obtenidos de manera comparativa entre las tres muestras. En la Tabla A.2.5 se sintetizan las lesiones óseas relevadas por individuos/elementos óseos, junto con las lesiones buco-dentales presentadas en el Capítulo 6.

\subsection{Lesiones de estrés metabólico-nutricional}

\subsubsection{Delta Superior del río Paraná}

Para el análisis de hiperostosis porótica (HP) y cribra orbitalia (CO) fue posible observar cráneos o porciones del cráneo (órbitas y/o bóveda) de 11 individuos de distintas edades, de ambos sexos y de los dos sitios arqueológicos que conforman esta muestra bioarqueológica. En ningún individuo se registraron lesiones en la bóveda craneana, mientras que dos presentaron $\mathrm{CO}$; ambos casos representan el $18,2 \%$ de la muestra (Tabla 7.1). Se trata de dos subadultos (un adolescente y un infante) del sitio LTC1, con lesiones de tipo leves (Tabla 7.2). En el adolescente femenino, los microporos observados en la única órbita presente se encontraban en estado de remodelación (Figura 7.1a). Por su parte, en el infante la lesión registrada de forma bilateral estaba activa al momento de su muerte (Figura 7.1b). Si bien ambos casos corresponden a subadultos, no existe asociación estadística entre la presencia de este tipo de estrés y la edad de los individuos $(p=0,2)$. Tampoco se obtuvieron valores que indiquen la relación entre la ocurrencia de las lesiones y el sexo $(p=1)$. 
Tabla 7.1. Prevalencias de hiperostosis porótica y cribra orbitalia en la muestra del DS.

\begin{tabular}{|c|c|c|c|c|c|c|c|}
\hline & \multicolumn{2}{|c|}{ HP } & \multicolumn{2}{|c|}{$\mathrm{CO}$} & \multicolumn{2}{|c|}{ Total } \\
\hline & & $\mathrm{A} / \mathrm{O}$ & $\%$ & $\mathrm{~A} / \mathrm{O}$ & $\%$ & $\mathrm{~A} / \mathrm{O}$ & $\%$ \\
\hline \multirow{6}{*}{ 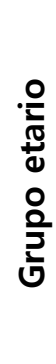 } & Infante & $0 / 1$ & 0 & $1 / 2$ & 50 & $1 / 2$ & 50 \\
\hline & Adolescente & $0 / 3$ & 0 & $1 / 3$ & 33,3 & $1 / 3$ & 33,3 \\
\hline & Adulto joven & $0 / 1$ & 0 & $0 / 1$ & 0 & $0 / 1$ & 0 \\
\hline & Adulto medio & $0 / 2$ & 0 & $0 / 2$ & 0 & $0 / 2$ & 0 \\
\hline & Adulto mayor & $0 / 1$ & 0 & $0 / 1$ & 0 & $0 / 1$ & 0 \\
\hline & Adulto in. & $0 / 2$ & 0 & $0 / 2$ & 0 & $0 / 2$ & 0 \\
\hline \multirow{4}{*}{ 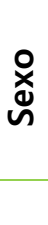 } & $\mathbf{F}$ & $0 / 6$ & 0 & $1 / 6$ & 16,6 & $1 / 6$ & 16,6 \\
\hline & $M$ & $0 / 2$ & 0 & $0 / 2$ & 0 & $0 / 2$ & 0 \\
\hline & In. & $0 / 2$ & 0 & $1 / 3$ & 33,3 & $1 / 3$ & 33,3 \\
\hline & Total & $0 / 10$ & 0 & $2 / 11$ & 18,2 & $2 / 11$ & 18,2 \\
\hline
\end{tabular}

Referencias: $\mathrm{A}=$ afectado; $\mathrm{O}=$ observado; In.=indeterminado; $\mathrm{F}=$ femenino; $\mathrm{M}=$ masculino.

Tabla 7.2. Características de las lesiones de cribra orbitalia registradas en la muestra del DS.

\begin{tabular}{|cccccc|}
\hline Individuo & Grupo etario & Sexo & CO & Estado & Severidad \\
LTC1-P1 & adolescente & F & órbita der. $^{*}$ & remodelado & leve \\
LTC1-A4 & infante & - & Bilateral & activo & leve \\
\hline
\end{tabular}

Referencias: $\mathrm{F}=$ femenino; ${ }^{*}=$ órbita izquierda ausente.

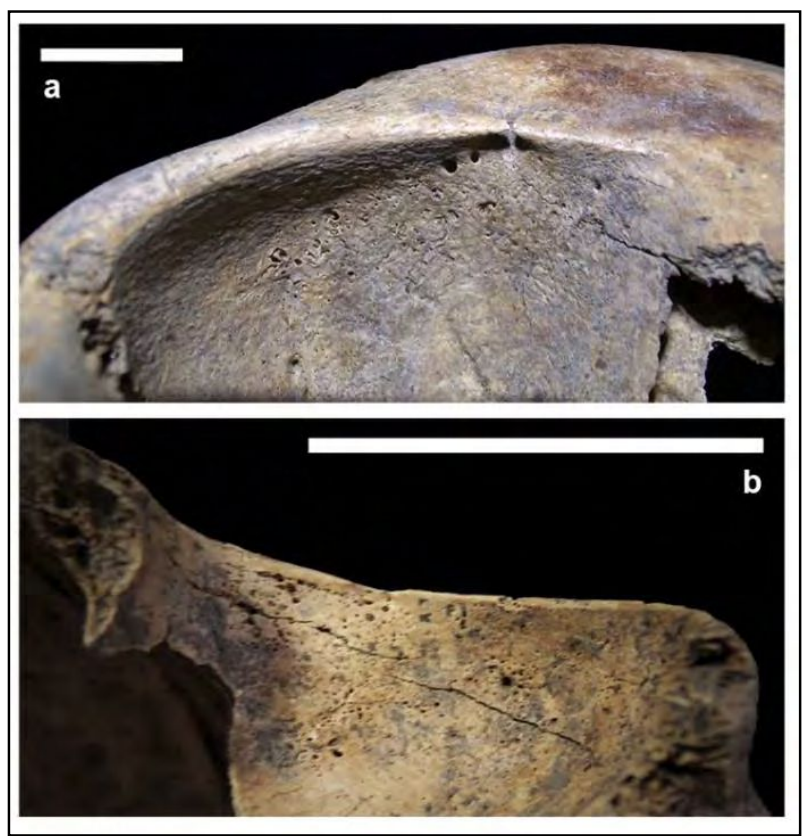

Figura 7.1. Cribra orbitalia registradas en la muestra bioarqueológica del DS: a) órbita derecha de LTC1-P1; b) órbita izquierda de LTC1-A4. Escala=2 cm. 


\subsubsection{Cuenca inferior del río Uruguay}

Para evaluar hiperostosis porótica (HP) y cribra orbitalia (CO), pudieron ser analizados 26 cráneos de individuos de distintas edades, de ambos sexos y de 7 de los 8 sitios arqueológicos que componen esta muestra bioarqueológica (excepción: Fajina Quemada). Se registraron estos tipos de lesiones en tres individuos, que representan el 11,5\% de la muestra (Tabla 7.3). Los tres individuos poseen HP y uno de ellos también CO (Tabla 7.4). En el occipital de un adulto masculino del sitio T1CNM se observaron poros de distintos tamaños que, en general, se encontraban activos al momento de muerte y con una severidad leve. Por su parte, un adolescente del sitio T2-CSM también presenta poros aislados y activos en el occipital, sumado a la porosidad leve y activa en ambos techos de las órbitas. Finalmente, el adulto joven femenino se destaca de los anteriores por la severidad media de HP: en los parietales se observó cierta porosidad e incipiente estructura trabecular; mientras que en el occipital se registraron poros pequeños y grandes, en su mayoría remodelados, con una notoria estructura trabecular (Figura 7.2). No se encontró asociación estadística entre la ocurrencia de estas lesiones y los grupos de edad (subadultos vs. adultos: $p=0,3$ ). Por otro lado, si bien los femeninos presentaron prevalencias levemente mayores que los masculinos, ambas variables son independientes $(p=1)$.

Tabla 7.3. Prevalencias de hiperostosis porótica y cribra orbitalia en la muestra de CIRU.

\begin{tabular}{|c|c|c|c|c|c|c|c|}
\hline & \multicolumn{2}{|c|}{ HP } & \multicolumn{2}{|c|}{$\mathrm{CO}$} & \multicolumn{2}{|c|}{ Total } \\
\hline & & $A / O$ & $\%$ & A/O & $\%$ & $\mathrm{~A} / \mathrm{O}$ & $\%$ \\
\hline \multirow{5}{*}{$\begin{array}{l}\text { 은 } \\
\frac{\pi}{0} \\
0 \\
0 \\
\frac{0}{2} \\
\frac{2}{0}\end{array}$} & Infante & $0 / 1$ & 0 & $0 / 1$ & 0 & $0 / 1$ & 0 \\
\hline & Adolescente & $1 / 2$ & 50 & $1 / 2$ & 50 & $1 / 2$ & 50 \\
\hline & Adulto joven & $1 / 8$ & 12,5 & $0 / 7$ & 0 & $1 / 8$ & 12,5 \\
\hline & Adulto medio & $0 / 1$ & 0 & $0 / 1$ & 0 & $0 / 1$ & 0 \\
\hline & Adulto in. & $1 / 14$ & 7,1 & $0 / 7$ & 0 & $1 / 14$ & 7,1 \\
\hline \multirow{4}{*}{$\stackrel{\stackrel{P}{x}}{\stackrel{\sim}{\sim}}$} & F & $1 / 8$ & 12,5 & $0 / 6$ & 0 & $1 / 8$ & 12,5 \\
\hline & $M$ & $2 / 14$ & 8,3 & $1 / 11$ & 9,1 & $2 / 14$ & 8,3 \\
\hline & In. & $0 / 4$ & 0 & $0 / 1$ & 0 & $0 / 4$ & 0 \\
\hline & Total & $3 / 26$ & 11,5 & $1 / 18$ & 5,5 & $3 / 26$ & 11,5 \\
\hline
\end{tabular}

Referencias: $\mathrm{A}=$ afectado; $\mathrm{O}=$ observado; In.=indeterminado; $\mathrm{F}=$ femenino; $\mathrm{M}=$ masculino. 
Tabla 7.4. Características de las lesiones de cribra orbitalia e hiperostosis porótica registradas en la muestra de CIRU.

\begin{tabular}{|ccccccc|}
\hline Individuo & Grupo etario & Sexo & HP & CO & Estado & Severidad \\
\hline T1-CNM-83 & adulto & M & occipital & - & activo & leve \\
\hline T2-CSM-81 & a joven & F & $\begin{array}{c}\text { parietales y } \\
\text { occipital }\end{array}$ & no & remodelado & media \\
\hline T2-CSM-82 & adolescente & M & occipital & bilateral & activo & leve \\
\hline
\end{tabular}

Referencias: $a=$ adulto; $M=$ masculino; $F=$ femenino.

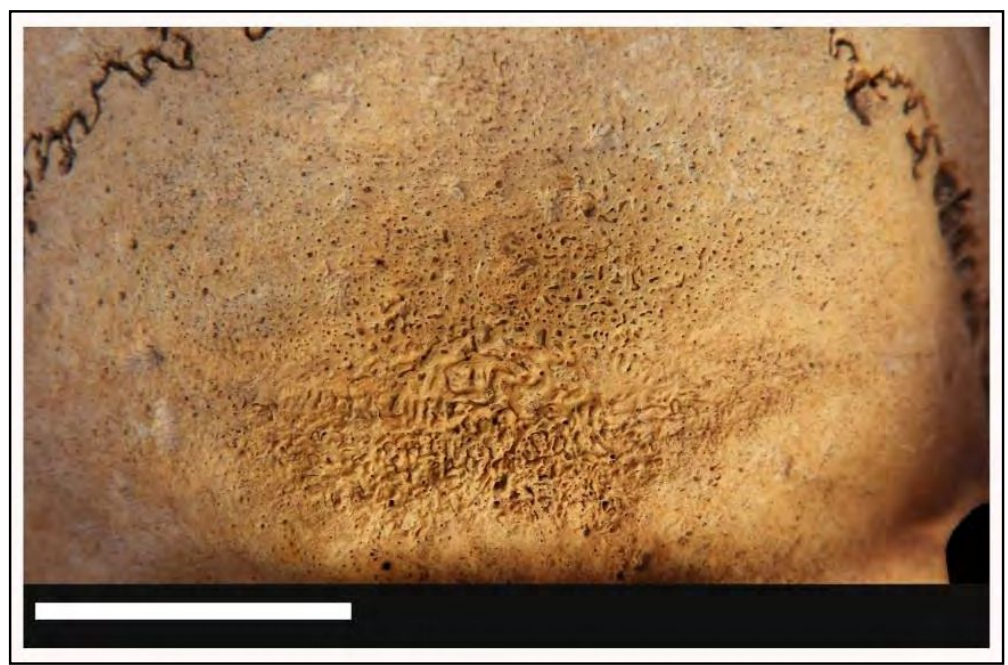

Figura 7.2. Hiperostosis porótica en el occipital del individuo T2-CSM-81. Escala=2 cm.

\subsubsection{Delta Inferior del río Paraná y ambientes litorales adyacentes}

Se analizaron 27 cráneos y fragmentos de bóveda de los tres sitios que componen esta muestra bioarqueológica, sin registrarse lesiones de hiperostosis porótica y cribra orbitalia.

\section{2 Lesiones infecciosas}

\subsubsection{Delta Superior del río Paraná}

Fueron analizados 1109 elementos óseos pertenecientes al menos a 37 individuos, de distintas edades y ambos sexos. El 2,2\% $(n=24)$ de los huesos presentó lesiones atribuibles a patologías infecciosas; los mismos corresponden a dos individuos adultos que representan el 5,4\% de la muestra (Tabla 7.5). Ambos casos son del sitio LTC1 y corresponden a individuos femeninos; a nivel individual 
no hay asociación estadística entre el sexo y la ocurrencia de patologías infecciosas $(p=0,2)$; sí existe asociación si se analiza a nivel de elementos óseos ( $\chi 2=19,9$; $p=0,0000006)$. En cuanto a la edad, se registró la dependencia de las variables tanto a nivel individual $(p=0,5)$ como de elementos óseos $(p=0,004)$. A continuación, para cada uno de los esqueletos, se describen las lesiones en los elementos óseos y luego se presenta la interpretación del caso atendiendo al diagnóstico diferencial realizado.

Tabla 7.5. Prevalencias de lesiones infecciosas en la muestra del DS.

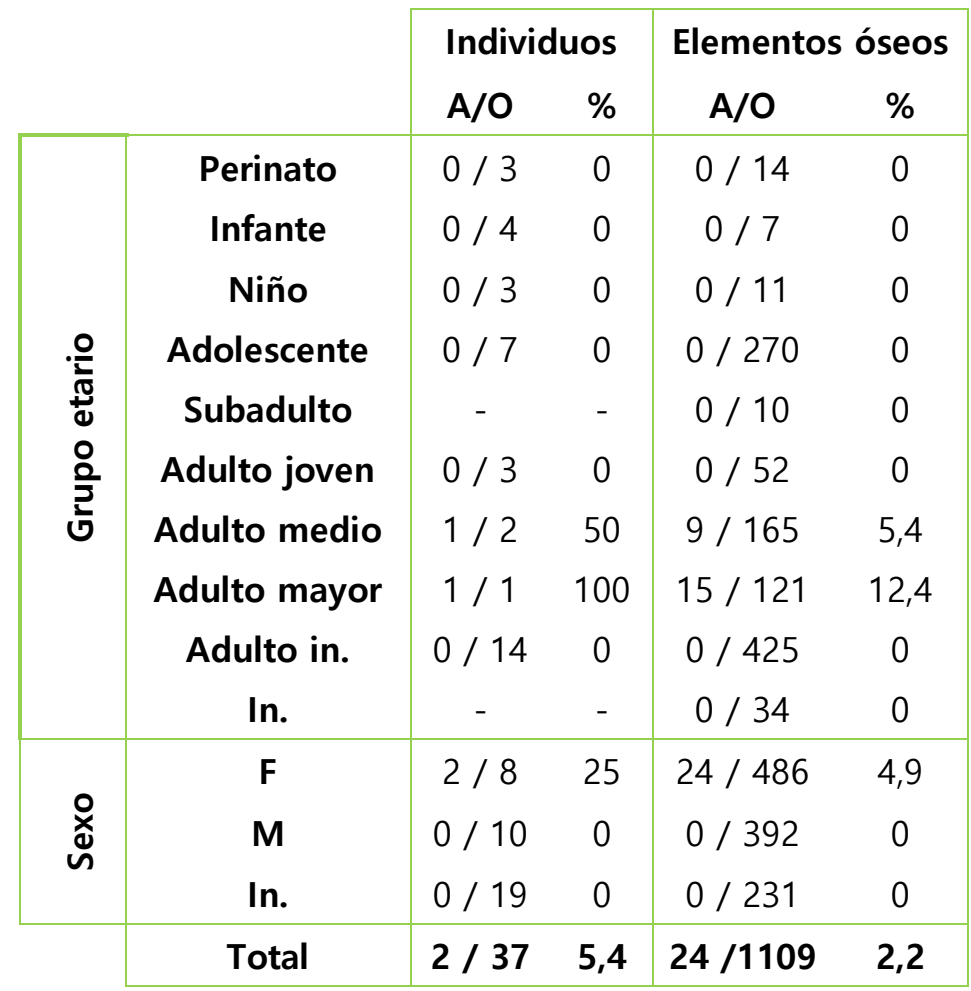

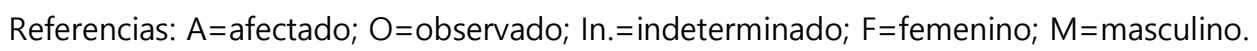

En el individuo LTC1-P3, adulto mayor (50-59 años) femenino, se observaron lesiones en 15 elementos óseos: 4 del miembro superior y 11 del inferior. Los radios presentan el mismo tipo de reacción ósea que, según el tejido mixto presente, parecerían encontrarse en proceso de remodelación al momento de muerte del individuo. En ambos casos, el contorno del elemento se encuentra levemente modificado, dando la apariencia de estar ampliada la diáfisis (Figura 7.3a). En la epífisis proximal del cúbito derecho se destaca una reacción ósea con tejido primario sobre el proceso olecraneano, con bordes difusos y modificando el 
contorno típico del olécranon; la carilla articular de la epífisis no se encuentra afectada (Figura 7.3.b). Por otro lado, la cara anterior de la diáfisis distal presenta una leve reacción ósea de bordes difusos, con un aspecto estriado indicando el proceso de remodelación en el que se encontraba. El cúbito izquierdo, al igual que su contralateral, presenta el mismo tipo de lesión en la epífisis proximal, aunque de menor severidad. Además, en la diáfisis distal sobre la cara anterior se observa una lesión localizada, estando allí aumentada la diáfisis y con un pequeño foramen en el centro.

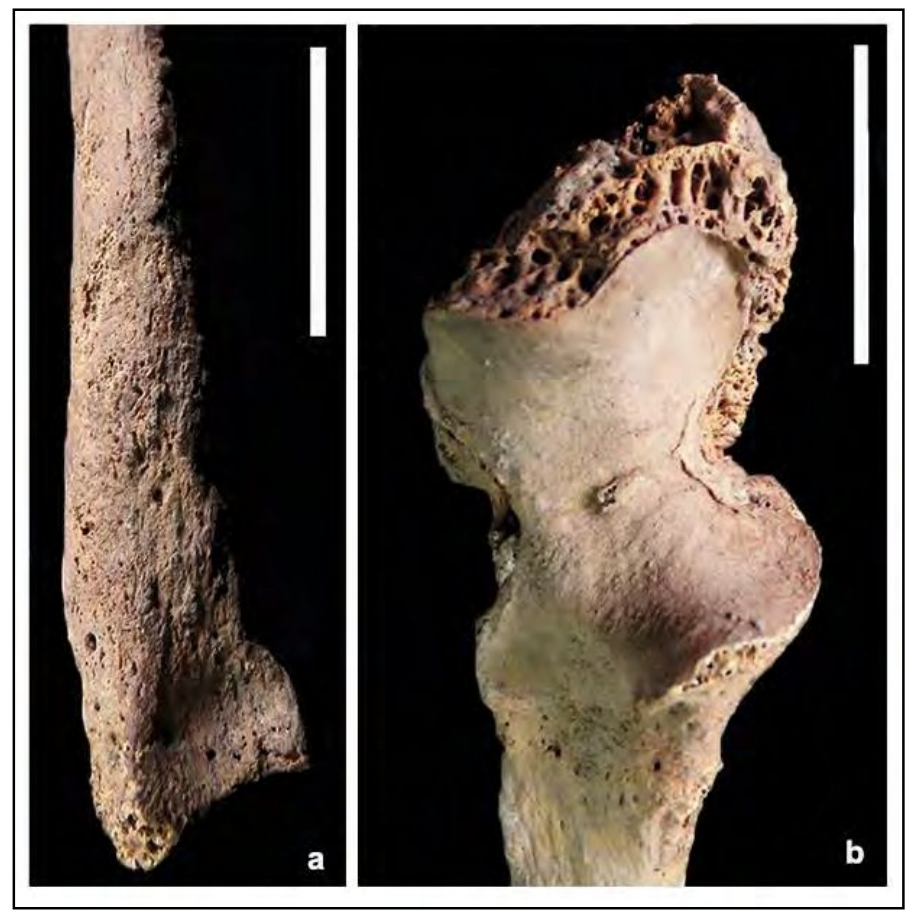

Figura 7.3. Lesiones óseas en el miembro superior de LTC1-P3: a) diáfisis distal del radio izquierdo; b) epífisis proximal del cúbito derecho. Escala $=3 \mathrm{~cm}$.

En el miembro inferior, los huesos largos en los que se registraron lesiones fueron el fémur derecho y ambas tibias y peronés. Asimismo, el calcáneo izquierdo y cinco metatarsos. En la cara anterior de la metáfisis distal del fémur derecho, pese a la fractura postdepositacional del cortical, se observó una reacción ósea caracterizada por tejido inmaduro y bordes difusos; la misma se extiende hacia la región articular, la cual a su vez presenta desarrollo osteofítico, desgaste y eburnado del hueso subcondral (Figura 7.4). 


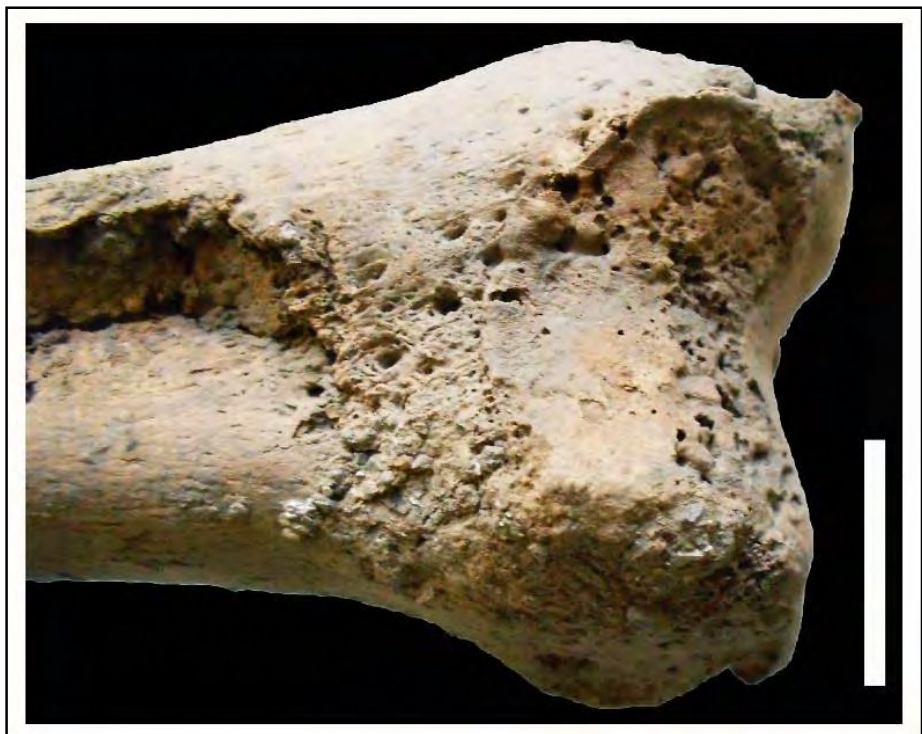

Figura 7.4. Lesiones óseas en epífisis distal del fémur derecho de LTC1-P3. Escala=3 cm.

Las tibias son los huesos más afectados del esqueleto, encontrándose lesiones en todas las secciones y caras y teniendo el contorno modificado (Figuras 7.5, 7.6, 7.7). A lo largo de las diáfisis -a pesar de algunos desprendimientos corticales de origen tafonómico-, se observan zonas con reacciones periósticas. Algunas de ellas estaban activas al momento de muerte, dado el tejido primario presente; mientras que la mayoría se encontraba en estado de remodelación. En ambos huesos se registraron surcos lineales en las diáfisis: en la tibia derecha hay un doble surco en la cara lateral de la diáfisis distal, mientras que en el mismo sector en la tibia izquierda hay un triple surco (Figura 7.5). Estos canales han sido interpretados como posibles huellas de vasos sanguíneos que suelen ser encontrados en asociación con zonas de periostitis en la corteza de los huesos largos (Wells 1963; Buikstra y Ubelaker 1994).

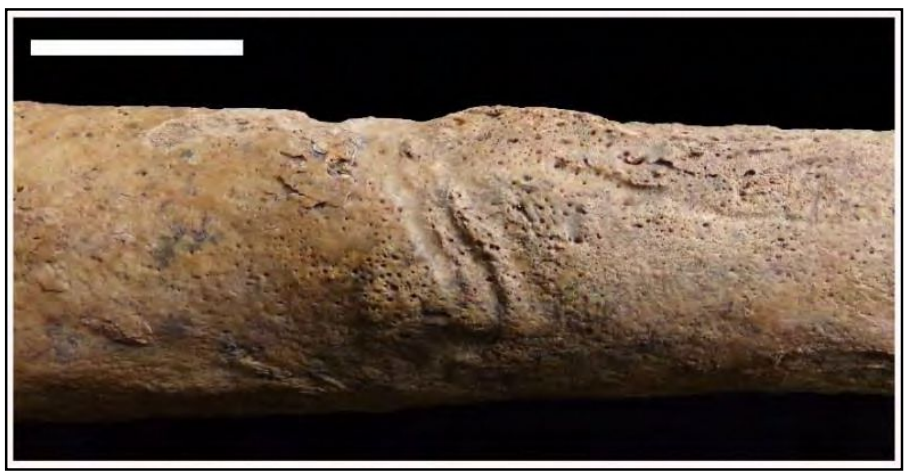

Figura 7.5. Surcos vasculares en la diáfisis de la tibia izquierda de LTC1-P3. Escala $=3 \mathrm{~cm}$. 
Al evaluar macroscópicamente las tibias se observaron algunos aspectos que, para poder analizarlos con mejor detalle, se procedió a realizarles radiografías y tomografía axial computada. A partir de estos estudios, en la tibia derecha fueron distinguidas cuatro lesiones que merecen ser descriptas minuciosamente (Figura 7.6). A mitad de diáfisis sobre la cara medial se observó macroscópicamente una reacción ósea ya esclerótica (Figura 7.6a); en un corte transversal de la TAC, esto se corresponde con una lesión lítica con aumento del tejido cortical (Figura 7.6.cl). En la diáfisis distal, sobre la cara anterior y lateral, se distingue en la radiografía un adelgazamiento del cortical (Figura 7.6b); al observar esta región en cortes tomográficos, se corresponde con una lesión lítica (Figura 7.6.cll). Asimismo, sobre la cara anterior en la metáfisis distal, macroscópicamente se distingue una cavidad cuyos bordes están rotos debido a procesos postdepositacionales (Figura 7.6a); al evaluar las imágenes tomográficas, en un corte longitudinal se observó que esta cavidad superficial se prolonga hacia el interior del hueso llegando a la zona medular del mismo, correspondiéndose con una cloaca de drenaje (Figura 7.6.cllI). Finalmente, en la mitad de la diáfisis se destaca a ojo desnudo una depresión sobre la cresta anterior, de coloración más oscura, con un aspecto más brilloso y suave al tacto en comparación con el resto del cortical; hacia el centro de esta depresión, se observa un círculo apenas más deprimido de tejido óseo poroso y con una coloración más clara (Figura 7.7a). Tanto en la radiografía lateral como en un corte longitudinal de las imágenes tomográficas, se corresponde con una zona más radiopaca. Dadas las características del hueso superficial en esta zona (depresión con distinta coloración, brillo y suavidad) y una mayor cantidad y aparente densidad de hueso cortical, esta lesión podría ser una cloaca de drenaje remodelada y que en el centro de la misma se encontraba aún en proceso de remodelación al momento de muerte del individuo. 


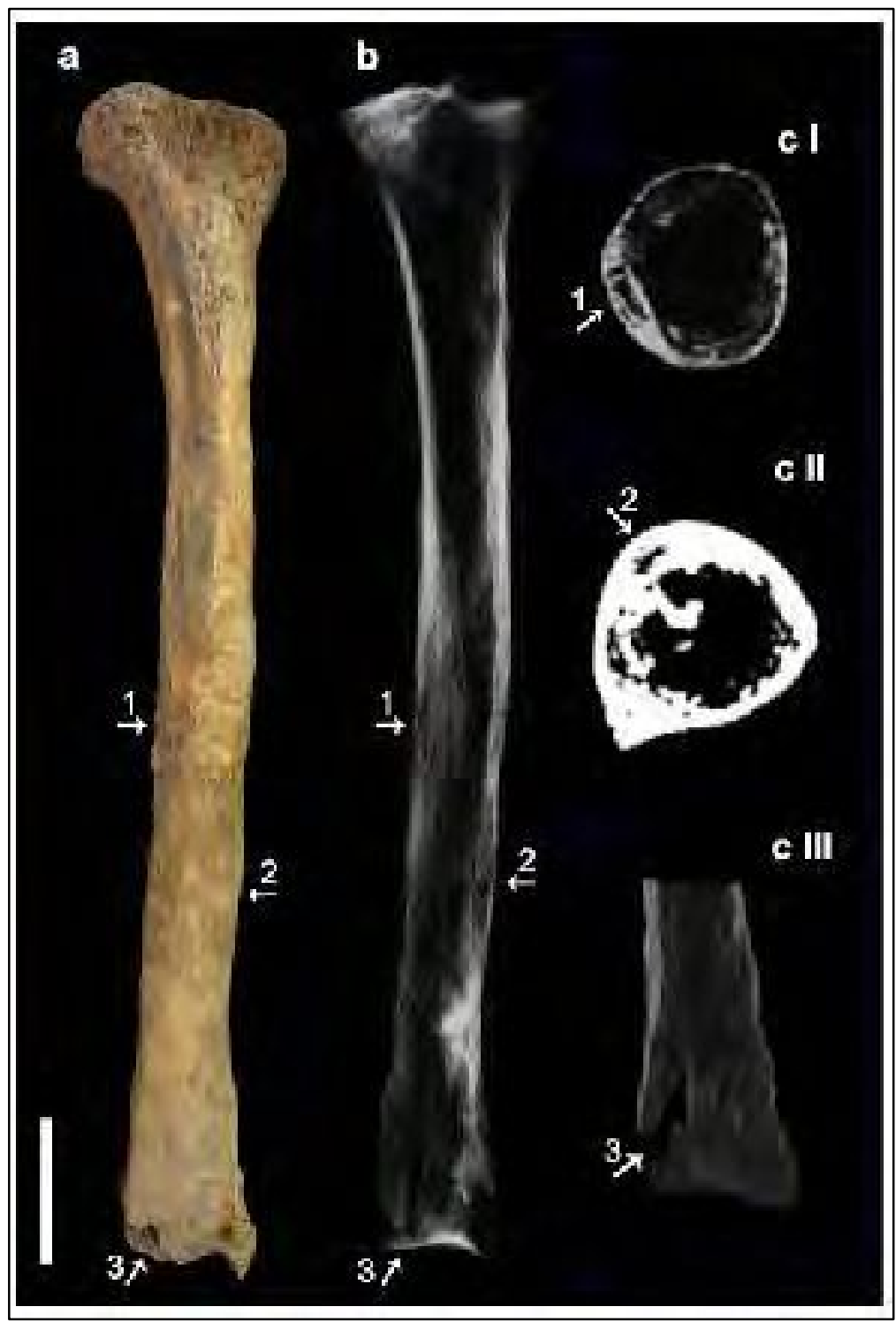

Figura 7.6. Lesiones óseas en la tibia derecha de LTC1-P3: a) cara lateral-anterior; b) Rx lateral; c I y II) secciones transversales de TAC; c III) sección sagital de TAC; las flechas 1, 2 y 3 indican la ubicación de las lesiones líticas observadas. Escala $=5 \mathrm{~cm}$.

En el caso de la tibia izquierda, en la cara lateral sobre la diáfisis medial, el tejido cortical presenta algunos desprendimientos de origen tafonómico y se destacan dos forámenes que podrían corresponderse con posibles cloacas (Figura 7.7b). En la radiografía, en esta zona se distingue que el cortical es de aspecto menos denso y la cavidad medular adyacente se observa radiolúcida. Por otro lado, la cara posterior del maléolo medial presenta una cloaca abierta de bordes bien definidos y redondeados (Figura 7.7c).

Los peronés poseen los mismos tipos de reacciones óseas en tres secciones de su diáfisis, sin verse comprometidas las carillas articulares. Por sus características, 
cada uno de los elementos está afectado casi en su totalidad; hacia el sector proximal se encuentra en un grado avanzado de remodelación (tejido laminar) mientras que hacia el sector distal las lesiones están activas -tejido inmaduro (Figura 7.7d). Es interesante notar que, en el sector distal del lado medial, las reacciones activas son colindantes con las reacciones presentes en las tibias.

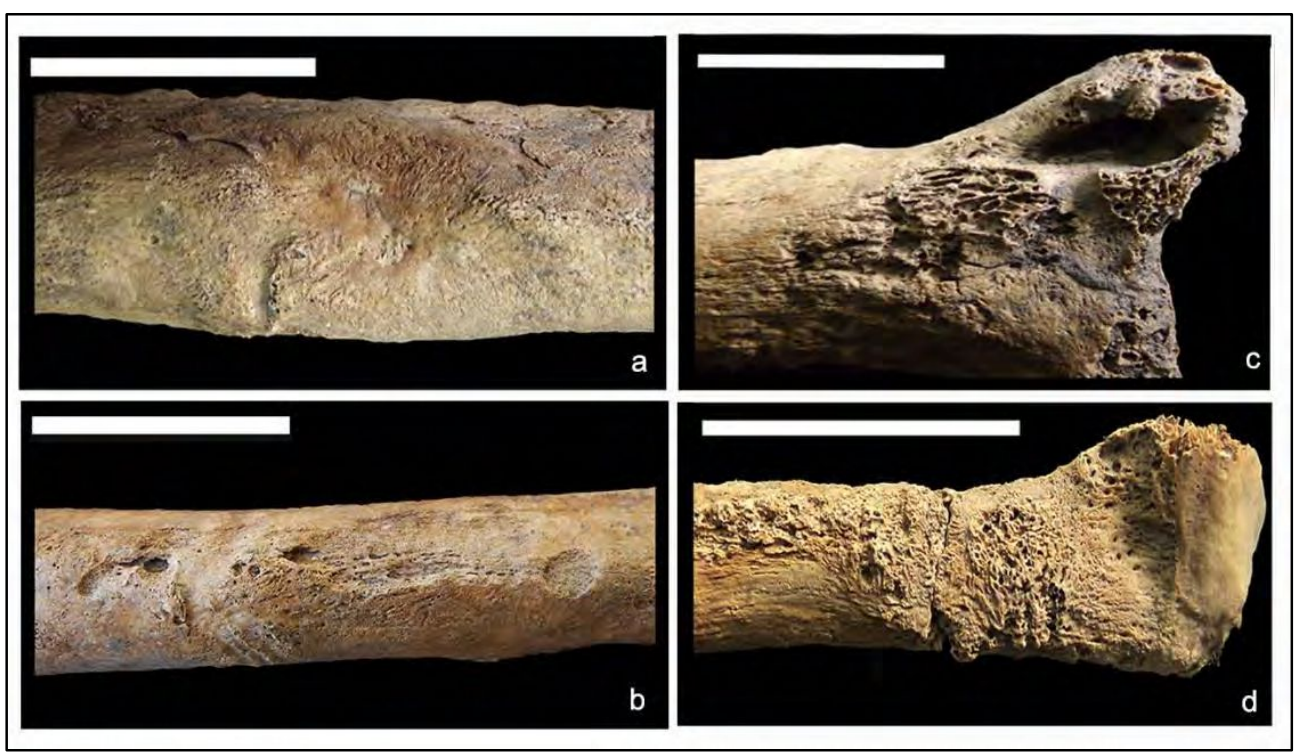

Figura 7.7. Lesiones óseas en el miembro inferior de LTC1-P3: a) diáfisis medial de la tibia derecha; b) diáfisis medial de la tibia izquierda; c) diáfisis distal de la tibia izquierda; d) diáfisis distal del peroné izquierdo. Escalas $=5 \mathrm{~cm}$.

El calcáneo izquierdo presenta tejido inmaduro en las caras posterior y externa, sin verse comprometidas las carillas articulares (Figura 7.8a). En los metatarsos primero, tercero y cuarto derechos y el tercero izquierdo, las diáfisis mediales presentan una leve capa de tejido óseo de carácter laminar, de la misma coloración que el resto del elemento. Por último, se destaca la morfología del segundo metatarso derecho; en este elemento no se registraron reacciones óseas, sino un acortamiento del largo desde la epífisis distal y agudizamiento del diámetro en ese extremo. Se encuentra totalmente remodelado en este sector y se observa la vascularización media a alta de la epífisis proximal (Figura 7.8.b). 


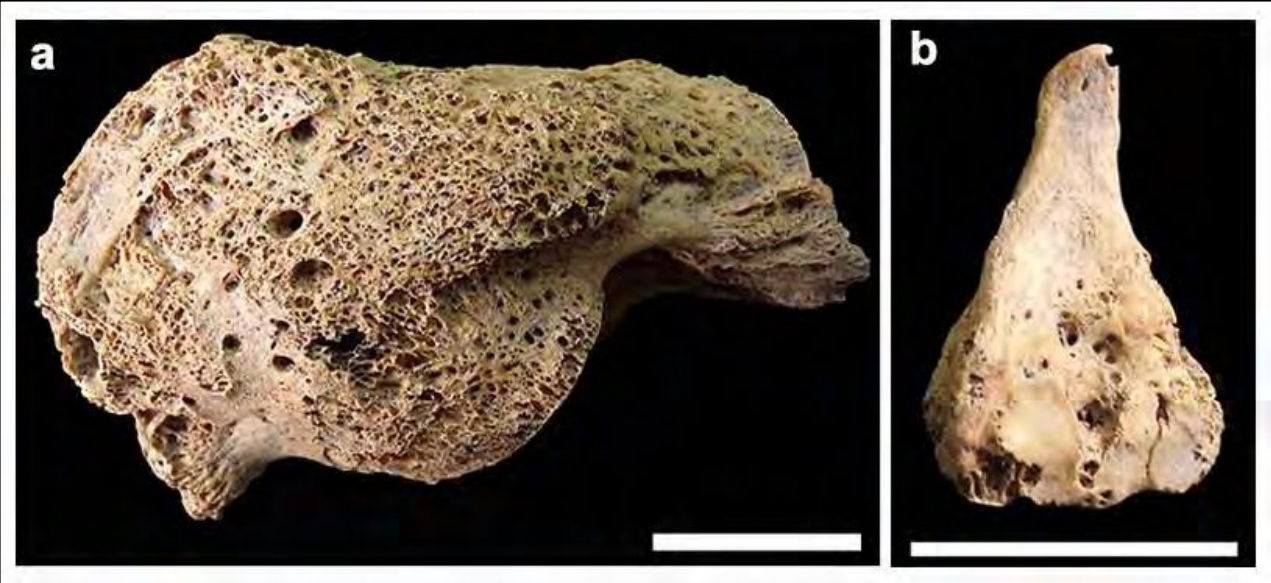

Figura 7.8. Lesiones óseas en huesos del pie de LTC1-P3: a) cara externa del calcáneo izquierdo; b) cara lateral del segundo metatarso derecho. Escala $=2,5 \mathrm{~cm}$.

Al analizar los huesos con reacciones óseas que posee este esqueleto, lo primero que se distingue claramente es el carácter sistémico de la patología, es decir, que la misma afectó a todo el individuo y no estuvo restringida a una región anatómica en particular. En segundo lugar, se destaca la bilateralidad de los huesos largos afectados, que tienen generalmente los mismos tipos de lesiones y en las mismas regiones.

El hueso largo donde no se manifiesta la bilateralidad de las reacciones es el fémur. Este elemento además es el único en el que las reacciones comprometieron la epífisis distal, la cual registra a su vez rasgos de osteoartrosis. Las epífisis proximales de ambas tibias también presentan el mismo desarrollo osteartrósico. Es probable que las lesiones infecciosas en ambas piernas puedan haber afectado la movilidad del individuo, impactando sobre la articulación de las rodillas y produciendo la osteoartrosis relevada.

Teniendo en cuenta la morfología del segundo metatarso derecho, en el diagnóstico diferencial se incluye a la lepra, una infección crónica causada por Mycrobacterium leprae. Esta patología afecta al sistema nervioso periférico y a la piel y, en los casos avanzados, también al esqueleto (Waldron 1994; Ortner 2003). Los cambios óseos son específicos (cuando el hueso es directamente infectado por la bacteria) o secundarios (como resultado de otros efectos como traumas, infección crónica, deformidad) (Waldron 1994). Las principales lesiones se producen en la región rinomaxilar, metacarpos y falanges de manos y pies. También la 
infección del pie puede afectar la tibia distal y el peroné causando periostitis bilateral y simétrica (Aufderheide y Rodríguez-Martín 1998; Ortner 2003). En la región del rinomaxilar, los cambios consisten principalmente en una reabsorción del proceso alveolar en el centro del maxilar superior, destrucción de la espina nasal anterior, reabsorción del tabique nasal y de los márgenes de la abertura nasal (Waldron 1994; Aufderheide y Rodríguez-Martín 1998). Estas lesiones han sido llamadas 'facies leprosa' (Møller-Christensen et al. 1952). En las manos y pies, generalmente en metacarpos y metatarsos, ocurre la pérdida concéntrica de hueso cortical causando una remodelación diafisiaria con patrones concéntricos o de cuchilla, y deformidad de la cavidad de las articulaciones. Esta remodelación comienza en los extremos distales del hueso, pudiendo extenderse hacia la región proximal (Aufderheide y Rodríguez-Martín 1998; Ortner 2003). Específicamente en los metatarsos, la remodelación destructiva puede dar como resultado una diáfisis en forma de cuchilla del hueso y esto se considera como patognomónico de la lepra. Sin embargo, si no hay otras lesiones que pueden asociarse con este diagnóstico, deben ser consideradas otras patologías (Ortner 2003). En el caso de este esqueleto, el metatarso derecho registrado con una morfología en forma aguzada podría asociarse con lepra. Sin embargo, dado que no fueron encontrados en la excavación todos los huesos del pie (faltando entre ellos varias de las falanges), que es el único metatarso/metacarpo que posee estas características y que en la región rinomaxilar no se registraron lesiones compatibles con lepra, se descarta tal diagnóstico.

Si se consideran en conjunto las reacciones periósticas en varios huesos largos, específicamente en las tibias y los peronés, la presencia de cloacas en varios elementos y la cavidad medular comprometida, pueden vincularse tales lesiones con osteomielitis (Ortner 2008; Waldron 2009). Esta infección se encontraba activa al momento de muerte del individuo, dada la presencia de tejido inmaduro en algunos elementos óseos y en sectores de las tibias y los peronés. Sin embargo, también se han registrado zonas con tejido mixto y laminar, denotando que esta infección era de tipo crónica y ya habían comenzado a remodelarse algunas lesiones. 
Existen diferentes tipos de osteomielitis, los cuales se mencionan y evalúan a continuación. Una de las osteomielitis es la secundaria a una fractura; si esta infección se vuelve crónica, la fractura no cicatriza y no ocurre la unión de las partes óseas fracturadas (Sia y Berbari 2006; McNally y Nagarajah 2010). En el esqueleto analizado no fueron registradas señales que indiquen fracturas mal curadas. Otro tipo de osteomielitis es la secundaria a un foco contiguo de infección, frecuente en individuos diabéticos que padecen heridas (por ej. úlceras) en los pies, propagándose la infección al hueso subyacente. La mayoría de las úlceras se ubican generalmente alrededor de las cabezas del primer y quinto metatarso y la falange distal del primer dedo, y afecta a estos huesos (Hartemann-Heuitier y Senneville 2008). Por diseminación, la infección puede extenderse a falanges proximales y a las cabezas de los metatarsos dos y cuatro. En la parte posterior del pie, el calcáneo también suele verse afectado así como el astrágalo, la tibia y el navicular (Ledermann et al. 2002). El diagnóstico de osteomielitis del pie es dificultoso; suele basarse en signos clínicos, la utilización de imágenes (TAC principalmente) y biopsia ósea (Jeffcoate y Lipsky 2004). El esqueleto LTC1-P3 presenta reabsorción ósea de la cabeza del segundo metatarso derecho, pequeñas capas de tejido laminar en las diáfisis de varios metatarsos, reacción ósea activa en el calcáneo izquierdo y una cloaca en el maléolo de la tibia derecha. Estas lesiones podrían corresponderse con un cuadro clínico semejante, aunque se esperaría que los huesos afectados sean de la misma lateralidad, lo que no ocurre con el calcáneo. Además, la presencia de otros huesos de los miembros inferiores y superiores indica una infección ósea generalizada que escaparía a la osteomielitis localizada en el pie de individuos diabéticos.

La osteomielitis hematógena es típica de niños, desarrollándose en la metáfisis de los huesos largos. En los adultos, este tipo de infección se presenta en huesos planos y cuerpos vertebrales (Bohndorf 2004). Sin embargo, un niño que tuvo esta patología y sobrevivió a ella puede sufrir una reactivación en su adultez luego de un período de latencia e involucrar varios años de su vida (Brady et al. 2006). En la osteomielitis crónica, puede haber signos de cloacas curadas (Mcnally y Nagarajah 2010). El esqueleto de adulto estudiado presenta osteomielitis generalizada en varias regiones del cuerpo, con signos de cronicidad y probables 
cloacas de drenaje remodeladas. Estas características permitirían asociarlas con este tipo de osteomielitis.

En esta evaluación de las lesiones óseas, no deben obviarse otros aspectos. En el relevamiento de patologías dentales, en este individuo se registró una lesión periapical (quiste) en el $\mathrm{M}^{1} \mathrm{i}$, que habría sido causada por la exposición de la cámara pulpar debido al desgaste dental severo que presenta ese diente (véase Capítulo 6.2). Esta exposición de la pulpa dental al ambiente oral podría haber sido un lugar propicio para el ingreso del patógeno. De todas formas, la ausencia de reacciones periósticas y formación de nuevo hueso en la región del maxilar no evidencia la presencia de osteomielitis (Dias y Tayles 2007; para un ejemplo similar véase Flensborg et al. 2013). Por otro lado, en el cráneo de este esqueleto fue registrado un traumatismo; se trata de una lesión en el centro del frontal (véase el apartado 7.4 en este mismo capítulo). Si bien tal lesión no evidencia macroscópicamente un gran compromiso del tejido óseo involucrado y no se relevaron otras reacciones periósticas en el cráneo, hasta el momento no debe descartarse como posible vía de ingreso del patógeno que desencadenó el proceso infeccioso.

El otro individuo de esta muestra bioarqueológica que presentó lesiones atribuibles a procesos infecciosos corresponde a LTC1-P4, un adulto medio (35-44 años) femenino. Se relevaron lesiones patológicas en nueve huesos. En el esqueleto axial, se observaron lesiones en el cráneo; mientras que en el esqueleto postcraneal, se encuentran afectados huesos del miembro superior (cúbito izquierdo) e inferior (ambos fémures, tibias y peronés y la rótula derecha).

En el cúbito izquierdo, en la zona de la cara posterior del proceso oleocraneano, el tejido se encuentra vascularizado sin discriminar formación de nuevo hueso por sobre el cortical. Hacia la mitad distal de la diáfisis, el contorno del elemento está modificado y aumentado en diámetro. En la cara medial de la diáfisis distal se observa tejido de tipo mixto, medianamente vascularizado. Al comparar este elemento con su contralateral (sin ninguna lesión), se observa una gran diferencia en la morfología.

Ambos fémures están afectados desde la mitad de la diáfisis hacia la región distal. El fémur derecho presenta tejido inmaduro localizado en la cara lateral a 
mitad de diáfisis, que podría asociarse con un nodo en proceso de curación (Figura 7.9a). En el caso del fémur izquierdo, en la diáfisis medial sobre la cara anterior, se observa una capa de tejido laminar que parece incrementar el contorno diafisiario. Ambos huesos presentan surcos coincidentes con huellas vasculares (Wells 1963); cada uno tiene una doble marca hacia la diáfisis distal en la cara interna. Por otro lado, la cara externa de la rótula derecha presenta tejido esclerótico y formación de nuevo hueso; también se distingue una cavidad en el cuadrante superior externo (Figura 7.9b). Ninguna de las superficies articulares del fémur y la rótula se encuentran afectadas.

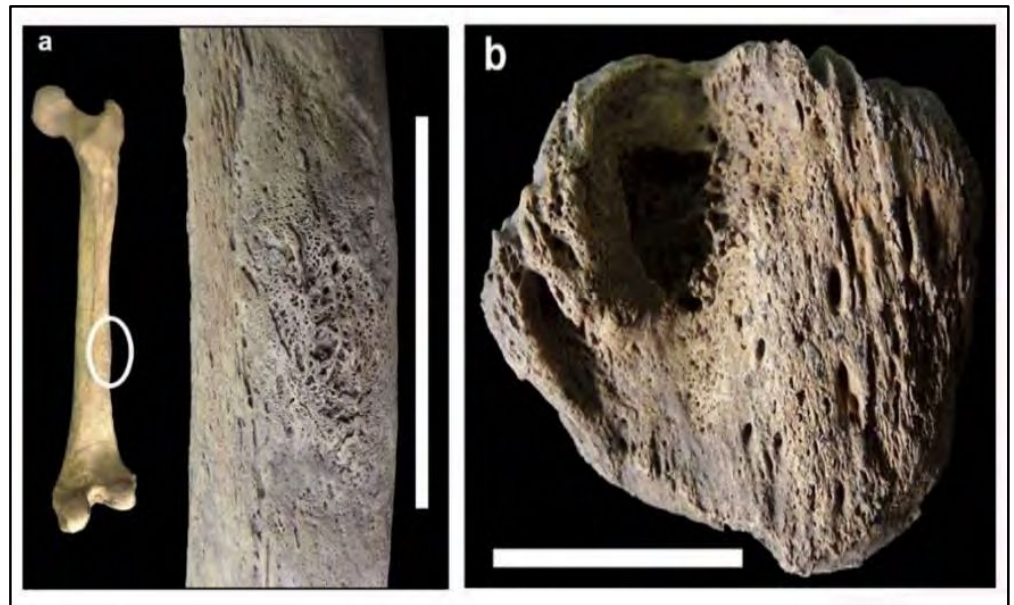

Figura 7.9. Lesiones óseas en el miembro inferior de LTC1-P4: a) diáfisis medial del fémur derecho; b) cara externa de la rótula derecha. Escala $=5 \mathrm{~cm}$ (Figura $7.9 \mathrm{a}$ ) y $2,5 \mathrm{~cm}$ (Figura 7.9.b).

La tibia derecha se encuentra afectada en la totalidad de su diáfisis, presentando reacciones óseas en distintos grados de remodelación (Figura 7.10a). En las caras lateral y medial de la diáfisis proximal, se observa reacción ósea ya esclerótica. También se encuentra marcada la zona de inserción del sóleo, presentando incluso pequeñas osificaciones; en esta misma región del hueso, según las imágenes radiológicas y tomográficas, pareciera haber una lesión lítica de bordes difusos (Figura 7.10.b, cl). En la mitad distal del elemento el diámetro de la diáfisis aumenta de tamaño, correspondiendo con una reducción de la cavidad medular dado un gran crecimiento del tejido cortical y esponjoso, como puede observarse en las imágenes de Rx y de TAC (Figura 7.10.cll). Por otro lado, en las 
caras posterior y lateral de la diáfisis distal, una región localizada -que aumenta el contorno diafisiario- corresponde a una lesión lítica con un borde muy bien definido en el tejido cortical (Figura 7.10.clll). Finalmente, se observaron dos posibles nodos estriados con cavitación central (Hackett 1976) en la cresta anterior (Figura 7.11.a) y la cara lateral de la diáfisis distal (Figura 7.11.b).

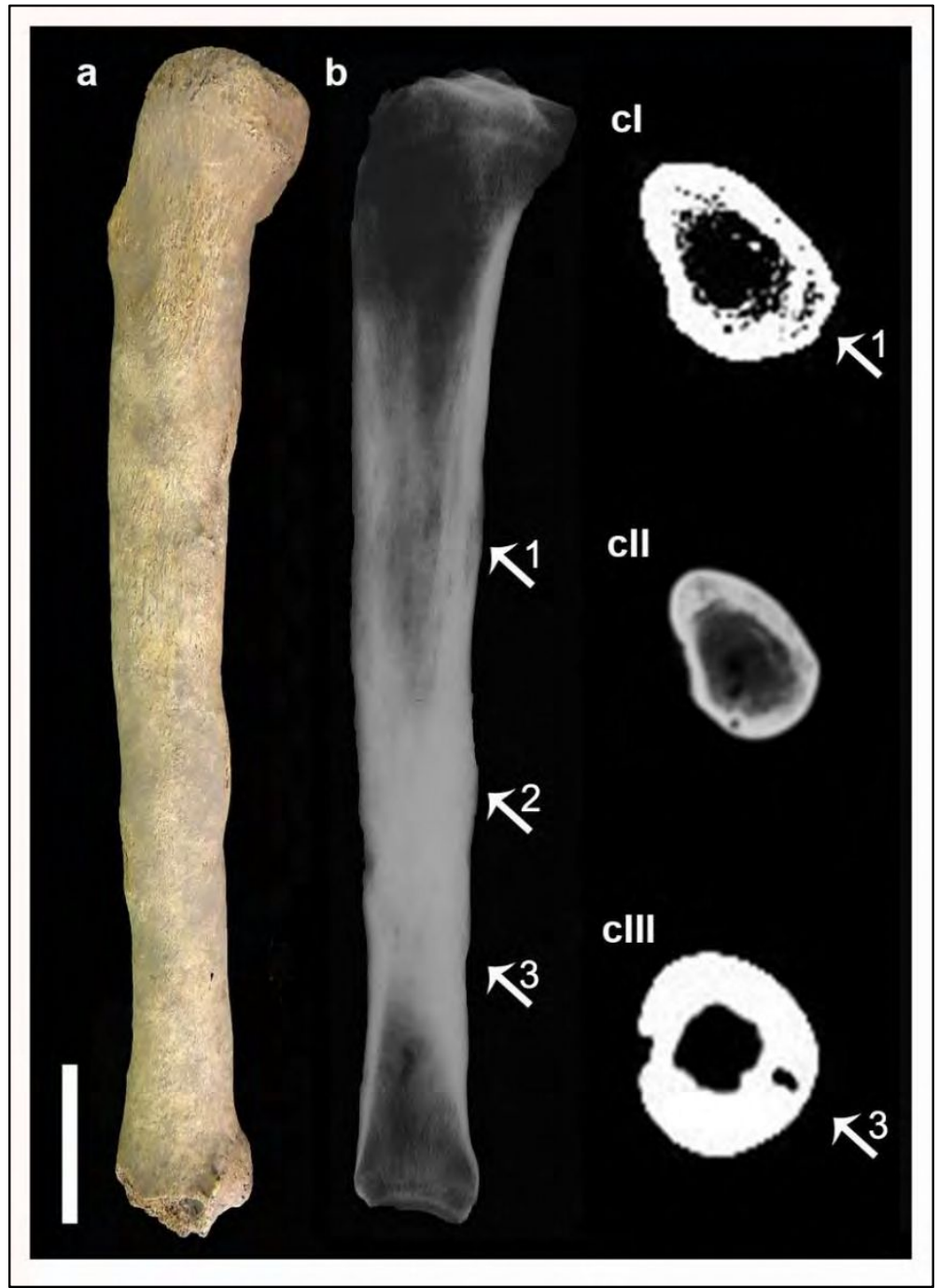

Figura 7.10. Lesiones óseas en la tibia derecha de LTC1-P4: a) cara lateral; b) Rx lateral; C I, II y III) secciones transversales de TAC; las flechas 1 y 3 indican la ubicación de las lesiones líticas observadas; la flecha 2 indica el lugar correspondiente al corte de TAC cll.

Escala $=5 \mathrm{~cm}$.

La tibia izquierda también se ve afectada a lo largo de su diáfisis, pero con una mayor presencia de hueso esclerótico que su contralateral. Hacia la diáfisis distal, presenta la morfología modificada y su diámetro exterior incrementado. Además, ambas tibias muestran surcos vasculares en la diáfisis: la tibia derecha 
tiene dos marcas simples sobre la cara externa en la diáfisis proximal; la tibia izquierda presenta una marca simple sobre la cara externa en la mitad de la diáfisis (Wells 1963).

El peroné derecho presenta lesiones en su mitad distal, observándose un engrosamiento espiculado del periostio sobre la cara medial (Figura 7.11.c). Por otro lado, en la diáfisis proximal, sobre la cresta de la cara anterior, se visualiza una pequeña capa de tejido laminar sobre el cortical (Figura 7.11.d). Esto último también fue registrado sobre la cresta de la cara medial a mitad de diáfisis del peroné izquierdo.

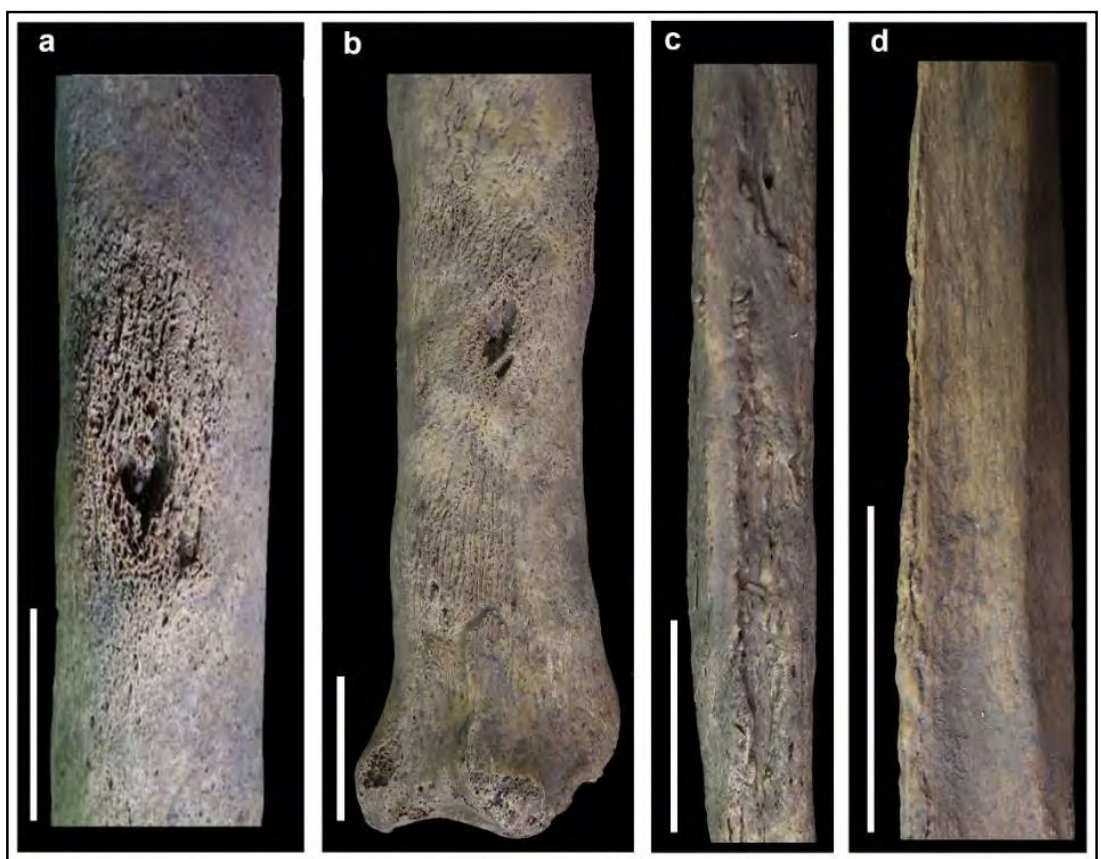

Figura 7.11. Lesiones óseas en el miembro inferior de LTC1-P4: a) cara anterior de la diáfisis distal de la tibia derecha; b) cara lateral de la diáfisis distal de la tibia derecha; c) diáfisis medial del peroné derecho y d) diáfisis proximal del peroné derecho. Escalas $=2,5 \mathrm{~cm}$.

Al examinar la bóveda craneana, en el centro del hueso frontal, se observaron dos depresiones adyacentes con las mismas características: forma circular-ovoide, remodelada y con engrosamiento óseo circundante; una de estas depresiones presenta una leve estriación del tejido óseo (Figura 7.12.a). Por otro lado, abajo de estas depresiones y por arriba de la órbita derecha, se observó una zona con coloración más clara y con irregularidad del tejido de la tabla externa; hay 
también algunos poros cerrados (Figura 7.12.b). Este mismo cambio de coloración y porosidades fue registrado en el lado izquierdo del frontal (Figura 7.12.c).

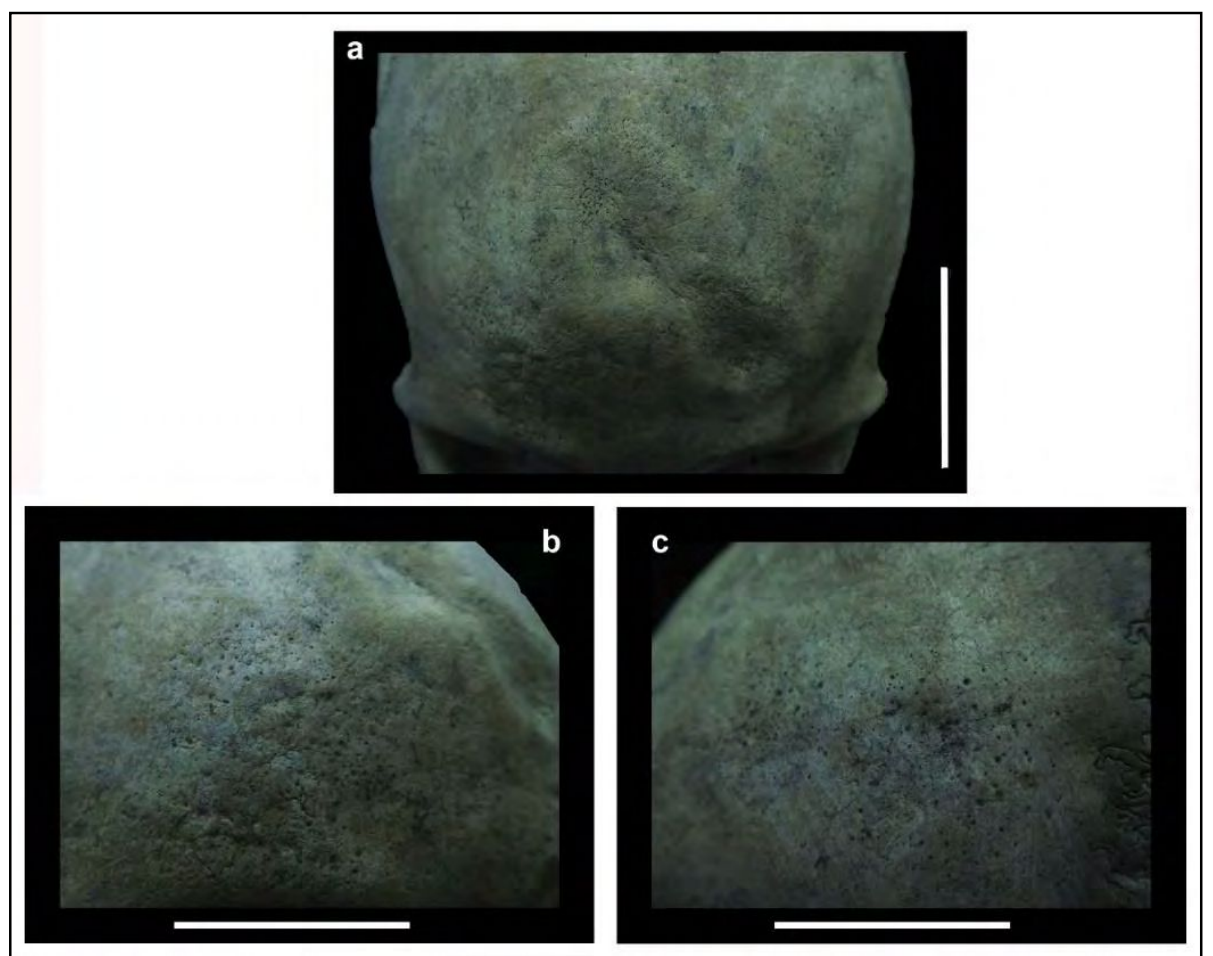

Figura 7.12. Lesiones óseas en el cráneo de LTC1-P4: a) sector central del frontal; b) sector derecho del frontal; c) sector izquierdo del frontal. Escalas $=3 \mathrm{~cm}$.

Al considerar las reacciones óseas en LTC1-P4, dos aspectos a tener en cuenta son la bilateralidad y la naturaleza sistémica de las lesiones que afectaron a varios huesos de ambas extremidades y sin comprometer en ningún caso a las carillas articulares. Los aspectos específicos de las reacciones indican que la infección ósea estaba activa al momento de muerte del individuo. Sin embargo, también se han registrado zonas con tejido remodelado, denotando su larga cronicidad. Dadas las características particulares de las lesiones relevadas, existen diferentes patologías que pueden considerarse en el diagnóstico diferencial.

Las úlceras crónicas en las piernas, debido a problemas vasculares como estasis venosa o venas varicosas, pueden producir reacciones óseas diafisiarias en tibias y peronés. Tales reacciones pueden incluir también formación de hueso espiculado, adelgazamiento del hueso cortical y esclerosis parcial o total de la membrana interósea; raramente producen respuestas líticas (Ortner 2003; Pinheiro 
et al. 2004). Algunas de estas reacciones han sido observadas en los huesos largos de las piernas. Sin embargo, otras evidencias registradas conducen a rechazar este diagnóstico, como por ejemplo la bilateralidad de las lesiones y el crecimiento óseo en el canal medular de la tibia derecha.

La enfermedad de Paget consiste en una anomalía ósea cuya etiología permanece incierta y que ocurre comúnmente en adultos mayores (>40 años), principalmente masculinos. Si bien generalmente comienza de forma localizada en un solo hueso, puede expandirse e involucrar varios elementos óseos (Ortner 2003). Esta patología se localiza principalmente en el esqueleto axial y, en los casos que se ve el esqueleto apendicular involucrado, los fémures y las tibias son los huesos largos generalmente más afectados. Específicamente, esta enfermedad implica tres fases: 1) lítica, 2) lítica y esclerótica y 3) esclerótica (Waldron 2009). Estos procesos de destrucción y de formación de hueso resultan en un patrón característico de mosaico a nivel histológico, lo cual es considerado como patognomónico de esta patología (Ortner 2003). En los huesos largos, la fase lítica comienza en el hueso subcondral y progresa a la metáfisis y diáfisis. Más tarde, se produce un engrosamiento de la corteza por deposición ósea endóstica y perióstica. Este nuevo hueso provoca que los huesos largos tiendan a curvarse, causando fracturas patológicas debido a la fragilidad del tejido óseo. Todas estas características (estructura ósea fibrosa, radiodensidad focal de las epífisis, etc.) son posibles de visualizarse en radiografías (Aufderheide y Rodríguez-Martín 1998; Ortner 2003). Teniendo en cuenta los aspectos recién descriptos sobre esta patología y que en el esqueleto LCT1-P4 no se observó ninguno de ellos -ni en huesos largos ni en el esqueleto axial-, la enfermedad de Paget se descarta.

La tuberculosis es una enfermedad infecciosa causada por una bacteria del género Mycobacterium. Específicamente, la especie $M$. tuberculosis es la causante de la transmisión directa entre humanos, frecuentemente a través del aparato respiratorio. El foco primario de infección se desarrolla en los pulmones y luego se puede diseminar a través del torrente sanguíneo hacia órganos distantes, incluyendo el tejido esquelético (Ortner 2003; Waldron 2009). Si bien cualquier parte del esqueleto humano puede verse afectado, generalmente la tuberculosis afecta al esqueleto axial y particularmente a los cuerpos vertebrales. Las lesiones 
tienden a ser destructivas más que formativas. También la tuberculosis puede causar lesiones en la tabla interna de la bóveda craneana (Ortner 2008). Raramente esta enfermedad afecta a las diáfisis de los huesos largos; y si esto ocurre es más común en niños y en las áreas metafisiarias y epifisiarias. En los raros casos en que se afecta la diáfisis, se observan lesiones en más de un hueso y se involucran las superficies articulares (Aufderheide y Rodríguez-Martín 1998; Ortner 2003). Dado que en el esqueleto estudiado predomina más la formación ósea que la destrucción, que el esqueleto axial se ve afectado pero por lesiones degenerativas (por ej, osteofitos marginales en cuerpo vertebrales y nódulo de Schmörl; Scabuzzo com. pers. 2016) y que las diáfisis de los huesos largos son los que muestran las lesiones, esta patología también fue descartada.

Tal como se describió en el diagnóstico diferencial del esqueleto LTC1-P3, las afecciones esqueletales que causa la lepra se producen en la región rinomaxilar, metacarpianos, falanges de manos y pies y también en la tibia y el peroné distal (Aufderheide y Rodríguez-Martín, 1998; Ortner, 2003). En este caso de estudio, los huesos observados con lesiones no se corresponden con el diagnóstico de lepra.

En el diagnóstico diferencial también fue considerada la treponematosis (véase las características de esta infección en Capítulo 4). Las áreas esqueletales que se encuentran afectadas suelen ser la bóveda craneana, antebrazo y pierna (Ortner 2008). Hackett (1976) describió detalladamente el desarrollo de las lesiones en el cráneo, siendo la caries sicca la lesión patognomónica de la treponematosis. También suele afectarse la región rinomaxilar de forma similar a la lepra, aunque sin llegar a involucrar los alveolos de la dentición anterior (Ortner 2008). En los huesos largos las lesiones suelen estar caracterizadas por formación ósea, destrucción ósea y/o una combinación de ambas. Particularmente en la tibia puede ocurrir una considerable formación ósea sobre todo en la cresta anterior, que debido al engrosamiento cortical, adquiere forma de sable (Hackett 1976; Ortner 2003). Por su parte, en la bóveda craneana y la tibia anterior, con superficies óseas cercanas a la piel, suelen presentarse lesiones activas o defectos gumatosos (Hackett 1976).

En el esqueleto LTC1-P4 se registraron lesiones óseas en el antebrazo izquierdo y ambas piernas, caracterizadas por formación ósea, posible nodo en proceso de curación en el fémur derecho y nodos estriados con cavitación central 
en la tibia derecha como los descriptos por Hackett (1976). Si bien ambas tibias no se encuentran arqueadas, su morfología externa se ve alterada y el contorno diafisiario parece aumentar; esto es coincidente con la obliteración de la cavidad medular por el engrosamiento del tejido cortical y crecimiento del tejido esponjoso, particularmente en la diáfisis distal. En conjunto, todos estos aspectos, y principalmente el último, parecen representar a la treponematosis. Asimismo, las lesiones registradas en la bóveda craneana (las depresiones escleróticas y el engrosamiento anormal del diploe), se corresponderían con los tipos de lesiones avanzadas registradas en cráneos de individuos con treponematosis (Hackett 1976: 31-40). Al considerar también las dos zonas adyacentes a las depresiones en la bóveda, con pequeñas irregularidades al tacto y porosidades en la tabla externa, éstas podrían interpretarse como estadios iniciales de las afecciones del cráneo que se manifiestan y son características de esta patología (Hackett 1976). Cabe recordar que, en este esqueleto, la región nasal y el paladar no presentan ningún tipo de lesión como las que suelen ser observadas en algunos individuos que padecieron treponematosis (Lovell et al. 2000; Cook y Powell 2012).

Distinguir el tipo de treponematosis (endémica, Yaws y venérea), basado en los cambios óseos, es una tarea difícil (Cook y Powell 2012). Igualmente, otros aspectos de los síndromes pueden aportar datos para su discusión. En el caso de la sífilis endémica y Yaws, alcanzan su desarrollo terciario -con incidencia en los huesos- varios años después de la fase inicial de la infección. Se transmiten principalmente por el contacto directo a través de lesiones cutáneas, aunque también se ha planteado la posibilidad de que sea por un insecto que actúe como vector (Powell y Cook 2005). Particularmente la sífilis endémica también puede contagiarse al compartir recipientes utilizados para comer y beber, por ejemplo (Powell y Cook 2005). La sífilis venérea se transmite de forma directa vía sexual, o de forma indirecta a través de objetos infectados o por lesiones abiertas exudantes. Este síndrome suele ocurrir en edades más tardías (15-30 años) y su desarrollo terciario puede ocurrir muchos años después (Aufderheide y Rodríguez-Martín 1998). Además de ser el síndrome más peligroso para la salud, dado que puede afectar el sistema nervioso y sanguíneo, también es transmisible vía placenta de la madre infectada hacia el feto. En el niño, se altera el desarrollo normal de los 
huesos y también de los dientes; en estos últimos son característicos los incisivos con malformación de Hutchinson (Jacobi et al. 1992; Powell y Cook 2005). De acuerdo a lo relevado en el esqueleto LTC1-P4, no hay indicios que permitan vincular las lesiones con sífilis venérea (principalmente las características dentales); por lo que se sugiere la treponematosis no venérea como diagnóstico.

Más allá de las lesiones observadas que se asocian con treponematosis, en el esqueleto LTC1-P4 se registraron también dos lesiones líticas en el tejido cortical de la tibia derecha. Este tipo de lesiones sugieren su vinculación con osteomielitis, de acuerdo a lo registrado en otros esqueletos (por ej. Flensborg et al. 2013). Por otro lado, la cavidad en la cara externa de la rótula también podría estar vinculada con este tipo de infección. Será necesario realizar una tomografía para poder discernir si esta lesión se vincula con osteomielitis o puede ser producto de artritis séptica, por ejemplo; sobre esto último es importante recordar que no se observaron modificaciones óseas en las áreas articulares que forman parte de la rodilla. En este sentido, posteriores estudios, sobre todo la realización de imágenes tomográficas, ayudarán a evaluar si este individuo pudo haber contraído otro tipo de infección, además de la treponematosis.

\subsubsection{Cuenca inferior del río Uruguay}

Para este conjunto se analizaron 816 elementos óseos correspondientes a 72 individuos. Sólo se registraron lesiones vinculadas con un proceso infeccioso en un elemento óseo $(0,1 \%)$ (Tabla 7.6$)$. Se trata de la bóveda craneana (ambos parietales y occipital) del individuo adulto (sexo indeterminado) del sitio San Luis Médanos, que representan el $1,4 \%$ de los individuos de la muestra (Tabla 7.6). Estadísticamente, no existe asociación entre la presencia de estas lesiones y la edad (subadultos vs. adultos; a nivel de elementos óseos: $p=1$; a nivel individual: $p=1$ ). 
Tabla 7.6. Prevalencias de lesiones infecciosas en la muestra de CIRU.

\begin{tabular}{|c|c|c|c|c|c|}
\hline & \multicolumn{2}{|c|}{ Individuos } & \multicolumn{2}{|c|}{ Elementos óseos } \\
\hline & & $\mathrm{A} / \mathrm{O}$ & $\%$ & $\mathrm{~A} / \mathrm{O}$ & $\%$ \\
\hline \multirow{6}{*}{ 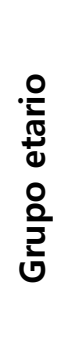 } & Infante & $0 / 4$ & 0 & $0 / 25$ & 0 \\
\hline & Niño & $0 / 7$ & 0 & $0 / 46$ & 0 \\
\hline & Adolescente & $0 / 3$ & 0 & $0 / 65$ & 0 \\
\hline & Adulto joven & $0 / 11$ & 0 & $0 / 204$ & 0 \\
\hline & Adulto medio & $0 / 4$ & 0 & $0 / 86$ & 0 \\
\hline & Adulto in. & $1 / 43$ & 2,3 & $1 / 390$ & 0,2 \\
\hline \multirow{4}{*}{ 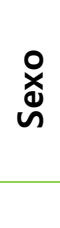 } & $\mathbf{F}$ & $0 / 15$ & 0 & $0 / 240$ & 0 \\
\hline & M & $0 / 18$ & 0 & $0 / 268$ & 0 \\
\hline & In. & $1 / 39$ & 2,6 & $1 / 308$ & 0,3 \\
\hline & Total & $1 / 72$ & 1,4 & $1 / 816$ & 0,1 \\
\hline
\end{tabular}

Referencias: $\mathrm{A}=$ afectado; $\mathrm{O}=$ observado; In.=indeterminado; $\mathrm{F}=$ femenino; $\mathrm{M}=$ masculino.

En el parietal derecho de la bóveda craneana del individuo SLM-65, en el sector hacia el frontal, se registró una zona con necrosis y destrucción gumatosa (Figura 7.13a), produciendo la apariencia conocida como "worm-eaten" (El-Najjar 1979). Esta lesión ectocraneal se extendió hacia el diploe, dándole aspecto irregular en corte transversal, pero sin llegar a afectar la tabla interna. El parietal izquierdo presenta las mismas características en el sector hacia el occipital, aunque no de forma tan nítida (Figura 7.13b). Por otro lado, en el parietal derecho hacia el occipital, se registró una capa de tejido ya esclerótico (Figura 7.13c). Mientras que las primeras lesiones se corresponderían con un estado activo de la patología al momento de muerte del individuo, la última se encuentra en estado remodelado denotando su cronicidad. 


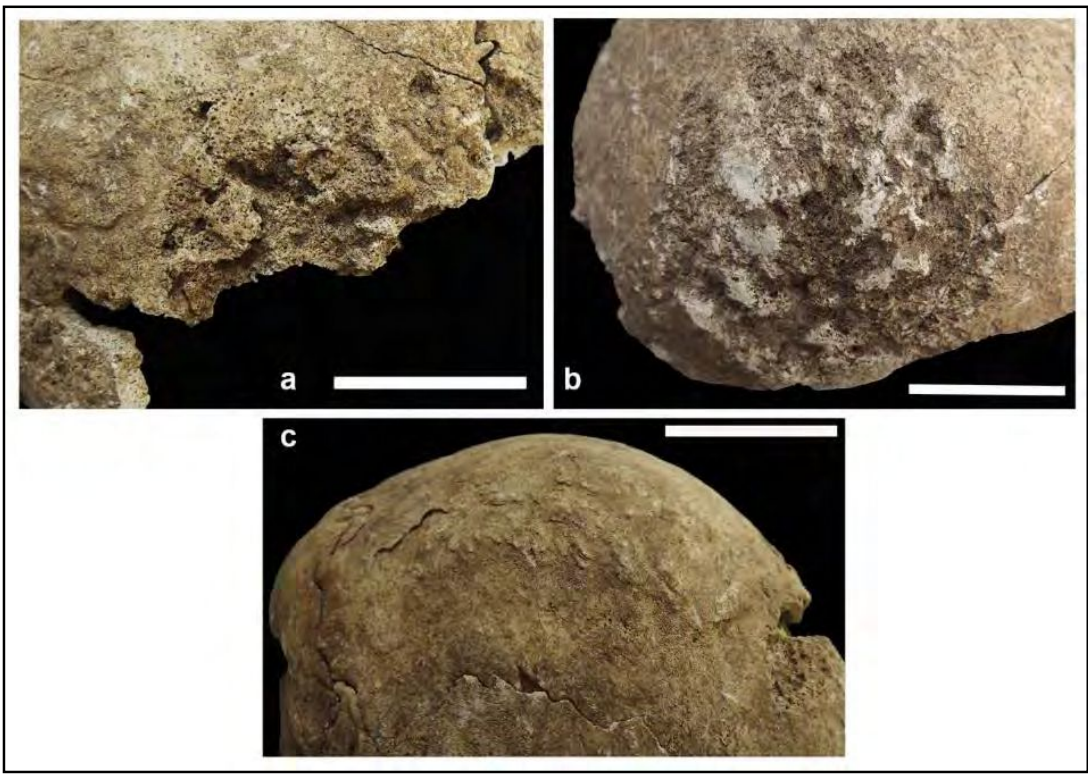

Figura 7.13. Lesiones en la bóveda craneana de SLM-65: a) parietal derecho hacia frontal; b) parietal izquierdo hacia occipital; c) parietal derecho hacia occipital. Escala=3 cm.

Numerosos investigadores han descripto que la presencia de áreas necróticas y gumatosas en la bóveda del cráneo con la apariencia de "worm-eaten", es característico de treponematosis (Hackett 1976; Steinbock 1976; El-Najjar 1979). Tales lesiones destructivas inician en la tabla externa del diploe, al extenderse la infección desde el tejido blando hacia el hueso. Al mismo tiempo que se va destruyendo el tejido óseo hasta llegar hacia el centro del diploe, comienza un proceso de regeneración ósea que con el tiempo se vuelve esclerótico (Steinbock 1976; El-Najjar 1979). Ambas características se encuentran presentes en el cráneo bajo estudio, permitiendo así interpretarlas como un posible caso de treponematosis. Lamentablemente este individuo se encuentra representado únicamente por este elemento óseo, lo cual no permite evaluar la posible presencia de lesiones en el esqueleto postcraneal. Si bien algunos autores han vinculado este tipo de lesiones craneanas con sífilis venérea (Steinbock 1976; El-Najjar 1979), en este caso de estudio con un único elemento óseo resulta prematuro tal interpretación. 


\subsubsection{Delta Inferior del río Paraná y ambientes litorales adyacentes}

Se relevó un total de 619 elementos óseos pertenecientes a un número mínimo de 16 individuos. En ningún caso se observaron lesiones óseas producto de procesos infecciosos.

\section{3 Lesiones de estrés inespecífico}

\subsubsection{Delta Superior del río Paraná}

Fueron analizaron 1109 elementos óseos pertenecientes al menos a 37 individuos. El 18,9\% ( $n=7)$ de los individuos presentó al menos un hueso con reacciones periósticas (RP); a nivel de elementos óseos, los huesos afectados representan el 1,1\% $(n=12)$ de la muestra (Tabla 7.7). De los siete individuos con lesiones, dos son adolescentes y cinco son adultos. Al comparar la presencia de reacciones periósticas con estos dos grupos de edad, existe asociación estadística a nivel de elementos óseos $(\chi 2=5,2 ; p=0,02)$; a nivel individual las variables se muestran independientes $(p=1)$. En cuanto al sexo, las prevalencias obtenidas fueron mayores en los individuos masculinos; estadísticamente no se asocia el sexo con la ocurrencia de las lesiones (a nivel óseo: $p=0,4$; a nivel individual: $p=0,6$ ). Como se aprecia en la descripción que se presenta a continuación para cada caso, todas las lesiones se relevaron sobre huesos largos y de éstas, el $83,3 \% \quad(n=10)$ sobre huesos del miembro inferior. 
Tabla 7.7. Prevalencias de lesiones de estrés inespecífico en la muestra del DS.

\begin{tabular}{|c|c|c|c|c|c|}
\hline & \multicolumn{2}{|c|}{ Individuos } & \multicolumn{2}{|c|}{ Elementos óseos } \\
\hline & & $A / O$ & $\%$ & A/O & $\%$ \\
\hline \multirow{10}{*}{ 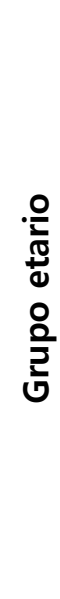 } & Perinato & $0 / 3$ & 0 & $0 / 14$ & 0 \\
\hline & Infante & $0 / 4$ & 0 & $0 / 7$ & 0 \\
\hline & Niño & $0 / 3$ & 0 & $0 / 11$ & 0 \\
\hline & Adolescente & $2 / 7$ & 28,6 & $6 / 270$ & 2,2 \\
\hline & Subadulto & - & - & $0 / 10$ & 0 \\
\hline & Adulto joven & $0 / 3$ & 0 & $0 / 52$ & 0 \\
\hline & Adulto medio & $0 / 2$ & 0 & $0 / 165$ & 0 \\
\hline & Adulto mayor & $0 / 1$ & 0 & $0 / 121$ & 0 \\
\hline & Adulto in. & $5 / 14$ & 29,4 & $6 / 425$ & 1,4 \\
\hline & In. & - & - & $0 / 34$ & 0 \\
\hline \multirow{4}{*}{ ֻे } & $\mathbf{F}$ & $1 / 8$ & 12,5 & $2 / 486$ & 0,4 \\
\hline & M & $3 / 10$ & 30 & 4 / 392 & 1 \\
\hline & In. & $3 / 19$ & 15,8 & $6 / 231$ & 2,6 \\
\hline & Total & $7 / 37$ & 18,9 & $12 / 1109$ & 1,1 \\
\hline
\end{tabular}

Referencias: $\mathrm{A}=$ afectado; $\mathrm{O}=$ observado; In.=indeterminado; $\mathrm{F}=$ femenino; $\mathrm{M}=$ masculino.

o LTC1-P6 - adolecente (19-20 años), sexo in.: se registraron RP en ambas tibias y peronés, con nivel alto de afectación. Las reacciones se ubican sobre las diáfisis; las carillas articulares no están involucradas. Específicamente, se observó en distintas partes de las diáfisis de cada hueso, una capa de tejido primario depositada sobre el cortical, con apariencia similar a "corteza de árbol" (Figura 7.14a). Dada la fragilidad de esta nueva capa ósea, se evidencia que en algunos sectores se ha desprendido, en momentos postdepositacionales, dejando al descubierto el tejido cortical.

- LTC1-P7 - adolescente (19-20 años), femenino: la tibia y el peroné izquierdo presentan RP, cuyo nivel de afectación fue bajo. En la tibia, sobre la cara medial en la diáfisis distal, se observó tejido inmaduro (reacción ósea activa) (Figura 7.14b). Por su parte, sobre la cresta anterior en la diáfisis proximal del peroné se observó una pequeña capa de tejido óseo mixto (en estado de remodelación); asimismo, la cara medial de la mitad distal de la diáfisis presenta reacción ósea activa. 
- LTC1-S3 - adulto in., masculino: en el fémur derecho, sobre la cara anterior en la diáfisis distal, se observó una pequeña RP (nivel de afectación bajo). Según el tejido óseo observado, la reacción se encontraba en estado de remodelación al momento de muerte del individuo (Figura 7.14c).

- LTC1-S4-1 - adulto in., masculino: sobre la cara posterior de la diáfisis distal del radio izquierdo se registró RP activa (nivel de afectación bajo), con límites bien definidos (Figura 7.14d).

- LTC1-S4 - adulto in., sexo in.: en un peroné derecho del paquete funerario LTC1-S4, se relevó una pequeña RP activa (tejido primario); la misma se localiza sobre la cara interna en la diáfisis distal (nivel de afectación bajo) (Figura 7.14e).

- LTC1-S5-1 - adulto in., sexo in.: en un radio derecho, en la cara posterior de la diáfisis distal se observó RP activa, con límites definidos (igual a la RP registrada en LTC1-S4-1); el nivel de afectación también fue bajo (Figura 7.14f).

- LTC1-AC y LTC1-A - adulto in., masculino: un fémur izquierdo hallado en la acumulación ósea y un fémur derecho hallado de forma aislada pudieron ser correspondidos mediante las tareas de ensamblaje anatómico. Ambos presentan RP en el tercio distal de sus diáfisis (nivel de afectación bajo). En el fémur derecho, sobre la cara anterior se registró una capa nueva de tejido óseo integrada al cortical; esta sección del hueso se encuentra levemente sobreelevada y presenta una coloración más clara en comparación con el resto de la diáfisis (Figura 7.14g). Por su parte, en la diáfisis distal del fémur izquierdo se observó una reacción ósea en proceso de remodelación que afectó todas las caras del hueso en esta zona diafisiaria; el tejido óseo también presenta una coloración más clara que el resto del hueso (Figura 7.14g). 


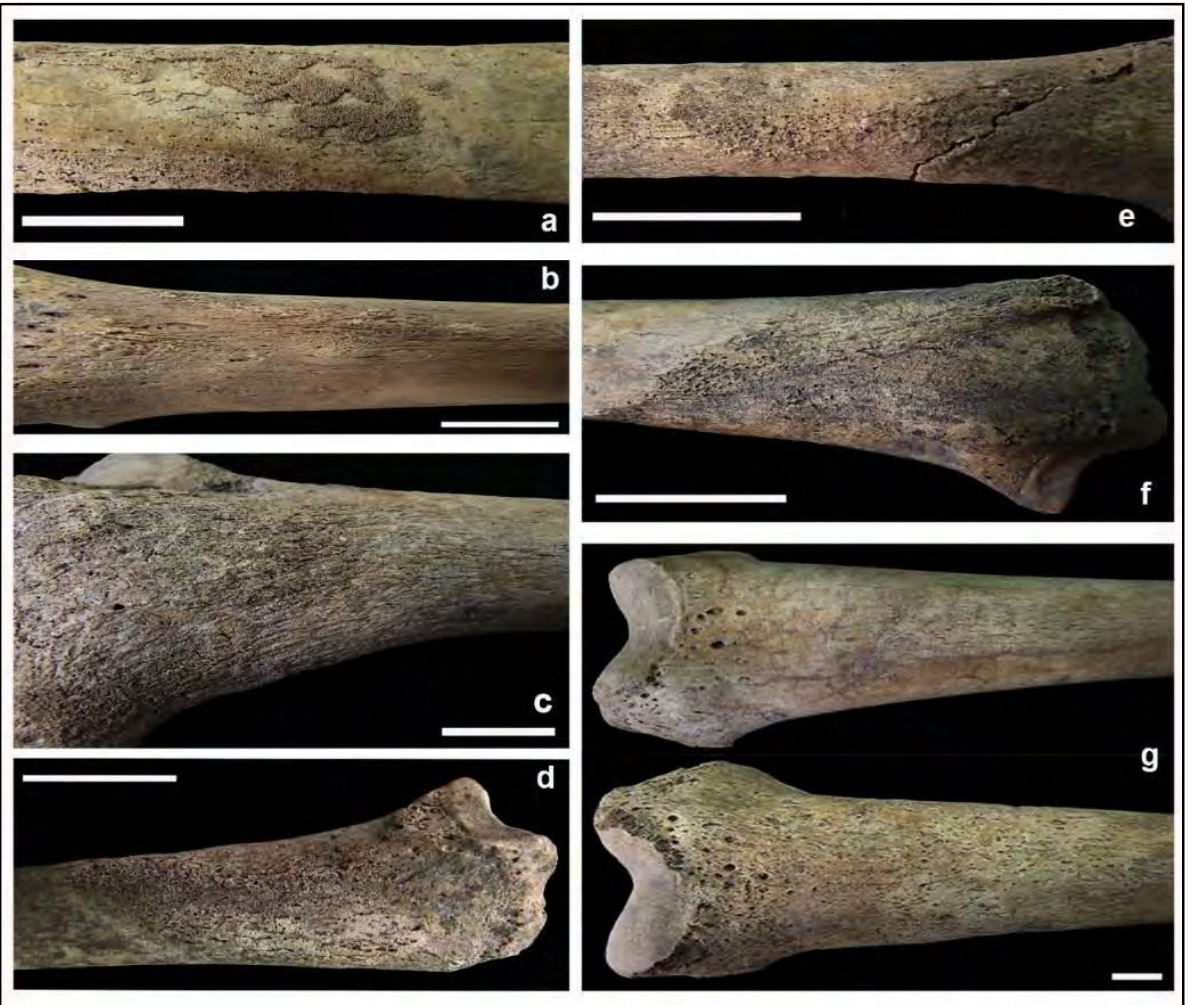

Figura 7.14. Lesiones de estrés inespecífico en la muestra del DS: a) diáfisis medial del peroné derecho de LTC1-P6; b) diáfisis distal de la tibia izquierda de LTC1-P7; C) diáfisis distal del fémur derecho de LTC1-S3; d) diáfisis distal del radio izquierdo de LTC1-S4-1; e) diáfisis distal del peroné derecho de LTC1-S4; f) diáfisis distal del radio derecho de LTC1-S5;

g) diáfisis distal del fémur derecho de LTC1-AC e izquierdo de LTC1-A. Escalas $=2 \mathrm{~cm}$.

Todas las lesiones recién descriptas corresponden a reacciones periósticas. Cualquier factor que desgarre, rompa, extienda o simplemente toque el periostio, puede estimularlo para iniciar la formación de nuevo hueso (Weston 2012). Por lo tanto, estas lesiones son consideradas como inespecíficas dada la multiplicidad de causas que pueden provocarlas; traumas, infecciones, estasis venosa y tumores son algunas de las más frecuentes (Chen et al. 2012; Weston 2012). Sin embargo, teniendo en cuenta la ubicación y distribución de las lesiones registradas en los huesos y esqueletos estudiados, se destacan algunas particularidades que posibilitan plantear probables diagnósticos. En primer lugar, los dos adolescentes con este tipo de lesiones las presentaron en tibias y peronés. En el caso específico de LTC1-P6 las lesiones fueron bilaterales (la ausencia de partes del esqueleto LTC1-P7 impide corroborar lo mismo), lo cual podría ser indicio de algún evento de estrés de tipo sistémico que afectó al individuo; de esta forma se descartaría que 
tales RP se deban a traumas o tumores. Otra posibilidad, dada la ubicación de las lesiones, es que sean debido a estasis venosa (i.e. circulación lenta del retorno sanguíneo). Sin embargo, que ambos casos corresponden a individuos adolescentes debilita tal diagnóstico, dado que esa patología suele ser más frecuente en adultos. En cuanto a los tres fémures afectados, las RP se ubicaron en la cara anterior de la diáfisis distal; en el caso de LTC1-S3 este elemento fue el único que presentó algún tipo de lesión ósea, mientras que en LTC1-AC/LTC1-A se constató la bilateralidad de las RP. Dado que esta área diafisiaria es propensa a sufrir traumas o golpes, es probable que ésta sea la causa de las lesiones observadas. Por último, las RP relevadas en los radios fueron similares en tanto se encuentran bien circunscriptas en la cara posterior de la diáfisis distal (Figura 7.13.d,f); esta delimitación coincide con el sector en el que se posiciona el músculo extensor corto del pulgar; esta zona distal del hueso se presenta libre de músculos y puede pensarse que las RP registradas en los radios se deban a traumas directos sobre el hueso.

\subsubsection{Cuenca inferior del río Uruguay}

De los 816 elementos óseos analizados correspondientes a 72 individuos, el 1,2\% $(n=10)$ presentó lesiones de estrés inespecífico. A nivel individual, el 11,1\% $(n=8)$ presentó al menos un hueso con este tipo de lesiones (Tabla 7.8). Si se observan las prevalencias por sexo, tanto a nivel individual como de elementos óseos, es mayor en los masculinos. Los valores obtenidos indican que la presencia de las lesiones y el sexo no se asocian estadísticamente (nivel individual: $p=0,2$; a nivel óseo: $p=0,1)$. Con respecto a la edad, las lesiones se registraron en un adolescente y siete adultos; al comparar la presencia de las lesiones según estos dos grupos de edad, no existe dependencia entre las variables (nivel individual: $p=0,6$; a nivel óseo: $p=0,3$ ). La mayor cantidad de lesiones fue registrada sobre huesos largos (70\%; $n=7)$, tanto del miembro superior como inferior. Asimismo, se relevaron lesiones en huesos del pie $(10 \% ; n=1)$ y de la cintura pélvica $(20 \% ; n=2)$. A continuación se detallan las lesiones. 
Tabla 7.8. Prevalencias de lesiones de estrés inespecífico en la muestra de CIRU.

\begin{tabular}{|c|c|c|c|c|c|}
\hline & \multicolumn{2}{|c|}{ Individuos } & \multicolumn{2}{|c|}{ Elementos óseos } \\
\hline & & $A / O$ & $\%$ & A/O & $\%$ \\
\hline \multirow{6}{*}{ 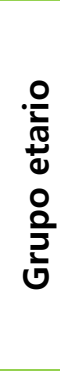 } & Infante & $0 / 4$ & 0 & $0 / 25$ & 0 \\
\hline & Niño & $0 / 7$ & 0 & $0 / 46$ & 0 \\
\hline & Adolescente & $1 / 3$ & 33,3 & $1 / 65$ & 1,5 \\
\hline & Adulto joven & $1 / 11$ & 9,1 & $2 / 204$ & 1 \\
\hline & Adulto medio & $1 / 4$ & 25 & $1 / 86$ & 1,2 \\
\hline & Adulto in. & $5 / 43$ & 11,6 & $6 / 390$ & 1,5 \\
\hline \multirow{4}{*}{ 文 } & $\mathbf{F}$ & $1 / 15$ & 7,3 & $1 / 240$ & 0,4 \\
\hline & M & $5 / 18$ & 28,2 & $6 / 268$ & 2,2 \\
\hline & In. & $2 / 39$ & 5,1 & $3 / 308$ & 1 \\
\hline & Total & $8 / 72$ & 11,1 & $10 / 816$ & 1,2 \\
\hline
\end{tabular}

Referencias: $\mathrm{A}=$ afectado; $\mathrm{O}=$ observado; In.=indeterminado; $\mathrm{F}=$ femenino; $\mathrm{M}=$ masculino.

- CL2-52 - adulto joven (30-35 años), masculino: los coxales tienen el mismo tipo de reacción ósea sobre dos sectores de la cara ventral del isquion (nivel de afectación bajo). Presentan baja a nula vascularización y se encuentran en estado de remodelación (Figura 7.15a).

- CL2-54 - adulto medio (40-49 años), femenino: sobre la cara lateral en la mitad proximal del cuarto metatarso izquierdo, se observa una excresencia ósea esclerótica (nivel de afectación bajo) (Figura 7.15b).

- CL2-67 - adulto in., masculino: en la mitad distal del cúbito derecho, el contorno de la diáfisis se encuentra ampliado (nivel de afectación medio). Esto se corresponde en la imagen radiológica (de frente), con una capa de tejido óseo paralela a la superficie y de apariencia laminar sobre el lado medial del hueso. Por otro lado, macroscópicamente se distingue RP activa en la cara posterior de la diáfisis distal y medial y en la cara anterior hacia la epífisis distal. Específicamente en la radiografía de perfil, en la zona de la epífisis distal, se observa que el tejido cortical está radiolúcido (Figura 7.15c).

- CL2-73 - adulto in., probable masculino: el fémur derecho presenta RP sobre todas las caras de la diáfisis, alcanzando un nivel de afectación alto. Esta reacción se caracteriza por ser una capa de tejido óseo por sobre el cortical, con aspecto de "corteza de árbol". Dada la delgadez de dicha capa, se observa que en 
diferentes regiones de la diáfisis se ha desprendido parte de ella de forma postdepositacional; en estas regiones el tejido cortical expuesto tiene una coloración más clara (Figura 7.15d).

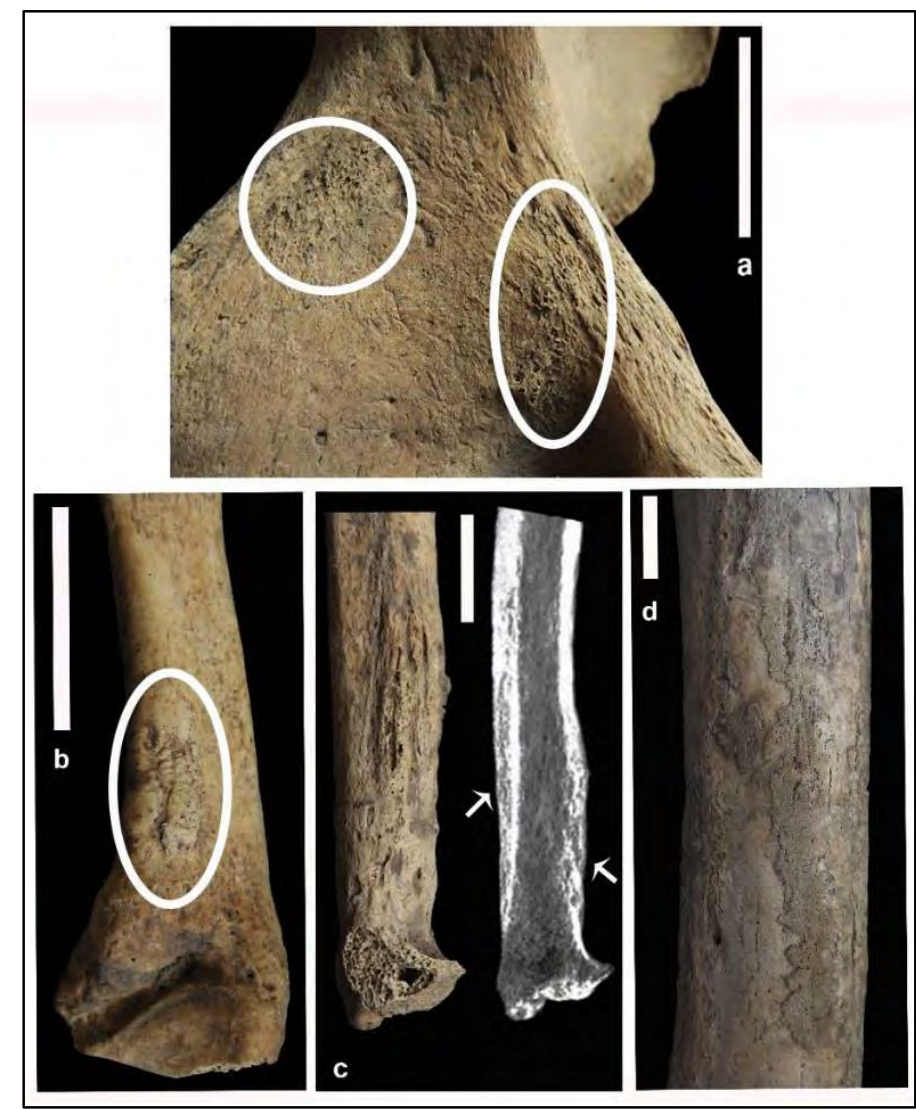

Figura 7.15. Lesiones de estrés inespecífico en la muestra de CIRU: a) isquion izquierdo de CL2-52; b) cuarto metatarso izquierdo de CL2-54; c) diáfisis distal del cúbito derecho de CL2-67 y Rx; d) diáfisis medial del fémur derecho de $C L 2-73$. Escalas $=2 \mathrm{~cm}$.

- SPL-87 - adulto in., masculino: el fémur derecho presenta RP activa sobre la diáfisis distal en las caras anterior y medial. Dicha reacción, que alcanza un nivel de afectación bajo, se caracteriza por tener aspecto de corteza de árbol. Si bien en la imagen radiológica de perfil se distingue la capa de hueso por sobre el cortical, macroscópicamente se observa que está en parte integrada al tejido cortical subyacente; esto podría deberse al comienzo del proceso de remodelación (Figura $7.16 a$ ). 
- SPL-207 - adulto in., sexo in.: en la cara medial de la diáfisis distal del peroné derecho se registró una RP con tejido mixto, en estado de remodelación; el nivel de afectación del hueso es bajo (Figura 7.16b).

- T1-CNM-215 - adulto in., sexo in.: el húmero y el fémur izquierdos presentan lesiones de estrés inespecífico. En el caso del húmero, sobre la cara posterior hacia el lado medial, se observa una reacción ósea activa (tejido primario), con alta vascularización y algunos orificios de considerable tamaño; hacia el lado lateral del hueso la reacción se vuelve más esclerótica (Figura 7.16c). Por su parte, el fémur en la diáfisis distal en la cara medial-anterior presenta una capa nueva de hueso en proceso de remodelación, de coloración más oscura que el tejido circundante. Asociada con esta reacción, se observó un surco vascular (Figura 7.16d).

- T2-CSM-82 - adolescente (18-21 años), masculino: el cúbito derecho presenta el contorno modificado y aumentado en la cara posterior a mitad de la diáfisis. Asimismo, en este sector se relevó una capa de tejido óseo en proceso de remodelación y con una coloración apenas más oscura que el resto del cortical (Figura 7.16e). 

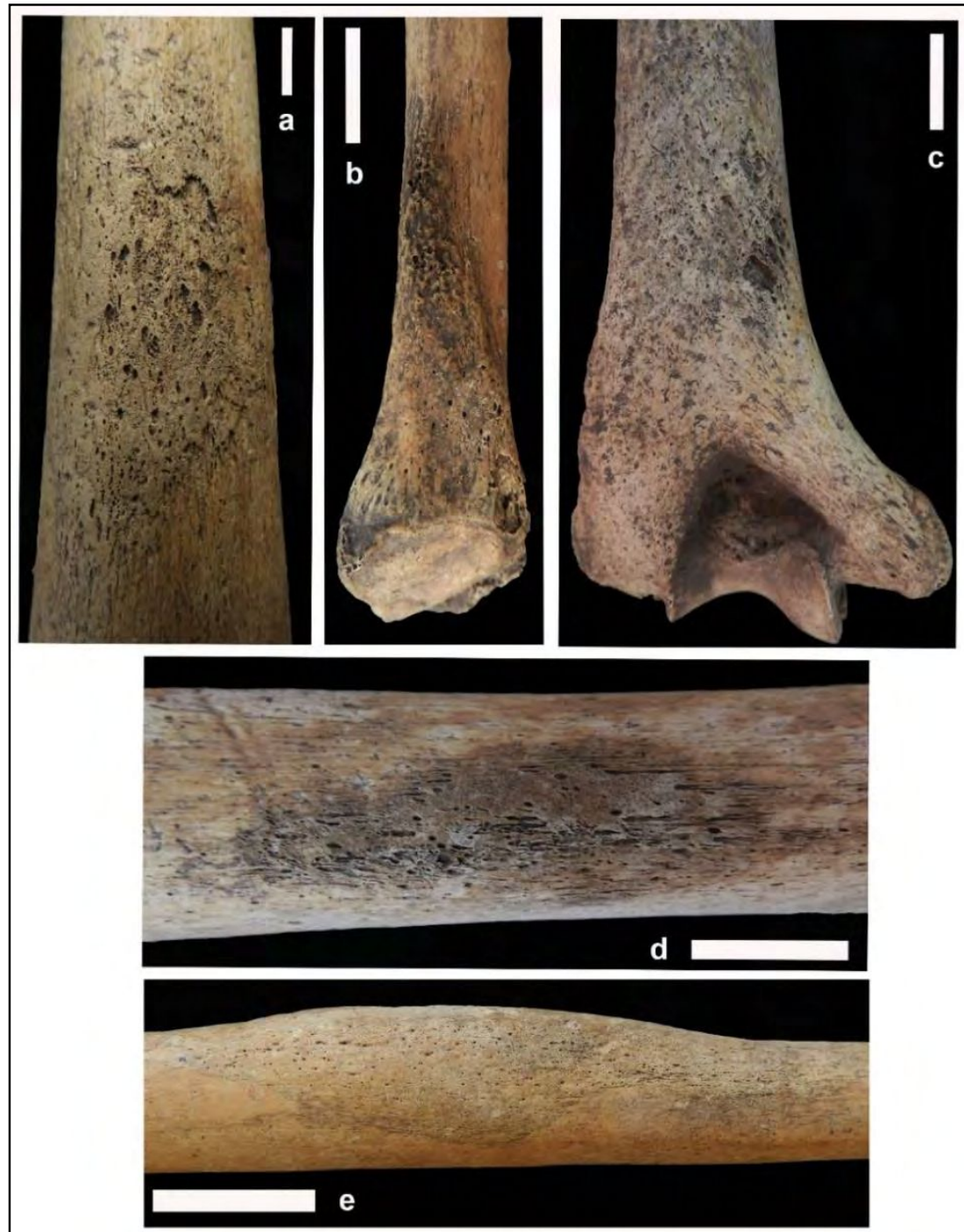

Figura 7.16. Lesiones de estrés inespecífico en la muestra de CIRU: a) diáfisis distal del fémur derecho de SPL-87; b) diáfisis distal del peroné derecho de SPL-207; c) diáfisis distal del húmero izquierdo de T1-CNM-215; d) diáfisis distal del fémur izquierdo de T1-CNM-215; e) diáfisis medial del cúbito derecho de T2-CSM-82. Escalas $=2 \mathrm{~cm}$.

De acuerdo a las descripciones de las lesiones registradas en esta muestra bioarqueológica, es posible discutir probables diagnósticos de algunas de ellas. En el caso de los coxales de CL2-52, ambos presentan RP en la misma zona y del lado interno. Considerando que este sector forma parte de la cavidad pélvica, la cual contiene diferentes órganos (reproductivos, digestivos y urinarios), es posible descartar traumas como el probable origen de las lesiones. Por otro lado, se observaron RP en tres fémures: mientras que en un caso (CL2-73) el nivel de afectación es alto, en los otros dos (SPL-87 y T1-CNM-215) las lesiones se localizan 
concretamente en un sector de las caras anterior-medial; esto es coincidente con lo observado en los fémures de la muestra bioarqueológica del DS, para los cuales se propone el trauma como posible origen de las RP. Al evaluar de forma conjunta todos los casos relevados, se destaca que la mayoría de los individuos presentó sólo un hueso afectado, lo cual conduce a descartar el carácter sistémico de las afecciones. Igualmente, se debe considerar que no se contó con la totalidad del esqueleto para ningún individuo, situación que constituye una limitante para evaluar las incidencias de las lesiones.

\subsubsection{Delta Inferior del río Paraná y ambientes litorales adyacentes}

Se relevaron 619 elementos óseos pertenecientes a un número mínimo de 16 individuos. Cabe recordar que en el caso concreto del sitio T1-LA, dadas las características de este conjunto, fue posible analizar las lesiones también a nivel esqueletal ( $\mathrm{NMI}=4$; véase en detalle Capítulo 5). El 2,6\% $(n=16)$ de los elementos presentó lesiones de estrés inespecífico; los mismos pertenecen al menos a seis individuos, que representan el $11,3 \%$ de la muestra (Tabla 7.9). Si se analizan las lesiones según el sexo, a nivel individual las prevalencias obtenidas son similares entre femeninos y masculinos y no existe asociación estadística $(p=1)$. A nivel de elementos óseos, la prevalencia es claramente mayor en femeninos y los valores obtenidos sí indican la dependencia entre la ocurrencia de estas lesiones y el sexo $(p=0,04)$. Igualmente, en este punto hay que tener en cuenta que los nueve huesos con lesiones pertenecen a un mismo esqueleto femenino. En cuanto a la distribución de las lesiones según la edad, los individuos afectados son adultos; no existe asociación estadística entre la presencia de las lesiones y el grupo de edad (subadultos vs. adultos; a nivel individual: $p=1$; a nivel óseo: $p=0,6$ ). Los elementos afectados fueron principalmente huesos de los miembros superiores e inferiores (75\%; $n=12)$. A continuación se detallan las lesiones. 
Tabla 7.9. Prevalencias de lesiones de estrés inespecíficas en la muestra del DI.

\begin{tabular}{|c|c|c|c|c|c|}
\hline & \multicolumn{2}{|c|}{ Individuos } & \multicolumn{2}{|c|}{ Elementos óseos } \\
\hline & & $\mathrm{A} / \mathrm{O}$ & $\%$ & $\mathrm{~A} / \mathrm{O}$ & $\%$ \\
\hline \multirow{7}{*}{$\begin{array}{l}\frac{0}{2} \\
\frac{0}{0} \\
0 \\
0 \\
\frac{0}{2} \\
\frac{2}{0}\end{array}$} & Niño & $0 / 1$ & 0 & $0 / 1$ & 0 \\
\hline & Adolescente & $0 / 5$ & 0 & $0 / 19$ & 0 \\
\hline & Subadulto & - & - & $0 / 6$ & 0 \\
\hline & Adulto joven & $0 / 5$ & 0 & $0 / 20$ & 0 \\
\hline & Adulto medio & $0 / 1$ & 0 & $0 / 1$ & 0 \\
\hline & Adulto in. & $6 / 41$ & 14,6 & 16 / 339 & 4,7 \\
\hline & In. & - & - & $0 / 241$ & 0 \\
\hline \multirow{4}{*}{ 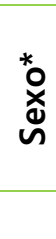 } & $\mathbf{F}$ & $1 / 10$ & 10 & $9 / 46$ & 19,6 \\
\hline & M & $2 / 21$ & 9,5 & $1 / 36$ & 2,8 \\
\hline & In. & $3 / 22$ & 13,6 & $6 / 537$ & 1,1 \\
\hline & Total & $6 / 53$ & 11,3 & $16 / 619$ & 2,6 \\
\hline
\end{tabular}

Referencias: $\mathrm{A}=$ afectado; $\mathrm{O}=$ observado; In.=indeterminado; $\mathrm{F}=$ femenino; $\mathrm{M}=$ masculino; * =entre los individuos femeninos se incluyen 3 a probables femeninos y entre los masculinos, a 7 probables masculinos.

- T1-LA-68 - adulto in., sexo in.: en tres huesos se relevaron RP con bajo nivel de afectación. Específicamente, el cúbito derecho y el izquierdo presentan a mitad de diáfisis en la cara medial una capa de tejido inmaduro sobre el cortical; la misma es de coloración más oscura, con aspecto de "corteza de árbol" y pareciera haber sufrido pequeños desprendimientos postdepositacionales (Figura 7.17a). Por otro lado, en el peroné derecho se registraron dos sectores con reacción ósea: en las caras lateral y medial a mitad de diáfisis hay una capa de tejido inmaduro de características similares a la de los cúbitos; en la cara medial en la metáfisis distal se observa una reacción ósea activa (Figura 7.17b).

- T1-LA-69 - adulto in., femenino: se relevaron RP en nueve huesos con bajo nivel de afectación en todos los casos. La clavícula derecha tiene una fina capa de tejido primario por sobre el cortical en la cara interna del cuerpo hacia la región proximal. El húmero izquierdo presenta una fina capa de tejido óseo por sobre el cortical en la metáfisis distal sobre la cara antero-medial (Figura 7.17c). Asimismo, el húmero derecho tiene el mismo tipo de reacción en las caras anterior y posterior a mitad de la diáfisis. Por otro lado, ambos coxales presentan una capa ósea de aspecto de "corteza de árbol" en la cara posterior entre las 
espinas ilíacas; en ambos casos de coloración más oscura y se ha desprendido parte de ella en el ala de los iliones (Figura 7.17d). El fémur izquierdo presenta, por debajo del cuello en la cara posterior, una capa de tejido primario con aspecto de "corteza de árbol", de coloración más oscura; en la cara lateral debajo y al costado del trocánter mayor también se observa una reacción ósea aunque en un estado de mayor remodelación (Figura 7.17e). Ambas tibias tienen sobre las distintas caras de sus diáfisis, sectores con capas de tejido primario de aspecto de "corteza de árbol", la cual ha sufrido desprendimientos (Figura 7.18f). Finalmente, en el calcáneo derecho, sobre la cara medial a mitad del elemento, se registró una fina capa de hueso en estado de remodelación (Figura 7.17g).

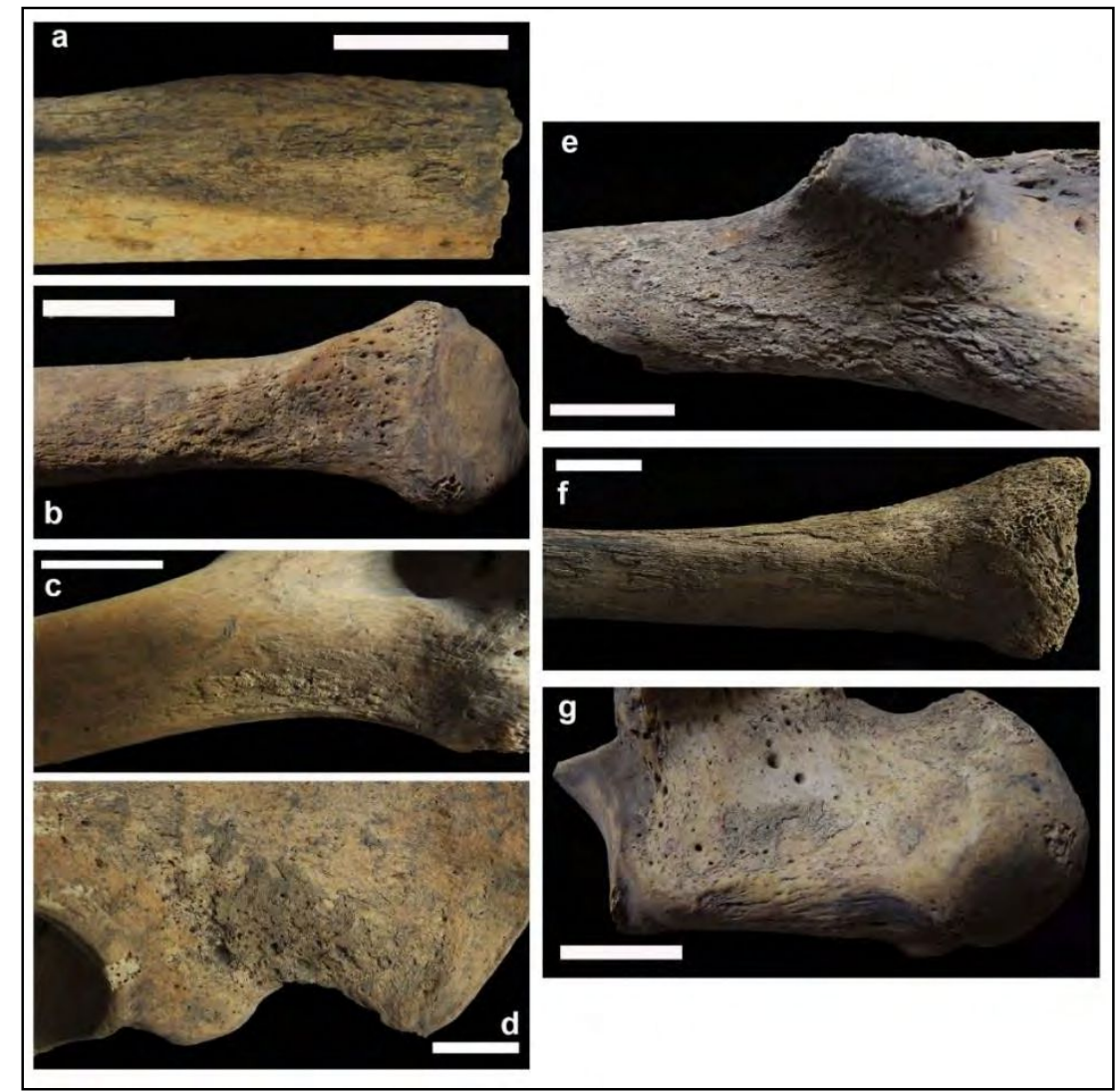

Figura 7.17. Lesiones de estrés inespecífico en la muestra del DI: a) diáfisis medial del cúbito derecho de T1-LA-68; b) diáfisis distal del peroné derecho de T1-LA-68; c) diáfisis distal húmero del izquierdo de T1-LA-69; d) ilion derecho de T1-LA-69; e) epífisis proximal del fémur derecho de T1-LA-69; f) epífisis distal de la tibia izquierda de T1-LA-69; g) cara medial del calcáneo derecho de T1-LA-69. Escalas $=2 \mathrm{~cm}$. 
- T1-PG-43 1/2 - adulto in., masculino: en el cúbito derecho, sobre mitad de diáfisis en la cara posterior, se observa macroscópicamente una zona en la que el contorno se encuentra modificado y aumentado. El tejido óseo en este sector presenta una coloración más clara y algunos poros; el nivel de afectación es bajo. Radiológicamente, esta zona se corresponde con una obstrucción casi total de la cavidad medular producto del crecimiento óseo (Figura 7.18a).

- EC-6441 - adulto in., probable masculino: el fémur izquierdo, en la diáfisis distal en su cara posterior, presenta una reacción ósea casi completamente remodelada, con bajo nivel de afectación. Asimismo, en la cara lateral se observa una reacción ósea activa. Finalmente, en esta misma zona distal de la diáfisis, pero sobre la cara anterior, se distingue una reacción ósea; la presencia de tierra y algunos desprendimientos corticales (en momentos postdepositacionales), imposibilita su observación con mayor detalle (Figura 7.18b).

- EC-6453 - adulto in., sexo in.: en la cara medial de la diáfisis distal de una tibia izquierda, se observa una reacción ósea con un grado alto de remodelación y bajo nivel de afectación (Figura 7.18c).

- AS-6480 - adulto in., sexo in.: un peroné izquierdo, sobre la cara medial en la diáfisis distal, presenta reacción ósea que contiene dos orificios cerrados; el contorno se encuentra levemente modificado y aumentado. El nivel de afectación del hueso es bajo. En imagen radiológica de perfil se observa esta reacción, al mismo tiempo que se distingue crecimiento óseo hacia la cavidad medular, obstruyéndola parcialmente (Figura 7.18d).

1 Bajo esta numeración (43 1/2), Torres extrajo del sitio T1-PG huesos postcraneales de al menos un individuo; es a partir de los coxales que determina el sexo del individuo (1911: 157). 

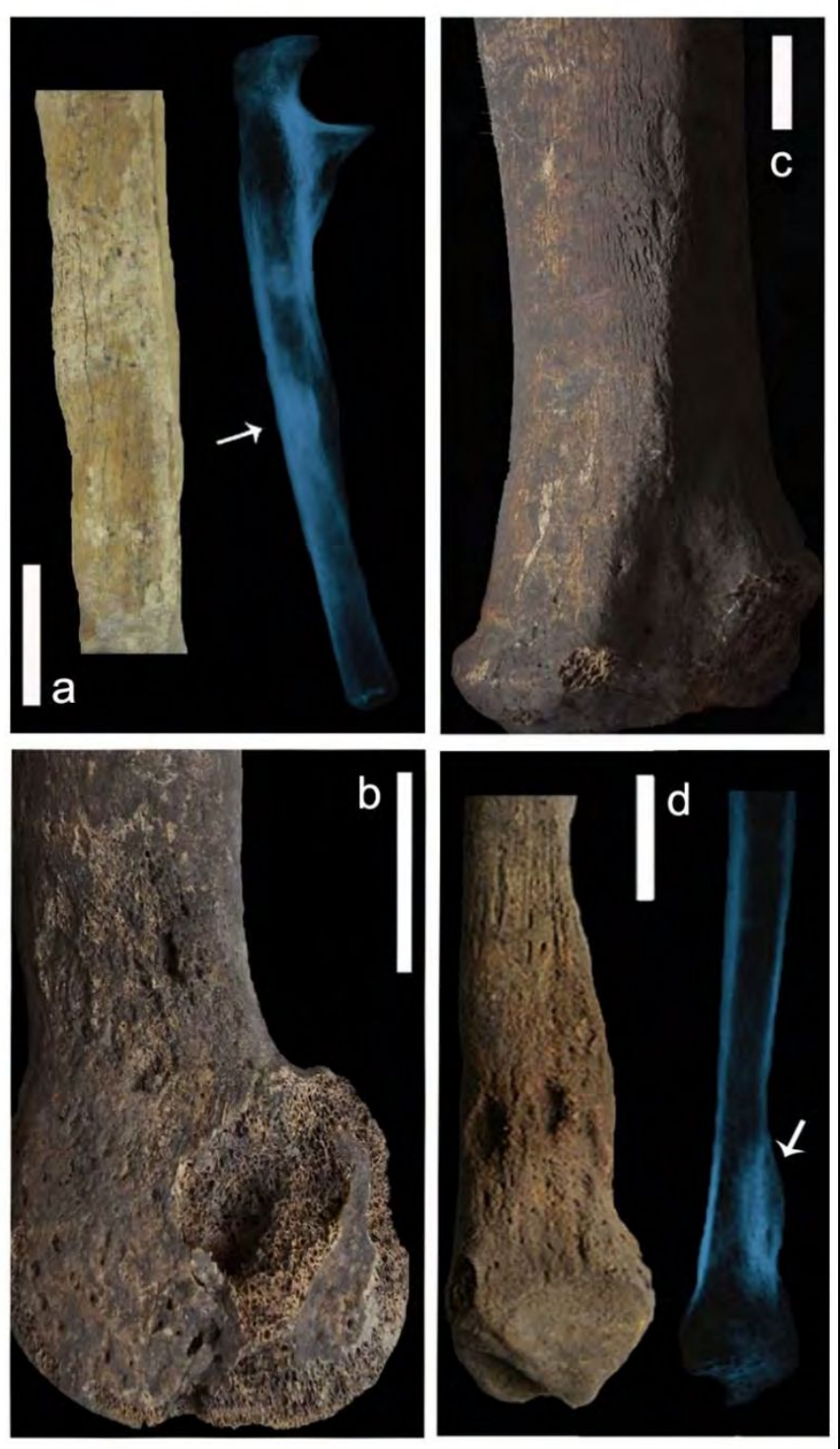

Figura 7.18. Lesiones de estrés inespecífico en la muestra del DI: a) diáfisis medial del cúbito derecho de T1-PG-43 1/2 y Rx; b) diáfisis distal del fémur izquierdo de EC-6441; c) diáfisis distal de la tibia izquierda de EC-6453; d) diáfisis distal del peroné izquierdo de AS-6480 y Rx. Escalas $=2 \mathrm{~cm}$.

Las descripciones de las lesiones registradas evidencian la presencia de RP en distintos huesos y con diferentes estadios de remodelación. Entre estos casos presentados cobra relevancia específicamente el individuo T1-LA-69, debido a que numerosos elementos $(n=9)$ de su esqueleto tienen RP; no sólo se vieron afectados huesos largos del miembro superior e inferior, sino también huesos de la cintura escapular y pélvica y un tarso. En casi todos ellos, las RP tienen la misma característica: capa delgada de tejido nuevo por sobre el cortical. Si bien, tal como 
fuera mencionado previamente, conocer el origen de las RP es una tarea difícil debido a su multicausalidad, es posible descartar en este caso la estasis venosa, tumores y traumas como los orígenes de tales lesiones, dado que son varios los huesos afectados. Procesos infecciosos, condiciones genéticas o patologías de índole sistémico en general, podrían ser las causantes de estas RP.

\section{4 Lesiones traumáticas}

\subsubsection{Delta Superior del río Paraná}

Se analizaron 1109 elementos óseos pertenecientes al menos a 37 individuos. Sólo un hueso fue registrado con lesión de tipo traumática, representando el $0,1 \%$ de los elementos. A nivel individual, corresponde al 2,7\% de la muestra (Tabla 7.10). Estadísticamente, no existe asociación entre la presencia de este tipo de lesiones y el sexo de los individuos (a nivel individual: $p=0,4$; a nivel de elementos: $p=1$ ). En cuanto a la edad, tampoco se obtuvieron resultados que indiquen relación de dependencia (subadultos vs. adultos; a nivel individual: $p=1$; a nivel óseo: $p=1)$.

Tabla 7.10. Prevalencias de lesiones traumáticas en la muestra del DS.

\begin{tabular}{|c|c|c|c|c|c|}
\hline & \multicolumn{2}{|c|}{ Individuos } & \multicolumn{2}{|c|}{ Elementos óseos } \\
\hline & & $A / O$ & $\%$ & $\mathrm{~A} / \mathrm{O}$ & $\%$ \\
\hline \multirow{10}{*}{ 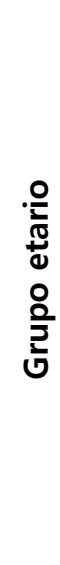 } & Perinato & $0 / 3$ & 0 & $0 / 14$ & 0 \\
\hline & Infante & $0 / 4$ & 0 & $0 / 7$ & 0 \\
\hline & Niño & $0 / 3$ & 0 & $0 / 11$ & 0 \\
\hline & Adolescente & $0 / 7$ & 0 & $0 / 270$ & 0 \\
\hline & Subadulto & - & - & $0 / 10$ & 0 \\
\hline & Adulto joven & $0 / 3$ & 0 & $0 / 52$ & 0 \\
\hline & Adulto medio & $0 / 2$ & 0 & $0 / 165$ & 0 \\
\hline & Adulto mayor & $1 / 1$ & 100 & $1 / 121$ & 0,8 \\
\hline & Adulto in. & $0 / 14$ & 0 & $0 / 425$ & 0 \\
\hline & In. & - & - & $0 / 34$ & 0 \\
\hline \multirow{4}{*}{ ֻ } & $\mathbf{F}$ & $1 / 8$ & 12,5 & $1 / 486$ & 0,2 \\
\hline & $M$ & $0 / 10$ & 0 & 0 / 392 & 0 \\
\hline & In. & $0 / 19$ & 0 & $0 / 231$ & 0 \\
\hline & Total & $1 / 37$ & 2,7 & $1 / 1109$ & 0,1 \\
\hline
\end{tabular}

Referencias: $\mathrm{A}=$ afectado; $\mathrm{O}=$ observado; In.=indeterminado; $\mathrm{F}=$ femenino; $\mathrm{M}=$ masculino. 
La lesión se registró en un adulto mayor femenino (LTC1-P3) que presenta en el frontal (por encima de la glabela) una depresión circular a ovoide (19,9 x 20,1 $\mathrm{mm}$ ), de escasa profundidad y sin alteración del tejido óseo (Figura 7.19). El trauma no fue letal para el individuo.

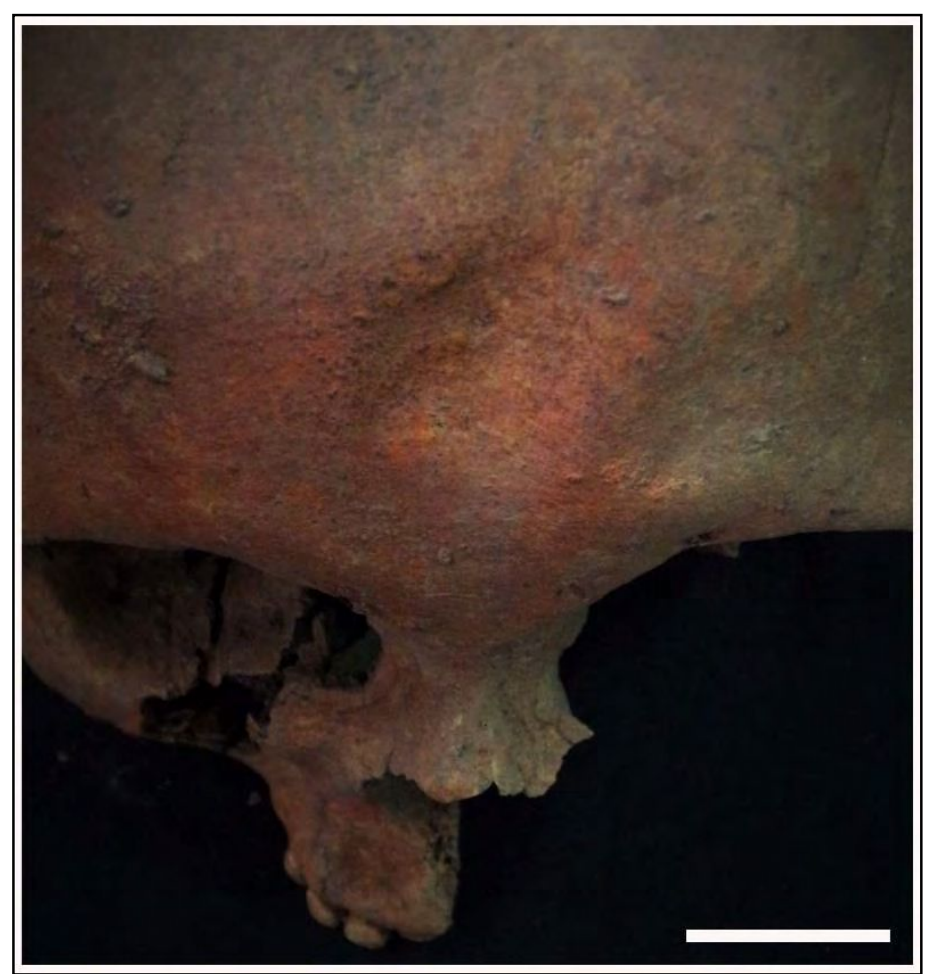

Figura 7.19. Traumatismo en el frontal de LTC1-P3. Escala $=3 \mathrm{~cm}$.

\subsubsection{Cuenca inferior del río Uruguay}

Se analizaron 816 elementos óseos de al menos 72 individuos. El 4,2\% de los individuos $(n=3)$ presentó una lesión ósea de tipo traumática; a nivel óseo esto representa el 0,4\% (Tabla 7.11). Los tres individuos afectados son masculinos; sin embargo no existe asociación estadística entre las lesiones y el sexo $(p=0,2)$. Con respecto a la edad, los traumas se registraron en un adolescente, un adulto joven y un adulto indeterminado; tampoco existe dependencia entre la presencia de las lesiones y la edad (subadultos vs. adultos; a nivel individual: $p=0,1$; a nivel óseo: $p=0,2)$. A continuación se detallan las lesiones. 
Tabla 7.11. Prevalencias de lesiones traumáticas en la muestra de CIRU.

\begin{tabular}{|c|c|c|c|c|c|}
\hline & \multicolumn{2}{|c|}{ Individuos } & \multicolumn{2}{|c|}{ Elementos óseos } \\
\hline & & $\mathrm{A} / \mathrm{O}$ & $\%$ & $\mathrm{~A} / \mathrm{O}$ & $\%$ \\
\hline \multirow{6}{*}{ 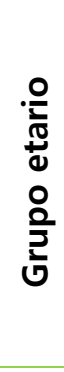 } & Infante & $0 / 4$ & 0 & $0 / 25$ & 0 \\
\hline & Niño & $0 / 7$ & 0 & $0 / 46$ & 0 \\
\hline & Adolescente & $1 / 3$ & 33,3 & $1 / 65$ & 1,5 \\
\hline & Adulto joven & $1 / 11$ & 9,1 & $1 / 204$ & 0,5 \\
\hline & Adulto medio & $0 / 4$ & 0 & $0 / 86$ & 0 \\
\hline & Adulto in. & $1 / 43$ & 2,3 & $1 / 390$ & 0,2 \\
\hline \multirow{4}{*}{ 艾 } & $\mathbf{F}$ & $0 / 15$ & 0 & $0 / 240$ & 0 \\
\hline & $M$ & $3 / 18$ & 16,7 & $3 / 268$ & 1,1 \\
\hline & In. & $0 / 39$ & 0 & $0 / 308$ & 0 \\
\hline & Total & $3 / 72$ & 4,2 & $3 / 816$ & 0,4 \\
\hline
\end{tabular}

Referencias: $\mathrm{A}=$ afectado; $\mathrm{O}=$ observado; In.=indeterminado; $\mathrm{F}=$ femenino; $\mathrm{M}=$ masculino.

- CL2-71 - adulto joven (25-34 años), masculino: el cráneo presenta tres lesiones. Una se ubica en el parietal derecho; consiste en una depresión ovoidecircular, de bordes bien delimitados $(5,51 \times 4,73 \mathrm{~mm})$, de poca profundidad y sin reacción ósea visible (Figura 7.20a). Otra se localiza en el parietal izquierdo; es una depresión ovalada, de dimensiones mayores a la anterior $(32,1 \times 15,8 \mathrm{~mm})$, de poca profundidad y se distingue cierta reacción ósea ya remodelada (Figura 7.20b). Finalmente, en el occipital se observa otra depresión ovalada ( 13 x 8,8 $\mathrm{mm}$ ), de poca profundidad y sin reacción ósea (Figura 7.20c).

- T1-CNM-83 - adulto in., masculino: en el cráneo se distinguió, en el parietal izquierdo, una depresión ovalada $(15,3 \times 7,9 \mathrm{~mm})$, de poca profundidad y con pequeños poros en su interior; algunos en proceso de cierre (Figura 7.20d).

o T2-CSM-82 - adolescente (18-21 años), masculino: el cráneo presenta una lesión traumática en el occipital por encima de la cresta nucal; es una depresión ovalada $(8,9 \times 5 \mathrm{~mm})$, de poca profundidad y sin reacción ósea (Figura 7.20e).

Dadas las características de las tres lesiones, ninguna resultó letal para los individuos y habrían ocurrido cierto tiempo anterior a su muerte. Según las ubicaciones en las bóvedas craneanas, las depresiones se localizan en la norma posterior, a excepción de la que se ubica en el parietal derecho de CL2-71 (norma lateral). 


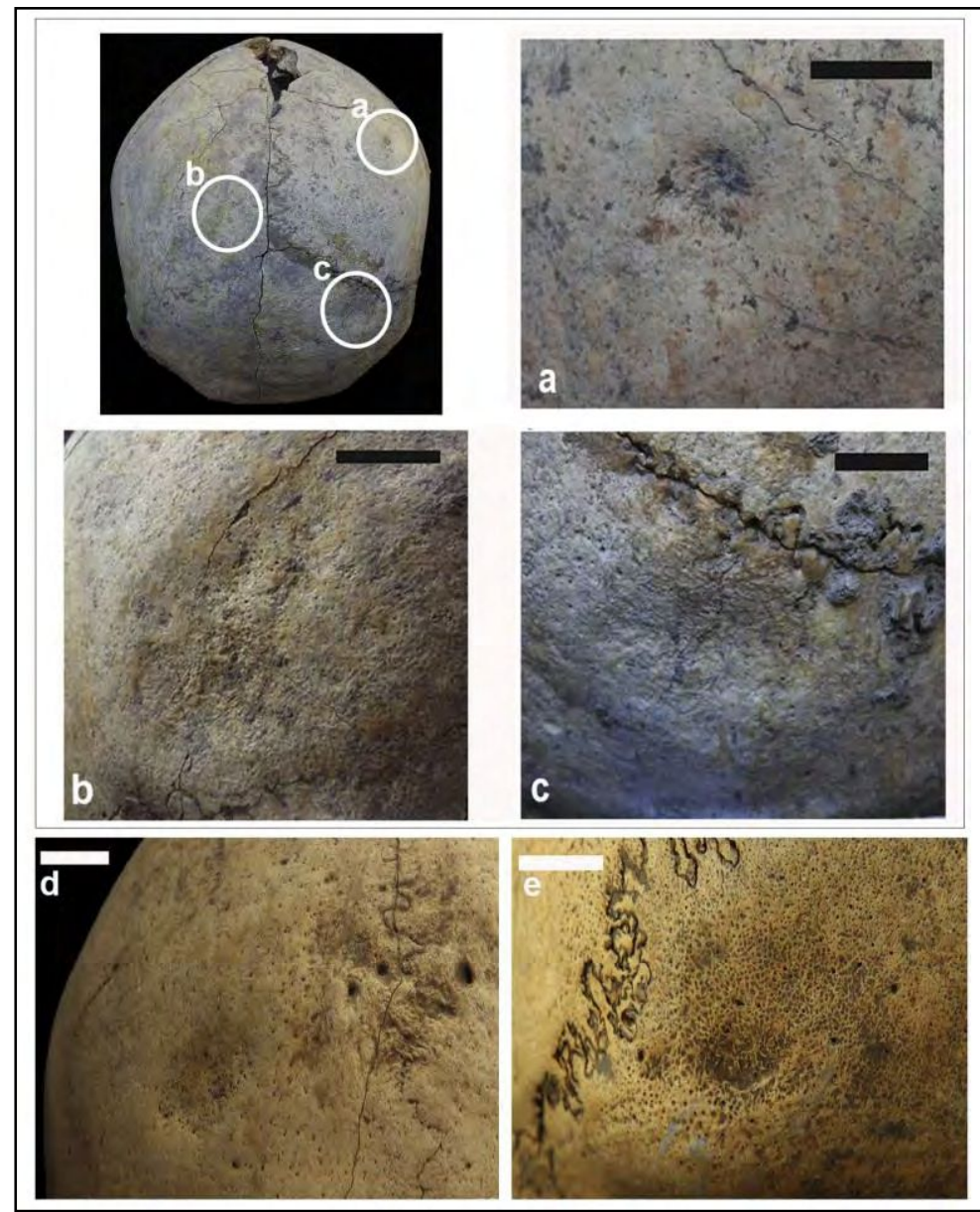

Figura 7.20. Lesiones traumáticas registradas en la muestra de CIRU: a) parietal derecho de CL2-71; b) parietal izquierdo de CL2-71; c) occipital de CL2-71; d) parietal izquierdo de T1CNM-83; e) occipital de T2-CSM-82. Escalas $=2 \mathrm{~cm}$.

\subsubsection{Delta Inferior del río Paraná y ambientes litorales adyacentes}

Se analizó un total de 619 elementos óseos pertenecientes a un número mínimo de 16 individuos. Fueron registradas dos lesiones traumáticas, que representan el 0,3\% de la muestra a nivel óseo y el 3,8\% a nivel individual (Tabla 7.12). Los individuos afectados son adultos de los dos sexos. Estadísticamente, no existe asociación entre la presencia de este tipo de lesiones y el sexo (a nivel individual: $p=1$; a nivel óseo: $p=1$ ) y tampoco con la edad (subadultos vs. adultos; a nivel individual: $p=1$; a nivel óseo: $p=1$ ). A continuación se detallan las lesiones. 
Tabla 7.12. Prevalencias de lesiones traumáticas en la muestra del DI.

\begin{tabular}{|c|c|c|c|c|c|}
\hline & \multicolumn{2}{|c|}{ Individuos } & \multicolumn{2}{|c|}{ Elementos óseos } \\
\hline & & A/O & $\%$ & $A / O$ & $\%$ \\
\hline \multirow{7}{*}{ 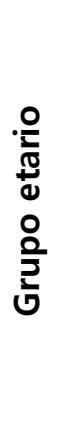 } & Niño & $0 / 1$ & 0 & $0 / 1$ & 0 \\
\hline & Adolescente & $0 / 5$ & 0 & $0 / 19$ & 0 \\
\hline & Subadulto & - & - & $0 / 6$ & 0 \\
\hline & Adulto joven & $0 / 5$ & 0 & $0 / 20$ & 0 \\
\hline & Adulto medio & $0 / 1$ & 0 & $0 / 1$ & 0 \\
\hline & Adulto in. & $2 / 41$ & 4,9 & 2 / 339 & 0,6 \\
\hline & In. & - & - & 0 / 241 & 0 \\
\hline \multirow{4}{*}{$\stackrel{\stackrel{ా}{x}}{\stackrel{\omega}{\sim}}$} & $\mathbf{F}$ & $1 / 10$ & 10 & $1 / 46$ & 2,2 \\
\hline & M & $1 / 21$ & 4,8 & $1 / 36$ & 2,8 \\
\hline & In. & $0 / 22$ & 0 & $0 / 537$ & 0 \\
\hline & Total & $2 / 53$ & 3,8 & $2 / 619$ & 0,3 \\
\hline
\end{tabular}

Referencias: $\mathrm{A}=$ afectado; $\mathrm{O}=$ observado; In.=indeterminado; $\mathrm{F}=$ femenino; $\mathrm{M}=$ masculino.

o T1-PG-28 - adulto in., femenino: la tibia izquierda presenta una fractura unicortical sobre la cresta tibial, en la diáfisis medial. Esta fractura produjo un leve arqueamiento antero-posterior del hueso, y según la imagen radiográfica de perfil, aún se encontraba en proceso de curación (Figura 7.21). En su obra de 1911, Torres hace mención a este elemento: "presenta, en la mitad de la diáfisis, al parecer una fractura en sentido transversal á la crista anterior, y en los contornos de la fractura se nota un aumento de la substancia ósea, de poca consideración" (1911: 164).

- T1-PG-37 - adulto in., masculino: en el cráneo, específicamente en el parietal izquierdo hacia el frontal, se observa una depresión ovalada (18,5 x $15 \mathrm{~mm})$, de poca profundidad, con escasas estrías en el tejido óseo (Figura 7.22). En la descripción ofrecida por Torres (1911), hace referencia a que este cráneo presenta "por la palpación, varias hendiduras, debidas posiblemente a un golpe" en el parietal izquierdo (1911: 128).

Ninguna de las dos lesiones relevadas puso en riesgo la vida de los individuos y habrían ocurrido cierto tiempo anterior a su muerte, dado el estado de remodelación en el que se encuentran. 


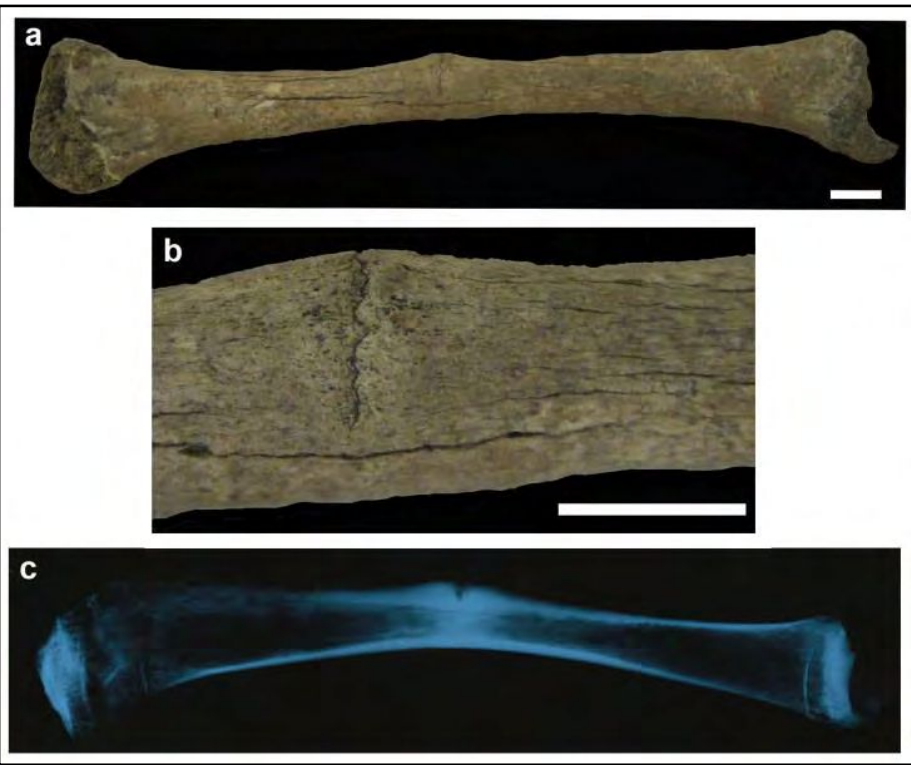

Figura 7.21. Lesión traumática en la tibia izquierda de T1-PG-28: a) cara posterior; b) detalle de la fractura en la diáfisis medial; c) imagen radiográfica. Escala $=2 \mathrm{~cm}$.

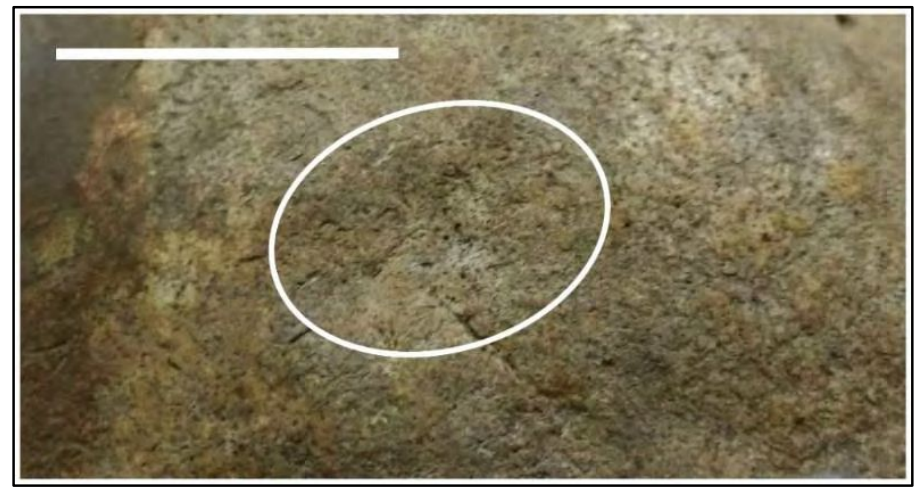

Figura 7.22. Lesión traumática en el parietal izquierdo de T1-PG-27. Escalas $=2 \mathrm{~cm}$.

\subsection{Integración y discusión de los resultados obtenidos}

En la Tabla 7.13 se resumen los resultados de cada uno de los tipos de lesiones óseas relevados en las tres muestras bioarqueológicas. A continuación se discuten los datos presentados atendiendo a su etiología y las inferencias que de ellos se desprenden. 
Tabla 7.13. Síntesis de los resultados obtenidos en las muestras bioarqueológicas.

\begin{tabular}{|c|c|c|c|c|}
\hline & & DS & CIRU & DI \\
\hline \multirow{3}{*}{$\begin{array}{l}0 \\
\text { ㄱ } \\
\text { 옾 }\end{array}$} & Individuos (\%) & 18,2 & 11,5 & 0 \\
\hline & Edad (asoc. est.) & no & no & - \\
\hline & Sexo (asoc. est.) & no & no & - \\
\hline \multirow{4}{*}{ 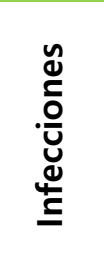 } & Individuos (\%) & 5,4 & 1,4 & 0 \\
\hline & Elementos óseos (\%) & 2,2 & 0,1 & 0 \\
\hline & Edad (asoc. est.) & sí (adultos) & no & - \\
\hline & Sexo (asoc. est.) & sí (femeninos) & - & - \\
\hline \multirow{4}{*}{ 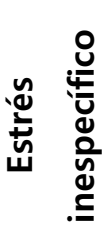 } & Individuos (\%) & 18,9 & 11,1 & 11,3 \\
\hline & Elementos óseos (\%) & 1,1 & 1,2 & 2,6 \\
\hline & Edad (asoc. est.) & sí (adultos) & no & no \\
\hline & Sexo (asoc. est.) & no & no & sí (femeninos) \\
\hline \multirow{4}{*}{ 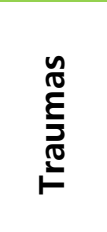 } & Individuos (\%) & 2,7 & 4,2 & 3,8 \\
\hline & Elementos óseos (\%) & 0,1 & 0,4 & 0,3 \\
\hline & Edad (asoc. est.) & no & no & no \\
\hline & Sexo (asoc. est.) & no & no & no \\
\hline
\end{tabular}

Referencias: asoc. est.=asociación estadística

La hiperostosis porótica y la cribra orbitalia constituyen expresiones óseas de hiperplasia medular. La presencia de estas lesiones en conjuntos osteológicos es usada como un indicador de la salud y nutrición de las poblaciones, y si bien su etiología puede deberse a diferentes condiciones, se las vincula principalmente con la anemia (Stuart-Macadam 1989; Aufderheide y Rodríguez Martín 1998; Ortner 2003; Blom et al. 2005; Roberts y Manchester 2005; Walker et al. 2009). Este tipo de lesiones fueron registradas en bajas a moderadas prevalencias en las muestras del DS y CIRU, y no se reportó ningún caso en la muestra del DI. Estadísticamente, las diferencias de las prevalencias en las tres muestras no son significativas (DS vs. CIRU: $p=0,6 ;$ DS vs. DI: $p=0,08 ; \mathrm{CIRU}$ vs. DI: $p=0,1)$. Las lesiones de HP y/o CO observadas estaban activas en tres individuos (un infante -DS-; un adolescente y un adulto masculinos - CIRU) y remodeladas en dos casos (adolescente femenino -DSy adulto joven femenino - $\mathrm{CIRU}$ ). La relación entre HP y CO aún no se comprende completamente. Por el momento, se considera como una posible explicación que la CO es la expresión temprana de la HP y que ésta podría ser indicio de anemia a 
largo plazo (Stuart-Macadam 1985; Walker 1986; Blom et al. 2005). Si bien los casos reportados en esta tesis constituyen una muestra pequeña, los dos adultos con HP podrían haber padecido anemia crónica, principalmente el adulto con las lesiones activas en la bóveda al momento de la muerte.

Diversos tipos de anemias pueden ser las causantes de la hiperplasia medular. Las anemias hereditarias (por ej. talasemia, anemia de células falciformes) han sido reportadas en poblaciones específicas, ninguna del continente americano antes de la llegada de los europeos (Aufderheide y Rodríguez-Martín 1998; Ortner 2003; Blom et al. 2005; Walker et al. 2009). Por lo tanto, este tipo de condición no es aplicable a las muestras bajo estudio. Ahora bien, existen diferentes formas no genéticas en las que puede ocurrir una baja concentración de hemoglobina en sangre. En la literatura bioarqueológica se ha asociado casi de forma directa la presencia de estas lesiones con la deficiencia de hierro en la dieta (Stuart-Macadam 1985; Ortner 2003). Sin embargo, trabajos posteriores han desestimado tal explicación, dado que la deficiencia de hierro no sólo puede ser causada por una ingesta empobrecida, mala absorción o hemorragias, sino también por procesos fisiológicos que aumentan su utilización. Es precisamente esto último lo que ocurriría con la hiperplasia medular, por lo que la deficiencia de hierro es el resultado y no su causa (Walker et al. 2009; Rostchild 2012). En este contexto, han cobrado relevancia otras explicaciones, como la ofrecida por Walker y colaboradores (2009) quienes proponen a la anemia megaloblástica (que causa la muerte prematura de glóbulos rojos y aumento de la eritropoyesis) en la etiología de la HP.

El déficit dietario crónico y la malabsorción de vitamina B12 y/o B9 son las causas más comunes de anemia megaloblástica (Walker et al. 2009). Debido a que el cuerpo humano no sintetiza la mayoría de las vitaminas esenciales para el metabolismo, estos micronutrientes tienen que ser incorporados a través del consumo de alimentos que los contienen. La vitamina B9 suele encontrarse por ejemplo en vegetales de hojas verdes, legumbres y vísceras de animales, mientras que la vitamina B12 en la mayoría de productos de origen animal (incluidos los peces). De acuerdo al amplio registro zooarqueológico que acompaña a los conjuntos osteológicos bajo estudio, el cual indica el consumo de mamíferos 
acuáticos y terrestres, aves y pescados (Bastourre 2014, 2017), no se habría visto comprometido el consumo de vitaminas (así como tampoco el de hierro). Esto también se evidencia a partir de los datos isotópicos obtenidos de muestras de huesos humanos de los sitios analizados (consumo de proteína animal y plantas $C_{3}$ ) y de los estudios arqueobotánicos en los sitios LTC1 y LDLG2 (véase en detalle Capítulos 5; Bonomo et al. 2017a).

Más allá de lo recién expuesto en cuanto a la dieta, es importante mencionar lo siguiente. Por un lado, debido a la plasticidad ósea que presentan los infantes (hasta los cuatro años), es más común que se genere erosión en el diploe frente a una hiperplasia medular a esta edad que en la adultez. Por otro lado, los adultos, al poseer una considerable reserva hepática de vitamina B12, las consecuencias óseas de una deficiencia en el consumo de este micronutriente se desarrollan de forma lenta. En cambio, los infantes poseen escasas reservas y los síntomas de tal deficiencia se presentan más rápido. Por lo tanto, la presencia de HP y $\mathrm{CO}$ en adultos (generalmente en estados remodelados) suele entenderse como evidencia del estrés metabólico que padeció el individuo durante su infancia (Stuart-Macadam 1985; Walker 1986). Esta etapa de crecimiento y desarrollo podría coincidir con la lactancia y el proceso de destete. Las mujeres, durante la menstruación, embarazo y lactancia suelen tener mayor riesgo de padecer anemia; si presentan bajos niveles de vitamina B12 durante el embarazo y/o la lactancia, esta deficiencia se transmite a los hijos. La posibilidad de que los infantes desarrollen anemia se incrementa cuando la lactancia se prolonga en el tiempo, disminuye la calidad de la leche materna y/o disminuyen también las reservas de vitamina B12 de la madre (Katzenberg et al. 1996; Walker et al. 2009). En el proceso de destete (introducción de otros alimentos y reducción gradual de la leche materna), el infante se enfrenta a la posibilidad de ingerir alimentos y agua contaminados con diversos patógenos, lo que implica la posibilidad de contraer infecciones parasitarias gastrointestinales -principalmente por transmisión vía oral y fecal (Katzenberg et al. 1996). Este tipo de infecciones es otra de las causas que producen anemias adquiridas, incluso que pueden agravar la anemia megaloblástica por deficiencia de vitamina B12 (Walker et al. 2009). Las condiciones de vida juegan un rol preponderante en el desarrollo de estas enfermedades diarreicas, como por 
ejemplo el tipo de asentamiento, la disponibilidad de agua potable, la higiene personal y la relación espacial con residuos alimenticios (Katzenberg et al. 1996; Walker et al. 2009).

De acuerdo a lo expuesto, se propone entonces que la acción sinérgica de diversos factores habría contribuido al desarrollo de anemia en estos individuos: empobrecimiento nutritivo de la leche materna por lactancia prolongada; proceso de destete con la incorporación de alimentos y agua contaminados; contextos de asentamientos con larga ocupación y condiciones de saneamiento e higiene que favorecieran la presencia de enfermedades infecciosas gastrointestinales. Los análisis paleoparasitológicos realizados en muestras de sedimento de la región pélvica y sacra de entierros humanos de los sitios LTC1 y LDLG2, han arrojado resultados negativos que permitan aportar a esta discusión (Dra. Beltrame, UNMdP, com. pers. 2018).

En relación con la presencia concreta de enfermedades infecciosas, en las muestras del DS y CIRU se registraron tres individuos adultos (dos femeninos y un indeterminado) con lesiones que, de acuerdo a su ubicación, características morfológicas e información clínica, se diagnosticaron como osteomielitis y treponematosis. En la muestra del DS el porcentaje de individuos afectados es mayor que en la muestra del CIRU, pero la diferencia no es significativa $(p=0,3)$. Por su parte, en la muestra del DI no se observaron elementos óseos con lesiones de este tipo de etiología. Sin embargo, para uno de los sitios analizados del DI (T1-PG) se cuenta con las descripciones de Torres (1911) sobre las lesiones infecciosas de un cráneo hallado por el autor; este elemento no pudo ser localizado al consultar la colección osteológica de este sitio en la División Antropología del Museo de La Plata. Se trata de la bóveda craneana (catalogada bajo el número 12 (38), de un probable adulto femenino, que si bien presenta toda la mitad posterior afectada, es en el parietal izquierdo donde el autor distingue mejor la lesión, a la que denomina "necrosis" y detalla de la siguiente forma:

"...en los contornos de la parte afectada se observa alteraciones de importancia, recubiertas por la lámina externa que indican un proceso de formación gradual. El volumen del hueso aumenta, y donde dicho volumen es efectivamente más considerable, con relación á los otros huesos del 
cráneo, la rarefacción del diploe no puede ser más evidente, y en ciertas partes desaparece totalmente" (1911: 130-131).

Asimismo, menciona la presencia de "osteítis del maxilar superior derecho, en sus caras externa é interna, y la del malar, especialmente en el proceso frontoesfenoidal. Esta osteítis se caracteriza, también, por venir asociada á ella un proceso proliferante" (1911: 130). Al tratar de encontrar explicación a estas lesiones de la bóveda, Torres menciona su analogía con un caso estudiado por R. Stegmann y revisado por R. Lehmann-Nitsche. El primer investigador considera dos posibles diagnósticos: una diploítis infecciosa o una osteomielitis extensa de la bóveda craneana. Sin embargo, Lehmann-Nitsche menciona que tal diagnóstico "no está determinado con precisión". Finalmente, Torres concluye, en relación con el cráneo, que "esta osteomielitis difusa, con proceso proliferante del malar derecho, es, por ahora, de origen desconocido" (1911: 133). Igualmente, el autor ofrece una única fotografía del cráneo (Torres 1911; Figura 7.23), en cuyo epígrafe escribe "¿osteomielitis gomosa de la bóveda craneana; deploitis infecciosas?" (1911: 130). En cuanto a los huesos largos asociados con este cráneo (se desconoce si pertenecen al mismo individuo o no), Torres menciona las tibias para las que no se reporta ningún tipo de patología (1911: 164).

A juzgar por la característica necrótica y gumatosa de la lesión en la bóveda y por la única fotografía presentada por Torres, el caso hace recordar a los reportados por diversos investigadores para patologías treponémicas (por ej., Hackett 1975, 1976; El-Najjar 1979); así como también a las lesiones destructivas activas observadas en el cráneo procedente del sitio SLM (Figura 7.13.a, b). Lamentablemente no se cuenta con más información que la antes mencionada sobre las lesiones en el malar de este cráneo nº12 (38), que permitan evaluarlas de forma integral junto con las de la bóveda. A partir de la información disponible, pueden asociarse tales lesiones con un proceso infeccioso, que posiblemente puedan corresponder a treponematosis. Aun así, este diagnóstico debe considerarse con cautela dado que sólo se basa en la descripción y fotografía brindada por Torres. 


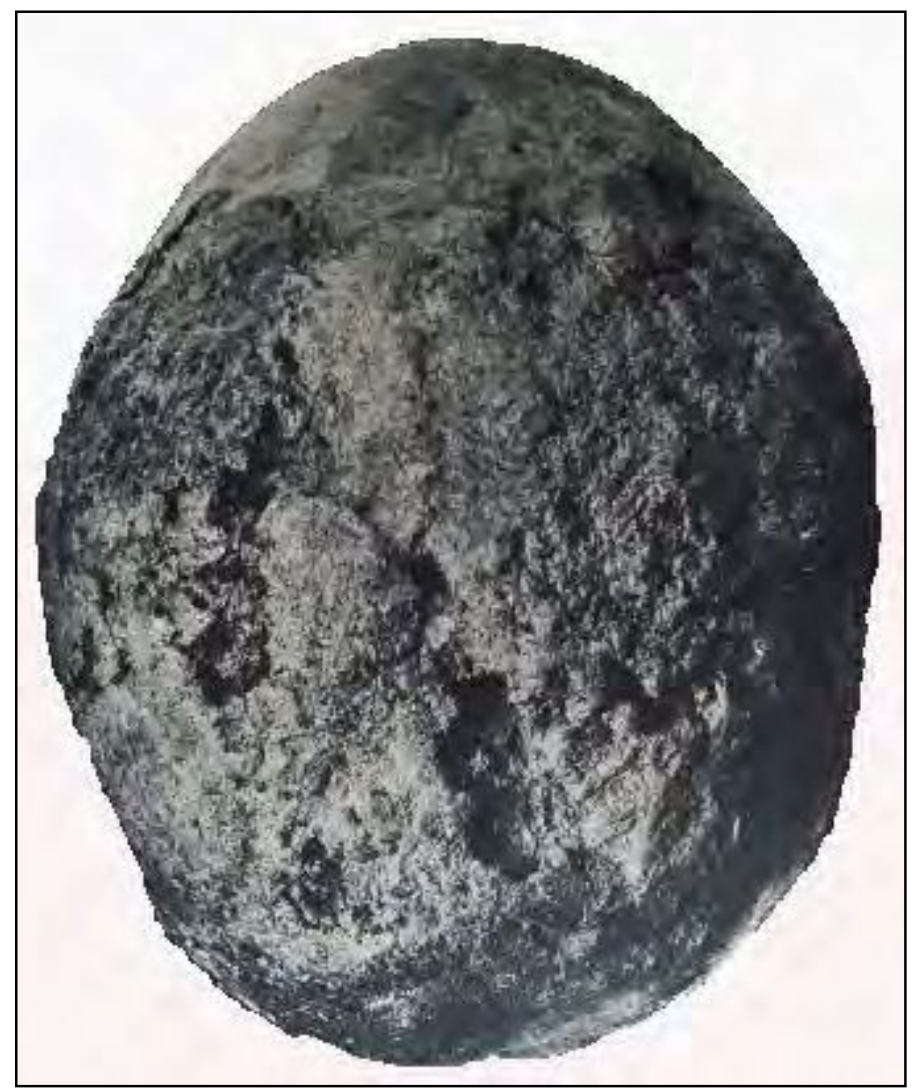

Figura 7.23. Lesión infecciosa en el cráneo n¹2 (38) de T1-PG (tomado de Torres 1911: 131).

Además de este cráneo, en la obra de Torres (1911) se alude al hallazgo en el mismo sitio de una tibia izquierda (catalogada con el número 431/2 $M$; correspondería a un adulto masculino) que presenta "signos de osteomielitis; la tibia del costado derecho de este individuo no ofrece, al parecer, un carácter semejante" (1911: 164). Este hueso tampoco fue localizado al consultar la colección. Si bien el autor ofrece tres fotografías de la tibia, en las que pueden observase sus caras anterior, medial y posterior (1911: 165-167), en ellas no es posible distinguir los signos infecciosos mencionados. En los otros elementos óseos catalogados bajo este mismo número (clavículas, húmeros, cúbito izquierdo, radios, coxales y fémures) no se describen lesiones de tipo infecciosas. En el cúbito derecho, que sí pudo ser localizado y analizado, se observó una lesión de estrés inespecífico caracterizada por una obstrucción casi total de la cavidad medular (Figura 7.18a). Dada la imposibilidad de conocer con precisión las lesiones en la tibia, se desconoce si lo registrado en el cúbito pueda estar o no relacionado con la osteomielitis a la que alude Torres. 
En definitiva, pese a que en la muestra del DI no se observaron lesiones infecciosas, a partir de la consulta de la publicación de Torres (1911) fue posible conocer que al menos dos de los individuos enterrados en ese sitio presentaron este tipo de patologías. Estos casos se suman a las bajas prevalencias obtenidas para las otras dos muestras bioarqueológicas bajo estudio.

Las lesiones registradas en el adulto femenino LTC1-P4 (DS) y el adulto SLM65 (CIRU) corresponderían a infecciones treponémicas, probablemente no venéreas. En ambos, además, se distingue la cronicidad del padecimiento. La posibilidad de alcanzar un diagnóstico como estos tiene la ventaja de saber cuáles habrían sido algunos de los síntomas que padecieron los individuos, lo cual resulta un abordaje interesante no sólo para conocer las condiciones de vida de esas personas sino también su entorno social. En el caso de Yaws, uno de los síndromes no venéreos, la lesión inicial ocurre en el lugar de la infección y dentro de cinco a ocho semanas después de la exposición. Esta lesión, que puede llegar a ulcerarse, se cura dentro de los seis meses posteriores. Luego de un período de latencia, ya en la etapa secundaria, surgen lesiones similares pero extendidas en distintas partes del cuerpo, y suelen estar acompañadas con la despigmentación cutánea en esas áreas. En esta etapa pueden comenzar a verse afectados los huesos. Ya en la etapa terciaria, que se manifiesta generalmente varios años después, las lesiones cutáneas y óseas se vuelven más severas y duraderas (Powell y Cook 2005). En el caso de la sífilis endémica, las primeras lesiones se pueden manifestar en distintas partes del cuerpo, como por ejemplo en la cavidad orofaríngea, en las comisuras de la boca y en pliegues húmedos del cuerpo (axilas, ingle, codos internos). El desarrollo posterior suele ser similar a Yaws, en tanto los períodos de latencia y el mayor daño óseo principalmente en la etapa terciaria (Powell y Cook 2005). Teniendo en cuenta estas manifestaciones, se puede pensar que, a diferencia de otras enfermedades que pudieron haber padecido los individuos estudiados, ésta era claramente visible -dadas las lesiones cutáneas que genera- por el entorno social del afectado. En un estudio biocultural de un esqueleto con sífilis venérea procedente de un sitio de Jamaica, se menciona que la población nativa conocía la enfermedad $y$, probablemente por su asociación con un 'carácter divino', se les prestaba considerable atención a las personas infectadas, tanto en la vida como en 
la muerte (Santos et al. 2013). Por el contrario, desde el descubrimiento en el siglo XVI de cómo se transmite la sífilis venérea, las personas con este síndrome solían ser estigmatizadas por su conexión con la actividad sexual (Powell y Cook 2005: 27). En el caso de los grupos humanos bajo estudio en esta tesis, conocer cómo trataban a las personas infectadas resulta imposible; aun así pueden plantearse dos grandes situaciones: una en el que las personas de su alrededor le ayuden y brinden un cuidado especial acorde a sus padecimientos y otra en el que el individuo se vea excluido de su grupo o tratado diferencialmente por su aspecto físico. En el caso concreto de LTC1-P4, su entierro no presenta diferencias sustanciales en relación con los otros individuos inhumados en el mismo lugar que permitan evaluar lo antes planteado.

Desde el siglo $\mathrm{XVI}$, el origen de la treponematosis, y sus síndromes ha cobrado interés entre diversos investigadores $y$, desde entonces, se han planteado y discutido distintas hipótesis. Como bien detallan Powell y Cook (2005: 31-37), las cuatro explicaciones fueron: la colombina (origen en el Nuevo Mundo, con llegada a Europa a partir de los viajes de Colón); la precolombina (ya existía en el Viejo Mundo antes de 1492); la unitaria (no son enfermedades distintas sino expresiones de una misma enfermedad); y la evolutiva. Esta última, la hipótesis más reciente, deja sin efecto a las primeras al proponer que los cuatro síndromes treponémicos surgieron en distintos momentos en América, Asia, África y Europa. A partir de esta tesis, el hallazgo de individuos afectados con treponematosis (al menos uno con fechado de $801 \pm 46$ años AP -LTC1-P4) adquiere relevancia al constituir una evidencia pre-colombina sudamericana más y sobre todo si se tiene en cuenta el escaso registro de esta patología no sólo en el Noreste Argentino, sino también en Argentina (véase discusión en Capítulo 8).

Por otro lado, al menos dos individuos más habrían estado expuestos a otro tipo de procesos infecciosos. Se trata de la osteomielitis reportada por Torres en un adulto masculino de T1-PG (DI) y de la osteomielitis de un adulto femenino de LTC1 (DS). En cuanto al último caso, a partir de analizar la totalidad del esqueleto y del diagnóstico diferencial, es probable que se trate de osteomielitis hematógena. De tratarse de este tipo de infección, el individuo la habría contraído en sus primeros años de vida y luego de un período de latencia sufrió una reactivación de 
la misma. Durante la niñez, en una etapa aguda de la osteomielitis, suelen presentarse los siguientes síntomas clínicos: fiebre, irritabilidad, signos de inflamación local, hinchazón, enrojecimiento y dolor; así como también la negativa a mover la extremidad comprometida si el dolor persiste (Ikpeme et al. 2010). Teniendo en consideración esto, es probable que haya requerido una atención especial el cuidado de este niño por parte de los adultos a cargo. Ya en adultos, puede ocurrir fiebre en bajo grado, escalofríos, hinchazón, enrojecimiento y calor local (Ikpeme et al. 2010).

Las evidencias de enfermedades infecciosas en las tres muestras bioarqueológicas, sugieren que otros individuos pudieron padecerlas pero no de forma suficientemente crónica como para generar lesiones como las relevadas. En este sentido, algunas de las reacciones periósticas observadas en las tres muestras podrían deberse a ello. Como ya fue expuesto en el Capítulo 4, se las consideran lesiones inespecíficas por las numerosas causas que pueden generarlas. En un intento de explicarlas, se discutieron posibles diagnósticos para alguna de ellas, según su morfología, ubicación en el elemento y distribución en el esqueleto. En algunos casos (por ej. T1-LA-69, DI) es probable que algún proceso sistémico haya producido la reacción del periostio como para desarrollar nuevo hueso en varios elementos del esqueleto. Mientras que, en otros individuos, con un único hueso afectado, una de las posibles causas que pudo haber generado tal lesión son los traumas. Las prevalencias observadas entre las tres muestras no presentan diferencias significativas, tanto a nivel individual (DS vs. CIRU: $\chi 2=2,6$; DS vs. DI: $\chi^{2}=0,8 ;$ CIRU vs. DI: $\left.\chi^{2}=0,4\right)$ como de elementos óseos (DS vs. CIRU: $\chi^{2}=0,08$; DS vs. DI: $\chi 2=5,6 ; C I R U$ vs. DI: $\chi 2=3,6)$.

Con respecto a las lesiones traumáticas presentes en cada una de las tres muestras bioarqueológicas, las prevalencias obtenidas fueron muy bajas $(<0,5 \%)$, sin diferencias estadísticamente significativas entre ellas, tanto a nivel individual (DS vs. CIRU: $p=1$; DS vs. DI: $p=1$; CIRU vs. DI: $p=1$ ) como de elementos óseos (DS vs. CIRU: $p=0,3$; DS vs. DI: $p=0,3$; CIRU vs. DI: $p=1$ ). Se observaron dos tipos de traumas. Por un lado, se registró una fractura en un hueso largo; específicamente se trata de una quebradura en una tibia de un individuo del DI. Dada su ubicación en la cara anterior en la diáfisis medial, es probable que tal lesión haya ocurrido de forma 
accidental; si bien se distinguió en la radiografía el proceso de remodelación, éste no había culminado completamente en el momento de la muerte del individuo.

El otro tipo de trauma incluye a las lesiones registradas en las bóvedas craneanas de un individuo del DS, en tres de CIRU y en uno del DI. Entre los cinco casos se observaron siete fracturas deprimidas de formas ovales-circulares, regulares, lisas y remodeladas, que habrían afectado solamente la tabla externa del diploe y ninguna resultó letal. En cuanto a las dimensiones, podrían agruparse en tres tamaños: pequeñas $(4,7$ a $8,5 \mathrm{~mm})$, medianas $(7,9$ a $15,3 \mathrm{~mm})$ y grandes $(15,8$ a $32,1 \mathrm{~mm}$ ). Considerando la ubicación de las lesiones, una es en la norma frontal, dos en la norma superior-lateral (parietales) y cuatro en la norma posterior (dos en parietal izquierdo, una en el parietal derecho y dos en el occipital). La lesión en el frontal se registró en un individuo femenino, mientras que los otros cuatro individuos son masculinos; uno de ellos presentó tres lesiones.

Este tipo de fracturas podrían corresponder a eventos accidentales fortuitos (por ej. caídas) o a eventos intencionales (por ej. peleas interpersonales). Con respecto a los accidentes, éstos pueden ocurrir en diferentes situaciones y es probable que generen lesiones de diferentes tamaños, formas y sobre cualquier parte del cráneo (Walker 1989). Los tamaños, las formas similares y las ubicaciones de las lesiones registradas escaparían a tales expectativas, por lo que se sugiere su vinculación con acciones intencionales. Asimismo, uno de los individuos presentó tres de estas lesiones, lo que apoyaría también esta propuesta. Por otro lado, si se tiene en cuenta que durante las peleas es común atacar a la cabeza y al cuello, dada la peligrosidad en cuanto al dolor y secuelas que pueden generar (Walker 1997), las lesiones observadas en las bóvedas coinciden con esto. Sin embargo, no fueron registrados otro tipo de traumas que suelen ser encontrados en contextos de violencia interpersonal, como por ejemplo fracturas en huesos faciales o fracturas Parry en el cúbito -asociadas con el movimiento defensivo de levantar el brazo para evitar un golpe (Lovell 1997; Ortner 2003; Jurmain et al. 2009).

En el caso de la lesión en el individuo femenino (DS), el golpe habría sido efectuado de forma frontal con una leve dirección vertical superior-inferior. Mientras que, en el caso de los tres hombres, las lesiones laterales y posteriores sugieren que podrían haber sido producto de ataques desde la espalda. La 
explicación de esta diferencia podría encontrar sustento en el contexto social y tipo de violencia sexualmente diferenciado. La mayor presencia de lesiones traumáticas en individuos masculinos -independientemente de la organización social de los grupos/poblaciones- se ha explicado en relación con su propensión a participar de luchas y peleas como resolución de conflictos o de actividades rituales (por ej. Walker 1989; Larsen 1997; Standen y Arriaza 2000a; Gordón y Ghidini 2007). En tanto que los traumas intencionales en mujeres suelen vincularse con disputas en contextos domésticos (Larsen 1997). Estadísticamente no se encontraron diferencias significativas en las muestras estudiadas, en cuanto al sexo, que permitan evaluar estos aspectos. Sí es claramente evidente en los cinco individuos el hecho de que los golpes se aplicaron con fuerza limitada, con la intención de herir y no de matar (Walker 1989; Lessa y Mendonça de Sousa 2004). 


\section{Capítulo 8}

\section{Discusión general y conclusiones}

En este capítulo se discuten los análisis y resultados obtenidos en esta tesis y se presentan las conclusiones alcanzadas. En primer lugar, se exponen algunas reflexiones sobre los desafíos metodológicos surgidos durante los análisis. En segunda instancia, se desarrollan las tendencias generales sobre la dieta y la salud inferidas para los grupos humanos que habitaron las tres áreas bajo estudio, teniendo en cuenta las expectativas paleopatológicas planteadas. Esta información se contextualiza y articula, principalmente, con los datos procedentes de otras líneas de estudio arqueológicas. Con base en lo desarrollado en estos apartados, al final del capítulo se expresan las conclusiones que culminan la presente investigación.

\subsection{Desafíos y reflexiones metodológicas}

El análisis paleopatológico de las muestras biarqueológicas estudiadas en este trabajo, presentó algunos retos que se tuvieron en consideración y se intentaron resolver durante los análisis. Estos desafíos se vinculan, mayormente, con los factores extrínsecos que afectaron la composición y representatividad de los conjuntos óseos analizados. La información del registro bioarqueológico, de las áreas consideradas en general y de los sitios de los cuales proceden las muestras estudiadas en particular, refleja una gran variedad de tipos de entierros. A la existencia de entierros primarios en distintas posiciones (dorsal, ventral y decúbito lateral), se reportan hallazgos de paquetes funerarios simples y múltiples, de acumulaciones óseas, de huesos aislados en las áreas inhumatorias, de esqueletos con ausencia y/o reubicación de huesos o regiones anatómicas, y contextos de posibles cremaciones (véanse Capítulos 3 y 5). Algunas de estas prácticas mortuorias, que incluyen remoción y selección de partes esqueletarias, impactan fuertemente en la representatividad de los esqueletos $y$, por ende, en las decisiones 
metodológicas a emplear en los análisis osteológicos. Tal como ya fue subrayado en otras investigaciones (por ej. Luna 2008; Scabuzzo 2010; Flensborg 2012), las unidades de análisis a emplear son diferentes (individuo o elemento óseo) y el grado de resolución alcanzado en los estudios impacta en las interpretaciones.

Los orígenes e historias particulares de cada una de las tres muestras bioarqueológicas también han impactado en los estudios. Como se detalló en el Capítulo 5, una de ellas (DS) se constituye por los entierros humanos hallados mediante técnicas de excavación actuales, controladas y sistemáticas y en trabajos de campo en los que participó la autora de esta tesis; en tanto que las otras dos muestras (CIRU y DI) proceden de trabajos de campo sin los estándares actuales de la práctica arqueológica y actualmente forman parte de colecciones de museos. Producto de esto, la información contextual de los entierros humanos no posee el mismo grado de detalle para cada una de las muestras. En cuanto a las muestras de CIRU y DI, hay que mencionar algunos puntos. Por un lado, quienes excavaron los sitios (Luis María Torres, Samuel Lothrop y Manuel Almeida) han dejado plasmado en sus escritos que, en ciertas ocasiones, no pudieron recuperar la totalidad de los huesos de los entierros debido a su mala preservación, siendo recurrente la mención al daño ocasionado por el arado. Por otro lado, particularmente para los sitios trabajados por Almeida, la totalidad de los entierros humanos hallados no fueron incluidos en el catálogo del Museo Arqueológico Manuel Almeida. Esto implicó que no se contara con información contextual de varios o de todos los entierros de algunos sitios (por ej. Cerro Lorenzo 2 o Cerro de los Pampas, respectivamente). En cuanto a los sitios del DI estudiados por Torres y Lothrop, el inventariado, la organización y la manipulación de los conjuntos óseos a lo largo del tiempo en el Museo de La Plata ha generado ciertos sesgos. Esto se concreta en dos hechos: la separación entre el cráneo y el postcráneo, y la ausencia de criterios explícitos mediante los cuales fueron agrupados e inventariados los elementos postcraneales (véase Capítulo 5). Además, en las colecciones consultadas de estos sitios del DI se destacan los pocos huesos de subadultos que fueron determinados, lo cual se contrasta con las menciones de Lothrop (diario de campo; Ramos van Raap y Bonomo 2016) sobre el hallazgo de entierros de niños y adolescentes. En este contexto, la consulta de distintos documentos (el informe 
elevado por Torres al director del Museo de La Plata; el diario de campo y fotografías de las excavaciones de Lothrop; los libros de Torres -1911- y Lothrop 1932-; y los catálogos de Restos Humanos y de Yacimientos del Museo Arqueológico Manuel Almeida; véase Capítulo 5), aportó valiosos datos para contextualizar los entierros humanos y reconocer algunos de los factores extrínsecos que impactaron sobre ellos. Otro aspecto interesante sobre las dificultades que presenta el estudio de colecciones de museo, se refleja particularmente en el conjunto óseo del sitio del DI excavado por Torres (Túmulo I del Paraná Guazú). En este caso concreto, no fueron relevados elementos óseos con lesiones de etiología infecciosa. Sin embargo, al consultar la obra de Torres (1911) pudo conocerse que algunos de los individuos enterrados en ese sitio presentaron patologías infecciosas. Esta situación es otro claro ejemplo de cómo los factores extrínsecos afectan a la representatividad de las muestras bioarqueológicas. Pese a todo lo recién expuesto, es importante resaltar que gracias a que los conjuntos óseos de estos sitios de CIRU y DI han sido conservadas en las colecciones del Museo Arqueológico Manuel Almeida y del Museo de La Plata, en algunos casos por más de 100 años, hoy es posible estudiar estas muestras con técnicas modernas e integrarlas a las problemáticas arqueológicas actuales.

Los aspectos hasta aquí mencionados plantean dos situaciones. Primero, la necesidad de realizar a futuro análisis tafonómicos en las muestras. Los elementos óseos estudiados pudieron identificarse en un elevado porcentaje y no se reconocieron alteraciones postdepositacionales que puedan ser interpretadas erróneamente como lesiones patológicas, conocidas como pseudopatologías (Aufderheide y Rodríguez-Martín 1998; Pérez 2006; Waldron 2009). Igualmente, un estudio tafonómico exhaustivo permitirá evaluar minuciosamente la preservación diferencial de partes esqueletarias y cómo ello impacta en la representatividad de las muestras, los perfiles de edad de muerte y las prevalencias de lesiones óseas y dentales. En segundo lugar, las particularidades de las muestras y las prácticas mortuorias en aquellos sitios con los que se cuenta con estos datos, ha llevado a tener que tratar a los huesos de algunos entierros $y / o$ sitios como un conjunto (véase Capítulo 5). En este punto, ha sido fundamental la aplicación de metodologías cuantitativas procedentes del campo de la zooarqueología (Lyman 
1994), con el fin de estimar principalmente el número mínimo de individuos representados. El empleo del ensamblaje anatómico (Todd y Frison 1992) permitió también ajustar estos números. Asimismo, ha sido importante la utilización de diferentes metodologías cuali y cuantitativas para determinar el sexo y estimar la edad, variables importantes para los análisis paleopatológicos ya que permiten evaluar la distribución de las lesiones según las categorías sexo-etarias. Más allá de esto, un gran número de individuos quedó agrupado bajo la categoría de adultos indeterminados, dada la imposibilidad de ajustar su rango etario.

Las metodologías elegidas en esta tesis para la estimación de edad en individuos adultos se basaron en los cambios morfológicos de la sínfisis del pubis y de la superficie auricular y retroauricular del ilion (véase Capítulo 4). Se han propuesto otras metodologías para estimar la edad de muerte, como por ejemplo la morfología esternal de la cuarta costilla (por ej. Isçan 1989; véase síntesis en Luna 2008) y el método de la obliteración de las suturas ectocraneales (Meindl y Lovejoy 1985). En cuanto al primero, la principal dificultad de su aplicación radica en identificar las epífisis esternocostales de la cuarta costilla, principalmente en conjuntos esqueletales (y caja torácica) incompletos, como ocurre en las muestras aquí estudiadas. Dado este inconveniente, este método no fue aplicado en esta tesis. En cuanto al segundo de los métodos mencionados, se ha enfatizado que éste resulta útil y complementario cuando es evaluado junto a otros indicadores (Acsádi y Nemeskéri 1970; Meindl y Lovejoy 1985), pero ha sido criticado por su bajo grado de confiabilidad (Barboza et al. 2004; Galera et al. 1998; Hershkovitz et al. 1997; Luna 2008). Si bien en varios casos de las muestras bioarqueológicas del CIRU y DI, se cuenta con cráneos en los que es posible estimar la edad mediante la sinostosis craneal, no se cuentan con otros indicadores complementarios. Por estos motivos, para no generar estimaciones erróneas, se decidió no utilizarlo en esta tesis. Por otro lado, otra metodología de estimación de edad es a partir de la evaluación del desgate dental. Diferentes estudios han encontrado resultados positivos en su aplicación (véase síntesis en Luna 2008), y en Argentina fue evaluado para una muestra de la región pampeana (Barrientos y L'Heureux 2001). Como fue mencionado en el Capítulo 6, será interesante indagar minuciosamente 
en la aplicación de esta metodología en las muestras estudiadas, a fin de poder precisar su composición etaria.

El alto porcentaje de individuos adultos indeterminados en las muestras bioarqueológicas estudiadas ha impactado directamente en los perfiles de edad de muerte construidos para cada una. En ellos se observa, en general, una mayor representación de adultos jóvenes por sobre los adultos medios y la casi ausencia de adultos mayores. En términos biológicos y sin condiciones sociales particulares (por ej. conflictos bélicos), no es esperable que haya mayor cantidad de adultos jóvenes que adultos medios (Bogin 2002). A su vez, tampoco es biológicamente esperable encontrar más representados a los adultos medios que los adultos mayores. Sin embargo, este tipo de patrón suele caracterizar a las muestras osteológicas en general (Weiss 1973; Bocquet-Appel y Masset 1982; García Guraieb 2010). Esta situación responde básicamente a las limitaciones que presentan las metodologías para estimar la edad en adultos, las cuales tienden a subestimar a los individuos mayores. Teniendo en cuenta todo lo expuesto hasta aquí, los perfiles de edad de muerte obtenidos en este trabajo responderían a la naturaleza de las muestras estudiadas y a los distintos procesos que éstas atravesaron y afectaron su composición. En este punto cabe recordar también el bajo porcentaje de individuos subadultos que caracteriza el perfil de edad de la muestra del DI, pese a las menciones de Lothrop de haber encontrado entierros de individuos de corta edad. Si bien estas situaciones han limitado las interpretaciones sobre las prevalencias de los indicadores analizados según la edad de los individuos, se pudieron obtener algunas tendencias generales que podrán ser re-evaluadas en análisis futuros.

\subsection{Tendencias sobre la dieta y la salud de los grupos prehispánicos que habitaron el sur del NEA}

\subsubsection{Indicadores de salud bucal y adecuación fisiológica y su relación con la dieta}

En las tres áreas del Noreste Argentino bajo estudio, como fue expuesto detalladamente en capítulos anteriores, la información arqueobotánica, isotópica y 
zooarqueológica indican la explotación de recursos vegetales silvestres y de animales que se obtuvieron mediante la caza y la pesca. Específicamente para el Delta del río Paraná, excluyendo a los guaraníes, los valores isotópicos dan cuenta del consumo predominante de vegetales $C_{3}$, además de herbívoros terrestres consumidores de esas plantas, mamíferos acuáticos y peces. Por otro lado, principalmente según las evidencias de fitolitos, almidones y macrorrestos vegetales carbonizados del DS, se practicó la horticultura de maíz, poroto y zapallo. Análisis en el DI también evidenciarían estas prácticas hortícolas, corroborando así las menciones de las fuentes etnohistóricas de los siglos XVI-XVII (por ej. García [1528] 1902 y Ramírez [1528] 1902). Tal como fue propuesto, estos cultivos no habrían tenido un papel significativo en la dieta de estos grupos. Específicamente sobre las especies vegetales silvestres explotadas para su consumo, en las tres áreas se identificaron algarrobo y palmeras (yatay y/o pindó). Asimismo, en el DS se registró arroz silvestre, y en CIRU y DI se reconocieron fitolitos afines a gramíneas (Acosta 2005; Loponte 2008; Zucol y Loponte 2008; Bonomo et al. 2011a, b; 2017a; Acosta y Loponte 2013; Acosta y Rios Roman 2013; Sánchez et al. 2013; Colobig et al. 2015; Castro 2017).

Diferentes estudios (por ej. Turner II 1979; Lukacs 1992) han vinculado el tipo de estrategia de subsistencia de los grupos con las tasas de caries. Investigaciones en el Golfo Pérsico revelaron que mientras los grupos agricultores exhiben porcentajes elevados de caries, los grupos con dietas mixtas tienen tasas intermedias y los grupos con subsistencia marina son los que presentan los números más bajos (Littleton y Frohlich 1993). Estas tendencias se explicaron a través de la vinculación entre el desarrollo de caries y la ingesta frecuente de carbohidratos en la dieta (Turner II 1979; Lukacs 1989, 1992; Hillson 2001, 2008). Al tener en cuenta estos planteos, y junto con la información arqueológica mencionada anteriormente, se esbozó como expectativa paleopatológica que las muestras bioarqueológicas presenten bajas a moderadas prevalencias de caries, acordes a grupos con dietas mixtas. Los resultados obtenidos para estas lesiones infecciosas indicaron muy bajos porcentajes en las tres muestras, sin diferencias estadísticas significativas entre ellas. Asimismo, acorde a las expectativas planteadas, fueron identificadas bajas prevalencias de lesiones periapicales y pérdidas dentales 
antemortem (véase más adelante). Estos valores, en conjunto, indicarían un bajo consumo de alimentos con componentes almidonosos y azucarados, como por ejemplo el arroz silvestre, el maíz y los frutos de las palmeras y el algarrobo. Particularmente los frutos de las palmeras presentan elevados niveles de hidratos de carbono (Goudel 2012) y los del algarrobo contienen valores altos de azúcares y moderados de almidón (Burkart 1943; Cano 1988; González 2016). Pese a registrar estas bajas tasas de caries, deben tenerse en cuenta algunas cuestiones relevantes. En primer lugar, como fue expuesto en el Capítulo 6, la atrición pudo haber generado una subestimación en el registro de caries, a partir de la eliminación de placa bacteriana de las superficies oclusales o de cavidades cariosas incipientes. En segundo lugar, la textura y el procesamiento de los alimentos inciden directamente en su cariogenicidad (Tayles et al. 2000; Lanfranco y Eggers 2012). Finalmente, el papel de la dieta en el desarrollo de caries no debe restringirse solo a la presencia de azúcares fermentables, sino que la conjunción de múltiples componentes presentes en las dietas mixtas puede mitigar el efecto de los carbohidratos en la salud bucal (Lanfranco y Eggers 2012; Giacaman 2017).

Un ejemplo de cómo el procesamiento de los alimentos influye en su potencial cariogénico lo constituye el almidón. Así lo demostró la investigación realizada por Tayles y colaboradores (2000) en grupos del sudeste asiático, los cuales practicaban el cultivo de arroz y aun así presentaban bajas tasas de caries. Una de las principales explicaciones a esta situación se debe a que, como subrayaron diferentes estudios, el almidón tiene una cariogenicidad baja por su lenta acumulación en la placa dental y digestión oral más lenta. Sus efectos sobre la desmineralización de los tejidos dentales dependen mayormente de la gelatinización que sufran. Mediante este proceso, dado por efecto térmico, los almidones se vuelven susceptibles a la rotura enzimática en la cavidad bucal y producen así moléculas altamente cariogénicas (Tayles et al. 2000; Lanfranco y Eggers 2012). Asimismo, la evidencia experimental muestra que los almidones cocidos tienen potencial cariogénico, pero sólo en presencia de determinadas enzimas salivales y cuando su consumo ocurre junto con azúcares (Giacaman 2017). En el Delta del río Paraná, diferentes análisis realizados en materiales cerámicos en algunos sitios arqueológicos reflejan la exposición al calor de ciertas plantas 
durante el procesamiento de los alimentos. Algunos de los cuencos cerámicos hallados en Los Tres Cerros 1 (DS) fueron utilizados para la cocción y servido de alimentos vegetales; entre los restos fitolíticos hallados en su interior se identificaron gramíneas panicoideas, oryzoideas y poóideas, entre otras (Castro, C. 2017). Por otro lado, los análisis en una cuchara de cerámica encontrada en Cerro Tapera Vázquez (Pre-Delta), indican que la misma habría sido utilizada para calentar y beber líquidos hechos a base de vegetales; su morfología y las alteraciones de la superficie externa por la exposición al fuego serían evidencias de su uso. Específicamente, el perfil lipídico obtenido de su interior sería compatible, probablemente, con aceites de semillas o ceras provenientes del recubrimiento de frutos, hojas o semillas. Además, según los microfósiles vegetales, la cuchara pudo haber contenido partes de gramíneas o palmeras, como así también "diferentes productos almidonosos provenientes de Zea mays, Phaselous vulgaris y probablemente de las Cannaceae" (Bonomo et al. 2012: 44). En sitios del DI y ambientes litorales adyacentes (Túmulo de Campana 2, La Bellaca 2 y Cerro Lutz), los análisis de ácidos grasos sobre restos cerámicos indican que estas vasijas habrían servido para el procesamiento y/o el consumo de granos, probablemente de maíz y algarrobo (Naranjo et al. 2010; Pérez et al. 2013). En conjunto, los análisis de fitolitos, almidones y ácidos grasos realizados sobre restos cerámicos hallados en dos de las tres áreas de estudio, demuestran el procesamiento, cocción y posterior consumo de alimentos almidonosos. Sin embargo, éstos no habrían incidido para el desarrollo de caries, de acuerdo a las bajas prevalencias registradas en las tres muestras bioarqueológicas.

En comparación con el almidón, el azúcar se descompone fácilmente, es muy ácido y, por lo tanto, altamente cariogénico (Tayles et al. 2000). En otras regiones de Argentina, para grupos cazadores-recolectores se han reportado moderadas prevalencias de caries y éstas fueron interpretadas como producto del consumo de vegetales silvestres altamente cariogénicos. Entre ellos se mencionan las vainas del algarrobo, las semillas de araucaria y el chañar, que son las especies a las que habrían tenido acceso estos grupos (L’Heureux 1998; Gil 2003; Novellino et al. 2004; Bernal et al. 2007; Fabra y González 2012). De acuerdo a las evidencias arqueobotánicas conocidas para el norte de la región pampeana y sur del NEA (por 
ej. Zucol y Loponte 2008; Bonomo et al. 2011a, b; Colobig et al. 2015), los frutos de algarrobo (que poseen altos valores de azúcares) pudieron haber sido consumidos de forma directa. Sin embargo, dadas las bajas prevalencias de caries observadas, no habrían sido un recurso importante en la dieta o bien, no habrían sido consumidos de manera frecuente como para favorecer lesiones infecciosas.

El otro aspecto mencionado previamente en cuanto al desarrollo de las caries, se vincula con la ingesta de otros componentes en la dieta. Numerosos estudios clínicos y experimentales han expuesto que el consumo de ácidos grados y proteínas tendrían efectos protectores frente a las caries (véase síntesis en Giacaman 2017). De esta forma, las dietas ricas en carne conducirían a bajas frecuencias de caries. Específicamente, el consumo elevado de pescado modifica los valores del $\mathrm{pH}$ bucal, generando un ambiente oral no propicio para el desarrollo de caries (Lanfranco y Eggers 2012). Teniendo en cuenta estos datos, resulta relevante integrar la información isotópica, zooarqueológica y etnohistórica. Como fue expuesto antes, los análisis realizados en sitios del Delta del Paraná reflejan la ingesta de herbívoros terrestres consumidores de plantas $C_{3}$ y de peces de agua dulce (Bonomo et al. 2017a; Salazar-García et al. 2018). A su vez, los conjuntos arqueofaunísticos reportados para las tres áreas hacen evidente la explotación y consumo de distintos recursos animales (véase Capítulo 3). Particularmente cobran relevancia los peces, ya que constituyen uno de los recursos más abundantes de las áreas de estudio, su obtención es segura y con la tecnología específica disponible en el área (canoas, redes, arpones) implica un bajo costo de energía en su captura (Limp y Reidhead 1979; Erlandson 2001; Bonomo et al. 2018). Por otro lado, también hay que mencionar que los frutos de las palmeras poseen no sólo elevados niveles de hidratos de carbono, sino también un buen perfil de ácidos grasos (Goudel 2012). En análisis realizados en fragmentos cerámicos de sitios del DI, se observaron varios de los ácidos que poseen los frutos de las palmeras yatay, indicando probablemente su procesamiento y consumo (Acosta y Rios Roman 2013).

En síntesis, las distintas evidencias arqueológicas refieren la ingesta de plantas por parte de los grupos humanos que habitaron el sur del NEA, principalmente más documentado para el Delta del Paraná. Según los resultados 
obtenidos en esta tesis, el consumo de estos recursos -almidonosos y azucaradosno se refleja en las patologías infecciosas bucales en ninguna de las tres muestras bioarqueológicas. Sin embargo, los bajos porcentajes de caries obtenidos no deben asociarse directamente con una dieta con un escaso componente vegetal, sino que otros factores deben tenerse en cuenta. Por un lado, el tipo de preparación de los alimentos, especialmente los almidonosos y su consumo junto con azúcares. Por otro, un aporte considerable de ácidos grasos (por ej. a través de los frutos de las palmeras y peces) y de proteínas (brindadas por los peces y herbívoros terrestres y acuáticos), que habrían actuado como agentes protectores de la formación de caries. Particularmente en cuanto a las evidencias de horticultura en las áreas del Delta del Paraná, el consumo de estos recursos domesticados podría explicar las prevalencias de caries más altas en estas muestras (1,5-1,7\%) en relación con la de CIRU (0,7\%), pero estadísticamente las diferencias no son significativas. Los resultados de los análisis isotópicos en curso de la muestra de CIRU permitirán obtener datos desde otra línea de estudio para evaluar lo observado en este trabajo de tesis.

En los análisis realizados por otros investigadores en conjuntos osteológicos del Delta del Paraná, se observan las mismas tendencias que las aquí presentadas: bajas prevalencias de caries, de lesiones periapicales y de pérdidas dentales antemortem (Torres 1911; Kozameh 1996; Mazza y Barrientos 2012; véase Capítulo 3). Para el Paraná Medio se reportaron frecuencias de caries entre 0 y $13 \%$ en diversos sitios asociados con la entidad Goya-Malabrigo (por ej. Arroyo Aguilar, La Lechuza, Isla Barranquita, Arroyo Arenal; Cornero y Puche 2000, 2007). Estos resultados, junto con los de análisis de la relación estroncio/calcio en huesos de los mismos individuos, fueron entendidos como reflejo de la dieta mixta que poseían estos grupos (Cornero y Puche 2000). Al promediar los porcentajes de caries calculados para cada uno de los conjuntos bioarqueológicos de esos sitios, se obtuvo una prevalencia de 4,9\% (Cornero y Puche 2000). Este porcentaje es mayor al calculado para cada una de las muestras analizadas en esta tesis. Inicialmente, esta diferencia podría interpretarse por un mayor consumo de vegetales por parte de los pobladores del Paraná Medio, en comparación con quienes habitaron el Delta del Paraná y Uruguay inferior. Sin embargo, como ya se hizo mención, hay 
otros factores, como el procesamiento de los alimentos y el consumo de proteínas, que actúan sobre la formación de caries. La continuación de los análisis, no sólo bioarqueológicos, sino también desde otras líneas de estudio, permitirá profundizar estos aspectos. En una escala regional más amplia, los estudios e interpretaciones presentados en esta tesis se complementan a los registros de caries en otros sectores de Argentina, tal como fue sintetizado y evaluado en un trabajo reciente de Menéndez (2016) sobre distintas regiones del país. Según este estudio, en Cuyo, Pampa, Norte de Patagonia y Delta del Paraná1, existe una mayor variación en las tasas de caries en comparación con las regiones del Noroeste (con elevadas tasas) y sur de Patagonia (con bajas tasas). Esta mayor variación en algunas de las regiones es entendida como resultado de las estrategias de economías mixtas que poseían los grupos humanos que allí habitaban (Menéndez 2016).

En relación con lo expuesto hasta aquí, es interesante incorporar a la discusión el análisis de cálculo y desgaste dental. En las tres muestras se obtuvieron altos y moderados porcentajes de tártaro a nivel individual y dental, respectivamente. Existen diferentes factores fisiológicos, culturales y dietarios que intervienen en la formación del cálculo dental (Hillson 1996; Lieverse 1999; Duckworth y Huntington 2006). En lo que respecta a la dieta, los datos no son concluyentes. Algunos autores vinculan la mineralización de la placa dental con el consumo de alimentos ricos en proteínas (como el pescado o la carne); otros sugieren su relación con las dietas ricas en carbohidratos y también se propone el papel de las dietas mixtas en su conformación (Lukacs 1989; Littleton y Frohlich 1993; Hillson 1996; Lieverse 1999; Greene et al. 2005; Delgado-Darias et al. 2006). Como fue expuesto en el Capítulo 6, al considerar las bajas prevalencias de caries y la ingesta de otros componentes en la dieta (i.e. recursos faunísticos), es probable que las tasas de cálculo dental registradas en las muestras estén relacionadas principalmente con una mayor ingesta de proteínas en relación con los carbohidratos. Igualmente, no debe descartarse que su depositación también esté

1 En el trabajo de Menéndez (2016), para la región del Delta del Paraná solo se consideraron los resultados obtenidos por Mazza y Barrientos (2012) en sitios del Delta Inferior. 
relacionada con la ingesta de almidones, aportados por ejemplo a través de harinas (veáse más adelante) (González 2016).

El análisis de los desechos alimenticios incorporados en el tártaro dental brinda información complementaria a los estudios arqueobotánicos realizados hasta el momento. En relación con los fitolitos graminoides (Poaceae) encontrados en muestras del DS y CIRU, no se pudo especificar de qué tipo de gramíneas se trata. Sí es claro que su presencia es una evidencia directa de la masticación de esta familia de plantas por parte de esos individuos. Esto no implica exclusivamente su consumo alimenticio, sino que también podría estar involucrado su uso medicinal; otra posibilidad es que estos fitolitos quedaron entrampados en el cálculo al ingerirse alimentos con restos de los elementos utilizados para su cocción, o por utilizar los dientes como herramienta para trabajar fibras vegetales (Musaubach 2012). En relación con los granos de almidón, éstos pudieron ser identificados en muestras de las dos áreas mencionadas. Lamentablemente algunos no resultaron diagnósticos, mientras que uno de los encontrados en una muestra de CIRU probablemente corresponda a maíz. Este caso registrado corresponde a una muestra de tártaro dental de un individuo inhumado en el sitio Cerro de los Pampas, asignado a Goya-Malabrigo (Castro, J.C. 2017). Este hallazgo, de confirmarse, adquiere relevancia ya que esta especie vegetal aún no ha sido identificada en los análisis arqueobotánicos realizados en esta área. Asimismo, su presencia sería indicio del consumo de vegetales domesticados como fue propuesto para las áreas del Delta del Paraná (Bonomo et al. 2011a, b). Aún no se cuenta con un fechado radiocarbónico para Cerro de los Pampas, el cual será interesante realizar para poder ubicar temporalmente el consumo de plantas domesticadas en la cuenca inferior del río Uruguay y contextualizar y discutir con otras evidencias hasta ahora conocidas.

El registro más temprano de plantas domesticadas en el sur del NEA está datado en ca. 1030 años AP (sitio Los Tres Cerros 1). Esta actividad de cultivo incluso podría remontarse a ca. 1700 años AP si se comprueba la presencia de maíz en otro de los sitios del DS (Laguna de los Gansos 1; Bonomo et al. 2017a). Otros estudios también han reportado la presencia de cultivos en sitios Goya-Malabrigo ubicados en el Paraná Medio (Colobig y Ottalagano 2013; Cornero y Rangone 2015; 
Píccoli 2015). Los estudios arqueobotánicos en recipientes cerámicos de cuatro sitios del noroeste de Entre Ríos (Puerto Cuartel 1, Arroyo Las Mulas 1, Arroyo Arenal y La Palmera 2), evidencian que estas vasijas contuvieron distintas gramíneas, así como también calabaza, batata y probablemente maíz (Colobig y Ottalagano 2013). Estos registros corresponden a contextos fechados entre ca. 950 y 1050 años AP (Colobig y Ottalagano 2013). Por otro lado, en análisis de muestras de cálculo dental, de sedimento de la cavidad ventral de esqueletos humanos y de fragmentos cerámicos de cuatro sitios del noreste de Santa Fe (La Lechuza, Arroyo Aguilar, El Carancho y El Inglés), se identificaron fitolitos graminoides, granos de almidón de maíz y de porotos y células epidérmicas de Arecaceae, Cyperaceae y Curcubitaceae (Cornero y Rangone 2015). Según los fechados de estos sitios, la presencia de calabaza, maíz y poroto en estas muestras corresponde al período entre ca. 1700 y 2000 años AP, siendo las evidencias más antiguas de la práctica hortícola para esta entidad arqueológica (Cornero y Rangone 2015).

En cuanto al desgaste dental, las tres muestras bioarqueológicas presentaron, en promedio, grados moderados de desgaste, tal como fue planteado como expectativa paleopatológica. También se registraron diferentes formas y direcciones de las superficies oclusales. Todos estos datos sobre el desgaste dental, como se discutió en el Capítulo 6, sugieren que las muestras no se ajustan estrictamente a los patrones esperados para los cazadores-recolectores o agricultores; más bien serían coincidentes con una dieta mixta, como así también lo demuestran las otras evidencias y líneas de estudio.

El desgaste moderado indica una dieta ligeramente abrasiva. La abrasión de las superficies oclusales de los dientes pudo deberse a la ingesta directa de alimentos fibrosos, granos y frutos. Los "rompecocos" (piedras con hoyuelos), registrados arqueológicamente en el sur del NEA (por ej. Torres 1911; Loponte 2008; Bonomo et al. 2009; Castro, J.C. 2017), representarían una evidencia indirecta del consumo de frutos (generalmente vinculados con los de las palmeras) que se habrían utilizado para romper sus duros endocarpos. Otra fuente de incorporación de partículas abrasivas (por ej. granos de arena o limo y fitolitos de oxalato de calcio presentes en cenizas) pudo ser a partir de la cocción de los alimentos sobre el fuego, su manipulación sobre el suelo y el consumo de pescado seco (Littleton y 
Frohlich 1993; Lalueza Fox et al. 1996). Como mencionan algunas fuentes etnohistóricas para las islas del río Paraná, la práctica de ahumar diferentes tipos de pescado y otras carnes previamente secas constituía una forma de conservar alimentos durante todo el año, especialmente para el invierno (Santa Cruz [1540] 1918). También el desgaste pudo verse favorecido por el consumo de harinas y los granos que ésta presente. Según los análisis arqueobotánicos en algunos sitios del Delta del Paraná, la falta de alteraciones térmicas en los granos de almidón identificados en recipientes cerámicos sería indicio de que éstos fueron utilizados para almacenar maíz, algarrobo y frijoles; probablemente hayan sido guardados como harina, que se podía consumir mezclada con agua en forma de sopas (Bonomo et al. 2011a). A estas referencias se suman los hallazgos de artefactos de molienda en sitios del DI que probablemente se utilizaron para la molienda de los granos (por ej. Bonomo et al. 2009). En el caso del Pre-Delta del Paraná, en el sitio Cerro Tapera Vázquez fue hallada una mano de mortero donde se identificaron granos de almidón de porotos (Bonomo et al. 2011c). Más allá de estos registros, hay que tener en cuenta que se desconoce el grado de tamizaje alcanzado en la molienda, el cual influye en el tamaño de los granos presentes en las harinas y en el consecuente desgaste que se produce a nivel de los dientes (Littleton y Frohlich 1993). En conjunto, estos tipos de procesamiento de los alimentos estarían reflejados en los patrones cóncavos observados en la dentición posterior con mayores grados de desgaste, ya que las partículas ingeridas aceleran la pérdida de esmalte dental y provocan el "ahuecamiento" o cupping de la dentina.

Otras prácticas culinarias realizadas favorecieron la reducción de la dureza y fibrosidad de la comida, y de esta forma el impacto sobre las superficies oclusales de los dientes fue menor. Como se mencionó en otras oportunidades, en el registro cerámico del Delta del Paraná se identificaron cuencos destinados a la cocción de alimentos. Análisis de ácidos grasos realizados en vasijas del DI sugieren que algunas de ellas pudieron haber sido utilizadas no sólo en la cocción de recursos vegetales, sino también para el hervido de algunas presas como peces y coipo (Pérez et al. 2013). En las fuentes escritas del silgo XVI, Fernández de Oviedo y Valdés relata las diferentes formas de procesamiento del pescado que realizaban los pobladores del extremo sur de la cuenca del Plata. Específicamente, menciona 
que este recurso era asado, cocido (posiblemente haga referencia al hervido o fritado) y que también se elaboraba manteca de pescado (Fernández de Oviedo y Valdés [1547] 1851: 178; véase en detalle Apolinaire y Bastourre 2016). Estas formas de cocción de los alimentos no estarían reflejadas solamente en los valores moderados de desgaste -que además se observó en vinculación con la edad de los individuos-, sino también en las bajas prevalencias reportadas en las muestras de pérdidas dentales antemortem y de lesiones periapicales producidas por la exposición de la cámara pulpar. Todas estas formas de procesamiento y consumo de los alimentos habrían generado los patrones y grados moderados de desgaste.

Un aspecto que merece discusión aparte se relaciona con los patrones de desgaste de la muestra de CIRU. Los análisis mostraron patrones redondeados de la dentición anterior del 26,1\% de los individuos. Estas piezas dentales son las que presentan los grados más altos de desgaste y están acompañadas, en los mismos individuos, con un predominio de patrones cóncavos en la dentición posterior. Cabe recordar que estos moderados porcentajes de patrones redondeados y elevado desgaste de dientes anteriores no fueron reportados en las otras dos muestras. A modo comparativo, las mismas tendencias de un predominio de patrones cóncavos en molares y redondeado en la dentición anterior fueron reportadas en la región pampeana para grupos con economías cazadorasrecolectoras de entre fines del Holoceno temprano y el Holoceno medio (L'Heureux 2014). Si bien los grados de desgaste observados en ese estudio fueron en general más elevados que los obtenidos en esta tesis, la autora entiende que los patrones registrados se deben a una dieta con una baja a moderada proporción de vegetales y el consumo de carne, y la incorporación de abrasivos mediante la molienda y actividades de procesamiento como el asado y cocción directa sobre el fuego (L'Heureux 2014). Teniendo en cuenta estos datos, lo observado en esta tesis sugiere que un moderado porcentaje de individuos de la muestra de CIRU presentó mayor estrés masticatorio en comparación con las otras dos muestras. Esta situación podría encontrar explicación en el consumo de una mayor cantidad de granos y frutos, pescado seco o harinas con bajo grado de tamizaje. A partir de la ampliación de los estudios arqueobotánicos y análisis de uso de recipientes cerámicos en esta área, estas interpretaciones iniciales podrán ser puestas a prueba. 
Finalmente, es interesante recordar que, en general, se registraron promedios de desgaste dental levemente más altos en los individuos masculinos en las tres muestras bioarqueológicas; incluso también en los dientes con patrones redondeados en la muestra del Uruguay. La misma tendencia en la diferencia sexual, aunque más clara, presentaron las prevalencias de cálculo dental en las muestras del DS y CIRU. Estas disparidades en cuanto al sexo, si son analizadas en conjunto, podrían ser indicio de un consumo diferenciado de alimentos entre hombres y mujeres. Tal como fue interpretado en otros trabajos (por ej. DelgadoDarias et al. 2006), al relacionar la depositación de cálculo con el consumo de proteínas, las diferencias sexuales registradas podrían deberse a una mayor ingesta de proteínas por parte de los hombres. Asimismo, podrían indicar una división sexual no sólo en el consumo de los alimentos, sino además en la obtención de los recursos. Una mayor presencia de cálculo dental en individuos masculinos también fue reportada para muestras de varios sitios del DI (Mazza y Barrientos 2012). Con la continuación de los estudios en otras muestras será interesante observar si se repite esta situación, como una característica de todas las poblaciones que habitaron el sur del NEA. Más allá de estas diferencias sexuales, los futuros análisis permitirán también evaluar si existieron distinciones entre individuos, como fue propuesto a partir de objetos de metal hallados junto a individuos enterrados en sitios del DI (Túmulo I y II del Paraná Guazú y Túmulo I del Brazo Gutiérrez; Bonomo et al. 2017b). Estos objetos fueron interpretados como posibles marcadores de diferencias sociales dentro de los grupos, al ser símbolos de prestigio que exhibían los líderes indígenas -tal como se detalla en el registro etnohistórico- y que podrían ser indicio de un acceso diferencial a los bienes de intercambio (Bonomo et al. 2017b).

\subsubsection{Estrés metabólico-nutricional, enfermedades infecciosas y nucleamiento poblacional}

La hiperostosis porótica (HP), la cribra orbitalia (CO) y las líneas de hipoplasia del esmalte dental (HLED) son lesiones óseas y dentales frecuentemente utilizadas para evaluar el estado de salud y nutrición de las poblaciones humanas 
del pasado (Aufderheide y Rodríguez-Martín 1998; Ortner 2003; Roberts y Manchester 2005). Específicamente, como fue detallado en capítulos anteriores, estos biondicadores son considerados como evidencias de estrés metabóliconutricional durante los primeros años de vida (por ej. Stuart-Macadam 1985; Walker 1986; Lukacs 1989; Goodman y Rose 1991; Hillson 1996, 2008; Ortner 2003; Walker et al. 2009). Si bien resulta difícil conocer los factores específicos que generaron el estrés sistémico en los individuos, y que condujeron al desarrollo de estos indicadores óseos y dentales, su estudio conjunto brinda información sobre las condiciones de vida de los grupos humanos del pasado.

En los análisis realizados en esta tesis se relevaron bajas prevalencias de HP y CO en las muestras del DS y CIRU, y no se registró ningún caso en la del DI. Esto último no significa que los individuos que habitaron esta área estuvieron exentos de padecer estas lesiones; de hecho, las diferencias de las prevalencias entre las tres muestras no resultaron significativas estadísticamente. Asimismo, hay que considerar que para otro sitio del DI (Túmulo II del Paraná Guazú), Torres (1911) describió la presencia de tres adultos con este tipo de lesiones en las bóvedas craneanas (véase Capítulo 3).

En las muestras aquí analizadas se registraron diferencias en la cronicidad de las lesiones. Mientras que se registraron como remodeladas en un adolescente (LTC1-P1) y un adulto joven (T2-CSM-81), el estrés estaba aún presente al momento de muerte en un infante (LTC1-A4), un adolescente (T2-CSM-82) y un adulto (T1CNM-83). En el caso de estos dos últimos individuos, como ya se discutió en el Capítulo 7, es probable que hayan padecido anemia de forma crónica. Entre los distintos factores que habrían contribuido al desarrollo de estos eventos de estrés sistémico durante la infancia-niñez de estos individuos, en el Capítulo 7 se propuso la acción sinérgica de diversos factores: el empobrecimiento nutritivo de la leche materna por una lactancia prolongada; el proceso de destete en el cual se pueden incorporar alimentos y agua contaminados; y situaciones de asentamientos estables con largas ocupaciones y condiciones de saneamiento e higiene que favorecen la presencia de enfermedades infecciosas gastrointestinales. Un ejemplo de la vinculación entre la contaminación de los alimentos y el desarrollo de anemia, puede encontrarse en el estudio realizado en grupos prehispánicos con distintas 
economías del sur de Patagonia. A partir del relevamiento de HP y CO, se encontró una mayor prevalencia de HP en individuos con una dieta principalmente marina (Suby 2014). Para el autor, junto con información clínica y datos biológicos de los parásitos marinos modernos, estos resultados sugieren que factores nutricionales (ingesta de recursos marinos) y zoonóticos (parásitos en los animales explotados) serían los principales causantes del desarrollo de anemia entre las poblaciones con ese tipo de dieta. Considerando este antecedente, no debe descartarse la posibilidad de que haya ocurrido una situación similar en las muestras bajo estudio. Los análisis paleoparasitológicos realizados para algunos entierros de la muestra del DS arrojaron resultados negativos como para poder evaluar esta hipótesis; y lamentablemente para las otras dos muestras no se cuenta con sedimentos para ser examinados. En este sentido, será interesante analizar más muestras procedentes de los sitios del DS e integrar muestras de sitios arqueológicos trabajados por otros/as investigadores/as.

En cuanto a las HLED, se relevaron moderadas prevalencias a nivel individual en la muestra del DS y bajas prevalencias en CIRU y DI. La mayor frecuencia en la muestra del DS resultó en una diferencia estadísticamente significativa en comparación con las otras dos muestras, lo cual indicaría una mayor incidencia de las circunstancias de estrés en la salud de los individuos de esta área. Sin embargo, esto debe tomarse con cautela y referido sólo a la muestra bioarqueológica estudiada, ya que para varios sitios del DI se reportaron prevalencias similares de HLED que las obtenidas en esta tesis para el DS (Mazza y Barrientos 2012). En los contados casos en los que se pudieron estimar las edades de los individuos en las que se produjo el estrés que generó la formación de HLED, éstas corresponden entre 1,5 y 3 años de vida en los individuos masculinos (LTC1-P2; CL2-76) y entre 3 y 3,5 años en el individuo femenino (LTC1-P4). Como fue detallado en el Capítulo 6, este tipo de estrés podría estar vinculado también con el proceso de incorporación de alimentos menos nutritivos y/o contaminados, los cuales pueden generar infecciones gastrointestinales severas como para desarrollar un estrés sistémico. Para dilucidar la etiología en la formación de HLED, resulta interesante el caso de estudio realizado por García Guraieb (2010) en la cuenca del Lago Salitroso (Santa Cruz). La posibilidad de cruzar los resultados de las edades más frecuentes en las 
que ocurrieron las HLED relevadas junto con datos isotópicos de $\delta^{15} \mathrm{~N}$, le permitieron confirmar a la autora la existencia de un desfasaje entre la edad de ocurrencia de tales defectos y el momento del destete, siendo las hipoplasias resultado de un proceso multifactorial (acumulativo) que ocurrió posteriormente al cambio en la dieta. En este sentido, será interesante en un futuro realizar análisis isotópicos de $\delta^{15} \mathrm{~N}$ en los individuos subadultos de las muestras bioarqueológicas estudiadas, que permitan evaluar el momento en el que se dio el destete y la incidencia de éste en el desarrollo de eventos de estrés sistémicos, representados mediante HLED. Estos datos servirán también en la discusión de las causas propuestas para las lesiones de HP y CO comentadas anteriormente, principalmente sobre el empobrecimiento nutritivo de la leche materna por una lactancia prolongada.

En conjunto, las bajas a moderadas prevalencias de estos bioindicadores dentales y óseos indican que sólo un bajo porcentaje de los individuos analizados padecieron eventos de estrés metabólico-nutricional. Igualmente, es importante recordar que en las muestras del DS y CIRU, donde se relevaron HLED, las pérdidas postmortem (y quizá también el desgaste coronario) produjeron la subestimación de las prevalencias calculadas para este indicador, de modo que probablemente habrían sido más los individuos afectados. De acuerdo a lo relevado, los episodios de estrés fueron suficientes como para generar una respuesta a nivel óseo y dental, pero la mayoría de estos individuos habría podido sobrellevar las situaciones adversas y alcanzar la edad adulta. Esto es más evidente sobre todo en las HLED, que fueron todas observadas en adultos; en los casos del infante y del adolescente con lesiones activas de HP/CO, el estrés pudo haber sido más severo para su salud.

Entre las patologías óseas vinculadas con procesos infecciosos, se destaca el caso de un adulto femenino (LTC1-P3) de la muestra bioarqueológica del DS. Según el diagnóstico diferencial efectuado, las lesiones en su esqueleto son compatibles con osteomielitis; probablemente sea de tipo hematógena, por lo que el individuo habría contraído la infección bacteriana en sus primeros años de vida (véase Capítulo 7). Si tenemos en cuenta que la infección se dio probablemente cuando el individuo era infante o niño y al integrar este caso con las lesiones de estrés sistémico discutidas anteriormente (HP, CO y HLED), se vislumbra como factor 
común la vulnerabilidad de los infantes y niños a diferentes procesos patológicos, probablemente infecciosos en su mayoría. Este aspecto podrá ser profundizado con nuevos análisis paleopatológicos.

Además de los individuos que posiblemente estuvieron expuestos durante sus primeros años de vida a parásitos y/o bacterias y afectaron su salud, otros individuos también padecieron enfermedades infecciosas en su vida adulta. En las muestras bioarqueológicas estudiadas, los individuos con lesiones óseas vinculadas con este tipo de patologías representan un bajo porcentaje. Sin embargo, esto no necesariamente significa que las personas tuvieron escasa probabilidad de contraer enfermedades infecciosas, si no que éstas pudieron no haber sido lo suficientemente crónicas como para generar lesiones en el esqueleto como las relevadas (Wood et al. 1992). Algunas de las reacciones periósticas observadas en las tres muestras podrían vincularse con infecciones, aunque dada su etiología multifactorial no se puede asegurar esto. Particularmente en la muestra del DI, y como ocurrió con las lesiones de HP y $\mathrm{CO}$, no fueron relevados elementos óseos con lesiones de etiología infecciosa. Aun así, las minuciosas descripciones de Torres (1911) permitieron conocer que un individuo adulto masculino (T1-PG-431/2) enterrado en uno de los sitios estudiados en la tesis, Túmulo I del Paraná Guazúhabría presentado osteomielitis; cabe recordar que los huesos de este individuo no fueron localizados al consultar la colección (véase Capítulo 7). Estas escasas evidencias son complementadas a partir del reporte de esqueletos de otros sitios del DI con lesiones vinculadas con procesos infecciosos. De acuerdo a los antecedentes de estudios patológicos (véase Capítulo 3), en tres sitios arqueológicos de esa área (Túmulo I del Brazo Largo, Torres 1911; sitio de la cuenca del Paraná Pavón y rincones del Ibicuy, Outes 1911; y Cerro Lutz, Kozameh et al. 2007) se encontraron cuatro esqueletos de adultos masculinos con lesiones que se atribuyen a infecciones. Específicamente, para tres de ellos se menciona a la osteomielitis como diagnóstico; las lesiones del individuo restante fueron atribuidas a un proceso infeccioso (Torres 1911; Outes 1911; Kozameh et al. 2007). Por otro lado, para el DS, los re-análisis de Kozameh y Brunás $(2009,2013)$ sobre el caso del individuo con enfermedad de Paget mencionado por Gaspary (1950), sugieren que tal enfermedad pudo ser producto de una afección viral (Kozameh y Brunás 2013). 
A los casos de osteomielitis registrados en las muestras bioarqueológicas de esta tesis y los reportados en otros trabajos, se combina otra patología infecciosa que adquiere mayor relevancia. Se trata de la presencia de treponematosis en tres individuos adultos (dos de ellos femeninos) en las tres áreas de estudio. Para el DS (LTC1-P4) y CIRU (SLM-65) se tuvo la posibilidad de analizar las lesiones y realizar un diagnóstico diferencial. En el caso del DI (Túmulo I del Paraná Guazú, T1-PG-12), la referencia se basa en el registro descriptivo y fotográfico de Torres (1911), por lo que este caso debe tomarse con recaudo ya que no pudo ser reanalizado. A estos tres casos se le suma la descripción de Torres (1911) de las múltiples lesiones óseas en el esqueleto de un adulto masculino inhumado en un sitio del DI (Túmulo I del Brazo Largo), que interpreta como "infección sifilítica hereditaria" (Torres 1911: 378). A juzgar por las descripciones y fotografías, principalmente de las tibias que presentan la característica forma de sable asociada con treponematosis (véanse Capítulos 4 y 7), este caso sería otra evidencia más de la existencia de tal enfermedad en el sur del NEA. En este caso reportado por Torres no se menciona la existencia de las malformaciones dentales típicas de la sífilis congénita, por lo que el carácter venéreo y hereditario no puede confirmarse, al menos por el momento. Entre los casos analizados en esta tesis, las múltiples lesiones observadas en LTC1-P4 sugieren que se trata de alguno de los síndromes no venéreos; mientras que a partir de las lesiones en la bóveda craneana del individuo SLM-65, no se puede especificar con mayor detalle de qué tipo de síndrome se trata.

Tomando como punto de partida el diagnóstico de treponematosis no venérea en el DS, la presencia de esta enfermedad ha sido asociada con una mala higiene comunitaria (Hackett 1976; Csonka y Pace 1985). Asimismo, en trabajos más recientes efectuados en diversos conjuntos bioarqueológicos prehispánicos de Estados Unidos, se indicó su asociación con el sedentarismo y la agregación poblacional (Hutchinson et al. 2005; Powell et al. 2005; Wilson 2005; Smith 2006; Smith y Betsinger 2015). Específicamente en el sur de Florida, se detalló además que las condiciones climáticas habrían facilitado el desarrollo de lesiones cutáneas treponémicas, dado el clima cálido y húmedo que caracteriza a esta región subtropical (Hutchinson et al. 2005: 108). A pesar del registro de prevalencias más altas de treponematosis en asociación con la agregación poblacional -variable 
importante en la transmisión de estas infecciones-, no hay que olvidar que diferentes factores, independientes del asentamiento, pueden afectar la expresión de la treponematosis. Entre ellos se menciona el contacto corporal, la higiene personal, la virulencia de la enfermedad, la naturaleza de los cuidados paliativos y la fragilidad individual (Smith y Betsinger 2015: 862).

La información recién sintetizada invita a integrar los casos de treponematosis reportados previamente con el contexto arqueológico y ambiental. En fuentes etnohistóricas del siglo XVI se menciona la existencia de grandes asentamientos poblacionales, como es el caso del diario de Pero Lopes de Sousa. Durante su viaje por el Río de La Plata y Delta Inferior del Paraná en 1531, este explorador portugués observa un conjunto de viviendas de esteras rectangulares que conformaban un gran asentamiento en la costa, el cual estuvo ocupado durante casi un mes por entre 500 a 600 personas (Politis 2014). De acuerdo al estudio realizado sobre este diario y esta referencia en particular, se interpretó que se trataba de una aldea permanente o semi-permanente $o$ un asentamiento de agregación, posiblemente vinculado con alguno de los grupos del complejo étnico chana-timbú (Politis 2014). Arqueológicamente, este complejo étnico estaría representado en la entidad Goya-Malabrigo, para la cual se propuso que los montículos serían los lugares de vivienda con períodos prolongados de ocupación, que en algunos casos conformarían aldeas (Politis y Bonomo 2012). Además de esta información, hay que tener en cuenta la susceptibilidad hidrometeorológica que caracteriza a las áreas bajo estudio (Castiñeira Latorre et al. 2017a; véase Capítulo 5). Durante momentos de inundación habría ocurrido el nucleamiento de las personas en las zonas más elevadas del paisaje, a veces durante lapsos prolongados de tiempo (i.e. meses) hasta que el nivel de los ríos disminuya. A su vez, en estos períodos de crecidas, los animales terrestres también se concentran en lugares elevados no cubiertos por el agua, como por ejemplo pequeños roedores que pueden transmitir diferentes enfermedades infecciosas (Bonomo 2012). En conjunto, todos estos datos sugieren cierta estabilidad de ocupación en los mismos asentamientos residenciales (Politis y Bonomo 2012). Como fue propuesto como expectativa paleopatológica, estos momentos de agregación poblacional pudieron haber generado un aumento de la incidencia de enfermedades infecciosas de 
transmisión directa y/o asociadas con las condiciones de higiene y salubridad. De acuerdo a lo observado en las muestras bioarqueológicas, estas situaciones se confirmarían con el desarrollo no sólo de treponematosis, sino también de otras enfermedades infecciosas; estas últimas evidenciadas en los casos de osteomielitis y probablemente en las lesiones de estrés sistémico.

Asociado con esta propuesta sobre la incidencia de enfermedades infecciosas, es importante recordar los datos obtenidos de los estudios realizados en LTC1, de donde proviene el esqueleto con lesiones treponémicas. En este sitio, como se detalló en el Capítulo 5, fue identificado el núcleo de inhumación en la base del montículo. La información geoarqueológica y zooarqueológica sugiere que este sector, en un período previo a la inhumación de numerosos individuos, fue empleado como lugar del descarte secundario de los restos óseos faunísticos producidos a partir de las actividades domésticas llevadas a cabo en la cima del montículo (Bastourre 2014). Esta área de descarte podría haber propiciado condiciones de mala higiene y salubridad y favorecer así el contagio de distintos microorganismos necesarios para desarrollar patologías infecciosas.

Si se consideran los casos observados en esta tesis y los antecedentes de otros trabajos, para el área de CIRU son menos los individuos afectados por infecciones. Pero dado los pocos casos reportados en total, esto no puede atribuirse a mejores condiciones de salud para los grupos que habitaron esa zona. Como fue mencionado previamente, diferentes factores pueden invisibilizar enfermedades infecciosas en los conjuntos esqueléticos, al mismo tiempo que algunas de las reacciones periósticas observadas en esa muestra puede deberse a procesos infecciosos. Particularmente sobre la treponematosis, hay que considerar que estos contados casos reportados implican no sólo la presencia de la enfermedad en el área, sino también la presencia de muchos otros individuos con la misma afección (Marden y Ortner 2011). Por lo tanto, es muy probable que otros individuos de los grupos estudiados hayan padecido treponematosis pero no llegaron a la fase terciaria, o las lesiones óseas no alcanzaron el grado de desarrollo como las observadas en los casos estudiados.

La treponematosis está bien documentada para tiempos prehispánicos en diversas regiones de América del Norte (Powell y Cook 2005). Contrariamente, para 
el sur de Sudamérica, se han reportado pocos casos de infecciones treponémicas y algunos de ellos sin confirmación certera (Allison et al. 1982; Standen et al. 1985; Standen y Arriaza et al. 2000b; Aspillaga et al. 2006; Rodríguez et al. 2007; Gomes et al. 2015). Específicamente en Argentina, se mencionaron sólo tres casos de treponematosis, diagnosticados mediante análisis macroscópicos. Uno de ellos corresponde a la región del Paraná Medio. Específicamente se trata de las lesiones en un cúbito derecho y ambas tibias de un adulto masculino, que fue hallado en el sitio La Lechuza (Cornero y Puche 2007). Los otros dos casos proceden de la región patagónica y están vinculados con los grupos cazadores-recolectores del Holoceno tardío. Por un lado, en el sitio Carsa, ubicado en la costa norte de Santa Cruz, se observaron múltiples huesos con lesiones (región nasal y palatina del cráneo, costillas, esternón, ambos fémures) en un adulto joven masculino, que fueron atribuidas a la forma no venérea de treponematosis (Castro et al. 2009). Por otro lado, en un sitio arqueológico ubicado al sur de Chubut, Cerro Yanquenao, el reanálisis de los restos esqueletales de un individuo masculino de entre 40-50 años de edad permitió observar lesiones patológicas en varios huesos: en el centro del frontal y en la región nasal del cráneo y en ambas tibias, peronés, radios y cúbitos. Este individuo, fechado en ca. 1150 años AP, habría padecido treponematosis (García Guraieb et al. 2009), lo cual fue confirmado posteriormente mediante estudios radiológicos y tomográficos (García Guraieb et al. 2015). En este contexto, la información presentada en esta tesis de tres individuos adultos con treponematosis (LTC1-P4, SLM-65 y Túmulo I Brazo Largo), y de un posible caso en el Túmulo I del Paraná Guazú (T1-PG-12; Torres 1911), constituyen hallazgos importantes al evidenciar un considerable número de individuos con esta enfermedad en el sur del NEA. Al recordar que la presencia de estos contados casos indica que muchos otros individuos probablemente también padecieron estas afecciones, esta densidad de casos treponémicos concentrados en el sur del NEA apoyaría su correspondencia con las características de los asentamientos, como fue detallado anteriormente. Por otro lado, al integrarse con los otros casos mencionados, permitirán, en futuro, evaluar tendencias paleoepidemiológicas de la treponematosis prehispánica en Sudamérica (García Guraieb et al. 2015). 


\subsubsection{Lesiones traumáticas y violencia interpersonal}

Los traumas en colecciones bioarqueológicas pueden brindar información sobre violencia interpersonal, accidentes domésticos, así como también aspectos vinculados con estrategias de subsistencia y organización del trabajo (Larsen 1997; Lovell 1997; Ortner 2003). En esta tesis se registraron contados casos de lesiones traumáticas en las tres muestras, sin diferencias significativas entre ellas. Como fue detallado en el Capítulo 7, un solo caso (T1-PG-28) se vincularía con eventos accidentales, mientras que las depresiones en las bóvedas craneanas en otros cinco individuos (LTC1-P3, CL2-71, T1-CNM-83, T2-CSM-82 y T1-PG-37) de las tres áreas podrían indicar algún tipo de violencia interpersonal. Al observar los tamaños y formas de las lesiones, los objetos utilizados habrían sido romos y sin filo. En el registro arqueológico de las áreas estudiadas existen pocos objetos con estas características que podrían asociarse con estas lesiones. En el Delta Superior los conjuntos líticos son escasos; se han encontrado muy pocos artefactos por sitio, los cuales habrían ingresado al área como artefactos terminados mediante amplias redes de intercambio con las llanuras entrerrianas (Bonomo y Blasi 2010; Apolinaire 2017). Entre ellos pueden mencionarse algunas bolas y preformas de bolas, que podrían haber funcionado como los objetos causantes de las lesiones. Entre el material lítico procedente de varios sitios ubicados en el departamento Gualeguaychú (CIRU) y estudiado por Castro, J.C. (2017), se identificaron numerosas formas a las que se les atribuyó su vinculación con actividades de subsistencia y tal vez con violencia interpersonal; son los casos de bolas, de diferentes materias primas y tamaños. Por otro lado, los rodados fluviales tienen una alta disponibilidad en la zona y eran usados para elaborar diferentes instrumentos (Castro, J.C. 2017), que también podrían haber sido utilizados en los conflictos interpersonales. En cuanto al Dl, entre los distintos grupos tipológicos identificados entre el material lítico, se destacan los esferoides que podrían corresponder a bolas de boleadora o pesas de red (Bonomo et al. 2009) y podrían haber causado las lesiones redondeadas en las bóvedas craneanas. Más allá de estos registros arqueológicos, los documentos escritos de los siglos XVI-XVIII mencionan que los grupos humanos que habitaban el Noreste Argentino confeccionaban distintos instrumentos, herramientas y artefactos con madera (Chiri 1975). Entre ellos, se destaca la 
manufactura de armas por parte de los timbú y caracaraes, como por ejemplo garrotes, flechas y lanzas, entre otros (Fernández de Oviedo y Valdés [1547] 1851). Algunos de estos artefactos también podrían haber sido utilizados en las confrontaciones.

Para esta misma área del Dl, Torres (1911) también reportó lesiones en cráneos que relaciona con probables golpes y que, según sus descripciones, parecen ser similares a las observadas en las muestras aquí estudiadas. Se trata de un individuo femenino y tres masculinos; las normas afectadas fueron en el frontal y en los parietales y en dos de los individuos masculinos se registraron múltiples lesiones (véase Capítulo 3). Los otros antecedentes de lesiones traumáticas reportados para el DI provienen del sitio Cerro Luz. Por un lado, se registraron dos hundimientos en el parietal de un adulto masculino y fueron atribuidos a probables traumas (Kozameh et al. 2007). Por otro lado, el esqueleto de un adulto masculino fue hallado con tres puntas óseas insertadas en la cavidad torácico-abdominal y columna vertebral (Mazza 2015). Este último caso cobra relevancia al ser el único, hasta el momento para el sur del NEA, en el que se evidencia claramente un evento de violencia interpersonal. Por otro lado, para el DS, Gaspary (1950) menciona un esqueleto con una fractura consolidada de ambos huesos del antebrazo. A partir de esta descripción es imposible discernir si se trata de una fractura producto de un evento accidental (por ej. fractura de Colles) o si puede ser resultado de un acto de defensa frente a un ataque.

Las fuentes etnohistóricas relativas al sector de islas del Paraná y Río de la Plata señalan la presencia de diferentes etnias y/o "parcialidades" dentro de ellas: chaná, chaná-timbú, timbú, beguá, chaná-beguá, caracaraes (véase síntesis en Apolinaire y Bastourre 2016). En uno de los documentos escritos de principios del siglo XVI, correspondiente a la expedición de Diego García de Moguer por el Río de la Plata, se explicita la coexistencia pacífica entre varios de los grupos arriba mencionados (García de Moguer en Becco 1994: 7-9). Las escasas evidencias de traumas relevadas en esta tesis, y las pocas mencionadas en otros trabajos, irían en concordancia con el bajo nivel de conflicto entre los diferentes grupos étnicos mencionado en los documentos etnohistóricos, lo cual fue planteado como expectativa paleopatológica. 
En otros documentos etnohistóricos también se resaltan las alianzas entre los distintos grupos antes mencionados para enfrentarse a los guaraníes y españoles (Apolinaire y Bastourre 2016). Particularmente sobre los guaraníes, distintos relatos (por ej. Fernández de Oviedo ([1547] 1851; Ramírez [1528] 1902) apuntan a su belicosidad y las relaciones conflictivas que tenían con los demás grupos del sector de islas del Delta del Paraná. De todas formas, la caracterización negativa de los grupos humanos con los que se contactaron los exploradores debe ser entendida en el contexto de los intereses propios de la conquista (Bonomo 2012). Por otro lado, el amplio registro arqueológico proporciona evidencias de la interacción social entre los pobladores locales y los grupos guaraníes (por ej. escasa alfarería corrugada, unguiculada y polícroma en sitios Goya-Malabrigo), que podría haberse dado a través del comercio, intercambio, trueque; así como también la difusión de ideas que se manifiestan en la imitación de objetos y conductas (Bonomo 2012; Bonomo et al. 2015; Castro, J.C. 2017). También es posible que los guaraníes hayan instalado aldeas permanentes e impuesto su cultura a las poblaciones nativas (Bonomo 2012). En el estudio realizado en esta tesis, las relaciones de enemistad expresadas en las fuentes escritas entre estos grupos y los guaraníes no pueden corroborarse; así como tampoco se pueden afirmar los vínculos de contacto/intercambio. De los cinco individuos con lesiones, tres de ellos proceden de sitios (LTC1, CL2, T2-CSM) para los que se cuenta con fechados anteriores a la llegada de los guaraníes al sur del NEA (la datación más temprana conocida hasta el momento pertenece al sitio Arroyo Fredes y corresponde a $690 \pm 70$ años AP; Loponte y Acosta 2003-2005). Sobre los otros dos individuos, uno procede de un sitio aún no fechado (T1-CNM) y para el restante (T1-PG) se cuenta con una datación que se solaparía con la presencia de los guaraníes. Estos datos deben tomarse con cautela dado que no son fechados efectuados sobre los individuos con los traumas, lo que proporcionaría mayor precisión a esta discusión. 


\subsection{Conclusiones}

Los modos de vida de los grupos humanos que habitaron en tiempos prehispánicos el sur del Noreste Argentino han sido abordados desde diferentes líneas de estudio (por ej. arqueobotánica, isotópica, tecnológica, zooarqueológica), dejando al descubierto la necesidad de realizar análisis paleopatológicos que aporten a la discusión sobre los patrones adaptativos de estas sociedades indígenas. Estos estudios, abordados en profundidad en esta tesis, permitieron obtener información complementaria sumamente útil sobre aspectos que no son inferibles a partir de otros componentes del registro arqueológico. La articulación y el diálogo entre los distintos registros fueron cruciales para alcanzar un análisis bioarqueológico integrador y holístico, que permitieran entender mejor aspectos relacionados, principalmente, con la dieta y la salud de las poblaciones que habitaron el sur del NEA durante el Holoceno tardío.

Particularmente desde los indicadores de salud bucal y adecuación fisiológica, los resultados en las tres muestras bioarqueológicas se ajustan a lo esperado para dietas mixtas, lo cual ya fue planteado desde otras líneas de estudio para el Delta Superior del Paraná. Los recursos animales constituyeron el componente principal de la alimentación, siendo probablemente los peces uno de los recursos explotados más importantes. Así queda evidenciado, principalmente, en las elevadas tasas de cálculo dental. Su consumo mayoritario también habría actuado como protector para las caries, de modo que el consumo de vegetales silvestres y domesticados -parte constitutiva importante y complementaria en la dieta- no quedó registrado en la salud bucal. Asimismo, los diferentes modos de procesamiento de los alimentos influyeron directamente en la salud bucal y el desgaste dental. Si bien todos estos aspectos se presentan en general en las tres muestras bioarqueológicas estudiadas, los grupos que habitaron la cuenca inferior del río Uruguay presentaron una dieta más abrasiva, relacionada con los modos de preparación de los alimentos (principalmente por la molienda, usando artefactos de piedra, y el asado y cocción directa sobre el fuego). Por otro lado, las tendencias parecen indicar un consumo de alimentos diferenciado entre hombres y mujeres en 
cuanto a la ingesta de proteínas, lo cual a su vez podría estar vinculado con patrones sexuales específicos en la obtención de los recursos explotados.

La existencia de aldeas con ocupación semipermanente (propuesto principalmente para el Delta Superior y cuenca inferior del río Uruguay) y los asentamientos en lugares sobreelevados como estrategia adaptativa frente a las condiciones ambientales inundables de las tres áreas estudiadas, incidieron en la salud de las personas. Algunos de los individuos padecieron eventos de estrés sistémico durante sus primeros años de vida, probablemente asociados con el desarrollo de enfermedades gastrointestinales; aun así pudieron sobrellevar tales condiciones adversas y alcanzar la adultez. La exposición a distintos microorganismos infecciosos habría sido recurrente en los momentos de nucleamiento poblacional $y$, en un bajo porcentaje, las patologías llegaron a alcanzar el tejido óseo. En estos casos, la vida de los individuos tampoco estuvo severamente comprometida como así lo demuestra la cronicidad de las lesiones óseas. Las bajas prevalencias de lesiones infecciosas relevadas no son entendidas como producto de bajas incidencias en contraer tales enfermedades. Es probable que más individuos hayan sido afectados por distintos micro-organismos, pero sin llegar a alcanzar el nivel óseo.

Las escasas evidencias de traumas en los individuos analizados, sustentan lo que algunas fuentes etnohistóricas mencionan para el complejo étnico chaná-timbú; esto es la existencia de buenas relaciones entre los distintos grupos o parcialidades étnicas que habitaron el sur del NEA. En tanto que la supuesta belicosidad de los grupos guaraníes no puede ser evaluada por el momento.

En conjunto, los resultados obtenidos de los análisis de distintos bioindicadores bucales y óseos expresan similitudes en cuanto a la dieta y la salud de los grupos humanos que habitaron el Delta Superior e Inferior del río Paraná y la cuenca inferior del río Uruguay. El trabajo realizado en esta investigación ha estado fuertemente influenciado por las particularidades de las muestras bioarqueológicas estudiadas. En tanto se amplíen los estudios bioarqueológicos y se los integre con nuevos resultados obtenidos de otras líneas de estudio, las tendencias aquí registradas podrán ser reevaluadas y puestas a prueba. Por el momento, esta tesis enriquece el conocimiento de los modos de vida de los grupos 
prehispánicos que habitaron el sur del NEA, así como también constituye un puntapié inicial para el desarrollo y profundización de futuras investigaciones bioarqueológicas. 


\section{Bibliografía}

Acosta, A. 2005. Zooarqueología de cazadores-recolectores del extremo nororiental de la provincia de Buenos Aires (humedal del río Paraná inferior, Región Pampeana, Argentina). Tesis doctoral inédita, Facultad de Ciencias Naturales y Museo, Universidad Nacional de La Plata, La Plata.

Acosta, A. y D. Loponte. 2013. Complejidad social y estrategias de subsistencia de las poblaciones cazadoras recolectoras del humedal del Paraná inferior. Cuadernos del Instituto Nacional de Antropología, Series Especiales 4: 60-74.

Acosta, A. y B. Mazza. 2016. Restos óseos humanos y faunísticos: su relación en el espacio mortuorio en contextos de cazadores-recolectores del humedal del Paraná inferior (Argentina). Pesquisas Antropología 72: 185-207.

Acosta, A. y V. Rios Roman. 2013. Explotación prehispánica de palmeras por grupos cazadores recolectores y horticultores del extremo sur de Sudamérica: el caso del humedal del Paraná inferior (Argentina). Pesquisas Antropologia 70 (6): 197-216.

Acosta, A., S. Ali, N. Buc, N. Davrieux, V. Di Prieto, D. Loponte, B. Mazza, L. Mucciolo, M. Pérez, V. Rios Roman, R. Sacur Silvestre, D. Vigliocco y R. Zattera. 2013. Variabilidad arqueológica en el tramo final del humedal del Paraná inferior durante el Holoceno tardío. Libro de resúmenes del 5to Encuentro de Discusión de Arqueología del Nordeste Argentino: 76-77.

Acosta, A., D. Loponte y P. Tchilingurian. 2010. Análisis comparativo sobre la estructura y los procesos de formación de los depósitos arqueológicos en el humedal del rio Paraná inferior (delta del Paraná). En: Arqueología de Cazadoresrecolectores en la Cuenca del Plata, editado por G. Cocco y M.R Feuillet Terzaghi; pp. 191-208. Centro de Estudios Hispanoamericanos, Santa Fe.

Acsádi, G. y J. Nemeskéri. 1970. History of human life span and mortality. Akadémiai Kiadó. Budapest. 
Allison, M.J., G. Focacci, M. Fount y M. Cebelin. 1982. La Sífilis ¿Una enfermedad Americana? Chungara, Revista de Antropología Chilena 9: 275-284.

Almeida, M.S. 1971. Exploraciones arqueológicas en el sur de Entre Ríos. Ms. 1983. El arte prehistórico. Bicentenario de Gualeguaychú. Homenaje de Diario El Día al cumplir 200 años de su fundación. 1783 - 18 de octubre - 1983. Gualeguaychú, Entre Ríos.

Ambrosetti, J.B. 1893. Sobre una colección de alfarerías Minuanes recogidas en la provincia de Entre Ríos. Boletín del Instituto Geográfico Argentino XIV: 242-257. 1894. Los paraderos precolombianos de Goya (Provincia de Corrientes). Boletín del Instituto Geográfico Argentino XV: 401-422.

1895. Los cementerios prehistóricos del Alto Paraná (Misiones). Boletín del Instituto Geográfico Argentino XVI: 227-263.

Ameghino, F. 1880. La Antigüedad del Hombre en el Plata. Ediciones Intermundo, Buenos Aires.

1889. Contribución al conocimiento de los mamíferos fósiles de la República Argentina. Actas de la Academia Nacional de Ciencias en Córdoba, Buenos Aires.

\section{Ammann, M.G., M. Arrieta, M.C. Croatto, L. Debernardi, O.J. Mendonça y M.A.} Bordach. 2010. Descripción e interpretación de marcadores bioarqueológicos del sitio Médano Petroquímica, departamento Puelén, Provincia de la Pampa. En: Mamül Mapu: Pasado y Presente desde la Arqueología Pampeana, editado por M. Berón, L. Luna, M. Bonomo, C. Montalvo, C. Aranda y M. Carrera Aizpitarte; pp. 105-112. Editorial Libros Del Espinillo, Ayacucho, Buenos Aires.

Aparicio, F. de. 1928. Notas para el estudio de la arqueología del Sur de Entre Ríos. Anales de la Facultad de Ciencias de la Educación 3: 1-63.

1939. El Paraná y sus tributarios. En: Historia de la Nación Argentina, editado por Ricardo Levene; pp. 419-442, vol. I. El Ateneo, Buenos Aires.

Apolinaire, E. 2017. Arqueología del suroeste de Entre Ríos: tecnología, subsistencia e interacción social en tiempos prehispánicos. Tesis doctoral inédita, Facultad de Ciencias Naturales y Museo, Universidad Nacional de La Plata. 
Apolinaire, E. y L. Bastourre. 2016a. Los documentos históricos de los primeros momentos de la conquista del Río de La Plata (S XVI-XVII): una síntesis etnohistórica comparativa. Relaciones de la Sociedad Argentina de Antropología XLI (2): 319-351.

2016b. Nets and canoes: a network approach to the preHispanic settlement system in the Upper Delta of the Paraná River (Argentina). Journal of Antropological Archaeology 44: 56-68.

Aranda C., P. Araújo Silva, M. Fugassa y A. Araújo. 2010. Primeros resultados paleoparasitológicos de una muestra de entierros del sitio Chenque I (Parque Nacional Lihué Calel, Provincia De La Pampa). En: Mamül Mapu: Pasado y Presente desde la Arqueología Pampeana, editado por M. Berón, L. Luna, M. Bonomo, C. Montalvo, C. Aranda y M. Carrera Aizpitarte; pp. 113-122. Editorial Libros Del Espinillo, Ayacucho, Buenos Aires.

Armelagos, G.J. 2003. Bioarchaeology as Anthropology. En: Archaeology Is Anthropology, editado por S.D. Gillespie y D. Nichols; No. 13, pp. 27-41. Archeological Papers of the American Anthropological Association Series.

Armelagos, G.J. y D.P. Van Gerven. 2003. A century of skeletal biology and paleopathology: Contrast, contradictions, and conflints. American Anthropologist 105 (1): 53-64.

Arrieta, M. 2012. Biología esqueletal y estrategias adaptativas. Salud y enfermedad en poblaciones prehistóricas del Noroeste argentino. Tesis doctoral inédita, Facultad de Ciencias Exactas, Físico-químicas y Naturales, Universidad Nacional de Río Cuarto.

Arrieta, M., M.A Bordach y O.J. Mendonça. 2014. Pre-Columbian tuberculosis in Northwest Argentina: skeletal evidence from Rincón Chico 21 cemetery. International Journal of Osteoarchaeology 24: 1-14.

Aspillaga, E., M. Castro, M. Rodríguez y C. Ocampo. 2006. Paleopatología y estilo de vida: el ejemplo de los Chonos. Magallania 34 (1): 77-85. 
Aufderheide, A. y C. Rodríguez-Martín. 1998. The Cambridge Encyclopedia of Human Paleopathology. Cambridge University Press. Cambridge.

Ávila, J.D. 2011. Resultados de los fechados radiocarbónicos del sitio Laguna El Doce, Departamento General López, Provincia de Santa Fe. Relaciones de la Sociedad Argentina de Antropología 36: 337-343.

Baigún, C., A. Puig y P.G. Minotti. 2008. Resource use in the Parana River Delta (Argentina): Moving away from an ecohydrological approach? Ecohydrology and Hydrobiology 8: 245-262.

Barboza, M.C. 2014. Análisis arqueofaunístico del sitio Paso del Tala (Goya, Corrientes, Argentina). Revista del Museo de Antropología 7 (2): 219-226.

Barboza, M.C. y M. Martín. 2015. Análisis del registro arqueofaunístico de grupos cazadores-recolectores del holoceno tardío de la llanura aluvial del Paraná medio (sitio Los Bananos, Departamento Goya, Corrientes, Argentina). Revista Chilena de Antropología 29: 136-140.

Barboza, M.C. y C.V. Píccoli. 2013. Ocupaciones humanas en la llanura aluvial del Paraná Medio durante el Holoceno tardío. El registro arqueológico del sitio Los Bananos (Goya, Corrientes, Argentina). Anuario de Arqueología 5: 117-132.

Barboza, M., M.A. Bordach y O.J. Mendonça. 2004. Osteología humana. Determinación de la edad y el sexo. El sitio SJ TIL 43. Universidad Nacional de Río Cuarto. Facultad de Ciencias Exactas, Físico-Químicas y Naturales. Río Cuarto.

Barrientos, G. 1997. Nutrición y dieta de las poblaciones aborígenes prehispánicas del sudeste de la región pampeana. Tesis doctoral inédita, Facultad de Ciencias Naturales y Museo, Universidad Nacional de La Plata.

1999. Metodología de análisis de hipoplasias de esmalte dental aplicada al estudio de poblaciones prehispánicas del sudeste de la región pampeana. Revista Argentina de Antropología Biológica 2: 307-322.

Barrientos, G. y L. L’Heureux. 2001. Determinación de la edad de muerte a través del análisis de la altura total de la corona dental en muestras del Holoceno 
temprano del Sudeste de la Región Pampeana. Revista Argentina de Antropología Biológica 3 (1): 7-21.

Bastourre, L. 2014. Estudios arqueofaunísticos en el Delta Superior del Paraná: el sitio Los Tres Cerros 1 (Provincia de Entre Ríos, Argentina). Revista Chilena de Antropología 30: 109-115.

2017. Procesamiento y consumo de peces en el sitio Los Tres Cerros 1 (departamento Victoria, Entre Ríos). En: Libro de resúmenes del Séptimo Encuentro de Discusión Arqueológica del Nordeste Argentino, Revista Scientia Interfluvius, pp. 15. Diamante, Entre Ríos.

Bastourre, L. y E. Apolinaire. 2017. Estudios arqueofaunísticos en un contexto estratigráfico de las Ilanuras interiores entrerrianas: el sitio Laguna del Negro 1 (departamento Gualeguay, Argentina). Boletim do Museu Paraense Emilio Goeldi: Ciencias Humanas 12 (2): 453-471.

Batalla, Y. y B. Di Lorenzo. 2016. Determinación de sexo a partir de métodos cuantitativos en la serie esqueletal del sitio Los Tres Cerros 1 (Entre Ríos). En: Libro de resúmenes del Séptimo Encuentro de Discusión Arqueológica del Nordeste Argentino, Revista Scientia Interfluvius, pp. 69. Diamante, Entre Ríos.

Becco, H. 1994. Cronistas del Río de la Plata. Caracas, Fundación Biblioteca Ayacucho.

Béguelin, M. 2009. Variación Geográfica en la Morfología del Esqueleto Postcraneal de las Poblaciones Humanas de Pampa y Patagonia durante el Holoceno Tardío: Una Aproximación Morfométrica. Tesis doctoral inédita, Facultad de Ciencias Naturales y Museo La Plata, Universidad Nacional de La Plata.

2010. Tamaño corporal y temperatura ambiental en poblaciones cazadorasrecolectoras del Holoceno tardío de Pampa y Patagonia. Revista Argentina de Antropología Biológica 12 (1): 27- 36.

Béguelin, M. y P. González. 2008. Estimación del sexo en poblaciones del sur de Sudamérica mediante funciones discriminantes para el fémur. Revista Argentina de Antropología Biológica 10 (2): 55-70. 
Béguelin M., F. Lotto y P. González. 2011. Estimación del sexo en cazadoresrecolectores de Sudamérica a partir de variables métricas del húmero. Intersecciones en Antropología 12: 61-68.

Bennike, P. 2008. Trauma. En: Advances on Human Paleopathology, editado por S. Mays y R. Pinhasi; pp. 309-328. John Wiley \& Sons. Ltd. West Sussex.

Bernal, V. 2008. Procesos de diferenciación biológica entre poblaciones humanas del Holoceno tardío de Patagonia. Una aproximación desde la variación métrica dental. Tesis doctoral inédita, Facultad de Ciencias Naturales y Museo, Universidad Nacional de La Plata.

Bernal, V. y L. Luna. 2011. The development of dental research in Argentine biological anthropology: current state and perspectives. HOMO Journal of Comparative Human Biology 62: 315-327.

Bernal, V., P. Novellino, P. González y I. Perez. 2007. Role of wild plant foods among Late Holocene hunter-gatherers from Central and North Patagonia (South America): an approach from dental evidence. American Journal of Physical Anthropology 133: 1047-1059.

Blakey M.L., T.E. Leslie y J.P. Reidy. 1994. Frequency and chronological distribution of dental enamel hypoplasia in enslaved African Americans: A test of the weaning hypothesis. American Journal of Physical Anthropology 95: 371-383.

\section{Blom, D.E., J.E. Buikstra, L. Keng, P.D. Tomczak, E. Shoreman y D. Stevens-} Tuttle. 2005. Anemia and childhood mortality: Latitudinal patterning along the coast of Pre-Columbian Peru. American Journal of Physical Anthropology 127: 152-169

Bó, R. y A. Malvárez. 1999. Las inundaciones y la biodiversidad en humedales. Un análisis del efecto de eventos extremos sobre la fauna silvestre. En: Tópicos sobre humedales subtropicales y templados de Sudamérica, editado por A. Malvárez; pp. 140-161. Montevideo: Oficina Regional de Ciencia y Tecnología de la UNESCO para America Latina y el Caribe. 
Bogin, B. 2002. The evolution of human growth. En: Human growth and development, editado por N. Cameron; pp. 295-320. Academic. Press, Amsterdam.

Bohndorf, K. 2004. Infection of the appendicular skeleton. European Radiology 14: $53-63$.

Boldsen, J.L. y G.R. Milner. 2012. An epidemiological approach to paleopathology. En: A companion to paleopathology, editado por A.L. Grauer; pp. 114-132. Chichester, UK: Wiley-Blackwell.

Bollini, G.A. y J.P. Atencio. 2016. Evaluación de métodos de determinación sexual en bioarqueología utilizando la dentición. Resumenes III Taller Nacional de Bioarqueología y Paleopatología. Ciencias Morfológicas 18 (1): 57.

Bollini, G., J.P. Atencio y S. Colantonio. 2012. Análisis odontométrico de cuatro series craneanas de aborígenes argentinos. Revista Argentina de Antropología Biológica 14: 69-80.

Bonomo, M. 2006. Un acercamiento a la dimensión simbólica de la cultura material en la región pampeana. Relaciones de la Sociedad Argentina de Antropología XXXI: 89-115.

2012. Historia prehispánica de Entre Ríos. Fundación de Historia Natural Félix de Azara. Buenos Aires.

2013. Reanálisis de la colección de Samuel Lothrop procedente del Delta del Paraná. Relaciones de la Sociedad Argentina de Antropología XXXVIII (1): 169198.

Bonomo, M. y A. Blasi. 2010. Base regional de recursos líticos del Delta del Paraná. Estudio petrográfico de artefactos y afloramientos en el sur de Entre Ríos. Revista Cazadores Recolectores del Cono Sur 4: 17-41.

Bonomo, M. y M. Farro. 2014. El contexto socio-histórico de las investigaciones de Samuel K. Lothrop en el Delta del Paraná, Argentina. Chungara, Revista de Antropología Chilena 46 (1): 131-143. 
Bonomo, M. y S. Latini. 2012. Arqueología y etnohistoria de la región metropolitana: las sociedades indígenas de Buenos Aires. En: Buenos Aires, la historia de su paisaje natural, editado por J. Athor; pp. 70-98. Fundación de Historia Natural Félix de Azara, Buenos Aires.

Bonomo, M. y G. Politis. 2018. Mound building, social complexity and horticulture in the lower Paraná river. Encyclopedia of Global Archaeology. En prensa.

Bonomo, M. F. Aceituno, G. Politis y M. Pochettino. 2011a. Pre-Hispanic horticulture in the Paraná Delta (Argentina): archaeological and historical evidence. World Archaeology 43 (4): 557-579.

Bonomo, M., E. Cabanillas y R. Montero. 2017b. Archaeometallurgy in the Paraná Delta (Argentina): composition, manufacture, and indigenous routes. Journal of Anthropological Archaeology 47: 1-11

Bonomo, M., I. Capdepont y A. Matarrese. 2009. Alcances en el estudio de colecciones. Los materiales arqueológicos del Delta del río Paraná depositados en el Museo de La Plata (Argentina). Arqueología Sudamericana 5: 68-101.

Bonomo, M., J.C. Castro y C. Silva. 2014. Tecnología y subsistencia en el sitio arqueológico Cerro Tapera Vázquez (Parque Nacional Pre-Delta, República Argentina). Cadernos del Lepaarq 11 (22): 21-81.

Bonomo, M., M.M. Colobig y N. Mazzi. 2012. Análisis de residuos orgánicos y microfósiles silíceos de la "cuchara" de cerámica del sitio arqueológico Cerro Tapera Vázquez (Parque Nacional Pre-Delta, Argentina). Revista do Museu de Arqueologia e Etnologia 22: 31-50.

Bonomo, M., M.M. Colobig, E. Passeggi, A. Zucol y M. Brea. 2011c. Multidisciplinary studies at Cerro Tapera Vázquez site, Pre-Delta National Park, Argentina: the archaeological, sedimentological and paleobotanical evidence. Quaternary International 245 (1): 48-61. 
Bonomo, M., R. Costa Angrizani, E. Apolinaire y F. Silva Noelli. 2015. A model for the Guaraní expansion in the La Plata Basin and litoral zone of southern Brazil. Quaternary International 356: 54-73.

Bonomo, M., G. Politis y J.C. Castro. 2010. Primeros resultados de las investigaciones arqueológicas en el Delta Superior del Paraná y su contribución al atlas arqueológico de la provincia de Entre Ríos. Folia Histórica del Nordeste 18: $33-58$.

Bonomo, M., G. Politis y C. Gianotti. 2011b. Montículos, jerarquía social y horticultura en las sociedades indígenas del delta del río Paraná (Argentina). Latin American Antiquity 22 (3): 297-333.

Bonomo, M., G. Politis, C. Silva, L. Bastourre, M.A. Ramos van Raap, C. Castiñeira, C. Scabuzzo y E. Apolinaire. 2016a. Estado actual de las investigaciones en la localidad arqueológica Laguna de los Gansos (Diamante, Entre Ríos). Revista del Museo de Antropología 9 (2): 51-66.

Bonomo, M., C. Scabuzzo, G. Politis y A. Zucol. 2017a. Stable carbon and nitrogen isotope studies in the Paraná River Delta (Argentina): an approach to prehispanic diets. Latin American Antiquity: 1-22.

Bonomo, M., F. Skarbun y L. Bastourre. 2018. Subsistencia y alimentación en arqueología. Una aproximación a las sociedades indígenas de América precolombina. Edulp, Editorial de la Universidad de la Plata, UNLP, La Plata. En prensa.

Bocquet-Appel, J. y C. Masset. 1982. Farewell to Paleodemography. Journal of Human Evolution 11: 321-333.

Bordach, M.A., O.J. Mendonça, M. Arrieta y L. Bernardi. 2014. Bioarchaeological Research in Argentina: Past, Present and Future Challenges. En: Archaeological Human Remains, Global Perspectives, editado por B. O'Donnabhain y M. C. Lozada; pp. 13-27. Springer Briefs in Archaeology. 
Bourlot, T. 2008. Guerreros, máscaras y narices decoradas. Culturas nativas del litoral entrerriano y la colección arqueológica Manuel Almeida. Museo Manuel Almeida, Gualeguaychú.

Brady, R.A., J.G. Leid, J.W. Costerton y M.E. Shirtliff. 2006. Osteomyelitis: Clinical Overview and Mechanisms of Infection Persistence. Clinical Microbiology Newsletter 29 (9): 65-72.

Brea, M., M.J. Franco, M. Bonomo y G. Politis. 2013. Análisis antracológico preliminar del sitio arqueológico Los Tres Cerros 1 (Delta Superior del río Paraná). Revista del Museo de La Plata, Sección Antropología 13 (87): 345-360.

Brickley, M. y R. Ives.

2008. The Bioarchaeology of Metabolic Bone Disease. Academic Press, San Diego.

Buc, N., y R. Silvestre. 2006. Funcionalidad y complementariedad de los conjuntos líticos y óseos en el humedal del nordeste de la Provincia de Buenos Aires: Anahí, un caso de estudio. Intersecciones en Antropología 7: 129-146.

Buikstra, J.E. 1977. Biocultural dimensions of archaeological study: a regional perspective. En: Biocultural Adaptation in Prehistoric America, editado por R.L. Blakely; Proceedings of the Southern Arthropological Society; Nro.11; pp. 67-84. University of Georgia Press, Athens.

1991. Out of the Appendix and into the Dirt: Comments on Thirteen Years of Bioarchaeological Research. En: What Mean These Bones?, editado por M.L. Powell, P.S. Bridges y A.M.W. Mires; pp. 172-188. Tuscaloosa: University of Alabama Press.

2006. On to the 21st century. En: Bioarchaeology: The Contextual Study of Human Remains, editado por J.E. Buikstra y L.A. Beck; pp. 347-357. Elsevier. Amsterdam.

Buikstra, J.E. y L.A. Beck. 2006. Bioarchaeology. The Contextual Analysis of Human Remains. Academic Press, New York.

Buikstra, J.E. y D.C. Cook. 1980. Paleopathology: an American account. Annual Review of Anthropology 9: 433-470. 
Buikstra, J.E. y D. Ubelaker. 1994. Standars for data collection from human skeletal remains. Arkansas Archaeological Survey Research Series No 44, Arkansas.

Burkart, A. 1943. Las Leguminosas Argentinas Silvestres y Cultivadas. Acme Agency. Buenos Aires.

Burkart, R., N. Bárbaro, R. Sánchez y D. Gómez. 1999. Ecorregiones de la Argentina. Administración de Parques Nacionales. Buenos Aires.

Bush, E. 1991. Concepts of health and stress. En: Health in Past Societies: Biocultural Interpretations of Human Skeletal Remains in Archaeological Context, editado por E. Bush y M. Zvelebil; pp. 11-22. BAR International Series 567. Oxford.

Bush, E. y M. Zbelevil. 1991. Pathology and health in past societies: an introduction. En: Health in Past Societies: Biocultural Interpretations of Human Skeletal Remains in Archaeological Context, editado por E. Bush y M. Zvelebil; pp. 3-9. BAR International Series 567. Oxford.

Buzon, M.R. 2012. The bioarchaeological approach to paleopathology. En: $A$ companion to Paleopathology, editado por A. Grauer; pp. 58-75. Willey-Balckwell, Malden.

Cabrera, A. 1971. Fitogeografía de la República Argentina. Boletín de la Sociedad Argentina de Botánica 14 (1-2): 1-42.

Caggiano, M.A. 1984. Prehistoria del noreste Argentino, sus vinculaciones con la República Oriental del Uruguay y sur de Brasil. Pesquisas, Antropología 38: 1-109.

Caggiano, M.A. y O. Flores. 2001. La ocupación humana en el delta del Paraná, a propósito de nuevos fechados radiocarbónicos. Actas del XIV Congreso Nacional de Arqueología Argentina 1-8. Rosario, UNR.

Caggiano, M.A., O. Flores, M.G. Méndez y S. Salceda. 1978a. Nuevos aportes para el conocimiento antropológico del Delta del Paraná. Relaciones de la Sociedad Argentina de Antropología XII: 155-174. 
1978b. Reseña sobre la investigación de los restos del sitio P.I.1., Delta del Paraná. Sapiens 2: 36-39. Museo Arqueológico Municipal "Dr. O.F.A. Menghin", Chivilcoy.

Calhoun, J.H., M.M., Manring y M. Shirtliff. 2009. Osteomyelitis of the long bones. Seminars in Plastic Surgery 23 (2): 59-72.

Calo, C.M. y L. Cortés. 2009. A contribution to the study of diet of Formative societies in Northwestern Argentina: isotopic and archaeological evidence. International Journal of Osteoarchaeology 19: 192-203.

Campillo, D. 2001. Introducción a la Paleopatología. Bellaterra Arqueología. España.

Cano, E. 1988. Pastizales naturales de La Pampa. Descripción de las especies más importantes. Tomo 1. Zona Semiárida. Convenio AACREA- Provincia de La Pampa. Santa Rosa.

Carnese, F. y H. Pucciarelli. 2007. Investigaciones Antropobiológicas en Argentina, desde la década de 1930 hasta la actualidad. Relaciones de la Sociedad Argentina de Antropología 32: 243-280.

Carnese, F., J. Cocilovo y A. Goicoechea. 1991-92. Análisis histórico y estado actual de la antropología biológica en Argentina. Runa 20: 35-67.

Carrara, M.T., M.S. Carballo y M.P. Valentini. 1998. Localización y prospección de sitios arqueológicos en la zona isleña aledaña a la ciudad de Rosario. Anuario de la Universidad Internacional SEK 4: 9-23.

Castiñeira Latorre, C., E. Apolinaire, A. Blasi, M. Bonomo, G. Politis, L. Bastourre y F. Mari. 2017a. Pre-Hispanic settlements in hydrometeorologically susceptible areas during the late Holocene: The Upper Delta of the Paraná River Case. The Holocene: 1-17.

Castiñeira Latorre, C., E. Apolinaire, A. Blasi, G. Politis, M. Bonomo y F. Mari. 2017b. Pre-Hispanic earthwork engineering variability in the Upper Delta of the Paraná River. A comparative study between Los Tres Cerros mounds (Entre Ríos province, Argentina). Journal of Archaeological Science, Reports 13: 322-332. 
Castiñeira Latorre, C., A. Blasi, M. Bonomo, G. Politis y E. Apolinaire. 2014. Modificación antrópica del paisaje durante el Holoceno tardío: las construcciones monticulares en el Delta Superior del río Paraná, Argentina. Revista de la Asociación Geológica Argentina 71 (1): 33-47.

\section{Castiñeira Latorre, C., A. Blasi, G. Politis, M. Bonomo, L. Del Puerto, R. Huarte, J.} Carbonari, F. Mari y F. García-Rodriguez. 2013. Origin and construction of mounds in the Upper Paraná Delta Wetlands (Argentina). Archaeological and Anthropological Sciences 5 (1): 37-57.

Castro, A., S. Salceda, M. Plischuk y B. Desántolo. 2009. Bioarqueología de rescate: Sitio Carsa (Costa Norte de Santa Cruz, Argentina). En: Arqueología de Patagonia: una mirada desde el último confín, compilado por M. Salemme, F. Santiago, M. Alvarez, E. Piana, M. Vázquez y E. Mansur; Tomo II, pp. 629-638. Editorial Utopías, Ushuaia.

Castro, C. 2017. Reconstrucción de vasijas asociadas a contextos funerarios en el sitio Los Tres Cerros 1 (Delta Superior del río Paraná, Entre Ríos). Comechingonia. Revista de Arqueología. Dossier Sexto Encuentro de Discusión Arqueológica del Nordeste Argentino. En prensa.

Castro, C. y C. Castiñeira Latorre. 2017. Variabilidad espacial y temporal de los cerritos del delta superior del río Paraná. En: Actas del XIX Congreso Nacional de Arqueología Argentina; pp. 3195-3197. Tucumán.

Castro, J.C. 2016. Late-Holocene indigenous occupation of the Uruguay river (Argentina). DIGit. Journal of the Flinders Archaeological Society 3: 42-53.

2017. Investigaciones arqueológicas en la cuenca media e inferior del río Uruguay. Tesis doctoral inédita, Facultad de Ciencias Naturales y Museo, Universidad Nacional de La Plata.

Castro, J.C. y R. Costa Angrizani. 2014. El sitio arqueológico Ensenada del Bellaco (Gualeguyachú, Entre Ríos) como indicador de la presencia guaraní en el río Uruguay inferior. Revista del Museo de Antropología, Dossier Arqueología del Litoral 7 (2): 235-242. 
Castro, J.C. y M. Del Papa. 2015. La estructura del registro bioarqueológico del río Uruguay inferior. Análisis de la colección osteológica humana del Museo Arqueológico Manuel Almeida (Gualeguaychú, Entre Ríos). Intersecciones en Antropología 16: 195-205.

Cavallotto, J., R. Violante y F. Colombo. 2005. Evolución y cambios ambientales de la llanura costera de la cabecera del río de la Plata. Revista de la Asociación Geológica Argentina 60: 353-367.

Cavallotto, J., R. Violante y G. Parker. 2004. Sea level fluctuation during the last 8600 yrs in the Río de la Plata (Argentina). Quaternary International 114: 155165.

Ceruti, C.N. 1993. Arqueología. En: Nueva Enciclopedia de la Provincia de Santa, editado por F.A. Renna; Tomo IV, pp. 557-580. Ediciones Sudamérica, Santa Fe.

1995. Hábitat natural y cultural. Historia de Santa Fe, Poblamiento, conquista y colonización. Colección Cuadernillos 1: 1-6.

2000. Ríos y praderas: Los pueblos del Litoral. En: Nueva Historia Argentina. Los pueblos originarios y la conquista, dirigido por M. Tarragó; pp. 107-146. Sudamericana, Buenos Aires.

2003. Entidades culturales presentes en la cuenca del Paraná Medio (margen entrerriana). Mundo de Antes 3: 111-135.

Ceruti, C.N. y M.I. González. 2007. Modos de vida vinculados con ambientes acuáticos del Nordeste y Pampa Bonaerense de Argentina. Relaciones de la Sociedad Argentina de Antropología 32: 101-140.

Chamberlain, A. 2006. Demography in Archaeology. Cambridge University Press, Cambridge.

Chen, E.M., S. Masih, K. Chow, G. Matcuk y D. Patel. 2012. Periosteal Reaction: Review of Various Patterns Associated With Specific Pathology. Contemporary Diagnostic Radiology 35 (17): 1-6. 
Chiri, O.C. 1975. El empleo de la madera y algunos otros productos vegetales por los indígenas del nordeste argentino según las referencias de algunas fuentes. Relaciones de la Sociedad Argentina de Antropología 9: 83-109.

Cigliano, E.M., R.A. Raffino y M.A. Caggiano. 1971. Resultados de las investigaciones arqueológicas efectuadas en la zona de Salto Grande (Provincia. de Entre Ríos). Revista del Museo de La Plata, Antropología 43 (7): 79-107.

Cione, A.L., A. Rizzo y E.P. Tonni. 1977. Relación cultura indígena-medio ambiente en un sitio de Rincón de Landa, Gualeguaychú, Entre Ríos, República Argentina. Nota preliminar. V Encuentro de Arqueología del Litoral: 122-141. Fray Bentos. Uruguay.

Clarke, N.G., y R.S. Hirsch. 1991. Physiological, pulpal, and periodontal factors influencing alveolar bone. En: Advances in Dental Anthropology, editado por. M. Kelley y C.S. Larsen; pp. 241-266. New York.

Cocco, G. 2010. Nuevos aportes al estudio de los procesos de formación del registro arqueológico en la provincia de Santa Fe. En: Mamül Mapu: Pasado y Presente desde la Arqueología Pampeana, editado por M. Berón, L. Luna, M. Bonomo, C. Montalvo, C. Aranda y M. Carrera Aizpitarte; pp. 47-58. Editorial Libros Del Espinillo. Ayacucho, Buenos Aires.

Codignotto J. 2004. Delta. Evolución Geológica. En: Atlas ambiental de Buenos Aires. http://www.atlasdebuenosaires.gov.ar.

Cohen, M.N. y G.J. Armelagos. 1984. Paleopathology at the Origins of Agriculture. Academic Press, New York.

Cohen, M.N., N.J. Wood y G.R. Milner. 1994. The Osteological Paradox Reconsidered. Current Anthropology 35: 629-637.

Colobig, M.M. y F. Ottalagano. 2013. Contextos de uso y consumo de vegetales por grupos cazadores-recolectores sudamericanos del Holoceno tardío: primeros estudios paleoetnobotánicos en la cuenca del Paraná medio. Actas del XVIII Congreso Nacional de Arqueología Argentina: 71. La Rioja, Argentina. 
Colobig, M.M., J.O. Sánchez y A. Zucol. 2015. Análisis de macrorrestos vegetales en el Sitio Arqueológico Los Tres Cerros 1 (isla Las Moras, Victoria, Entre Ríos). Revista del Museo de Antropología 8 (1):114-24.

Colobig, M.M., A. Zucol, M. Bonomo y G. Politis. 2014. Estudios arqueobotánicos del sitio Laguna de los Gansos 1 (Delta Superior del río Paraná, Argentina): análisis de microrrestos vegetales en materiales cerámicos. Trabajo presentado en el Taller "Micro Paleoetnobotánica": Relevancia de una Red Interdisciplinaria de Investigaciones en Fitolitos y Almidones, La Paloma, Uruguay.

Cook, D.C. 1979. Subsistence base and health in Prehistoric Illinois Valley: evidence from the human skeleton. Medical Anthropology 3: 109-124.

Cook, D.C. y M.L. Powell. 2006. The evolution of American paleopathology. En: Bioarchaeology. The Contextual Analysis of Human Remains, editado por J.E. Buikstra y L.A. Beck; pp. 281-322. Elsevier Academic Press, San Diego.

2012. Treponematosis: Past, Present, and Future. En: $A$ Companion to Paleopathology, editado por A. Grauer; pp. 250-267. Willey-Balckwell, Malden.

Cornero, S. 2009. Apuntes de arqueología de islas. Sitio El Castaño, boca de la Milonga, río Paraná. Anuario de Arqueología 1 (1): 153-160.

Cornero, S. y R. Puche. 1995. Análisis de elementos traza en un grupo de pescadores prehistóricos del Paraná Medio (Arroyo Aguilar, Santa Fe). Revista de la Escuela de Antropología III: 11-16.

2000. Diet and nutrition of prehistoric populations at the alluvial banks of the Paraná River. Medicina 60: 109-114.

2002. Cribra orbitalia (hiperostosis porótica) en una población prehistórica del Paraná Medio. Medicina 62: 169-172.

2007. Paleopatología en Argentina prehistórica. Salud y enfermedad entre los antiguos cazadores de Alejandra, Santa Fe, Argentina. En: Aproximaciones a la paleopatología en América Latina, editado por H.A. Sotomayor Tribín y Z. Cuellar Montoya; pp. 149-165. Academia Nacional de Medicina de Colombia, Bogotá. 
Cornero, S. y L. Rangone. 2015. Análisis arqueobotánicos en sitios de la entidad arqueológica Goya-Malabrgio ubicados en el centro-norte de Santa Fe. Anuario de Arqueología 7: 85-94.

Cruwys, E. 1989. Tooth wear and the archaeologist. The role of human tooth wear in archaeological research. En: Burial Archaeology Current Research Methods and Development, editado por C.A. Roberts, F. Lee y J. Bintliff; pp. 251-266. BAR British Series 211, Oxford.

Csonka, G. y J. Pace. 1985. Endemic nonvenereal treponematosis (Bejel) in Saudi Arabia. Reviews of Infectious Diseases 7 (2): S260-S265.

Delgado-Darias, T., J. Velasco-Vázquez, M. Arnay-de-la-Rosa, E. MartínRodríguez y E. González-Reimers. 2006. Calculus, periodontal disease and tooth decay among the prehispanic population from Gran Canaria. Journal of Archaeological Science 33: 663-670.

Del Papa, M. 2008. Estructuración espacial de la variación biológica humana en la República Argentina durante el Holoceno tardío final a través de los rasgos epigenéticos craneofaciales. Revista Argentina de Antropología Biológica 10 (2): 21-41.

Del Papa, M., C. Scabuzzo, M.A. Ramos van Raap, D. Bonilla y V. Pennini. 2016. Nuevos análisis bioarqueológicos de la colección osteológica del sitio Paraná Ibicuy 1 (Delta Inferior del Río Paraná, Entre Ríos). Intersecciones en Antropología 17: $263-267$.

Del Papa, M., V. Pennini y D. Bonilla. 2018. Deformaciones artificiales de la bóveda del cráneo en el Delta de Paraná y cuenca inferior del río Uruguay. Revista Argentina de Antropología Biológica. En prensa.

Della Negra, C. y P. Novellino. 2005. Aquihuecó: un cementerio Arqueológico, en el norte de la Patagonia, valle del Curi Leuvú, Neuquen, Argentina. Magallania 33: $165-172$. 
Deter, C.A. 2009. Gradients of occlusal wear in hunter-gatherers and agriculturalists. American Journal of Physical Anthropology 138: 247-254.

Dias, G.J. y N. Tayles. 1997. "Abscess cavity" - a Misnomer. International Journal of Osteoarchaeology 7: 548-554.

Dias G.J., A.K. Prasad y A.L. Santos. 2007. Pathogenesis of apical periodontal cysts: guidelines for diagnosis in palaeopathology. International Journal of Osteoarchaeology 17: 619-626.

Di Prado, V. 2015. Estudio comparativo de las prácticas de elaboración y uso de la alfarería prehispánica del centro-este de Argentina desde una perspectiva multirregional. Tesis doctoral inédita, Facultad de Ciencias Naturales y Museo, Universidad Nacional de La Plata.

2016. Primeras etapas de elaboración cerámica en Los Tres Cerros 1 (Victoria, Entre Ríos). Caracterización mediante petrografía de pastas. Intersecciones en Antropología, volumen especial Nuevos aportes a la arqueología de las tierras bajas sudamericanas 3: 23-32.

Di Prado, V. y C. Castro. 2014. Estrategia de remontajes aplicada sobre el registro cerámico del sitio Los Tres Cerros 1 (delta superior del río Paraná). Revista del Museo de Antropología 7 (2): 263-270.

Duckworth, R.M. y E. Huntington. 2006. On the relationship between calculus and caries. En: The Teeth and Their Environment, editado por R.M. Duckworth. Monographs in Oral Sciense 19: 1-28. Karger, Basel.

El-Najjar, M.Y. 1979. Human treponematosis and tuberculosis: evidence from the New World. American Journal of Physical Anthropology 51: 599-618.

El- Najjar, M.Y., D.J. Ryqn, C.G. Turner II y B. Lozoff. 1976. The etiology of porotic hyperostosis among the prehistoric and historic Anasazi Indians of southwestern Unites States. American Journal of Physical Anthropology 44: 477-488.

Erlandson, J.M. 2001. The archaeology of acuatic adaptations: paradigms for a New Millennium. Journal of Archaeological Research 9 (4): 287-350. 
Eshed, V., A. Gopher y I. Hershkovitz. 2006. Tooth wear and dental pathology at the advent of agriculture: new evidence from the Levant. American Journal of Physical Anthropology 130: 145-159.

Evans, D.T. 1973. A preliminary evaluation of tooth tartar among the preconquest Maya of the Tayasal area, El Peten, Guatemala. American Antiquity 38: 489-493.

Fabra, M. 2013. Variación epigenética craneofacial y dinámica evolutiva de poblaciones humanas del norte de la región pampeana durante el Holoceno tardío. Cuadernos del Instituto Nacional de Antropología y Pensamiento Latinoamericano. Series Especiales 1 (1): 75-86.

Fabra M. y C.V. González. 2012. Diet and oral health of populations that inhabited Central Argentina (Córdoba province) during Late Holocene. International Journal of Osteoarchaeology 25 (2): 160-175.

Fabra, M., C.V. González y S. Robin. 2015. Evidencias de violencia interpersonal en poblaciones del piedemonte y las llanuras de Córdoba (Argentina) a finales del Holoceno tardío. Revista RUNA 36 (1): 5-27.

Farro, M.E. 2008. Historia de las colecciones en el Museo de la Plata, 1884-1906: naturalistas viajeros, coleccionistas y comerciantes de objetos de historia natural a fines del Siglo XIX. Tesis doctoral inédita, Facultad de Ciencias Naturales y Museo, Universidad Nacional de La Plata.

Fazekas, I.G. y F. Kósa. 1978. Forensic Fetal Osteology. Budapest: Akadémiai Kiadó.

Fernández de Oviedo y Valdés, G. [1547] 1851. Historia general y natural de las Indias, Islas y Tierra-Firme del Mar Océano, 2 (1). Imprenta de la Real Academia de la Historia, Madrid.

Feuillet Terzaghi, M. 2010. Las estrategias de subsistencia asumidas tradicionalmente para grupos cazadores-recolectores en la actual provincia de Santa Fe. En: Arqueología de Cazadores recolectores de la Cuenca del Plata, compilado por G. Cocco y M. Feuillet Terzaghi; pp. 23-21. Centro de Estudios Hispanoamericanos, Santa Fe. 
Flensborg, G. 2011. Dento-alveolar lesions and palaeodietary inferences from the Paso Alsina 1 site (eastern Pampean-Patagonian transition, Argentina). HOMO Journal of Comparative Human Biology 62: 335-350.

2012. Análisis paleopatológico en el curso inferior del río Colorado (Pcia. De Buenos Aires). Exploración y evaluación del estado de salud de sociedades cazadorasrecolectoras en el Holoceno tardío. Tesis doctoral inédita, Facultad de Ciencias Sociales, Universidad Nacional del Centro de la Provincia de Buenos Aires.

2013. Paleopatologías bucales y tendencias paleodietarias en grupos cazadoresrecolectores de la transición Pampeano-Patagónica oriental durante el Holoceno tardío. Relaciones de la Sociedad Argentina de Antropología XXXVIII (1): 199-222.

Flensborg, G., G. Martínez y P. Bayala. 2015. Mortality profiles of hunter-gatherer societies: a case study from the eastern Pampa-Patagonia transition (Argentina) during the Final Late Holocene. International Journal of Osteoarchaeology 25: 816-826.

Flensborg, G., J. Suby y G. Martínez. 2013. A case of adult osteomyelitis in a final late Holoce huntergatherer population, eastern Pampa-Patagonian transition, Argentina. International Journal of Paleopathology 3: 128-133.

Fortich Baca, V.I. 1977. Acerca de algunos restos óseos humanos del Nordeste argentino. Relaciones de la Sociedad Argentina de Antropología XI: 91-100.

Frayer, D. y M. Wolpoff. 1985. Sexual dimorphism. Annual Review of Anthropology 14: 429-473.

Frenguelli, J. y F. De Aparicio. 1923. Los paraderos de la margen derecha del río Malabrigo (departamento de Reconquista, Prov. de Santa Fe). Anales de la Facultad de Ciencias de la Educación 1: 7-112.

Fugassa, M. 2006. Enteroparasitosis en poblaciones cazadoras-recolectoras de Patagonia Austral. Tesis doctoral inédita, Facultad de Ciencias Exactas y Naturales, Universidad Nacional de Mar del Plata.

Fugassa, M. y R. Barberena. 2006. Cuevas y zoonosis antiguas: paleoparasitología del sitio Orejas de Burro 1 (Santa Cruz, Argentina). Magallania 34 (2): 57-62. 
Fugassa, M. y R.A. Guichón. 2005. Análisis paleoparasitológico de coprolitos hallados en sitios arqueológicos de Patagonia Austral: definiciones y perspectivas. Magallania 33 (2): 13-19.

Galera, V., D. Ubelaker y L. Hayek. 1998. Comparison of macroscopic crania methods of age estimation applied to skeletons from the Terry Collection. Journal of Forensic Sciences 43 (5): 933-939.

García, D. 1528 1902. Memoria de Diego García. En: Historia del Puerto de Buenos Aires, editado por E. Madero; pp. 412-419. La Nación, Buenos Aires.

García Guraieb, S. 2006. Salud y enfermedad en cazadores recolectores del Holoceno tardío en la cuenca del Lago Salitroso (Santa Cruz). Intersecciones en Antropología 7: 37-48.

2010. Bioarqueología de cazadores-recolectores del Holoceno Tardío de la cuenca del Lago Salitroso (Santa Cruz): aspectos paleodemográficos y paleopatológicos. Tesis doctoral inédita, Facultad de Filosofía y Letras, Universidad de Buenos Aires.

García Guraieb, S. y M. Maldonado. 2014. Salud bucal en grupos cazadoresrecolectores patagónicos del Holoceno tardío del Lago Salitroso (Santa Cruz, Argentina). En: Avances Recientes de la Bioarqueología Latinoamericana, editado por L. Luna, C. Aranda y J. Suby, pp. 231-254. Buenos Aires.

García Guraieb S., V. Bernal, P. González, L.A. Bosio y A.M. Aguerre. 2009. Nuevos estudios del esqueleto del sitio Cerro Yanquenao (Colhue Huapi, Chubut). Veintiocho años después. Magallania 37 (2): 165-175.

García Guraieb, S., L.A. Bosio y J. Pereyra. 2015. Treponematosis en Sudamérica prehispánica: revisión y actualización de casos y evidencias. Libro de resúmenes del VI Congreso de la Asociación de Paleopatología en Sudamérica; pp. 201-203. Ciudad Autónoma de Buenos Aires.

García Guraieb, S., R. Goñi y L.A. Bosio. 2007. Lesiones traumáticas en un entierro del lago Salitroso (Santa Cruz, Argentina). En: Arqueología de Fuego-Patagonia. Levantando piedras, desenterrando huesos.. y develando arcanos, editado por F. 
Morello, M. Martinic, A. Prieto y G. Bahamonde; pp. 375-380. Ediciones CEQUA. Punta Arenas.

García Guraieb, S., R. Goñi y A. Tessone. 2015. Paleodemography of Late Holocene hunter-gatherers from Patagonia (Santa Cruz, Argentina): an approach using multiple archaeological and bioarchaeological indicators. Quaternary International 356: 147-158.

García Guraieb S., C. Mariano y C. Favier Dubois. 2010. El Buque Sur: un entierro primario múltiple de 2300 años en la costa del golfo San Matías, Río Negro, Argentina. Magallania 38 (1): 135-146.

García Laborde P., J. Suby, R.A. Guichón y R. Casali. 2010. El antiguo cementerio de la misión de Rio Grande, Tierra del Fuego: primeros resultados sobre patologías nutricionales-metabólicas e infecciosas. Revista Argentina de Antropología Biológica 12: 57-69.

García-Mancuso, R. 2014. Congruencia entre edad esquelética y desarrollo dentario en una muestra osteológica con edad cronológica documentada. Revista Argentina de Antropología Biológica 16 (2): 103-109.

Gaspary, F. 1950. Investigaciones arqueológicas y antropológicas en un cerrito de la Isla Los Marinos (Pcia. de Entre Ríos). Instituto de Arqueología, Lingüística y Folklore 23: 3-66.

Gatto, S. 1939. El paradero-cementerio de Brazo Largo (Delta del Paraná). Physis XVI: 365-376.

Gheggi, M.S. 2012. Patologías orales, dieta y modo de vida en Esquina de Huajra (Quebrada de Humahuaca, Jujuy). Revista Argentina de Antropología Biológica 14 (1): $65-77$.

Gheggi, M.S. y V. Seldes. 2012. Evidencias bioarqueológicas de conflicto ca. 10001432 AD en la Quebrada de Humahuaca y el Valle Calchaquí. Intersecciones en Antropología 13: 103-115. 
2014. Social change and health status in Prehispanic Northwest Argentina (Quebrada de Humahuaca, Jujuy) ca. 500-1550 AD. Journal of Anthropology and Archaeology 2 (2): 17-38.

Giacaman, R.A. 2017. Sugars and beyond. The role of sugars and the other nutrients and their potential impact on caries. Oral Diseases. 1-13.

Gianotti, C. y M. Bonomo. 2013. De montículos a paisajes: procesos de transformación y construcción de paisajes en el sur de la cuenca del Plata. Comechingonia. Revista de Arqueología 17 (2): 129-163.

Gil, A. 2003. Zea mays on the South American Periphery: chronology and dietary importance. Current Anthropology 44 (2): 295-300.

\section{Gomes, R., C. Jácome, J. Montalvo, B. Paredes, F. Peña y J. Zárate Delgado.} 2015. Estudio preliminar sobre un posible caso de treponematosis en un individuo del sitio La Trila, VII Región, Chile. Libro de resúmenes del VI Congreso de la Asociación de Paleopatología en Sudamérica; pp. 36-38. Ciudad Autónoma de Buenos Aires.

Gómez Otero, J. y P. Novellino. 2011. Diet, nutritional status and oral health in hunter-gatherers from the Central-Northern coast of Patagonia and the Chubut river lower valley, Argentina. International Journal of Osteoarchaeology 21: 643659.

González, A.R. 1947. Investigaciones arqueológicas en las nacientes del Paraná Pavón. Instituto de Arqueología Lingüística y Folklore "Dr. Pablo Cabrera", XVII. Universidad Nacional de Córdoba, Córdoba.

1977. Arte precolombino de la Argentina. Introducción a su historia cultural. Imprenta Coni, Buenos Aires.

González, C.V. 2016. Dieta y salud oral en poblaciones del centro de Argentina durante el Holoceno tardío. Tesis doctoral inédita, Facultad de Filosofía y Humanidades, Universidad Nacional de Córdoba. 
González, C.V. y M. Fabra. 2011. Estimaciones acerca de la salud de poblaciones que ocuparon la región austral de las sierras pampeanas en el holoceno tardío: una aproximación desde la Antropología Dental. Revista del Museo de Antropología 4: 161-178.

Goodman, A.H. 1991. Health, adaptation and maladaptation in past societies. En: Health in past societies: biocultural interpretations of human skeletal remains in archaeological context, editado por E. Bush y M. Zvelebil; pp. 31-38. BAR International Series 567. Oxford.

1993. On the interpretation of Health from Skeletal Remains. Current Anthropology 34 (3): 281-288.

Goodman, A.H. y G.J. Armelagos. 1989. Infant and childhood morbidity and mortality risks in archaeological populations. World Archaeology 21: 225-243.

Goodman, A.H. y J.C. Rose. 1991. Dental enamel hypoplasias as indicators of nutrittional satatus. En: Advances in Dental Anthropology, editado por A. Kelley y C. S. Larsen; pp. 279-293. Willey-Liss. New York.

Goodman, A.H., R. Brooke Thomas, A. Swedlung y G.J. Armelagos. 1988. Biocultural perspectives on stress of prehistoric, historical and contemporary population research. Yearbook of Physical Anthropology 31: 169-202.

Goodman, A.H., J. Lallo, G.J. Armelagos y J.C. Rose. 1984. Indications of stress from bones and teeth. En: Paleopathology at the origins of agriculture, editado por M.N Cohen y G.J. Armelagos; pp. 13-49. Academic Press, Orlando.

Gordón, F. 2015. Bioarchaeological patterns of violence in north Patagonia (Argentina) during the late Holocene. Implications for the study of population dynamics. International Journal of Osteoarchaeology 25 (5): 625-636.

Gordón, F. y G. Ghidini. 2007. Análisis bioarqueológico de la violencia interpersonal. El valle inferior del río Negro (República Argentina) durante el Holoceno tardío. Werken 9: 27-45. 
Goudel, F. 2012 Caracterização e Processamento de mapuitã, os frutos da palmeira jerivá (Syagrus romanzoffiana Cham.). Dissertação (mestrado), Centro de Ciências Agrárias, Universidade Federal de Santa Catarina, Brasil.

Greene, T.R., C.L. Kuba, y J.D. Irish. 2005. Quantifying calculus: a suggested new approach for recording an important indicator of diet and dental health. HOMO Journal of Comparative Human Biology 56: 119-132.

Greslebin, H.R. 1931. La estructura de los túmulos indígenas prehispánicos del departamento de Gualeguaychú provincia de Entre Ríos, República Argentina. Revista de la Sociedad de Amigos de la Arqueología V: 5-51.

Grippo, J.O., M. Simring y S. Schreiner. 2004. Attrition, abrasion, corrosion and abfraction revisited: a new perspective on tooth surface lesions. Journal of American Dental Association 135: 1109-1118.

Guarido, A.L., B. Mazza y E. Turk. 2016. Incineración de restos óseos humanos en el Humedal del Paraná inferior. Análisis del sitio arqueológico Las Ánimas. Actas del XIX Congreso Nacional de Arqueología Argentina, pp. 496-498. Tucumán.

Guatelli-Steinberg, D. y J. Lukacs. 1999. Interpreting sex differences in enamel hypoplasia in human and non-human primates: developmental, environmental, cultural considerations. Yearbook of Physical Anthropology 42: 73-126.

Guatelli-Steinberg, D., C.S. Larsen y D.L. Hutchinson. 2004. Prevalence and duration of linear enamel hypoplasia: a comparative study of Neandertals and Inuit Foragers. Journal of Human Evolution 47: 65-84.

Guichón, R.A. 1994. Antropología física de Tierra del Fuego, caracterización biológica de las poblaciones prehispánicas. Tesis doctoral inédita, Facultad de Filosofía y Letras, Universidad de Buenos Aires.

Guichón R.A, J.E. Buikstra, A.C. Stone, K.M. Harkins, J. Suby, M. Massone, A. Prieto, A.K. Wilbur, F. Constantinescu y C. Rodríguez-Martín. 2015. PreColumbian tuberculosis in Tierra del Fuego? Discussion of the paleopathological and molecular evidence. International Journal of Paleopathology XI: 92-101. 
Hackett, C.J. 1975. An Introduction to diagnostic criteria of Syphilis, Treponarid and Yaws (Treponematoses) in dry bones, and some implications. Virchows Archiv. A, Pathological Anatomy and Histology 368: 229-241.

1976. Diagnostic criteria of Syphilis, Yaws and Treponarid (Treponematoses) and some other diseases in dry bones (for use in Osteo-Archaeology). En: Sitzungsberichte der Heidelberger Akademie der Wissenschaften Mathematischnaturwissenschaftliche Klasse, Abhandlung 4, Springer-Verlag, Berlin.

Hammer, Ø., D.A.T. Harper y P.D. Ryan. 2001. PAST: Paleontological Statistics software package for education and data analysis. Palaeontologia Electronica 4 (1): 9.

Hartemann-Heurtier, A. y E. Senneville. 2008. Diabetic foot osteomyelitis. Diabetes \& Metabolism 34: 87-95.

Henry, A. y D. Piperno. 2008. Using plant microfossils from dental calculus to recover human diet: A case study from Tell al-Raqa'i, Syria. Journal Archaeological Science 35: 1943-1950.

Hershkovitz, I., B. Latimer, O. Dutuor, L. Jellema, S. WishBaratz, C. Rothschild y B. Rothschild. 1997. Why do we fail in aging from the sagittal suture? American Journal of Physical Anthropology 103: 393-399.

Hildelbolt, C., y S. Molnar. 1991. Measurement and description of periodontal disease in anthropological studies. En: Advances in Dental Anthropology, editado por M.A. Kelley y C.S. Larsen; pp. 225-240. New York.

Hillson, S. 1979. Diet and dental disease. Word Archaeology 11 (2): 147-162. 1996. Dental Anthropology. Cambridge University Press. Cambridge. 2001. Recording dental caries in archaeological human remains. International Journal Osteoarchaeology 11: 249-289.

2008. Dental pathology. En: Biological Anthropology of the Human Skeleton, Second Edition, editado por M.A. Katzenberg y S.R. Saunders, pp. 301-340. John Wiley \& Sons, Inc. 
Hillson, S. y S. Bond. 1997. Relationship of enamel hypoplasia to the pattern of tooth crown growth: a discussion. American Journal of Physical Anthropology 104: 89-103.

Hinton, R. 1981. Form and patterning of anterior tooth wear among aboriginal human groups. American Journal of Physical Anthropology 54: 555-564.

Hocsman, S. 1999. Tecnología lítica prehispánica en la cuenca inferior del arroyo Las Conchas (Depto. de Paraná, Pcia. de Entre Ríos): El sitio VU 4 como caso de estudio. Tesis de grado inédita, Facultad de Ciencias Naturales e Instituto Miguel Lillo, Universidad Nacional de Tucumán.

Hooton, E. 1930. The indians of Pecos Pueblo. A study of their skeletal remains. Yale University Press, New Haven, Conn.

Huss-Ashmore, R., A.H. Goodman y G.J. Armelagos. 1982. Nutritional inference from paleopathology. Advances in Archaeological Method and Theory 5: 395474.

Hutchinson, D.L., C.S Larsen, M.A. Williamson, V.D. Green-Clow, M.L. Powell. 2005. Temporal and spatial variation in the patterns of treponematosis in Georgia and Florida. En: The Myth of Syphilis: The Natural History of Treponematosis in North America, editado por M.L. Powell y D.C. Cook; pp: 92-116. University of Florida Press: Gainesville.

Ikpeme, I.A., N.E. Ngim y A.A. Ikpeme. 2010. Diagnosis and treatment of pyogenic bone infections. African Health Sciences 10 (1): 82-88.

Imbelloni, J. 1938. Tabla clasificatoria de los indios. Regiones biológicas y grupos humanos de América. Physis XII: 229-249.

Iriondo, M. y D. Kröhling. 2008. Cambios ambientales en la cuenca del río Uruguay (desde dos millones de años hasta el presente). Colección Ciencia y Técnica, Secretaría de Extensión de la Universidad Nacional del Litoral, Santa Fe. 
Isçan, M. 1989. Research strategies in age estimation: the multirregional approach. En: Age Markers in the Human Skeleton, editado por M. Isçan; pp. 325-339. Ch. C. Thomas Publisher. Springfield. Illinois.

Jacobi, K.P., D.C. Cook, R.S. Corruccini y J.S. Handler. 1992. Congenital syphilis in the past: slaves at Newton Plantation, Barbados, West Indies. American Journal of Physical Anthropology 89: 145-158.

Jeffcoate, W.J y B.A. Lipsky. 2004. Controversies in diagnosing and managing osteomyelitis of the foot in diabetes. Clinical Infectious Diseases 39 (2): S115-22.

Judd, M.A. y R. Redfern. 2012. Trauma. En: A Companion to Paleopathology, editado por A. Grauer, pp. 360-379. Willey-Balckwell, Malden.

Jurmain, R. 1990. Paleoepidemiology of a central California prehistoric population from CA-Ala-329. Degenerative disease. American Journal of Physical Anthropology 83: 83-94.

Jurmain, R., E.J. Bartelink, A. Leventhal, V. Bellifemine, I. Nechayev, M. Atwood y D. DiGiuseppe. 2009. Paleoepidemiological patterns of interpersonal aggression in a prehistoric central California population from CA-ALA-329. American Journal of Physical Anthropology 139: 462-473

Katzenberg, M.A., D.A. Herring y S.R. Saunders. 1996. Weaning and Infant Mortality: Evaluating the Skeletal Evidence. Yearbook of Physical Anthropology 39: 177-199.

Kerr, N.W., M.F. Bruce y J.F. Cross. 1990. Caries experience in Mediaeval Scots. American Journal of Physical Anthropology 83: 69-76.

King, T., L. Humphrey y S. Hillson. 2005. Linear hypoplasias as indicators of systemic physiological stress: evidence from two known age at death and sex populations from postmedieval London. American Journal of Physical Anthropology 128: 547-559. 
Klaus H.D. 2014. Frontiers in the bioarchaeology of stress and disease: Crossdisciplinary perspectives from patho-physiology, human biology, and epidemiology. American Journal of Physical Anthropology 155: 294-308.

Kozameh, L. 1996. Rastros biológicos y cultura. En: Arqueología. Solo Patagonia. Ponencias de las Segundas Jornadas de Arqueología de la Patagonia, editado por J. Gomez Otero; pp. 465-478. Centro Nacional Patagónico, CONICET.

2004. Lago Salitroso. Análisis dentario en dos restos humanos. En: Contra Viento y Marea. Arqueología de la Patagonia, editado por M.T. Civalero, P. Fernández y A.G. Guraieb; 339-346. INAPL-SAA. Buenos Aires.

Kozameh, L. y J.E Barbosa. 1992. Patrones de abrasión dentaria en restos esqueletales. En: Arqueología de la Cueva Haichol. Arqueología de los Pinares Cordilleranos del Neuquén, editado por J. Fernández; pp. 613-631. Anales de Arqueología y Etnología, Universidad Nacional de Cuyo, Mendoza.

Kozameh, L. y O. Brunás. 2009. Rastro de proceso osteomielítico en una clavícula. En: Puentes y Transiciones. Libro de Resúmenes del III Congreso de la Asociación de Paleopatología en Sudamérica; pp. 94. Necochea, Quequén, Argentina.

2011. Paleopatología: paget óseo en un resto prehispánico. Microscopía y datación. Actualizaciones en Osteología 7 (2): 93-95.

2013. Enfermedad de Paget en un individuo prehispánico del delta del Paraná, confirmado por exámen histológico y datación radiocarbónica. Cuadernos del Instituto Nacional de Antropología y Pensamiento Latinoamericano. Series Especiales 1 (1): 114-120.

Kozameh L., C. Bellelli y O.M. Brunás. 2009. Rastros fisiológicos y patológicos en un resto femenino del sitio Paso del Sapo 1. Consideraciones sobre cooperación entre cazadores-recolectores del valle medio del Río Chubut. En: Arqueología de Patagonia: una mirada desde el último confín, compilado por M. Salemme, F. Santiago, M. Alvarez, E. Piana, M. Vázquez y E. Mansur; pp. 639-647. Editorial Utopías, Ushuaia.

Kozameh, L., M. López, N. Testa y B. Mazza. 2007. Los cazadores-recolectores de Cerro Lutz, (sudeste de Entre Ríos). Indicadores esqueletales de actividades 
cotidianas. Actas de resúmenes ampliados del XVI Congreso Nacional de Arqueología. Argentina, Tomo I, pp. 183-188. San Salvador de Jujuy, Argentina.

Kozłowski, T. y H.W. Witas. 2012. Metabolic and endocrine diseases. En: $A$ Companion to Paleopathology, editado por A. Grauer; pp. 401-419. WilleyBalckwell, Malden.

Krapovickas, P. 1957. Excursión arqueológica a Rincón de Landa. Revista Geográfica Americana 41 (245): 149-156.

Lafon, C.R. 1971. Introducción a la arqueología del nordeste argentino. Relaciones de la Sociedad Argentina de Antropología V (2): 119-152.

1972. El replanteo para la arqueología del nordeste argentino. Antiquitas 14: 1-16.

Lalueza Fox C., J. Juan y R.M. Albert. 1996. Phytolith analysis on dental calculus, enamel surface, and burial soil: information about diet and paleoenvironment. American Journal of Physical Anthropology 101: 101-113.

Lamenza, G. y M. Santini. 2013. Arqueología del Chaco Meridional: nuevos aportes a la comprensión de la dinámica cultural chaqueña prehispánica. Suplemento Antropológico XLVIII (2): 145-220.

Lanfranco, L.P. y L. Eggers. 2010. The Usefulness of caries frequency, depth, and location in determining cariogenicity and past subsistence: a test on early and later agriculturalist from the Peruvian coast. American Journal of Physical Anthropology 143: 75-91.

2012. Caries through time: an anthropological overview. En: Contemporary approach to dental caries, editado por MY. Li; pp. 3-34. In Tech: Rijeka.

Langsjoen, O. 1998. Diseases of the dentition. En: The Cambridge Encyclopedia of Human Paleopathology, editado por A. Aufderheide y C. Rodríguez-Martín; pp. 393-412. Cambridge University Press. Cambridge.

Larsen, C.S. 1983. Behavioral implications of temporal change in cariogenesis. Journal of Archaeological Science 10: 1-8. 
1984. Health and disease in prehistoric California: the transition to agriculture. En: Paleopathology at the Origins of the Agriculture, editado por M. Cohen y G.J. Armelagos; pp. 347-392. Academic Press, Orlando.

1987. Bioarchaeological interpretation of subsistence economy and behavior from human skeletal remains. Advances in Archaeological Method and Theory 10: 339445.

1995. Biological changes in human populations with agriculture. Annual Review of Anthropology 24: 185-213.

1997. Bioarchaeology. Interpreting Behavior from the Human Skeleton. Cambridge University Press, Cambridge.

Larsen, C.S. y P.L. Walker. 2010. Bioarchaeology: health, lifestyle and society. En: $A$ Companion to Biological Anthropology, editado por C.S. Larsen; pp: 379-394. Oxford: Blackwell.

Larsen, C.S., R. Shavit y M.C. Griffin. 1991. Dental caries evidence for dietary change: an archeological context. En: Advances in dental anthropology, editado por M.A. Kelley y C. S. Larsen; pp. 179-202. Wiley-Liss. New York.

Ledermann, H.P., W. Morrison y M.E. Scheweitzer. 2002. MR image analysis of pedal osteomyelitis: distribution, patterns of spread, and frequency of associated ulceration and septic arthritis. Radiology 223: 747-755.

Lehmann-Nitsche, R. 1904. La arthritis deformans de los antiguos Patagones. Contribución a la antropo-patología. Revista del Museo de La Plata 11: 199-203. 1907. Nouvelles recherches sur la Formation Pampéenne et I'homme fossile de la République Argentine. Revista del Museo de La Plata XIV: 143-488.

1911. Catálogo de la sección antropológica del Museo de La Plata. Buenos Aires: Coni Hermanos.

Lessa, A. y S. Mendonça de Souza. 2004. Violence in the Atacama desert during the Tiwanaku period: social tension? International Journal of Osteoarchaeology 14: 374-388.

Lew, D.P. y F.A. Waldvogel. 2004. Osteomyelitis. Lancet 364: 369-379. 
Lewis, M.E. 2006. The Bioarchaeology of Children. Perspectives from Biological and Forensic Anthropology. Cambridge University Press. New York.

L'Heureux, G.L. 1998. Biología oral de las poblaciones prehispánicas del sudeste de la Región Pampeana. Tesis de licenciatura inédita, Escuela de Antropología, Facultad de Humanidades y Artes, Universidad Nacional de Rosario.

2000. Estudio comparativo de indicadores de adecuación fisiológica y salud bucal en muestras de restos humanos del Sudeste de la Región Pampeana. Relaciones de la Sociedad Argentina de Antropología 25: 51-73.

2014. Indicadores fisiológicos y patológicos bucales en las poblaciones representadas en el sitio Arroyo Seco 2. En: Estado actual de las investigaciones en el sitio arqueológico Arroyo Seco 2, Partido de Tres Arroyos, Provincia de Buenos Aires, Argentina, editado por G. Politis, M.A. Gutiérrez y C. Scabuzzo; pp. 371-514. Universidad Nacional del Centro de la Provincia de Buenos Aires, Facultad Ciencias Sociales, Tandil.

L'Heureux, G.L. y R. Barberena. 2008. Evidencias bioarqueológicas en Patagonia meridional: el sitio Orejas de Burro 1 (Pali Aike, provincia de Santa Cruz). Intersecciones en Antropología 9: 11-24.

L'Heureux, G.L., R.A. Guichón, R. Barberena y L.A Borrero. 2003. Durmiendo bajo el faro. Estudio de un entierro humano en Cabo Vírgenes (CV 17), provincia de Santa Cruz, República Argentina. Intersecciones en Antropología 4: 87-97.

Lieverse, A. 1999. Diet and the aetiology of dental calculus. International Journal of Osteoarchaeology 9: 219-232.

Limp, W.F. y V.A. Reidhead. 1979. An economic evaluation of the potential of fish utilization in riverine environments. American Antiquity 44: 70-77.

Lista, R. 1878. Les cementières et paraderos minuanes de la province de Entre Ríos. Revue d'Anthropology 7: 365-368.

Littleton, J. y B. Frohlich. 1993. Fish-Eaters and farmers: dental pathology in the Arabian Gula. American Journal of Physical Anthropology 92: 427-447. 
Loponte, D. 2008. Arqueología del Humedal del Paraná Inferior (Bajíos Ribereños Meridionales). Asociación Amigos del Instituto Nacional de Antropología y Pensamiento Latinoamericano, Buenos Aires.

Loponte, D. y A. Acosta. 2003-2005. Nuevas perspectivas para la arqueología "Guaraní" en el humedal del Paraná inferior y Río de la Plata. Cuadernos del Instituto Nacional de Antropología y Pensamiento Latinoamericano 20: 179-197.

Loponte, D. y L. Kozameh. 2009. Nuevos datos para el conocimiento de las dietas prehispánicas del delta superior. Comechingonia. Revista de Arqueología 12: 115118.

Loponte, D., A. Acosta y P. Tchlinguirian. 2015. El sitio arqueológico Escuela 31. Libro de resúmenes VI Encuentro de Discusión Arqueológica del Nordeste Argentino. Revista del Museo de la Plata, Arqueología 14 (89): 27R.

2016. Estructuras "monticulares", unidades arqueológicas y falsas premisas en la arqueología del Noreste argentino. Anuario de Arqueología 8: 45-76.

Loponte, D., P. Tchilinguirian y E. Silvestre. 2011. Caracterización de afloramientos de calizas silicificadas de la provincia de Entre Ríos (Argentina) y su vinculación con los circuitos de abastecimiento prehispánico. Avances y perspectivas en la Arqueología del Nordeste: 125-140.

Lothrop, S.K. 1932. Indians of the Paraná Delta, Argentina. Annals of the New York Academy of Science 32: 77-232.

Lovejoy, C., R. Meindl, T. Pryzbeck y R. Mensforth. 1985. Chronological methamorphosis of the auricular surface of the ilium: a new method for the determination of adult skeletal age at death. American Journal of Physical Anthropology 68: 15-28.

Lovell, N.C. 1997. Trauma analysis in paleopathology. Yearbook of Physical Anthropology 40: 139-170.

2000. Paleopathological description and diagnosis. En: Biological anthropology of the human skeleton, editado por M. Katzemberg y S. Saunders; pp. 217-248. John Willey \& Sons, Inc. New Jersey. 
2008. Analysis and interpretation of skeletal trauma. En: Biological Anthropology of the Human Skeleton, editado por M.A. Katzemberg y S.R. Saunders; pp.341-386. John Willey \& Sons, Inc. New Jersey.

Lovell, N.C., R. Jurmain y L. Kilgore. 2000. Skeletal evidence of probable treponemal infection in free-ranging African Apes. Primates 41 (3): 275-290.

Lukacs, J. 1989. Dental paleopathology: methods for reconstructing dietary patterns. En: Reconstruction of Life from the Skeleton, editado por M. Iscan y K. Kennedy; pp. 261-286. Alan R. Liss, Inc., New York.

1992. Dental paleopathology and agricultural intensification in South Asia: new evidence from Bronze Age Harappa. American Journal of Physical Anthropology 87: $133-150$.

1996. Sex differences in dental caries rates with the origin of agriculture in South Asia. Current Anthropology 37: 147-153.

2007. Dental trauma and antemortem tooth loss in prehistoric Canary Islanders: Prevalence and contributing factors. International Journal of Osteoarchaeology 17 (2): 157-173.

2008. Fertility and agriculture accentuate sex differences in dental caries rates. Current Anthropology 49: 901-914.

Lukacs, J. y L. Largaespada. 2006. Explain sex differences in dental caries prevalence: saliva, hormones, and 'life-history' etiologies. American Journal of Human Biology 18: 540-555.

Luna, L. 2006. Alcances y limitaciones del concepto de estrés en bioarqueología. Antípoda 3: 255-279.

2008. Estructura demográfica y estilo de vida de cazadores-recolectores en un ambiente de desierto. Sitio Chenque I (Parque Nacional Lihué Calel, Provincia de la La Pampa). Tesis doctoral inédita, Facultad de Filosofía y Letras, Universidad Nacional de Buenos Aires.

2012. Validación de métodos para la generación de perfiles de mortalidad a través de la dentición. Su importancia para la caracterización paleodemográfica. Revista Argentina de Antropología Biológica 14 (Número especial): 33-51. 
Luna, L. y C. Aranda. 2010. Asociación entre cantidad de indicadores dentales de estrés metabólico y edad de muerte en el Sitio Chenque I: su variación por sexo y patrones de inhumación. En: Mamül Mapu: Pasado y Presente desde la Arqueología Pampeana, editado por M. Berón, L. Luna, M. Bonomo, C. Montalvo, C. Aranda y M. Carrera Aizpitarte; pp. 211-226. Editorial Libros del Espinillo, Ayacucho, Argentina.

2014. Trends in oral pathology of hunter-gatherers from Western Pampas, Argentina. Anthropological Science 122 (2): 55-67.

Luna, L. y J. Suby. 2014. Recent advances in palaeopathology and the study of past societies in Argentina, southern South America. Anthropological Science 122 (2): $53-54$.

Luna, L., C. Aranda, L.A. Bosio y M. Berón. 2008. A case of multiple metastasis in hunter-gatherers from Argentine Pampean Region. International Journal of Osteoarchaeology 18: 492-506.

Lyman, R. 1994. Vertebrate Taphonomy. Cambridge Manuals in Archaeology. Cambridge University Press, Cambridge.

Maat, G.J.R. y E.A. Van der Velde. 1987. The Caries-Attrition Competition. International Journal of Anthropology 2: 281-292.

Marcuzzo, F.F. 2017. Bacia hidrográfica do rio Uruguai: altimetria e áreas. Trabajo presentado en XXII Simpósio Brasileiro de Recursos Hídricos, Florianópolis. Associação Brasileira de Recursos Hídricas.

Marcuzzo, F.F., D.B. Almeida y C.J.R. Souza. 2016. Bacia hidrográfica internacional do rio Uruguai e consistência dos seus divisores de água na escala 1:3.000. Trabajo presentado en $48^{\circ}$ Congresso Brasileiro de Geología, Porto Alegre.

Marden, K. y D.J. Ortner. 2011. A case of treponematosis from pre-columbian Chaco Canyon, New Mexico. International Journal of Osteoarchaeology 21: 19-31. 
Maresh, M.M. 1970. Measurements from roentgenograms. En: Human growth and development, editado por R.W. McCammon; pp. 157-200. Springfield IL: C.C. Thomas.

Martin, S.A., D. Guattellie-Steinberg, P. Sciulli y P.L. Walker. 2008. Brief Communication: Comparison of Methods for estimating chronologial age at lineal enamel formation on anterior dentition. American Journal of Physical Anthropology 135: 362-365.

Martin, D.L., R.P. Harrod y V.R. Pérez. 2013. Bioarchaeology: an integrated approach to working with human remains. Springer, New York.

Mast, N.H. y D. Horwitz. 2002. Osteomyelitis: a review of current literature and concepts. Operative Techniques in Orthopaedics 12: 232-241.

Mays, S. 2008. Metabolic bone disease. En: Advances in Human Paleopathology, editado por R. Pinhasi y S. Mays; pp. 215-251. John Wiley \& Sons. Ltd. West Sussex.

Mazza, B. 2010a. Avances en el conocimiento de los entierros secundarios del humedal del Paraná inferior. En: Arqueología Argentina en el Bicentenario de la Revolución de Mayo, Actas del XVII Congreso Nacional de Arqueología Argentina, editado por J.R. Bárcena y H. Chiavazza; Tomo II, pp. 665-669. Mendoza: Zeta Editores.

2010b. Cerro Lutz: Aproximaciones al estudio de las prácticas mortuorias de las sociedades cazadoras-recolectoras del humedal del Paraná inferior. La Zaranda de Ideas, Revista de Jóvenes Investigadores en Arqueología 6: 91-116.

2015. Estudio de los patrones de variación morfológica en restos humanos del humedal del Paraná inferior. Inferencias acerca de las pautas de diferenciación social en sociedades cazadoras-recolectoras del Holoceno tardío a partir de marcadores óseos de actividad. Tesis doctoral inédita, Facultad de Filosofía y Letras, Universidad Nacional de Buenos Aires.

2016. Auditory exostoses in pre-hispanic populationes of the Lower Paraná Wetlands, Argentina. International Journal of Osteoarchaeology 26: 420-430. 
Mazza, B. y G. Barrientos. 2012. Patologías orales de origen infeccioso en muestras de poblaciones cazadoras-recolectoras del Holoceno tardío procedentes del humedal del Paraná inferior, Argentina. En Libro de resúmenes del XII Congreso Latinoamericano de Antropología Biológica. Costa Rica.

Mazza, B. y M. Béguelin. 2013. Determinación sexual de los entierros secundarios del sitio arqueológico Cerro Lutz mediante funciones discriminantes de huesos largos. Cuadernos del Instituto Nacional de Antropología y Pensamiento Latinoamericano - Serie especial 1 (1): 121-134.

Mazza, B. y D. Loponte. 2012. Las prácticas mortuorias en el humedal del Paraná inferior. Arqueología Iberoamericana 13: 3-21.

Mazza, B. y M. Fabra. 2015. Estudio de la variación epigenética craneofacial en el humedal del Paraná inferior (Argentina) durante el Holoceno tardío. Chungara, Revista de Antropología Chilena 47: 691-701.

McNally, M. y K. Nagarajah. 2010. Osteomyelitis. Orthopaedics and Trauma 24 (6): 416-429.

Meindl, R. y C. Lovejoy. 1985. Ectocranial suture closure: a revised method for the determination of skeletal age at death based on the lateral anterior sutures. American Journal of Physical Anthropology 68: 57-66.

Mendonça de Souza, S. y R.A. Guichón. 2012. Paleopathology in Argentina and Brazil. En: The History of palaeopathology: pioneers and prospects, editado por J.E. Buikstra, C.A. Roberts y S.M. Schreiner; pp. 329-341. Oxford University Press, New York.

Menéndez, L. 2010. Patologías bucales en cráneos humanos del noreste de Patagonia: tendencias temporales en la dieta y estado de salud de las poblaciones del Holoceno-tardío del valle inferior del río Negro. Magallania 38: $115-126$.

2016. Spatial variation of dental caries in Late Holocene samples of southern South America: a geostatistical study. American Journal of Human Biology 28: 825-836. 
Menéndez, L., M. Osterrieth, F. Oliva. 2009. A first phytolith approximation to diet study in the archaeological site Gascón 1, Pampean Region, República Argentina. Quaternary International 204: 84-94

Mensforth, R., O. Lovejoy, J. Lallo y G.J. Armelagos. 1978. The role of constitutional factors, diets and infectious disease in the etiology of porotic hyperostosis and periostal reactions in prehistoric infants and children. Medical Anthropology 2: 1-59.

Minotti, P. y M. Borro. 2011. Pulsos de inundación y seca. En: Contribuciones al conocimiento de los humedales del Delta del Río Paraná: herramientas para la evolución de la sustentabilidad ambiental, editado por P. Kandus, P. Minotti y M. Borro; pp. 8-9. San Martín, UNSAM.

Mitchell, P. 2003. The archaeological study of epidemic and infectious disease. Word Archaeology 35 (2): 171-179.

Møller-Christensen, V., S.N. Bakke, R.S. Melson y A.E. Waaler. 1952. Changes in the anterior nasal spine and the alveolar process of the maxilla in leprosy. International Journal of Leprosy 20 (3): 335-340.

Molnar, S. 1971. Human tooth wear, tooth function and cultural variability. American Journal of Physical Anthropology 34: 175-189.

1972. Tooth wear and culture: a survey of tooth functions among some prehistoric populations. Current Anthropology 13: 511-526.

Muñoz, J., S. Milera, C. Romero y A. Brizuela. 2005. Bosques nativos y selvas ribereñas en la provincia de Entre Ríos. En: Temas de la biodiversidad del litoral fluvial argentino. INSUGEO, Miscelánea 14: 169-182.

Musaubach, M.G. 2012. Potencialidad de estudios arqueobotánicos sobre tártaro dental de cazadores recolectores de la provincia de La Pampa, Argentina. Revista Argentina de Antropología Biológica 14: 105-113.

Naranjo, G., L. Malec y M. Pérez. 2010. Análisis de ácidos grasos en alfarería arqueológica del humedal de Paraná inferior. Avances en el conocimiento de su 
uso. En: Arqueología Argentina en el Bicentenario de la Revolución de Mayo. Actas del XVII Congreso Nacional de Arqueología Argentina, editado por J. R. Bárcena y H. Chiavaza; Tomo IV, pp. 1493-1498. Mendoza.

Noelli, F.S. 1993. Sem tekohá não há tekó (em busca de um modelo etnoarqueológico da aldeia e da subsistencia Guarani e sua aplicação a uma área de domínio no delta do rio Jacuí-RS). Porto Alegre. Tesis de Maestría inédita, Pontifícia Universidade Católica do Rio Grande do Sul, Porto Alegre.

Novellino, P. 2002. Bioarqueología en el sur de Mendoza. En: Entre Montañas y Desiertos: Arqueología del Sur de Mendoza, editado por A. Gil y G. Neme; pp. 119-140. Sociedad Argentina de Antropología, Buenos Aires.

Novellino, P. y A. Gil. 2007. Estrés nutricional, hipoplasias y explotación de recursos en el centro sur de Mendoza (Argentina). Intersecciones en Antropología 8: 1729.

Novellino, P. y R.A. Guichón. 1997-1998. Comparación de indicadores de dieta y salud entre el Sur de Mendoza y el Sur de San Juan-Norte de Mendoza. Relaciones de la Sociedad Argentina de Antropología XXIXXII: 125-138.

Novellino, P, A. Gil, G. Neme y V. Duran. 2004. El consumo de maíz en el Holoceno tardío del Oeste Argentino: isótopos estables y caries. Revista Española de Arqueología Americana 34: 85-110.

Novellino, P., J. Gómez Otero y S. Dahinten. 2007. Bioarqueología de restos humanos del nordeste de la provincia del Chubut: primeros resultados. Resúmenes de la XVI Congreso Nacional de Arqueología Argentina. Tomo III: 417-420. Universidad Nacional de Jujuy. Facultad de Humanidades y Ciencias Sociales.

Novellino, P., R.A. Guichón y H. Lagiglia. 1996. Indicadores biológicos en restos humanos del Sur de Mendoza: sitio Jaime Prats. Arqueología 6: 69-82. 
Ogden, A. 2008. Advances in the paleopathology of teeth and jaws. En: Advances in Human Paleopathology, editado por R. Pinhasi y S. Mays; pp. 282-307. John Wiley \& Sons. Ltd. West Sussex.

Ortner, D.J. 2003. Identification of pathological conditions in human skeletal remains. Academic Press. Florida.

2008. Differential diagnosis of skeletal lesions in infectious disease. En: Advances on Human Paleopathology, editado por S. Mays y R. Pinhasi; pp. 191-214. John Wiley \& Sons. Ltd. West Sussex.

2012. Differential diagnosis and issues in disease classification. En: A Companion to Paleopathology, editado por A. Grauer; pp. 250-267. Willey-Balckwell, Malden.

Ortner, D.J. y W.G. Putschar. 1981. Identification of pathological conditions in human skeleton remains. Smithsonian Contributions to Anthropology 28. Smithsonian Institution, Washington.

Ottalagano, F. 2009. Aproximaciones al simbolismo de los grupos cazadoresrecolectores del Paraná medio: un abordaje del arte mobiliar cerámico. Tesis doctoral inédita, Facultad de Humanidades y Artes, Universidad Nacional de Rosario.

2012. Estado actual y nuevas perspectivas de estudio para la arqueología del Paraná medio entrerriano. Anuario de Arqueología 4: 233-248.

Ottalagano, F. y D. Loponte. 2017. Stable isotopes and diet in complex huntergatherers of Paraná River Basin, South America. Archaeological and Anthropological Sciences 9 (5): 865-877.

Outes, F. 1911. Variaciones y anomalías, anátomo-antropológicas en los huesos del cráneo de los primitivos habitantes del sur de Entre Ríos. Revista del Museo de La Plata XVIII, Segunda serie, Tomo V: 53-144.

1912. Cráneos indígenas del departamento de Gualeguaychú (Prov. de Entre Ríos). Anales de la Sociedad Científica Argentina 73: 5-37.

1918. Nuevo jalón septentrional en la dispersión de representaciones plásticas de la cuenca paranaense y su valor indicador. Anales de la Sociedad Científica Argentina 85: 53-66. 
Peralta, E.A. 2015. Subsistencia y movilidad en la cuenca media del Atuel en el Holoceno Tardío: una perspectiva bioarqueológica, aplicando el análisis de marcadores de estrés ocupacional. Tesis de licenciatura inédita, Facultad de Filosofía y Letras, Universidad de Buenos Aires.

Peralta, E.A. y A. Gil. 2016. Dieta, movilidad y plantas domésticas: estereotipos y datos en el Valle del Atuel (Mendoza-Argentina). Actas del XIX Congreso Nacional de Arqueología Argentina: 1344-1345.

Pérez, P.J. 2006. The paleopathological and taphonomical context in human evolution and its records. International Congress Series 1296: 23-40.

Pérez, M., I. Acosta, G. Naranjo, L. Malec. 2013. Uso de la alfarería y conductas alimenticias en el humedal del Paraná Inferior a través del análisis de ácidos grasos. Cuadernos del Instituto Nacional de Antropología y Pensamiento Latinoamericano - Series Especiales 1 (1): 26-45.

Pérez Jimeno, L. 2005. Análisis ictioarqueológico de un sitio del humedal paranaense del holoceno tardío (Florencia, Santa Fe. Argentina). Resúmenes del XI Congreso Nacional de Arqueología Uruguaya; pp. 13. Asociación Uruguaya de Arqueología, Salto.

Phenice, T.W. 1969. A newly development visual method of sexing the os pubis. American Journal of Physical Anthropology 30: 297-301.

Píccoli, C.V. 2009. Estudio bioarqueológico de la colección osteológica proveniente del sitio Laguna El Doce (Departamento General López, Provincia de Santa Fe). Tesis de Licenciatura inédita, Facultad de Humanidades y Artes, Universidad Nacional de Rosario.

2015. Estudios de los paisajes arqueológicos en el sector de islas y borde frontal de la terraza baja de la llanura aluvial del Paraná Medio. Departamento de Goya. Tesis doctoral inédita, Facultad de Humanidades y Artes, Universidad Nacional de Rosario.

Píccoli, C.V. y M.C. Barboza. 2009. Análisis dental de la colección del sitio Laguna El Doce (Dpto. General López, Santa Fe). En: Libro de Resúmenes de las 9nas 
Jornadas Nacionales de Antropología Biológica; pp: 25. Puerto Madryn: Centro Nacional Patagónico.

Pinheiro, J., E. Cunha, C. Cordeiro y D.N. Veira. 2004. Bridging the gap between forensic anthropology and osteoarchaeology - A case of vascular pathology. International Journal of Osteoarchaeology 1: 137-144.

Podgorny, I. 1999. De la antigüedad del hombre en el Plata a la distribución de las antigüedades en el mapa: los criterios de organización de las colecciones antropológicas del Museo de La Plata entre 1897 y 1930. História, Ciências, Saúde-Manguinhos 6: 81-101.

Poenitz, E. 1970. Un yacimiento en el centro de Entre Ríos. Su relación con el problema del patrimonio arqueológico charrúa. Boletín de Arqueología 1: 21-38.

Politis, G. 2014. Las implicancias arqueológicas del Diario de Pero Lopes de Sousa (1531) durante su viaje al Río de la Plata y al Delta Inferior del río Paraná. Revista del Museo de Antropología 7 (2): 317-326.

Politis, G. y M. Bonomo. 2012. La entidad arqueológica Goya-Malabrigo (ríos Paraná y Uruguay) y su filiación arawak. Revista de Arqueologia de la Sociedade de Arqueologia Brasileira 25 (1): 10-46.

2015. Una revisión del Túmulo de Campana. Relaciones de la Sociedad Argentina de Antropología XL (1): 149-181.

Politis, G., L. Bastourre, V. Di Prado, M. Bonomo, G. Moreira y A. Matarrese. 2017. El Túmulo II del Brazo Largo. Aportes para la arqueología del Delta Inferior del río Paraná. Revista del Museo de Antropología 10 (2): 71-88.

Politis, G., M. Bonomo, C. Castiñeira y A. Blasi. 2011. Archaeology of the Upper Delta of the Paraná River (Argentina): mound construction and anthropic landscapes in the Los Tres Cerros locality. Quaternary International 245: 74-88.

Popkin, B.M. 1993. Nutritional patterns and transitions. Population and development review 19 (1): 138-157. 
Powell, M.L. y D.C. Cook. 2005. The myth of the syphilis. The Natural History of treponematosis in North America. University Press of Florida: Florida.

Powell, M.L., K. Jacobi, M.E. Danforth, L.E. Eisenberg. 2005. Syphilis in mound builder's bones: treponematosis in the central Southern United States. En: The Myth of Syphilis: The Natural History of Treponematosis in North America, editado por M.L. Powell y D.C. Cook; pp: 117-161. University of Florida Press: Gainesville.

Ramírez, L. 1528 1902. Carta de Luis Ramírez (1528). En: Historia del Puerto de Buenos Aires, editado por E. Madero; pp. 389-411. La Nación, Buenos Aires.

Ramos van Raap, M.A. 2018. Caracterización del registro mortuorio de la entidad arqueológica Goya-Malabrigo. En: Nuevas perspectivas sobre la entidad arqueológica Goya-Malabrigo, editado por G. Politis y M. Bonomo. Editorial Universitaria de la Universidad Nacional del Centro de la provincia de Buenos Aires. En prensa.

Ramos van Raap, M.A. y M. Bonomo. 2016. Nuevos estudios de la colección bioarqueológica de los sitios Arroyo Malo, El Cerrillo y Arroyo Sarandí (Delta del Paraná). Intersecciones en Antropología, volumen especial 3: 71-82.

Ramos van Raap, M.A. y C. Scabuzzo. 2017. Bioarqueología de la cuenca inferior del río Uruguay. Primeros resultados del análisis de la colección Manuel Almeida. En: Libro de resúmenes del Séptimo Encuentro de Discusión Arqueológica del Nordeste Argentino, Revista Scientia Interfluvius, pp. 55. Diamante, Entre Ríos.

Reid, D.J. y M.C. Dean. 2000. Brief communication: the timing of linear hypoplasias on human anterior teeth. American Journal of Physical Anthropology 113: 135139.

2006. Variation in modern human enamel formation times. Journal of Human Evolution 50: 329-346.

Reitsema, L. y B.K. Mcllvaine. 2014. Reconciling "stress" and "health" in physical anthropology: what can bioarchaeologists learn from other subdisciplines? American Journal of Physical Anthropology 155: 181-185. 
Ringuelet, R. 1961. Rasgos fundamentales de la zoogeografía de la Argentina. Physis 22 (63): 151-170.

1975. Zoogeografía y ecología de los peces de aguas continentales de la Argentina y consideraciones sobre las áreas ictiológicas de América del Sur. Ecosur 2 (3): 1 122.

Ritzman, T.B., B.J. Baker y G.T. Schwartz. 2008. A fine line: a comparison of methods for estimating ages linear enamel hypoplasia formation. American Journal of Physical Anthropology 135: 348-361.

Roberts, C. y K. Manchester. 2005. Archaeology of Disease. 3ed ed. Sutton Publishing, Stroud.

Rodríguez, J.A. 1997. Avances en la arqueología de Yacyretá (Corrientes, Argentina). En: Actas del XII Congreso Nacional de Arqueología Argentina; pp. 409- 415. La Plata, Buenos Aires.

1998. Esquemas de integración cultural y síntesis en la arqueología del Nordeste argentino. En: Homenaje a Alberto Rex González. 50 años de aportes a desarrollo y consolidación de la Antropología argentina, editado por FFyL-UBA; pp. 121153. Buenos Aires.

2001. Nordeste prehispánico. En: Historia Argentina Prehispánica, dirigido por E. E. Berbeberían y A. E. Nielsen; Tomo II, pp. 693-736. Editorial Brujas. Argentina.

Rodríguez, J.A. y C.N. Ceruti. 1999. Las tierras bajas del nordeste y el litoral mesopotámico. En: Nueva Historia de la Nación Argentina; Tomo I, pp. 109-133. Academia Nacional de la Historia. Editorial Planeta. Buenos Aires.

Rodríguez, M., E. Aspillaga y B. Arensburg. 2007. El estudio bioantropológico de las colecciones esqueletales del archipiélago de Chiloé: perspectivas y limitaciones. En: Arqueología de Fuego-Patagonia. Levantando piedras, desenterrando huesos...y develando arcanos, editado por F. Morillo, M. Martinic, A. Prieto y G. Bahamonde; pp. 269-278. Ediciones CEQUEA. Punta Arenas, Chile.

Rothschild, B. 2012. Extirpolation of the mythology that porotic hyperostosis is caused by iron deficiency secondary to dietary shift to maize. Advances in Anthropology 2 (3): 157-160. 
Sacur Silvestre, R., N. Buc, A. Acosta y D. Loponte. 2013. Estrategias de captura de presas y sistemas de armas de los cazadores-recolectores que habitaron el humedal del Paraná inferior: una aproximación experimental y arqueológica. Comechingonia. Revista de Arqueología 17: 27-57.

Salazar-García, D., M. Bonomo y C. Scabuzzo. 2018. Análisis de la alimentación a partir del estudio isotópico de carbono y nitrógeno en sitios de la entidad arqueológica Goya-Malabrigo del Delta del río Paraná. En: Nuevas perspectivas sobre la entidad arqueológica Goya-Malabrigo, editado por G. Politis y M. Bonomo. Editorial Universitaria de la Universidad Nacional del Centro de la provincia de Buenos Aires. En prensa.

Salega, M.S. 2017. Prácticas cotidianas, niveles de actividad física y modos de vida en poblaciones del sector austral de las Sierras Pampeanas durante el Holoceno tardío. Tesis doctoral inédita, Facultad de Filosofía y Humanidades, Universidad Nacional de Córdoba.

Salega, M.S. y M. Fabra. 2013. Niveles de actividad física en poblaciones de las sierras y las llanuras de la provincial de Córdoba (Argentina) durante el Holoceno tardío. Revista Relaciones de la Sociedad Argentina de Antropología XXXVIII (2): 401-420.

Sánchez, J.O., M.M. Colobig, A. Zucol, G. Politis, M. Bonomo y C. Castiñeira. 2013. Primeros resultados sobre el uso prehispánico de los vegetales en el sitio arqueológico Los Tres Cerros 1 (Victoria, Entre Ríos, Argentina): análisis del registro biosilíceo. Darwiniana 1 (2): 201-219.

Santa Cruz, A. [1540] 1918. Islario General de todas las islas del mundo. Madrid, Imprenta del Patronato de Huérfanos de Intendencia e Intervención Militares.

Santos, A.L., M.T. Gardner y P. Allsworth-Jones. 2013. Treponematosis in PreColumbian Jamaica: a biocultural approach to the human cranium found in Bull Savannah. Journal of Archaeological Science 40: 490-496. 
Scabuzzo, C. 2010. Actividad, patología y nutrición de los cazadores-recolectores pampeanos. Tesis doctoral inédita, Facultad de Ciencias Naturales y Museo, Universidad Nacional de La Plata.

2012. Estudios bioarqueológicos de marcadores de estrés ocupacional en cazadores recolectores pampeanos del Holoceno temprano medio. Análisis de la serie esqueletal de Arroyo Seco 2. Revista Argentina de Antropología Biológica 14: 1731.

2013. Estudios bioarqueológicos del sitio Paso Mayor, sudoeste de la provincia de Buenos Aires. Revista del Museo de Antropología 6: 49-62.

Scabuzzo, C. y M.A. Ramos van Raap. 2011. Primeros estudios bioarqueológicos en el sitio Los Tres Cerros 1 (departamento de Victoria, Entre Ríos). Comechingonia. Revista de Arqueología 5: 191-197.

2017. Nuevos resultados de los estudios osteológicos del sitio Los Tres Cerros 1 (Delta Superior del río Paraná). Comechingonia. Revista de Arqueología, Dossier Sexto Encuentro de Discusión Arqueológica del Nordeste Argentino. En prensa.

2018. Alcances, limitaciones y decisiones en el relevamiento de la enfermedad degenerativa articular. En: Libro de Resúmenes IV Taller Nacional de Bioarqueología y Paleopatología; pp. 38. Córdoba.

Scabuzzo, C., M.A. Ramos van Raap, M. Bonomo y G. Politis. 2015. Estudios bioarqueológicos en el sitio Los Tres Cerros 1 (Delta Superior del río Paraná, Entre Ríos, Argentina). Boletim do Museu Paraense Emílio Goeldi. Ciências Humanas 10 (2): 509-535.

Schaefer, M., S.M. Black y L. Scheuer. 2009. Juvenile osteology: a laboratory and field manual. Amsterdam, Academic.

Schinder, G. y R.A. Guichón. 2003. Isótopos estables y estilo de vida en muestras óseas humanas de Tierra del Fuego. Magallania 31: 33-44.

Schmitz, P.I., C.N. Ceruti, A.R. González y A. Rizzo. 1972. Investigaciones arqueológicas en la zona de Goya (Corrientes), Argentina. Dédalo, Revista de Arqueología y Etnología 8 (15): 11-121. 
Sciulli, P. W. 1997. Dental evolution in prehistoric Native Americans of the Ohio Valley Area. I. Wear and pathology. International Journal of Osteoarchaeology 7: 507-524.

Scott, E.C. 1979. Dental wear scoring technique. American Journal of Physical Anthropology 51: 213-218.

Scott, G.R. y C.G. Turner II. 1988. Dental anthropology. Annual Review Anthropology 17: 99-126.

Seldes, V. 2002. Indicadores de estrés nutricional y dieta en poblaciones del Chaco santiagueño. Relaciones de la Sociedad Argentina de Antropología XXVII: 115130.

2006. Bioarqueología de poblaciones prehistóricas de la quebrada de Humahuaca (Jujuy, Argentina). Estudios Atacameños 31: 47-61.

Selye, H. 1956. The stress of life. McGraw-Hill. Nueva York.

Serrano, A. 1922. Arqueología de Las Tejas (provincia de Santa Fe). Revista Universitaria del Litoral 1 (12): 65-110.

1930. Un nuevo tipo de instrumento de piedra del litoral argentino. Revista de la Sociedad "Amigos de la Arqueología" IV: 205-209.

1932. Exploraciones arqueológicas en el río Uruguay Medio. Memorias del Museo de Paraná 2 (Arqueología). 89 p. Paraná.

1936. Etnografía de la antigua provincia del Uruguay. Paraná.

1950. Los primitivos habitantes de Entre Ríos. Paraná, Biblioteca Entrerriana "General Perón", Ministerio de Educación, Provincia de Entre Ríos.

1972. Líneas fundamentales de la arqueología del litoral (una tentativa de periodización). Córdoba, Instituto de Antropología, Universidad Nacional de Córdoba.

Sia, I.G. y E.F. Berbari. 2006. Osteomyelitis. Best Practice \& Research Clinical Rheumatology 20 (6): 1065-1081.

Silva, C. 2014. Tecnología cerámica del sitio Laguna de los Gansos 1 (Dpto. Diamante, Entre Ríos). En: VII Congreso de Arqueología de la Región Pampeana 
Argentina, editado por F. Leiteri, G. Cocco y G. Fritegotto; pp. 5-8. Santa Fe, Argentina.

2015. Primeros resultados de las excavaciones arqueológicas en el sitio Cerro Farall (departamento Diamante, Entre Ríos). En: Libro de Resúmenes del VI Encuentro De Discusión Arqueológica Del Nordeste Argentino. Revista del Museo de La Plata, Arqueología 14 (89): 47R.

Smith, B.H. 1984. Patterns of molar wear in hunter-gatherers and agriculturalists. American Journal of Physical Anthropology 63: 39-56.

Smith, M.O. 2006. Treponemal disease in the Middle Archaic to Early Woodland periods of the western Tennessee river Valley. American Journal of Physical Anthropology 131: 205-217.

Smith, M.O. y T.K. Betsinger. 2015. Subsistence and settlement correlates of treponemal disease: temporal patterns in Pre-Columbian East Tennessee. International Journal of Osteoarchaeology 25: 855-865.

Sofaer J.A. 2006. The body as material culture: a theoretical osteoarchaeology. Cambridge, UK: Cambridge University Press.

Standen, V. y B.T. Arriaza. 2000a. Trauma in the preceramic coastal populations of Northern Chile: violence or occupational hazards? American Journal of Physical Anthropology 112: 239-249.

2000b. La treponematosis (Yaws) en las poblaciones prehispánicas del Desierto de Atacama (norte de Chile). Chungará (Arica) 32 (2): 185-192.

Standen, V., M. Allison y B.T. Arriaza. 1985. Patologías óseas de la Población Morro 1, asociada al Complejo Chinchorro: Norte de Chile. Chungara, Revista de Antropología Chilena 13: 175-185

Steckel, R.H. y J.C. Rose. 2002. A health index from skeletal remains. En: The backbone of history: health and nutrition in the Western Hemisphere, editado por R.H. Steckel y J.C. Rose; pp. 61-93. Cambridge, UK: Cambridge University Press. 
Steinbock, R.T. 1976. Paleopathological Diagnosis and Interpretation. C. C Thomas, Springfield, Illinois.

Stuart-Macadam, P. 1985. Porotic Hyperostosis. Representative of a childhood condition. American Journal of Physical Anthropology 66: 391-398.

1989. Porotic Hyperostosis: relationship between orbital and vault lesions. American Journal of Physical Anthropology 80: 187-193.

Suby, J. 2007a. Propiedades estructurales de restos óseos humanos y paleopatologia en Patagonia austral. Tesis doctoral inédita, Facultad de Ciencias Exactas y Naturales, Universidad Nacional de Mar del Plata.

2007b. Metodologías de análisis de densidad mineral ósea sobre restos óseos humanos de Patagonia Austral. Tafonomía y paleopatología. En: Arqueología de Fuego-Patagonia. Levantando piedras, desenterrando huesos.. y develando arcanos, editado por F. Morello, M. Martinic, A. Prieto y G. Bahamonde; pp. 381390. Ediciones CEQUA. Punta Arenas.

2012. La salud de nuestros antepasados: una mirada sobre la Paleopatología. Quequén: Laboratorio de Ecología Evolutiva Humana.

2014. Porotic hyperostosis and cribra orbitalia in human remains from southern Patagonia. Anthropological Science 122 (2): 69-79.

Suby, J. y R.A. Guichón. 2009. Diet, nutrition and femur robusticity in Southern Patagonia. Some experiences and perspectives. International Journal of Osteoarchaeology 19: 328-336.

Suby, J., L. Luna, C. Aranda y G. Flensborg. 2017a. Paleopatología: la evolución de nuestra salud. Revista Ciencia Hoy 26 (157): 11-15.

2017b. First approximation to paleodemography through age-at-death profiles in hunter-gatherers from Southern Patagonia during middle-late Holocene. Quaternary International 438: 174-188.

Suby, J., M. Salemme M y F. Santiago. 2008. Análisis paleopatológico de los restos humanos del sitio Puesto Pescador 1 (Tierra del Fuego). Magallania 36 (1): 5364.

Tavarone, A. y M. Fabra. 2017. Primeras evidencias sobre el uso de los recursos vegetales en el sitio arqueológico El Diquecito (costa sur, laguna Mar Chiquita, 
Córdoba). Una aproximación desde el studio de microindicadores vegetales contenidos en cálculos dentales humanos. En: Libro de resúmenes del Séptimo Encuentro de Discusión Arqueológica del Nordeste Argentino, Revista Scientia Interfluvius, pp. 24. Diamante, Entre Ríos.

Tayles, N., K. Domett y K. Nelsen. 2000. Agriculture and dental caries? The case of rice in Prehistoric Southeast Asia. World Archaeology 32 (1): 68-83.

Temple, D.H. y A.H. Goodman. 2014. Bioarcheology has a "Health" problem: conceptualizing "Stress" and "Health" in bioarcheological research. American Journal of Physical Anthropology 155: 186-191.

Ten Kate, H.F.C. 1892. Contribution à la craneologie des Araucans argentins. Revista del Museo de La Plata IV: 209-220.

Todd, T. 1920. Age changes in the pubic bone: I. The white male pubis. American Journal of Physical Anthropology 3: 285-334.

Todd, L. y G. Frison. 1992. Reassembly of bison skeletons from the Horner site: a study in anatomical refitting. En: Piecing together the past: applications of refitting studies in archaeology, editado por J. Hofman y G. Enloe; pp. 63-82. Oxford, BAR International Series 579.

Torres, L.M. 1903. Los cementerios indígenas del sur de Entre Ríos y su relación con los del Uruguay, túmulos de Campana (Buenos Aires) y Santos (Brasil). Anales del Museo Nacional de Buenos Aires 9: 57-75.

1911. Los primitivos habitantes del Delta del Paraná. Biblioteca Centenaria 4, Universidad Nacional de La Plata, Buenos Aires.

Turner II, C.G. 1979. Dental anthropological indications of agriculture among the Jomon people of central Japan. American Journal of Physical Anthropolology 51: 619-636.

Ubelaker, D. 1987. Estimating age at death from immature human skeletons: an overview. Journal of Forensic Sciences 32: 1254-1263. 
1989. Human Skeletal Remains. Excavation, Analysis, Interpretation. $2^{\circ}$ Ed. Taraxacum, Washington.

Verneau, R. 1903. Les anciens Patagons. Contribution a l'étude des races précolombiennes de l'Amérique du Sud. Monaco: Institut de Paléontologie Humaine.

Vignati, M. 1938. Cráneos pintados del cementerio indígena de San Blas. Revista del Museo de La Plata 1: 35-52.

Waldron, T. 1994. Counting the Dead: The epidemiology of Skeletal Populations. John Willey \& Sons. Chichester.

2009. Paleopathology. Cambridge University Press. New York.

Waldvogel, F.A., G. Medoff y M.N. Swartz. 1970. Osteomyelitis: a review of clinical features, therapeutic considerations and unusual aspects (Third of three parts). New England Journal of Medicine 282 (6): 316-322.

Walker, P.L. 1986. Porotic Hyperostosis in a Marine-Dependent California. American Journal of Physical Anthropology 69: 345-354.

1989. Cranial injuries as evidence of violence in prehistoric southern California, Santa Bárbara. American Journal of Physical Anthropology 80: 313-323.

1997. Wife beating, boxing, and broken noses: skeletal evidence for the cultural patterning of violence. En: Troubled Times: Violence and Warfare in the Past, editado por D.L. Martin y D.W. Frayer; pp. 145-180. Gordon and Breach Publishers: Toronto.

Walker, P.L y J.M. Erlandson. 1986. Dental evidence for prehistoric dietary change on the northern Channel Islands, California. American Antiquity 51: 375-383.

Walker, P.L., R.R. Bathurst, R. Richman, T. Gjerdrum y V. Andrushko. 2009. The causes of porotica hyperostosis and cribra orbitalia: A reappraisal of the iron deficiency anemia hypothesis. American Journal of Physical Anthropology 139: 109-125. 
Wapler, U., E. Crubézy y M. Schultz. 2004. Is cribra orbitalia synonymous with anemia? Analysis and interpretation of cranial pathology in Sudan. American Journal of Physical Anthropology 123: 333-339.

Weiss, K.M. 1973. Demographic models for anthropology (Memoirs of the Society for American Archaeology, No. 27). American Antiquity 38 (2), Part 11.

Wells, C. 1963. Cortical grooves on the tibia. Man 63: 112-114.

Wesolowski, V., S. Mendonça de Souza, K.J. Reinhard y G. Ceccantini. 2010. Evaluating microfossil content of dental calculus from Brazilian sambaquis. Journal of Archaeological Science 37: 1326-1338.

Weston, D.A. 2008. Investigating the specificity of periosteal reactions in Pathlogy Museums Specimens. American Journal of Physical Anthropology 137: 48-59. 2009. Brief Communication: Paleohistopathological analysis of pathology museum Specimens: can periosteal reaction microsstructure explain lesion etiology? American Journal of Physical Anthropology 140: 186-193.

2012. Nonspecific Infection in Paleopathology: Interpreting Periosteal Reactions. En: A Companion to Paleopathology, editado por A. Grauer; pp. 250-267. WilleyBalckwell, Malden.

White, T.D. y P.A. Folkens. 2005. The human bone manual. Elsevier Academic Press, San Diego.

Wilson, D.E. 2005. Treponematosis in the East Texas gulf coastal plain. En: The Myth of Syphilis: The Natural History of Treponematosis in North America, editado por M.L. Powell y D.C. Cook; pp: 162-176. University of Florida Press: Gainesville.

Wood, L. 1996. Frequency and chronological distributions of linear enamel hypoplasia in North American Colonial Skeletal Sample. American Journal of Physical Anthropology 100: 247-259 
Wood, J.W., G.R. Millner, H.C. Harpending y K.M. Weiss. 1992. The osteological Paradox. Problems of inferring prehistoric health from skeletal samples. Current Anthropology 33 (4): 343-369.

Wright, L.E. y C.J. Yoder. 2003. Recent Progress in Bioarchaeology: Approaches to the Osteological Paradox. Journal of Archaeological Research 11 (1): 43-70.

Zeballos, E. y P. Pico. 1878. Informe sobre el túmulo prehistórico de Campana. Anales de la Sociedad Científica Argentina 6:244-260.

Zuckerman, M.K., B.L. Turner y G.J. Armelagos. 2012. Evolutionary thought in paleopathology and the rise of the biocultural approach. En: $A$ companion to Paleopathology, editado por A. Grauer; pp. 34-57. Willey-Balckwell, Malden.

Zucol, A. y D. Loponte. 2008. Análisis comparativo metodológico y estudio de la abundancia fitolítica en tártaro de dientes humanos de sitios arqueológicos de la provincia de Buenos Aires, Argentina. En Matices Interdisciplinares en Estudios Fitolíticos y de Otros Microfósiles, editado por M. A. Korstanje y M. d. P. Babot; pp. 39-46. BAR International Series S1870, Inglaterra. 


\section{Apéndice 1}

Tabla A.1.1

Nomenclatura utilizada para cada tipo diente según su desarrollo

\begin{tabular}{|c|c|c|}
\hline Elemento dental & $\begin{array}{c}\text { Dentición } \\
\text { decidua }\end{array}$ & $\begin{array}{c}\text { Dentición } \\
\text { permanente }\end{array}$ \\
\hline Primer incisivo superior & $\mathrm{i}^{1}$ & $\mathrm{I}^{1}$ \\
Segundo incisivo superior & $\mathrm{i}^{2}$ & $\mathrm{I}^{2}$ \\
Canino superior & $\mathrm{c}^{1}$ & $\mathrm{C}^{1}$ \\
Primer premolar superior & - & $\mathrm{Pm}^{1}$ \\
Segundo premolar superior & - & $\mathrm{Pm}^{2}$ \\
Primer molar superior & $\mathrm{m}^{1}$ & $\mathrm{M}^{1}$ \\
Segundo molar superior & $\mathrm{m}^{2}$ & $\mathrm{M}^{2}$ \\
Tercer molar superior & - & $\mathrm{M}^{3}$ \\
Primer incisivo inferior & $\mathrm{i}_{1}$ & $\mathrm{I}_{1}$ \\
Segundo incisivo inferior & $\mathrm{i}_{2}$ & $\mathrm{I}_{2}$ \\
Canino inferior & $\mathrm{c}_{1}$ & $\mathrm{C}_{1}$ \\
Primer premolar inferior & - & $\mathrm{Pm}_{1}$ \\
Segundo premolar inferior & - & $\mathrm{Pm}_{2}$ \\
Primer molar inferior & $\mathrm{m}_{1}$ & $\mathrm{M}_{1}$ \\
Segundo molar inferior & $\mathrm{m}_{2}$ & $\mathrm{M}_{2}$ \\
Tercer molar inferior & - & $\mathrm{M}_{3}$ \\
\hline
\end{tabular}

Aclaración: para diferenciar lateralidad, agregar la letra D (derecho) o I (izquierdo). 
Ficha A.1.1

Inventario de la dentición (adultos)

\begin{tabular}{|l|l|l|l|}
\hline Sitio arqueológico & & Ubicación & \\
\hline Entierro $\mathrm{n}^{\circ}$ & & Individuo $\mathrm{n}^{\circ}$ & \\
\hline Edad & & Sexo & \\
\hline Año campaña arq. & & Sector & \\
\hline Cuadrícula & Nivel & $\mathrm{N}^{\circ}$ campo & $\mathrm{N}^{\circ}$ análisis \\
\hline
\end{tabular}
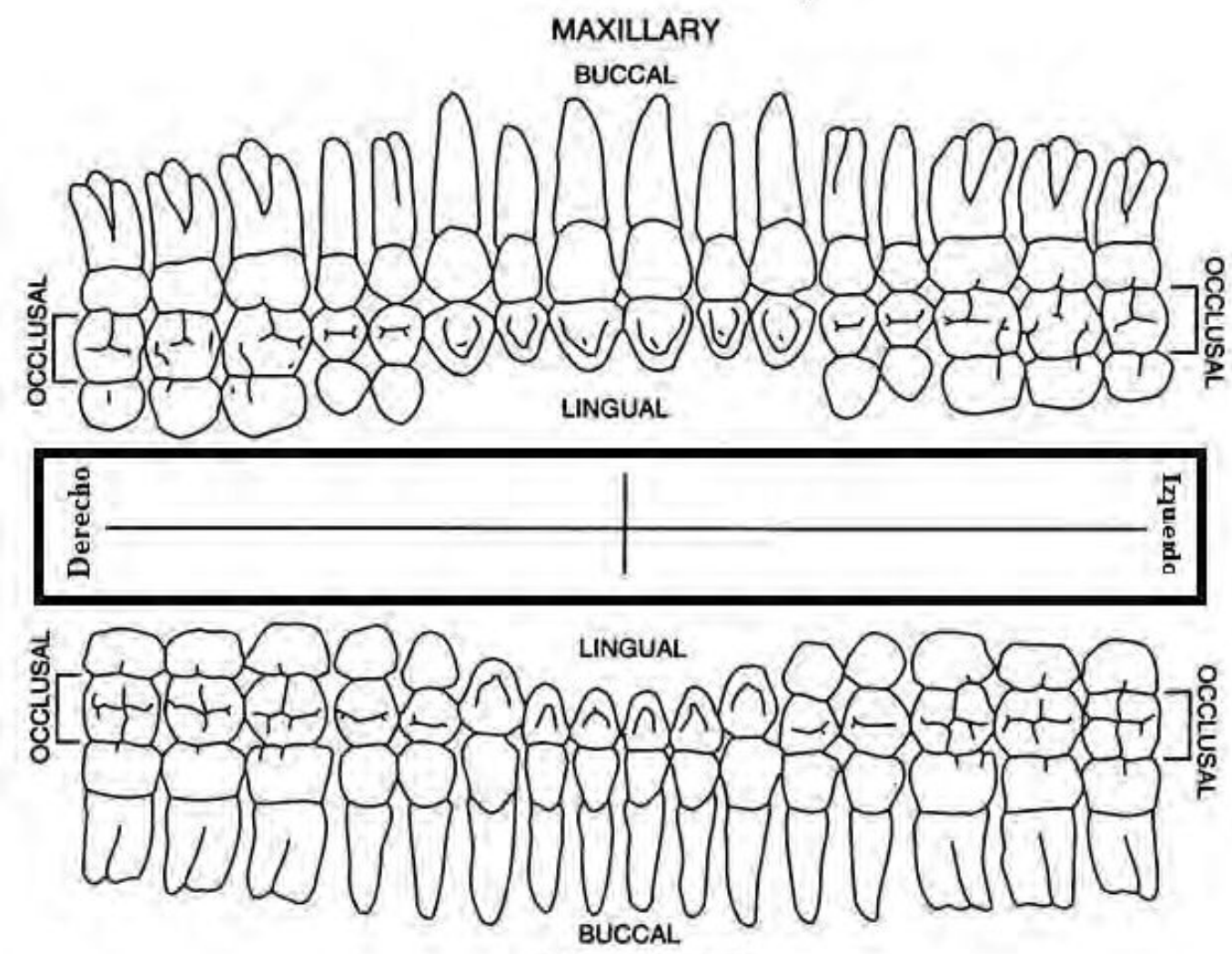

MANDIBULAR

CÓDIGO (Buikstra y Ubelaker 1994: 48-49)

1. Presente, pero no en oclusión

2. Presente, completamente desarrollado, en oclusión

3. Ausente, sin hueso alveolar asociado

4. Ausente, con alveolo en reabsorción o todo reabsorbido: pérdida premortem

5. Ausente, sin reabsorción alveolar: pérdida postmortem

6. Ausente, ausencia congénita

7. Presente, imposible realizar mediciones, pero otras observaciones son registradas (e.g.caries)

8. Presente, pero no observable (e.g. diente deciduo o permanente en cripta) 


\section{Registro de patologías orales}

REFERENCIAS (marcar la/s letra/s correspondiente/s)

a) Caries

b) Lesión Periapical

c) Pérdida dental antemortem d) Cálculo dental

f) Hipoplasia del esmalte dental
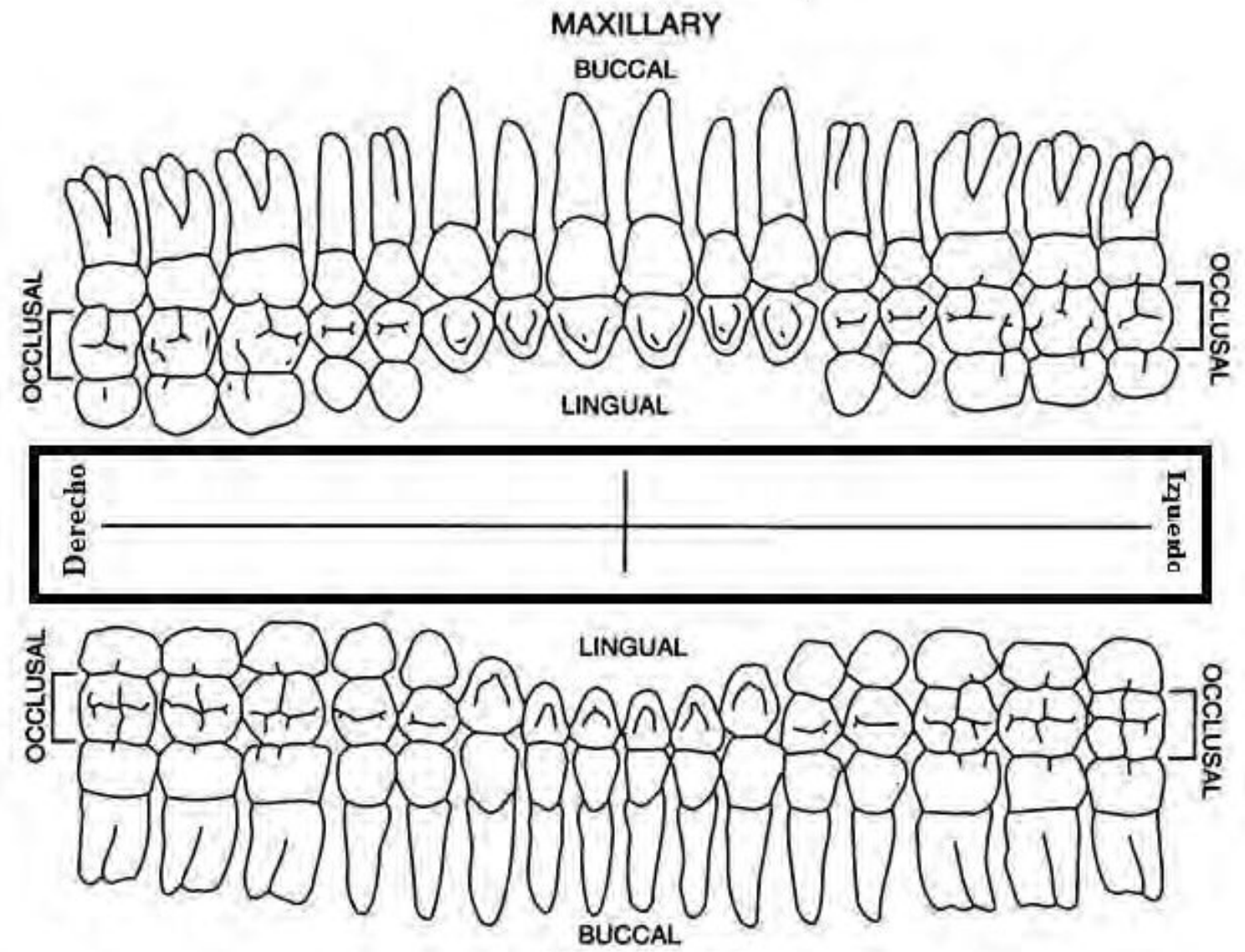

MANDIBULAR 
Apéndice 1

\begin{tabular}{|c|c|c|c|c|c|c|c|c|c|c|c|c|}
\hline \multirow{3}{*}{$\begin{array}{c}\text { MAX } \\
\text { DER } \\
\mathbf{M}^{3}\end{array}$} & \multirow{2}{*}{ Caries } & \multirow{2}{*}{$\begin{array}{c}\text { Lesión } \\
\text { periapical }\end{array}$} & \multirow{2}{*}{ PDAM } & \multirow{2}{*}{ HED } & \multirow{2}{*}{ Cálculos } & \multicolumn{5}{|c|}{ Desgaste } & \multicolumn{2}{|c|}{ Tipo desgaste } \\
\hline & & & & & & BM & BD & LM & LD & Total & Dirección & Forma \\
\hline & & & & & & & & & & & & \\
\hline \multicolumn{13}{|l|}{$\mathbf{M}^{2}$} \\
\hline \multicolumn{13}{|l|}{$\mathbf{M}^{1}$} \\
\hline \multicolumn{13}{|l|}{$\mathbf{P m}^{2}$} \\
\hline \multicolumn{13}{|l|}{$\mathbf{P m}^{1}$} \\
\hline \multicolumn{13}{|l|}{$\mathbf{C}^{1}$} \\
\hline \multicolumn{13}{|l|}{$\mathbf{I}^{2}$} \\
\hline \multicolumn{13}{|l|}{$\mathbf{I}^{1}$} \\
\hline \multirow{2}{*}{$\begin{array}{r}\text { MAX } \\
\text { IZQ }\end{array}$} & \multirow{2}{*}{ Caries } & \multirow{2}{*}{$\begin{array}{c}\text { Lesión } \\
\text { periapical }\end{array}$} & \multirow{2}{*}{ PDAM } & \multirow{2}{*}{ HED } & \multirow{2}{*}{ Cálculos } & \multicolumn{5}{|c|}{ Desgaste } & \multicolumn{2}{|c|}{ Tipo desgaste } \\
\hline & & & & & & BM & BD & LM & LD & Total & Dirección & Forma \\
\hline $\mathbf{I}^{\mathbf{1}}$ & & & & & & & & & & & & \\
\hline $\mathbf{I}^{2}$ & & & & & & & & & & & & \\
\hline $\mathbf{C}^{1}$ & & & & & & & & & & & & \\
\hline $\mathbf{P m}^{1}$ & & & & & & & & & & & & \\
\hline $\mathbf{P m}^{2}$ & & & & & & & & & & & & \\
\hline $\mathbf{M}^{1}$ & & & & & & & & & & & & \\
\hline $\mathbf{M}^{2}$ & & & & & & & & & & & & \\
\hline $\mathbf{M}^{3}$ & & & & & & & & & & & & \\
\hline
\end{tabular}

\begin{tabular}{|c|c|c|c|c|c|c|c|c|c|c|c|c|}
\hline \multirow{3}{*}{$\begin{array}{c}\text { MND } \\
\text { DER } \\
M_{3}\end{array}$} & \multirow{2}{*}{ Caries } & \multirow{2}{*}{$\begin{array}{l}\text { Lesión } \\
\text { periapical }\end{array}$} & \multirow{3}{*}{ PDAM } & \multirow{3}{*}{ HED } & \multirow{2}{*}{ Cálculos } & \multicolumn{5}{|c|}{ Desgaste } & \multicolumn{2}{|c|}{ Tipo desgaste } \\
\hline & & & & & & BM & BD & LM & LD & Total & Dirección & Forma \\
\hline & & & & & & & & & & & & \\
\hline \multicolumn{13}{|l|}{$\mathbf{M}_{2}$} \\
\hline \multicolumn{13}{|l|}{$\mathbf{M}_{1}$} \\
\hline \multicolumn{13}{|l|}{$\mathbf{P m}_{2}$} \\
\hline \multicolumn{13}{|l|}{$\mathbf{P m}_{1}$} \\
\hline \multicolumn{13}{|l|}{$\mathrm{C}_{1}$} \\
\hline \multicolumn{13}{|l|}{$I_{2}$} \\
\hline \multicolumn{13}{|l|}{$\mathbf{I}_{1}$} \\
\hline MND & \multirow{2}{*}{ Caries } & \multirow{2}{*}{$\begin{array}{c}\text { Lesión } \\
\text { periapical }\end{array}$} & \multirow{2}{*}{ PDAM } & \multirow{2}{*}{ HED } & \multirow{2}{*}{ Cálculos } & \multicolumn{5}{|c|}{ Desgaste } & \multicolumn{2}{|c|}{ Tipo desgaste } \\
\hline IZQ & & & & & & BM & BD & LM & LD & Total & Dirección & Forma \\
\hline $\mathbf{I}_{1}$ & & & & & & & & & & & & \\
\hline $\mathbf{I}_{2}$ & & & & & & & & & & & & \\
\hline $\mathrm{C}_{1}$ & & & & & & & & & & & & \\
\hline $\mathbf{P m}_{1}$ & & & & & & & & & & & & \\
\hline $\mathbf{P m}_{2}$ & & & & & & & & & & & & \\
\hline $\mathbf{M}_{1}$ & & & & & & & & & & & & \\
\hline $\mathbf{M}_{2}$ & & & & & & & & & & & & \\
\hline $\mathbf{M}_{3}$ & & & & & & & & & & & & \\
\hline
\end{tabular}


Ficha A.1.2

Registro de patologías óseas

\begin{tabular}{|l|l|l|l|}
\hline Sitio arqueológico & & Ubicación & \\
\hline Entierro $\mathrm{n}^{\circ}$ & & Individuo $\mathrm{n}^{\circ}$ & \\
\hline Edad & & Sexo & \\
\hline Año campaña arq. & & Sector & \\
\hline Cuadrícula & Nivel & $\mathrm{N}^{\circ}$ campo & $\mathrm{N}^{\circ}$ análisis \\
\hline
\end{tabular}
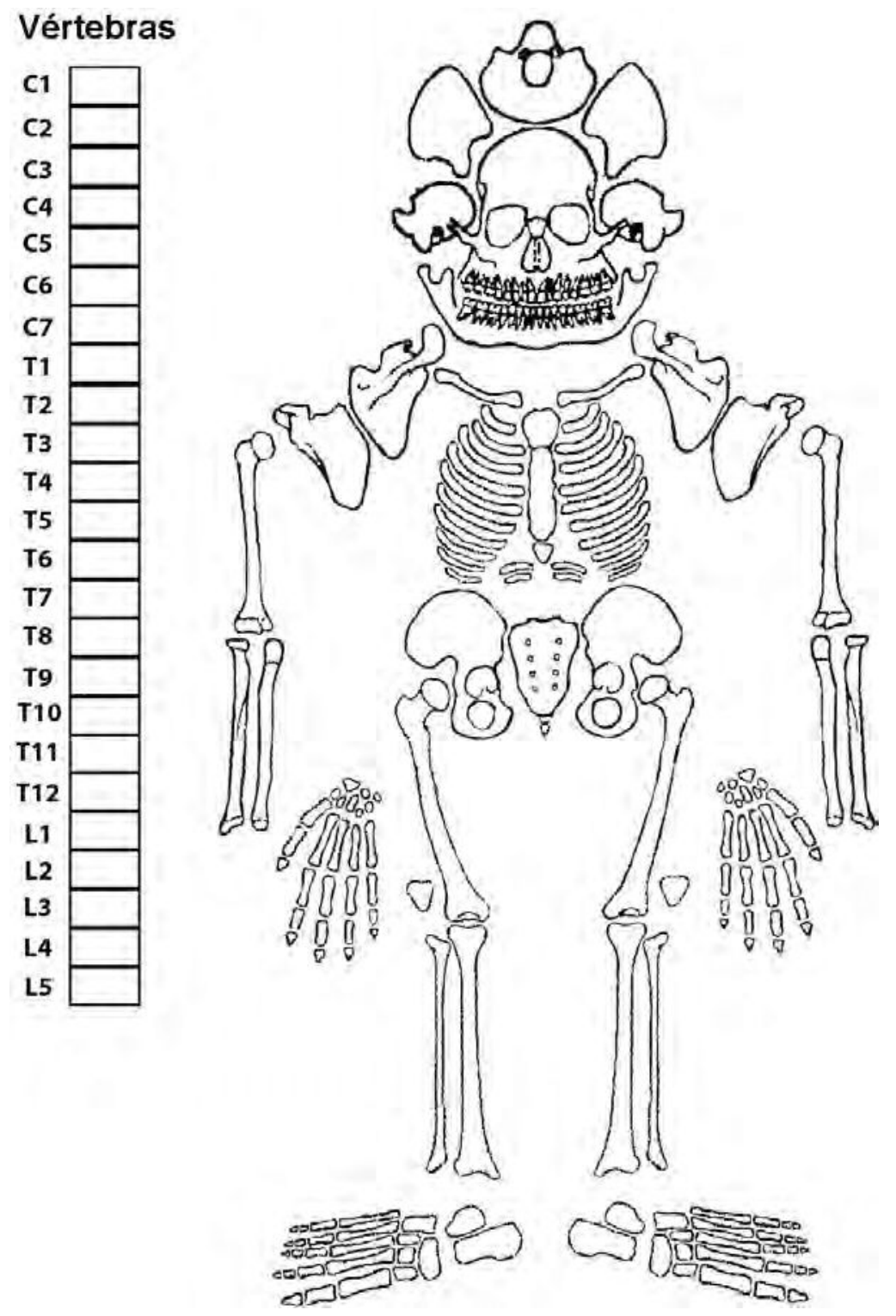


\begin{tabular}{|l|l|}
\hline ELEMENTO & LATERALIDAD \\
\hline SECCIÓN & CARA \\
\hline TIPO DE HUESO & BORDES DE LA LESIÓN \\
\hline DESCRIPCIÓN & \\
& \\
& \\
\hline FOTOGRAFÍAS & \\
\hline
\end{tabular}




\section{Apéndice 2}

Tabla A.2.1.

Cálculos de abundancia anatómica del paquete funerario LTC1-S1.

\begin{tabular}{|c|c|c|c|c|c|c|c|c|}
\hline \multirow{2}{*}{ Unidad anatómica } & \multirow{2}{*}{ NISP } & \multicolumn{3}{|c|}{$\mathbf{F}$} & \multirow{2}{*}{ NMI } & \multirow{2}{*}{ NME } & \multirow{2}{*}{ MAU } & \multirow{2}{*}{ MAU\% } \\
\hline & & D & I A & In. & & & & \\
\hline cráneo & 1 & & 1 & & 1 & 1 & 1 & 66,6 \\
\hline mandíbula & 0 & & & & 0 & 0 & 0 & 0 \\
\hline vért. cervicales & 0 & & & & 0 & 0 & 0 & 0 \\
\hline vért. torácicas & 4 & & 2 & & 1 & 2 & 0,17 & 11,3 \\
\hline vért. lumbares & 3 & & 3 & & 1 & 3 & 0,6 & 40 \\
\hline costilla & 3 & 1 & & 2 & 1 & 1 & 0,1 & 6,6 \\
\hline clavícula & 2 & 1 & 1 & & 1 & 2 & 1 & 66,6 \\
\hline esternón & 0 & & & & 0 & 0 & 0 & 0 \\
\hline escápula & 2 & 1 & 1 & & 1 & 2 & 1 & 66,6 \\
\hline húmero & 2 & 2 & & & 2 & 2 & 1 & 66,6 \\
\hline radio & 2 & & 1 & 1 & 1 & 2 & 1 & 66,6 \\
\hline cúbito & 1 & & 1 & & 1 & 1 & 0,5 & 33,3 \\
\hline carpos & 1 & & 1 & & 1 & 1 & 0,1 & 6,6 \\
\hline metacarpos & 0 & & & & 0 & 0 & 0 & 0 \\
\hline falanges mano & 0 & & & & 0 & 0 & 0 & 0 \\
\hline coxal & 2 & 1 & 1 & & 1 & 2 & 1 & 66,6 \\
\hline sacro & 1 & & 1 & & 1 & 1 & 1 & 66,6 \\
\hline fémur & 3 & 1 & 2 & & 2 & 3 & 1,5 & 100 \\
\hline rótula & 0 & & & & 0 & 0 & 0 & 0 \\
\hline tibia & 0 & & & & 0 & 0 & 0 & 0 \\
\hline peroné & 0 & & & & 0 & 0 & 0 & 0 \\
\hline tarsos & 0 & & & & 0 & 0 & 0 & 0 \\
\hline metatarsos & 1 & & 1 & & 1 & 1 & 0,1 & 6,6 \\
\hline falanges pie & 0 & & & & 0 & 0 & 0 & 0 \\
\hline dientes sueltos & 1 & & & & 1 & 1 & - & - \\
\hline TOTAL & 29 & & & & & 25 & & \\
\hline
\end{tabular}

Referencias: $\mathrm{NISP}=$ número mínimo de especímenes óseos; $\mathrm{F}=$ fusionados; $\mathrm{D}=$ derecho; $\mathrm{I}=$ izquierdo; $\mathrm{A}=$ axial; In.=indeterminado; $\mathrm{NMI}=$ número mínimo de individuos; $\mathrm{NME}=$ número mínimo de elementos; $M A U=$ unidades anatómicas mínimas; $M A U \%=$ porcentaje de unidades anatómicas mínimas. 
Tabla A.2.2.

Cálculos de abundancia anatómica del paquete funerario LTC1-S2.

\begin{tabular}{|c|c|c|c|c|c|c|c|c|c|c|c|}
\hline \multirow{2}{*}{ Unidad anatómica } & \multirow{2}{*}{ NISP } & \multicolumn{3}{|c|}{$L / F$} & \multicolumn{3}{|c|}{$\mathbf{F}$} & \multirow{2}{*}{ NMI } & \multirow{2}{*}{ NME } & \multirow{2}{*}{ MAU } & \multirow{2}{*}{ MAU\% } \\
\hline & & D & $\mathbf{I}$ & A In & D & I A & In. & & & & \\
\hline cráneo & 1 & & & 1 & & & & 1 & 1 & 1 & 50 \\
\hline mandíbula & 1 & & & & & 1 & & 1 & 1 & 1 & 50 \\
\hline vért. cervicales & 8 & & & 1 & & 7 & & 2 & 8 & 1,1 & 55 \\
\hline vért. torácicas & 6 & & & 4 & & 2 & & 2 & 6 & 0,5 & 25 \\
\hline vért. lumbares & 0 & & & & & & & 0 & 0 & 0 & 0 \\
\hline costilla & 47 & 1 & 2 & 2 & 7 & 8 & 3 & 2 & 23 & 0,9 & 45 \\
\hline clavícula & 4 & 1 & 1 & & 1 & 1 & & 2 & 4 & 2 & 100 \\
\hline esternón & 0 & & & & & & & 0 & 0 & 0 & 0 \\
\hline escápula & 4 & 1 & 1 & & 1 & 1 & & 2 & 4 & 2 & 100 \\
\hline húmero & 0 & & & & & & & 0 & 0 & 0 & 0 \\
\hline radio & 0 & & & & & & & 0 & 0 & 0 & 0 \\
\hline cúbito & 0 & & & & & & & 0 & 0 & 0 & 0 \\
\hline carpos & 0 & & & & & & & 0 & 0 & 0 & 0 \\
\hline metacarpos & 2 & & & & 1 & 1 & & 1 & 2 & 0,2 & 10 \\
\hline falanges mano & 1 & & & & & 1 & & 1 & 1 & 0,1 & 5 \\
\hline coxal & 4 & 1 & 1 & & 1 & 1 & & 2 & 4 & 2 & 100 \\
\hline sacro & 0 & & & & & & & 0 & 0 & 0 & 0 \\
\hline fémur & 2 & 1 & 1 & & & & & 1 & 2 & 1 & 50 \\
\hline rótula & 0 & & & & & & & 0 & 0 & 0 & 0 \\
\hline tibia & 0 & & & & & & & 0 & 0 & 0 & 0 \\
\hline peroné & 0 & & & & & & & 0 & 0 & 0 & 0 \\
\hline tarsos & 0 & & & & & & & 0 & 0 & 0 & 0 \\
\hline metatarsos & 0 & & & & & & & 0 & 0 & 0 & 0 \\
\hline falanges pie & 0 & & & & & & & 0 & 0 & 0 & 0 \\
\hline TOTAL & 80 & & & & & & & & 56 & & \\
\hline
\end{tabular}

Referencias: NISP= número mínimo de especímenes óseos; L/F=con línea de fusión; $\mathrm{F}=$ fusionados; $\mathrm{D}=$ derecho; $\mathrm{I}=$ izquierdo; $\mathrm{A}=$ axial; In.=indeterminado; $\mathrm{NMI}=$ número mínimo de individuos; $\mathrm{NME}=$ número mínimo de elementos; $\mathrm{MAU}=$ unidades anatómicas mínimas; MAU\%=porcentaje de unidades anatómicas mínimas. 
Tabla A.2.3.

Cálculos de abundancia anatómica del paquete funerario LTC1-S4.

\begin{tabular}{|c|c|c|c|c|c|c|c|c|c|c|c|c|c|}
\hline \multirow{2}{*}{$\begin{array}{c}\text { Unidad } \\
\text { anatómica }\end{array}$} & \multirow{2}{*}{ NISP } & \multicolumn{3}{|c|}{$S / F$} & \multicolumn{2}{|r|}{$L / F$} & \multicolumn{3}{|c|}{$\mathbf{F}$} & \multirow{2}{*}{ NMI } & \multirow{2}{*}{ NME } & \multirow{2}{*}{ MAU } & \multirow{2}{*}{ MAU\% } \\
\hline & & D I & I A I & In. & D & I A In. & D & I & A In. & & & & \\
\hline cráneo & 9 & & 1 & & & & & & 1 & 2 & 2 & 2 & 57,1 \\
\hline mandíbula & 2 & & 1 & & & & & & 1 & 2 & 2 & 2 & 57,1 \\
\hline vért. cervicales & 0 & & & & & & & & & 0 & 0 & 0 & 0 \\
\hline vért. torácicas & 0 & & & & & & & & & 0 & 0 & 0 & 0 \\
\hline vért. lumbares & 6 & & & & & & & & 3 & 1 & 3 & 0,6 & 17,1 \\
\hline costilla & 25 & 43 & 3 & 4 & & & & & 1 & 2 & 12 & 0,5 & 14,2 \\
\hline clavícula & 1 & & & & & & 1 & & & 1 & 1 & 0,5 & 14,2 \\
\hline esternón & 0 & & & & & & & & & 0 & 0 & 0 & 0 \\
\hline escápula & 1 & & & & & & & 1 & & 1 & 1 & 1 & 28,6 \\
\hline húmero & 6 & 2 & & & 1 & & 2 & 1 & & 5 & 6 & 3 & 85,7 \\
\hline radio & 4 & & & & & 1 & & 2 & & 3 & 4 & 2 & 57,1 \\
\hline cúbito & 4 & & & & 1 & & 1 & 2 & & 3 & 4 & 2 & 57,1 \\
\hline carpos & 7 & & & & & & & 7 & & 1 & 7 & 0,9 & 25,7 \\
\hline metacarpos & 5 & & & & & & & 5 & & 1 & 5 & 0,5 & 14,2 \\
\hline falanges mano & 12 & & & & & & 2 & 10 & & 1 & 12 & 0,4 & 11,4 \\
\hline coxal & 4 & & & & 1 & & 1 & 1 & 1 & 3 & 4 & 2 & 57,1 \\
\hline sacro & 1 & & & & & & & & 1 & 1 & 1 & 1 & 28,6 \\
\hline fémur & 7 & 2 & 2 & & 1 & 1 & 1 & 1 & & 4 & 7 & 3,5 & 100 \\
\hline rótula & 0 & & & & & & & & & 0 & 0 & 0 & 0 \\
\hline tibia & 4 & 1 & 1 & & & 1 & 1 & 1 & & 3 & 4 & 2 & 57,1 \\
\hline peroné & 3 & & & & & & 2 & 1 & & 2 & 3 & 1,5 & 42,8 \\
\hline tarsos & 0 & & & & & & & & & 0 & 0 & 0 & 0 \\
\hline metatarsos & 0 & & & & & & & & & 0 & 0 & 0 & 0 \\
\hline falanges pie & 1 & & & & & & & & 1 & 1 & 1 & 0,1 & 2,8 \\
\hline hueso in. & 1 & & & & & & & & & 1 & 1 & - & - \\
\hline TOTAL & 103 & & & & & & & & & & 80 & & \\
\hline
\end{tabular}

Referencias: NISP= número mínimo de especímenes óseos; $S / F=\sin$ fusionar; $L / F=c o n$ línea de fusión; F=fusionados; $\mathrm{D}=$ =derecho; I=izquierdo; $\mathrm{A}=$ axial; In.=indeterminado; $\mathrm{NMI}=$ número mínimo de individuos; $\mathrm{NME}=$ número mínimo de elementos; $\mathrm{MAU}=$ unidades anatómicas mínimas; MAU\%=porcentaje de unidades anatómicas mínimas. 
Tabla A.2.4.

Cálculos de abundancia anatómica del paquete funerario LTC1-S5.

\begin{tabular}{|c|c|c|c|c|c|c|c|c|c|}
\hline \multirow{2}{*}{$\begin{array}{c}\text { Unidad } \\
\text { anatómica }\end{array}$} & \multirow{2}{*}{ NISP } & \multicolumn{4}{|c|}{$\mathbf{F}$} & \multirow{2}{*}{ NMI } & \multirow{2}{*}{ NME } & \multirow{2}{*}{ MAU } & \multirow{2}{*}{ MAU\% } \\
\hline & & D & I & A & In. & & & & \\
\hline cráneo & 0 & & & & & 0 & 0 & 0 & 0 \\
\hline mandíbula & 0 & & & & & 0 & 0 & 0 & 0 \\
\hline vért. cervicales & 0 & & & & & 0 & 0 & 0 & 0 \\
\hline vért. torácicas & 1 & & & 1 & & 1 & 1 & 0,1 & 6,6 \\
\hline vért. lumbares & 2 & & & 2 & & 1 & 2 & 0,4 & 26,6 \\
\hline costilla & 3 & 1 & 1 & & 1 & 1 & 3 & 0,1 & 6,6 \\
\hline clavícula & 1 & & 1 & & & 1 & 1 & 0,5 & 33,3 \\
\hline esternón & 0 & & & & & 0 & 0 & 0 & 0 \\
\hline escápula & 0 & & & & & 0 & 0 & 0 & 0 \\
\hline húmero & 1 & & 1 & & & 1 & 1 & 0,5 & 33,3 \\
\hline radio & 2 & 2 & & & & 2 & 2 & 1 & 66,6 \\
\hline cúbito & 3 & 2 & 1 & & & 2 & 3 & 1,5 & 100 \\
\hline carpos & 0 & & & & & 0 & 0 & 0 & 0 \\
\hline metacarpos & 1 & 1 & & & & 1 & 1 & 0,1 & 6,6 \\
\hline falanges mano & 0 & & & & & 0 & 0 & 0 & 0 \\
\hline coxal & 0 & & & & & 0 & 0 & 0 & 0 \\
\hline sacro & 0 & & & & & 0 & 0 & 0 & 0 \\
\hline fémur & 0 & & & & & 0 & 0 & 0 & 0 \\
\hline rótula & 1 & & 1 & & & 1 & 1 & 0,5 & 33,3 \\
\hline tibia & 0 & & & & & 0 & 0 & 0 & 0 \\
\hline peroné & 0 & & & & & 0 & 0 & 0 & 0 \\
\hline tarsos & 0 & & & & & 0 & 0 & 0 & 0 \\
\hline metatarsos & 0 & & & & & 0 & 0 & 0 & 0 \\
\hline falanges pie & 0 & & & & & 0 & 0 & 0 & 0 \\
\hline TOTAL & 15 & & & & & & 15 & & \\
\hline
\end{tabular}

Referencias: NISP= número mínimo de especímenes óseos; $\mathrm{F}=$ fusionados; $\mathrm{D}=$ derecho; $\mathrm{I}=$ izquierdo; $\mathrm{A}=$ axial; In.=indeterminado; $\mathrm{NMI}=$ número mínimo de individuos; $\mathrm{NME}=$ número mínimo de elementos; MAU=unidades anatómicas mínimas; MAU\%=porcentaje de unidades anatómicas mínimas. 
Tabla A.2.5. Integración de los resultados de las lesiones buco-dentales y óseas relevadas en las tres muestras bioarqueológicas.

\begin{tabular}{|c|c|c|c|c|c|c|c|c|c|c|c|c|}
\hline & \multirow{2}{*}{$\begin{array}{c}\text { INDIVIDUO / } \\
\text { HUESO }\end{array}$} & \multirow{2}{*}{ GRUPO ETARIO } & \multirow{2}{*}{ EDAD (años) } & \multirow{2}{*}{ SEXO } & \multicolumn{4}{|c|}{ INDICADORES BUCO-DENTALES } & \multicolumn{4}{|c|}{ INDICADORES ÓSEOS } \\
\hline & & & & & CARIES & L. PERIAPICALES & PDAM & HLED & METAB.-NUTR. & INFEC. & INESP. & TRAUM. \\
\hline \multirow{16}{*}{ 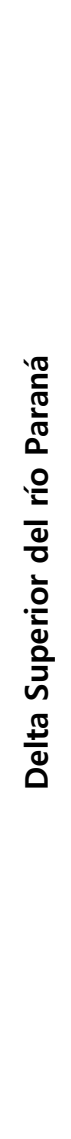 } & LTC1-P1 & adolescente & $17-20$ & $\mathrm{~F}$ & $x$ & & & & $x$ & & & \\
\hline & LTC1-P2 & adulto & in. & M & $x$ & $x$ & $x$ & $x$ & & & & \\
\hline & LTC1-P3 & adulto mayor & $50-59$ & $\mathrm{~F}$ & & $\mathrm{x}$ & & & & $x$ & & $x$ \\
\hline & LTC1-P4 & adulto medio & $35-44$ & $\mathrm{~F}$ & & $\mathrm{x}$ & & $x$ & & $x$ & & \\
\hline & LTC1-P6 & adolescente & $19-20$ & in. & & & & & & & $x$ & \\
\hline & LTC1-P7 & adolescente & $19-20$ & $\mathrm{~F}$ & & & & & & & $x$ & \\
\hline & LTC1-S1-2 & adulto medio & $45-49$ & $\mathrm{~F}$ & $x$ & & $x$ & & & & & \\
\hline & LTC1-S3 & adulto & in. & M & & & & & & & $\mathrm{x}$ & \\
\hline & LTC1-S4 & adulto & in. & in. & & & & & & & $x$ & \\
\hline & LTC1-S4-1 & adulto & in. & M & & & & & & & $\mathrm{x}$ & \\
\hline & LTC1-S5-1 & adulto & in. & in. & & & & & & & $\mathrm{x}$ & \\
\hline & LTC1-S6 & adulto & in. & $\mathrm{F}$ & $x$ & & & & & & & \\
\hline & LTC1-AC & adulto & in. & M & & & & & & & $x$ & \\
\hline & LTC1 - A4 & infante & $2-4$ & in. & & & & & $x$ & & & \\
\hline & LDLG2-1 & adulto joven & $22-26$ & M & & & & & & & & \\
\hline & LDLG2-2 & adulto & in. & in. & $x$ & & & $\mathrm{x}$ & & & & \\
\hline
\end{tabular}


Apéndice 2

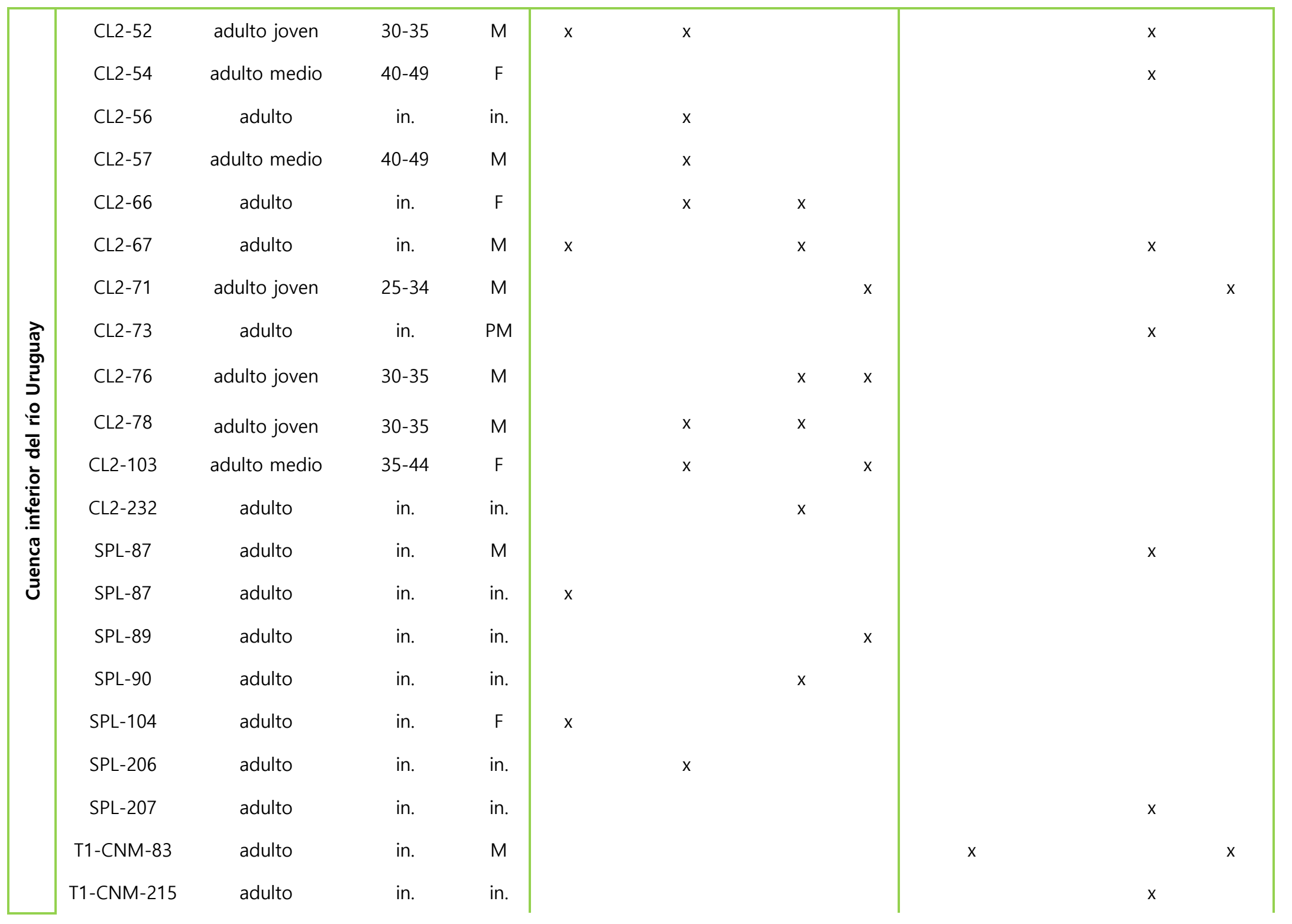


Apéndice 2

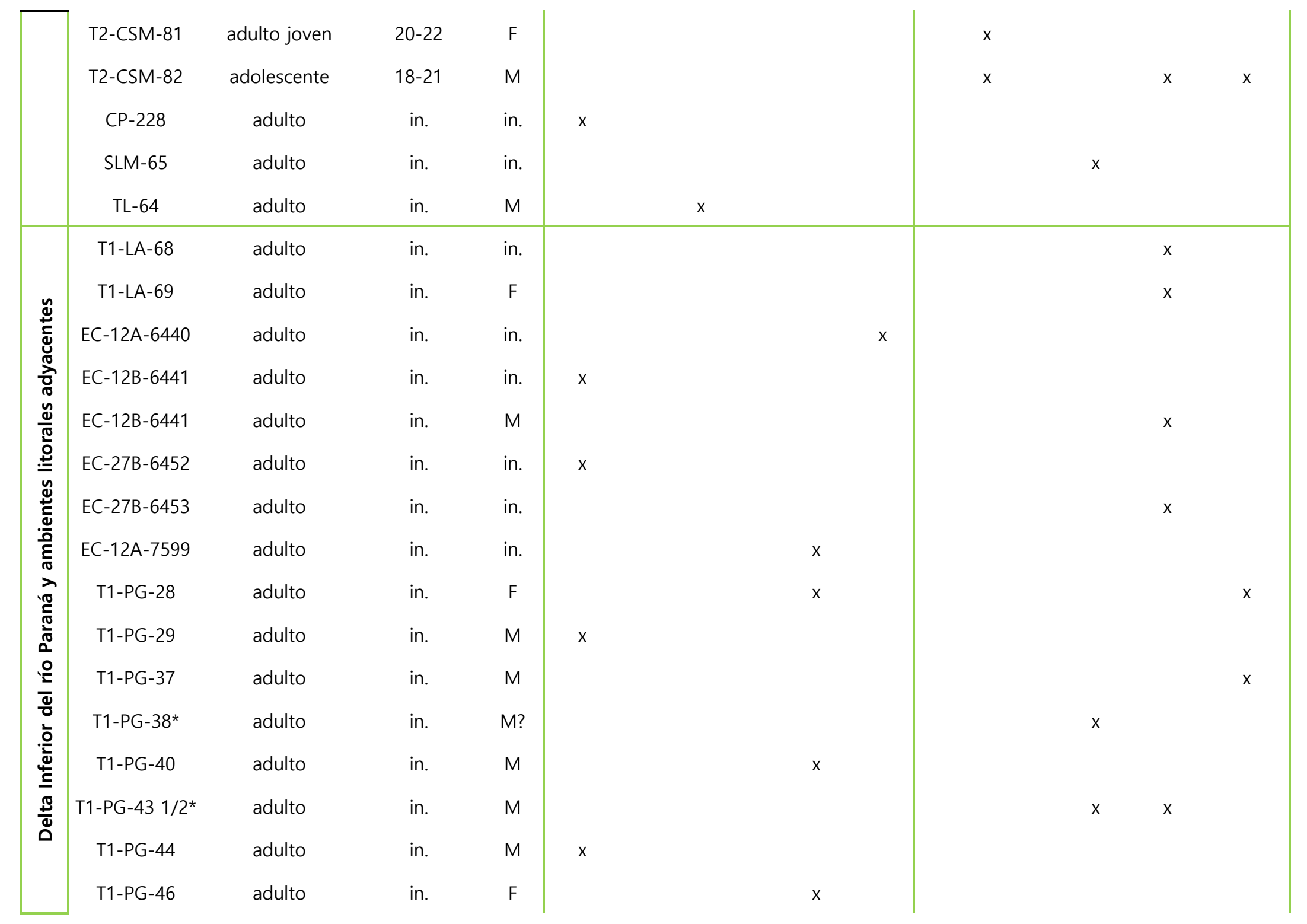




\begin{tabular}{|c|c|c|c|c|c|c|}
\hline AS-12C-6463 & adulto & in. & in. & & $x$ & \\
\hline AS-12B-6466 & adulto & in. & in. & & $x$ & \\
\hline AS-12C-6468 & adulto & in. & in. & $x$ & $x$ & \\
\hline AS-12C-6468 & adulto & in. & in. & & $x$ & \\
\hline AS-12A-6469 & adulto & in. & in. & & $x$ & \\
\hline AS-29A-6480 & adulto & in. & in. & & & $\mathrm{x}$ \\
\hline AS-42A-6489 & adulto & in. & in. & & $x$ & \\
\hline
\end{tabular}

Referencias: L.=lesiones; PDAM=pérdidas dentales antemortem; HLED=hipoplasias lineales del esmalte dental; metab.-nutr.=metabóliconutricionales; infec.=infecciosas; inesp.=inespecíficas; traum.=traumáticas; ${ }^{*}$ las lesiones óseas infecciosas de estos individuos se conocen a partir de las descripciones de Torres (1911); in.=indeterminado. 